\begin{tabular}{l|l} 
Universidad & Campus \\
Politécnica & de Excelencia \\
de Cartagena & Internacional
\end{tabular}

\title{
Diseño de una Metodología Analítica para la Decisión Multicriterio
}

\author{
Tecnologías Industriales
}

TESIS DOCTORAL

Autor: D. Gerardo González-Cela Echevarría

Director: Dr. Javier Martínez Torres

Codirector: Dr. Antonio Guillamón Frutos 


\section{CONFORMIDAD DE SOLICITUD DE AUTORIZACIÓN DE DEPÓSITO DE TESIS DOCTORAL POR EL DIRECTOR DE LA TESIS}

D/D $\mathrm{D}^{\mathrm{a}}$. Javier Martínez Torres y Antonio Guillamón Frutos, director y codirector de la Tesis doctoral: Diseño de una Metodología Analítica para la Decisión Multicriterio.

\section{INFORMA:}

Que la referida Tesis Doctoral, ha sido realizada por D. Gerardo González-Cela Echevarría, dentro del Programa de Doctorado: TECNOLOGÍAS INDUSTRIALES, dando mi conformidad para que sea presentada ante el Comité de Dirección de la Escuela Internacional de Doctorado para ser autorizado su depósito.

$\mathrm{X}$ Informe positivo sobre el plan de investigación y documento de actividades del doctorando/a emitido por el Director/ Tutor (RAPI).

La Rama de conocimiento por la que esta tesis ha sido desarrollada es:

$\begin{array}{ll}\square & \text { Ciencias } \\ \square & \text { Ciencias Sociales y Jurídicas } \\ \mathrm{X} & \text { Ingenieria y Arquitectura }\end{array}$

En Cartagena, a 9 de diciembre de 2019

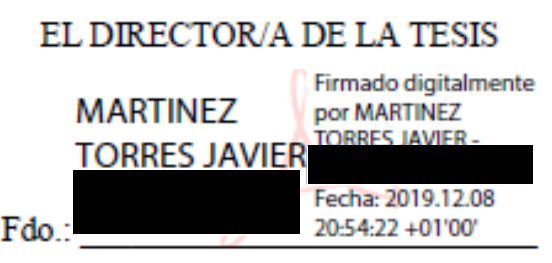

EL CODIRECTOR/A DE LA TESIS

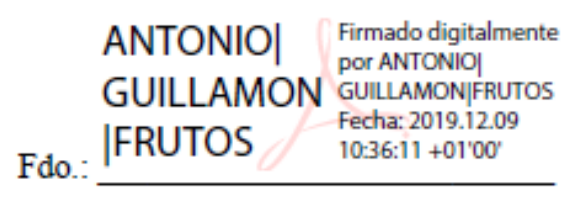




\title{
CONFORMIDAD DE DEPÓSITO DE TESIS DOCTORAL
} POR LA COMISIÓN ACADÉMICA DEL PROGRAMA

D/D ${ }^{2}$. JUAN SUARDÍAZ MURO, Presidente/a de la Comisión Académica del Programa TECNOLOGĹAS INDUSTRIALES.

\section{INFORMA:}

Que la Tesis Doctoral titulada, "Diseño de una metodología analítica para la decisión.", ha sido realizada, dentro del mencionado Programa de Doctorado, por D/D ${ }^{2}$.GERARDO CASIMIRO GONZALEZ-CELA ECHEVARRIA, bajo la dirección y supervisión de los Doctores Dr. D. Javier Martínez Torres y Dr. D. Antonio Guillamón Frutos.

En reunión de la Comisión Académica, visto que en la misma se acreditan los indicios de calidad correspondientes y la autorización del Director/a de la misma, se acordó dar la conformidad, con la finalidad de que sea autorizado su depósito por el Comité de Dirección de la Escuela Internacional de Doctorado.

Evaluación positiva del plan de investigación y documento de actividades por el Presidente de la Comisión Académica del programa (RAPI).

La Rama de conocimiento por la que esta tesis ha sido desarrollada es:

\section{Ciencias}

Ciencias Sociales y Juridicas

$\mathrm{X}$ Ingeniería y Arquitectura

En Cartagena, a 09 de diciembre de 2019

\section{EL PRESDENTE DE LA COMISIÓN ACADÉMICA}

\author{
JUAN] Firmado \\ SUARDIAZ digitalmente por \\ Fdo: |MURO MURO
}




\section{RESUMEN:}

El enfrentamiento del hombre a decisiones complejas es un asunto frecuente debido, especialmente, al requerimiento de intentar alcanzar diversos propósitos simultáneamente. El decisor se enfrenta a la incertidumbre con la presión añadida de las consecuencias que puede arrastrar su decisión hacia la organización a la que pertenece.

El problema de la decisión radica en el conflicto que normalmente subyace entre los deseos, que dificilmente satisfacen todas las pretensiones. Lo corriente es que se presenten varias alternativas cuyas ventajas e inconvenientes son difíciles de evaluar en su justa medida. Las personas encargadas de resolver el problema, habitualmente expertos en la materia con sus juicios u opiniones, normalmente, son el único medio de atajo entre unos conocimientos limitados y la necesidad de dar solución al problema adoptando una decisión. Este remedio soporta las contrariedades propias del ser humano que, como individuo, llevan implícita la subjetividad y, como ser social dentro de una organización, sufre los sesgos propios de las decisiones grupales.

Este trabajo persigue el desarrollo de una metodología basada en un decisor analítico adaptable para cada caso de estudio. El objetivo global es aportar una metodología de toma de decisiones que permita rebajar la subjetividad presente en el mayor grado posible y el sesgo propio de las decisiones grupales, basándose en el algoritmo AHP desarrollado por Saaty y apoyando la valoración de algunos de los criterios mediante herramientas objetivas como pudieran ser: la simulación numérica en varios ámbitos, datos estadísticos históricos, gestión de proveedores, gestión de riesgos, etc. 


\section{ABSTRACT:}

Man's confrontation with complex decisions is a frequent affair, especially due to the requirement to try to achieve different purposes simultaneously. The decision-maker is faced with uncertainty with the added pressure of consequences that his decision may drag towards the organization to which he belongs.

The problem of decision lies in the conflict that normally underlies desires, which hardly satisfies all pretensions. It is usual that several alternatives are presented, the advantages and disadvantages of which are difficult to evaluate in their proper measure. People in charge of solving the problem, usually experts in the field, with their judgments or opinions, are usually the only way to find a shortcut between limited knowledge and the need to solve the problem by making a decision. This solution supports the inherent setbacks of the human being who, as an isolated individual, implicitly holds subjectivity and, as a social being within an organization, suffers from the biases of group decisionmaking.

This Thesis pursues the development of a methodology based on an analytical decision maker built ad hoc for each case of study. The overall objective is to provide a decisionmaking methodology that allows the reduction of subjectivity present to the greatest level possible and the bias of group decision-making, based on the AHP algorithm developed by Saaty and supporting the evaluation of some of the criteria through objective tools such as: numerical simulation in various areas, historical statistical data, supplier management, risk management, etc. 
A mi mujer María Luisa

y a mis tres hijos

Gerardo, Jaime y Fátima 


\section{Agradecimientos}

En primer lugar, quiero expresar mi reconocimiento y agradecimiento a mi director tesis, Javier Martínez Torres, verdadero impulsor de este trabajo. Tu ayuda, paciencia, conocimientos, claridad de ideas $\mathrm{y}$, sobre todo, tu capacidad para motivarme e impulsarme hacia un progreso pausado pero incesante, han sido el verdadero motor de avance y guía del rumbo mantenido en esta tesis, que aquí concluye. Muchas gracias Doctor.

A los profesores de la UPCT, Antonio Guillamón, mi codirector de tesis, tu auxilio ha sido imprescindible en todas las gestiones técnicas y burocráticas; siempre me has prestado de manera incondicional todas las facilidades para llevar este proyecto adelante. A Juan Suardiaz, coordinador del programa de Doctorado. A mi tutor Silvestre Paredes y a la UPCT por darme la oportunidad de presentar este trabajo. Muchas gracias.

A mis profesores de los CUD de las tres academias militares durante los másteres de Investigación Operativa y Estadística, todos ellos fueron dejando una huella indeleble en la que me refugio con bastante frecuencia. Joaquín Sancho, me presentaste a Taguchi. Raquel Villacampa, tus apuntes son impresionantes. Álvaro Lozano, explicas y encarnas a la perfección el concepto de estocasticidad. Nuevamente, Javier Martínez, me bajaste a la mina de los datos, con casco, pico y pala. María Victoria Sebastián, la simpatía de la lógica. Ángeles Dena, sembraste las raíces de mi interés en la optimización. Daniel Casanova, marcaste el camino con sencillez y resolución. Nina Skorin-Kapov, la metaheurística es fácil. Carlos Ruiz, desterraste el método de decisión mediante dedos oscilantes. Antonio Otal, el Excel es un juguete. Manuel Caravaca, la simulación no lo es todo. Manuel Fernández, generoso en redes neuronales. Rubén Vigara, redemostraste el muestreo. Antonio Oller, hiciste interesante el análisis multivariante. Noemí Martínez, las encuestas no son para aficionados. Ana Esther, las técnicas de series temporales son atemporales en el tiempo. Silvia Vilariño, correlacionada con la causalidad. Y Montse Aiger, contigo hago la despedida y cierre de esta actividad grupal. Confío en no haber olvidado a ninguno. A todos, muchas gracias.

A todos los profesores del CUD de Marín, empezando por su director José María Pousada, gracias por todas las facilidades y medios que has puesto a mi disposición en estos últimos años. Javier Guzmán, amigo y profesor, virtuoso de: matemáticas, Matlab, 
Excel, y no sé cuántas cosas más; tu auxilio ha sido y es, inapreciable. Roberto Bellas, tu colaboración ha sido muy valiosa. Marco Campo, codirector de mi TFM y padre del ingenio. Norberto Fernández, Javier Rodríguez, José María Núñez y Rafael Carreño. Muchas gracias.

A mis compañeros de la Armada, sin los cuales no hubiese sido posible realizar esta tesis. Ramón Touza, profesor exigente de amplios conocimientos y experiencia, tu asistencia e ideas me resultaron vitales. Íñigo Moreu, verdadero apoyo y confianza en mi persona, aunque no seas muy "creyente" en la IO. José María Núñez y Vicente Rubio, director y jefe de estudios de la ENM, indispensable vuestro consentimiento y colaboración en los experimentos. José Antonio Carrillo, Ignacio Cuartero, Eduardo Gómez, Álvaro Herráiz, Heitor Martínez, Santiago Fernández, Ricardo Gómez, Antonio González-Tánago, Cipriano Pereira, Juan Gómez, Santiago Mariño, Miguel Perales, Gonzalo Leira y algunos más que seguramente me dejo en el tintero, perdón. Por supuesto, estoy también muy agradecido a los alumnos que participaron en el experimento de la ENM. Deseo que cuando embarquen de oficiales en las fragatas F-110, recuerden con cariño ese caluroso día de junio de 2017 en el que siendo Aspirantes les tocó "evacuar" el CIC simulado en el Patio de Aulas. A todos muchas gracias.

Por último, mi agradecimiento más íntimo a toda mi familia, padres, hermanos, cuñados y especialmente a mi mujer María Luisa y a mis tres hijos, Gerardo, Jaime y Fátima. Ellos son los que más me han motivado y animado durante la realización de esta tesis y, a la vez, la han padecido. Han sido muchas las horas compartidas en las que, juntos, estudiamos y trabajamos. Espero que les queden en el recuerdo. 


\section{Contenido}

Contenido Índice de Figuras ............................................................................. v

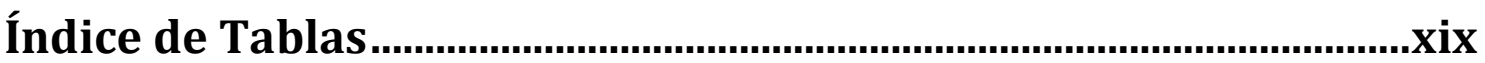

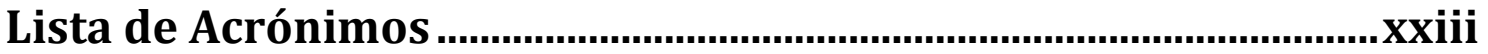

Producción Científica ........................................................................XXV

Capítulo 1. Introducción...................................................................... 1

1.1. Motivación y Objetivos.....................................................................................................

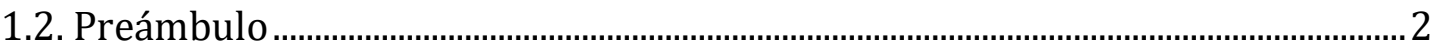

1.3. Breve Recorrido Histórico de la MCDM ........................................................................

1.4. Enfoque del Estudio Relativo a las Decisiones Grupales ......................................... 16

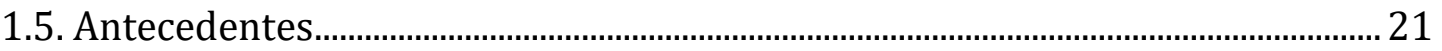

1.5.1. Beneficios industriales.........................................................................................................27

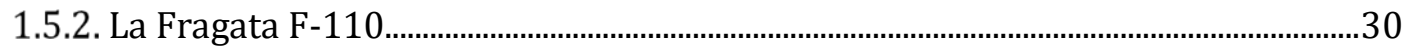

Capítulo 2. Estado del arte ................................................................ 39

2.1. MODM. Programación multiobjetivo......................................................................... 39

2.1.1. La Matriz de Pagos...................................................................................................................40

2.1.2. El Método de las Restricciones ....................................................................................................41

2.1.3. El Método de las Ponderaciones .................................................................................................42 
2.1.4. MODM. Programación Compromiso

2.1.5. MODM. Programación por Metas.........................................................................................45

2.1.6. MADM. Métodos Multicriterio Discretos ………………………………………….............46

2.2. MADM. Proceso de Análisis Jerárquico (AHP) ........................................................ 51

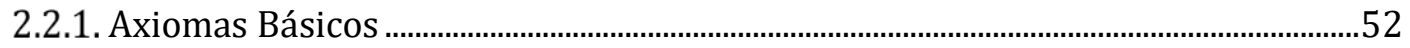

2.2.2. Metodología del Proceso Analítico Jerárquico...............................................................52

2.2.3. Cálculo del Vector de Pesos o Utilidades .....................................................................59

2.2.4. Algoritmo para el Cálculo de la Relación de Consistencia ............................................60

2.2.5. Cálculo del Vector de Soluciones ……………………………………………………......62

2.2.6. Programa de Ayuda a la Decisión de Líneas de Acción (ADLA)...................................64

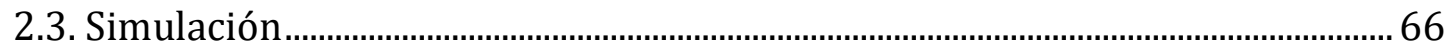

2.3.1. Modelo Analítico vs. Simulación..................................................................................68

2.3.2. Ventajas del Modelo de Simulación................................................................................70

2.3.3. Aplicaciones de los Modelos de Simulación ................................................................70

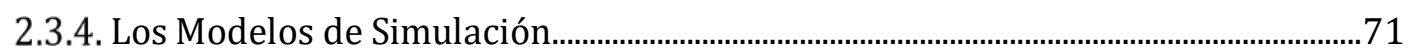

2.3.5. Modelo Basado en Agentes ..........................................................................................73

2.3.6. Fases Simulación ............................................................................................................

Capítulo 3. Metodología y Casos de Estudio ...................................... 76

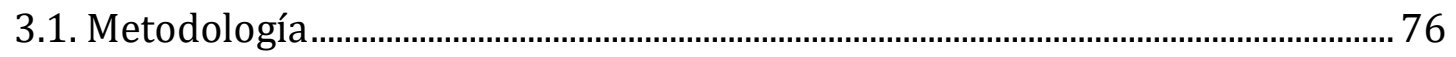

3.2. Estudio de la Decisión del Diseño Óptimo en la Distribución del Centro de Información y Combate de la Fragata F-110 …………..................................................... 79

3.2.1. Representación del Problema y Selección de Criterios....................................................84

3.2.2. Evaluación de los Criterios. Evaluación de las Alternativas ........................................93

3.2.3. Contribución de las Alternativas. Problema Objetivo ……………………....................98

3.2.4. Jerarquización de las Alternativas ........................................................................... 121

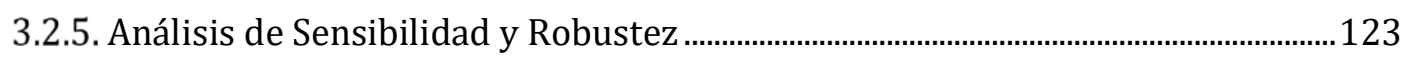

3.3. Estudio de la Decisión del Comedor Óptimo en la Fragata F-110................... 129 
3.3.1. Representación del Problema y Selección de Criterios

3.3.2. Evaluación de los Criterios. Evaluación Subjetiva de las Alternativas 137

3.3.3. Contribución de las Alternativas. Problema Objetivo 139

3.3.4. Jerarquización de las Alternativas 175

3.3.5. Análisis de Sensibilidad y Robustez 179

3.4. Estudio de la Decisión del Posicionamiento Óptimo de las Ametralladoras en la Fragata F-110 184

3.4.1. Representación del Problema y Selección de Criterios. 189

3.4.2. Evaluación de los Criterios. Evaluación Subjetiva de las Alternativas. 197

3.4.3. Contribución de las Alternativas. Problema Objetivo 201

3.4.4. Jerarquización de las Alternativas 224

3.4.5. Análisis de Sensibilidad y Robustez

Capítulo 4. Conclusiones y Líneas Futuras de Investigación 235

4.1. Conclusiones . 235

4.2. Líneas Futuras de Investigación. 239

Bibliografía 241

APÉNDICES A-1

Apéndice A. Estudio del CIC A-1

Apéndice B. Estudio del Comedor . B-1 Apéndice C. Estudio de las Ametralladoras. C-1 


\section{Índice de Figuras}

Figura 1-1 Análisis teórico del pensamiento en grupo ( [67]) ……................................ 18

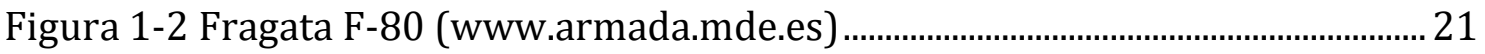

Figura 1-3 Fragata F-100 (www.armada.mde.es) ……....................................................... 21

Figura 1-4 Fases de transformación de Documento de Necesidad Operativa

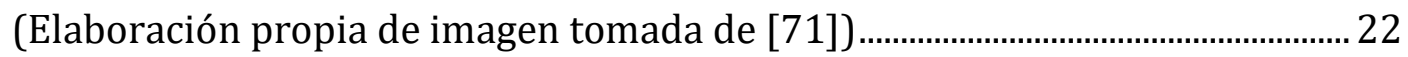

Figura 1-5 Programa de Obtención de recursos materiales (Elaboración propia de

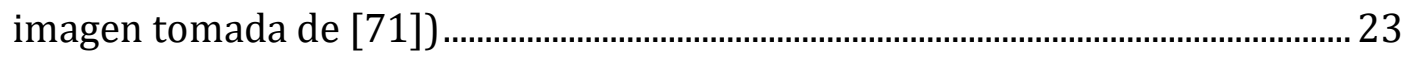

Figura 1-6 Fase de apoyo a la redacción del REM F-110. (Elaboración propia de

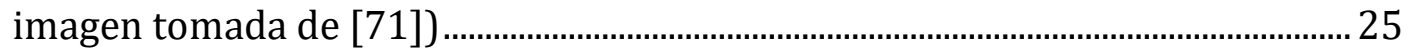

Figura 1-7 Impresión artística de la F-110 (Navantia) ....................................................... 26

Figura 1-8 F-110 Misiones genéricas y escenarios (DGAM).............................................. 30

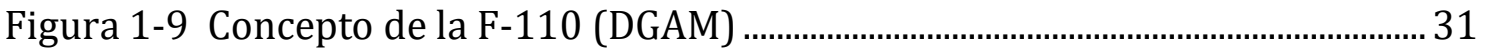

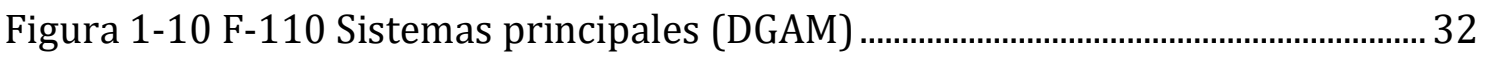

Figura 1-11 Mástil integrado (MASTIN) (Navantia)............................................................ 33

Figura 1-12 Tarjeta Plan de Combate (Armada española) .................................................. 37

Figura 1-13 Organización administrativa (Armada española) .......................................... 38

Figura 2-1 Pasos en el procedimiento AHP (elaboración propia de esquema extraído

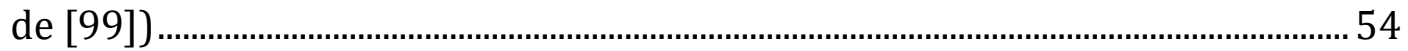

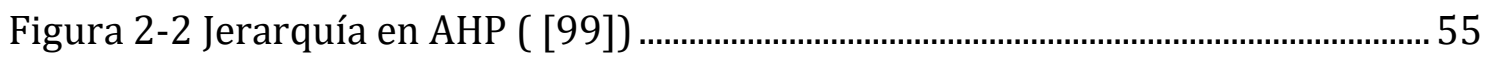

Figura 2-3 Ejemplo de diagrama de criterios en ADLA ( [111]) ...................................... 66 
Figura 2-4 Modelo del mundo real para optimizar un sistema (AnyLogic) 67

Figura 2-5 Modelo analítico en Excel (Elaboración propia de imagen de AnyLogic) 68

Figura 2-6 Nivel de abstracción de los modelos (Elaboración propia de imagen de [113]) 70

Figura 2-7 Esquema del modelado de una simulación (Elaboración propia de imagen de [113]) 72

Figura 2-8 Selección del método de modelo (Elaboración propia de imagen de [113])

Figura 3-1 Fases del proceso de toma de decisiones (Elaboración propia de [116])

Figura 3-2 Metodología planteada del decisor desarrollado (Elaboración propia) 78

Figura 3-3 Vista del CIC de la F-102 Almirante Don Juan de Borbón (www.armada.mde.es) 80

Figura 3-4 CIC del USS Vincennes (Tim Masterson)........................................................ 83

Figura 3-5 Lanzamiento de un misil desde la F-105 (Armada Española) 83

Figura 3-6 Recreación artística del CIC de la Fragata F-100, tipo LADO (Armada española) 86

Figura 3-7 Modelo CIC tipo LADO de la F-110 (Elaboración propia).............................. 86

Figura 3-8 Sala de control (NASA) 87

Figura 3-9 DDG-1000 Zumwalt (The US Navy). 87

Figura 3-10 Imagen del CIC del Zumwalt (The US Navy) 87

Figura 3-11 Fragata Holandesa Evertsen (www.seaforces.org) ...................................... 88

Figura 3-12 Imagen del CIC del Evertsen (www.seaforces.org)..................................... 88

Figura 3-13 Modelo CIC tipo NASA de la F-110 (Elaboración propia) .......................... 89

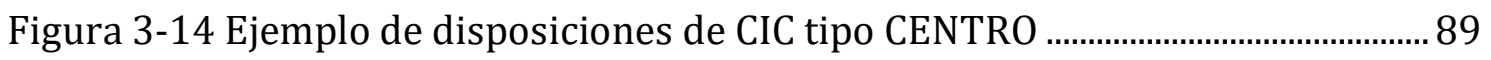

Figura 3-15 Modelo CIC tipo CENTRO de la F-110 (Elaboración propia) ..................... 90 
Figura 3-16 Modelo preliminar AHP (Elaboración propia) ………….............................. 90

Figura 3-17 Modelo definitivo AHP (Elaboración propia) ................................................. 91

Figura 3-18 Imágenes de referencia de los tres tipos de CIC (Elaboración propia) 94

Figura 3-19 Valoración global de las alternativas del multicriterio subjetivo

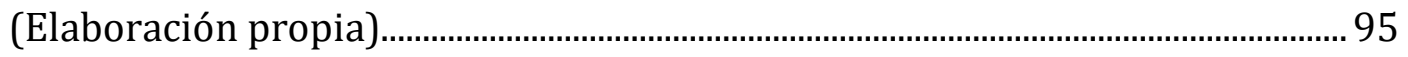

Figura 3-20 Comparación por parejas CENTRO vs NASA (ADLA) ................................... 96

Figura 3-21 Gráfica de barras para el análisis dinámico de sensibilidad que se ha obtenido como resultado del multicriterio subjetivo (ADLA) 97

Figura 3-22 Gráfica de reasignación de pesos para conmutación de alternativas. La flecha y la cifra en rojo indican el \% en que ha sido necesario disminuir el peso del criterio de Mando y Control para que se produzca la conmutación en el resultado de NASA a CENTRO (barras naranjas) (ADLA) ........................................... 98

Figura 3-23 División en celdas del espacio y representación del movimiento de personas (imagen tomada de [135]) …………....................................................... 101

Figura 3-24 Esquema de DEE para CIC tipo NASA (Elaboración propia) .................. 103

Figura 3-25 Experimento evacuación NASA13. Se aprecia en la imagen un pasillo longitudinal (proa-popa) y tres puertas de salida (Pathfinder). 103

Figura 3-26 Disposición original del CIC “CENTR004” (Elaboración propia) ........ 104

Figura 3-27 Malla de triángulos definida para generar rutas de evacuación (Elaboración propia) 107

Figura 3-28 Imagen de puerta y escotilla estanca en la F-102 (Gonzalo Leira)..... 108

Figura 3-29 Ejemplo de cuello de botella, el compartimento dispone de una única salida (Elaboración propia) 109

Figura 3-30 Distribuciones del tiempo de evacuación (Elaboración propia) .......... 111

Figura 3-31 Estadísticas del DEE del CIC tipo LADO ....................................................... 113

Figura 3-32 Estadísticas del DEE del CIC tipo CENTRO .................................................. 114

Figura 3-33 Estadísticas del DEE del CIC tipo NASA …..................................................... 116 
Figura 3-34. Fotografía de una representación del CIC tipo "Centro04" para la experimentación real. La línea roja simboliza el perímetro y los conos verdes las puertas de salida (José M. Núñez) 118

Figura 3-35 Utilidad del subcriterio de Evacuación basado en una función de utilidad. (Elaboración propia). 121

Figura 3-36 Valoración global de los CIC con el multicriterio objetivo (Elaboración propia)....

Figura 3-37 Gráfica de análisis gráfico de sensibilidad, resultado del multicriterio objetivo (ADLA) 123

Figura 3-38 Gráfica de barras para el análisis dinámico de sensibilidad que se ha obtenido como resultado del multicriterio objetivo (ADLA) 124

Figura 3-39 Gráfica de reasignación de pesos para conmutación de alternativas. La flecha y la cifra en rojo indican el \% en que ha sido necesario disminuir el peso del criterio de Mando y Control para que se produzca la conmutación en el resultado de NASA a LADO (barras naranjas) (ADLA). 125

Figura 3-40 Gráficas de reasignación de pesos para conmutación de alternativas. A la izquierda el multicriterio subjetivo (variación de opinión del 15\%), a la derecha el multicriterio objetivo (variación de opinión del 52\%) (ADLA).... 126

Figura 3-41 Servicio de aprovisionamiento (Organigrama extraído de [81]) ........ 130

Figura 3-42 Comedor de oficiales a bordo del Juan Carlos I durante el reparto de la comida (Foto: Juanjo Fernández) 130

Figura 3-43 Alternativa 4 Optimizada (Navantia)........................................................... 133

Figura 3-44 Alternativa 5 (Navantia) ……….............................................................. 134

Figura 3-45 Alternativa 6 (Navantia) ………............................................................. 135

Figura 3-46 Modelo AHP confeccionado con los expertos para el problema del comedor (Elaboración propia) 135

Figura 3-47 Diagrama de matrices y escala de Saaty (Elaboración propia)...... 138

Figura 3-48 Imagen del comedor Alt5 con el 100\% de ocupación de asientos (recuadro rojo indica el perímetro). El comedor de oficiales y suboficiales (en 
estribor recuadro azul) también está completo, pero no ha sido objeto de este estudio.

Figura 3-49 Estadísticas del experimento de tiempo en desalojar el comedor Alt.40pt (Elaboración propia).

Figura 3-50 Estadísticas del experimento de tiempo en desalojar el comedor Alt5 (Elaboración propia).

Figura 3-51 Imagen de un tronco de escalas tomada en la F-102 (Gonzalo Leira)

Figura 3-52 Estadísticas del experimento de tiempo en desalojar el comedor Alt6 (Elaboración propia)

Figura 3-53 ANOVA: Alt40pt; Alt5; Alt6 146

Figura 3-54 Distribución de llegada de personas al comedor en el desayuno en la F103.

Figura 3-55 Distribución de llegada de personas al comedor en el desayuno en la F105.

Figura 3-56 Distribución de llegada de personas al comedor en la comida en la F103 150

Figura 3-57 Distribución de llegada de personas al comedor en la comida en la F105 150

Figura 3-58 Distribución de llegada de personas al comedor en la cena en la F-103 150

Figura 3-59 Distribución de llegada de personas al comedor en la cena en la F-105 150

Figura 3-60 Imagen de la línea de servicio en el comedor de la F-105 ("Cristóbal Colón"). 151

Figura 3-61 Distribución de llegada de alumnos al comedor en el desayuno en el portaviones.

Figura 3-62 Distribución de llegada de alumnos al comedor en la comida en el portaviones. 152 
Figura 3-63 Informe de resumen del tiempo en la línea durante el desayuno en la F103.

Figura 3-64 Informe de resumen del tiempo en la línea durante la comida en la F103 155

Figura 3-65 Informe de resumen del tiempo en la línea durante la cena en la F-103

Figura 3-66 Prueba de bondad de ajuste a una Normal de los tiempos en línea para la cena en la F-103 (eliminados los datos atípicos). 156

Figura 3-67 Informe de resumen del tiempo en la línea durante el desayuno en la F105 157

Figura 3-68 Informe de resumen del tiempo en la línea durante la comida en la F105 158

Figura 3-69 Informe de resumen del tiempo en la línea durante la cena en la F-105

Figura 3-70 Prueba de bondad de ajuste a una Normal de los tiempos en línea para la cena en la F-105 (eliminados los datos atípicos). 159

Figura 3-71 Gráfica de caja de los tiempos en la línea de las fragatas (los datos atípicos de las cenas se han eliminado). 160

Figura 3-72 Gráfica de dispersión en el eje de abscisas: hora incorporación a la cola; en el eje de ordenadas: tiempo en sentarse a la mesa 162

Figura 3-73 Gráfica Box-Plot de los tiempos en realizar la ingesta en todos los buques 163

Figura 3-74 Tiempos empleados en la ingesta F-103. 163

Figura 3-75 Gráfica de caja de la duración de las comidas en la F-103. 164

Figura 3-76 Tiempos empleados en la ingesta F-105 164

Figura 3-77 Tiempos empleados en la ingesta JCI. 165

Figura 3-78 Ejemplo de una simulación de saturación con 160 personas (Alt5), tasa de llegada $\operatorname{Exp(320).~En~la~imagen,~sobre~la~fila~de~procesos,~se~observa~que:~las~}$ 160 personas han acudido al comedor, 3 no han podido incorporarse al pasillo 
del comedor por culpa del tumulto, 90 están en la cola, 5 en la línea, 40 están comiendo y 22 ya lo han abandonado.

Figura 3-79 Esquema de los procesos en la simulación en AnyLogic (Elaboración propia).

Figura 3-80 Gráfica de barras con los promedios de tiempo de ocupación del comedor 172

Figura 3-81 Gráfica de barras con los promedios del tiempo empleado en la comida 173

Figura 3-82 Gráfica de barras con los promedios del tiempo en cola. 174

Figura 3-83 Gráfica de barras con los promedios de la velocidad de movimiento en los comedores 174

Figura 3-84 Utilidad del subcriterio de Desalojo Z/C basado en una función (gráfica sin escala) (Elaboración propia). 176

Figura 3-85 Utilidad del subcriterio de Libertad de movimientos basado en una función (gráfica sin escala) (Elaboración propia) 177

Figura 3-86 Problema decisional en árbol (Elaboración propia) 178

Figura 3-87 Gráfica de barras para el análisis dinámico de sensibilidad que se ha obtenido como resultado del multicriterio subjetivo (ADLA) 180

Figura 3-88 Gráfica de reasignación de pesos para conmutación de alternativas. La flecha y la cifra en rojo indican el \% en que ha sido necesario disminuir el peso del criterio DESTINO para que se produzca la conmutación en el resultado de la Alt6 a la Alt40pt (ADLA). 181

Figura 3-89 El USS Cole siendo remolcado tras sufrir el ataque en su costado de babor (Don L. Maes). 184

Figura 3-90 Tanquero Limburg en llamas tras el ataque por su costado de estribor (BBC) 185

Figura 3-91 Imagen satélite del estrecho de Bab El Mandeb (Google). 186

Figura 3-92 Ataque a la fragata saudí de la clase Al Madinah (Euronews) 186

Figura 3-93 Ametralladora Mk-38 (Bae Systems) 188 
Figura 3-94 Ametralladora 12,7 mm RWS HITROLE (LEONARDO)

Figura 3-95 Opción A (Elaboración propia sobre imagen de F-110 de DGAM) ..... 191

Figura 3-96 Opción B (Elaboración propia sobre imagen de F-110 de DGAM) ..... 192

Figura 3-97 Opción C (Elaboración propia sobre imagen de F-110 de DGAM)...... 193

Figura 3-98 Opción D (Elaboración propia sobre imagen de F-110 de DGAM)..... 193

Figura 3-99 Opción E (Elaboración propia sobre imagen de F-110 de DGAM) ..... 194

Figura 3-100 Opción F (Elaboración propia sobre imagen de F-110 de DGAM)... 195

Figura 3-101 Modelo AHP confeccionado con los expertos para el problema de las ametralladoras (Elaboración propia) 195

Figura 3-102 Hoja Excel enviada a los expertos para el relleno de MCP en el problema de las ametralladoras (Elaboración propia). 198

Figura 3-103 Recreación de un ataque simultáneo de tres FIACs (embarcaciones naranjas) a una F-110 (Elaboración propia sobre imagen de Google Maps) 202

Figura 3-104 Ejemplo de Matlab de un ataque con el resultado de: Éxito. Se neutralizan las tres lanchas quedando reflejado por los asteriscos. 204

Figura 3-105 Ejemplo de Matlab de un ataque con el resultado de: Fracaso. Se neutralizan dos lanchas y la tercera (trayectoria verde) consigue alcanzar el buque (trayectoria azul) 204

Figura 3-106 Ejemplo de la gráfica de probabilidad de impacto de la ametralladora Mk-38. En verde la curva de disparo en Modo ráfaga y en rojo en Modo "tiro a tiro" 206

Figura 3-107 Ejemplo de gráfica de probabilidad de impacto de la ametralladora de $12,7 \mathrm{~mm}$. En verde la curva de disparo en Modo ráfaga y en rojo en Modo "tiro a tiro" 206

Figura 3-108 Gráfico de los porcentajes de lanchas neutralizadas. Opción A ........ 207

Figura 3-109 Informe de resumen de tiempo. Opción A .................................................. 208

Figura 3-110 Box-Plot de disparos por arma. Opción A 208 
Figura 3-111 Promedio de disparos por ametralladora. Opción A (Elaboración propia sobre imagen de F-110 de DGAM) ................................................................ 209

Figura 3-112 Gráfico de los porcentajes de lanchas neutralizadas. Opción B ........ 210

Figura 3-113 Informe de resumen de tiempo. Opción B .............................................. 210

Figura 3-114 Box-Plot de disparos por arma. Opción B .................................................. 211

Figura 3-115 Promedio de disparos por ametralladora. Opción B (Elaboración propia sobre imagen de F-110 de DGAM) ............................................................... 211

Figura 3-116 Gráfico de los porcentajes de lanchas neutralizadas. Opción C......... 212

Figura 3-117 Informe de resumen de tiempo. Opción C ................................................ 213

Figura 3-118 Box-Plot de disparos por arma. Opción C ............................................... 213

Figura 3-119 Promedio de disparos por ametralladora. Opción C (Elaboración propia sobre imagen de F-110 de DGAM) ........................................................... 214

Figura 3-120 Gráfico de los porcentajes de lanchas neutralizadas. Opción D ........ 215

Figura 3-121 Informe de resumen de tiempo. Opción D.............................................. 215

Figura 3-122 Box-Plot de disparos por arma. Opción D................................................. 216

Figura 3-123 Promedio de disparos por ametralladora. Opción D (Elaboración propia sobre imagen de F-110 de DGAM) ................................................................. 216

Figura 3-124 Gráfico de los porcentajes de lanchas neutralizadas. Opción E......... 217

Figura 3-125 Informe de resumen de tiempo. Opción E ............................................... 217

Figura 3-126 Box-Plot de disparos por arma. Opción E ............................................... 218

Figura 3-127 Promedio de disparos por ametralladora. Opción E (Elaboración propia sobre imagen de F-110 de DGAM) ……......................................................... 218

Figura 3-128 Gráfico de los porcentajes de lanchas neutralizadas. Opción F......... 219

Figura 3-129 Informe de resumen de tiempo. Opción F ............................................... 220

Figura 3-130 Box-Plot de disparos por arma. Opción F ................................................. 220

Figura 3-131 Promedio de disparos por ametralladora. Opción F (Elaboración propia sobre imagen de F-110 de DGAM) ............................................................. 221 
Figura 3-132 Sectores de ataque. Las flechas negras marcan un ejemplo de ataque de tres lanchas por el sector proel (Elaboración propia sobre imagen de F-110 de DGAM)

Figura 3-133 Gráficas comparativas de las variables objeto de la simulación....... 224

Figura 3-134 Utilidad del sub-subcriterio Éxito (gráfica sin escala) (Elaboración propia).

Figura 3-135 Utilidad del sub-subcriterio Tiempo de Fuego (gráfica sin escala) (Elaboración propia).

Figura 3-136 Utilidad del sub-subcriterio Munición Consumida (gráfica sin escala) (Elaboración propia).

Figura 3-137 Valoración global de las alternativas (Elaboración propia)................ 228

Figura 3-138 Utilidad de las alternativas para DESTINO ARMAS (ADLA)................ 228

Figura 3-139 Utilidad de las alternativas para EFICACIA ARTILLERA (ADLA) ..... 229

Figura 3-140 Gráfica de barras para el análisis dinámico de sensibilidad (ADLA)

Figura 3-141 Gráfica de reasignación de pesos para conmutación de alternativas. La flecha y la cifra en rojo indican el \% en que ha sido necesario disminuir el peso del criterio DESTINO ARMAS para que se produzca la conmutación en el resultado de la Opción F a la Opción C (ADLA) 231

Figura 4-1 Problema de la decisión multicriterio de la DGAM (Elaboración propia)

Figura en Apéndice A-1 Esquema de ayuda enviado a los expertos (Elaboración

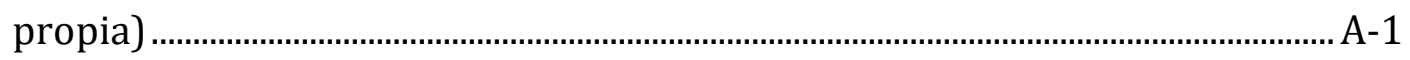

Figura en Apéndice A-2 Escala de Saaty facilitada a los expertos ............................... A-1

Figura en Apéndice A-3 Matrices de asignación de pesos a los criterios ................... A-2

Figura en Apéndice A-4 Matrices para la valoración de las alternativas.................... A-3 
Figura en Apéndice A-5 Imagen ejemplo de un experimento de 10 réplicas que resulta insuficiente A-1

Figura en Apéndice A-6 CIC tipo LADO con número de pasillos igual a cero (Elaboración propia). A-1

Figura en Apéndice A-7 CIC tipo LADO con número de pasillos igual a uno (Elaboración propia). A-1

Figura en Apéndice A-8 CIC tipo LADO con número de pasillos igual a dos (Elaboración propia). A-2

Figura en Apéndice A-9 CIC tipo NASA con número de pasillos igual a cero (Elaboración propia). A-2

Figura en Apéndice A-10 CIC tipo NASA con número de pasillos igual a uno (Elaboración propia). A-3

Figura en Apéndice A-11 CIC tipo NASA con número de pasillos igual a dos (Elaboración propia). A-3

Figura en Apéndice A-12 CIC tipo CENTRO con número de pasillos igual a cero (Elaboración propia). A-4

Figura en Apéndice A-13 CIC tipo CENTRO con número de pasillos igual a uno (Elaboración propia). A-4

Figura en Apéndice A-14 CIC tipo CENTRO con número de pasillos igual a dos (Elaboración propia). A-5

Figura en Apéndice A-15 Prueba de varianzas iguales del experimento LADO..... A-1

Figura en Apéndice A-16 ANOVA del experimento CIC tipo LADO

Figura en Apéndice A-17 Prueba de varianzas iguales del experimento CENTRO A-1 Figura en Apéndice A-18 ANOVA del experimento CIC tipo CENTRO A-2

Figura en Apéndice A-19 Prueba de varianzas iguales del experimento NASA..... A-1 Figura en Apéndice A-20 ANOVA del experimento CIC tipo NASA A-2 Figura en Apéndice A-21 Prueba de varianzas iguales entre experimentos CIC... A-1 Figura en Apéndice A-22 ANOVA entre experimentos CIC A-2 
Figura en Apéndice A-23 Gráfica de evacuación/tiempo en una réplica de un experimento NASA 03

Figura en Apéndice A-24 Rutas seguidas por los individuos en dos réplicas A-1

Figura en Apéndice A-25 Vista cenital de una réplica de un experimento NASA 03 en la que se aprecia un cuello de botella en rojo, cuya duración es inferior al 10\% del tiempo total de evacuación.

Figura en Apéndice A-26 Gráfica del flujo de personas por las distintas puertas (pers/seg) durante una réplica de un experimento NASA14 A-2

Figura en Apéndice A-27 CIC tipo Centro04. A-3

Figura en Apéndice A-28 CIC tipo Centro04 con personal en Zafarrancho de Combate

Figura en Apéndice A-29 Dimensiones reales de un CIC tipo Centro04. A-3

Figura en Apéndice A-30 CIC tipo Nasa04. A-4

Figura en Apéndice A-31 CIC tipo Nasa04 con el personal en Zafarrancho de Combate A-4

Figura en Apéndice A-32 Dimensiones reales de un CIC tipo Nasa04 A-4

Figura en Apéndice A-33 Gráfica de valores individuales de Real_Centro04 Pathfinder A-1

Figura en Apéndice A-34 Gráfica de valores individuales de Real_Nasa04 Pathfinder A-1

Figura en Apéndice A-35 Prueba de varianzas iguales entre experimentos Comedor

Figura en Apéndice A-36 ANOVA entre experimentos Comedor. A-2

Figura en Apéndice C-1 ANOVA diferencia de las medias de disparo por arma. Opción A C-1

Figura en Apéndice C-2 ANOVA diferencia de las medias de disparo por arma. Opción B. C-1 
Figura en Apéndice C-3 ANOVA diferencia de las medias de disparo por arma. Opción C

Figura en Apéndice C-4 ANOVA diferencia de las medias de disparo por arma. Opción D

Figura en Apéndice C-5 ANOVA diferencia de las medias de disparo por arma. Opción E C-3

Figura en Apéndice C-6 ANOVA diferencia de las medias de disparo por arma. Opción $\mathrm{F}$ C-3

Figura en Apéndice C-7 Distribuciones y estadísticos descriptivos de la ametralladora de 12,7mm de Br que se intercambia de posición. Arriba en la opción B está a proa y abajo en la opción F está a popa 3

Figura en Apéndice C-8 . Distribuciones y estadísticos descriptivos de la ametralladora №2. Arriba la opción B, abajo la opción F. 4

Figura en Apéndice C-9 Distribuciones y estadísticos descriptivos de la ametralladora №3. Arriba la opción B, abajo la opción F

Figura en Apéndice C-10 Distribuciones y estadísticos descriptivos de la ametralladora №4. Arriba la opción B, abajo la opción F. 6

Figura en Apéndice C-11 Distribuciones y estadísticos descriptivos de la ametralladora Mk38 de Br que se intercambia de posición. Arriba en la opción B está a popa y abajo en la opción F está en proa 7

Figura en Apéndice C-12 Distribuciones y estadísticos descriptivos de la ametralladora №6. Arriba la opción B, abajo la opción F 8 


\section{Índice de Tablas}

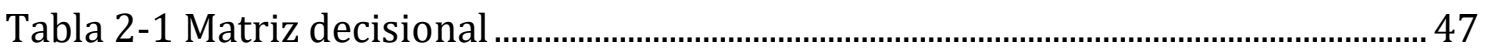

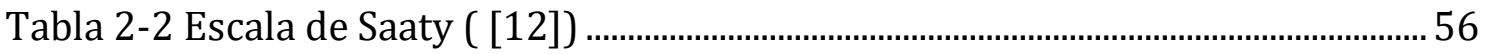

Tabla 2-3 Ejemplo de matriz de asignación de pesos a los criterios ................................ 57

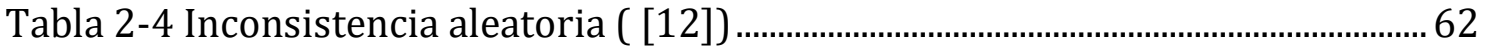

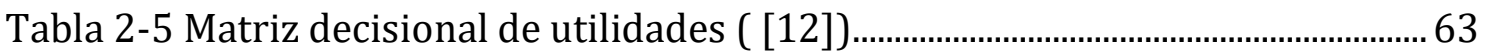

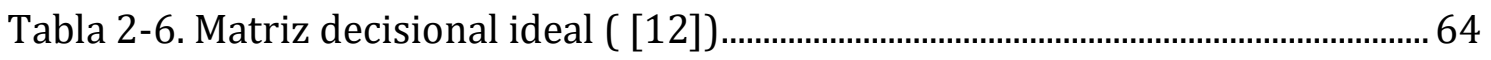

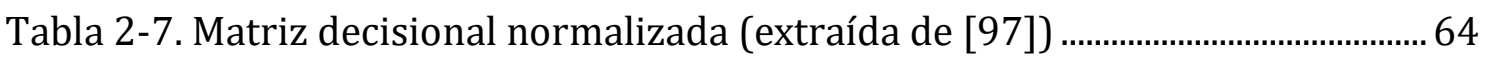

Tabla 3-1 Tabla de pesos de criterios/subcriterios/sub-subcriterios (Elaboración

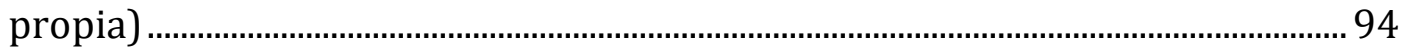

Tabla 3-2 Matriz decisional multicriterio subjetivo (Elaboración propia) ................ 95

Tabla 3-3 Diseño estadístico experimento evacuación (Elaboración propia) ........ 102

Tabla 3-4 Tiempos de evacuación del experimento del CIC tipo LADO (Elaboración

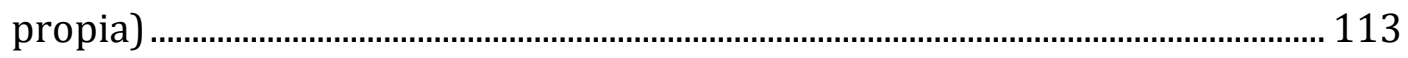

Tabla 3-5 Tiempos de evacuación del experimento del CIC tipo CENTRO (Elaboración propia).

Tabla 3-6 Tiempos de evacuación del experimento del CIC tipo NASA (Elaboración

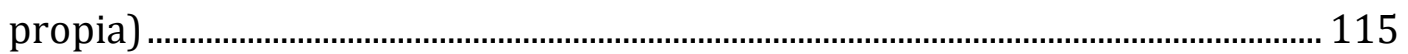

Tabla 3-7. Estadísticas descriptivas de los tiempos de evacuación reales del experimento "Centro04” (Elaboración propia) 118 
Tabla 3-8. Estadísticas descriptivas de los tiempos de evacuación reales del experimento "Nasa04" (Elaboración propia) ............................................................ 119

Tabla 3-9. Tiempos de evacuación de los otros experimentos.................................... 120

Tabla 3-10 Matriz decisional multicriterio objetivo (Elaboración propia)............. 123

Tabla 3-11 Matrices consolidadas por los expertos para asignación de pesos ...... 138

Tabla 3-12 MCP subjetivas para valoración de la contribución de las alternativas. Problema del comedor.................................................................................................... 139

Tabla 3-13 Tabla resumen de los análisis realizados a los datos................................. 148

Tabla 3-14 Tabla resumen de resultados de contrastes de hipótesis de los tiempos en la línea (Elaboración propia) .............................................................................. 161

Tabla 3-15 Tabla resumen de resultados de contrastes de hipótesis de los tiempos de las comidas (Elaboración propia) ......................................................................... 166

Tabla 3-16 Promedios de duración de las comidas en la F-103 (Elaboración propia)

Tabla 3-17 Promedio de los resultados de la simulación con AnyLogic (Elaboración propia).

Tabla 3-18 Resumen de los resultados ANOVA de los experimentos con AnyLogic (Elaboración propia). 175

Tabla 3-19 Pesos de criterios/subcriterios (Elaboración propia) 177

Tabla 3-20 Valoración global de los comedores con el multicriterio objetivo (Elaboración propia) 178

Tabla 3-21 Sub-matriz para DESTINO (Elaboración propia) 179

Tabla 3-22 Sub-matriz para DOTACIÓN (Elaboración propia) 179

Tabla 3-23 MCP consolidadas con las respuestas de los expertos. Problema de las ametralladoras. 198

Tabla 3-24 MCP subjetivas para la valoración de la contribución de las alternativas. Problema de las ametralladoras. 200

Tabla 3-25 Promedio de disparos por ametralladora. Opción A 208 
Tabla 3-26 Promedio de disparos por ametralladora. Opción B

Tabla 3-27 Promedio de disparos por ametralladora. Opción C ................................... 213

Tabla 3-28 Promedio de disparos por arma. Opción D.................................................. 216

Tabla 3-29 Promedio de disparos por arma. Opción E ................................................... 218

Tabla 3-30 Promedio de disparos por arma. Opción F ................................................. 220

Tabla 3-31 Resultados de ataques filtrados por sectores............................................. 223

Tabla 3-32 Datos resumidos para aplicar en las funciones de utilidad ..................... 223

Tabla 3-33 Tabla de pesos de criterios/subcriterios/sub-subcriterios (Elaboración

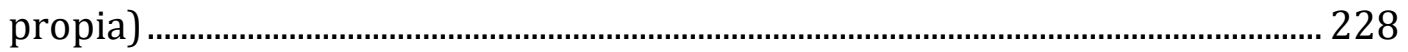

Tabla en Apéndice A-1 Tabla Excel elaborada para aplicación del estimador del número de réplicas. Datos de 10 réplicas del experimento NASA 13 ................A-1

Tabla en Apéndice A-2 Tabla de tiempos generada para los experimentos .............. A-1 


\section{Lista de Acrónimos}

\begin{tabular}{|c|c|}
\hline AAW & Guerra Antiaérea (Anti Air Warfare) \\
\hline ADLA & Ayuda a la Decisión de Líneas de Acción \\
\hline AHP & Proceso de Análisis Jerárquico (Analytic Hierarchy Process) \\
\hline AJEMA & Almirante Jefe del Estado Mayor de la Armada \\
\hline ASUW & Guerra Antisuperficie (Anti Surface Warfare) \\
\hline ASW & Guerra Antisubmarina (Anti Submarine Warfare) \\
\hline BAM & Buque de Acción Marítima \\
\hline BMD & Defensa de Misiles Balísticos (Balistic Missile Defense) \\
\hline $\mathrm{Br}$ & Babor \\
\hline $\mathrm{CIC}$ & Centro de Información y Combate \\
\hline $\mathrm{CO}$ & Comandante \\
\hline DEE & Diseño Estadístico de Experimentos \\
\hline DGAM & Dirección General de Armamento y Material \\
\hline DIPER & Dirección de Personal de la Armada \\
\hline DIVPLA & División de Planes del EMA \\
\hline DNO & Documento de Necesidad Operativa \\
\hline ELECTRE & ELimination Et Choix Traduisant la REalité \\
\hline EMA & Estado Mayor de la Armada \\
\hline ENM & Escuela Naval Militar \\
\hline $\mathrm{EO} / \mathrm{IR}$ & Electro - óptico / Infrarrojo \\
\hline $\mathrm{Er}$ & Estribor \\
\hline EXT & Exteriores \\
\hline $\mathrm{F}-100$ & Fragata clase Álvaro de Bazán \\
\hline $\mathrm{F}-110$ & Fragata tipo F-110 \\
\hline $\mathrm{F}-80$ & Fragata clase Santa María \\
\hline FDS & $\begin{array}{l}\text { Simulador de Dinámica del Fuego y Humo (Fire Dynamics Simulator and } \\
\text { Smokeview) }\end{array}$ \\
\hline FIAC & Embarcación de Ataque Rápido en Litoral (Fast Inshore Attack Craft) \\
\hline FIFO & Primero en Llegar Primero en Salir (First In First Out) \\
\hline FSEG & Fire Safety Engineering Group \\
\hline GIMO & Gabinete de Investigación Militar Operativa \\
\hline HSD & Diferencia Honestamente Significativa (Honestly Significant Difference) \\
\hline$I+D$ & Investigación y Desarrollo \\
\hline IAM & Inconsistencia Aleatoria Media \\
\hline IC & Índice de Consistencia \\
\hline
\end{tabular}




\begin{tabular}{|c|c|}
\hline IMO & Organización Marítima Internacional \\
\hline INT & Interiores \\
\hline JAL & Jefatura de Apoyo Logístico de la Armada \\
\hline JEMAD & Jefe de Estado Mayor de la Defensa \\
\hline LF & Línea Futura \\
\hline LSD & Diferencia Menos Significativa (Least Significant Difference) \\
\hline MADM & $\begin{array}{l}\text { Métodos de Toma de Decisión Multi-atributo (Multi Atribute Decision } \\
\text { Making) }\end{array}$ \\
\hline MASTIN & Mástil Integrado \\
\hline MAUT & Teoría de la Utilidad Multiatributo \\
\hline MCDM & Toma de Decisiones Multi-criterio (Multiple Criteria Decisión Maker) \\
\hline MCP & Matrices de Comparación por Parejas \\
\hline MGS & Machine Gun System \\
\hline MIRADO & $\begin{array}{l}\text { Material, Infraestructura, Recursos humanos, Adiestramiento, Doctrina y } \\
\text { Organización }\end{array}$ \\
\hline MIVES & Modelo Integrado de Valor para una Evaluación Sostenible \\
\hline MND & Documento de Necesidad Operativa \\
\hline MODM & $\begin{array}{l}\text { Métodos de Toma de Decisión Multiobjetivo (Multi Objetive Decision } \\
\text { Making) }\end{array}$ \\
\hline NATO (OTAN) & Organización del Tratado del Atlántico Norte \\
\hline NIST & National Institute of Standars and Technology \\
\hline NSC & Reglamento Naval para Buques (Naval Ship Code) \\
\hline 01 & Objetivo Principal \\
\hline OEM & Objetivo de Estado Mayor \\
\hline OMI & Organización Marítima Internacional \\
\hline OPINTEL & Inteligencia Operacional (Operational Intelligence) \\
\hline OS & Objetivo Secundario \\
\hline$P_{i}$ & Probabilidad de impacto \\
\hline PROMETHEE & Preference Ranking Organization METHod for Enrichment Evaluation \\
\hline $\mathrm{RC}$ & Relación de Consistencia \\
\hline REM & Requisitos de Estado Mayor \\
\hline RWS & Estación Remota de Artillería (Remote Weapon System) \\
\hline SAR & Búsqueda y Rescate (Search and Rescue) \\
\hline SCOMBA & Sistema de Combate \\
\hline SEDEF & Secretario de Estado de Defensa \\
\hline SOLAS & $\begin{array}{l}\text { Convenio Internacional para la Seguridad de la Vida Humana en el Mar } \\
\text { (Safety of Life at Sea) }\end{array}$ \\
\hline TAO & Oficial de Acción Táctica \\
\hline UAV & Vehículo Aéreo no Tripulado (Unnamed Aerial Vehicle) \\
\hline$U_{e}$ & Utilidad Éxito \\
\hline$U_{m}$ & Utilidad de la Munición \\
\hline$U_{t}$ & Utilidad del Tiempo \\
\hline$V_{p}$ & Vector de Prioridades \\
\hline VT-RF & Tiempo Variable- Radiofrecuencia (Variable Time - Radio Frecuency) \\
\hline$V_{u}$ & Vector de Utilidades \\
\hline $\mathrm{Z} / \mathrm{C}$ & Zafarrancho de Combate \\
\hline
\end{tabular}




\section{Producción Científica}

Parte de los resultados de esta tesis han sido publicados mediante los siguientes artículos científicos en revistas JCR:

- "A Framework for Integrating Human Factors in the Early Stages of Ship Design: Application to the Mess Halls of a Surface Combatant". González-Cela, Gerardo; Bellas, Roberto; Carreño, Rafael; Martínez, Javier; Touza, Ramón. J SHIP PROD DES “Journal of Ship Production and Design”. March 2019. ISSN: 2158-2866. JCR 2019.

\section{SNAME https://www.sname.org/pubs/authoroppo/journalofshippro duction}

- "Optimal Design of Spanish Navy F-110 Frigates Combat Information Center". González-Cela, Gerardo; Bellas, Roberto; Martínez, Javier; Touza, Ramón; Carreño, Rafael. NAV ENG J "Naval Engineers Journal” 130(1):79-90. March 2018. ISSN: 0028-1425. JCR 2019.

\section{$\Rightarrow$ AMERTCA SOCIet OF Naval EngINeERS http://www.navalengineers.org/Publications/Naval- \\ Engineers-Journal}

- "Optimum Configuration of the Secondary Artillery of the F-110 Spanish Frigates". González-Cela, Gerardo; Campo, Marco; Martínez, Javier; Carreño, Rafael; Bellas, Roberto; Touza, Ramón; Dena, Ángeles. J SHIP PROD DES “Journal of Ship Production and Design". Under Review. ISSN: 2158-2866. JCR 2019. 
Asimismo, parte de los resultados alcanzados durante el proceso de investigación de esta tesis fueron presentados en el siguiente congreso nacional:

- Comunicación oral en el XXXVII Congreso Nacional de Estadística e Investigación Operativa y las XI Jornadas de Estadística Pública, celebrado en Oviedo entre el 29 de mayo y el 1 de junio de 2018, organizados por la Universidad de Oviedo, con el siguiente título: "Estudio de optimización del comedor en la nueva fragata F-110".

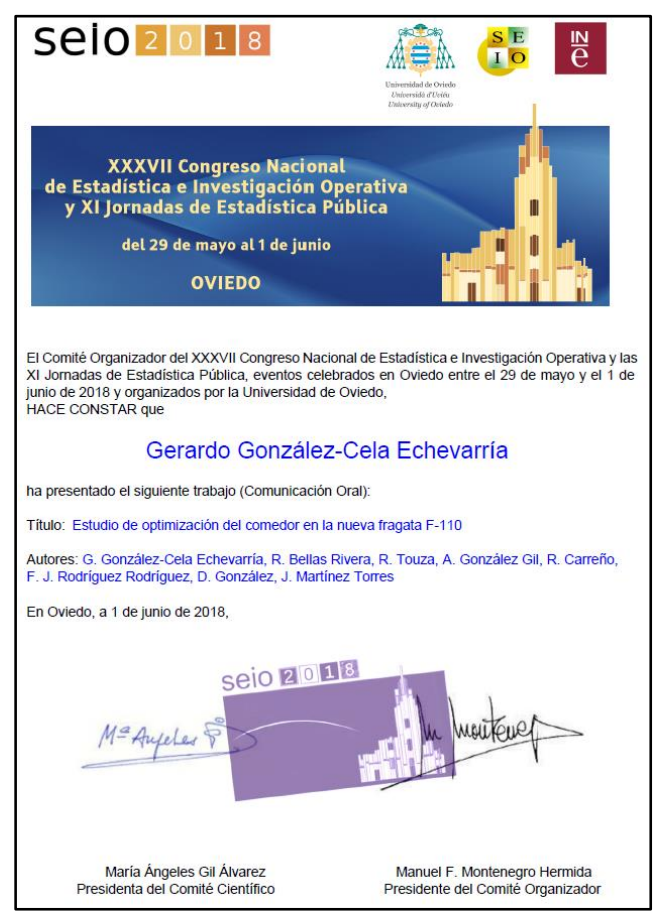




\section{Capítulo 1. Introducción}

\subsection{Motivación y Objetivos}

El objetivo principal (O1) de esta tesis es proporcionar un método analítico de ayuda en los procesos de trabajo que se generan para la toma de decisiones, fundamentalmente en el ámbito grupal, dentro de un entorno multicriterio. Como objetivos secundarios, se plantean los siguientes: objetivo secundario primero (OS1), analizar herramientas de simulación actuales; objetivo secundario segundo (OS2), desarrollo ad hoc de software en problemas donde no se encuentren herramientas de simulación adecuadas; y objetivo secundario tercero (OS3), reducción de la subjetividad en las decisiones multicriterio.

Esta idea surgió como consecuencia de una petición de colaboración del Estado Mayor de la Armada (EMA) al Gabinete de Investigación Militar Operativa (GIMO), acerca de unas decisiones importantes que debía adoptar concernientes a la construcción de unos nuevos buques denominados fragatas F-110.

EI EMA como principal órgano asesor del Almirante Jefe de Estado de la Armada [1] (AJEMA), se ve inmerso de manera continuada en la resolución problemas de diversa índole que, lógicamente, implican la toma de decisiones. Frecuentemente esta decisión supone escoger "la mejor" entre las distintas alternativas factibles.

Con esta tesis no se persigue una aportación acotada a la teoría general de la toma de decisiones, es decir, no se persigue una metodología única y restringida, sino enunciar un planteamiento flexible que se adapta a la particularidad de cada problema y que descansa de manera incondicional sobre el rigor científico que proporciona el método 
"Proceso de Análisis Jerárquico" (Analytic Hierarchy Process - AHP) que fue introducido por Saaty en 1977 [2].

\subsection{Preámbulo}

Escasos textos relacionados con la teoría de la decisión no comienzan resaltando la cotidianeidad del enfrentamiento del hombre a decisiones difíciles debidas, principalmente, a la necesidad de alcanzar diversos aspectos simultáneamente. La dificultad de la decisión radica en el conflicto que habitualmente subyace entre los deseos, que raramente satisfacen todos los aspectos. En estos casos, es donde la decisión a adoptar debe de resultar de un compromiso entre ellos.

Como sostiene Gal, et al. [3] , "desde la época de nuestros primeros ancestros humanos, hace muchos miles de años, se han tenido que tomar decisiones que han comprometido a múltiples objetivos en conflicto". ¿Dedicamos nuestros recursos a cazar la opción del mamut que implica "alto riesgo + alto beneficio", o cazamos algunos antílopes pequeños? ¿En qué momento comenzamos a almacenar alimentos para pasar el invierno, incluso cuando eso significaba menos comida para hoy? La evolución adaptó nuestros límites para poder tomar tales decisiones de manera efectiva gracias a la intuición. Pero a medida que el mundo se ha vuelto más complejo y cambiante, más amplio es el rango de objetivos a optimizar, y más difícil es encontrar soluciones óptimas. Incluso la palabra "óptima" debe entrecomillarse, ya que el concepto de optimalidad se torna cada vez más como un concepto confuso.

López [4], enfatiza que: "Las situaciones en las que un decisor, individual o colectivo, se ve confrontado con una elección en presencia de criterios múltiples son universales. Así, se podría decir que uno de los tópicos contemporáneos que ha alcanzado mayor predicamento en la práctica totalidad de los ámbitos y sectores de la sociedad es el de la necesidad de adoptar decisiones".

Ríos en [5], reseña que se puede aseverar que con la publicación en 1943 del tratado de Von Neumann, con sus aportaciones esenciales de la teoría de juegos y de la teoría de la utilidad, se marca el punto de partida del enfoque de los problemas de decisiones mediante el método científico. Este enfoque abarca campos tan diversos como el económico, militar, tecnológico, diplomático, político, social, etc. 
En los años 60 tuvo un gran auge la optimización tradicional en la teoría de la decisión. Existía un solo criterio en los problemas planteados y se podía idear la solución en los términos de maximizar o minimizar. Un problema clásico de optimización es el conocido como "problema de la dieta de los soldados de la Segunda Guerra mundial", en el que se planteaba cómo combinar varios alimentos de forma que los soldados recibiesen el total de aporte necesario de vitaminas, hierro, etc., alcanzando el mínimo coste de la ración de combate.

Así, en esos procesos de toma de decisiones, Romero [6] expone que el paradigma del análisis se podía y se puede esquematizar en las siguientes fases: Primeramente, se determina el conjunto de soluciones factibles. A continuación, basándose en un cierto criterio se establece una ordenación. Y finalmente, manejando métodos matemáticos más o menos sofisticados, se busca entre las soluciones factibles aquella que ha obtenido un mayor grado de deseabilidad, denominándose "solución óptima".

Desgraciadamente, los procesos reales de toma de decisiones se desvían del marco teórico anterior ya que prácticamente todas las decisiones involucran más de un criterio. Así, en los años 70 empezó a surgir un nuevo planteamiento del problema de la decisión. En los problemas reales suelen aparecen más de un criterio, pero es que, además, estos suelen entrar en conflictos del tipo: si quiero aumentar el beneficio también aumento el riesgo o si quiero aumentar la operatividad aumento también el gasto, etc.

Es decir, el problema de la dieta se ha complicado considerablemente. Se ha pasado de minimizar el coste, sujeto a las restricciones de aporte de vitaminas, hierro, etc., a un problema más complejo en donde se tiene que minimizar el coste de la ración, pero también maximizar la variedad y minimizar el volumen y peso del recipiente, todo sujeto, a su vez, a una colección de restricciones. Vemos pues, que ahora se tiene más de una función objetivo o criterio y, además estas, están en compromiso entre sí, esto es, si se intenta maximizar la variedad se aumentará el coste y seguramente el volumen del recipiente, y viceversa.

En la vida real también existe otro tipo de problema relativo a la elección de una alternativa entre varias posibles. Por ejemplo, antiguamente, si el Estado Mayor de la Armada necesitaba elegir entre varios posibles sistemas de armas, se basaba en la intuición y experiencia de los miembros que estuviesen allí destinados; se podría decir 
que tomar la decisión era relativamente sencillo. Ahora, los factores o criterios para la toma de la decisión han aumentado, para la elección de un nuevo sistema hay que tener en cuenta, el coste, posibilidad de reinversión nacional, cuestiones políticas, alcance, capacidades, tipo de mantenimiento, etc. ila decisión ya no es tan evidente!

Resumidamente, el decisor se encuentra en disposición de escoger entre varias posibilidades denominadas alternativas, cuyo conjunto es llamado "conjunto de elección". Para escoger una alternativa dentro este "conjunto de elección" el decisor tiene diversos "puntos de vista" denominados criterios. Estos criterios igualmente son, al menos parcialmente, contradictorios, en el sentido de que si el decisor enfoca desde uno de dichos puntos de vista, no escogerá la misma alternativa que si se basa en otro criterio.

La combinación de las matemáticas con el uso de ordenadores se ha convertido en una potente herramienta de ayuda en el proceso de búsqueda de la decisión. La programación matemática consigue soluciones satisfactorias frente a una colección de objetivos en conflicto. Sin embargo, el uso de esta herramienta debe estar sustentada en una base teórica rigurosa con respecto a la noción de optimalidad y las propiedades de los métodos que se aplican al hallazgo de la solución. Por otro lado, los métodos y resultados de la ayuda a la decisión multicriterio deben ser utilizados de una manera efectiva por los decisores, es decir, "les debe permitir comprender las opciones disponibles y expresar juicios de valor, sin que tengan que ser expertos en estos fundamentos teóricos subyacentes", como cita Gal, et al. [3].

Actualmente, existen muchas metodologías distintas para resolver los problemas de toma de decisiones multicriterio que se enmarcan en lo que se denomina el paradigma multicriterio o técnicas de decisión multicriterio o Multiple Criteria Decisión Maker (MCDM). Científicos de una amplia variedad de disciplinas, como matemáticas, economía o psicología, han contribuido enormemente al desarrollo en este campo.

Básicamente, las técnicas de decisión multicriterio se pueden dividir en dos ramas:

- Decisión multicriterio continua o Decisión multiobjetivo o (Multi Objetive Decision Making - MODM), que se corresponde con el problema antes citado 
relativo a la ración del soldado, es decir, un problema de optimización con dos o más funciones objetivo.

- Decisión multicriterio discreta o Decisión multiatributo (Multi Atribute Decision Making -MADM), que se utiliza para seleccionar "la mejor alternativa" dentro de un conjunto explícito de ellas y que corresponde al segundo problema planteado relativo a la elección de un sistema de armas entre varios posibles.

Los métodos de decisión multiobjetivo (MODM) se orientan a la utilización de técnicas de optimización matemática y, en su mayoría, implican un procedimiento de análisis relacionado con el proceso de diseño de cálculos. El MODM usualmente comprende la maximización de problemas matemáticos que involucran más de una función objetivo que necesita ser optimizada simultáneamente. Principalmente, se creó MODM para resolver problemas en programación y diseño matemáticos a través de las mejores alternativas. Sin embargo, los métodos de decisión de atributos múltiples (MADM) conllevan un enfoque desarrollado para seleccionar los mejores criterios o alternativas. Esto se usa en problemas de toma de decisiones que involucran varias alternativas. Este modelo se basa en la lista de criterios elegidos, sus parámetros y las variables que uno desea monitorear en el proceso de toma de decisiones.

Dentro de las técnicas denominadas decisión multiatributo (MADM) está el método denominado "Proceso de Análisis Jerárquico" (Analytic Hierarchy Process - AHP) introducido por Saaty en 1977 [2]. El AHP Consiste básicamente en descomponer un problema en una estructura jerárquica en cuyo vértice superior se sitúa el principal objetivo del problema, en la base se encuentran las posibles alternativas a escoger y en los niveles intermedios se representan los criterios multinivel en los que se descompone el problema. Así, la función es determinar para un objetivo concreto la alternativa más adecuada de entre las que se consideran a estudio.

El diseño de las jerarquías requiere experiencia y conocimiento del problema que se plantea, siendo indispensable disponer de toda la información necesaria y la colaboración de expertos en los distintos criterios seleccionados. El método AHP es un modelo de decisión que interpreta los datos y la información directamente, mediante la realización de juicios y medidas en una escala de razón dentro de una estructura jerárquica establecida. Uno de los axiomas básicos en los que se basa la teoría AHP es la 
comparación recíproca: El decisor debe ser capaz de realizar comparaciones y establecer la idoneidad de sus preferencias. Aquí radica una parte importante de la metodología AHP.

En 1846, Weber en [7] estableció su ley de la sensación (o Ley de Weber), que formulaba la relación matemática que existe entre la intensidad de un estímulo y la sensación producida por éste. Según su ley, se observa un cambio en la sensación si el estímulo aumenta en un porcentaje constante del estímulo en sí. Fechner en [8], siguió los estudios empezados por Weber, que habían concluido que existen tres tipos de umbrales en la percepción de las sensaciones: un umbral máximo, que es la magnitud a partir de la cual no percibimos ningún cambio en la sensación; un umbral mínimo, que es la mínima magnitud o cantidad de estímulo necesaria para captar una sensación; y finalmente, un umbral diferencial, que es la cantidad de estímulo que hay que añadir para que el sistema psicológico pueda captar un cambio en una sensación [9]. Es decir, las personas no pueden captar un conjunto infinito de sensaciones y, por ende, no pueden tomar decisiones de un conjunto infinito de opciones. Por ejemplo, ¿quién es capaz de distinguir la importancia entre dos valores muy muy cercanos?, como podría ser entre los valores 1007,00001 y 1007,00002.

Miller en [10], mediante experimentos psicológicos, concluye que a los individuos les resulta enormemente difícil comparar, simultáneamente, mucho más allá de siete objetos. Propuestas de escalas, existen múltiples y parten de distintas teorías psicológicas (ver la evaluación de escalas en [11]), pero Saaty en [12], siguiendo el razonamiento de Miller, establece su escala con el número nueve como límite superior y el número uno como límite inferior, con una diferencia de unidades entre los valores de escala sucesivos.

Como se ha mencionado anteriormente, el decisor puede ser una o varias personas $y$, es aquí, cuando el problema de la decisión puede adquirir una nueva dimensión que nos conecta directamente con las ciencias sociales: el sesgo de las decisiones grupales. Históricamente es conocido el hecho de que algunos métodos para combinar las preferencias individuales en preferencias colectivas son inconsistentes (Nanson [13], Arrow [14], Sen [15]). 
Para Allport [16], los enfoques de estudio relativos a cómo los grupos toman decisiones han ido evolucionando. Estudios sociológicos que comenzaron en los años 50, demostraron que las decisiones en grupo realzaban los puntos de vista predominantes inicialmente; es decir, incide un proceso denominado polarización grupal. Este es un fenómeno que pone de manifiesto los mecanismos de influencia del grupo pequeño sobre las actitudes de sus miembros.

La hipótesis de Polarización, según Janis [17], predice que generalmente la discusión favorecerá una actitud compartida para los miembros del grupo. Es decir, en el proceso de toma de decisiones, cuando un grupo altamente cohesionado o de mentalidad muy parecida, se encuentra muy condicionado por la búsqueda de consenso, resulta más difícil que las personas se manifiesten en contra de las opiniones de los demás. Por tanto, un alto nivel de cohesión puede deteriorar la percepción de la realidad llevando a tomar decisiones incorrectas.

Otro factor importante relacionado a los procesos de toma de decisiones es la subjetividad. La Real Academia Española (RAE), define el adjetivo "subjetivo" como: Perteneciente o relativo al modo de pensar o de sentir del sujeto, y no al objeto en sí mismo. Se puede considerar, por tanto, que independientemente de la técnica empleada de ayuda a la decisión existe un máximo común divisor a todo método y este es la subjetividad. No existe método, técnica o planteamiento del problema de la decisión, en la que no subyazca en mayor o menor medida, una cierta dosis de subjetividad que aporta sesgos indeseables, pues, al fin y al cabo, siempre algún sujeto está presente en cualquier planteamiento y resolución del problema de la decisión.

En este contexto, con este trabajo se ha diseñado una metodología de ayuda a la decisión analítica que, en la medida de lo posible, aporta la máxima objetividad reduciendo con ello, los sesgos implícitos al difícil proceso de la toma de decisiones.

\subsection{Breve Recorrido Histórico de la MCDM}

Aunque en el preámbulo ya se han adelantado algunas pinceladas, es interesante añadir este nuevo apartado específico acerca del "joven" recorrido histórico de la MCDM, en el que se ha tomado como referencia el libro de Köksalan et al. [18] y las aportaciones de Francisco Rúa en [19] (Catedrático de Métodos Cuantitativos para la Economía y la 
Empresa en la Universidad de Málaga y miembro titular de la International Society on MCDM [20]).

Se podría decir, que la primera referencia conocida en relación con la toma de decisiones multicriterio se remonta a Benjamin Franklin (1706-1790) quien, supuestamente para decidir asuntos importantes, ideó un sistema simple plasmado sobre una hoja de papel. Por una cara, se escriben los argumentos a favor de una decisión; y por la otra, se escriben los argumentos en contra. Posteriormente, se tachan los argumentos de cada cara de la hoja que sean de igual importancia relativa. Cuando todos los argumentos de una cara están tachados, el lado que tiene los argumentos restantes es el lado del argumento que debe apoyarse [21]. Aunque, según se sugiere en [22], ya en el Siglo XVI san Ignacio de Loyola había discurrido un método bastante semejante, que reside en considerar las ventajas y las desventajas de aceptar una propuesta; a la vez que, considerar las ventajas y las desventajas de no aceptarla.

Marie-Jean-Antoine-Nicolas de Caritat (más conocido por su título, Marqués de Condorcet, 1743-1794), matemático, político y científico francés, fue pionero en la aplicación de las matemáticas a las ciencias sociales, en particular a las elecciones. Escribió el famoso ensayo sobre la aplicación del análisis de la probabilidad de decisiones por mayoría en 1785 [23]. En este documento describió el teorema del jurado de Condorcet, la paradoja de Condorcet y el llamado Método de Condorcet. La paradoja de Condorcet es quizás la más conocida: Establece que las preferencias colectivas pueden convertirse en intransitivas, aunque las preferencias individuales sean transitivas. Condorcet, no estuvo de acuerdo con otro erudito contemporáneo, el militar, matemático y politólogo francés Jean-Charles de Borda (1733-1794), que defendía el uso de la suma de clasificaciones.

Georg Cantor (1845-1918) fue un matemático alemán nacido en San Petersburgo, Rusia. Es conocido por ser el creador de la teoría de conjuntos y otras muchas aportaciones fundamentales a las matemáticas (descubridor de los infinitos). Los conceptos matemáticos utilizados en MCDM se cimentan en muchas de sus contribuciones. Desde 1992, la Sociedad Internacional de MCDM entrega los premios Georg Cantor.

Francis Edgeworth (1845-1926) fue una persona influyente en el desarrollo de la economía neoclásica. Fue el primero en aplicar conceptos matemáticos formales a la 
toma de decisiones. Desarrolló los fundamentos de la teoría de la utilidad, introduciendo la noción de indiferencia y la famosa caja de Edgeworth [24]; un instrumento gráfico utilizado para representar y analizar el intercambio de dos bienes entre dos sujetos y, así, mostrar la eficiencia en el intercambio. Fue nombrado profesor de Economía en el King's College de Londres en 1888, y más tarde fue profesor de Economía Política en la Universidad de Oxford.

Más recientemente, el economista Vilfredo Pareto (1848-1923), nacido en París de padres inmigrantes italianos, fue el primero en estudiar matemáticamente la agregación de criterios conflictivos en un único índice integrado. También fue el primero en introducir el concepto de eficiencia (que se conoció como óptimo de Pareto), uno de los conceptos clave de la economía y de la teoría moderna en MCDM. La asignación óptima de recursos se logra cuando no es posible mejorar a nadie sin empeorar al menos a otra persona. Pareto se graduó en el Instituto Politécnico de Turín en 1869. Curiosamente, a lo largo de su vida, Pareto criticó activamente las políticas económicas del gobierno italiano, a pesar de que no estudió seriamente economía hasta que tuvo más de cuarenta años. En 1893, sucedió a Leon Walras como profesor de Economía en la Universidad de Lausana. Sus principales publicaciones son "Cours d'économie politique" [25] y "Manual of Political Economy" [26]. En 1906, Pareto reelaboró la caja de Edgeworth: Dada una cierta cantidad de recursos en una caja de Edgeworth, la curva de contrato es el conjunto Pareto eficiente de asignaciones en una situación de mercado de dos agentes. Tanto la obra de Pareto como la de Edgeworth han tenido unos significativos efectos sobre la economía, la ciencia de la negociación y el MCDM moderno. También desde 1992, la Sociedad Internacional de MCDM entrega los premios Edgeworth-Pareto.

\section{Orígenes del análisis de decisión y Utilidad esperada}

Una reflexión de los orígenes del análisis de la decisión estaría incompleta sin mencionar las primeras contribuciones de Frank Ramsey (1903-1930), que presentó el primer conjunto de axiomas para elegir entre alternativas con resultados inciertos, que conducen a un modelo de la utilidad esperada (subjetiva) [27].

Leonard Savage (1917-1971) siguió los pasos de Ramsey al desarrollar su propia teoría de la elección, que es similar, pero utiliza una terminología diferente [28]. 
En 1944, John von Neumann (1903-1957) y Oskar Morgenstern (1902-1977) introdujeron su versión de la teoría de la utilidad esperada, aparentemente sin conocer las contribuciones de Ramsey, estableciendo las bases para un enfoque moderno de la MCDM [29].

La contribución de John Nash (1928-2015) a la teoría de juegos no cooperativos de npersonas (ver [30]) y a la solución del llamado problema de negociación (ver [31]), son fundamentales y han tenido una gran influencia en la economía moderna. Nash recibió el Premio Nobel de Economía en 1994.

Gerard Debreu (1921-2004), Premio Nobel de Economía en 1983, es otro de los primeros que contribuyó, con publicaciones muy influyentes, a la teoría de la utilidad y el beneficio (ver [32], [33]).

En 1938, Paul Samuelson (1915-2009) publicó un artículo titulado " A Note on the Pure Theory of Consumer's Behavior " [34], describiendo un concepto que más tarde llamó "preferencia revelada". Samuelson recibió el Premio Nobel en Economía en 1970 por sus muchas contribuciones a la economía.

Ward Edwards (1927-2005) es considerado uno de los padres de la investigación en la conducta de la decisión. Publicó dos artículos transcendentales: "The Theory of Decision Making" [35], en 1954, donde Edwards introdujo a los psicólogos en el modelo de utilidad esperada y planteó la pregunta: ¿se comportan las personas como si tuvieran una función de utilidad?; y "Behavioral Decision Theory" [36], en 1961, del que germinó el campo de la toma de decisiones conductuales, el documento discutió temas como la forma en que la gente toma decisiones y la forma en que se podrían mejorar. Sin duda alguna, actualmente, cada vez es más reconocido que deberíamos tener una mejor comprensión de cómo los humanos toman decisiones con el fin de proporcionar un mejor apoyo a los decisores.

Otra persona muy influyente en la teoría de la toma de decisiones es Herbert Simon (1916-2001), que junto con Allen Newell (1927-1992) es considerado uno de los padres de la inteligencia artificial, un campo que también ha influido en el MCDM moderno. Simon, en contra de la corriente principal de la economía, afirmó que la toma de decisiones no obedece a los postulados del "hombre racional". En una serie de artículos 
y libros que comienzan en la década de 1940, Simon escribió acerca de la toma de decisiones. Entre otras cosas, desarrolló una teoría del comportamiento basada en una racionalidad limitada o restringida. (ver [37]). Simon afirmó que los humanos no son maximizadores de utilidad, sino que buscan un nivel de satisfacción mediante el establecimiento de unos niveles de aspiración. Si son capaces de alcanzar tales niveles de aspiración, son felices. Los niveles de aspiración juegan un papel importante en las técnicas modernas de MCDM. Simon ganó el Nobel Premio de Economía en 1978.

El teorema de imposibilidad de Arrow, o también llamado la paradoja de Arrow, demuestra que ningún sistema de agregación puede convertir las preferencias (ordinales) de los individuos en una clasificación para toda la comunidad, y que al mismo tiempo se cumplan ciertos criterios razonables, con tres o más opciones discretas entre las que elegir. Estos criterios se denominan: Principio de no-dictadura, Dominio no restringido o universalidad, No imposición o eficiencia (débil) de Pareto, Independencia de alternativas irrelevantes y Principio anti-estratégico. El teorema lleva el nombre del economista Kenneth Arrow (1921-2017) quien presentó el teorema en su tesis doctoral y lo dio a conocer en su libro "Social Choice and Individual Values" [14], de 1951. Sobre el teorema de Arrow se ha generado mucha investigación acerca de cómo "sortear" la dificultad original, modificando alguna de las suposiciones. Arrow fue uno de los galardonados con el Premio Nobel de Economía de 1972.

Duncan Luce (1925-2012) y Howard Raiffa (1924-2016) en 1957 publicaron “Games and Decisions: Introduction and Critical Survey" [38], que se podría catalogar como un predecesor de la teoría de la decisión actual. Poco después en 1959, Ron Howard (nacido en 1934), actualmente profesor en el Departamento de Ingeniería y Economía de Sistemas en la universidad de Stanford escribió "Sequential Decision Processes" [39], con G. E. Kimball (1906-1967). Juntamente con James Matheson, Howard también escribió "Decision Analysis: Applied Decision Theory", publicado en las Actas de la Cuarta Conferencia Internacional sobre la Investigación Operativa de 1966, donde supuestamente utilizaron el término "análisis de las decisiones" por primera vez. Howard Raiffa publicó dos importantes libros sobre el análisis de decisiones durante los años 60, el primero con Robert Schlaifer en 1961, "Applied Statistical Decision Theory" 
[40] y la segunda en 1968, "Decision Analysis Introductory Lectures on Choices Under Uncertainty" [41] . Este último se centra en el conocido método del árbol de decisiones. Sin relación con Neumann y Morgenstern, Ragnar Frisch (1895-1973), un Premio Nobel noruego de Economía, publicó un artículo relativamente desconocido en 1961 (ver [42]), donde desarrolló una técnica basada en entrevista para obtener la función de utilidad (importancia) de una persona. Frisch quiso experimentar su método en el Parlamento noruego, pero su intento fracasó. Los diputados simplemente no querían que se hiciesen públicas sus "funciones de utilidad".

Un contribuyente muy prolífico a la teoría de la utilidad fue Peter Fishburn (nacido en 1936). Hizo muchas contribuciones fundamentales a la teoría de la elección social y la utilidad durante su carrera. Fishburn escribió dos libros muy conocidos en la década de 1960: "Decision and Value Theory" [43], en 1964 y "Utility Theory for Decision Making" [44], en 1970. Ambos libros profundizan en la teoría de la utilidad.

Los métodos ELECTRE comprenden una familia de métodos MCDM que se originó en Francia a mediados de la década de 1960. El acrónimo ELECTRE quiere decir ELimination Et Choix Traduisant la REalité (eliminación y elección que traduce la realidad). El método fue propuesto por primera vez por Bernard Roy (1934-2017) y sus colegas de SEMA, una empresa de consultoría. Un equipo de trabajo en SEMA estaba trabajando en un problema multicriterio concreto de cómo las empresas elegían entre las posibles nuevas actividades a las que dedicarse. Habiendo encontrado problemas utilizando las sumas ponderadas, Bernard Roy fue llamado como consultor. Roy tenía experiencia en teoría de grafos y junto con el grupo de trabajo de SEMA desarrolló el método ELECTRE original. Se aplicó por primera vez en 1965, para ayudar a elegir la mejor o las mejores de un conjunto dado de acciones; pronto se aplicó también a los problemas de ordenamiento y clasificación. El método se hizo más popular cuando un artículo titulado "La méthode ELECTRE" de Bernard Roy apareció en la revista francesa de investigación operativa "Revue d'Informatique et de Recherche Opérationelle" [45], en 1968. Más tarde se convirtió en ELECTRE I y las evoluciones han continuado con ELECTRE II (1971), ELECTRE III (1978), ELECTRE IV (1982), ELECTRE IS y ELECTRE TRI. Bernard Roy es ampliamente reconocido como el padre del método ELECTRE, que fue uno de los enfoques primigenios en lo que, a veces, se conoce como la Escuela Francesa de la toma de 
decisiones. Por lo general, este método se considera el origen y médula central de los "métodos de superación" en la toma de decisiones [46].

\section{Orígenes de la programación matemática multiobjetivo}

Es difícil hablar de las raíces de la programación matemática multiobjetivo sin empezar por reconocer las contribuciones de George Dantzig (1914-2005) a la programación lineal. La historia de la programación lineal es fascinante. En 1947, George Dantzig propuso el algoritmo simplex como un método eficiente para resolver problemas de programación lineal (ver [47]). Luego trabajó en el programa SCOOP (Scientific Computation of Optimum Programs), un programa de investigación del gobierno de los Estados Unidos, buscando hacer más eficientes las operaciones logísticas en tiempos de guerra. Mientras, en la Unión Soviética, Leonid Kantorovich (1912-1986) había propuesto un proyecto similar en 1939 (ver [48]), desafortunadamente, su contribución permaneció desconocida para el mundo occidental. Posiblemente, lo que hizo que las contribuciones de Dantzig fueran tan importantes, fue el desarrollo simultáneo de los ordenadores, haciendo posible el uso del algoritmo simplex para resolver problemas del mundo real y, por ello, la programación lineal se popularizó rápidamente en la industria. El conocido libro de texto de Saul Gass, "Linear programming: methods and applications" [49], publicado en 1958, ayudó a que su aplicación se extendiera enormemente.

Algunos investigadores llevaron la programación lineal hacia problemas de programación no lineal, en particular Harold Kuhn (1925-2014) y Albert Tucker (19051995), su trabajo "Nonlinear Programming" [50], en 1951 es un clásico, también el libro de G. Zoutendijk, "Methods of Feasible Directions" [51], publicado en 1960. La programación matemática tenía un problema: no era adecuada para resolver problemas multiobjetivo per se. Pero desde un principio, los investigadores se dieron cuenta de que podían utilizar ponderaciones para combinar varios objetivos en un único objetivo compuesto o sustitutivo. Por consiguiente, se puede aseverar, que la programación matemática proporcionó la base y marco teórico necesarios para la programación matemática multiobjetivo.

A principios de los años 50, Tjalling Koopmans (1910-1985), Premio Nobel de Economía en 1975, extendió el trabajo de Pareto introduciendo la noción de "vector eficiente" en 
el contexto de un problema de asignación de recursos, allanando el camino para una programación matemática multiobjetivo. Véase "Analysis of Production as an Efficient Combination of Activities" [52], de Koopmans, publicado en 1951.

Dos documentos influyentes de Saul Gass (nacido en 1926) y Thomas Saaty (1926-2017) abordando la función objetiva paramétrica, publicados en 1954 y 1955, merecen ser mencionados (ver [53] y [54]). Su algoritmo podía utilizarse para generar soluciones eficientes variando los pesos de una función de valor compuesto (agregado), una técnica muy extendida en los primeros métodos de programación lineal de multiobjetivo.

En 1955, Abraham Charnes (1917-1992), William Cooper (1914-2012), y R.O. Ferguson publicó un artículo "Optimal Estimation of Executive Compensation by Linear Programming" [55], en Management Science que contenía la esencia de la programación por metas, aunque el término meta, se usó por primera vez en el libro de Charnes y Cooper, "Management Models and Industrial Applications of Linear Programming" [56], en 1961. La idea de la programación por metas es simple y se relaciona con el concepto de Simon de nivel de aspiración. Se pide al decisor que especifique los valores objetivo para las metas y se formula el problema como una forma de minimizar las diferencias ponderadas a esos valores objetivo. De forma alternativa, en lugar de pesos, se podría utilizar un modelo lexicográfico para los objetivos. En la versión original, todas las funciones de restricción y objetivo se asumieron de forma lineal. Por lo tanto, la programación por objetivos podría considerarse como una generalización de la programación lineal.

Gracias al trabajo de Charnes y Cooper se impulsó e incitó a numerosos estudiosos a continuar trabajando en la programación por metas, que ha vivido un flujo constante de publicaciones de investigación. Entre los primeros colaboradores se encuentran Bruno Contini (nacido en 1936) y Stanley Zionts (nacido en 1937), ambos alumnos de Cooper, quienes desarrollaron un modelo de negociación multicriterio, "Restricted Bargaining for Organizations with Multiple Objectives" [57], publicado en 1968.

Otras publicaciones influyentes sobre programación por metas fueron "Management Goals and Accounting for Control" [58], de Yuji Ijiri en 1965 y "Goal Programming for Decision Analysis" [59], de Sang Lee en 1972. 
Arthur M. Geoffrion (nacido en 1937) publicó dos importantes artículos a finales de la década de 1960, ayudando a sentar las bases teóricas para la programación matemática multiobjetivo. El primero fue sobre la resolución de programas matemáticos bi-criterio (ver [60]) publicado en 1967. El documento mostró en detalle cómo generar la frontera eficiente para el caso de dos objetivos. El segundo trabajo desarrolló el concepto de "eficiencia apropiada" y la teoría de la maximización vectorial [61]. En este documento se redefinió el concepto fundamental de eficiencia para eliminar la existencia de situaciones anómalas y gracias a la definición de eficiencia apropiada se evitaron algunos de los inconvenientes inherentes a definiciones anteriores.

Varios estudiosos abordaron la valoración vectorial de los criterios en forma de control automático u óptimo. Uno de los primeros fue Lotfi A. Zadeh (1921-2017) en su breve documento "Optimality and Non-Scalar-Valued Performance Criteria" en 1963, escribe:

"Una de las debilidades más graves de las teorías actuales del control óptimo es que se basan en el supuesto de que el rendimiento de un sistema puede medirse por un solo número... El problema con este concepto de optimización es que, en general, hay más que una consideración que entra en la evaluación del rendimiento del sistema y, en la mayoría de los casos, estas consideraciones no pueden ser asimiladas a través de una valoración de magnitud escalar de los criterios"

Zadeh, también hizo una aportación novedosa a lo que se conoció como análisis de robustez al inventar la teoría de conjuntos difusos. Muchos de los expertos en MCDM siguieron los pasos de Zadeh sugiriendo técnicas MCDM difusas. El artículo original fue publicado en 1965, se titulaba "Fuzzy Sets" [62]. La teoría de conjuntos difusos o lógica difusa de Zadeh se ha extendido considerablemente y se aplica a diversos campos, desde la teoría de control hasta la inteligencia artificial.

En la década de los 70 se produjeron muchas contribuciones fundamentales en la teoría y el desarrollo de métodos para la toma de decisiones multicriterio, incluyendo la publicación del libro de Ralph Keeney y Howard Raiffa sobre la teoría de la utilidad del multiatributo (1976) y el libro de Jared Cohon sobre la programación y planificación multiobjetivo (1978) [63]. Se desarrollaron muchos métodos importantes de programación matemática interactiva (Benayoun, et al., 1971; Geoffrion, Dyer y Feinberg, 1972; y Zionts y Wallenius, 1976). La optimización vectorial también avanzó, 
en particular gracias a los esfuerzos de Ralph E. Steuer. Bernard Roy avanzó en este campo desarrollando diferentes versiones de los métodos ELECTRE y estableciendo el Grupo de Trabajo Europeo sobre Ayuda a la Decisión de Criterios Múltiples (MCDA), que celebró su 74ạ reunión en octubre de 2011. Po-Lung Yu y Milan Zeleny aportaron avances en el campo con el desarrollo de teorías y métodos. Hacia el final de la década, Andrzej Wierzbicki desarrolló el concepto de la función "scalarizing" de logros. A finales de los años 70, Thomas L. Saaty publicó la primera versión de su célebre trabajo sobre el Proceso de Análisis Jerárquico.

Se podría afirmar que desde los 80, los principales avances en MCDM están relacionados con el uso de los ordenadores cada vez más potentes que permiten su uso en la resolución de problemas cada vez más complejos.

\subsection{Enfoque del Estudio Relativo a las Decisiones Grupales}

La incertidumbre es un rasgo esencial de nuestra vida cotidiana. Cuando es necesario tomar decisiones importantes, por ejemplo, la construcción de instalaciones que pueden suponer un riesgo para la salud pública o el medio ambiente es corriente que se presenten varias alternativas cuyas ventajas e inconvenientes son difíciles de evaluar en su justa medida. En estos casos "Ios juicios u opiniones de las personas encargadas de resolver el problema, habitualmente expertos en la materia, son el único medio de cubrir el vado existente entre una información y un conocimiento limitados y la necesidad de dar solución al problema adoptando una decisión" [64].

Muchos autores concuerdan en que los juicios acerca de un problema pueden ser clasificados en: implícitos (informales), o explícitos (formales). Los juicios informales suelen abordar el problema de forma global sin considerar los detalles con detenimiento. Por el contrario, las opiniones formales se obtienen descomponiendo el problema en subproblemas que se adicionan de forma lógica y coherente.

La parte de la psicología que se dedica al estudio de: la percepción, los procesos de pensamiento y la elaboración de juicios; es la psicología del conocimiento, que ha determinado "la existencia de diversos mecanismos típicos de inferencia en condiciones de incertidumbre que, cuando no se utilizan adecuadamente, dan lugar a la presencia de sesgos en las opiniones que emiten las personas" [64]. Estos sesgos se traducen en 
que esas opiniones no son consistentes con la información en que se basan y no reflejan el nivel real de incertidumbre que posee la persona.

Uno de los sesgos más estudiados acerca de las opiniones y decisiones de las personas es el del pensamiento grupal, conducente a veces a resultados catastróficos como, por ejemplo, el accidente del Challenger [65].

En el transcurso de esta tesis se ha trabajado con expertos pertenecientes al mismo colectivo: la Armada Española. Es necesario, por tanto, hacer una breve reflexión acerca del sesgo por pensamiento grupal, pues la Armada, como organización jerarquizada con una fuerte cultura de empresa profundamente enraizada en su personal, posee muchas de las particularidades que favorecen a que pudiera que florecer este sesgo.

Irving Janis, psicólogo social de Yale, estaba anonadado con la cuestión de: cómo grupos de expertos reconocidos pueden tomar decisiones tan desastrosas. No por ello, los consideraba estúpidos, inútiles o malvados. Más bien, los veía como víctimas del pensamiento grupal.

Janis [17], define el pensamiento grupal como: "un modo de pensar que la gente adopta cuando están muy involucrados dentro de un grupo cohesionado, cuando entre las personas que participan en el mismo, la búsqueda de la unanimidad prevalece sobre su motivación para evaluar de manera realista la otra alternativa". De acuerdo con su definición, el pensamiento grupal sólo se produce cuando la cohesión es alta. Requiere que los miembros compartan un fuerte grado de unión y de voluntad de mantener las relaciones en el seno del grupo a toda costa. Cuando los participantes trabajan en modo de pensamiento grupal, automáticamente aplican la regla que Janis define como: "conservar la armonía grupal a cada decisión que enfrentan".

Algunos psicólogos están alineados en la creencia de que los grupos de alta cohesión son más eficaces que los grupos de baja cohesión, en el logro de sus respectivos objetivos [66]. Janis sostiene que, el "súper pegamento" de la solidaridad que une a las personas a menudo hace que su proceso mental se ciegue, y que la tendencia a favor del consenso de los grupos puede hacer que tomen decisiones equivocadas:

"Cuanto mayor sea la amabilidad y el espíritu de equipo entre los miembros de un grupo de toma de decisiones, mayor es el peligro de que el pensamiento crítico independiente 
sea reemplazado por el pensamiento de grupo. ... La limitación social consiste en el fuerte deseo de los miembros de preservar la armonía del grupo, que los inclina a evitar crear cualquier discordancia de argumentos o rupturas".

Sobre la base teórica del pensamiento en grupo (Figura 1-1), Janis enumera ocho síntomas que indican si la búsqueda del consenso ha llevado al grupo al fracaso por incurrir en un pensamiento de mentalidad grupal. Los dos primeros se derivan del exceso de confianza en la capacidad del grupo. Los siguientes dos reflejan una visión estrecha que los miembros utilizan para ver el problema. Los últimos cuatro, son signos de una fuerte presión de conformidad dentro del grupo [67].

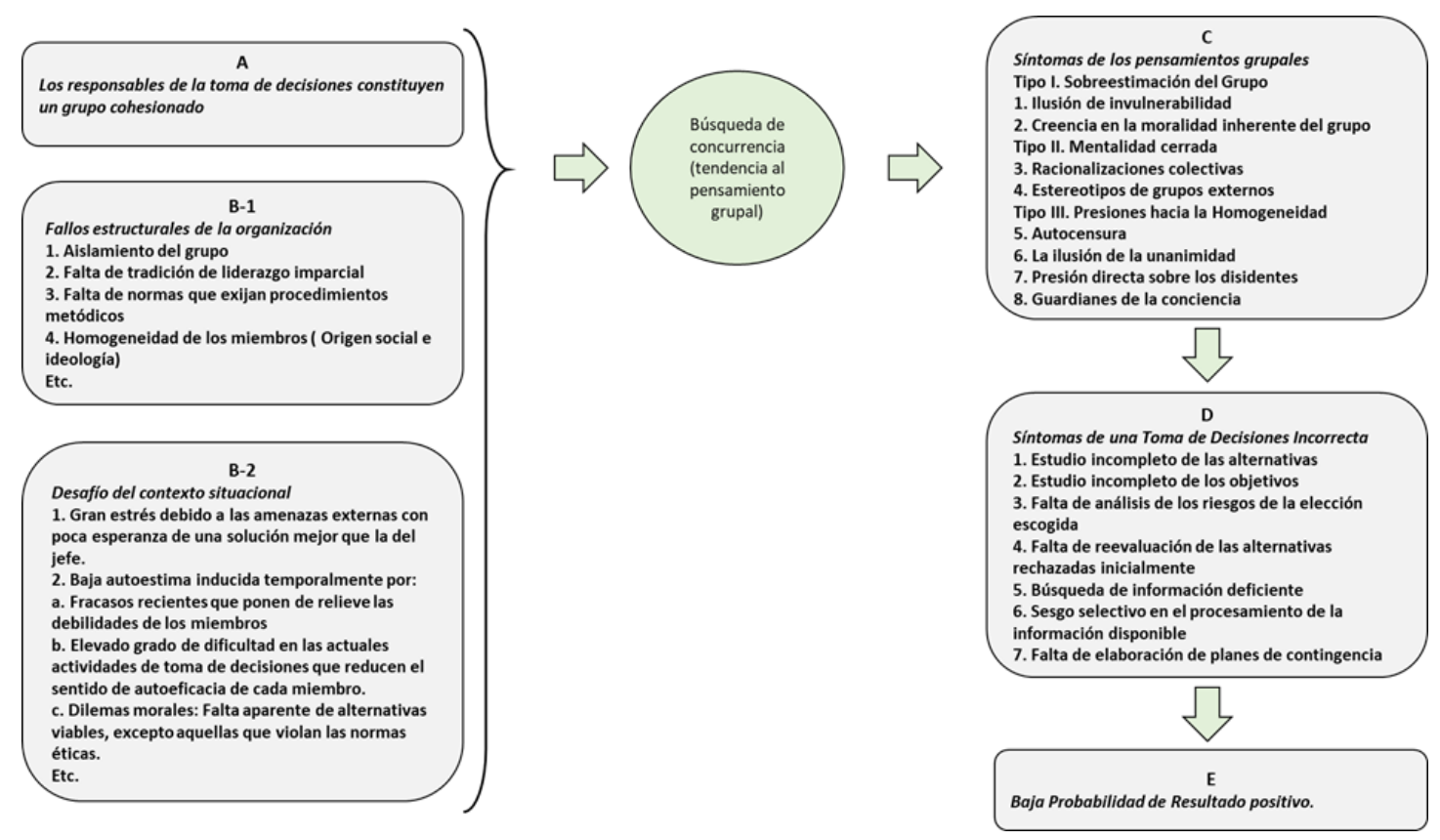

Figura 1-1 Análisis teórico del pensamiento en grupo ( [67])

Así, conforme a lo expuesto en [67] los síntomas de pueden enumerar (Recuadro C de Figura 1-1) en los siguientes:

1. Ilusión de invulnerabilidad. Esta actitud se resume como: "todo va a salir bien porque somos un grupo especial".

2. Creencia en la moralidad inherente del Grupo. Bajo la influencia del pensamiento grupal, los miembros asumen automáticamente la corrección de su causa.

3. Racionalización colectiva. Compartición de ideas erróneas. Se podría entender como un apoyo colectivo para: "no escuchar el mal, no ver el mal, no hablar mal". 
4. Estereotipos externos. Por ejemplo, el empleo del sarcasmo para ridiculizar a otras personas.

5. Autocensura. Por ejemplo, el empleo de modales y palabras muy moderadas.

6. La ilusión de la unión. La ficción de que todos están totalmente de acuerdo con una decisión. Interpretación de los silencios como un acuerdo.

7. Presión directa sobre los que disienten.

8. Autoproclamados Guardianes de la Conciencia. O "Guardianes de la Mente" protegen al líder de que los asalten con ideas problemáticas.

El término pensamiento en grupo de Janis [17], tiene cierta similitud con la siniestra expresión "doble-pensar" de Orwell [68], y con frecuencia se empleó como un término general para referirse a cualquier plan de grupo mal concebido. En posteriores extensiones de su teoría, Janis enfatizó que no todas las malas decisiones son el resultado del pensamiento grupal, y no todos los casos de pensamiento grupal terminan fallando [67].

La Figura 1-1 muestra la teoría extendida de Janis sobre el pensamiento en grupo. Los cuadros de la izquierda establecen las condiciones previas para una tendencia a la búsqueda de la concurrencia y los cuadros de la derecha muestran el camino que toma el grupo cuando piensa en grupo.

El recuadro A muestra que la cohesión es uno de los principales factores que contribuyen al pensamiento grupal. Sin embargo, no todos los grupos terminan sucumbiendo al pensamiento grupal. La cohesión es necesaria pero no es condición suficiente para la búsqueda de una concurrencia excesiva.

La probabilidad de pensar en grupo aumenta cuando hay fallos estructurales dentro de la organización (recuadro B-1) y la decisión debe ser tomada durante una época de mucho estrés y baja autoestima (recuadro B-2). El secreto del cortocircuito del proceso consiste en alterar los factores de las casillas B que actúan como catalizadores en grupos cohesivos. Los puntos que un dirigente inteligente puede cambiar son los tres primeros en el recuadro B-1, relativo al aislamiento del grupo, la falta de liderazgo imparcial y falta de normas de procedimiento. 
Un grupo muy unido en la cúspide de una organización frecuentemente está aislado de opiniones externas, por ello, Janis sugiere dividirlo en subgrupos que trabajen simultáneamente sobre el mismo tema. Cada subgrupo puede recurrir a la experiencia de subordinados de confianza a los que se debe animar a dar su consejo libremente.

Desafortunadamente, la misma fuerza de la personalidad que hace ascender a un líder puede tener un efecto escalofriante en la franqueza del grupo. Algunos líderes pueden dirigir una discusión imparcial sin imponer sus opiniones, pero más beneficioso para la investigación abierta es que el líder abandone periódicamente el grupo para que los miembros se sientan libres de expresar sus puntos de vista personales.

Debido a que muchos grupos no tienen procedimientos establecidos para asegurar un escrutinio cercano de las soluciones favorecidas, Janis recomendó que se asigne el papel de evaluador crítico a cada miembro. En lugar de representar a su propia circunscripción o área de especialización, cada participante asumiría la responsabilidad de todo el plan. Por supuesto, la solicitud de comentarios críticos de un líder es un ejercicio vacío si él o ella muestra irritación o interrumpe el debate cuando el grupo comienza a dividir una idea apreciada por él.

Si estas medidas fallan, se puede detectar la presencia del pensamiento grupal por el examen de efectos enumerados en el lado derecho de la Figura 1-1. Ya se han comentado los síntomas del pensamiento grupal del recuadro $\mathrm{C}$ que, inevitablemente, llevan a los siete procedimientos defectuosos catalogados en el recuadro D.

No necesariamente siempre ocurre el desastre. Los grupos que hacen todo mal pueden tener suerte de vez en cuando. Hay, también, muchas ocasiones rutinarias en las que un modo de pensar en grupo es realmente útil porque permite un consenso rápido y amistoso sobre cuestiones de menor importancia. Pero según Janis, cuando un grupo se enfrenta a un gran reto o a una importante decisión, la búsqueda de concurrencia casi siempre produce una solución inferior. No parece haber una manera definitiva de probar que la teoría de Janis es correcta (o incorrecta), pero su concepto de pensamiento grupal continúa captando adeptos en aquellos que han visto a grupos muy unidos tomar decisiones terribles. 
Sirvan estas líneas anteriores para ilustrar unos de los posibles sesgos en la toma de decisiones que se pretender reducir con el diseño de esta nueva metodología.

\subsection{Antecedentes}

En este punto se pretende exponer brevemente cuál ha sido el marco experimental, paraguas bajo el cual, se ha trabajado y desarrollado esta tesis.

En la actualidad la Armada cuenta con dos tipos de fragatas [69]: Seis fragatas de la clase Santa María (F-80) (Figura 1-2), que a partir del año 2022 empiezan a cumplir el tiempo estimado de vida operativa, es decir, el final de su vida útil tras 35 años de servicio; y cinco fragatas denominadas clase Álvaro de Bazán (F-100) (Figura 1-3) , de las cuales, la primera cuenta con 16 años de servicio.

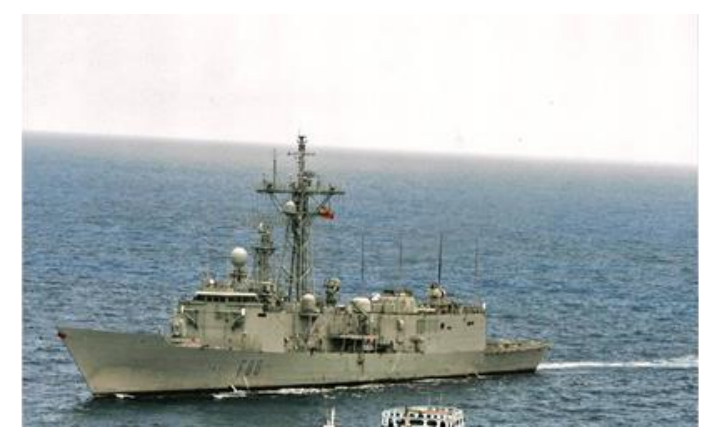

Figura 1-2 Fragata F-80 (www.armada.mde.es)

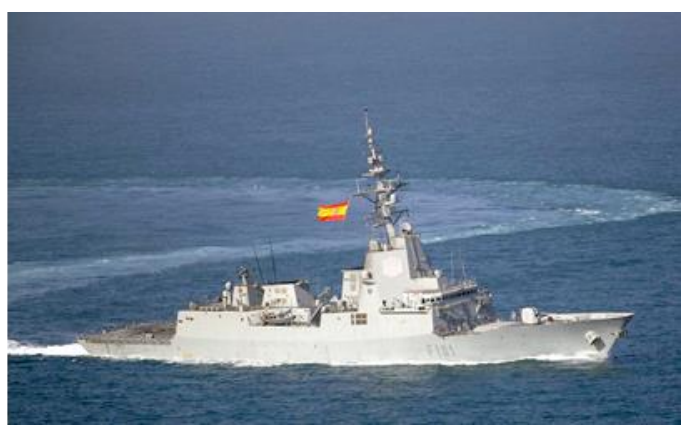

Figura 1-3 Fragata F-100 (www.armada.mde.es)

La Armada lleva más de 10 años trabajando en la necesidad de las nuevas fragatas F-110 que estarán destinadas a ser el relevo de la actual clase F-80.

El comienzo del proceso de obtención de las fragatas F-110 arrancó en el año 2009, con la publicación por parte del AJEMA del documento denominado “Líneas Generales para la definición del futuro buque F-110". Ese mismo año, se organizaron unas Jornadas Tecnológicas con participación de la Armada y la industria nacional e internacional, para analizar las últimas tendencias en diseño y construcción naval, y analizar los sensores y armas del futuro.

Como indica la instrucción del Secretario de Estado de la Defensa (SEDEF) [70]: "El proceso de obtención de recursos materiales se articula en fases y etapas. Los resultados obtenidos de la ejecución de las actividades establecidas en cada una de ellas se recogen en hitos documentales, sobre los que las autoridades implicadas en el proceso 
fundamentan su toma de decisiones y se pronuncian sobre la continuidad del mismo, con la excepción de la etapa de Preparación de la ejecución que, en función de la alternativa de obtención por la que se opte, podrá contar o no con un hito decisorio. Los hitos que ponen fin a cada una de las etapas constituyen puntos de decisión o control en los que se analizan los resultados de la actividad ya desarrollada y se dan directrices para continuar el proceso una vez valorados los riesgos asociados con el objetivo de asegurar que la línea de acción seleccionada es apropiada para satisfacer la necesidad que la originó y los resultados esperados de ella compensan el esfuerzo de su puesta en ejecución; que es practicable desde el punto de vista técnico, tecnológico o industrial; y que es previsible la viabilidad de su financiación."

Un año más tarde, en junio de 2010, conforme a la normativa en vigor del Ministerio de Defensa [70], el AJEMA firmó el Documento de Necesidad Operativa (DNO). EI DNO puede referirse como primer hito documental y es requisito indispensable para iniciar un programa de armamento.

Del DNO emanan: Primero, una serie de requisitos operativos, técnicos, logísticos y físicos; y posteriormente unas especificaciones técnicas del buque.

El proceso de obtención de recursos materiales, se podría decir que se desarrolla, principalmente, durante dos primeras fases [70] (Figura 1-4):

- Fase Conceptual

- Fase de Definición y Decisión

El DNO se encuadra dentro de la fase conceptual (ver Figura 1-4).

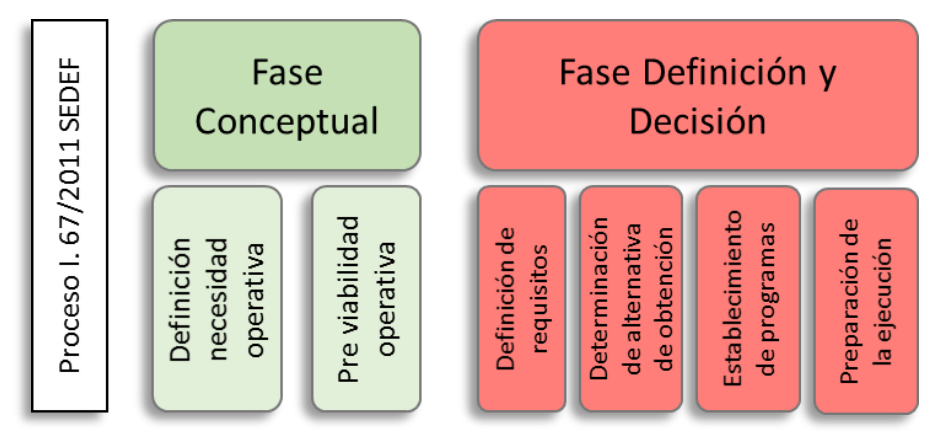

Figura 1-4 Fases de transformación de Documento de Necesidad Operativa (Elaboración propia de imagen tomada de [71]) 
La importancia de estas dos primeras fases es capital, especialmente en lo referente al aspecto económico, como señala Antón en [72]: “Durante estas dos fases, se produce el mayor compromiso en coste de todo el Proceso de Obtención y, como está demostrado que el coste de los cambios tiene una tendencia exponencial a medida que avanza el proceso, las decisiones que se tomen durante las dos primeras fases del Proceso, imperativamente, deben ser lo más precisas posible."

En [73], se indica que el diseño inicial del buque es la fase más crucial, ya que los defectos en el diseño de los buques pueden dar lugar a una serie de modificaciones costosas o incluso a un rediseño completo del barco. Mas del 70\% de las implicaciones de coste son en la primera fase de diseño, aunque los gastos que se realizan durante esta primera fase suponen menos del $5 \%$ de la inversión [74]. El principal factor que contribuye al aumento de los costes de construcción son los cambios incorporados al final del proceso de diseño [75].

En el año 2010 el EMA dio el pistoletazo de comienzo al Proceso de Obtención de la F110 (Figura 1-5), mediante la redacción de una actualización al DNO, seguido de la escritura del Objetivo de Estado Mayor (OEM) en enero de 2013 [71].

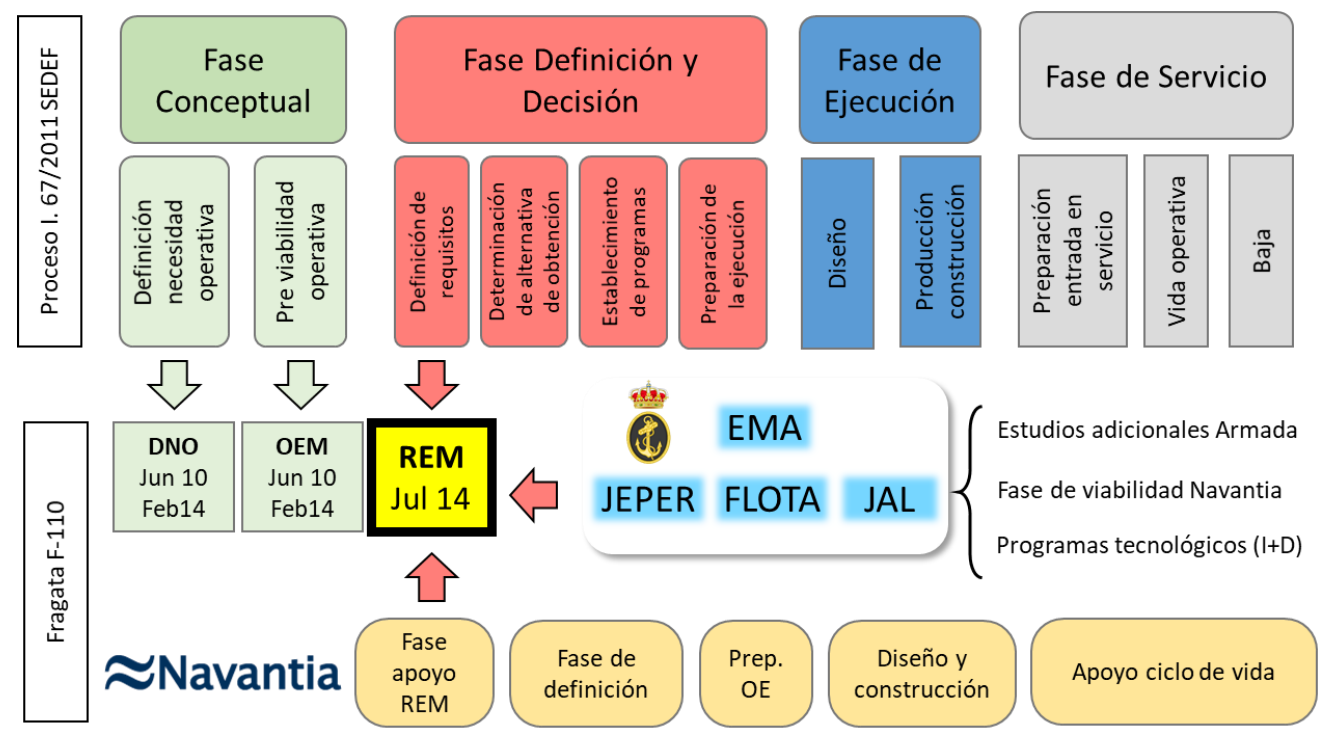

Figura 1-5 Programa de Obtención de recursos materiales (Elaboración propia de imagen tomada de [71])

En septiembre de 2013, con el propósito de dar cumplimiento al novedoso proceso regulado en la Instrucción del SEDEF, se formó un equipo dedicado exclusivamente a la redacción de los Requisitos de Estado Mayor (REM). El objetivo por conseguir era una definición operativa rigurosa, que abarcase de forma completa todas las capacidades 
del buque y que, además, analizase los factores MIRADO $^{1}$ tal como establece la mencionada instrucción del SEDEF. Este equipo, formado por oficiales del EMA y de la Jefatura de Apoyo Logístico (JAL), estuvo conformado por un total de 65 oficiales y suboficiales de la Armada, que elaboraron los estudios adicionales en las áreas fundamentales del buque. Estos estudios, entre los que destaca el de «Operaciones en el litoral», son la base para la formulación, en diciembre de 2013, de la primera versión del REM de la fragata F-110.

En enero de 2014, comenzó la Fase de Apoyo a los REM (Figura 1-6), ingenieros de Navantia [76] e Indra [77], comenzaron a trabajar con el equipo ya formado del EMA y de la JAL en la depuración de esta primera versión del documento REM. Analizaron en detalle la viabilidad de todos los requisitos, su coherencia, se realizaron estimaciones de costes, dimensiones del buque, etc.

Esta Fase de Apoyo se ha manifestado crucial y, probablemente, ha establecido un referente para futuros Procesos de Obtención. Durante un periodo de seis meses, se realizaron más de 50 estudios detallados y 650 propuestas de modificación a las sucesivas ediciones de los REM. Después de cinco minuciosas revisiones, en las que participaron los expertos y a las que se incorporaron las últimas aportaciones de la JAL, de la Flota y de la Dirección de Personal (DIPER), el REM de la F-110 quedó finalmente listo y fue aprobado por el AJEMA el día 16 de julio de 2014. Siendo, posteriormente, validado por el Jefe de Estado Mayor de la Defensa (JEMAD) [71].

1 MIRADO: Material, Infraestructura, Recursos humanos, Adiestramiento, Doctrina y Organización; factores que configuran una Capacidad militar. 


\section{Fase de "Apoyo a la redacción del REM" F-110}

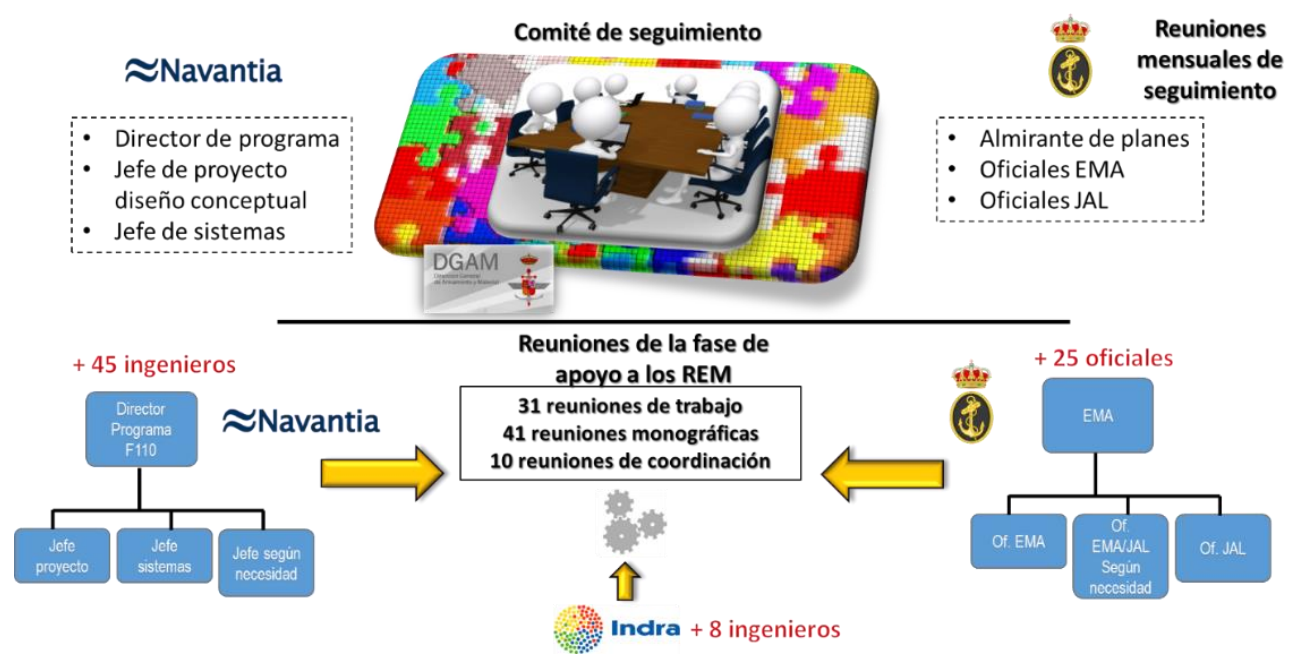

Figura 1-6 Fase de apoyo a la redacción del REM F-110. (Elaboración propia de imagen tomada de [71])

Como se puede comprobar, el proceso de obtención de una fragata es muy largo y complejo. Tiene una duración superior a los diez años desde su concepción inicial hasta el comienzo de la construcción del primer buque. Estas características del programa de construcción y el largo ciclo de vida de un buque, aproximadamente 35 años, suponen la realización de continuas adaptaciones durante su desarrollo y obliga a incorporar nuevas tecnologías en sus sistemas para evitar obsolescencias tempranas.

Por ello, el Consejo de Ministros en junio de 2015, propuso la realización, vía I+D, de una serie de Programas Tecnológicos que permitiesen incorporar nuevos sistemas y equipos de origen nacional en futuras plataformas con un grado de madurez técnica adecuado. Para este programa se previeron unas necesidades de financiación de más de 170 millones de euros. Estos programas son fundamentales para desarrollar los sensores (radares, guerra electrónica, sistema electroóptico), el Sistema de Combate (SCOMBA) y el Mástil Integrado (MASTIN).

En octubre de 2015, también aprobado en Consejo de Ministros, se anunció el contrato para la Fase de Definición de la fragata F-110 por un importe de casi 20 millones de euros. La financiación de este programa se realizó con Programas Especiales de Armamento a través del Ministerio de Industria y Energía.

El objeto de esa Fase de Definición era la asistencia técnica de Navantia en la elaboración de la documentación técnica, de gestión y económica necesaria que permitiese definir 
un buque, y apoyar a la Dirección General de Armamento y Material en la elaboración del documento de viabilidad y las especificaciones de diseño.

Tal como se anunció en el Consejo de Ministros del 2 de octubre de 2015, la fragata F110 (Figura 1-7) será "un sistema de armas nuevo y complejo que integra sistemas avanzados, que cubrirá misiones operativas y estratégicas esenciales para la defensa y la seguridad, en los que debe primar en todo momento, mantener la independencia funcional y operativa y el principio de libertad de acción".

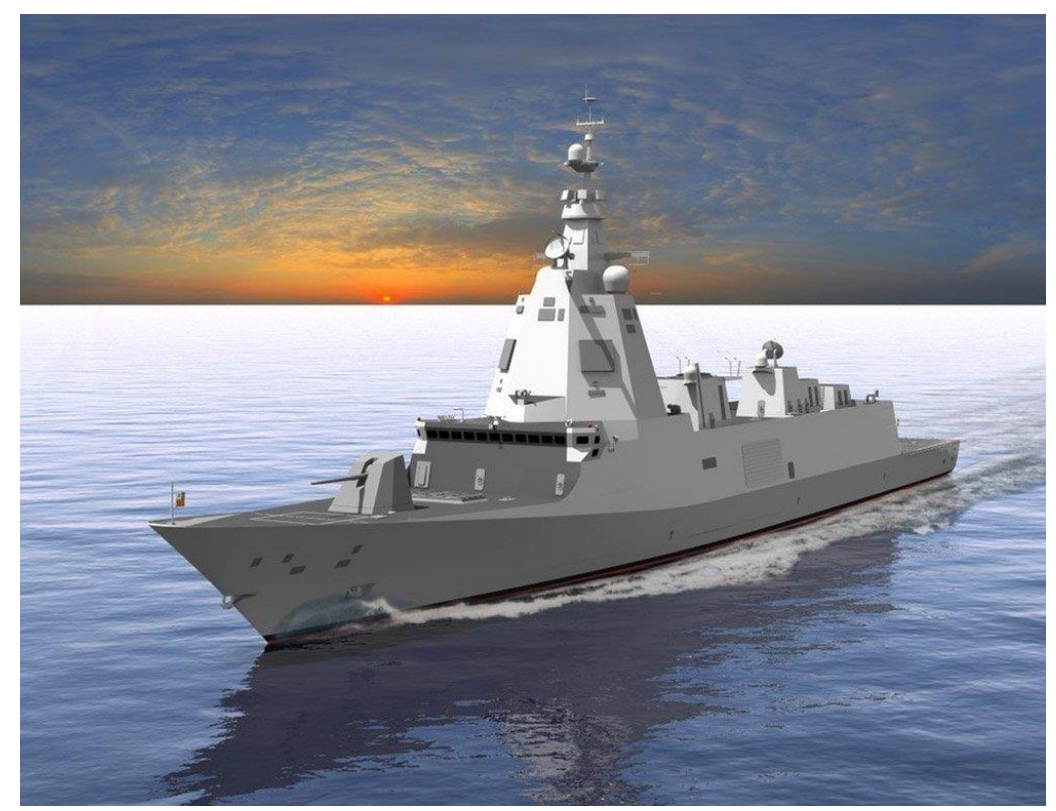

Figura 1-7 Impresión artística de la F-110 (Navantia)

Dentro de todas esas actividades mencionadas, que se han extendido hasta finales de 2018, a la Sección de Planes de Definición de Capacidades de la División de Planes del EMA, que dentro de sus cometidos está el de "Elaborar el diseño de la Armada del futuro y establecer las líneas maestras en asuntos de infraestructura a partir de la determinación de necesidades, identificando las unidades y medios necesarios en cuanto a plataformas, sistemas e instalaciones, definiendo los requisitos operativos que deban cumplir y estableciendo prioridades. En este proceso, dirigirá el periodo conceptual y de definición y decisión del proceso de obtención de armamento y material en la Armada hasta la firma de la orden de ejecución, en que pasará a ser responsabilidad de la División de Logística, teniendo presente la viabilidad en términos del recurso financiero y de personal para apoyar la definición de dichos medios" [3], se le plantearon diversos conflictos que le obligaron a tomar decisiones acerca del diseño 
del nuevo buque. Algunos de estos conflictos fueron derivados al GIMO en una petición de ayuda para su resolución. Como consecuencia de estas peticiones de ayuda, se planteó el idear una metodología analítica de ayuda a la decisión en la que en un decisor analítico construido ad hoc respondiese a cada caso de estudio y que, en todos los casos, se pudiese reducir el grado de subjetividad y sesgos en las opiniones de los decisores.

\subsubsection{Beneficios industriales}

Es interesante insistir nuevamente sobre la relevancia del marco experimental en el que se ha trabajado en el desarrollo en esta tesis, pues este, no puede ser más sugestivo: El diseño y construcción de la fragata F-110.

El proyecto de la nueva fragata representa un importante reto de contenidos industrial y tecnológico, el Ministerio de Defensa en [78] destaca de este programa que:

- “Desarrollará y difundirá tecnologías avanzadas e innovaciones con carácter estratégico que afectarán a áreas de conocimiento y sectores diversos".

- "Generará nuevos activos industriales y de servicios, contribuyendo a la creación de empleo en sectores con alto nivel de cualificación y de futuro".

- “Contribuirá al impulso y crecimiento de empresas nacionales e integradoras de productos con alto valor añadido facilitando la cooperación entre ellas".

- $\quad$ "Posibilita la colaboración entre empresas públicas y privadas mejorando la competitividad industrial para poder acceder a mercados globales".

- $\quad$ "Será la plataforma integradora de otros proyectos nacionales de I + D en desarrollo".

- $\quad$ "Será un elemento clave para continuar en el mercado de exportación de productos complejos en países tecnológicamente avanzados".

El astillero Navantia, con este programa de construcción, quiere adentrase en el importante mercado de exportación naval militar mundial, que supone unos 6.000 millones de dólares anuales. Y, como se subraya en [78]: "Para tener éxito en la exportación, la competitividad de los productos de Navantia es fundamental y el modelo de colaboración Defensa/Armada-Navantia es uno de los pilares sobre el cual edificar esta competitividad. En este ámbito, el programa de las fragatas F-110 es clave para la modernización de la Flota de la Armada y, para asegurar el futuro de Navantia en la 
exportación de este tipo de productos, manteniendo la senda iniciada con las fragatas F-100."

La incorporación en la F-110 del MASTIN que puede ser configurado con diferentes soluciones de sensores y antenas $y$, por consiguiente, se puede adaptar a las necesidades requeridas por el misil seleccionado; la disposición del espacio multimisión, que amplía sus capacidades en todos los segmentos de guerra; la integración a bordo de vehículos no tripulados; y su capacidad para la instalación futura de armas de energía dirigida que le puede proporcionar la propulsión eléctrica; le confieren al buque una versatilidad que puede ser interesante para un mercado expectante.

Como se señala en [78], la actividad de Navantia tiene importantes efectos de arrastre macroeconómicos y sobre el empleo, debidos al carácter de industria de integración que tiene el sector de construcción naval. Esto implica que, "para llevar a cabo su actividad, Navantia realiza demandas de consumos intermedios, equipos y de empleo a múltiples sectores de la economía española, por una cantidad muy elevada respecto a la facturación directa de cada proyecto que Navantia lleva a cabo. Además, estos efectos de arrastre de Navantia se amplifican al transmitirse a lo largo de las sucesivas cadenas de valor de los proveedores de los proyectos de construcción naval que realiza".

Un dato que puede servir de ilustración de estos potentes efectos de arrastre de Navantia como industria de integración es que, en los períodos de máxima carga de trabajo durante la última década, la relación entre trabajadores de la industria auxiliar en las instalaciones de Navantia y trabajadores de la plantilla propia podía llegar acercarse a un ratio de 2 a 1.

El análisis del impacto sobre la demanda agregada, el PIB y el empleo de la actividad de construcción de cinco fragatas F-110, se realiza teniendo en cuenta los multiplicadores de la demanda agregada, multiplicadores del PIB y del empleo que genera cada unidad monetaria de facturación de Navantia, y extrapolándolos al caso concreto de las cifras de actividad que generaría la construcción de las F-110. Estos multiplicadores tienen en cuenta tanto los efectos directos, como los efectos indirectos sobre otros sectores que la actividad de Navantia generaría con este proyecto concreto [78]. 
El cálculo de los multiplicadores de la demanda, PIB y empleo se ha realizado utilizando las tablas input-output simétricas para España publicadas por la OCDE para 2009 (último dato disponible con inclusión del sector naval para España). Estos multiplicadores se encuentran en línea con los de otros estudios recientemente publicados sobre el impacto macroeconómico y el empleo en España tanto del sector naval como del Ministerio de Defensa.

En base a los informes del sector naval militar, de los escenarios identificados para el desarrollo del sector Naval español, y del informe sobre el Impacto económico, cultural y social de la Defensa realizado por el Ministerio de Defensa, Navantia ha generado una estimación de impacto macroeconómico y en el empleo proporcionando los siguientes resultados [78]:

- $\quad$ "Por cada unidad monetaria (euros) de facturación de Navantia con este proyecto de construcción de cinco fragatas F-110, se genera una demanda agregada total en la economía española de 3,1 unidades monetarias (euros)".

- $\quad$ "Por cada unidad monetaria (euros) de facturación de Navantia con el proyecto de construcción de cinco fragatas F-110, el PIB de la economía española se incrementa en 1,2 unidades monetarias (euros)".

- $\quad$ "Por cada millón euros anuales de facturación del proyecto, se generarán cerca de 17 empleos anuales directos e indirectos durante 9 años (periodo previsto aproximado de duración de la construcción de las cinco fragatas F110)".

Según [78], conforme a lo anterior, se determina el impacto macro promedio anual en valores monetarios y en número de ocupados de la construcción de 5 fragatas F-110, teniendo en cuenta unos ingresos previstos por unidad construida de 740 millones de euros durante un período de 9 años, de manera que se obtienen los siguientes resultados en términos monetarios y en número de empleos medios anuales durante el período de construcción del programa F-110:

- "Durante 9 años se generaría un valor añadido directo e indirecto para la economía de aproximadamente 590 millones de euros anuales".

- "Durante 9 años se generarían anualmente cerca de 7.000 ocupados directos e indirectos por la puesta en marcha del programa F-110. De ellos, más de 1.300 
serían empleados directos, más de 2.000 empleados de la Industria Auxiliar de Navantia y más de 3.500 serían empleados indirectos generados por otros suministradores".

\subsubsection{La Fragata F-110}

Para una mejor comprensión de la investigación y del trabajo realizado en esta tesis, en este punto se expondrá someramente, qué es la fragata F-110, cómo es la organización de un buque de guerra, y más adelante, se explicará con algo más de detalle los equipos, sistemas y funcionamiento de compartimentos, que han sido la substancia del estudio y aplicación de la metodología diseñada.

Como menciona González-Aller en [71]: "Las fragatas F-110 están ideadas para ser buques equilibrados en todas las áreas de la guerra naval, es decir, que podrán operar en escenarios de alta intensidad y de baja intensidad, por lo que deberán ser suficientemente versátiles como para operar en el entorno litoral, donde el patrón de operaciones es más complejo en todos los aspectos" (Figura 1-8).

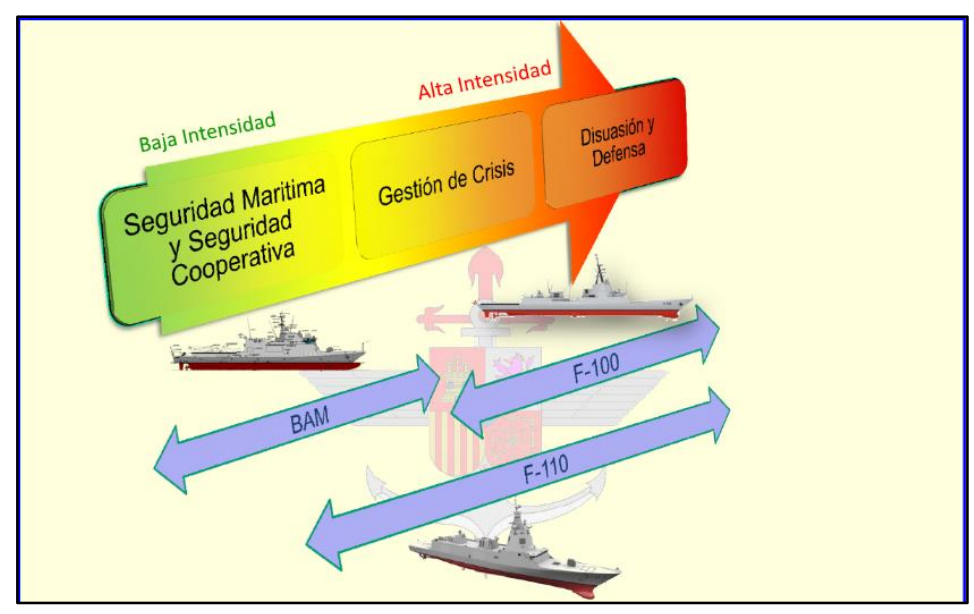

Figura 1-8 F-110 Misiones genéricas y escenarios (DGAM)

Detrás de las definiciones de capacidades y sistemas del buque que se definen durante el largo periodo del proceso de obtención, subyacen sus cometidos, que serán variados y complicados, ya que la interacción de la mar, la tierra y la actividad humana que confluye en el litoral, hacen de este escenario un ambiente especialmente demandante para las armas y los sensores. 
En concordancia con lo definido por el AJEMA en [79], su cometido principal será la protección de buques, civiles y militares y la defensa de los intereses marítimos y, también, tendrá cometidos de proyección sobre tierra, como la infiltración de unidades militares embarcadas, guerra naval especial, operaciones de fuerza avanzada previas a las operaciones anfibias, fuego naval de apoyo, guerra asimétrica o colaboración con unidades de guerra de minas (Figura 1-9).

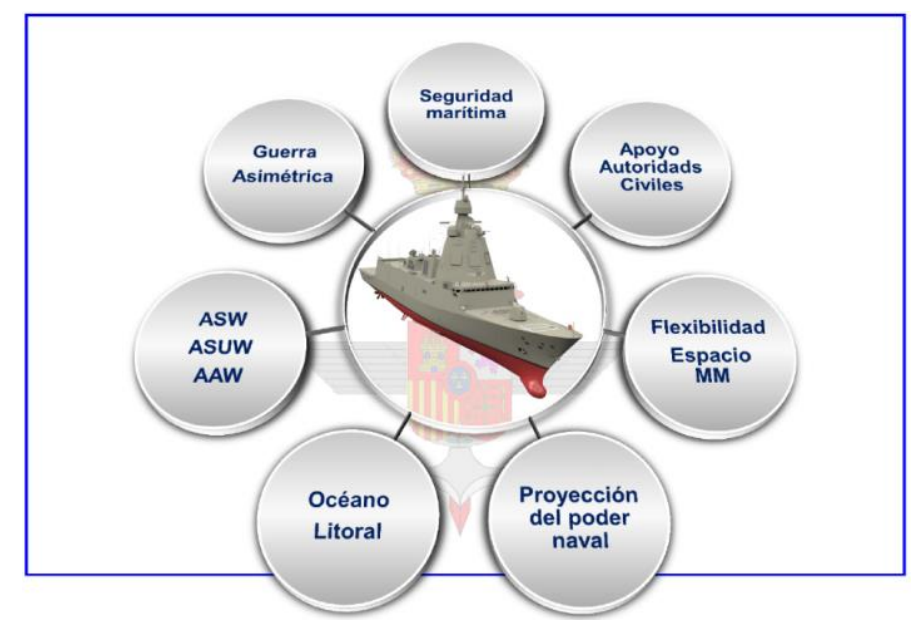

Figura 1-9 Concepto de la F-110 (DGAM)

Para cumplir las misiones mencionadas anteriormente, la F-110 responde a los siguientes objetivos de diseño:

- Diseñado para operaciones oceánicas y en el ambiente litoral.

- Dotación reducida.

- Bajo coste de operación y de apoyo al ciclo de vida.

- Alto nivel de supervivencia.

- Baja probabilidad de detección.

- Capaz de soportar daños y completar su misión.

- Sistema de combate equilibrado en todos los segmentos de guerra; defensa de área AAW, capacidad ASW completa, operaciones de Guerra Electrónica, defensa asimétrica.

- Capacidad modular (embarque de dos helicópteros, UAV, etc.).

El diseño preliminar de la fragata F-110 (Figura 1-10) contempla un buque de 5.500 toneladas de desplazamiento y unos 145 metros de eslora aproximadamente. Para el 
diseño de la planta propulsora se ha estudiado, primero el histórico de velocidades que los buques habitualmente emplean en cada una de sus actividades operativas y qué porcentaje corresponde a cada una de ellas, después se ha investigado la planta propulsora que mejor se ajusta a esas necesidades de velocidad. Tras esos análisis y teniendo en cuenta también criterios logísticos, se ha llegado a la conclusión de instalar una planta combinada con motores eléctricos para bajas y medias velocidades (hasta 18 nudos aprox.) y la turbina de gas para propulsión de alta velocidad (más de 18 nudos).

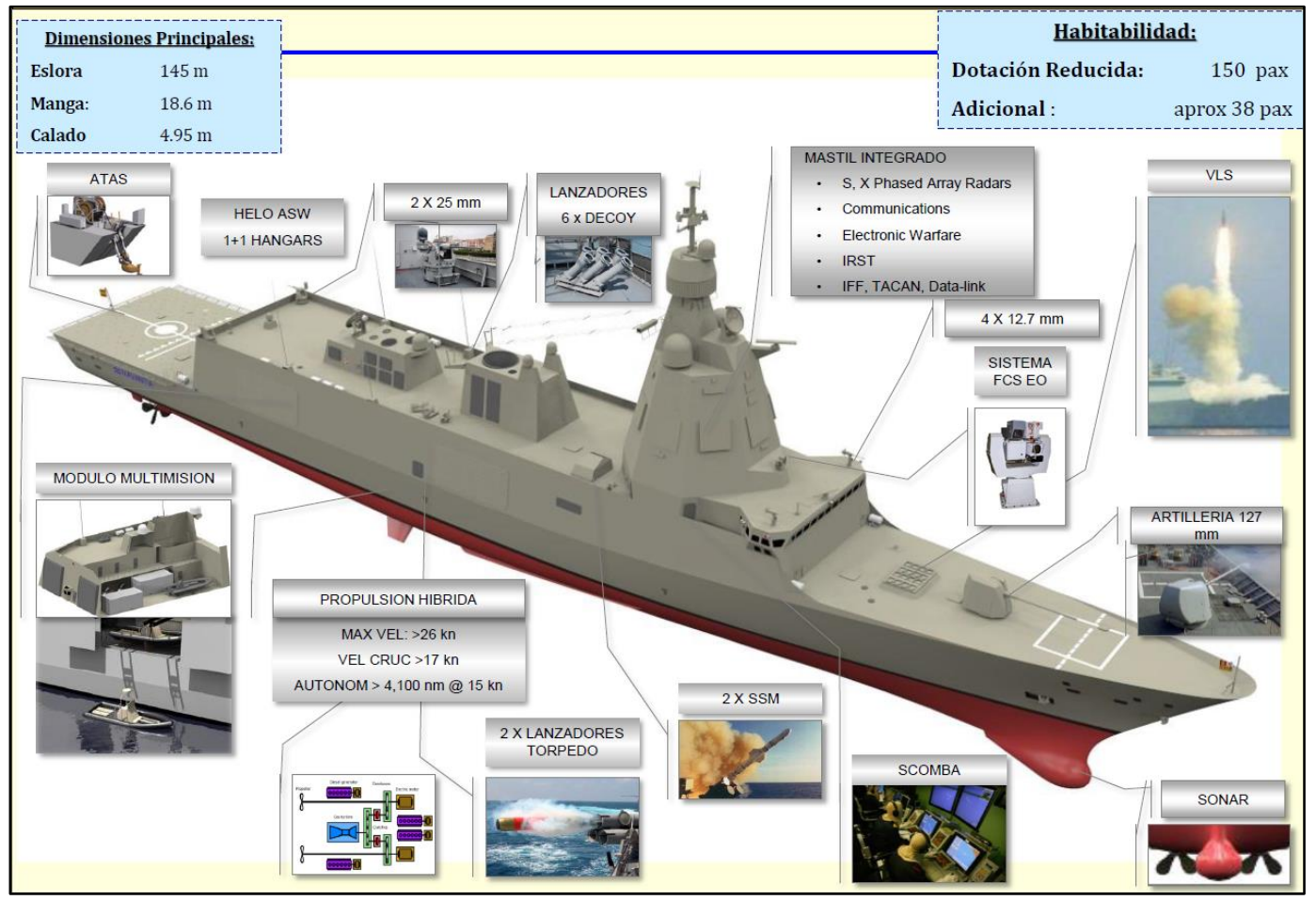

Figura 1-10 F-110 Sistemas principales (DGAM)

La fragata F-110 tendrá capacidad de defensa de área especialmente preparada para proporcionar defensa aérea en el litoral. Sin embargo, no estará diseñada para la defensa contra los misiles balísticos de largo alcance (BMD). Para poder cumplir estos cometidos en un escenario complejo como es el del litoral, el diseño del sistema de guerra antiaérea es clave, y contará con radares de última generación, sensores optrónicos y fuertes contramedidas electrónicas. En cuanto a misiles, dispondrá de dos tipos de misiles de defensa aérea, uno de medio alcance y otro para la defensa antimisil cercana. 
La artillería principal del buque será del calibre de cinco pulgadas, y la artillería secundaría que tendrá como función prioritaria la guerra asimétrica, será automática y con un sistema electroóptico de altas prestaciones.

Con respecto a la lucha antisubmarina está previsto que disponga de un sónar de casco y otro de profundidad variable. En cuanto a la capacidad de armas antisubmarinas la fragata dispondrá de torpedos.

Como hito en cuanto a las decisiones de diseño, hasta ahora, cabe destacar su superestructura integrada, es decir, su mástil integrado (Figura 1-11). Los sensores electromagnéticos y los sistemas de comunicaciones del buque se dispondrán de forma integrada en la superestructura del buque con el objetivo de minimizar las interferencias mutuas, optimizar el empleo operativo del espectro electromagnético y reducir al mínimo las averías y el coste de sostenimiento [80].

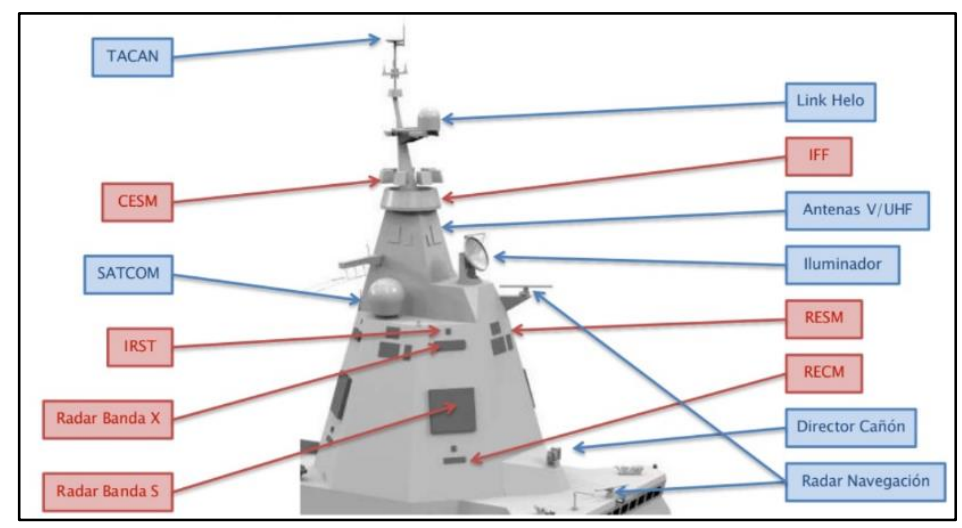

Figura 1-11 Mástil integrado (MASTIN) (Navantia)

\subsubsection{La organización de un buque de guerra}

En este punto se explicará, escuetamente, cómo está organizado un buque de guerra para explotar al máximo sus capacidades.

En la definición del buque de guerra en [81] se comienza exponiendo que: "Un buque de guerra está integrado por material y personal. Actúa o cumple su misión en unas condiciones muy variables y a veces muy adversas: la mar, meteorológicas, situaciones o circunstancias, etc. Se tiene, por tanto, los componentes básicos de cualquier organización: el Hombre, el Material y el Ambiente". 
Si se dispone de un grupo de personas numeroso (la dotación), que con unos medios materiales y a merced de las distintas condiciones ambientales, pretenden lograr un fin o misión y se quiere que las actividades individuales, coordinándolas y ordenándolas, converjan hacia ese fin, es imprescindible proveerle de una organización adecuada.

Un buque bien organizado puede funcionar bien o mal, dependerá de muchos factores (adiestramiento, mantenimiento, estado operativo, personalidad de su Comandante, etc.), pero un buque mal organizado se puede afirmar que no funcionará en absoluto, o por lo menos no como debiera: "al máximo rendimiento y con la mayor eficacia".

Para tratar de determinar la organización adecuada se debe precisar cuál es la misión o finalidad perseguido por el ente que aquí tratamos, es decir, por el buque de guerra.

$$
\text { BUQUE DE GUERRA = BARCO + ARMAS + DOTACION }
$$

\subsubsection{Misiones del Buque de Guerra.}

La misión es difícil definirla. Es la razón de ser del Buque de Guerra, origina la organización y la modifica si esta varía. Un buque de guerra puede tener distintas, variadas y discontinuas misiones o finalidades generales (combatir, petrolear en la mar, efectuar una visita de cortesía, etc.) o específicas (atacar a un submarino, rastrear minas, efectuar un levantamiento hidrográfico, etc.) según el tipo y clase o situación y circunstancia. Pero la Organización Interna debe ser normalizada, común a todos los buques de guerra de cualquier clase y en cualquier circunstancia; sólo puede haber una misión, y habrá que descubrir cuál es esa misión común, que satisfaga a todos ellos en todo momento. Por ello, se podría razonar: si el ente orgánico es el Barco, las Armas y la Dotación y, el barco navega, las armas combaten y la dotación utiliza, la misión será "utilizar el barco y sus armas para navegar y combatir". Esta será pues la misión "general", y a las otras se les llamarán misiones "particulares".

¿Qué busca pues la Organización Interior o cuál es su misión? Se pueden definir como misiones de la Organización Interior:

- Obtener el máximo rendimiento del personal y del material.

- Obtener con el mínimo esfuerzo la máxima eficacia.

- La utilización de las armas. 
- La efectividad en el combate.

- El manejo, mantenimiento y combate del buque del modo más eficiente posible.

Las dos primeras son comunes a toda Organización, las dos siguientes son comunes a cualquier elemento de las Fuerzas Armadas. La última se estima la más adecuada.

Un buque de guerra precisa de una Organización que sirva para las diferentes y variadas misiones "particulares" de cada momento. Su organización debe adaptarse a las distintas situaciones o circunstancias por las que atraviesa el buque en puerto y en la mar, en paz o en guerra, combatiendo o efectuando una maniobra marinera. Los órganos necesarios y las funciones a desarrollar en ciertos casos pueden no ser aptos, y efectivamente no lo son, para otros, tienen que ser distintos: unos equipos de trabajo para mantenimiento en puerto, unas dotaciones cubriendo las armas para el combate, unos grupos activos en cubierta para la maniobra, unos reposteros sirviendo comidas, etc.

¿Puede concebirse una organización distinta para cada caso particular? Evidentemente, no. Aparte de la consiguiente confusión y complicación que ello supondría, existe un hecho que hay que tener en cuenta: El buque de guerra y la misión "general" (utilizar el barco para navegar y combatir) permanecen inmutables, no cambian. Entonces si las misiones "particulares" son diferentes y los órganos y funciones pueden ser distintos, la solución lógica parece ser, variar el plan de estructura en cada paso y conseguir que esta variación sea mínima.

\subsubsection{Organizaciones operativa y administrativa}

Se conciben un mínimo de dos estructuras básicas, coincidentes en sus elementos y componentes (personal, medios), pero distintas, que se pueden considerar como los dos límites extremos de la gama de posibilidades y tomar como punto de partida para los demás casos:

- Una estructura dinámica, activa, operativa, de combate, a la que se llama “Organización Operativa”.

- Otra estructura estática, administrativa "tipo orgánica" que se denomina "Organización administrativa". 
Existe pues una "Organización Operativa" y una "Organización Administrativa", ambas totalmente interrelacionadas, que constituyen la Organización del Buque: Única Organización donde figurarán todas las circunstancias que se han mencionado y donde se asignarán funciones y misiones a todo el personal del buque.

La "Organización Operativa” corresponderá a la organización del buque para el combate (Zafarrancho de Combate), y de ella se partirá para la organización de las demás situaciones operativas, pero ya teniendo en cuenta la "Organización Administrativa".

La “Organización Administrativa” corresponderá a la distribución funcional del personal y del material, en general. De ella se parte, teniendo en cuenta la "Organización Operativa", para las situaciones administrativas (organización puramente militar de la dotación, mantenimientos, alojamientos, servicios, etc.).

El Artículo 212 de las Reales Ordenanzas establece que "toda Unidad, Base, Arsenal o Centro constituido en unidad orgánica independiente contará con su Manual de Organización sancionado por el AJEMA, que tendrá como finalidad la de servir de guía al personal en ella destinado en lo referente a sus relaciones orgánicas, deberes, atribuciones y responsabilidades, tanto en su funcionamiento general como en el aspecto administrativo".

El Manual de Organización debe contener la Organización General y el Plan de Combate, las descripciones generales de los servicios, que constituyen la "Organización Administrativa" y de los Controles que constituyen la que Ilamamos "Organización Operativa", sus relaciones orgánicas, las de sus Jefes y sus responsabilidades y la asignación de deberes y delegación de atribuciones.

También contendrá normas generales para regular las actividades, mediante una equilibrada distribución del tiempo, de forma que se atienda al fin fundamental de la Unidad, Base, Arsenal o Centro, al mantenimiento, al adiestramiento y a la formación cultural, moral, religiosa y física del personal de la dotación.

\subsubsection{Plan de Combate}

Este documento refleja los puestos a cubrir por cada miembro de la dotación, (todos los recogidos en la Plantilla) en todas y cada una de las situaciones del buque. Dada la 
amplitud del documento, suele estar dividido por Servicios. Consiste en una tabla en la que se colocan en filas todos los individuos de la dotación, por su número de organización y en las columnas todas las posibles situaciones del buque. Cruzando filas y columnas se obtiene el puesto a desempeñar.

A fin de que todo miembro de la dotación conozca el puesto que tiene asignado, al embarcar recibirá una tarjeta con su número a bordo, en la que se le dice los puestos que debe ocupar en cada situación. Esta tarjeta tiene una forma parecida a la de la Figura $1-12$.
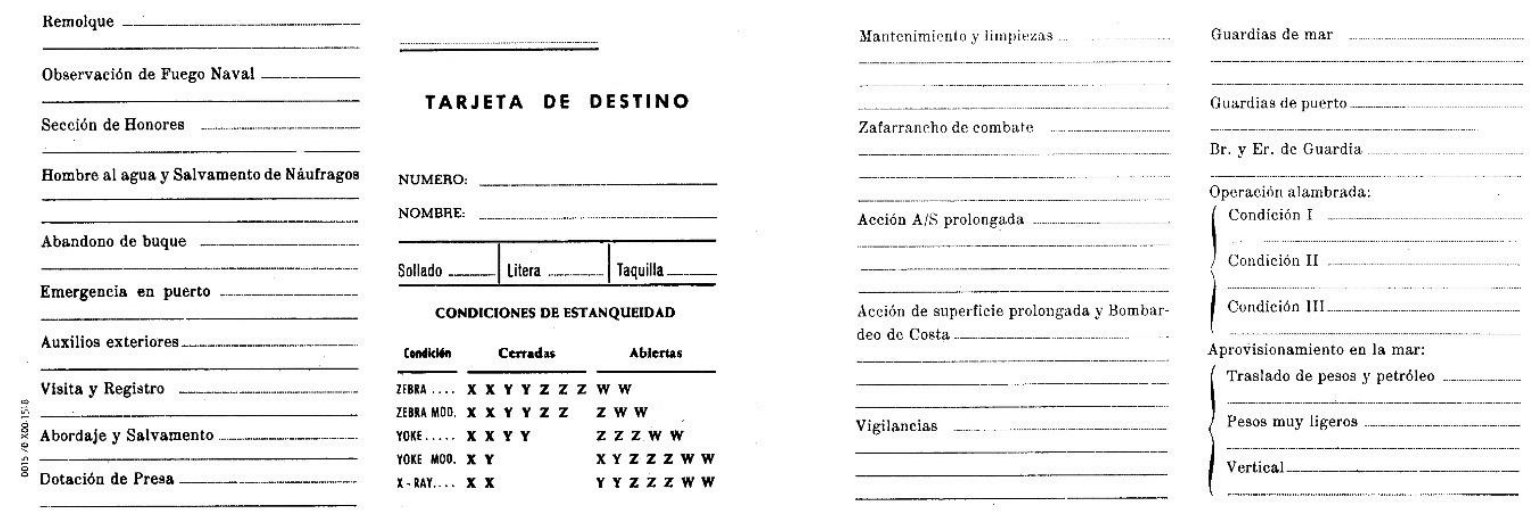

Figura 1-12 Tarjeta Plan de Combate (Armada española)

Así pues, la tarjeta de embarque es una personalización del Plan de Combate para cada individuo.

\subsubsection{Los Servicios del Buque}

Como ya se ha mencionado, el Manual de Organización contiene la Organización General del buque y las descripciones generales de los servicios, que constituyen la "Organización Administrativa" ( Figura 1-13). 


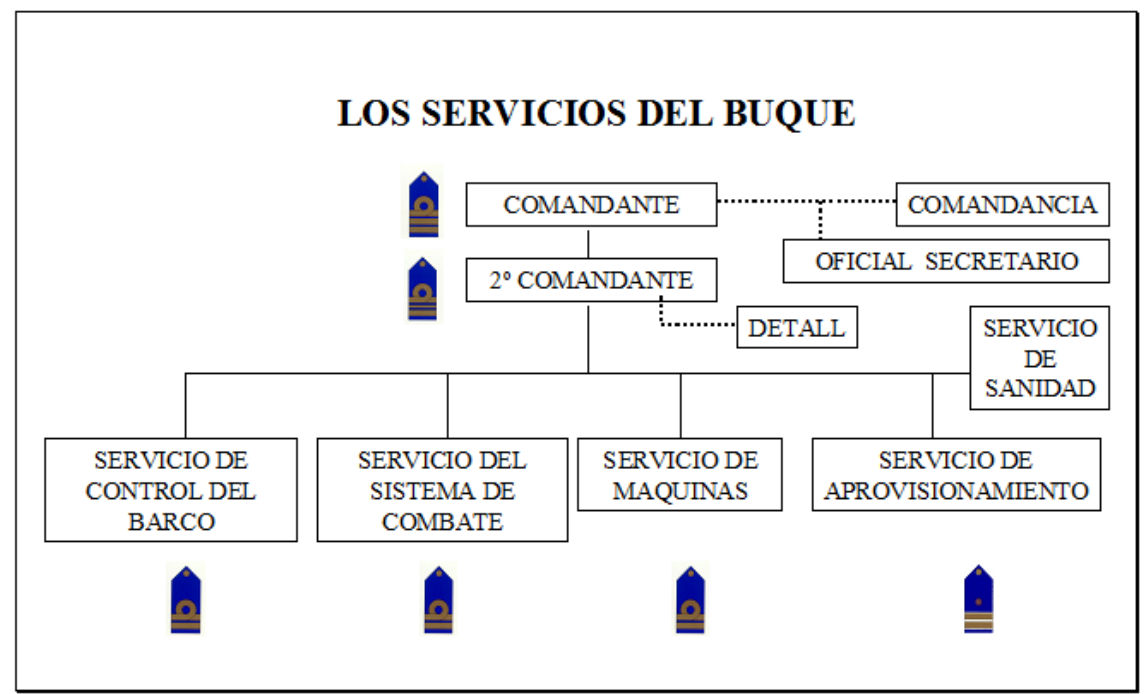

Figura 1-13 Organización administrativa (Armada española)

Los Servicios son entes "orgánico - administrativos", cuyos objetivos son: "mantener la doctrina orgánico - operativa, la instrucción y el adiestramiento del personal, el mantenimiento del material y la moral, disciplina y bienestar del personal asignado".

Cada Servicio tendrá su propio Jefe y su personal asignado, así como espacios, equipos y material, y será autónomo en su desenvolvimiento normal. El Jefe de cada servicio a bordo tendrá la misión básica de alcanzar y mantener el más alto nivel de eficacia.

Para el desempeño de sus funciones se ajustarán a lo previsto en las órdenes diarias, directrices o instrucciones del Comandante, recibidas directamente o a través del Segundo Comandante, e informará al Comandante del estado general de su servicio y en especial de aquellas circunstancias que puedan afectar a la capacidad operativa o a la seguridad del buque, poniéndolo también en conocimiento del Segundo Comandante. 


\section{Capítulo 2. Estado del Arte}

El Estado del Arte es un concepto que se puede definir como: base teórica sobre la que se sustenta un documento. En consecuencia, en este punto se hace necesario mencionar, brevemente, pues el campo es amplísimo y está profusamente documentado en múltiples libros, revistas, etc., algunas de las técnicas relacionadas con la teoría de la decisión multicriterio.

Como ya se había comentado, básicamente, las técnicas de decisión multicriterio se pueden dividir en dos ramas:

- Decisión multicriterio continua o Decisión multiobjetivo o (Multi Objetive Decision Making - MODM). Esta rama aborda la tarea de búsqueda de soluciones eficientes utilizando información técnica (expresiones matemáticas de los atributos, restricciones, etc.).

- Decisión multicriterio discreta o Decisión multiatributo (Multi Atribute Decision Making -MADM), que se utiliza para seleccionar "la mejor alternativa" dentro de un conjunto explícito de ellas.

A continuación, se expondrán algunas técnicas de la teoría de la decisión multicriterio, en las que se ha tomado como referencia el texto de [6].

\subsection{MODM. Programación multiobjetivo}

También llamada optimización vectorial. Tiene gran eficacia cuando el contexto decisional está definido por un conjunto de objetivos a optimizar que deben satisfacer un determinado conjunto de restricciones. Se debe recordar que habitualmente los distintos objetivos del contexto decisional suelen entrar en conflicto, por tanto, es 
imposible la optimización sincrónica de todos ellos. El enfoque de la programación multiobjetivo trata de establecer el conjunto de soluciones eficientes o Pareto óptimas, es decir, primero establecer el conjunto de soluciones factibles (factible implica que cumple con las restricciones) y, de este, extraer el subconjunto de las soluciones eficientes, de manera que no exista otra solución factible que proporcione una mejora en un atributo sin producir un empeoramiento en al menos otro de los atributos.

Así, se puede plantear la estructura de un programa multiobjetivo de la siguiente forma

$$
\text { Eff } \mathrm{f}(x)=\left[\mathrm{f}_{1}(x), \ldots, \mathrm{f}_{\mathrm{i}}(x), \ldots, \mathrm{f}_{\mathrm{q}}(x)\right] ; \text { sujeto } a: x \in F
$$

donde:

Eff significa la búsqueda de soluciones eficientes.

$\mathrm{f}_{\mathrm{i}}(x) \quad$ Es la expresión matemática del atributo i-ésimo.

$x \quad$ Es el vector de variables de decisión.

$F \quad$ Es el conjunto de restricciones (habitualmente lineales) que definen el conjunto de soluciones posibles.

La búsqueda de soluciones eficientes se establece en un sentido maximizador, cuanto más de un atributo mejor, o minimizador, cuanto menos de un atributo mejor. El enfoque de la programación multiobjetivo consiste en separar del conjunto de soluciones posibles un subconjunto propio del mismo cuyos elementos sean Pareto óptimos. En este proceso únicamente se emplea información estrictamente técnica, sin ninguna influencia subjetiva de los decisores como, por ejemplo: expresiones matemáticas de los atributos, restricciones, etc. Planteado el problema en estos términos, la operatividad de la programación multiobjetivo consistirá en desarrollar una serie de técnicas que permitan que, a partir de la estructura formulada anterior, se genere el conjunto de soluciones eficientes.

\subsubsection{La Matriz de Pagos}

La obtención de la matriz de pagos es el primer paso en la aplicación de la programación multiobjetivo a un problema concreto. La matriz de pagos permite cuantificar el nivel de conflicto existente entre los objetivos que estemos considerando. La mecánica 
operativa para obtener la matriz de pagos se sintetiza en la siguiente manera: se optimiza cada objetivo separadamente, calculándose seguidamente los valores alcanzados por los demás objetivos en cada solución óptima. De esta forma, se obtiene una matriz cuadrada, cuya dimensión coincide con el número de objetivos, y cuya diagonal principal se denomina "punto ideal", que sería la solución en la que todos los objetivos alcanzan su valor óptimo; esto raramente es alcanzable. El peor elemento de cada columna de la matriz de pagos se denomina "punto anti-ideal", que sería el valor máximo o mínimo contrario al objetivo de minimizar o maximizar.

El "punto ideal", pese a su frecuente inaccesibilidad, es de gran utilidad en el desarrollo de potentes métodos multiobjetivo y el "punto anti-ideal" igualmente es útil, puesto que nos permite definir un intervalo de valores para cada atributo de gran utilidad para operativizar algunas técnicas multiobjetivo.

\subsubsection{El Método de las Restricciones}

Este método que presentó Marglin [82], demostró que, si en un problema multiobjetivo uno de los objetivos se optimiza mientras que los demás objetivos se añaden al conjunto de restricciones como restricciones paramétricas, para cada conjunto de valores que se dé al vector de términos independientes se genera un punto eficiente.

Así, para un problema decisional con $q$ objetivos a maximizar, la aplicación del método de las restricciones conduce al siguiente planteamiento matemático de tipo paramétrico

$$
\begin{gathered}
\operatorname{Max}_{k}(x) \\
\text { sujeto } a: x \in F ; f_{j}(x) \geq L_{j} j=1,2, \ldots, k-1, k+1, \ldots, q
\end{gathered}
$$

donde $F$ representa el conjunto de soluciones posibles. Por medio de variaciones paramétricas de los términos independientes $L_{j}$ iremos generando el conjunto eficiente. Debe señalarse que este método garantiza la generación de soluciones eficientes sólo cuando las restricciones paramétricas son activas en el óptimo, es decir, cuando la correspondiente variable de holgura o artificial se hace cero, por lo que la restricción se satisface como igualdad. Por el contrario, si en el óptimo, alguna de las restricciones paramétricas no es activa, es decir, que se satisface como desigualdad, y además existen óptimos alternativos, entonces la solución generada por el método de las restricciones 
puede ser no eficiente. Este caso, aunque es teóricamente posible, no es frecuente que se presente en la práctica, por lo que el método de las restricciones no pierde su carácter de potente generador de puntos eficientes.

El método de las restricciones requiere la realización de $p^{q-1}$ iteraciones de ordenador, siendo $q$ el número de objetivos y $p$ el número de conjuntos de valores que se den a los términos independientes de los objetivos incluidos como restricciones paramétricas.

\subsubsection{El Método de las Ponderaciones}

Si en un problema multiobjetivo, a cada objetivo se le asocia un peso no negativo y, a continuación, se procede a la agregación de todos los objetivos, la optimización de dicha función agregada y ponderada genera para cada conjunto de pesos un punto extremo eficiente [83]. Así, para un problema matemático decisional con $q$ objetivos a maximizar, la aplicación de las ponderaciones conduce al siguiente planteamiento matemático de tipo paramétrico

$$
\begin{gathered}
\operatorname{Max} W_{1} f_{1}(x)+W_{2} f_{2}(x)+\cdots+W_{q} f_{q}(x) \\
\text { sujeto } a: X \in F ; W_{i} \geq 0
\end{gathered}
$$

Para cada vector de pesos $W$ se obtienen un punto extremo eficiente. Por consiguiente, variando paramétricamente los pesos, se puede generar el conjunto eficiente.

Debe observarse que el método de las ponderaciones garantiza soluciones eficientes sólo cuando todos los pesos elegidos son mayores que cero $\left(W_{i} \geq 0\right)$. En caso de que uno de los pesos sea igual a cero y además existan óptimos alternativos, entonces la solución generada por este método puede ser no eficiente. De nuevo, esta situación es posible pero no suele presentarse en la práctica, por lo que no afecta a la potencialidad operativa del método.

Una diferencia del método de las ponderaciones con el de las restricciones es que este no genera puntos eficientes interiores, genera sólo puntos extremos.

Es conveniente recordar que, en este método, igual que sucede con los demás métodos multiobjetivo, no se introducen en el análisis las preferencias de los decisores y, por tanto, este método carece de subjetividad. Los pesos $W$ elegidos no guardan ninguna relación con las preferencias de los decisores, simplemente juegan el papel de 
parámetros que se hacen variar arbitrariamente con el propósito de generar los puntos extremos eficientes.

El método de las ponderaciones requiere la realización de $p^{q-1}$ iteraciones de ordenador, siendo $q$ el número de objetivos y $p$ el número de sistemas de pesos probados. En este método se parametrizan los coeficientes de la función objetivo en vez de los términos independientes, como así sucede en el método de las restricciones.

Es necesario mencionar que ambos métodos, no garantizan la solución del conjunto eficiente; proporcionan una buena aproximación a él. Esta aproximación será más consistente, en tanto en cuanto, se disminuya la escala de los pesos en el método de las ponderaciones o se aumente el número de conjuntos de valores que se asignen a los términos independientes en el método de las restricciones.

Existen otras técnicas multiobjetivo, pero con estos métodos aquí comentados se considera que se alcanza el objetivo de exponer de manera muy somera algunos ejemplos de esta técnica.

\subsubsection{MODM. Programación Compromiso}

En [84], [85] y [86] se desarrollan este enfoque de gran potencia operativa. La idea principal de la programación compromiso es utilizar el "punto ideal" como punto de referencia, para finalmente seleccionar un punto del conjunto eficiente denominado solución de compromiso que se define como la solución eficiente más próxima al punto ideal [85].

El concepto fundamental en la programación compromiso es el de la distancia. Este, no es solo un concepto en sentido geométrico, sino que adquiere una clara significación hacia el sentido de las preferencias del decisor y, por tanto, está condicionado por su subjetividad.

Para la definición de la distancia más próxima, es decir, una distancia que ha de ser minimizada, [85] define el grado de proximidad $d_{i}$ del objetivo i-ésimo y su ideal como

$$
d_{i}=\left|f_{i}^{*}-f_{i}(x)\right|
$$

donde 


$$
f_{i}^{*}=\max f_{i}(x)
$$

como los valores absolutos de distancia de los distintos objetivos pueden ser muy diferentes, se hace necesario normalizarlos para obtener grados de proximidad homogéneos

$$
d_{i}=\frac{\left|f_{i}^{*}-f_{i}(x)\right|}{\left|f_{i}^{*}-f_{* i}\right|}
$$

donde $d_{i}$ representa el grado de proximidad del objetivo i-ésimo normalizado y $f_{* i}$ representa el anti-ideal de dicho objetivo. El grado de proximidad normalizado estará acotado entre 0 y 1 , cuando un objetivo alcance su valor ideal, su grado de proximidad será cero y, por el contrario, será uno cuando el objetivo alcance el valor anti-ideal.

Las preferencias del decisor, $W_{i}$, representan la discrepancia entre la realización del objetivo i-ésimo y su ideal. El problema de convierte en la minimización

$$
\operatorname{Min} L_{p}=\left[\sum_{i=1}^{n} W_{i}^{p}\left|\frac{\left|f_{i}^{*}-f_{i}(x)\right|}{\left|f_{i}^{*}-f_{* i}\right|}\right|^{p}\right]^{1 / p}
$$

donde el conjunto de pesos $W_{i}$ es una ponderación preferencial de los criterios.

Para los distintos valores de $p$ se obtienen diferentes métricas. Así, para $p=\infty$, se minimiza la máxima desviación de entre todas las desviaciones individuales y, por consiguiente, sólo la desviación mayor influye en el proceso de minimización, resultando un problema lineal (Tchebychev). En el caso de $p=1$, el problema se convierte en una agregación lineal de distancias ponderadas, también de carácter lineal.

Para obtener la mejor solución compromiso para métricas distintas de $p=\infty$ y $p=1$, es necesario recurrir a algoritmos no lineales, que pueden alcanzar un coste computacional muy alto. Este coste se reduce gracias a la demostración de [84] en la que se demostró que, en caso de dos objetivos, el conjunto compromiso [86] está entre los puntos $L_{1}$ y $L_{\infty}$, que definen un subconjunto de la frontera eficiente. En caso de problemas con más de dos objetivos, pueden existir soluciones compromiso que no pertenezcan al intervalo cerrado $\left[L_{1}, L_{\infty}\right]$, aunque es poco probable que esto se presente en la práctica, por lo que usualmente se mantiene la potencialidad de la programación compromiso. 


\subsubsection{MODM. Programación por Metas}

La utilidad de los métodos anteriormente expuestos se reduce ampliamente en problemas decisionales de un tamaño elevado. Así, un problema con seis atributos, varios cientos de variables de decisión y de restricciones, no es computacionalmente abordable a través de métodos de optimización multiobjetivo. Para enfrentarse a este tipo de problemas de gran dimensión hace falta recurrir a procedimientos más flexibles. Dentro de esta línea pragmática puede encuadrarse la programación por metas (goal programming). La programación por metas se apoya en una lógica no de optimización, sino como se ha acuñado en [87], en una lógica satisfaciente.

Simon hace ver que, en las complejas organizaciones actuales, el contexto decisional está definido por información incompleta, recursos limitados, multiplicidad de objetivos, conflictos de intereses, etc. En este tipo de contexto el centro decisor más que optimizar una o varias funciones objetivo intenta que una serie de metas relevantes se aproximen lo más posible a unos niveles de aspiración fijados de antemano. Este tipo de complejidad se encuentra presente en muchos problemas relacionados con la planificación, diseño o explotación de sistemas [88].

La programación por metas puede decirse que surge con [89], en el que se aplica el concepto a un problema de regresión condicionada para analizar un problema de fijación de salarios para ejecutivos. No obstante, pese a la potencialidad del enfoque, hasta mediados de los años setenta las aplicaciones de la programación por metas son bastante escasas. Sin embargo, a partir de esa fecha y debido principalmente a los trabajos de Lee [90] e Ignizio [91] se produce una enorme eclosión de trabajos en los que se desarrollan tanto aspectos teóricos de la programación por metas como aplicaciones de este enfoque a áreas muy diversas [88].

Puede decirse que las metas constituyen una especie de restricciones blandas que pueden violarse sin que por ello se generen soluciones imposibles. La cantidad de violación puede medirse introduciendo dos variables de desviación, una negativa $n$ y otra positiva $p$. En términos matemáticos se expresa

$$
f(x)+n-p=t
$$

donde $t$ se define como nivel de aspiración. 
La formulación de un problema en un modelo de programación por metas comienza por fijar los atributos que se consideren relevantes, para posteriormente, asignarle a cada uno de ellos un nivel de aspiración. Se entiende por nivel de aspiración $t_{i}$ el nivel de logro que el decisor desea alcanzar para el atributo i-ésimo.

A continuación, se conecta el atributo con el nivel de aspiración por medio de las variables de desviación negativa y positiva, respectivamente

$$
f_{i}(x)+n_{i}-p_{i}=t_{i}
$$

La variable de desviación negativa cuantifica la falta de logro de una meta con respecto a su nivel de aspiración, mientras que la variable de desviación positiva juega el papel opuesto; es decir, la cuantificación del exceso de logro de una meta con respecto a su nivel de aspiración [88].

Un concepto esencial es el de variable de desviación que se dice que es no deseada cuando al decisor le conviene que la variable en cuestión alcance su valor más pequeño, esto es, cero [92]. Una vez determinadas las variables de desviación no deseadas, el paso siguiente es comenzar un proceso de minimización que en sus formas más empleadas son: Programación por metas ponderadas y Programación por metas lexicográficas.

\subsubsection{MADM. Métodos Multicriterio Discretos}

A diferencia de los métodos descritos anteriormente, este tipo de problemas no genera un conjunto infinito de soluciones factibles, sino que las posibles soluciones suelen ser un conjunto, normalmente finito, de alternativas a considerar. Si bien es cierto, que la mayoría de los conceptos y métodos de los problemas del tipo continuos son aplicables a problemas multicriterio discretos, existen una serie de métodos y enfoques teóricos especialmente diseñados para el contexto discreto [6].

El punto de partida de cualquier análisis decisional multicriterio de tipo discreto es la matriz decisional, en la que se representa la siguiente estructura 


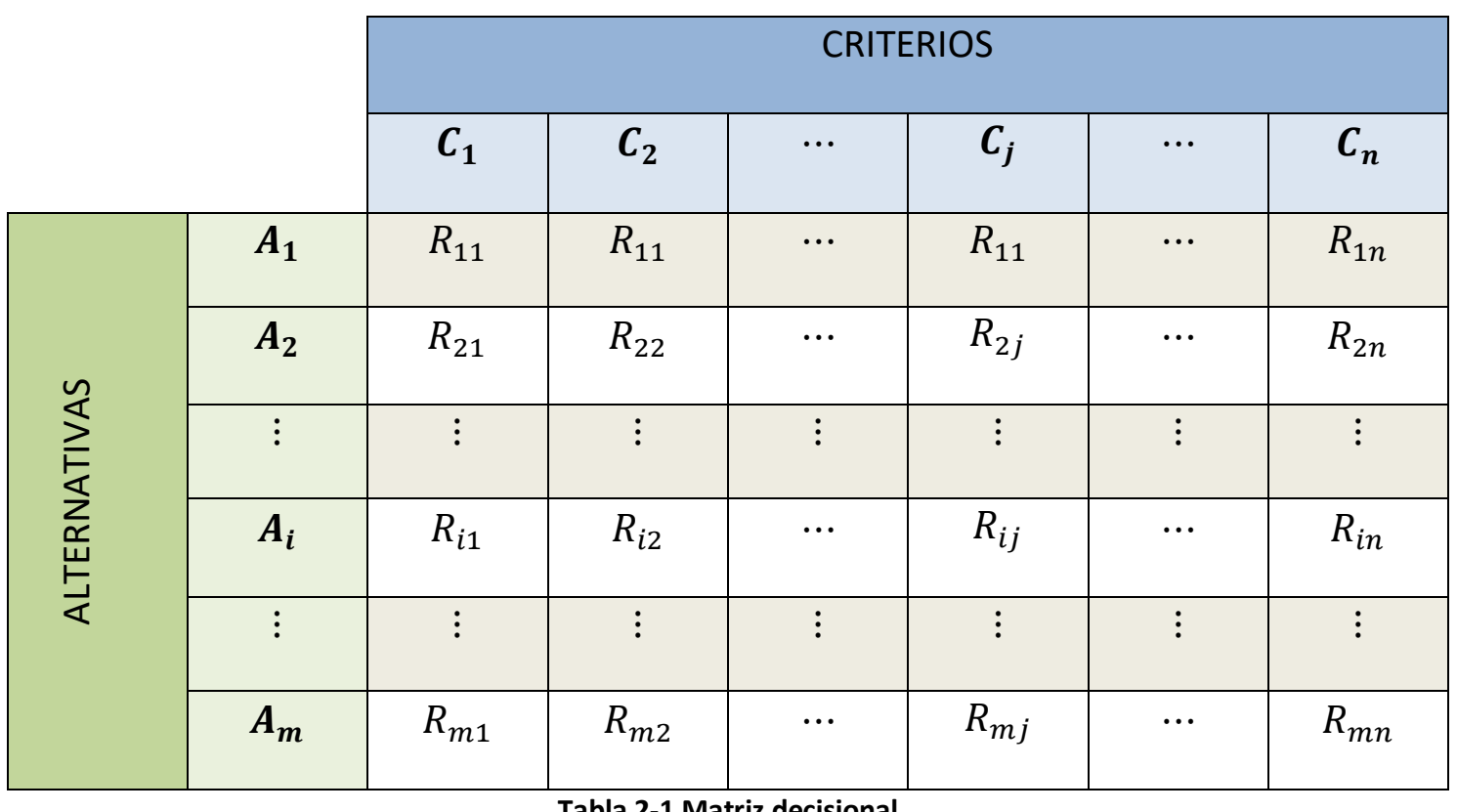

Donde un el conjunto de $m$ puntos $A$ representan las posibles alternativas, el conjunto de $n$ puntos $C$ representan los criterios, y el conjunto $m \times n$ puntos $R$ representan los resultados alcanzados por cada alternativa en cada uno de los atributos considerados, cada uno de ellos en su escala de medición y, lógicamente en un sentido, esto es, si se quiere maximizar o minimizar.

Previamente a la aplicación de cualquier técnica, si hay alguna alternativa que esté dominada por otra, se podría desechar puesto que, a priori, no la elegiría un decisor racional. No obstante, es importante ser cauto a la hora de eliminar alternativas dominadas. Hay que tener en cuenta que, el hecho de que una alternativa sea dominada significa simplemente que hay otra que seguro es mejor, pero no quiere decir que dicha alternativa dominada sea necesariamente una "mala" alternativa desde el punto de vista del decisor. De la misma manera una alternativa eficiente, no tiene porqué ser considerada como una "buena" alternativa por parte del decisor [19].

Las siguientes técnicas que se comentarán, son algunas de las más conocidas para la resolución del análisis decisional multicriterio de tipo discreto. Son técnicas que incorporan las indispensables preferencias del decisor, preferencias que cómo no, indefectiblemente vienen acompañadas de la subjetividad propia de la experiencia y otros factores de tipo sociológico del decisor. 
Los tres enfoques principales son: los métodos de superación, la teoría de la utilidad multiatributo y el proceso analítico jerárquico.

A continuación, se comentarán superficialmente los dos primeros tomando como referencia la descripción de [93], y se explicará con mayor detalle el proceso analítico jerárquico, pues es la semilla y médula en la que se cimienta esta tesis.

\subsubsection{MADM. Métodos de Superación}

Como se relata en [19], los métodos de superación (out-ranking methods) intentan construir lo que se denomina relaciones de superación entre las distintas alternativas del problema. Establecen una relación de preferencia entre un conjunto de soluciones, donde cada una de ellas muestra un grado de dominación sobre las otras respecto a un criterio. Estos métodos son capaces de tratar con información incompleta y difusa, y permite clasificar las alternativas en función de la relación de preferencia existente entre ellas. De forma que se puede generalizar que: una alternativa supera a otra si es al menos tan buena como ella en una mayoría de criterios, y no es notoriamente peor en los otros. Obviamente, la dificultad de los métodos, y las diferencias entre los distintos enfoques existentes, radica en cómo establecer y valorar numéricamente esos: "en una mayoría de los criterios" y "notoriamente peor".

Los métodos ELECTRE [45], se basan en establecer, para cada par de alternativas, un coeficiente de concordancia, que mide el número de criterios, ponderados con sus respectivos pesos, para los que la primera alternativa es al menos tan buena como la segunda, y un coeficiente de discordancia, que mide la máxima diferencia de utilidad entre la segunda y la primera. Posteriormente, el decisor fija un umbral de concordancia y un umbral de discordancia, de forma que una alternativa supera a otra si su coeficiente de concordancia está por encima de su umbral correspondiente, y el de discordancia está por debajo del suyo.

En la versión ELECTRE III [94] , se utiliza por primera vez en estos métodos el concepto de pseudo-criterio, que consiste en una matización de los criterios a través de la introducción de umbrales de indiferencia (diferencias de valores que son indiferentes para el decisor) y de preferencia estricta (diferencias a partir de las cuales una alternativa es claramente preferible a otra para el criterio considerado). Este concepto 
será utilizado posteriormente de forma muy extensa en los métodos PROMETHEE (Preference Ranking Organization METHod for Enrichment Evaluation) desarrollados en [95]. Los métodos PROMETHEE, aparte de los pseudo-criterios, se basan en la asignación de pesos a los criterios, y en la construcción de los llamados flujos de entrada y salida que miden, para cada alternativa, en qué grado son superadas por el resto.

Las primeras versiones de ambas familias de métodos producían, en general, un orden parcial de las alternativas, es decir, se establecen relaciones de superación, pero no necesariamente entre todos los pares de alternativas, de forma que existen alternativas que no son comparables entre sí [19].

En todos estos métodos, se deber ser cauto al presentar los resultados al decisor, debiéndose realizar un análisis de sensibilidad sobre los parámetros utilizados en los modelos, pues pequeñas variaciones en alguno podrían alterar el orden obtenido para las distintas alternativas.

\subsubsection{MADM. Teoría de la Utilidad Multiatributo}

La Teoría de la Utilidad Multiatributo (MAUT) desarrollada en [96], se basan en definir funciones que determinen el grado de satisfacción de cada alternativa respecto a cada criterio, para posteriormente construir una función que mida la utilidad global de cada una de las alternativas, de manera que éstas se ordenan en orden creciente del valor de la función.

Aunque habitualmente se utiliza un modelo aditivo, asignando un peso a cada criterio, también se pueden utilizar modelos multiplicativos o más complejos. La Teoría de Utilidad Multiatributo tiene buenas propiedades teóricas, en cuanto a la existencia y caracterización de las soluciones óptimas del decisor, pero puede ser una tarea complicada diseñar las distintas funciones de utilidad de forma que respondan fielmente a las preferencias del decisor.

Los métodos basados en la metodología MAUT se diseñan para ello, es decir, se diseñan de manera que contienen elementos que ayudan al decisor a obtener las utilidades cardinales de forma consistente. Un buen ejemplo de ello es el método MACBETH [97]. 
El método MIVES (Modelo Integrado de Valor para una Evaluación Sostenible) es un derivado de los anteriores, en el cual se facilita las ecuaciones que definen las diferentes funciones de satisfacción.

A pesar de todos los métodos reflejados y otros muchos más que existen que no se han comentado, por no ser el objetivo de esta tesis, la vida real es bastante compleja. Siempre existe una incertidumbre en las valoraciones o en las comparaciones. Es por ello, que muchos de estos métodos utilizan herramientas como la teoría fuzzy, el método de Montecarlo o los números Grey. Además, cuando la toma de decisiones no es individual, suelen existir diferentes grupos con diferentes intereses, con lo que es necesario llegar a un consenso entre ellos. El método Delphi es una herramienta útil para cuando hay diferentes decisores, es un método de estructuración de un proceso de comunicación grupal que es efectivo a la hora de permitir a un grupo de individuos, como un todo, tratar un problema complejo [98].

Envolviendo a todo lo reflejado para cualquiera de las metodologías sobre la decisión, subyace: la subjetividad; que es aquello que hace referencia a la cualidad de lo subjetivo (del latín subiectivus), es decir, de aquello que es propio o pertenece al sujeto y, por tanto se puede asociar a la manera de pensar y sentir de un individuo y que en oposición a lo externo, es una experiencia interna; que en oposición a lo objetivo, depende de la perspectiva personal e individual.

La subjetividad es inherente a cada individuo e indefectiblemente lo aleja de la lógica. En el terreno científico, se busca lograr la mayor objetividad posible para producir conocimiento basado en la elaboración de hipótesis lógicas y coherentes. Si bien, en el terreno de la teoría de la decisión multicriterio no es posible, ni deseable, la objetividad absoluta, sí es deseable ayudar al decisor a reducir su subjetividad, a reducir sus apreciaciones priorizadas por emociones estereotipadas, a reducir sus opiniones sesgadas por sus experiencias personales, etc. 


\subsection{MADM. Proceso de Análisis Jerárquico (AHP)}

Esta técnica se encuadra dentro de la familia metodológica denominada escuela americana, centrada en el estudio de las Funciones de Utilidad Multicriterio, liderada por Ralf Keeney y Howard Raiffa [96], entre otros. El método llamado AHP (Analiytic Hierarchy Process), consiste básicamente en descomponer un problema en una estructura jerárquica, en cuyo vértice superior está el principal objetivo del problema, en la base se encuentran las posibles alternativas a escoger y en los niveles intermedios se representan los criterios.

Como se acaba de mencionar, esta técnica a partir de una serie de criterios multinivel en los que se descompone el problema tiene la función de determinar para un objetivo concreto la alternativa más adecuada de entre las que se consideran a estudio.

El diseño de las jerarquías requiere experiencia y conocimiento del problema que se plantea, para la cual es indispensable disponer de toda la información necesaria.

La segunda característica del método es que, en cada nivel de la jerarquía, se realizan comparaciones entre pares de elementos de ese nivel, en base a la importancia o contribución de cada uno de ellos al elemento de nivel superior al que están ligados. Este proceso de comparación conduce a una escala de Medida relativa de prioridades o pesos de dichos elementos. Las comparaciones por pares se realizan por medio de ratios de preferencia (si se comparan alternativas) o ratios de importancia (si se comparan criterios), que se evalúan según una escala numérica propuesta por el método, que más adelante se presentará. Los pesos o prioridades relativas deben sumar la unidad.

La tercera característica del AHP es que la información obtenida es generalmente redundante y más o menos inconsistente. Las matrices de comparaciones por pares contienen juicios redundantes en el sentido de que en una matriz de tamaño $(n x n)$ se suelen emitir $n x(n-1) / 2$ juicios (ya que conocido un término $a_{i j}$ obtiene fácilmente el término $a_{j i}$ por la propiedad de reciprocidad), cuando de hecho solo se necesitarían $(n-1)$ juicios si se utilizase el álgebra (pues si se conoce el término $a_{i j}$ y el término $a_{j k}$ es posible conocer, mediante sencillos cálculos, el término $\left.a_{i k}\right)$. Esta diferencia en el número de juicios supone tiempo invertido que se podría haber evitado y puede producir inconsistencias dentro de la matriz. Sin embargo, desde otro punto de vista, 
esta redundancia resulta útil para mejorar la exactitud de los juicios y se aprovecha para, mediante la técnica matemática, reducir los errores y mejorar la consistencia de la matriz.

Por último, una vez evaluada la contribución de cada elemento a los elementos del nivel de la jerarquía inmediatamente superior, se calcula la contribución global de cada alternativa al objetivo principal o meta mediante una agregación de tipo aditivo.

En resumen, según Saaty, el método AHP es un modelo de decisión que interpreta los datos y la información directamente mediante la realización de juicios y medidas en una escala de razón dentro de una estructura jerárquica establecida. Es un método de selección de alternativas (estrategias, inversiones, etc.) en función de una serie de criterios o variables, las cuales suelen estar en conflicto.

\subsubsection{Axiomas Básicos}

Los axiomas básicos en los que se basa la teoría AHP son:

- Axioma de comparación recíproca: El decisor debe ser capaz de realizar comparaciones y establecer la fuerza de sus preferencias. La intensidad de estas preferencias debe satisfacer la condición recíproca: "Si $A$ es $x$ veces preferido que $B$, entonces $B$ es $(1 / x)$ veces preferido que $A^{\prime \prime}$.

- Axioma de homogeneidad: "Las preferencias se representan por medio de una escala limitada".

- Axioma de independencia: "Cuando se expresan preferencias, se asume que los criterios son independientes de las propiedades de las alternativas".

- Axioma de las expectativas: "Para el propósito de la toma de una decisión, se asume que la jerarquía es completa".

\subsubsection{Metodología del Proceso Analítico Jerárquico}

Las etapas generales de la metodología AHP propuestas por Saaty [12] en su formulación inicial son:

1ํㅡㄹ Etapa. Modelización: En esta etapa se construye una estructura jerárquica en la que quedan representados todos los aspectos considerados relevantes en el proceso de 
resolución: actores, escenarios, factores, elementos e interdependencias. La jerarquía resultante debe ser completa, representativa, no redundante y minimalista. Su construcción es la parte más creativa del proceso de resolución, pudiendo aparecer posiciones enfrentadas entre los distintos participantes.

2a Etapa. Valorización: En la segunda etapa se incorporan las preferencias, gustos y deseos de los actores mediante los juicios incluidos en las denominadas matrices de comparación por pares. Estas matrices cuadradas reflejan la dominación relativa de un elemento frente a otro respecto a un atributo o propiedad común. El significado teórico es el siguiente, de los dos elementos comparados, se toma como referencia el que posee en menor medida o grado la característica en estudio y se da un valor numérico de las veces que "el mayor" incluye, recoge, domina o es más preferido que "el menor" respecto al atributo estudiado.

3ํㅡtapa. Priorización y síntesis: Esta última etapa proporciona las diferentes prioridades consideradas en la resolución del problema. Se entiende por prioridad una unidad abstracta válida para cualquier escala en la que se integran las preferencias que el individuo tiene al comparar aspectos tangibles

En el problema de decisión se consideran tres tipos de prioridades:

- Las prioridades locales: Que son las prioridades de los elementos que cuelgan de un nodo común.

- Las prioridades globales: Que son la importancia de esos elementos respecto a la meta global fijada para el problema. La forma de calcularlas prioridades globales consiste en aplicar el principio de composición jerárquica: multiplicando los diferentes pesos que aparecen en el recorrido de la jerarquía desde el elemento inferior hasta la meta.

- La prioridad final o total: De una alternativa se obtiene agregando las prioridades globales obtenidas para esa alternativa en los diferentes caminos a que la unen con la meta. El método habitualmente empleado en AHP para la agregación es el equivalente a la suma ponderada.

4a Etapa. Análisis de sensibilidad: Se suele hacer para examinar el grado de sensibilidad del resultado obtenido en una decisión al realizar cambios en las prioridades de los criterios principales de un problema. Lo que se lleva a cabo es un cambio en la prioridad 
de un determinado criterio manteniendo las proporciones de las prioridades de los otros criterios, de manera que todos ellos, incluido el criterio alterado, al modificarse sigan sumando la unidad.

Estas etapas generales se pueden concretar en una serie de pasos, que se resumen en el diagrama flujo de la Figura 2-1.

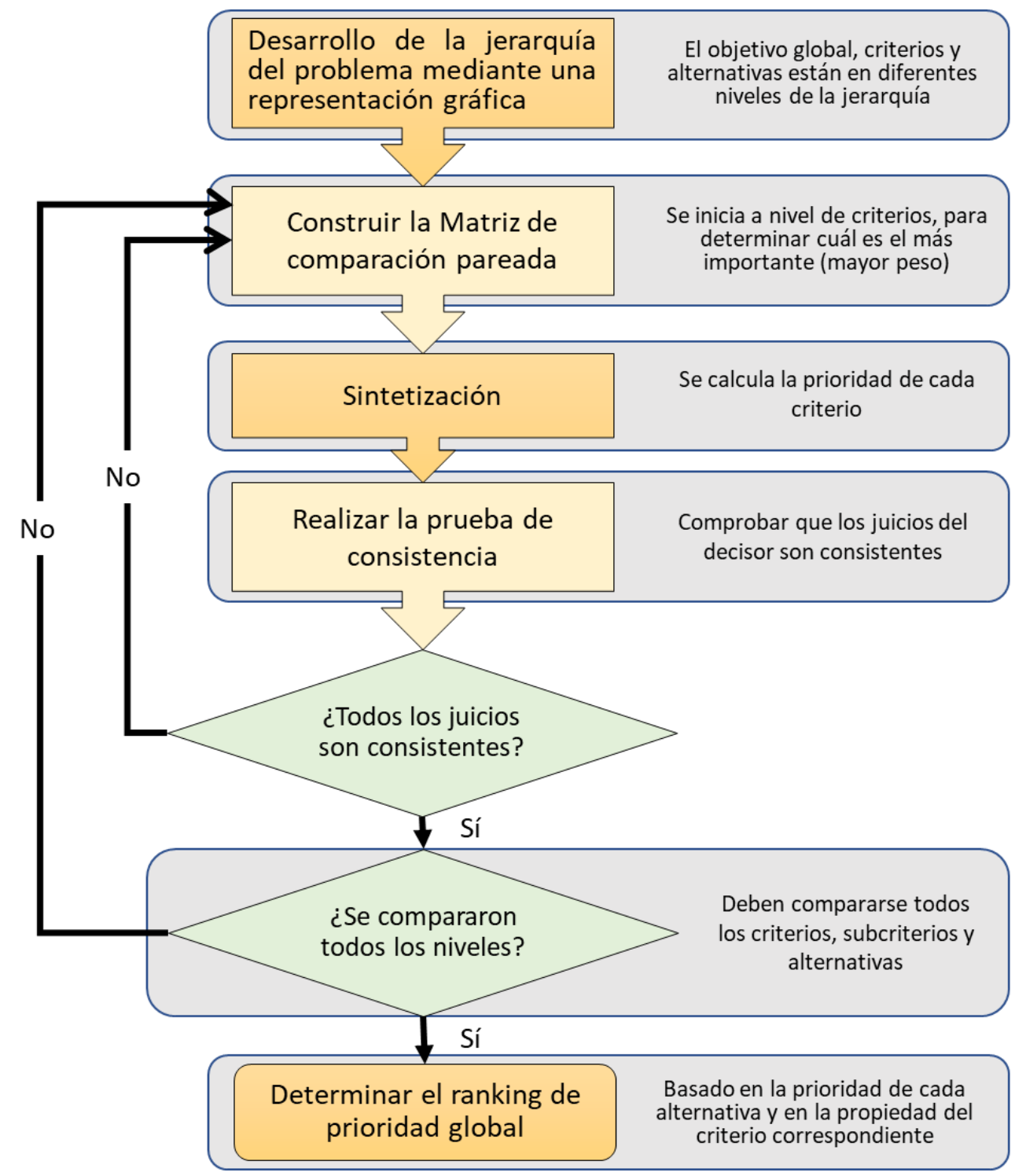

Figura 2-1 Pasos en el procedimiento AHP (elaboración propia de esquema extraído de [99])

Paso 1: Modelización. Estructurar el problema como una jerarquía.

El primer paso del método AHP consiste en modelar el problema de decisión que se pretende resolver como una jerarquía. Este hecho es una de las principales características del método, de ahí que el término "jerárquico" aparece en su denominación. En la Figura 2-2, se presenta la forma general que adopta una jerarquía. 


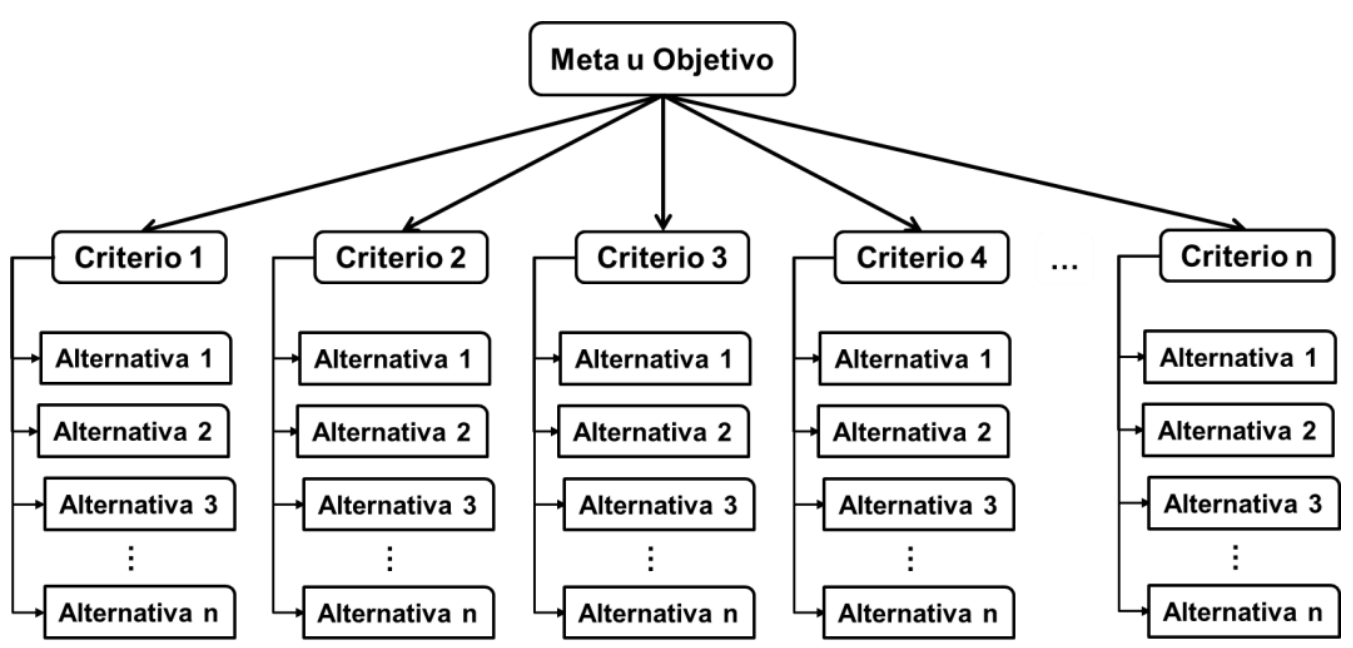

Figura 2-2 Jerarquía en AHP ( [99])

En el vértice superior de la jerarquía se sitúa la meta u objetivo que se pretende alcanzar. El problema de decisión consiste en elegir la alternativa que mejor contribuye a la consecución de la meta del nivel superior de la jerarquía.

En el siguiente nivel, en orden descendente desde la meta, se sitúan los criterios. Como ya se comentó, los criterios de decisión corresponden a aspectos tales como atributos, objetivos o parámetros que constituyen los ejes fundamentales a partir de los cuales el decisor justifica, transforma y argumenta sus preferencias. La selección adecuada de los criterios constituye una etapa fundamental en cualquier proceso de toma de decisión, ya que un planteamiento inadecuado de los mismos puede llevar a resultados poco satisfactorios o incluso a invalidar todo el proceso: se deben definir los criterios que son importantes en el problema.

Una vez definidos los criterios puede darse el caso en que éstos a su vez se puedan descomponer en otros subcriterios formando otra jerarquía descendente. Durante la construcción de esta jerarquía de criterios y subcriterios se debe analizar el problema en profundidad con el fin de representarlo de la forma más completa y global posible (aunque dejando abierta la posibilidad de algunos cambios en los elementos), considerar el entorno que rodea al problema, identificar los atributos que contribuyen a la solución y considerar a las personas interesadas en el problema.

Finalmente, en el último nivel de la jerarquía se sitúan las alternativas, que son el conjunto de posibles opciones definidas sobre las que la unidad decisora realiza una decisión. El Proceso Analítico Jerárquico pretende ser una herramienta de ayuda al 
decisor en el proceso de elección de la alternativa que mejor contribuye a alcanzar la meta del problema planteado.

Paso 2: Establecimiento de las prioridades entre los criterios.

El objetivo de este paso es construir un vector de prioridades o pesos que evalúe la importancia relativa que la unidad decisora otorga a cada criterio.

El problema clave que se plantea en este punto es responder a cómo se puede asignar un valor numérico a cada criterio que represente, del modo más ajustado posible, la preferencia del decisor de un criterio frente a otro.

El método AHP utiliza una estrategia de asignación indirecta por la que el decisor sólo tiene que realizar una valoración sobre la importancia del criterio verbalizada en términos cualitativos y después acudir a una escala, que previamente ha sido establecida, para obtener los valores numéricos que se corresponden con su valoración. Por tanto, como paso previo a la resolución del problema de asignación de pesos, se debe definir la correspondencia entre la valoración cualitativa del decisor y la asignación numérica.

La escala sugerida por Saaty es la siguiente (Tabla 2-2):

\begin{tabular}{|c|l|l|}
\hline \multicolumn{3}{|c|}{ Escala de Saaty } \\
\hline $\begin{array}{c}\text { Escala } \\
\text { numérica }\end{array}$ & \multicolumn{1}{|c|}{ Escala verbal } & \multicolumn{1}{c|}{ Explicación } \\
\hline 1 & Igual importancia. & $\begin{array}{l}\text { Los dos elementos contribuyen igualmente } \\
\text { a la propiedad o criterio. }\end{array}$ \\
\hline 3 & $\begin{array}{l}\text { Moderadamente más importante un } \\
\text { elemento que el otro. }\end{array}$ & $\begin{array}{l}\text { El juicio y la experiencia previa favorecen a } \\
\text { un elemento frente al otro. }\end{array}$ \\
\hline 5 & $\begin{array}{l}\text { Fuertemente más importante un } \\
\text { elemento que en otro. }\end{array}$ & $\begin{array}{l}\text { El juicio y la experiencia previa favorecen } \\
\text { fuertemente a un elemento frente al otro. }\end{array}$ \\
\hline 7 & $\begin{array}{l}\text { Mucho más fuerte la importancia de } \\
\text { un elemento que la del otro. }\end{array}$ & $\begin{array}{l}\text { Un elemento domina fuertemente. Su } \\
\text { dominación está probada en la práctica. }\end{array}$ \\
\hline 9 & $\begin{array}{l}\text { Importancia extrema de un elemento } \\
\text { frente al otro. }\end{array}$ & $\begin{array}{l}\text { Un elemento domina al otro con el mayor } \\
\text { orden de magnitud posible. }\end{array}$ \\
\hline Nota: se pueden utilizar valores intermedios para una mejor aproximación.
\end{tabular}

Tabla 2-2 Escala de Saaty ( [12])

El decisor debe establecer las prioridades mediante comparación entre pares y, así, determinar los pesos relativos de los criterios. Los números de la escala representan la proporción en la que uno de los elementos que se consideran en la comparación 
pareada domina al otro respecto a una propiedad o criterio que tienen en común. El elemento menor tiene el valor recíproco o inverso respecto al mayor, es decir, si $x$ es el número de veces que un elemento domina a otro, entonces este último es $1 / x$ veces dominado por el primero, de tal modo que $\frac{1}{x} \cdot x=x \cdot \frac{1}{x}=1$, este es el principio del axioma de comparación reciproca que se mencionó antes.

Un ejemplo de matriz obtenida tendría una forma similar a la siguiente (Tabla 2-3):

\begin{tabular}{|l|c|c|c|}
\hline & Criterio 1 & Criterio 2 & Criterio 3 \\
\hline Criterio 1 & 1 & 3 & $1 / 7$ \\
\hline Criterio 2 & $1 / 3$ & 1 & 5 \\
\hline Criterio 3 & 7 & $1 / 5$ & 1 \\
\hline
\end{tabular}

Tabla 2-3 Ejemplo de matriz de asignación de pesos a los criterios

Para establecer los pesos de los criterios $(w)$, este método de matrices de comparación por parejas emplea los conceptos matemáticos de valor propio (autovalor) y vector propio (autovector) que se explica en los puntos siguientes.

Paso 3: Comprobar la consistencia de los juicios.

El decisor cometerá ciertas inconsistencias en sus juicios y resulta conveniente medir el grado de inconsistencia de los juicios emitidos por el decisor, dado que, si no se ha sido cuidadoso con las valoraciones, el vector de prioridades o pesos obtenidos pueden ser poco representativo.

Paso 4: Establecimiento de las prioridades locales entre los subcriterios.

Si en la modelización del problema de decisión como una jerarquía se ha considerado la descomposición de algunos o todos los criterios en subcriterios, antes de continuar debe calcularse el vector de pesos asociado a dichos subcriterios.

El procedimiento es el mismo que el descrito en el paso anterior, pero en este caso se deberán realizar las comparaciones pareadas entre subcriterios para determinar su importancia relativa respecto al criterio inmediatamente superior en la jerarquía. De este modo, es posible calcular el vector de pesos asociados a un conjunto de subcriterios respecto a su criterio "padre". 
Paso 5: Establecimiento de las prioridades locales entre las alternativas.

Una vez obtenidos los pesos o la ponderación de los criterios y subcriterios en los pasos anteriores, se procede a la valoración de las alternativas para así poder calcular las prioridades locales correspondientes. Para ello, con cada criterio o subcriterio del último nivel de la jerarquía se plantea la matriz $R$ de juicios por comparación pareada entre alternativas. El procedimiento es el explicado en el Paso 2, pero esta vez, se establece el nivel de prioridad de una alternativa sobre otra tomando como base de comparación el grado de cumplimiento o satisfacción de cada criterio o subcriterio. La escala que utilizar es la misma.

Una vez planteada la matriz $R$ de comparación entre alternativas, se procede como ya se ha comentado: se calcula el vector de pesos o prioridades y el índice de consistencia de los juicios. Una vez realizadas estas operaciones, si el índice de consistencia es aceptable, para cada criterio o subcriterio se obtiene un vector de pesos locales de las alternativas.

Paso 6: Establecimiento de las prioridades totales asociadas a cada alternativa.

Obtenidos los vectores de prioridad de todas las alternativas respecto de cada subcriterio, se obtiene una matriz, la que se multiplica por el vector de prioridad de los subcriterios respecto al criterio del cual se desprenden. Así se obtiene el vector de preferencias de cada alternativa con respecto a ese criterio. Este procedimiento se repite para cada criterio.

Paso 7: Análisis de sensibilidad

Como último paso de la metodología AHP puede realizarse un análisis de sensibilidad que confirme que realmente los resultados obtenidos son robustos y no son fruto del azar.

La realización de este análisis puede facilitarse y agilizarse si se emplea para ello herramientas informáticas de cálculo. Este análisis consiste en realizar variaciones en el valor de un peso y observar numérica y gráficamente cómo este cambio afecta al resto de los pesos del problema y a la priorización de alternativas. 


\subsubsection{Cálculo del Vector de Pesos o Utilidades}

Se va a describir el método de cálculo del vector de pesos o utilidades mediante Matrices de Comparación por Parejas (MCP), que tal y como se expuso en los pasos del procedimiento AHP, se empleará en los siguientes casos:

- Determinar los pesos de los criterios y subcriterios.

- Establecer las utilidades de las distintas alternativas, para aquellos criterios en los que no debe hacerse una valoración subjetiva.

Para el cálculo se seguirán los siguientes pasos que corresponden al denominado Método aproximado:

Paso 1. Cálculo del cuadrado de la matriz.

Se parte de la MCP sobre la que se quiere realizar el cálculo, se trata por lo tanto de una matriz cuadrada $A$ de dimensión $m \times m$

$$
A=\left(\begin{array}{ccc}
A_{11} & \cdots & A_{1 m} \\
\vdots & \ddots & \vdots \\
A_{m 1} & \cdots & A_{m m}
\end{array}\right)
$$

se calcula la matriz $C=A \times A=A^{2}$

$$
C=\left(\begin{array}{ccc}
C_{11} & \cdots & C_{1 m} \\
\vdots & \ddots & \vdots \\
C_{m 1} & \cdots & C_{m m}
\end{array}\right)
$$

Paso 2. Normalización de la matriz.

Se normaliza la matriz $C$ y obtenemos por lo tanto la siguiente matriz

$$
\begin{gathered}
N=\left(\begin{array}{ccc}
N_{11} & \cdots & N_{1 m} \\
\vdots & \ddots & \vdots \\
N_{m 1} & \cdots & N_{m m}
\end{array}\right) \\
N=\left(\begin{array}{ccc}
C_{11} / \sum_{i=1}^{m} C_{i 1} & \cdots & C_{1 m} / \sum_{i=1}^{m} C_{i m} \\
\vdots & \ddots & \vdots \\
C_{m 1} / \sum_{i=1}^{m} C_{i 1} & \cdots & C_{m m} / \sum_{i=1}^{m} C_{i m}
\end{array}\right)
\end{gathered}
$$


Paso 3. Cálculo del vector de pesos o prioridades.

A partir de la matriz normalizada $N$ se obtiene el vector de prioridades $(V p)$, calculando la media de la cada fila de la matriz $N$

$$
V p=\left(\begin{array}{c}
\sum_{i=1}^{m} N_{1 i} / m \\
\ldots \\
\sum_{i=1}^{m} N_{m i} / m
\end{array}\right)=\left(\begin{array}{c}
V_{1} \\
\ldots \\
V_{m}
\end{array}\right)
$$

Paso 4. Asignación de pesos o utilidades.

Una vez obtenido el vector de pesos o prioridades, estos valores serán asignados directamente como pesos en el caso de MCP de los criterios.

En el caso de estar trabajando con una MCP para determinar las utilidades de las alternativas en un determinado criterio será necesario realizar un cambio de escala, por lo que cada valor del vector de utilidades $(V u)$ habrá que dividirlo por el valor máximo del vector esto es

$$
V u=\left(\begin{array}{c}
V_{1} / \max \left(V_{1}, \ldots, V_{m}\right) \\
\cdots \\
V_{m} / \max \left(V_{1}, \ldots, V_{m)}\right.
\end{array}\right)
$$

hay que tener en cuenta que el vector viene dado en la escala $[0,1]$.

\subsubsection{Algoritmo para el Cálculo de la Relación de Consistencia}

La inconsistencia surge cuando algunos juicios de la Matriz de Comparación por Parejas se contradicen unos a otros. Dado que el decisor puede no estar seguro de sus juicios o realiza malas apreciaciones al comprar un elemento con otro, los valores de la MCP puede que no sean consistentes.

La consistencia es un concepto fundamental en este tipo de técnicas, ya que una consistencia baja puede ser síntoma de aleatoriedad en los juicios del decisor.

Por ello, además de obtener el vector de prioridades, la herramienta deberá calcular la Relación de Consistencia (RC) que nos indicará el nivel de inconsistencia de la MCP y por lo tanto del nivel de validez de los resultados. 
Para calcular este índice se seguirán los siguientes pasos:

Paso 1.

Para cada fila de la MCP se calcula la suma ponderada en base a la suma del producto de cada valor de la fila por la prioridad del elemento correspondiente.

Siguiendo con la notación del punto anterior, partimos de la matriz $A$ y del vector de prioridades $V$

$$
\begin{gathered}
A=\left(\begin{array}{ccc}
A_{11} & \cdots & A_{1 m} \\
\vdots & \ddots & \vdots \\
A_{m 1} & \cdots & A_{m m}
\end{array}\right) \\
V_{p / u}=\left(\begin{array}{c}
V_{1} \\
\vdots \\
V_{m}
\end{array}\right)
\end{gathered}
$$

A partir de los cuales calculamos la mencionada suma ponderada $(S p)$

$$
S p=\left(\begin{array}{ccc}
A_{11} \times V_{1} & . .+. . & A_{1 m} \times V_{m} \\
\vdots & \ddots & \vdots \\
A_{m 1} \times V_{1} & . .+. . & A_{m m} \times V_{m}
\end{array}\right)=\left(\begin{array}{c}
S p_{1} \\
\vdots \\
S p_{m}
\end{array}\right)
$$

Paso 2.

La suma ponderada obtenida para cada fila se divide por la prioridad del elemento correspondiente, obteniendo la siguiente matriz

$$
\left(\begin{array}{c}
S p_{1} / V_{1} \\
\vdots \\
S p_{m} / V_{m}
\end{array}\right)
$$

Paso 3.

Se realiza un promedio de los resultados anteriores y se obtiene $\lambda_{\max }$

$$
\lambda_{\max }=\left(S p_{1} /_{V_{1}}+\cdots+S p_{m} / V_{m}\right) /_{m}
$$

Y una vez obtenido $\lambda_{\max }$ se calcula el Índice de Consistencia (IC) mediante la siguiente operación

$$
I C=\left(\lambda_{\max }-m\right) /(m-1)
$$


Paso 4.

Aunque el Índice de Consistencia es una medida de consistencia de la matriz, su valor depende del tamaño de la matriz, por lo que es posible que un determinado IC sea tolerable para una determinada dimensión de una matriz y no lo sea para otra de dimensión diferente.

Es, por tanto, que se aplica la Inconsistencia Aleatoria Media (IAM) desarrollada por Saaty, para así obtener un índice que dé una indicación de la consistencia de la matriz independientemente de su dimensión.

Por ello, se calcula la Relación de Consistencia (RC), que se presentará en todas las MCP de la herramienta, de la siguiente manera:

$$
R C=\frac{I C}{I A M}
$$

de tal forma que el valor de la IAM se extrae de la siguiente Tabla 2-4

\begin{tabular}{|c|c|c|c|c|c|c|c|c|c|}
\hline \multicolumn{1}{|c|}{ Índices aleatorios por tamaño de matriz } \\
\hline Tamaño matriz & 2 & 3 & 4 & 5 & 6 & 7 & 8 & 9 & 10 \\
\hline Índice aleatorio & 0,00 & 0,52 & 0,89 & 1,11 & 1,25 & 1,35 & 1,40 & 1,45 & 1,49 \\
\hline
\end{tabular}

Tabla 2-4 Inconsistencia aleatoria ( [12])

\subsubsection{Cálculo del Vector de Soluciones}

Se detallan a continuación los cálculos finales para obtener el vector de evaluaciones o importancia relativa, es decir la solución al problema planteado. Para ello, se pueden utilizar las dos siguientes metodologías, para posteriormente poder aplicar una media ponderada por los pesos de los criterios.

- Método ideal.

- Método de las normalizaciones o distributivo.

Una vez obtenida la matriz decisional de utilidades (Tabla 2-5), es necesario aplicar alguno de los dos métodos reseñados en el párrafo anterior para poder realizar los cálculos finales. 
Matriz decisional de utilidades.

\begin{tabular}{|c|c|c|c|}
\cline { 2 - 4 } \multicolumn{1}{c|}{} & Criterio 1 & $\ldots \ldots \ldots$ & Criterio $\boldsymbol{n}$ \\
\hline Alternativa 1 & $U_{11}$ & $U_{1 i}$ & $U_{1 n}$ \\
\hline$\ldots \ldots \ldots \ldots .$. & $U_{i 1}$ & $U_{i i}$ & $U_{i n}$ \\
\hline Alternativa $\boldsymbol{m}$ & $U_{m 1}$ & $U_{m i}$ & $U_{m n}$ \\
\hline
\end{tabular}

Tabla 2-5 Matriz decisional de utilidades ( [12])

\section{1) Método ideal.}

Esta metodología nace como consecuencia de los problemas detectados con la forma en que se usan las comparaciones por pares y la forma en que el AHP evalúa las alternativas. Primero, Belton y Gear en [100] observaron que el AHP puede revertir la clasificación de las alternativas cuando se introduce una alternativa idéntica a una de las alternativas ya existentes (Rank reversal, ver [101]). Dyer y Wendell en [102] también estudiaron el hecho de que la reversión de rango igualmente ocurre en el AHP cuando se consideran copias cercanas. Saaty en [103] y posteriormente en [104], en respuesta a las críticas de Dyer en [105], proporcionó algunos axiomas y pautas sobre qué tan cerca puede estar una copia cercana a una alternativa original, sin causar una inversión de rango. En [100], para superar esta deficiencia, se propuso que cada columna de la matriz de decisión de AHP se dividiera por la entrada máxima de esa columna. Por lo tanto, introdujeron una variante del AHP original, que se llamó inicialmente: AHP revisado. Posteriormente, Saaty en [106] aceptó la variante anterior, que ahora se llama: Método Ideal AHP. Además de esta versión revisada, otros autores también introdujeron otras variantes al AHP original. Sin embargo, el AHP en el modo original o ideal, es el método más aceptado y es considerado por muchos como el método MADM más fiable.

Como ya se ha adelantado, se parte de la matriz decisional que contiene las utilidades de cada alternativa, para cada criterio. A continuación, se calcula la matriz decisional ideal, dividiendo cada elemento de la matriz por el valor máximo de su columna o criterio (Tabla 2-6). 
Matriz decisional ideal.

\begin{tabular}{|c|c|c|c|}
\hline & Criterio 1 & $\ldots \ldots \ldots$ & Criterio $n$ \\
\hline Alternativa 1 & $U_{11} / \max \left(U_{11}, . U_{m 1}\right)$ & $\cdots$ & $U_{1 n} / \max \left(U_{1 n, .} . U_{m n}\right)$ \\
\hline ……….... & $U_{i 1} / \max \left(U_{11}, . U_{m 1}\right)$ & $\cdots$ & $U_{i n} / \max \left(U_{1 n}, . U_{m n}\right)$ \\
\hline Alternativa $m$ & $U_{m 1} / \max \left(U_{11, \cdots} U_{m 1}\right)$ & $\cdots$ & $U_{m n} / \max \left(U_{1 n, .} U_{m n}\right)$ \\
\hline
\end{tabular}

Tabla 2-6. Matriz decisional ideal ( [12])

Una vez obtenida esta matriz se debe calcular el vector de media ponderada con los pesos de los criterios, para que después de normalizado se obtenga el vector de evaluaciones o de prioridades relativas.

\section{2) Método de la normalización o distributivo.}

Al igual que en el método anterior, partimos de la matriz decisional que contiene las utilidades de cada alternativa para cada criterio. A continuación, calculamos la matriz decisional normalizada o distributiva, dividiendo cada elemento de la matriz por la suma de los elementos de su columna o criterio (Tabla 2-7).

Matriz decisional normalizada o distributiva.

\begin{tabular}{|c|c|c|c|}
\cline { 2 - 4 } \multicolumn{1}{c|}{} & Criterio 1 & $\cdots \cdots \cdots$ & Criterio $n$ \\
\hline Alternativa 1 & $U_{11} / \sum_{1}^{m} U_{i 1}$ & $\cdots \cdots$ & $U_{1 n} / \sum_{1}^{m} U_{i n}$ \\
\hline$\ldots \ldots \ldots \cdots \cdots$ & $U_{i 1} / \sum_{1}^{m} U_{i 1}$ & $\cdots \cdots \cdots$ & $U_{i n} / \sum_{1}^{m} U_{i n}$ \\
\hline Alternativa m & $U_{m 1} / \sum_{1}^{m} U_{i 1}$ & $\cdots \cdots \cdots$ & $U_{m n} / \sum_{1}^{m} U_{i n}$ \\
\hline
\end{tabular}

Tabla 2-7. Matriz decisional normalizada (extraída de [99])

Una vez obtenida esta matriz se calcula directamente el vector de evaluaciones o de prioridades relativas, aplicando la media ponderada con los pesos de los criterios.

\subsubsection{Programa de Ayuda a la Decisión de Líneas de Acción (ADLA)}

Para implementar la metodología de AHP existen diversos programas de ayuda y, quizás, Expert Choice [107] es uno de los más populares y de los que más significativamente ha 
contribuido a su enorme aceptación. No obstante, en esta tesis se ha utilizado el programa propiedad del Ministerio de Defensa: ADLA (este software es similar a otros muchos de los cuales se puede encontrar una amplia relación en [108]).

ADLA es una herramienta para la comparación de líneas de acción y toma de decisión en función de los criterios que se analicen. Está desarrollado por GMV [109] en colaboración con el GIMO, que es quién ha dirigido los requisitos, ha revisado y ha evaluado el correcto funcionamiento de la aplicación [110].

Es una herramienta de ayuda a la decisión basada en la metodología denominada Proceso Analítico Jerárquico (AHP). Esta metodología está basada en matemáticas y psicología, permitiendo realizar un análisis multicriterio que consigue una resolución más realista y efectiva del problema.

Para aplicar la metodología a este software, previamente se crea un escenario en el que se definen los siguientes conceptos:

- Objetivo del estudio. Será el propósito del problema que se defina para el estudio. Se debe identificar.

- Alternativas disponibles. Serán las distintas alternativas a comparar con el objetivo del estudio. Se deben definir.

- Criterios y subcriterios para evaluar las alternativas. Son los factores en los que se jerarquiza el problema, a tener en cuenta para la comparación. Los criterios se pueden descomponer en subcriterios, y estos a su vez en otros sub-subcriterios, en una descomposición multinivel, que permiten acercar más la comprensión del problema.

- Valoración a asignar a cada criterio para las distintas alternativas, siguiendo diferentes métodos: cuantitativo, cualitativo o subjetivo, con el que se podrá calcular la utilidad de cada criterio para cada alternativa. La herramienta permite varios tipos de valoración, además del método de comparación por parejas y proporciona el grado de inconsistencia de los datos introducidos.

- Pesos a asignar a cada uno de los criterios y subcriterios definidos, cada uno a su nivel. Con estos datos se priorizan los criterios que, junto con las valoraciones, permiten obtener la comparación de las alternativas bajo estudio. 
- Prioridades de los criterios y valoraciones de las alternativas, obtenidos como resultados de los cálculos obtenidos.

- Análisis de sensibilidad, para valorar la robustez de los resultados obtenidos, en función de los pesos dados a los criterios.

En la Figura 2-3 se muestra el diagrama de criterios que muestra un ejemplo del modelo.

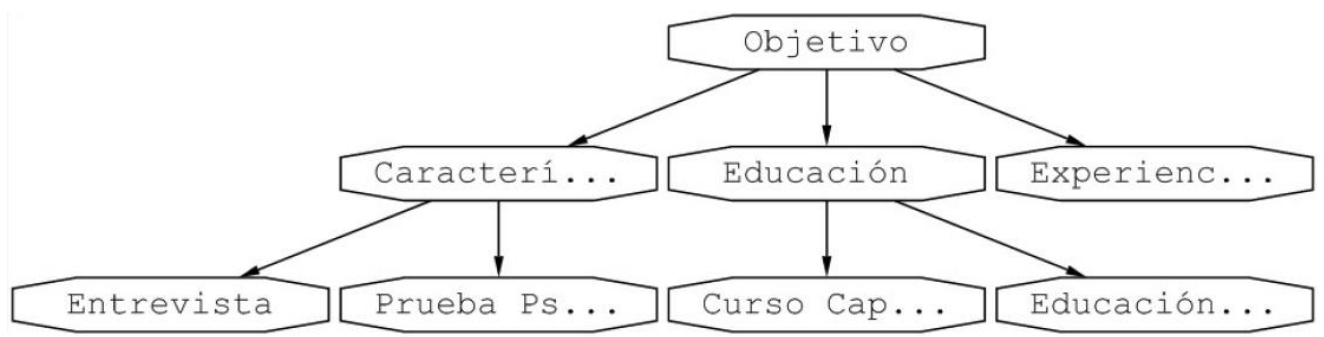

Figura 2-3 Ejemplo de diagrama de criterios en ADLA ( [111])

Los resultados de comparación de alternativas y los estudios de sensibilidad para cada uno de los criterios se presentan tanto de forma analítica como gráfica.

El escenario y los resultados se pueden guardar en ficheros, de tal modo que cada usuario pueda utilizar la herramienta para hacer su análisis y después poder mostrarla solamente con cargar su fichero.

\subsection{Simulación}

En el diseño de la metodología de esta tesis, no solo se reconoce y señala la significativa utilidad de la simulación, sino que, además, en la resolución ad hoc de los problemas de decisión que se expondrán más adelante se hace un uso amplio de ella.

La simulación ocupa un lugar muy alto entre las técnicas más utilizadas de investigación operativa actuales. En cierto sentido, se usa la simulación para tomar decisiones cotidianas en todos los ámbitos. Antes de tomar una decisión, las personas para su ayuda en ese proceso generalmente desarrollan un modelo mental o a veces incluso un modelo físico de su forma de entender el entorno. Posteriormente, modifican el modelo con varias combinaciones y varios escenarios posibles de contratiempos para generar cierta información que pueda ser utilizada para tomar decisiones racionales.

Casi todas nuestras decisiones personales que se toman a diario se basan en modelos mentales. Por ejemplo, cuando un individuo se prepara para ir al aeropuerto a tomar un 
vuelo, uno puede imaginar (modelo mental) que lo componen los distintos preparativos de equipaje necesarios, la ruta al aeropuerto, posibles retrasos, etc.

Un modelo físico podría emplearse, por ejemplo, para reorganizar los servicios en un hospital (un sistema existente), en lugar de mover los pesados equipos médicos y el mobiliario, se dibujan a escala los planos y se reorganiza rápidamente la ubicación de los distintos servicios, eligiendo el arreglo más eficaz de funcionamiento del hospital. Para diseñar un nuevo edificio (un futuro sistema inexistente), los arquitectos crean maquetas para mejorar su modelo mental de la apariencia del edificio y, así, estudiar la disposición de los distintos servicios.

Existe pues, la necesidad de un modelo que, una vez construido y a veces incluso mientras se construye, se pueda explorar y ayude a entender la estructura y comportamiento del sistema, a probar cómo se comportará bajo una variedad de condiciones, a comparar escenarios y a optimizar procesos. Los procesos de construcción de modelos y experimentación predicen los resultados de las decisiones que se podrán implementar posteriormente (Figura 2-4).

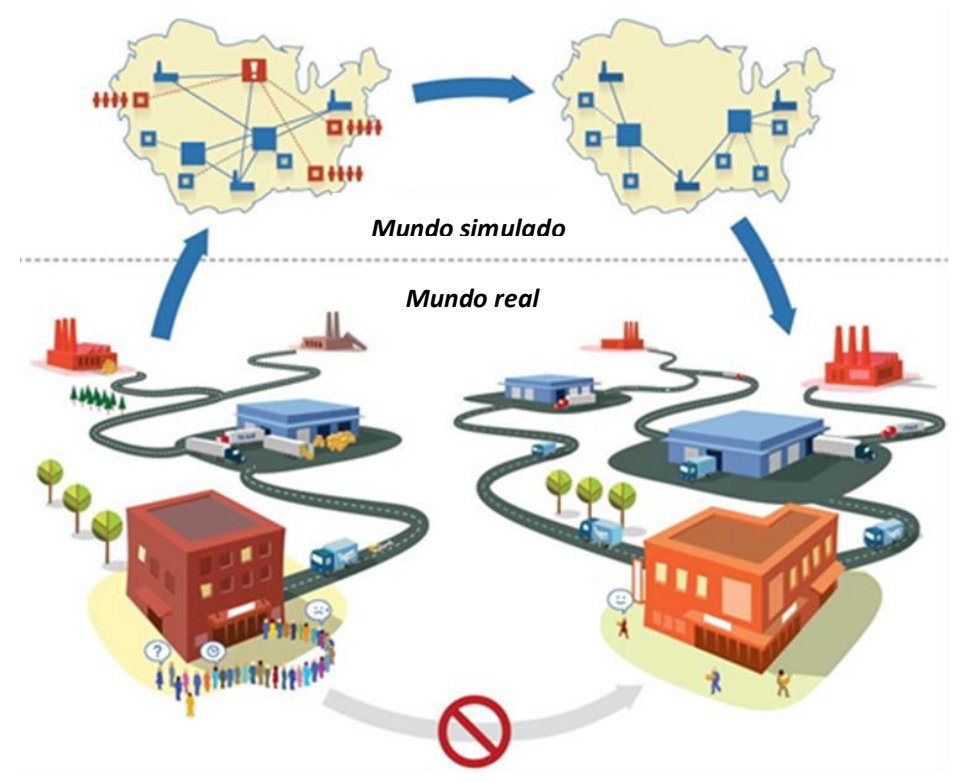

Figura 2-4 Modelo del mundo real para optimizar un sistema (AnyLogic)

Los ordenadores son unas poderosas herramientas de modelos, y ofrecen un mundo virtual flexible donde se puede crear casi cualquier cosa imaginable. Por supuesto, hay muchas herramientas de modelos en ordenador, desde hojas de cálculo básicas que 
permiten a cualquier persona modelar los gastos, hasta las herramientas de modelos de simulación complejas.

La simulación de sistemas puede definirse como "la práctica de construir modelos para representar sistemas del mundo real existentes, o sistemas hipotéticos futuros, y de experimentar con estos modelos para explicar el comportamiento del sistema, mejorar el rendimiento del sistema, o diseñar nuevos sistemas con mejores rendimientos" [112]. A diferencia de los métodos analíticos tradicionales, que generalmente utilizan modelos matemáticos, los tipos de modelos considerados en la simulación son los que mejor se representan por medio de programas informáticos. Los datos sobre el rendimiento del sistema se obtienen de los mismos programas informáticos y no del sistema del mundo real que se está estudiando.

A pesar de su falta de elegancia matemática, la flexibilidad que ofrece, la diversidad de ámbitos de problemas a los que se aplica y el grado de realismo del modelado, que permite (en comparación con otros métodos de análisis de sistemas y de diseño, como las técnicas matemáticas), la simulación por ordenador, desde que apareció, ha ido ganando popularidad como potente herramienta de análisis y diseño de sistemas. La simulación se emplea actualmente en numerosos ámbitos de trabajo.

\subsubsection{Modelo Analítico vs. Simulación}

Una de las herramientas más extendidas de cualquier empresa es el Excel, que tiene varias ventajas: es muy fácil de usar y permite agregar scripts a sus fórmulas a medida que la lógica de su hoja de cálculo se vuelve más sofisticada (Figura 2-5).

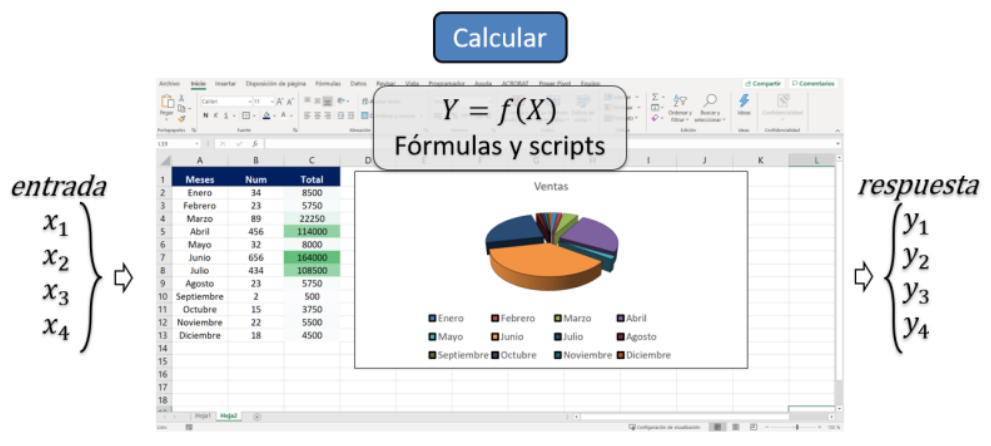

Figura 2-5 Modelo analítico en Excel (Elaboración propia de imagen de AnyLogic) 
El conjunto de técnicas detrás del modelo basado en hojas de cálculo es simple: se introducen los datos de entrada en unas celdas y se obtiene los resultados en otras. Las fórmulas, y en modelos más complejos scripts, enlazan los valores de entrada y salida. Admite varios complementos que permiten realizar variaciones de parámetros, realizar experimentos Montecarlo, experimentos de optimización, etc.

Sin embargo, existe un gran número de problemas en los que la solución analítica (basada en fórmulas) es difícil de aplicar o simplemente no existe. Esta clase de problemas incluye sistemas dinámicos de:

- Comportamiento no lineal

- Memoria

- Influencias no intuitivas entre variables

- Dependencias temporales y causales

- Todo lo anterior combinado con incertidumbre y un gran número de parámetros En la mayoría de estos casos es imposible obtener las fórmulas correctas y mucho menos el componer un modelo mental del sistema.

Por ejemplo, si se trata de optimizar una flota de camiones, es difícil utilizar una hoja de cálculo para gestionar factores como: los horarios de viaje, los tiempos de carga y descarga, las restricciones de tiempo de entrega y las capacidades de los puntos finales. La disponibilidad de un vehículo en una ubicación, fecha y hora determinadas depende de una secuencia de eventos precedentes y determinar dónde enviar el vehículo cuando está inactivo obliga a analizar secuencias de eventos futuros. Las fórmulas que expresan dependencias estáticas entre variables correctamente no funcionan para representar sistemas con un comportamiento dinámico. Es por eso, que se utiliza otra tecnología de modelos para analizar sistemas dinámicos: el modelo de simulación.

Un modelo de simulación es siempre un modelo ejecutable que crea una trayectoria de los cambios de estado del sistema. Se asemeja a un conjunto de reglas que indican al sistema cómo pasar de un estado actual a un estado futuro. Las reglas pueden tomar muchas formas, incluyendo ecuaciones diferenciales, diagramas de estado, diagramas de flujo del proceso y programación. Se generan las salidas del modelo y se observa cómo funciona. 


\subsubsection{Ventajas del Modelo de Simulación}

El modelo de simulación tiene varias ventajas:

- Los modelos de simulación permiten analizar sistemas y encontrar soluciones donde otros métodos, como los cálculos analíticos y programación lineal, fallan.

- Una vez elegido el nivel de abstracción, es más fácil desarrollar un modelo de simulación que un modelo analítico. Normalmente requiere menos reflexión, y el proceso de desarrollo es escalable y modular.

- La estructura de un modelo de simulación refleja de manera natural la estructura del sistema.

- En un modelo de simulación, se pueden medir valores y rastrear entidades dentro del nivel de abstracción, y se pueden agregar mediciones y análisis estadístico en cualquier momento.

- La capacidad de jugar y animar el comportamiento del sistema en el tiempo es una de las grandes ventajas de la simulación.

\subsubsection{Aplicaciones de los Modelos de Simulación}

En la Figura 2-6 se muestra una serie de aplicaciones para modelos de simulación, con su correspondiente nivel de abstracción.

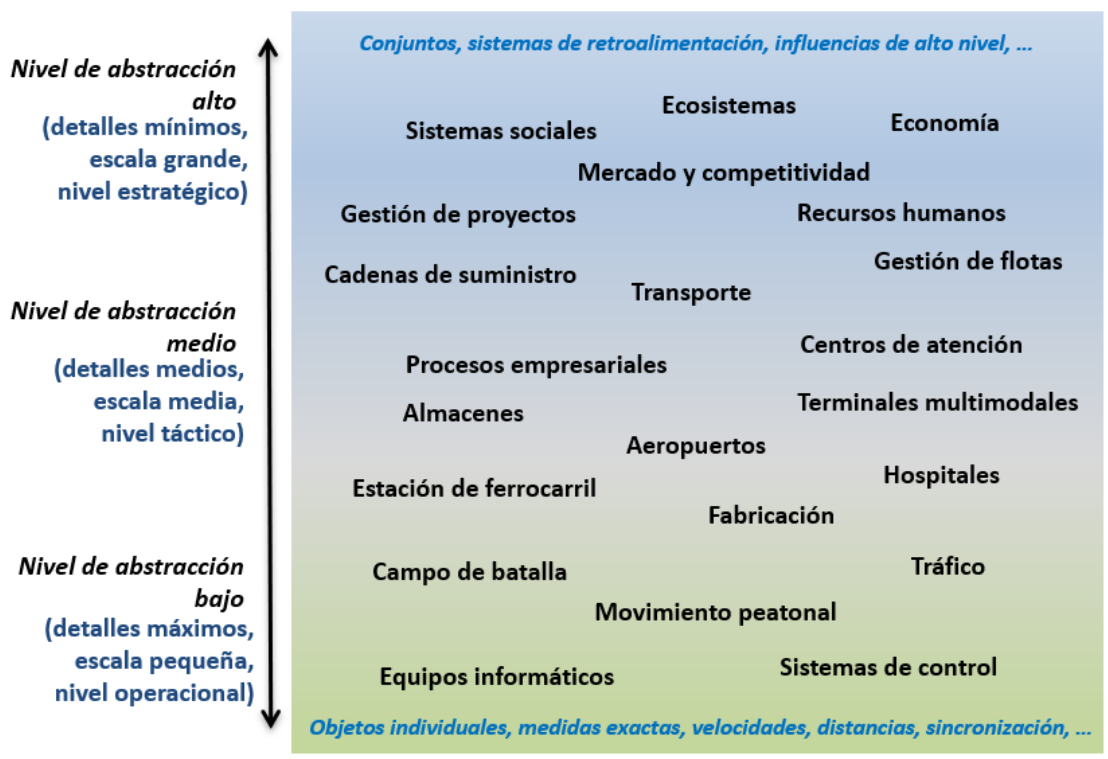

Figura 2-6 Nivel de abstracción de los modelos (Elaboración propia de imagen de [113]) 
En la parte inferior están los modelos que utilizan a nivel físico representaciones con mucho detalle de objetos del mundo real. En este nivel se tiene en cuenta la interacción física, las dimensiones, las velocidades, las distancias, los tiempos, etc. La evacuación de un campo de fútbol, los cruces de tráfico controlados por los semáforos, acciones de soldados en el campo de batalla, el funcionamiento de un comedor en un buque, son ejemplos de problemas que requieren un modelado de baja abstracción.

Los modelos de la parte superior son muy abstractos y suelen utilizar conjuntos, como las poblaciones de consumidores o las estadísticas de empleo, en lugar de objetos individuales. Dado que sus objetos interactúan a un nivel alto, pueden ayudar a entender las relaciones de, por ejemplo, cómo el gasto en publicidad influye en las ventas, sin que exista la necesidad de modelar los pasos intermedios.

Otros modelos tienen un nivel de abstracción intermedio. Si se modela el servicio de urgencias de un hospital, preocupa el espacio físico, porque se quiere saber cuánto tiempo tarda alguien en caminar desde la sala de urgencias hasta la sala de rayos $X$, pero en este caso la interacción física entre las personas, en principio, es irrelevante porque se supone que en un hospital no hay congestiones.

El decidir el nivel correcto de abstracción es crítico para el éxito de un proyecto. Habitualmente lo mejor es empezar con un nivel alto de abstracción e ir descendiéndolo conforme el modelo evoluciona.

\subsubsection{Los Modelos de Simulación}

Para asignar a un sistema del mundo real su modelo de simulación se puede manejar el esquema de la Figura 2-7. Hay tres tipos de modelos:

- Sistemas dinámicos

- Eventos discretos

- Basado en agentes

Cada modelo se ubica en un rango específico de nivel de abstracción. Los sistemas dinámicos suponen una abstracción muy alta y se suelen utilizar para modelos estratégicos. Los sistemas de modelado de eventos discretos tienen una abstracción media y media-baja. Y el modelado basado en agentes puede variar desde modelos muy 
detallados donde los agentes representan personas u objetos físicos, hasta los modelos altamente abstractos donde los agentes representan compañías o gobiernos competidores.

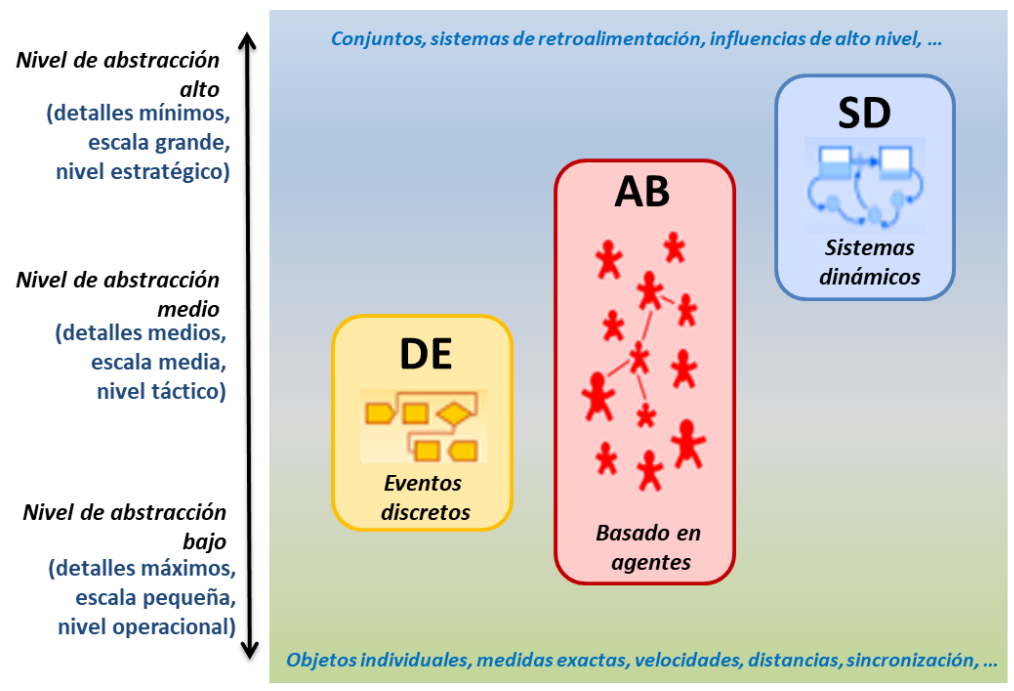

Figura 2-7 Esquema del modelado de una simulación (Elaboración propia de imagen de [113])

Después de haber considerado cuidadosamente el sistema que se desea modelar y cuáles son los objetivos, se debe seleccionar el método.

En la Figura 2-8 se observa un ejemplo del dilema del analista que debe determinar cómo modelar un supermercado. El analista se plantea tres opciones:

1) Construir una estructura de retroalimentación donde las ventas están en un bucle con anuncios, calidad de servicio, precios y fidelización de los clientes.

2) Construir un diagrama de flujo de procesos donde los clientes son entidades y los empleados son recursos.

3) Construir un modelo basado en agentes donde los consumidores son agentes afectados por la publicidad, la comunicación y sus interacciones con otros clientes y empleados. 


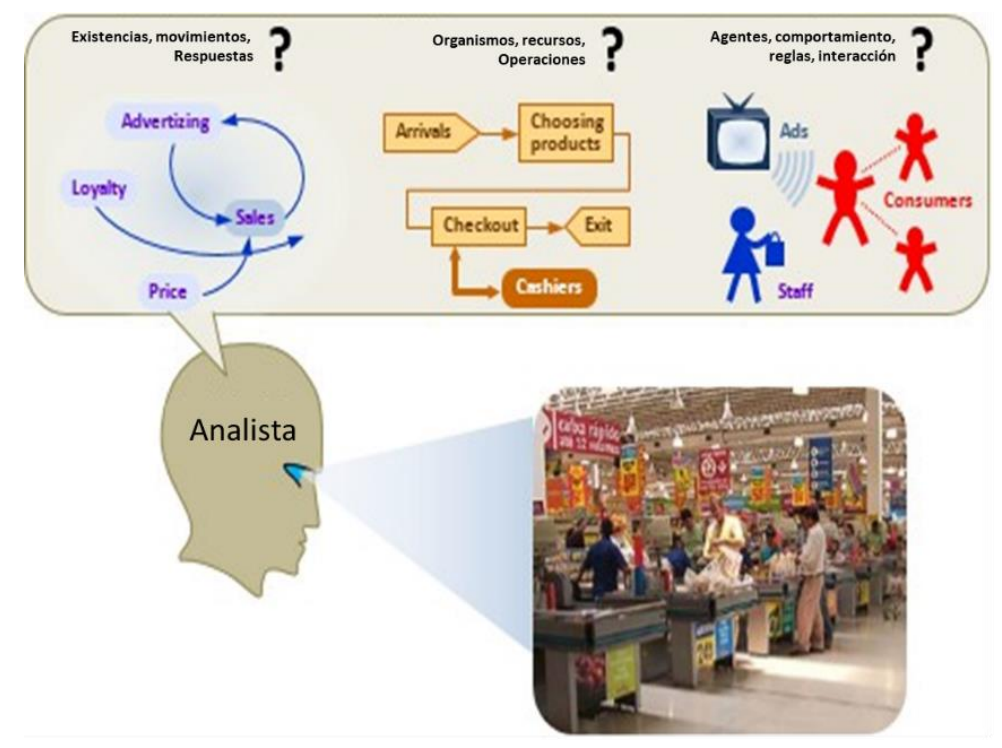

Figura 2-8 Selección del método de modelo (Elaboración propia de imagen de [113])

\subsubsection{Modelo Basado en Agentes}

El modelo basado en agentes es un método relativamente nuevo comparado con los otros dos. Aproximadamente desde hace 15 años está en un proceso de rápido crecimiento gracias a la mejora de potencia de los ordenadores. Los modelos basados en agentes son los más exigentes.

El modelo basado en agentes ofrece a un analista otra forma de ver el sistema:

- Se puede no saber cómo se comporta un sistema, pero se puede comenzar a construir un modelo identificando los objetos (agentes) y definiendo sus comportamientos. Después, se puede conectar los agentes que se han creado y permitirles interactuar o ponerlos en un entorno que tenga su propia dinámica. El comportamiento global del sistema emerge de los muchos (diez, cientos, miles, millones) comportamientos individuales concurrentes [113].

No existe un lenguaje estándar para el modelado basado en agentes, su estructura proviene de editores gráficos.

Hay muchas maneras de especificar el comportamiento de un agente. Normalmente el agente tiene una noción de su estado y, sus acciones y reacciones, dependen ese estado. Los agentes basados en este modelo pueden representar cosas muy diversas: vehículos, 
unidades de equipo, proyectos, productos, ideas, organizaciones, inversiones, pedazos de tierra, personas en diferentes roles, etc.

\subsubsection{Fases Simulación}

Una posible guía de los pasos que pueden seguirse en un estudio de simulación son los siguientes (extraído de [114]):

1. Definición del problema. Consiste en definir claramente por qué se estudia el sistema y qué objetivos se persigue con ello, es decir, cuáles son las preguntas a contestar.

2. Planificación del proyecto. Tiene como objetivo estimar qué recursos son necesarios para llevar a cabo el estudio: dinero, personal, hardware de computación, recursos software, etc. Si estos recursos no están disponibles debe replantearse el alcance del estudio.

3. Definición del sistema. Debe definirse qué aspectos de la realidad constituyen el sistema bajo estudio.

4. Formulación conceptual del modelo. Desarrollo de un modelo preliminar, bien gráficamente (mediante diagramas de bloques) o en seudocódigo, en el que se definen los componentes, las variables descriptivas y las interacciones (la lógica) que constituyen el modelo del sistema.

5. Diseño preliminar del experimento. Consiste en definir qué acción se va a ejercer sobre el modelo y cómo se va a medir su comportamiento. Se trata, por tanto, de definir qué variables son las entradas y cuáles las salidas, cómo va a modificarse el valor de las entradas y cómo van a recogerse los datos de salida.

6. Preparación de los datos de entrada. Debe establecerse el procedimiento a seguir para asignar valores a cada una de las variables de entrada durante la simulación.

7. Traducción del modelo. Consiste en describir las partes del modelo y su funcionamiento empleando un lenguaje de simulación. De este modo ya puede ejecutarse la simulación.

8. Verificación y validación. Se trata de estudiar si el modelo opera como debiera y si la salida del modelo es creíble y representativa del comportamiento del sistema. 
9. Diseño experimental final. En este punto se diseña un experimento que proporcione la información necesaria para poder contestar a las preguntas planteadas en el estudio. Típicamente el experimento consiste en cierto número de réplicas de la simulación realizadas en condiciones bien definidas.

10. Experimentación. Realización del experimento de simulación diseñado anteriormente.

11. Análisis e interpretación. Consiste en inferir conclusiones a partir de los datos obtenidos de la simulación.

12. Implementación y documentación. Una vez obtenidos los resultados, analizados y extraídas las conclusiones, estas deben ser presentadas de la forma más adecuada. El modelo debe ser documentado y preparado de modo que pueda ser reutilizado para posteriores estudios. Finalmente, deben tomarse acciones (si esta era la finalidad del estudio) a partir de las conclusiones obtenidas.

Respecto a la distribución del esfuerzo en [115], se apunta como un posible criterio de referencia la regla 40-20-40, consistente en:

- Emplear el 40 \% del esfuerzo y del tiempo del proyecto en los pasos 1 a 6 (comprensión del problema, diseño del modelo y del experimento).

- Emplear el 20 \% del esfuerzo en el paso 7 (programación del modelo).

- Finalmente, emplear el $40 \%$ restante en los pasos 8 a 12 (verificación, validación, diseño y realización del experimento, análisis de los resultados, implementación y documentación).

En esta tesis se han empleado fundamentalmente los softwares de simulación, Pathfinder, AnyLogic, y el sistema de cómputo numérico Matlab, que desarrolla un lenguaje de programación propio. En los apartados donde se expone la aplicación de la metodología, al ser softwares más desconocidos, se expondrán someramente el Pathfinder y el AnyLogic. 


\section{Capítulo 3. Metodología y Casos de Estudio}

En este punto se explicará en qué consiste la metodología diseñada para la resolución de problemas de decisión multicriterio y su aplicación en tres casos de estudio prácticos.

\subsection{Metodología}

Según Budnick et al. [116], los procesos científicos de toma de decisiones basada en la investigación operativa se pueden organizar en ocho pasos, subdivididos a la vez en tres etapas (Figura 3-1).

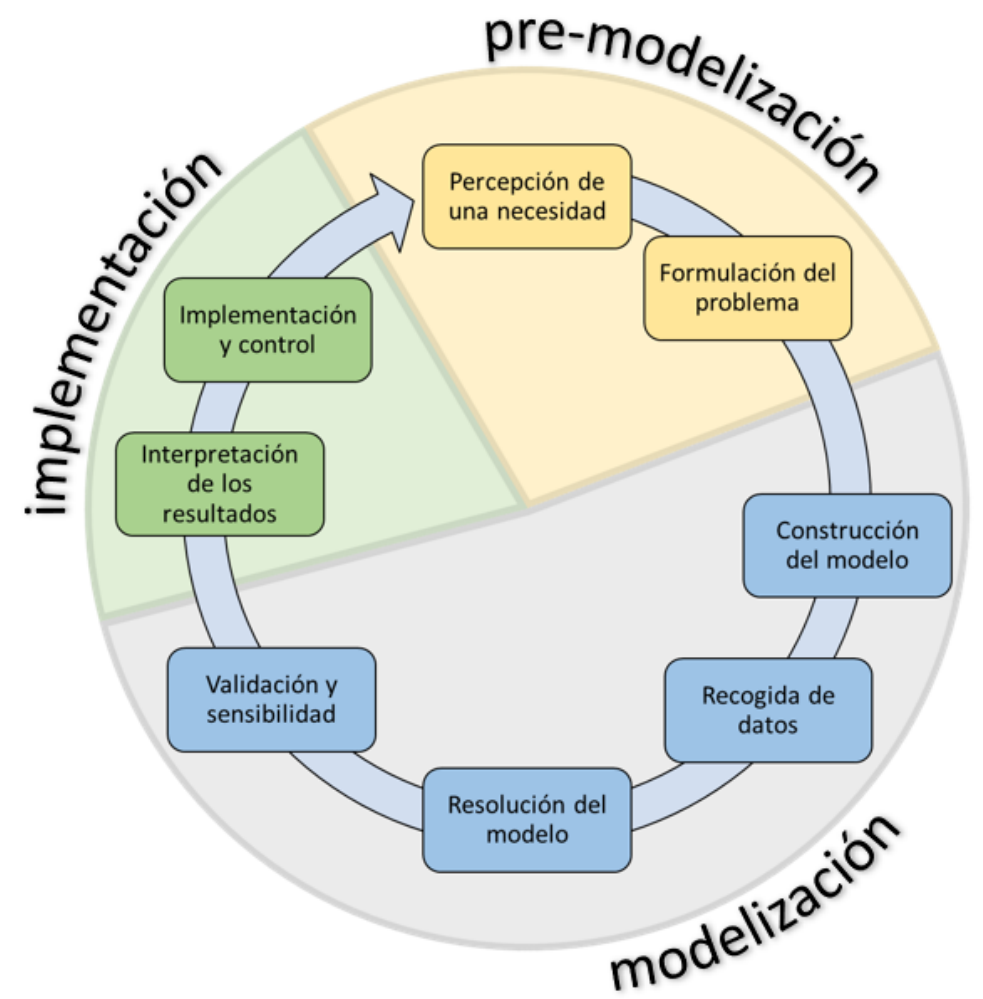

Figura 3-1 Fases del proceso de toma de decisiones (Elaboración propia de [116]) 
La enumeración conforme a [116] es:

- Etapa de pre-modelización. Consta de dos pasos:

1. “Percepción de una necesidad. Percepción, por parte del decisor, de que se necesita llevar a cabo alguna acción, o de que alguna acción debe optimizarse".

2. “Formulación del problema. Traslación de la percepción de una necesidad a un establecimiento específico de dicha necesidad y de los criterios mediante los que se juzgará la solución del problema".

- Etapa de modelización. Consta de cuatro pasos:

3. “Construcción del modelo. Construcción de una representación matemática del problema".

4. "Recogida de datos. Recolección de los elementos específicos del modelo, que caracterizan las condiciones actuales del problema".

5. “Resolución del modelo. Manipulación matemática de los datos de entrada para producir unos resultados".

6. "Validación y sensibilidad. Testeo de los resultados del modelo para garantizar su validez, y determinar las implicaciones de posibles errores al estimar los datos de entrada".

- Etapa de implementación. Consta de dos pasos:

7. “Interpretación de los resultados. Volver a examinar cuidadosamente los criterios del problema a la luz de los resultados del modelo".

8. “Implementación y control. Análisis de los cambios tecnológicos y de comportamiento requeridos, en el corto y en el largo plazo".

Así, las fases del proceso de toma de decisiones forman un ciclo cerrado, ya que en la mayoría de los procesos reales de decisión el proceso no concluye, sino que se realimenta e invita a una reconsideración de todos los elementos decisionales, técnicos, etc. del modelo, para corregirlos y ajustarlos mejor al problema que se desea resolver. Este ajuste abarca, tanto los modelos matemáticos por parte del analista, como las posibles reconsideraciones de preferencias y criterios por parte de los expertos decisores [19]. 
La metodología que se ha diseñado repercute en este proceso de la toma de decisiones fundamentalmente en su fase de modelización y se asienta sobre la técnica AHP. EI nuevo método, aunque se podría concluir que se incrusta en las tres etapas de [116] (ver Figura 3-1), esencialmente, modeliza los pasos que comprenden desde la construcción del modelo, hasta el paso de validación y sensibilidad. Esta nueva metodología sirve para los procesos científicos de toma de decisiones multicriterio, esto implica que las alternativas deben estar definidas.

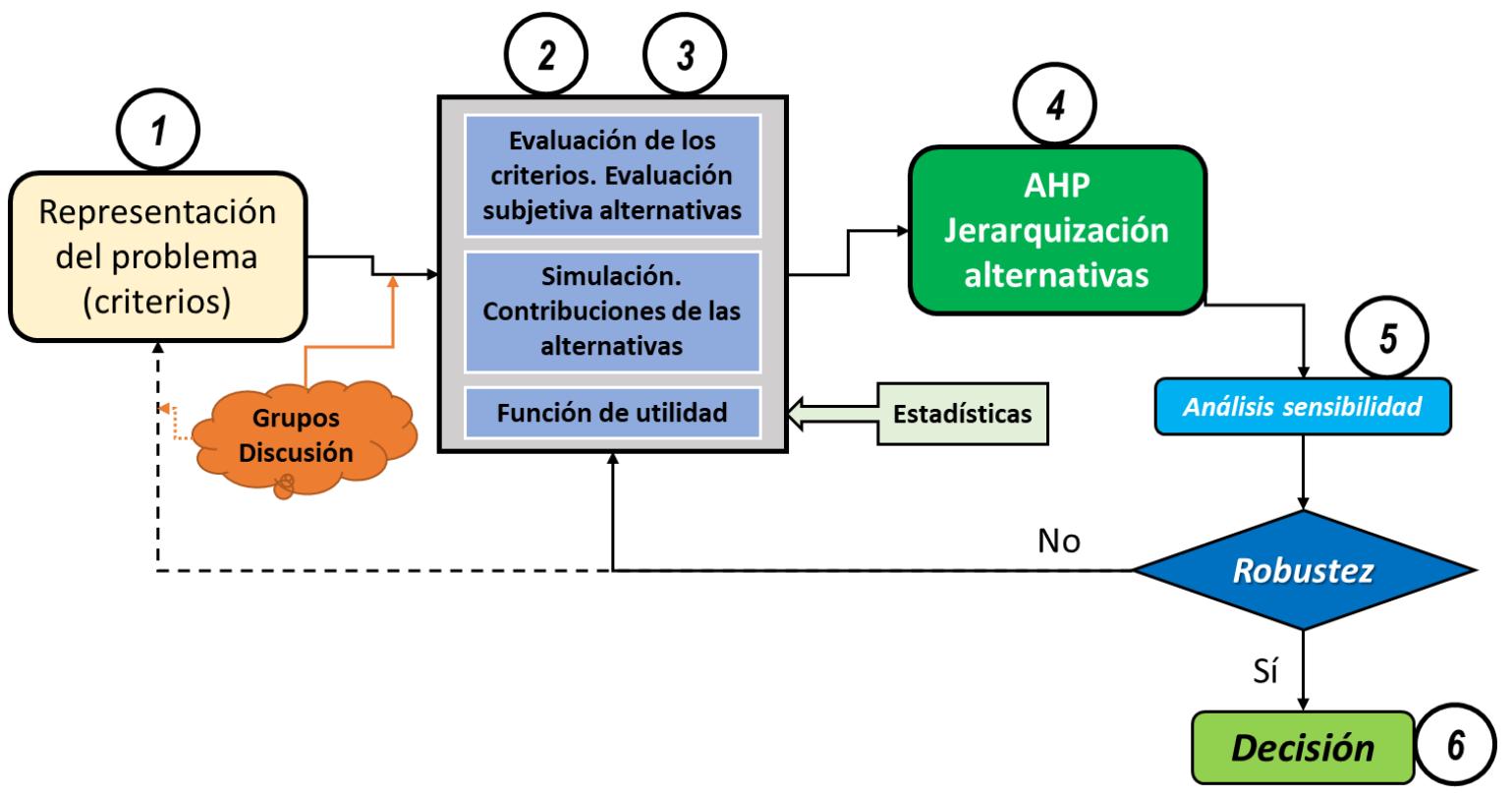

Figura 3-2 Metodología planteada del decisor desarrollado (Elaboración propia)

La nueva metodología se descompone en las fases que se pueden ver en la Figura 3-2. Se enuncian a continuación:

1. Representación del problema. Se establecen con el órgano decisor aquellos criterios que servirán para modelar el problema en una estructura jerárquica multinivel de objetivos, criterios, subcriterios y alternativas conforme la metodología AHP [12]. Estos criterios serán la base de las ponderaciones por parte del grupo de expertos decisores.

2. Evaluación de criterios. Los expertos decisores, de manera individual y anónima, evalúan los criterios asignándoles unos pesos que resulten consistentes con sus preferencias subjetivas. Esta información se recoge en matrices de comparación por pares. 
3. Contribuciones de las alternativas. Esta fase es la médula de la metodología. En el método clásico AHP, esta fase se resuelve mediante la interacción con los expertos decisores que deben mostrar sus juicios de valor confrontando cada alternativa con cada criterio, se podría aseverar que la subjetividad es de un $100 \%$. En esta fase de la nueva metodología se busca reducir la subjetividad del modelo en aquellos juicios que sean susceptibles de ello, explotando técnicas de simulación, estadísticas históricas, valoraciones de riesgos, empleo de funciones de utilidad, etc. Para ello, se debe estudiar el problema y buscar las técnicas ad hoc que mejor se puedan adaptar al problema.

4. Jerarquización de las alternativas. Se resuelve, con ayuda de un software, el algoritmo de Saaty para jerarquizar las alternativas de cara a la decisión final.

5. Análisis Sensibilidad. Se realiza un análisis de sensibilidad que nos indicará la robustez del modelo. Esta información es vital para los expertos decisores, puesto que, les permite comprobar si pequeñas diferenciaciones en la valoración de criterios producen o no, conmutaciones en la jerarquización de las alternativas.

6. Decisión. Una vez analizada la robustez ,y retroalimentado el modelo en caso de ser necesario, se define la jerarquización final, esto es, la decisión que proporciona el analista, argumentada con los análisis realizados.

\subsection{Estudio de la Decisión del Diseño Óptimo en la Distribución del Centro de Información y Combate de la Fragata F-110}

En este apartado, primero se explicará brevemente qué es el Centro de Información y Combate $(\mathrm{CIC})$ y, posteriormente, se mostrará cómo se aplicó la metodología ideada en esta tesis al problema de decisión del Estado Mayor de la Armada acerca de: ¿Qué disposición de equipos y consolas tácticas será la más efectiva en el CIC de la futura fragata F-110? 


\section{El Centro de Información y Combate (CIC) [117]}

El Comandante de un buque de guerra necesita un centro asesor que en todo momento lo mantenga informado sobre los detalles de la situación táctica y asimismo le recomiende la acción más adecuada a llevar a cabo para hacer frente a dicha situación. En todos los buques de guerra existe este centro asesor del mando que se conoce con las siglas CIC. En otras Marinas también se le denomina Operations Room (Figura 3-3).

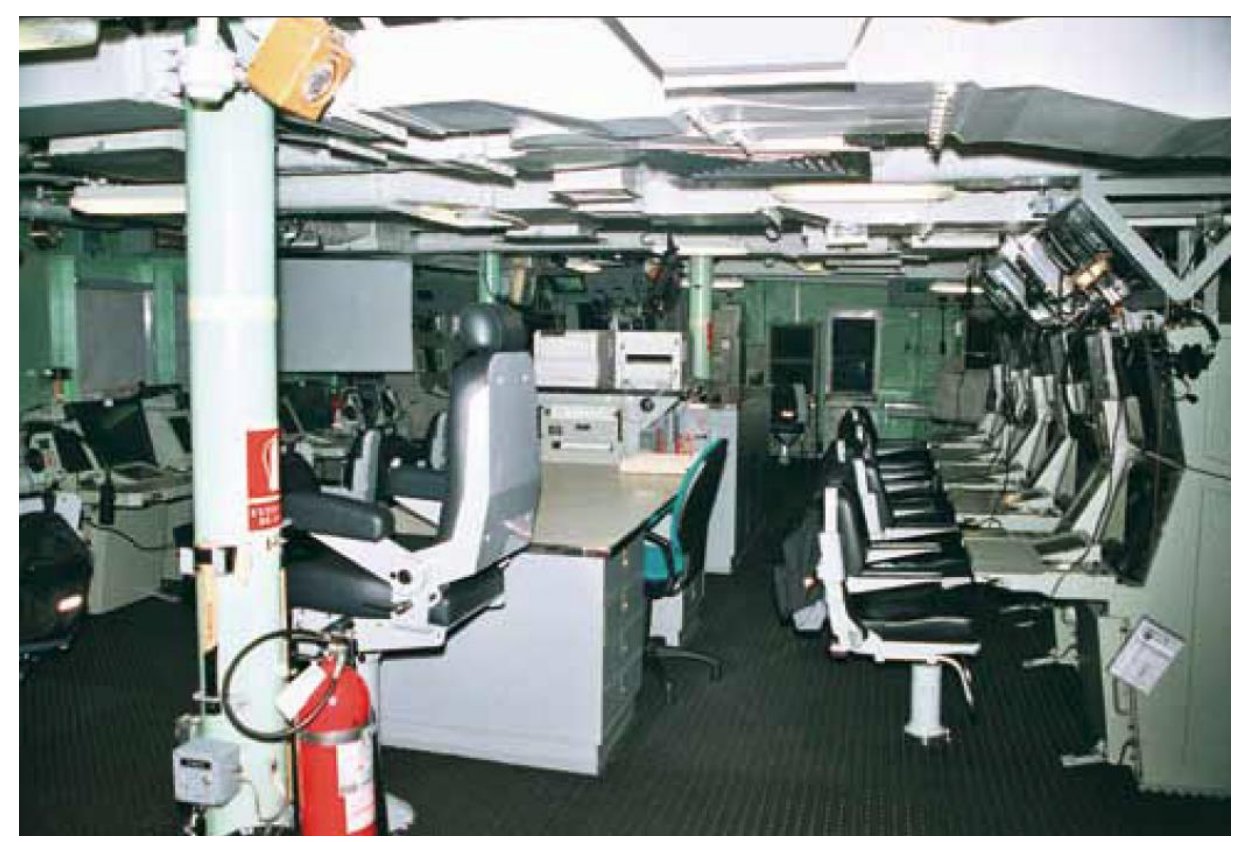

Figura 3-3 Vista del CIC de la F-102 Almirante Don Juan de Borbón (www.armada.mde.es)

EI CIC puede considerarse como el "cerebro" del buque. A él llegan todos los datos concernientes a la situación táctica, que deben ser convenientemente registrados y evaluados. Con la información recibida, el CIC se debe formar una idea clara de la situación para poder recomendar la línea de acción a seguir por el Comandante y que éste pueda tomar una decisión.

Se trata, pues, de un Centro cuya principal misión es asistir al Mando, recomendando las acciones más adecuadas, siendo el Comandante del buque el responsable de la decisión adoptada. También desde el CIC se combate, pues las armas del buque son controladas desde las consolas allí dispuestas.

De esto, puede desprenderse que, para poder cumplir su misión de asistencia al Mando, el trabajo del $\mathrm{CIC}$ debe pasar por las siguientes etapas: 
- Recoger. Consiste en adquirir por todos los medios disponibles la mayor cantidad de información posible concerniente a la situación táctica actual. Antes de salir a la mar, se habrá recopilado todas las instrucciones relativas a las operaciones que se van a llevar a cabo y los informes de inteligencia pertinentes.

En esta etapa la función primordial es la búsqueda, que procederá primariamente de los sensores propios, para lo cual, se tiene que sacar el máximo rendimiento de todos los sensores disponibles a bordo (radar, ESM, sonar, visual, infrarroja, electroóptica). También en esta fase de recogida de información, se debe incluir toda aquella información procedente de elementos externos, es decir, procedente de otras unidades (Buques, aviones, etc.).

- Exponer. La segunda etapa consiste en presentar toda la información acopiada de cualquier fuente. Esta es procesada para eliminar todos los datos que no sean esenciales. La información resultante de este primer filtro es expuesta en el CIC y puede ya ser difundida a otros puestos de Control y a otros buques. Esta exposición se efectúa por medio de punteos en cartas náuticas, tableros, consolas y registros. Actualmente, casi toda la información se expone sobre consolas tácticas que son imprescindibles. Tienen una magnífica capacidad de presentación sintética en grandes pantallas y gozan de la versatilidad de poder seleccionar cualquier sensor dependiendo de la acción que se esté desarrollando.

- Evaluar. Esta es la fase más importante y, a la vez, es la más difícil. Consiste en el filtrado y correlación de la información táctica con el fin de conseguir que los datos esenciales puedan ser presentados al Mando y a los puestos de Control de tal forma que puedan ser utilizados de la mejor manera posible. Cada miembro del equipo del $\mathrm{CIC}$ se enfrenta constantemente con situaciones que requieren un juicio claro. Normalmente, un Oficial es el responsable específico de la Evaluación, si bien la mayoría del personal del $\mathrm{ClC}$, particularmente los operadores de consolas se encuentran con la necesidad de una evaluación constante en la realización de sus trabajos individuales.

- Difundir. La última etapa es la de difusión de la información a los puestos de Control del buque y otras unidades. Esta información habrá pasado ya por la evaluación de la etapa anterior. Para realizar esta difusión, el CIC cuenta con Comunicaciones 
Interiores y Exteriores. La información difundida debe reunir las cualidades, de veracidad, claridad, brevedad y rapidez.

Las funciones que realiza el $\mathrm{ClC}$ de un buque de guerra son muy variadas y adecuadas a los medios y equipos con los que cuenta cada buque (ver Figura 3-4 y Figura 3-5). No obstante, estas diferentes funciones se pueden agrupar en dos grupos esenciales:

- Funciones de coordinación y control

- Funciones de asistencia

Dentro del grupo de funciones de coordinación y control se incluyen aquellas funciones que el $\mathrm{ClC}$ realiza ayudando al Mando en el desarrollo de una determinada acción o en una determinada situación táctica. Algunas de estas funciones son las siguientes:

- Control antiaéreo: Consiste en disponer de toda la información correspondiente a la situación aérea, controlar las aeronaves en apoyo cercano a la fuerza, informar a la fuerza de los planes aéreos y en general de los movimientos de las aeronaves amigas e informar a las aeronaves, en el caso de que el buque ejerza su control, de la situación en la superficie y de todos aquellos datos que sirvan para garantizar su seguridad, hacer una distribución de sectores de búsqueda a las distintas unidades operando en la zona, o asignación y distribución de blancos, caso de que se actúe como Comandante de la Guerra Antiaérea de una Fuerza.

- Control antisuperficie: Consiste en disponer de toda la información correspondiente a la situación en la superficie, incluyendo el conocimiento de todos los datos, no solo los referentes a los movimientos de los buques amigos y enemigos, sino también de las posibilidades de sus medios ofensivos. Caso de actuar como Comandante de la Guerra antisuperficie de una Fuerza, también se dirigirían las acciones de las distintas unidades desde dicho control, asignando sectores de patrulla, zonas de búsqueda, haciendo distribución de blancos, etc.

- Control antisubmarino: Abarca este control el conocimiento de los datos correspondientes a todos los contactos submarinos amigos y enemigos; así como, las posibilidades de las armas antisubmarinas, tanto de los submarinos como de los buques de superficie y aeronaves, con el fin de proporcionar al 
Mando la información precisa para disponer tanto, de los medios de defensa como de ataque en la forma más conveniente y acertada. Esta información incluye datos batitérmicos.

- Control de guerra electrónica: El CIC controla todas las emisiones Electromagnéticas, Ópticas, Acústicas, Caloríficas, etc. existentes en la zona, conociendo las características de las propias para poder detectar cualquier emisión del adversario. Incluye además las funciones del correcto uso de las emisiones propias con el fin de asegurar la utilización de los equipos propios ante el enemigo, y de negar al enemigo la utilización de sus equipos de detección.

- Control de Armas: Desde donde se controlan las acciones de designación de blancos y asignación de armas a las direcciones de tiro, así como el empleo de las armas.

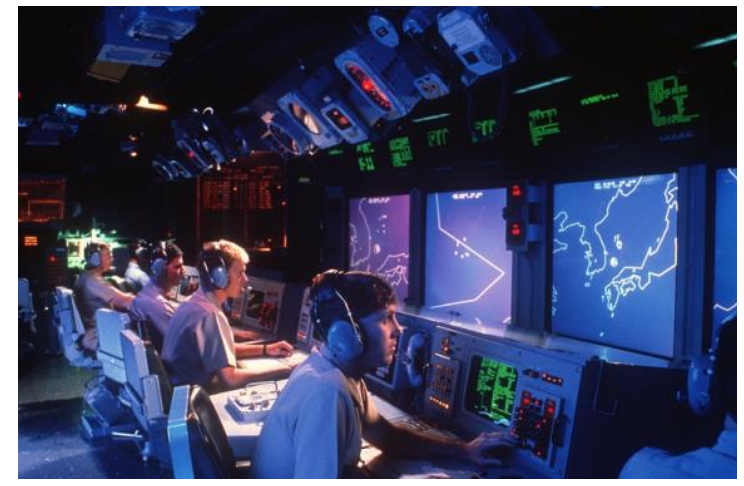

Figura 3-4 CIC del USS Vincennes (Tim Masterson)

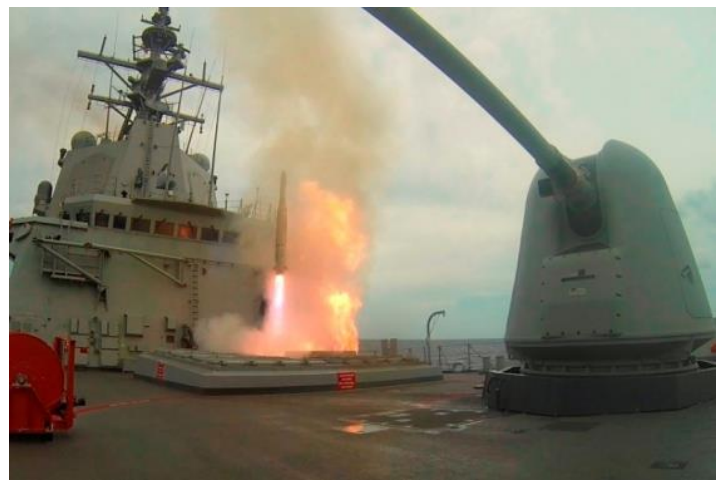

Figura 3-5 Lanzamiento de un misil desde la F-105

(Armada Española)

Las Funciones de asistencia son consecuencia de las funciones anteriores, consisten en proporcionar todos los datos que sean de utilidad para el desempeño correcto de las misiones encomendadas como, por ejemplo:

- Navegación en baja visibilidad

- Entradas y salidas de puerto por canal dragada

- Operaciones de minado

- Maniobras y evoluciones

- Hombre al agua

- Bombardeo de costa

- Búsqueda y Rescate (Search and Rescue - SAR) 
- Etc.

\subsubsection{Representación del Problema y Selección de Criterios}

Para la representación del problema se requirió la colaboración expertos en la materia de la Sección de Planes de Definición de Capacidades de la DIVPLA, ellos conformaban el órgano decisor. Esta colaboración se efectuó mediante múltiples intercambios de consultas e información y se fraguó con dos reuniones en el Estado Mayor de la Armada con los oficiales expertos, responsables de la dirección del periodo conceptual y de definición y decisión del proceso de obtención de la fragata F-110 [70].

En una la primera reunión, se les explicó a los expertos del EMA la metodología del proceso de análisis jerárquico (AHP), en el cual se requería la descomposición del problema en una estructura jerárquica con al menos tres niveles básicos (objetivo, criterios y alternativas), de esta manera se conseguiría una visión general del problema. El objetivo estaba fijado por el EMA y derivaba de un requerimiento que esa misma Sección de Planes: Estudiar la mejor disposición de equipos y consolas del CIC acorde a las misiones de la F-110.

Como hipótesis del problema se plantearon los siguientes puntos:

- El Comandante y el Oficial Táctico deben tener el mejor control posible del CIC.

- El conocimiento de la situación táctica por parte del equipo del $\mathrm{CIC}$ debe ser un factor decisivo.

- Las formas de comunicación entre puestos pueden ser visuales (pantallas, gestos) a la voz o por comunicaciones interiores entre puestos.

- Además de puestos en consolas, el buque tiene la necesidad de atender los diferentes sistemas de mando y control exteriores (SACOMAR, chats, NSWAN, etc.) Es necesario considerar también los puestos que no disponen de consola táctica (Célula de Inteligencia, Supervisores, etc.)

- Los puestos se agrupan en subcontroles. Es necesario tener en cuenta los cometidos que realiza cada subcontrol/puesto, de qué subcontroles/puestos recibe órdenes y a cuáles informa. 
- Los escenarios tácticos a los que se enfrentará la F110 no están definidos en detalle, pero se cuenta con suficientes datos para estimarlos.

Una exhaustiva investigación en tendencias de diseño de otras Armadas sirvió para definir las alternativas, fijando el decisor tres: Lado, Nasa y Centro.

\subsubsection{Las Alternativas}

Las tendencias actuales de diseño en la disposición de equipos en los $\mathrm{CIC}$ se pueden encuadrar en tres tipos:

- $\mathrm{CIC}$ con el cuadro de mando en los mamparos (LADO)

- $\mathrm{CIC}$ con el cuadro de mando en el centro del compartimento (CENTRO)

- $\mathrm{CIC}$ con el cuadro de mando tipo aula (NASA)

Para cualquiera que fuese la alternativa escogida, se acordó trasladar al astillero Navantia, encargado de la construcción, el cumplimiento de todo aquello que fuese aplicable de las recomendaciones y guías sobre las disposiciones de las salas de control (ver [118], [119], [120], [121], [122], [123] y [124]).

\subsubsection{CIC Tipo LADO}

Es el tipo de diseño actual en las fragatas F-100 (Figura 3-6). Es similar a los buques de construcción norteamericana de la clase Arleigh Burke [125], cuyo primer buque de la serie fue entregado a la Armada estadounidense en 1991. Este tipo de disposición se distingue, porque las consolas tácticas se orientan hacia los mamparos (paredes) y normalmente se agrupan conforme a las actividades a las que están destinadas, es decir, se agrupan conforme a las distintas "guerras" que se pretenden combatir: antisubmarina, antiaérea, antisuperficie, electrónica, etc.

Este diseño también se caracteriza porque, al estar la mayoría de las consolas orientadas hacia los mamparos, los operadores están de espaldas unos a otros.

En el centro del $\mathrm{CIC}$ suelen colocarse mesas de trabajo y/o de reunión donde se exponen las cartas náuticas y donde fundamentalmente trabaja el equipo supervisor de la operatividad de equipos y sistemas. Allí, se reúne toda la información que refleja la situación interna del buque, permitiendo al Comandante que pueda fijar sus prioridades y consiga un mejor empleo táctico del barco. 
Este tipo de $\mathrm{CIC}$, al igual que los otros dos tipos, dispone de grandes pantallas de ordenador sobre los mamparos, donde se refleja la información necesaria para tener una visión táctica general de las operaciones en curso.

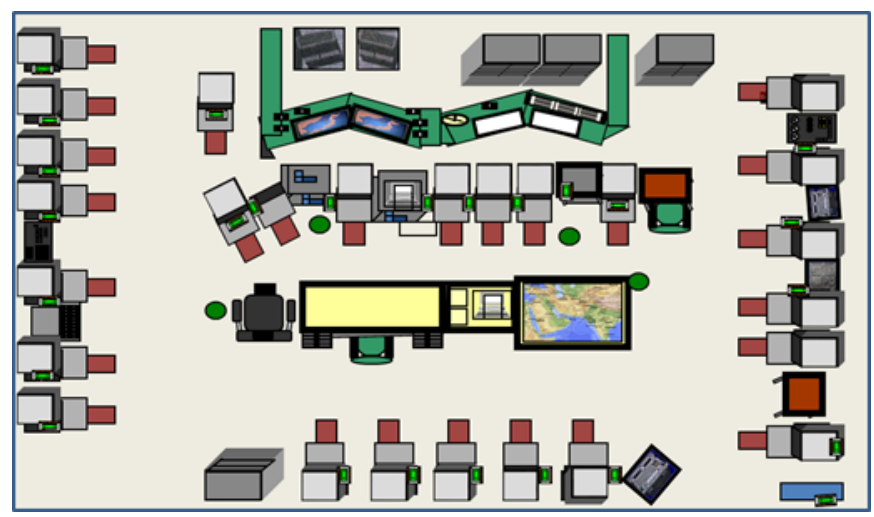

Figura 3-6 Recreación artística del CIC de la Fragata F-100, tipo LADO (Armada española)

Los distintos tipos de $\mathrm{CIC}$ se han modelado a partir del diseño preliminar del buque, con los planos de la distribución de equipos y consolas del prototipo (no se anexan por ser Confidenciales). Los modelos se han realizado mediante el software Pyrosim [126]. En la Figura 3-7 se puede observar un modelo de CIC con distribución de tipo LADO.

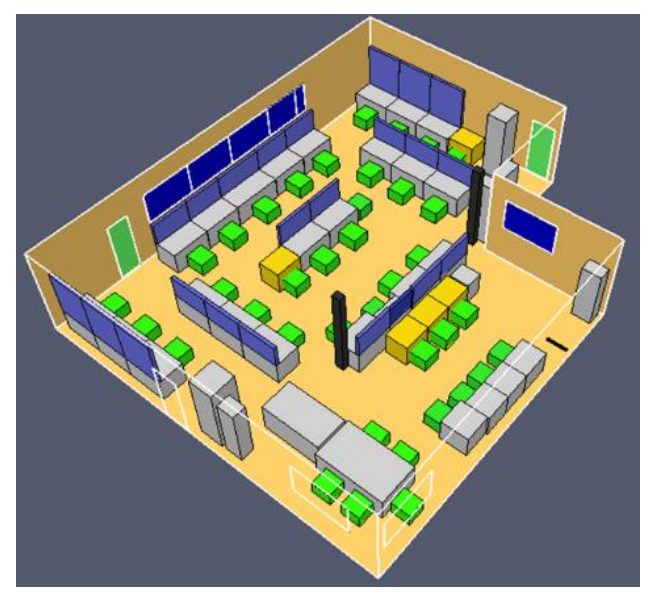

Figura 3-7 Modelo CIC tipo LADO de la F-110 (Elaboración propia)

\subsection{CIC Tipo NASA}

Esta novedosa disposición del $\mathrm{CIC}$ se denomina así, por la similitud con las salas de control de lanzamiento de la NASA (Figura 3-8). Estas, siempre se han dispuesto de manera que varias filas de consolas, especializadas en diversos campos, se ocupan de todos y cada uno de los aspectos de la estación espacial. Hay consolas para dirigir las salidas extra vehiculares, otras para los momentos en que hay vehículos acoplados, para 
vigilar los sistemas energéticos, para la salud de los astronautas, etc., así como una dedicada al director de vuelo. Unas grandes pantallas frontales permiten a todos los ingenieros y técnicos ver toda la información disponible.

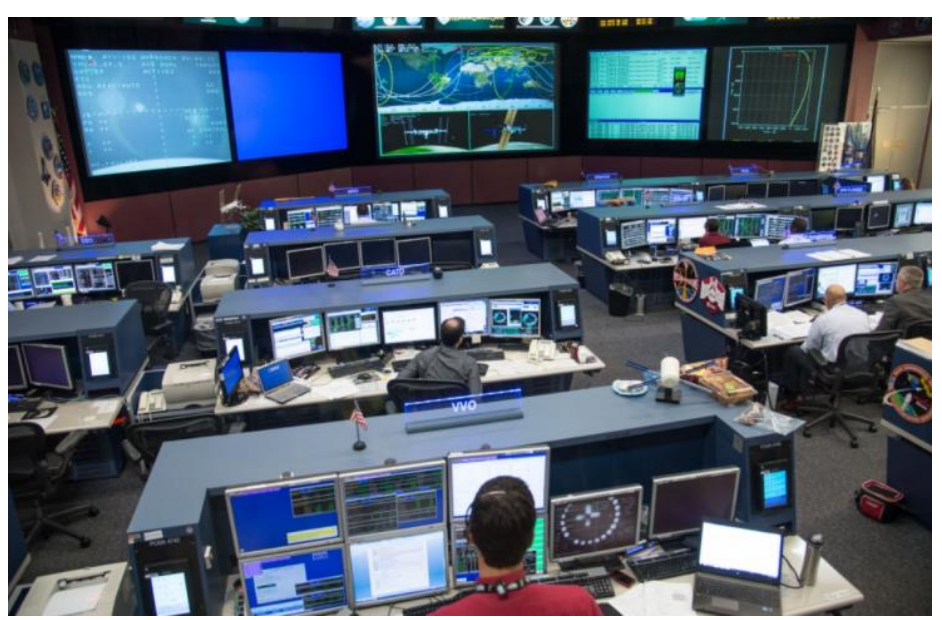

Figura 3-8 Sala de control (NASA)

El destructor norteamericano primero de la serie DDG-1000, denominada clase Zumwalt, entregado a la Armada estadounidense en el año 2016 (Figura 3-9), es "rompedor" en muchos aspectos [125]. Tras varias décadas de lo que podríamos definir como "diseño tradicional" de construcción naval, la Armada norteamericana construye un buque con un concepto revolucionario. Este contundente diseño va acompañado de las más modernas tecnologías en sensores, propulsión y armamento. También ha visto como el tradicional Operations Room (CIC) ha adoptado la innovadora disposición de consolas similar a una sala de control de la NASA (Figura 3-10).

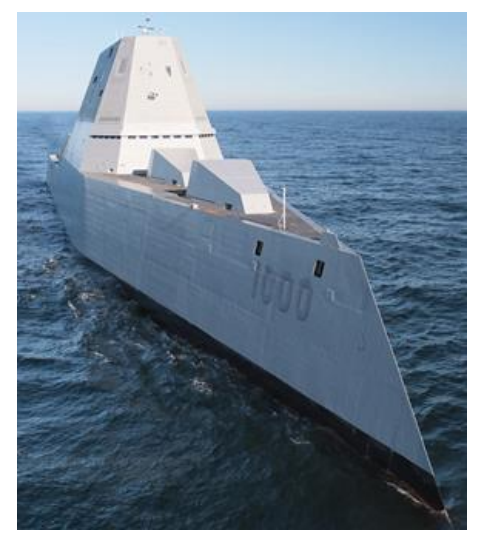

Figura 3-9 DDG-1000 Zumwalt (The US Navy)

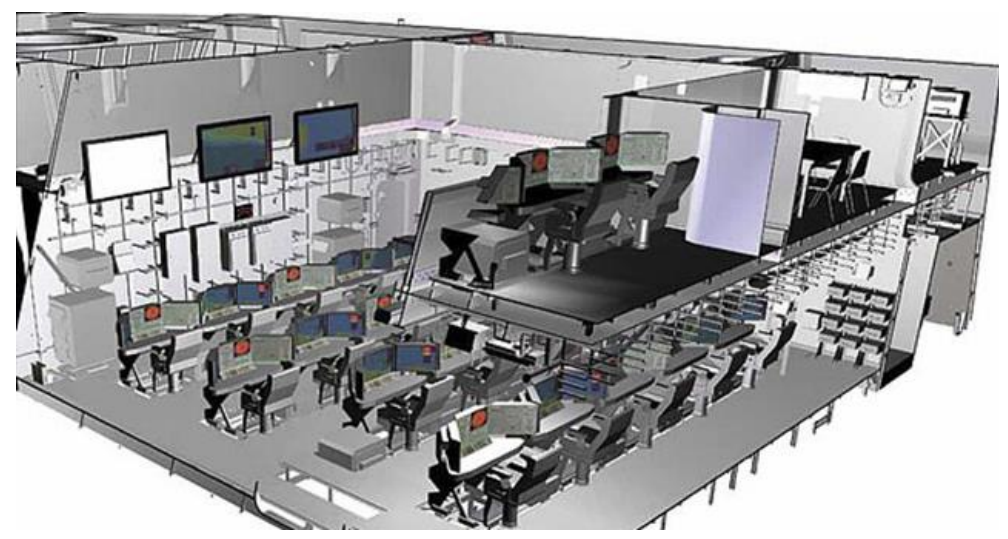

Figura 3-10 Imagen del CIC del Zumwalt (The US Navy) 
No solo la Armada estadounidense se está decantando por esta disposición. La Armada holandesa en sus fragatas de última construcción, las fragatas clase De Zeven Provincien [127], la disposición de equipos tiene una distribución que puede clasificarse como de tipo NASA (Figura 3-11; Figura 3-12).

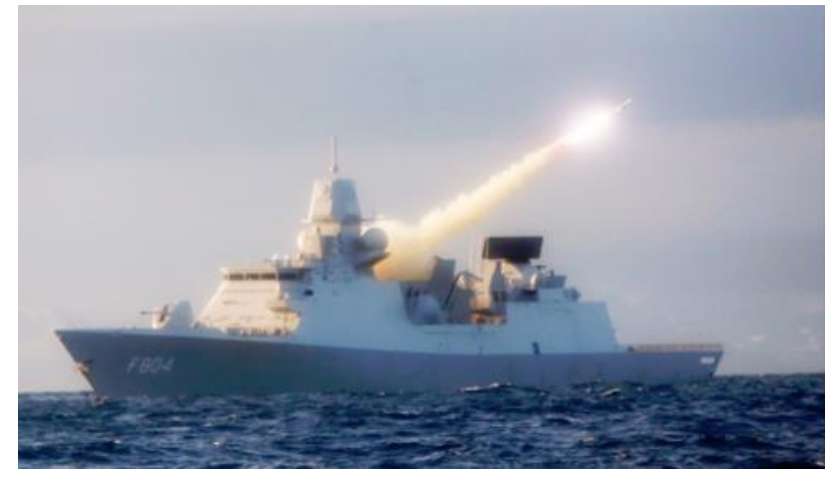

Figura 3-11 Fragata Holandesa Evertsen (www.seaforces.org)

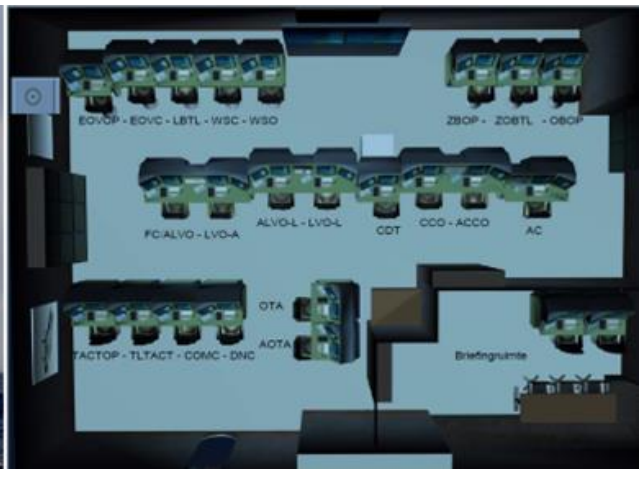

Figura 3-12 Imagen del CIC del Evertsen

(www.seaforces.org)

La revista IHS Jane's Navy International, Abril 2016 [128], aborda en un artículo los importantes avances en tecnología que incorporan los buques de guerra modernos, y como estos avances conllevan un exponencial aumento de la información que se tiene que procesar en unos tiempos de respuesta cada vez menores. Entre otros temas relativos a las nuevas consolas tácticas de la casa Saab [129], pone de manifiesto que dicha casa comercial ha estudiado la óptima disposición y organización del CIC y ha llegado a la conclusión de que ésta es una disposición similar a un aula, con los operadores con sus monitores orientados hacia una pared con grandes pantallas, es decir, tipo NASA. Si bien, el artículo no explica el ni el cómo, ni el por qué han llegado a semejante conclusión.

En definitiva, este diseño se caracteriza porque la mayoría de las consolas están orientadas hacia el mamparo de proa, donde se disponen grandes pantallas electrónicas de información (Figura 3-13). 


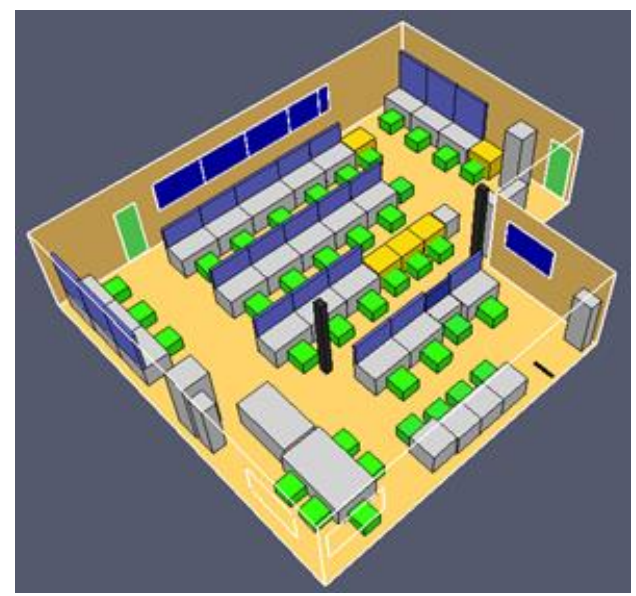

Figura 3-13 Modelo CIC tipo NASA de la F-110 (Elaboración propia)

\subsection{CIC Tipo CENTRO}

Este tipo de disposición de $\mathrm{ClC}$, se caracteriza porque una serie de consolas en el centro del compartimento, ocupan su posición de forma que están enfrentadas unas a otras formando una especie de "rectángulo" (Figura 3-14).

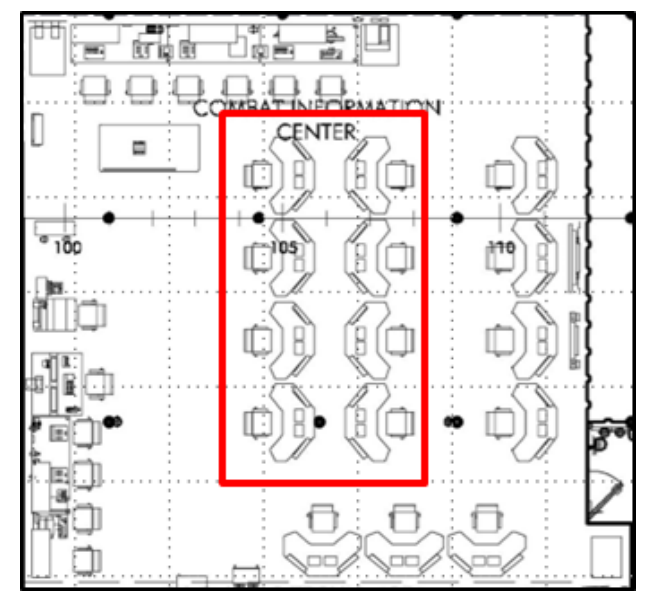

Figura 3-14 Ejemplo de disposiciones de CIC tipo CENTRO

La Armada inglesa en sus destructores más modernos, los Type 45 denominados clase HMS Daring [130], han adoptado este tipo de distribución. Otra Armada que se decanta por esta distribución del CIC, es la italiana en sus nuevas fragatas FREMM de reciente construcción [131].

En la Figura 3-15 se puede observar un modelo de CIC tipo CENTRO. 


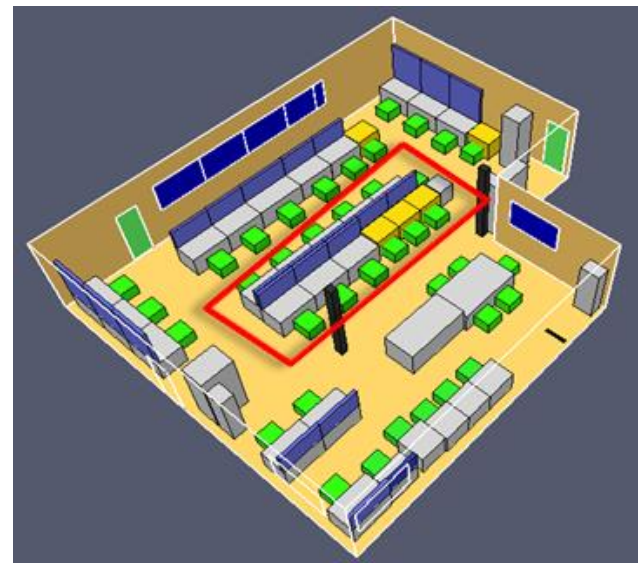

Figura 3-15 Modelo CIC tipo CENTRO de la F-110 (Elaboración propia)

\subsubsection{Definición de Criterios}

Dentro de la fase uno de la metodología, en la definición de criterios, es clave el adecuado trabajo conjunto entre analista y expertos.

Por ello, se solicitó que, de manera independiente y con el objetivo de evitar sesgos de pensamiento grupal, ideasen cuáles eran a su juicio los posibles criterios en los que basarse, para resolver el conflicto de la decisión.

Una vez se recibieron las propuestas de criterios y subcriterios por parte de los expertos, se realizó un primer modelo refundido del problema conforme a las propuestas recibidas y se les reenvió a los oficiales expertos con vistas a revisarlo en una segunda reunión presencial (ver Figura 3-16).

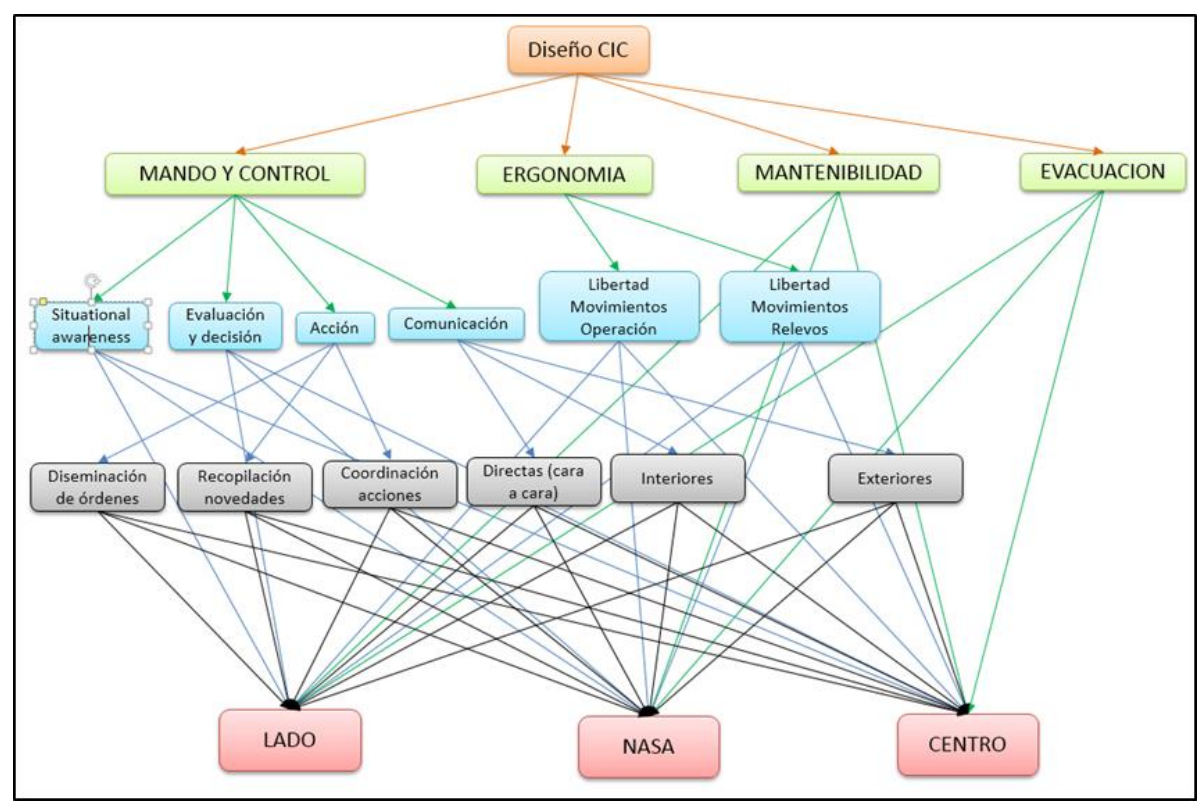

Figura 3-16 Modelo preliminar AHP (Elaboración propia) 
En una segunda reunión con los expertos, con el primer modelo de la Figura 3-16 como referencia, se modificaron y concretaron los criterios del modelo definitivo, resultando la representación del problema que se puede apreciar en la Figura 3-17.

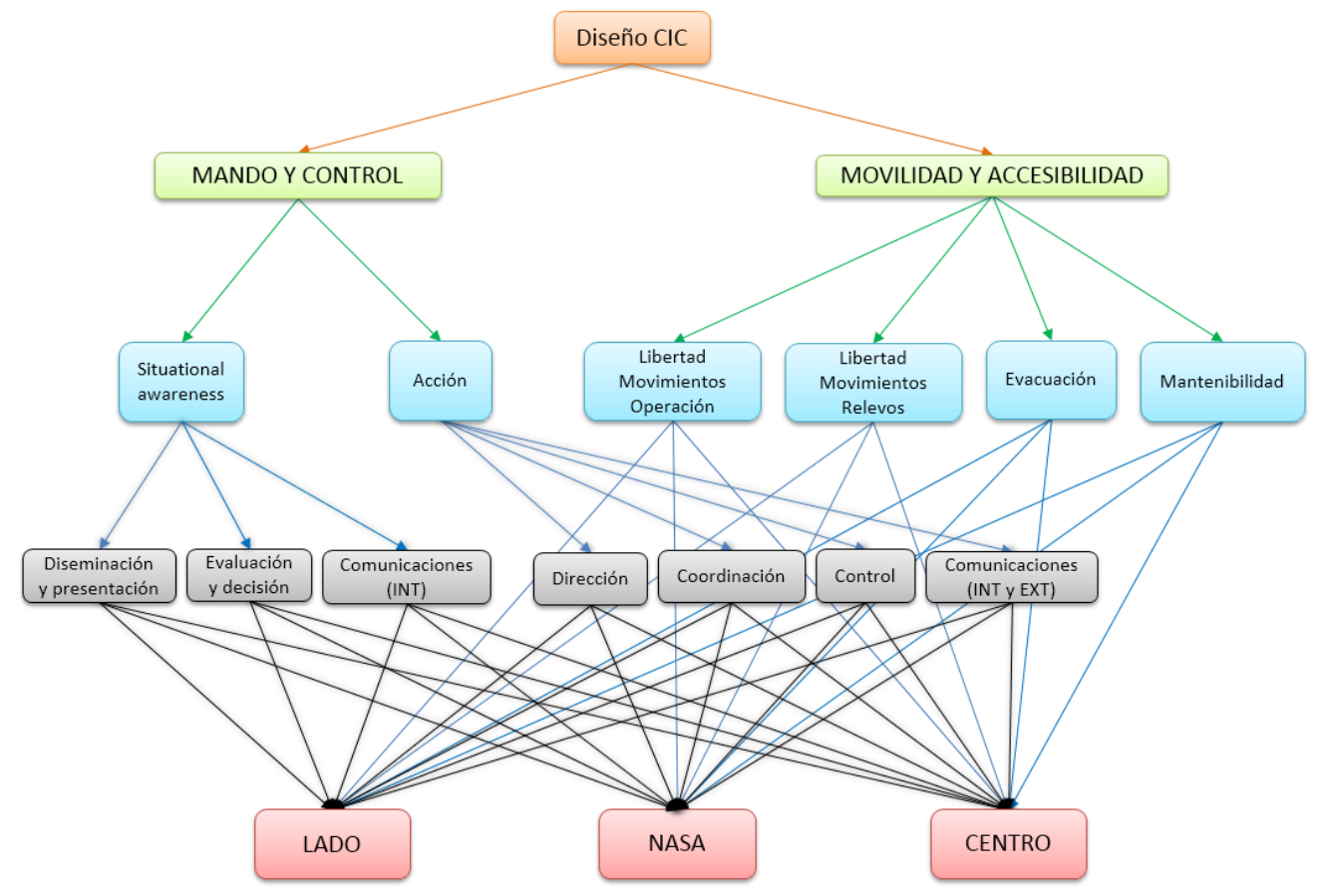

Figura 3-17 Modelo definitivo AHP (Elaboración propia)

Este modelo definido por los expertos contempla:

- 2 criterios

- 6 subcriterios

- 7 sub-subcriterios

- 3 alternativas.

Todo ello, genera un total de cinco matrices de comparación por parejas para la asignación de pesos de evaluación a los criterios, subcriterios y sub-subcriterios. Y un total de 11 matrices de comparación por parejas para la asignación de valoraciones de contribución de las alternativas a los distintos criterios.

Con el objetivo de poder servirse de este modelo para la valoración con otros expertos ajenos a su concepción, se procedió a la descripción de los criterios y subcriterios:

- Situational awareness (Conciencia de la situación).

- Diseminación y presentación. Grado de eficacia en el que la información disponible es presentada y diseminada entre los 
operadores para que estos adquieran conciencia de la situación táctica. Incluye: Detección, identificación y reconocimiento de contactos específicos (aéreos, submarinos y de superficie); así como la de un entorno particular completo (AAW, ASUW o ASW). También debe considerarse la OPINTEL (Operational Intelligence) que engloba un entorno más amplio de información de inteligencia sobre las fuerzas oponentes en tiempo real.

- Evaluación y decisión. Grado de eficacia en el que esa información disponible es evaluada frente a una amenaza, escenario o reacción preplaneada. Esa evaluación determinará una decisión (que será más o menos acertada en función de la calidad de la evaluación) para tomar acción de una forma u otra.

- Comunicaciones (INT). Grado de eficacia con el que los flujos de información necesarios para completar los dos criterios anteriores se transmiten entre los distintos niveles (CO/TAO, Coordinador, Supervisor/Operador). En este criterio se evaluarán únicamente las comunicaciones interiores que pueden ser de diversas formas: circuitos establecidos de comunicaciones, cara a cara, gestos...

- Acción.

- Dirección. Grado de eficacia en la que las intenciones u operaciones se encaminan entre los distintos niveles correctamente, permitiendo una ejecución conforme la decisión adoptada.

- Coordinación. Grado de eficacia en el que posibles adaptaciones en tiempo o espacio de las intenciones u operaciones son encaminadas correctamente entre los distintos niveles permitiendo adaptar la acción a circunstancias cambiantes.

- Control. Grado de eficacia en la supervisión de las órdenes dadas para desarrollar la decisión.

- Comunicaciones (INT y EXT). Grado de eficacia con el que los flujos de información, necesarios para completar los tres criterios anteriores, se transmiten entre los distintos niveles (Comandante/Oficial táctico, Coordinador, Supervisor/Operador) y a 
otras unidades. En este criterio se evaluarán las comunicaciones interiores (que pueden ser de diversas formas: circuitos establecidos de comunicaciones, cara a cara, gestos...) y las exteriores (sólo circuitos de comunicaciones).

- Libertad de movimiento en operación. Grado de eficacia en el que los operadores tienen mayor libertad de movimiento, es decir, se estorban menos físicamente.

- Libertad de movimiento en relevos. Grado de eficacia en el que los relevos de vigilancia o Zafarrancho de combate se realizan facilitando tránsitos, disminuyendo el nivel de ruido y facilitando un mejor mantenimiento de la conciencia de la situación.

- Evacuación. Grado de eficacia a la hora de permitir una evacuación más rápida y segura del CIC.

- Mantenibilidad. Grado de eficacia a la hora de realizar mantenimientos en consolas $\mathrm{u}$ otros equipos, tanto con el buque en puerto como mantenimientos simultáneos a la operación.

Otra importante valoración que se tuvo en cuenta antes de proceder a la evaluación de los criterios fue el apreciar que las principales diferencias de efectividad aflorarán en momentos de saturación de actividades o en modos de operación "casualty" (sin comunicaciones interiores, fallos de consolas, etc.), por tanto, las comparaciones deben hacerse pensando en el buque inmerso en operaciones reales de combate y no en ejercicios de adiestramiento.

\subsubsection{Evaluación de los Criterios. Evaluación de las Alternativas}

Se elaboró una tabla de Excel con las dieciséis matrices (Apéndice A) y se envió a los expertos para su relleno conforme a la escala de Saaty que, por sencillez, se restringió a los números impares. Se les solicitó que el relleno fuese independiente pues resulta interesante para el método que existan discrepancias entre los juicios.

Los expertos trabajaron con la referencia de los modelos visuales de la Figura 3-18.

Estos modelos son necesarios para hacerse una composición de lugar, y poder evaluar y decidir en las comparativas entre criterios y alternativas. 

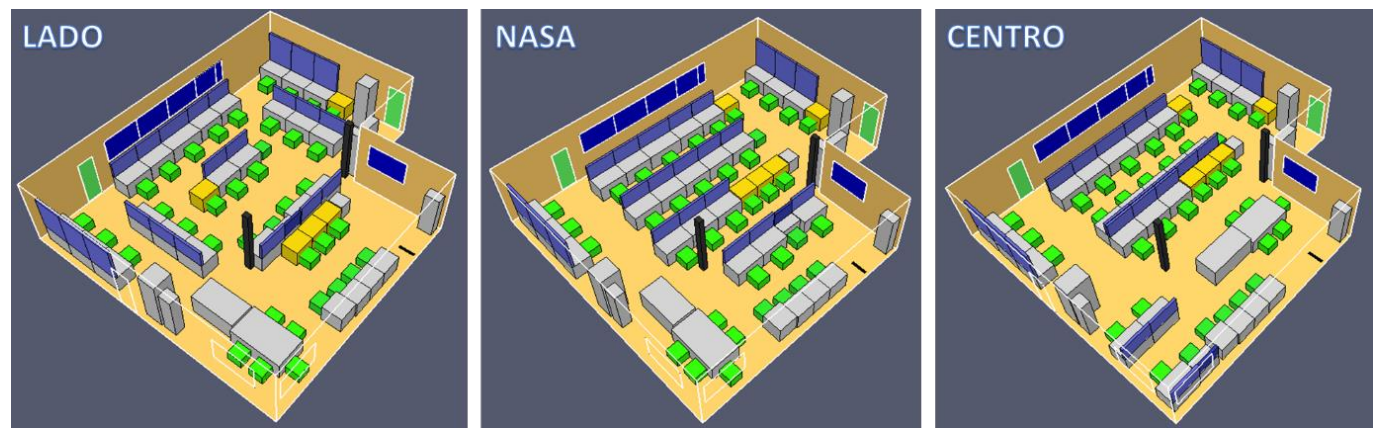

Figura 3-18 Imágenes de referencia de los tres tipos de CIC (Elaboración propia)

Una vez recibida la respuesta con las tablas Excel rellenas, se procedió a realizar las matrices consolidadas de las opiniones subjetivas de los expertos y a trabajar con ella en el programa ADLA.

\subsubsection{AHP, Análisis de Sensibilidad y Robustez. Problema Subjetivo}

En este apartado se explica cómo se han aplicado los juicios subjetivos de los expertos directamente sobre el programa ADLA, con el objetivo de poder comparar, posteriormente, cuánto varían los resultados cuando se apliquen las técnicas ad hoc que esta tesis propone.

Conforme a lo comentado, se trabajó sobre el ADLA resolviendo un problema AHP clásico, con los siguientes resultados de asignación de pesos en los distintos niveles (ver Tabla 3-1).

\begin{tabular}{|c|c|c|c|c|}
\hline $\begin{array}{l}\text { Criterios } \\
\text { MANDO Y } \\
\text { CONTROL } 87,50 \%\end{array}$ & \multicolumn{2}{|l|}{ subcriterios } & \multicolumn{2}{|l|}{ subsubcriterios } \\
\hline \multicolumn{5}{|l|}{$\begin{array}{l}\text { MANDOY Y } \\
\text { CONTROL } 87,50 \%\end{array}$} \\
\hline & Situational awareness & $25,00 \%$ & & \\
\hline & & & Diseminación y presentación & $56,79 \%$ \\
\hline & & & Evaluación y decisión & $33,39 \%$ \\
\hline & & & Comunicaciones (INT) & $9,82 \%$ \\
\hline & Acción & $75,00 \%$ & & \\
\hline & & & Dirección & $50,32 \%$ \\
\hline & & & Coordinación & $24,02 \%$ \\
\hline & & & Control & $16,56 \%$ \\
\hline & & & Comunicaciones (INT y EXT) & $9,10 \%$ \\
\hline
\end{tabular}

\begin{tabular}{|c|c|c|}
\hline $\begin{array}{r}\text { MOVILIDADY } \\
\text { ACCESIBILIDAD }\end{array}$ & & \\
\hline & Libertad movimientos Operación & $7,26 \%$ \\
\hline & Libertad movimientos relevos & $38,61 \%$ \\
\hline & Evacuación & $44,46 \%$ \\
\hline & Mantenibilidad & $9,67 \%$ \\
\hline
\end{tabular}

Tabla 3-1 Tabla de pesos de criterios/subcriterios/sub-subcriterios (Elaboración propia) 
En la valoración global de las alternativas (Figura 3-19) ha resultado mejor valorada la alternativa tipo NASA con un $43,63 \%$.

\begin{tabular}{rr}
\multicolumn{2}{c}{ Alternativas } \\
\hline LADO & $16,16 \%$ \\
CENTRO & $40,21 \%$ \\
NASA & $43,63 \%$
\end{tabular}

Figura 3-19 Valoración global de las alternativas del multicriterio subjetivo (Elaboración propia)

En la Tabla 3-2, se pueden observar los cálculos intermedios realizados para evaluar la valoración final de las alternativas. En la primera fila de la tabla aparecen los criterios con sus pesos. En las columnas debajo de los criterios aparecen los porcentajes con que cada criterio contribuye a las distintas alternativas. Por ejemplo, se puede observar que a la alternativa NASA, el criterio MANDO Y CONTROL que tiene un peso del $87,5 \%$, contribuye con un $47,4 \%$. Esto, son 6 puntos porcentuales más que la contribución a la alternativa CENTRO, que es del 41,15\%. Esta diferencia de 6 puntos a favor de NASA le permite superar la diferencia de más de 16 puntos de contribución del criterio MOVILIDAD Y ACCESIBILIDAD a favor de la alternativa CENTRO (ver barra roja en Figura 3-20). La alternativa LADO es muy inferior a la valoración final de las otras alternativas.

\begin{tabular}{|c|c|c|}
\cline { 2 - 3 } \multicolumn{1}{c|}{} & MANDO Y CONTROL (87,5\%) & MOVILIDAD Y ACCESIBILIDAD (12,5\%) \\
\hline LADO (16,6\%) & $11,45 \%$ & $49,12 \%$ \\
\hline CENTRO $(40,21 \%)$ & $41,15 \%$ & $33,66 \%$ \\
\hline NASA $(43,63 \%)$ & $47,40 \%$ & $17,22 \%$ \\
\hline
\end{tabular}

Tabla 3-2 Matriz decisional multicriterio subjetivo (Elaboración propia)

Como se ha visto, la alternativa mejor valorada tras el proceso de decisión multicriterio es la de tipo NASA. Ahora bien, resulta elegida por una diferencia de menos de 4 puntos respecto a la alternativa tipo CENTRO. Por tanto, es muy necesario realizar un análisis de sensibilidad. 


\section{CENTRO vs NASA}

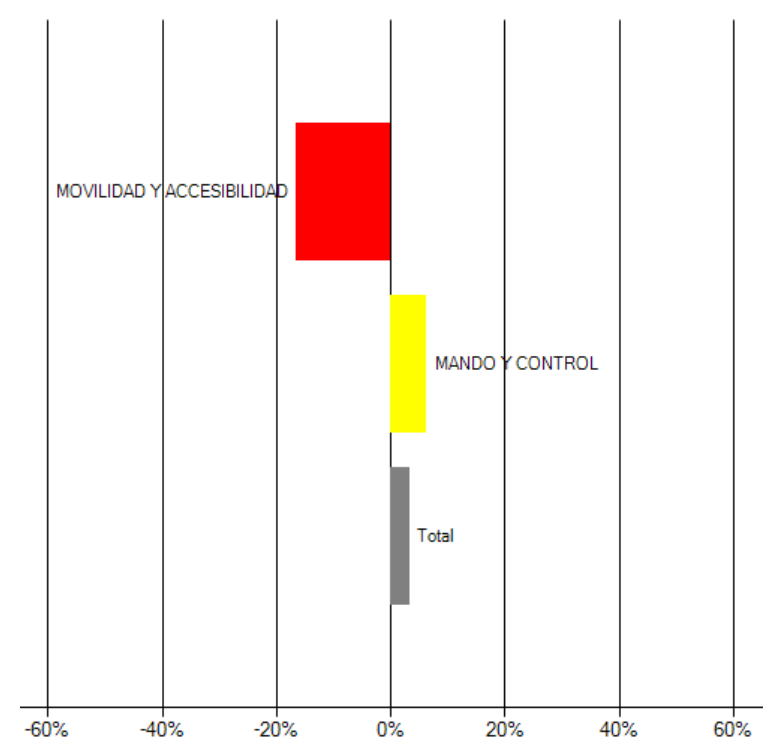

Figura 3-20 Comparación por parejas CENTRO vs NASA (ADLA)

\section{$\underline{\text { Análisis de sensibilidad }}$}

La ordenación de las alternativas depende de todas las evaluaciones, pesos y procedimientos del método. Estos, se han ido efectuando hasta la obtención de la ordenación y queda comprobar si las decisiones son lo suficientemente robustas y no se ven afectadas por ligeros cambios en los datos o si, por el contrario, algún pequeño cambio en la subjetividad del decisor cambia el resultado. Aunque los datos de los decisores expertos no suelen cambiarse, es conveniente que conozcan si sus decisiones son críticas, y también es interesante que puedan experimentar con los datos hasta graduarlos oportunamente.

Sobre la Figura 3-21 se exponen los resultados de los pesos asignados al criterio de MANDO Y CONTROL $(87,5 \%)$ y al criterio de MOVILIDAD Y ACCESIBILIDAD (12,5\%), sobre el gráfico de barras (azul), y las valoraciones de las alternativas sobre el otro gráfico de barras (naranja). 


\section{Análisis dinámico de sensibilidad}
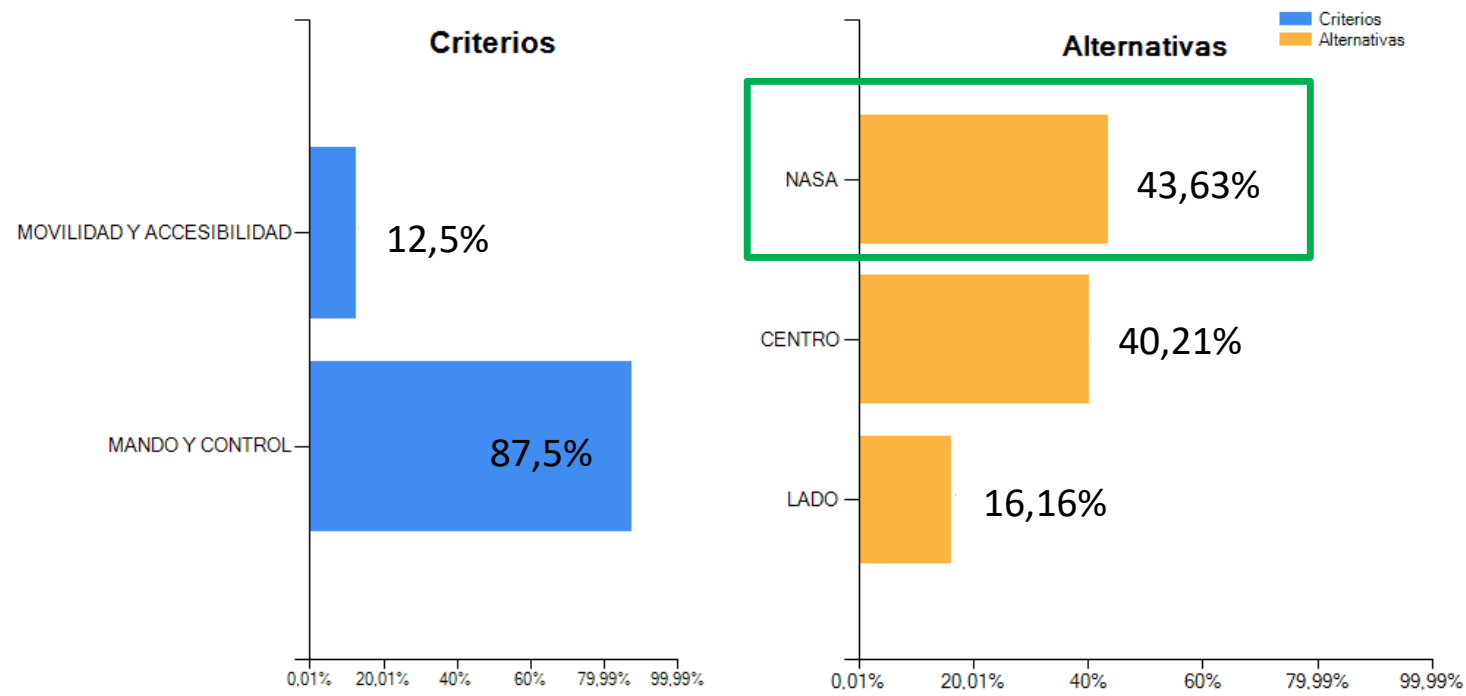

Figura 3-21 Gráfica de barras para el análisis dinámico de sensibilidad que se ha obtenido como resultado del multicriterio subjetivo (ADLA)

En la Figura 3-22, se puede observar que si el experto decisor cambiase sobre la matriz comparativa dos a dos la diferencia de pesos entre los dos criterios MANDO Y CONTROL y MOVILIDAD Y ACCESIBILIDAD hasta una diferencia menor entre ellas de un $44,14 \%$ (MANDO Y CONTROL 72,07\% y MOVILIDAD Y ACCESIBILIDAD 27,93\%), el resultado conmutaría a favor de la alternativa CENTRO. Esto supondría un cambio de juicio de los expertos de más de un $15 \%$ a favor del criterio de MOVILIDAD Y ACCESIBILIDAD. Esta diferencia de cambio de criterio tan grande parece poco probable, lo que demuestra que la decisión es bastante robusta.

Para que resultase "ganadora" la alternativa tipo LADO, sería necesario cambiar los pesos de los criterios en más de un 53\% a favor del criterio MOVILIDAD Y ACCESIBILIDAD. 


\section{Análisis dinámico de sensibilidad}

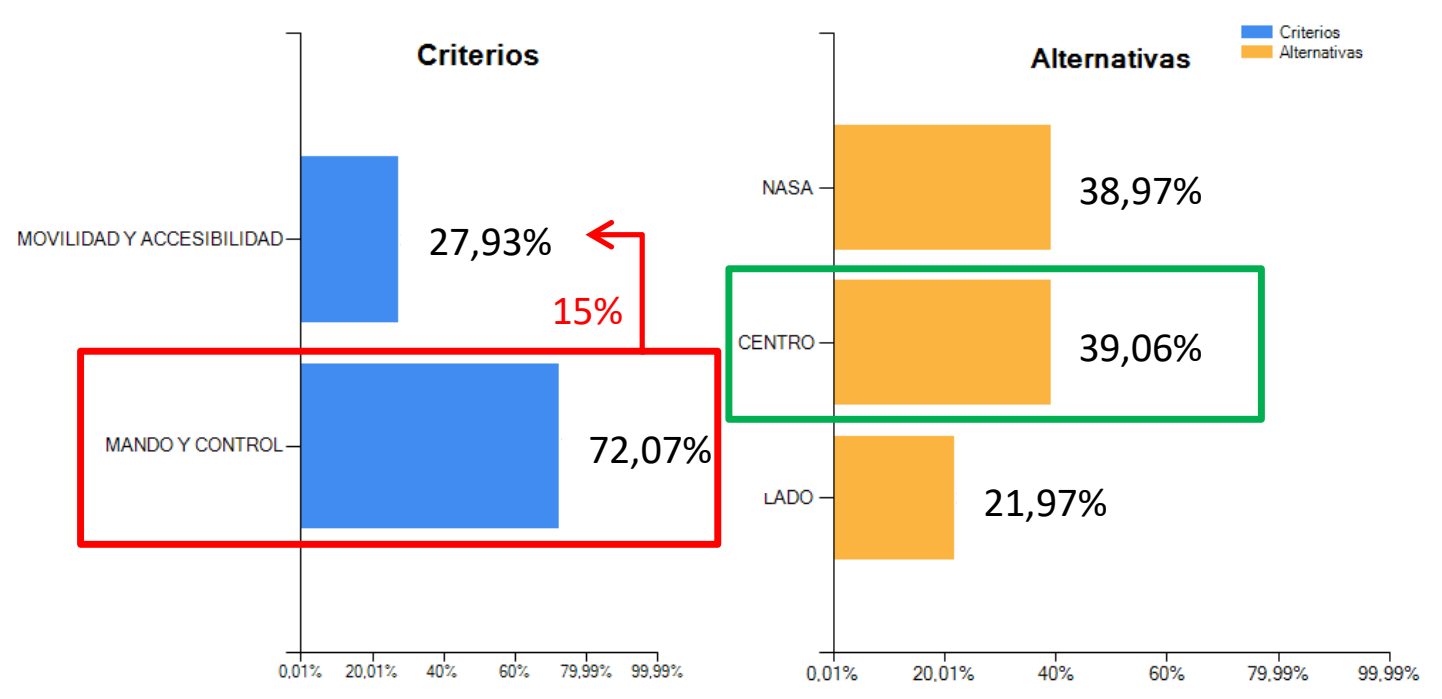

Figura 3-22 Gráfica de reasignación de pesos para conmutación de alternativas. La flecha y la cifra en rojo indican el \% en que ha sido necesario disminuir el peso del criterio de Mando y Control para que se produzca la conmutación en el resultado de NASA a CENTRO (barras naranjas) (ADLA)

\subsubsection{Contribución de las Alternativas. Problema Objetivo}

Como ya se ha mencionado en la explicación de la metodología, en esta fase se busca reducir la subjetividad del modelo en aquellos juicios que sean susceptibles. Para ello, se debe estudiar el problema y buscar las técnicas ad hoc que mejor se puedan adaptar al problema.

En un trabajo conjunto con los expertos se acordó desglosar el problema en dos estudios independientes en el tiempo, de los cuales, por falta de tiempo y presupuesto, solo se pudo realizar el primero:

- Estudio 1. Simulación por ordenador, para determinar tiempos de evacuación y de relevos de guardia, cuellos de botella, etc.

Objeto: Simular en ordenador el CIC de las fragatas F-110.

Variables a analizar: Disposiciones de equipos, rutas de escape y tiempos de evacuación.

Técnicas: Simulación Montecarlo, Diseño de experimentos, Técnicas de muestreo y Análisis estadístico inferencial.

- Estudio 2. Experimentación, con dos fases: 
- Fase 1. Experimento de descubrimiento, en el que expertos aporten opiniones y nuevas fuentes de posibles investigaciones.

Objeto: Determinar posibles soluciones al problema operativo del $\mathrm{ClC}$ y aportar ideas innovadoras sobre el asunto. Se emplearía el programa PASW Data Collection Author [132], del cual el Servicio de Estadística del Órgano Central del Ministerio de Defensa posee licencia.

Técnicas: Técnicas de elaboración de encuestas, Teoría de muestras, Análisis estadístico descriptivo y Análisis estadístico inferencial.

- Fase 2. Experimentación sobre un prototipo que, mediante la virtualización de un $\mathrm{CIC}$, se analice el comportamiento de las diferentes disposiciones.

Objeto: Virtualizar el CIC mediante ordenadores del tipo PC simulando las distintas consolas sobre las que correría una aplicación elaborada para el experimento, con personal real que en cada uno de los puestos. Para realizar esta virtualización, y permitir adoptar las distintas posibles configuraciones es necesario disponer de un local con dimensiones similares al CIC de las futuras fragatas F-110. La aplicación que debe desarrollarse para el experimento podrá monitorizar las comunicaciones entre puestos, ordenar acciones y almacenar una serie de datos que serán analizados posteriormente mediante estudios estadísticos.

Técnicas: Programación, Redes de ordenadores, Procesos Estocásticos, Análisis estadístico descriptivo y Análisis estadístico inferencial.

Con el propósito de reducir la subjetividad al problema de decisión multicriterio, se realizó un estudio sobre el subcriterio de Evacuación. Para ello, primero se estudió la normativa de referencia y, posteriormente, se preparó un modelo de diseño estadístico de experimentos (DEE) para los tres tipos de CIC, que se implementó sobre un software de simulación de evacuaciones. El DEE que se diseñó fue el mismo para los tres tipos de $\mathrm{CIC}$. 


\subsubsection{La Evacuación del CIC. Subcriterio Evacuación}

El diseño de los buques para barcos civiles se realiza de acuerdo con reglas prescriptivas del IMO SOLAS [133]. Progresivamente, cada vez más barcos militares se subrogan a estas normas, como lo hace la propia norma NATO Naval Ship Code (NSC) [134]. La norma NSC precisa en el Capítulo 7, denominado "Escape, Evacuation and Rescue", que el objetivo es que los buques de guerra "sean adecuadamente proyectados, construidos, equipados, mantenidos y provistos de los procedimientos para el escape, evacuación y rescate de todo el personal que se prevea que puede embarcar en ellos, ante todas aquellas previsibles situaciones de emergencia y averías que puedan sufrir".

En ese Capítulo 7 del NSC se establecen los estándares mínimos que deben cumplir las rutas de escape y medios de salvamento para lograr la evacuación del buque de un modo seguro y eficiente, así como los procedimientos para verificar que estos medios cumplen con su función adecuadamente [135].

EI NSC, entre los requisitos que establece, cabe destacar aquellos que se exigen a las rutas de escape y que deben ser considerados en las etapas iniciales del proyecto de un buque de guerra:

- Las rutas de escape deben estar optimizadas para que el escape hasta los puntos de reunión, botes y balsas de rescate, así como la posterior evacuación de la dotación, se realice de un modo efectivo antes del tiempo objetivo que se determine en función del tipo de buque. Para ello se deberá tener en cuenta:

- El número de personas que se prevé que embarque, sus características físicas y el grado de conocimiento del buque.

- La distribución del personal a bordo para todas y cada una de las distintas condiciones de navegación: día y noche, zafarrancho de combate, etc.

- La condición de estanqueidad establecida. Aquellas puertas y escotilla que se encuentren cerradas supondrán un retraso en la marcha hacia los botes.

- Las averías y daños que pueda sufrir el buque, especialmente aquellas que puedan limitar o impedir el paso a través de rutas de escape previstas o la destrucción de medios de rescate. 
Una vez establecidas las rutas de escape y distribuidos los medios de evacuación, es preciso demostrar que el buque puede ser evacuado en un plazo inferior al tiempo máximo establecido por el NSC. Es deseable que esta verificación pueda hacerse antes de que la construcción del buque se encuentre excesivamente avanzada. Para ello, el NSC sugiere el empleo de una metodología similar a la exigida a los buques de carga y pasaje por la IMO, descrita en [136].

Esta guía ofrece en realidad dos metodologías para la estimación del tiempo máximo de evacuación del buque:

- Método Simplificado: que no es más que una representación "hidráulica" del movimiento de las personas. En este caso los individuos avanzan, uno a continuación del otro, por las rutas de escape de un modo similar a un fluido en el interior de tuberías. Este método es el adecuado para etapas iniciales del proyecto ya que es fácil de modelar y permite introducir cambios sin dificultad en la disposición general del buque. Sin embargo, representa pobremente el movimiento real de las personas.

- Método Avanzado: representación “individual” del movimiento de las personas. En este tipo de simulaciones, la superficie por la que pueden desplazarse los individuos se divide en celdas y cada individuo decide, en función del entorno y la ocupación de las celdas vecinas, la dirección en la que se mueve (Figura 3-23).

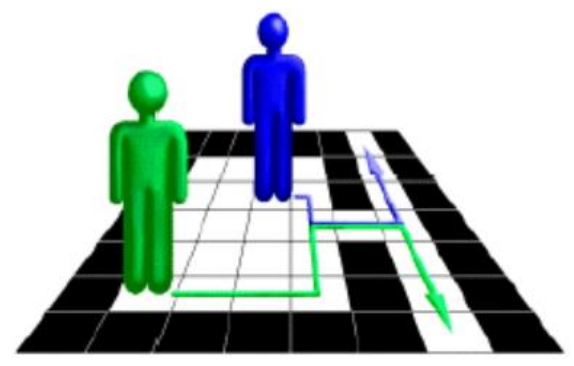

Figura 3-23 División en celdas del espacio y representación del movimiento de personas (imagen tomada de [135])

Este último, es el método que emplean la mayor parte de programas de simulación comercial pudiendo llegar a incorporar el efecto del humo o la escora del buque en el modelo. 


\subsubsection{Diseño Estadístico de Experimentos}

De los múltiples factores que pueden influir en la variable tiempo de evacuación de un compartimento, nos interesan los factores relacionados con el objetivo de este trabajo, es decir, los relacionados con la ubicación de los equipos (obstrucciones a efectos de evacuación) y puertas de escapes. Se descartó cualquier otro factor externo no relacionado con la disposición del CIC.

Los objetivos que se persiguieron con el DEE fueron dos:

- Analizar la influencia sobre el tiempo de evacuación de las variaciones de "niveles" de los factores.

- Averiguar si existe diferencia de tiempos de evacuación entre los diferentes modelos de $\mathrm{ClC}$.

Para la consecución de estos objetivos se diseñó un DEE multifactorial completo de dos factores con tres niveles $\left(3^{2}\right)$, lo que obligó a realizar 9 experimentos (ver Tabla 3-3) por cada tipo de $\mathrm{CIC}$ (27 experimentos en total).

Los factores seleccionados fueron el "número de pasillos" y el "número de puertas de escape". Los niveles seleccionados para los factores fueron tres, estos representaban variaciones a la cantidad. Es necesario explicar que el factor "número de pasillos" no es literal, simplemente expresaba una idea esquemática de la dispersión o concentración entre consolas. EI DEE fue validado por los expertos del EMA, considerando tanto los factores como los niveles, adecuados y asimilables a la realidad de los posibles tipos de $\mathrm{CIC}$.

\begin{tabular}{|c|c|c|}
\hline D.E.E. LADO & D.E.E. CENTRO & D.E.E. NASA \\
\hline Lado03 & Centro03 & Nasa03 \\
\hline Lado04 & Centro04 & Nasa04 \\
\hline Lado05 & Centro05 & Nasa05 \\
\hline Lado13 & Centro13 & Nasa13 \\
\hline Lado14 & Centro14 & Nasa14 \\
\hline Lado15 & Centro15 & Nasa15 \\
\hline Lado23 & Centro23 & Nasa23 \\
\hline Lado24 & Centro24 & Nasa24 \\
\hline Lado25 & Centro25 & Nasa25 \\
\hline
\end{tabular}

Tabla 3-3 Diseño estadístico experimento evacuación (Elaboración propia) 
La designación que se le dio a cada experimento es la siguiente: primero la alternativa de tipo de disposición de $\mathrm{CIC}$, seguido de dos dígitos, en el que el primero representaba el "número de pasillos" y el segundo representaba el número de puertas de escape del compartimento. El número de pasillos oscila entre cero y dos $(\{0,1,2\}$ tres niveles) y el número de puertas de escape oscila entre tres y cinco puertas $(\{3,4,5\}$ tres niveles). Así, un experimento Centro25, es una alternativa de disposición tipo CENTRO, que cuenta con "dos pasillos" y cinco puertas de escape.

En la Figura 3-24, se puede observar un ejemplo esquemático de un DEE para un determinado tipo de $\mathrm{CIC}$.

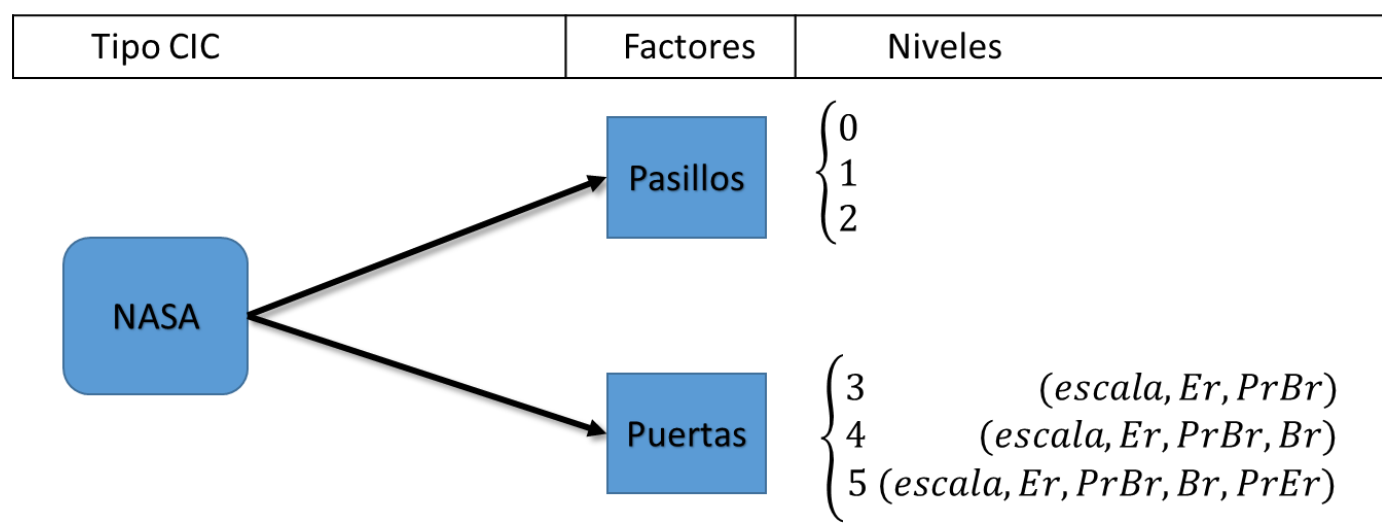

Figura 3-24 Esquema de DEE para CIC tipo NASA (Elaboración propia)

Un ejemplo gráfico de un experimento para una determinada disposición es conforme a la Figura 3-25.

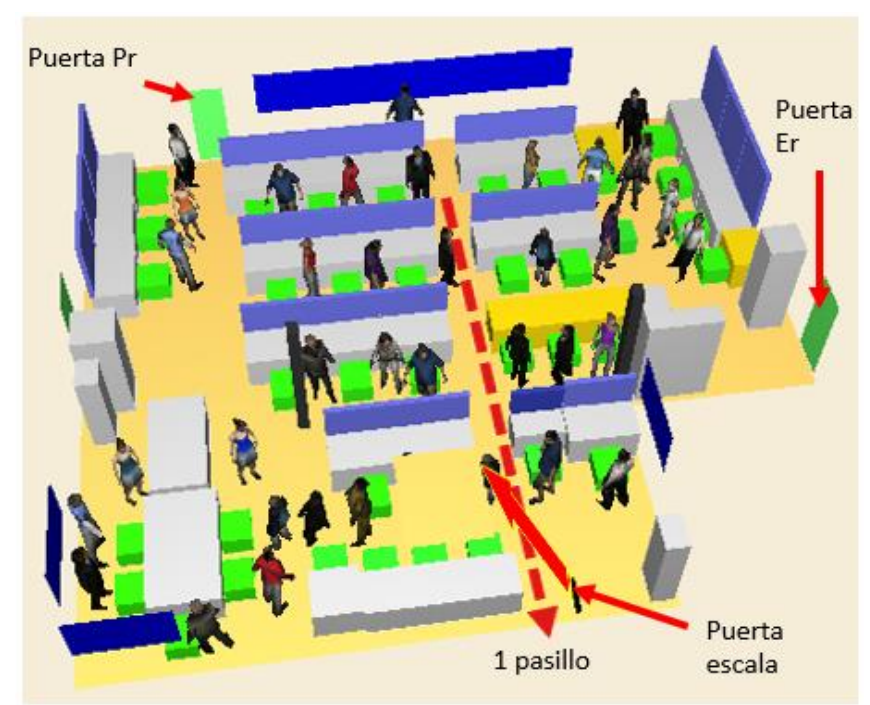

Figura 3-25 Experimento evacuación NASA13. Se aprecia en la imagen un pasillo longitudinal (proa-popa) y tres puertas de salida (Pathfinder) 
Como ya se ha mencionado, el plano del CIC del prototipo inicial de diseño de Navantia es confidencial y, por tanto, no se puede anexar. Ello no impide describirlo como una disposición que se podría denominar tipo CENTRO, con cero pasillos y cuatro puertas de escape, es decir, enmarcado dentro del DEE sería un "Centro 04". Su grado de ocupación máximo es de 40 puestos aproximadamente, situación se produce cuando el buque está en Zafarrancho de Combate. Esta disposición, en una versión ilustrativa primigenia (ver Figura 3-26), ha servido de referencia en todo lo concerniente al modelado de las diferentes disposiciones que hubo que realizar para el DEE.

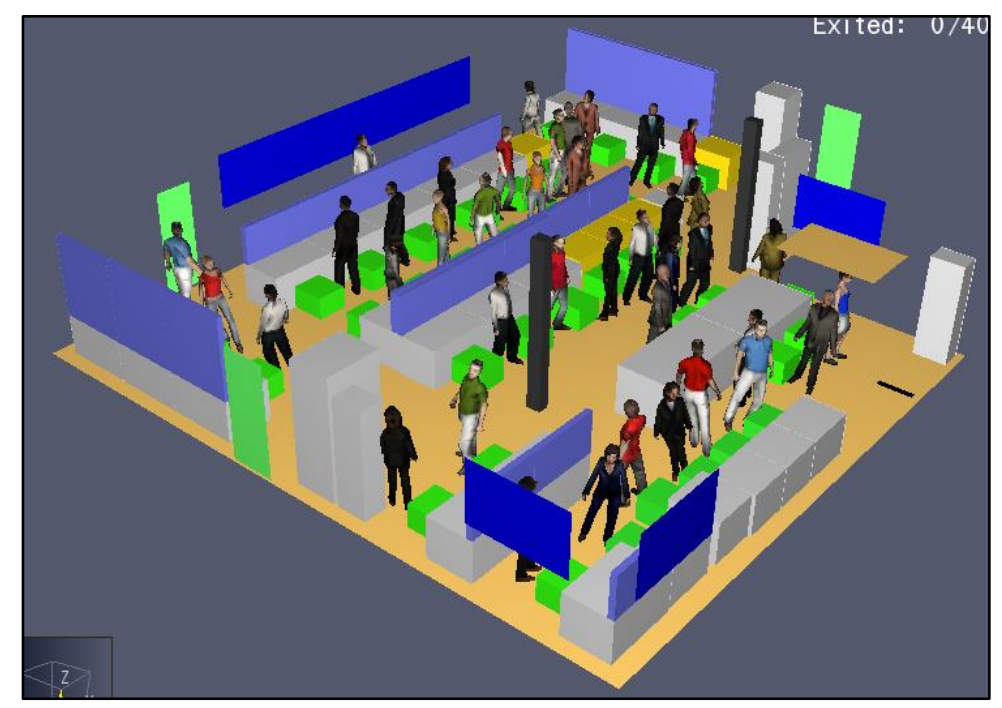

Figura 3-26 Disposición original del CIC “CENTRO04” (Elaboración propia)

En la planificación de los experimentos se ha respetado el principio de aleatorización, como se explicará más adelante.

El tamaño muestral inicial de réplicas para cada experimento se estableció en diez (10). A priori, no es fácil estimar el tamaño muestral, por ello, es aconsejable sobreestimarlo. Esto, conlleva el inconveniente del importante consumo de tiempo que el software requiere para la experimentación, por tanto, se aplicó un estadístico para conocer el número de réplicas necesarias para estimar la media poblacional dentro de un intervalo razonable (A.2), que en caso de resultar insuficiente obligase a aumentar el número de réplicas. 


\subsubsection{Simulación}

Para el diseño y modelado de los distintos tipos de CIC con sus variaciones a los factores se empleó el programa Pyrosim (ver modelos en A.3) y para llevar a cabo la simulación del DEE se utilizó el programa Pathfinder [137]. Ambos programas pertenecen a la compañía Thunderhead [138], que ofrece una licencia libre por treinta días.

\subsection{El software Pathfinder}

La simulación, inicialmente, se pretendió realizar con el software EXODUS. Este es una herramienta de modelización de evacuación para la industria de la seguridad y dispone de una versión marítima orientada expresamente a la evacuación de buques. EXODUS está desarrollado por el Grupo de Ingeniería de Seguridad contra Incendios de la Universidad de Greenwich (FIRE SAFETY ENGINEERING GROUP - FSEG - Faculty of Architecture, Computing \& Humanities University of Greenwich [139]), y están especializados en la ingeniería computacional de incendios, incluidas la modelización de los incendios y evacuación. Pero, la dificultad de disponer de la licencia obligó a investigar otros softwares de simulación.

Tras una exploración de alternativas (AENEAS [140], PedGo [141], EVI [142]), INCONTROL [143], AnyLogic [144]), se decidió la utilización del software Pathfinder. Este programa está especializado en la creación aplicaciones gráficas muy intuitivas para el manejo de programas de ingeniería técnicos que son muy potentes y a la vez muy complejos.

Pathfinder es un simulador de movimiento de personas que opera mediante un módulo de evacuación denominado EVAC [145], y proporciona al usuario una interfaz gráfica para la delineación y simulación de la evacuación, así como, las herramientas de visualización 2D y 3D para el análisis de resultados. Este software se combina con el Pyrosim, de los mismos desarrolladores, que es un software simulador de la dinámica de fuegos basado en Fire Dynamics Simulator and Smokeview (FDS) y que cuenta con el respaldo del National Institute of Standars and Technology (NIST) del U.S. Department of Commerce [146].

El planteamiento que sigue el software en la evacuación es a través de la simulación del comportamiento mediante fuerzas motivadas por las condiciones del entorno, es decir, 
el individuo puede tomar decisiones. Muchos de los métodos de simulación de multitudes derivan del método propuesto por Dirk Helbing et al. [147] , el cual se basa en la existencia de unas "fuerzas sociales" que repelen a los individuos condicionando su movimiento (ver A.4). La mayor ventaja de este método radica en la posibilidad de simular un comportamiento realista incluso cuando se produce contacto entre personas. Este modelo de fuerzas es en el que se ha basado el NIST para implementar su modelo de evacuación [148].

El modelo cumple con las pautas para la validación que plantea la Organización Marítima Internacional (OMI) en la MSC/Circ. 1238 [149].

En Pathfinder, el entorno de movimiento queda definido por una red de triángulos 3D trazada para que coincida con las dimensiones reales de un modelo. Esta malla de movimiento se puede introducir manual o automáticamente de datos importados (por ejemplo, de la geometría FDS Pyrosim) (ver Figura 3-27).

Las paredes y otras áreas intransitables quedan representadas de manera hueca y los ocupantes no pueden moverse en zonas donde no se haya generado la malla de movimientos. Las puertas están en los bordes de la malla de movimientos y tienen una representación especial (puertas en verde sobre la Figura 3-27). Las escaleras también tienen una representación especial y la velocidad de movimiento de los ocupantes se reduce en función de la inclinación.

Cada ocupante queda definido por: su posición dentro del compartimento, por su perfil que especifica altura, velocidad, etc., y por la definición de su comportamiento que determina sus "intenciones". El comportamiento permite secuencias de instrucción de modo que, por ejemplo, un ocupante pueda esperar en su ubicación por un tiempo determinado y después proceder hacia un ascensor o una puerta. 


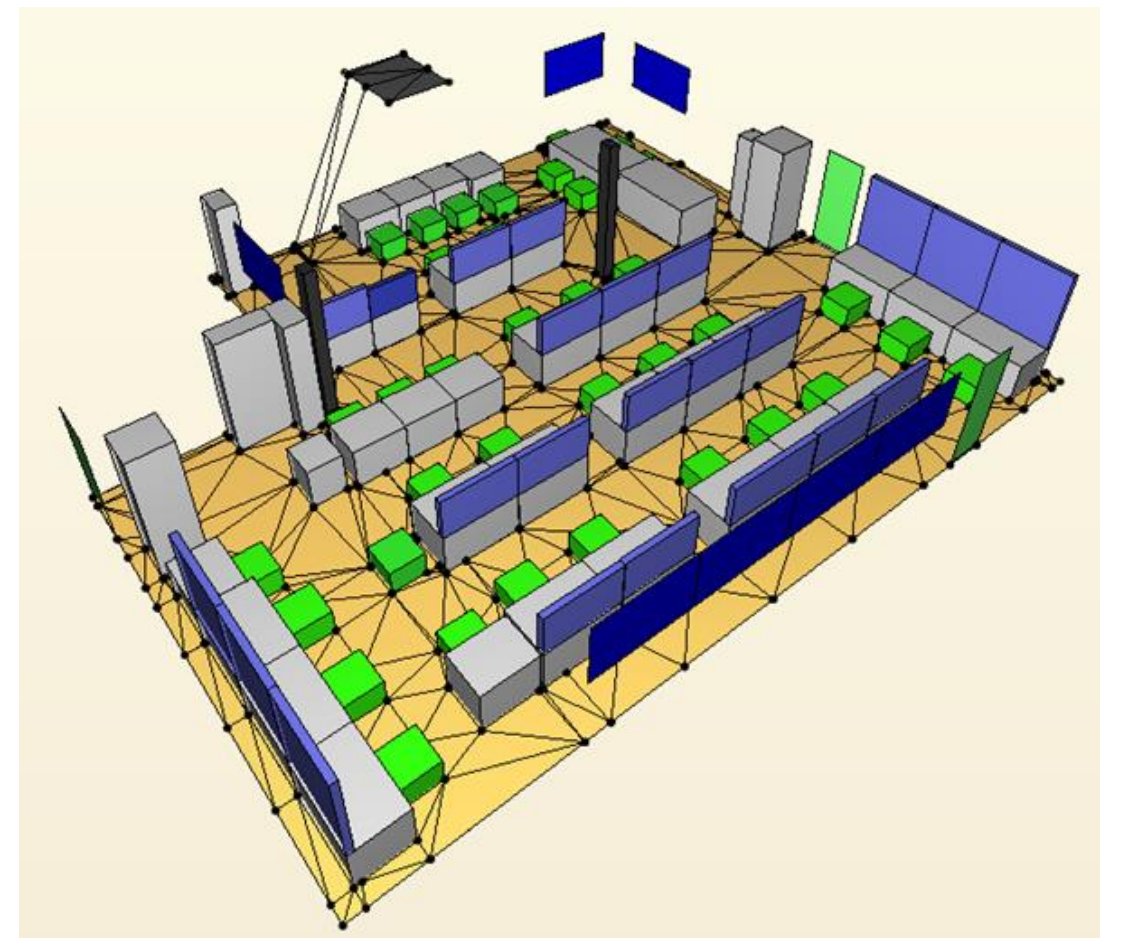

Figura 3-27 Malla de triángulos definida para generar rutas de evacuación (Elaboración propia)

\subsection{Experimentos de Evacuación del CIC}

Para la realización de los experimentos hubo que tener en cuenta una serie de carencias del software Pathfinder:

- No dispone de una versión "navalizada" o marítima y, por tanto, no es posible simular la apertura de puertas estancas (ver Figura 3-28), pero al tratarse de la evacuación de un único compartimento se considera que es válido para la realización de los experimentos. Esta carencia se simuló mediante otras opciones que se detallan más adelante.

- Es determinista en cuanto a resultados, es decir, que para unos mismos parámetros de los individuos y para una misma configuración del compartimento, el tiempo de evacuación es el mismo, es constante. 


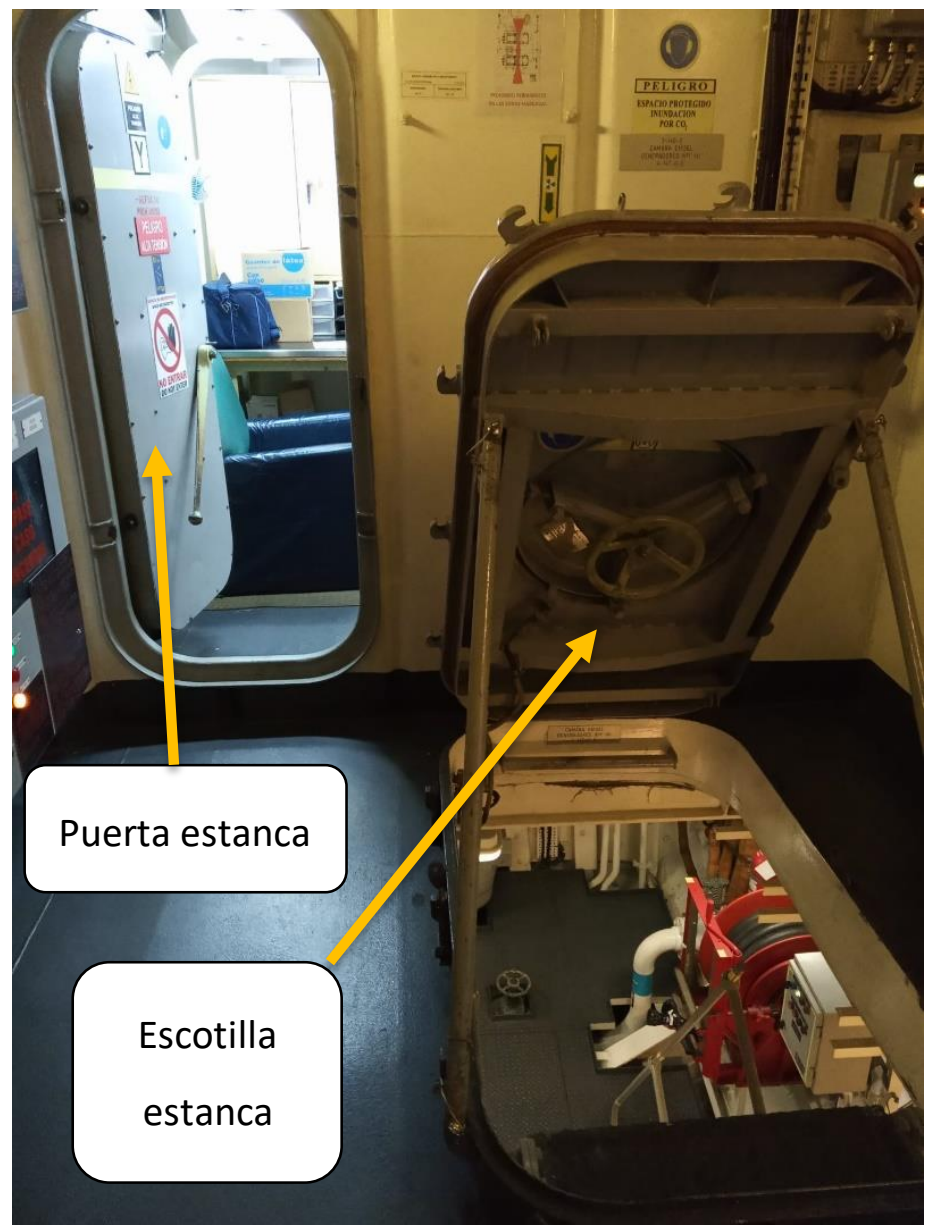

Figura 3-28 Imagen de puerta y escotilla estanca en la F-102 (Gonzalo Leira)

En todos los experimentos se utilizaron los mismos parámetros de comportamiento del personal durante la evacuación. El programa admite varias configuraciones de comportamiento, pero como entre los objetivos que se persiguen con la experimentación no estaba el conocimiento de tiempo real de evacuación (objetivo imposible de alcanzar hasta que se conozca el diseño definitivo), sino una comparativa entre alternativas y en qué grado le afectan las variaciones de los factores propuestos, se optó por la configuración por defecto del programa con variaciones a los parámetros de velocidad de los individuos, del "tiempo de destrucción de equipos" (Delay time) y nivel de determinación de los individuos para dirigirse hacia una puerta u otra.

Por ello, para darle la necesaria estocasticidad a los resultados, se configuró el siguiente comportamiento genérico de variables de entorno:

- Velocidad de evacuación: Distribución Uniforme, $U[2,04 ; 2,17] \mathrm{m} / \mathrm{s}$. Esta variable indica velocidad la velocidad de marcha de los individuos. Está 
basada en datos reales de medición de evacuación en buques de la Armada española [150].

- Door choice: Distribución Uniforme, $U[15 \% ; 100 \%]$. Esta variable mide el nivel de predisposición de un individuo para cambiar de decisión cuando, al dirigirse a la puerta más cercana, en caso de encontrarse con un cuello de botella (ver Figura 3-29; más de 4 individuos por metro cuadrado) que le ralentiza e impide prácticamente avanzar optar por otra alternativa. Por ejemplo, si la aleatoriedad de la distribución le ha asignado un $15 \%$, el individuo se dirigirá a otra puerta con una probabilidad del $85 \%$, mientras que, si tiene asignado un $100 \%$, continuará hacia la puerta más cercana sin cambio de criterio y esperará a que se descomponga el cuello de botella.

- Initial Delay: Distribución Normal,N(20,6)[mín.10 ; máx.60]seg. Esta variable asigna a cada individuo un tiempo de retardo antes de comenzar la evacuación. Con este tiempo se simula la obligatoriedad de destrucción de equipos a la que está sometida el personal que ocupa su puesto en Zafarrancho de Combate en el $\mathrm{CIC}$, así como el tiempo de retardo de la apertura de puertas estancas. La destrucción de equipos del $\mathrm{CIC}$, comprende desde la simple destrucción de un ordenador hasta la destrucción de consolas "navalizadas" que hace necesario el empleo de una maza o un hacha.

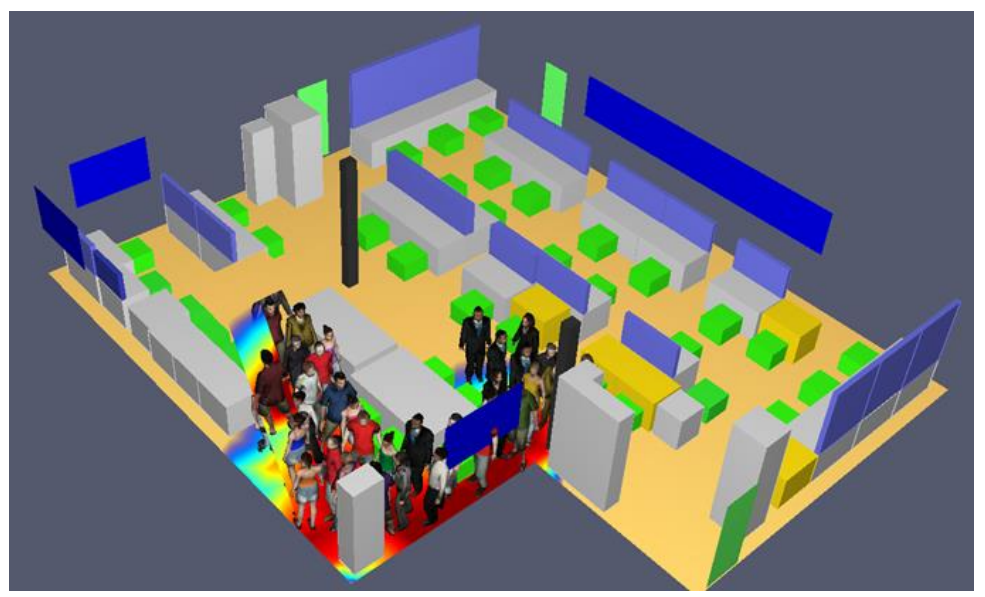

Figura 3-29 Ejemplo de cuello de botella, el compartimento dispone de una única salida (Elaboración propia)

Los datos de la variable de entorno Initial Delay no son reales, son una modificación de la suma del tiempo real de apertura de puertas estancas (dato confidencial [150]), más 
una modificación de la estimación del tiempo de destrucción de diferentes equipos del $\mathrm{CIC}$, dato que maneja la Armada (dato confidencial).

Para garantizar la estocasticidad de la simulación, previamente a la realización de cada réplica, era necesario reiniciar el comando "Randomize" y, con ello, se reasignaban aleatoriamente nuevas variables de entorno a los ocupantes.

Es importante destacar que en ninguno de los veintisiete experimentos se produjo un cuello de botella por un tiempo superior al 10\% del tiempo de evacuación, que es el tiempo límite indicado por la Organización Marítima Internacional (OMI) [136].

Un aspecto controvertido en los estudios de evacuación es acerca de cuál distribución modela mejor el tiempo de evacuación de un recinto. Algunos afirman que sigue una distribución Logarítmica Normal, aunque también es cierto, que otros muchos utilizan una distribución Normal [151](ver Figura 3-30).

Frecuentemente los experimentos de evacuación en otros ámbitos se simulan con colectivos muy heterogéneos (distintas edades, distintas capacidades o limitaciones de movimiento, etc.) [152]. Esto, contribuye a que los tiempos de evacuación se dilaten, circunstancia que facilita que una distribución asimétrica sea más adecuada.

En buques civiles, las velocidades de marcha se indican para una distribución demográfica predefinida de la población de pasajeros y tripulantes, tomados de estudios relevantes en la dinámica peatonal [153]. En nuestro experimento, que trata de representar la realidad de una tripulación de la Armada, se trabaja con un grupo de individuos que conocen perfectamente el compartimento, gozan de una adecuada motivación y, sobre todo, poseen un correcto adiestramiento alcanzado gracias a los frecuentes ejercicios de abandono de buque que se realizan a bordo.

Por todo ello se considera que la distribución Normal es la que mejor se ajusta a los tiempos de evacuación para esta simulación, sin necesidad de realizar ninguna prueba de normalidad a las muestras, que por otra parte al ser demasiado pequeñas (inicialmente 10 réplicas) no obtendríamos evidencias estadísticas suficientes para ser concluyentes con los resultados. 


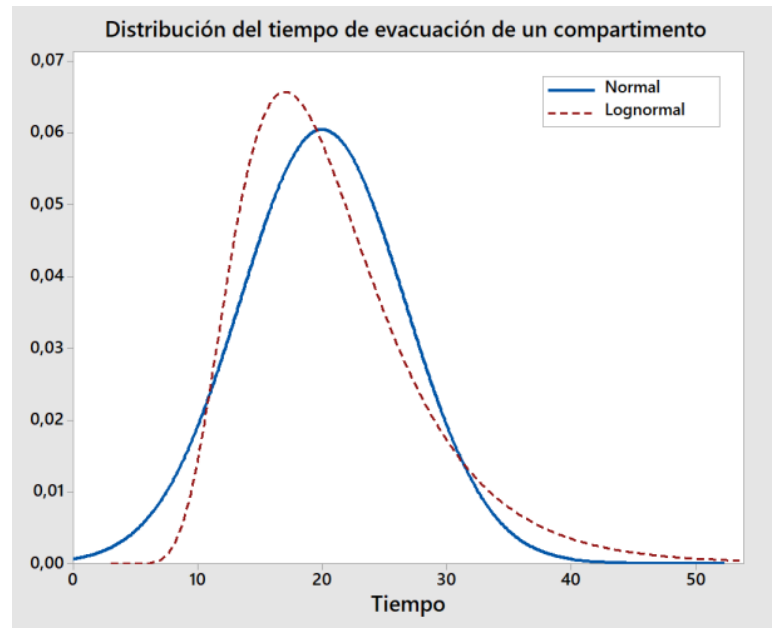

Figura 3-30 Distribuciones del tiempo de evacuación (Elaboración propia)

Para analizar en detalle con pruebas estadísticas los datos generados en el DEE se empleó el software Minitab, inicialmente, se realizó el Análisis de la Varianza (ANOVA) de los tres experimentos de forma individual y, posteriormente, se realizó el contraste ANOVA entre ellos.

Entre las diferentes opciones para realizar el contraste ANOVA se escogieron las siguientes:

- Prueba de varianzas iguales [154]. Al ser las muestras menores de 20 observaciones, se ha empleado el método de Levene [155] y el método de comparaciones múltiples. El método de cálculo para la prueba de Levene se basa en la modificación de Brown et al. [156] del procedimiento de Levene. Este método considera las separaciones de las observaciones con respecto a la mediana en vez de respecto a la media de su muestra. Con ello, se aumenta la robustez de la prueba para muestras pequeñas.

Los intervalos de comparación del método de comparaciones múltiples se calculan utilizando algoritmos similares al método de comparaciones múltiples para las medias propuesto por Hochberg et al. [157].

- Análisis de varianza de un solo factor.

- Para los Intra-experimentos se ha empleado el método de Tukey. El número de comparaciones dentro de cada experimento es elevado $\left(C_{9}^{2}=\right.$ $\left.\left(\begin{array}{l}9 \\ 2\end{array}\right)=\frac{9 !}{2 !(9-2) !}=36\right)$, y la aplicación reiterada del procedimiento mediante la prueba $\mathrm{F}$ de Fisher, para un nivel de significación $\alpha$ dado, 
puede conducir a un número grande de rechazos de la hipótesis nula, aunque no existan diferencias reales. Wilcox en [158], afirma que cuando se desean realizar todas las comparaciones por pares y se quiere mantener la probabilidad del error de Tipo I igual a $\alpha$, es perfectamente legítimo omitir la prueba $\mathrm{F}$ y usar otros procedimientos de contraste de medias. Una forma de solventar estas posibles deficiencias mencionadas es emplear el método de la diferencia honesta significativa propuesto por Tukey o método HSD (Honestly Significant Difference) basada en el rango estudentizado [159].

- Entre-experimentos se ha empleado el método de la F de Fisher [160]. Esta técnica de comparación por parejas (entre experimentos son únicamente 3 comparaciones), se denomina método de la diferencia mínima significativa o método LSD (Least Significant Difference), se basa en la construcción de prueba de hipótesis para la diferencia de media de cualquier par. A su vez, es una prueba de contraste robusta frente a pequeñas desviaciones respecto a la normalidad.

\section{Experimentos en el CIC tipo LADO}

Los resultados obtenidos de la simulación en el Pathfinder se pueden observar sobre la Tabla 3-4. Se realizó un contraste de hipótesis para valorar si existen diferencias significativas entre las medias poblacionales de las muestras (Contraste ANOVA), resultando que no se puede rechazar la hipótesis nula en favor de la alternativa, con un nivel se significación de $\alpha=0,05$ (ver A.5). Esto significa que no se tienen evidencias estadísticas de que las variaciones de nivel de los factores establecidos dentro del DEE produzcan tiempos de evacuación de media poblacional distintos, por tanto, se puede concluir que estas variaciones no afectan al tiempo de evacuación. La media de los tiempos de evacuación de las réplicas es de 37,05 segundos (ver Figura 3-31). 

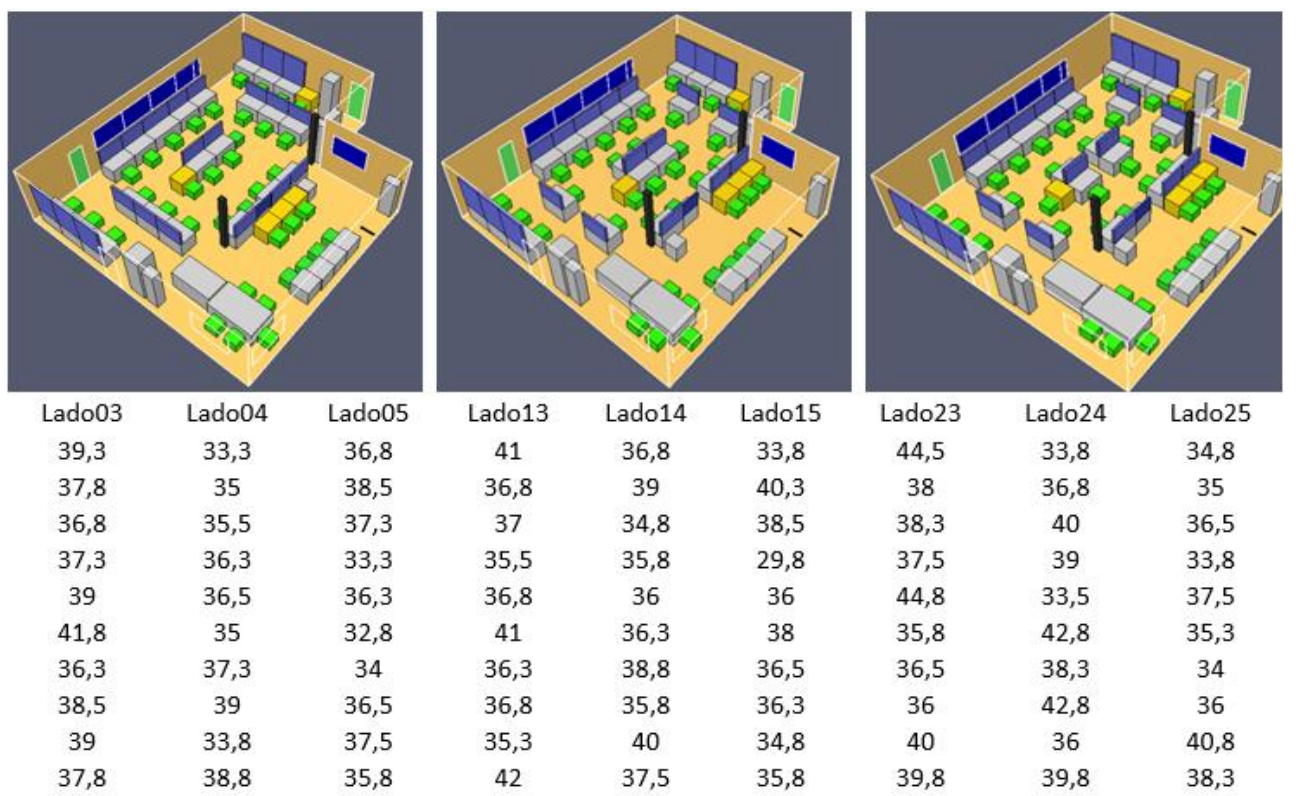

$\begin{array}{ccc}41 & 36,8 & 33,8 \\ 36,8 & 39 & 40,3 \\ 37 & 34,8 & 38,5 \\ 35,5 & 35,8 & 29,8 \\ 36,8 & 36 & 36 \\ 41 & 36,3 & 38 \\ 36,3 & 38,8 & 36,5 \\ 36,8 & 35,8 & 36,3 \\ 35,3 & 40 & 34,8 \\ 42 & 37,5 & 35,8\end{array}$

$\begin{array}{ccc}\text { Lado23 } & \text { Lado24 } & \text { Lado25 } \\ 44,5 & 33,8 & 34,8\end{array}$

$38 \quad 36,8 \quad 35$

$38,3 \quad 40 \quad 36,5$

$37,5 \quad 39 \quad 33,8$

$44,8 \quad 33,5 \quad 37,5$

$35,8 \quad 42,8 \quad 35,3$

$36,5 \quad 38,3 \quad 34$

$36 \quad 42,8 \quad 36$

$\begin{array}{lll}40 & 36 & 40,8\end{array}$

Tabla 3-4 Tiempos de evacuación del experimento del CIC tipo LADO (Elaboración propia)

Tiempos CIC LADO

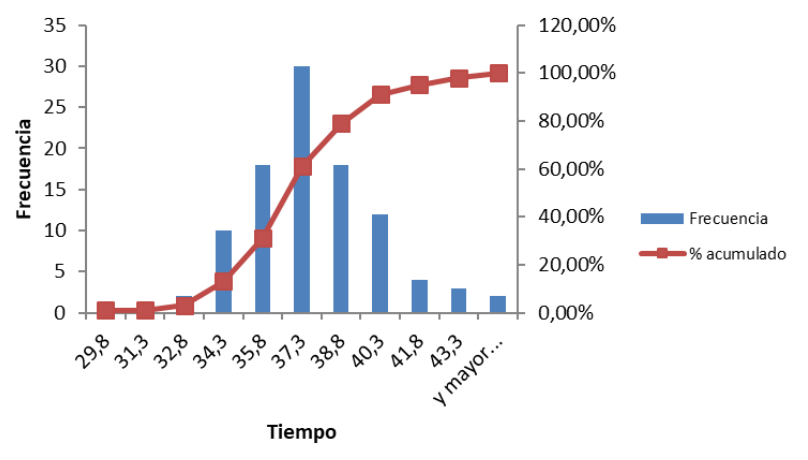

\begin{tabular}{|rc|}
\hline LADO & \\
\hline Media & 37,053 \\
Error típico & 0,255 \\
Mediana & 36,8 \\
Moda & 36,8 \\
Desviación estándar & 2,549 \\
Varianza de la muestra & 6,497 \\
Curtosis & 1,018 \\
Coeficiente de asimetría & 0,535 \\
Rango & 15 \\
Mínimo & 29,8 \\
Máximo & 44,8 \\
Suma & 3705,3 \\
Cuenta & 100 \\
Nivel de confianza(95,0\%) & 0,506 \\
\hline
\end{tabular}

Figura 3-31 Estadísticas del DEE del CIC tipo LADO

\section{Experimentos en el CIC tipo CENTRO}

Los resultados obtenidos de la simulación en el Pathfinder se pueden observar sobre la Tabla 3-5 . Se realizó un contraste de hipótesis para valorar si existen diferencias significativas entre las medias poblacionales de las muestras (Contraste ANOVA), resultando que no se puede rechazar la hipótesis nula en favor de la alternativa, con un nivel se significación de $\alpha=0,05$ (ver A.6). Esto significa que no se tienen evidencias estadísticas de que las variaciones de nivel de los factores establecidos dentro del DEE 
produzcan tiempos de evacuación de media poblacional distintos, por tanto, se puede concluir que estas variaciones no afectan al tiempo de evacuación. La media de los tiempos de evacuación es de 37,75 segundos (ver Figura 3-32).
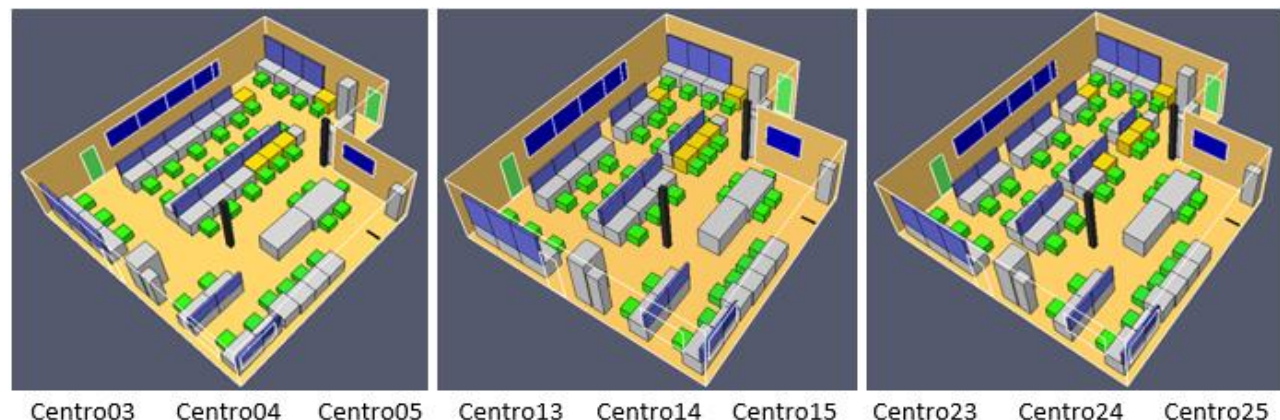

$\begin{array}{ccc}42 & 43 & 42,5 \\ 38,8 & 37 & 38 \\ 40,5 & 36 & 34,8 \\ 37 & 36,8 & 41,3 \\ 40 & 33,5 & 34,3 \\ 35,3 & 34,3 & 30,5 \\ 37,3 & 36,3 & 33 \\ 41,8 & 31 & 37,5 \\ 39,8 & 44 & 39,8 \\ 35,8 & 35,5 & 36 \\ & 40,8 & 37,8 \\ & 43 & 36,3 \\ & 37,5 & 38,5 \\ & 34,3 & 36 \\ & 42,5 & 34,8 \\ & 39,5 & 33,8 \\ & 40,3 & 39,8 \\ & 38,5 & 35,3 \\ & 38 & \\ & 35 & \end{array}$

$\begin{array}{ccc}37 & 36 & 36 \\ 35,8 & 35,8 & 40,5 \\ 35,5 & 35,3 & 36,8 \\ 36,3 & 37,5 & 40,8 \\ 37,8 & 40,3 & 40,3 \\ 38 & 34,5 & 37,5 \\ 37,8 & 34,8 & 36,3 \\ 36,3 & 33 & 42,3 \\ 38,5 & 34,3 & 36,3 \\ 44,8 & 40,3 & 37,5\end{array}$

$\begin{array}{ccc}42,5 & 45,3 & 37,5 \\ 38,3 & 35,5 & 36,5 \\ 37 & 36 & 36,8 \\ 37,3 & 41,3 & 31,8 \\ 40,3 & 35,5 & 35,5 \\ 39 & 34,5 & 39,3 \\ 38,8 & 37,5 & 34,5 \\ 37 & 37,8 & 33,8 \\ 38,5 & 40 & 39,8 \\ 36,8 & 37,5 & 38,3 \\ & 46,3 & \\ & 44,5 & \\ & 40,3 & \\ & 35,5 & \end{array}$

Tabla 3-5 Tiempos de evacuación del experimento del CIC tipo CENTRO (Elaboración propia)

Tiempos CIC CENTRO

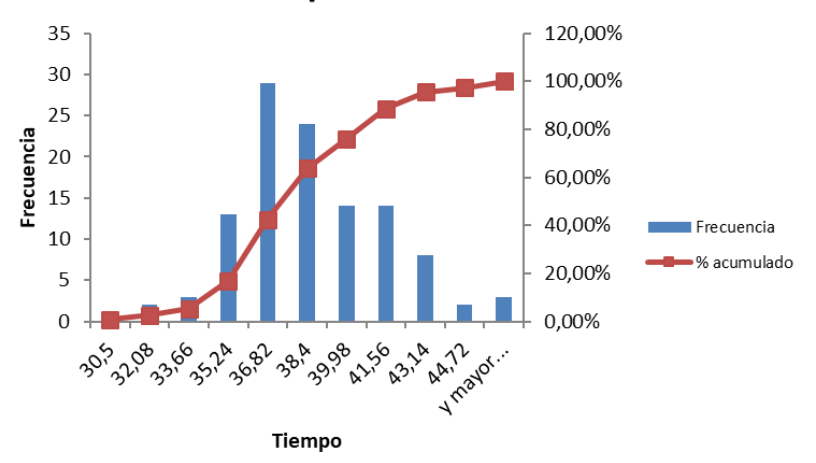

\begin{tabular}{|rc|}
\hline \multicolumn{2}{|c|}{ CENTRO } \\
\hline Media & 37,746 \\
Error típico & 0,284 \\
Mediana & 37,5 \\
Moda & 37,5 \\
Desviación estándar & 3,023 \\
Varianza de la muestra & 9,136 \\
Curtosis & 0,222 \\
Coeficiente de asimetría & 0,432 \\
Rango & 15,8 \\
Mínimo & 30,5 \\
Máximo & 46,3 \\
Suma & 4265,3 \\
Cuenta & 113 \\
Nivel de confianza(95,0\%) & 0,563 \\
\hline
\end{tabular}

Figura 3-32 Estadísticas del DEE del CIC tipo CENTRO 


\section{Experimentos en el CIC tipo NASA}

Los resultados obtenidos de la simulación en el Pathfinder se pueden observar sobre la Tabla 3-6. Se realizó un contraste de hipótesis para valorar si existen diferencias significativas entre las medias poblacionales de las muestras (Contraste ANOVA), resultando que no se puede rechazar la hipótesis nula en favor de la alternativa, con un nivel se significación de $\alpha=0,05$ (ver A.7). Esto significa que no se tienen evidencias estadísticas de que las variaciones de nivel de los factores establecidos dentro del DEE produzcan tiempos de evacuación de media poblacional distintos, por tanto, se puede concluir que estas variaciones no afectan al tiempo de evacuación. La media de los tiempos de evacuación es de 37,86 segundos (ver Figura 3-33).

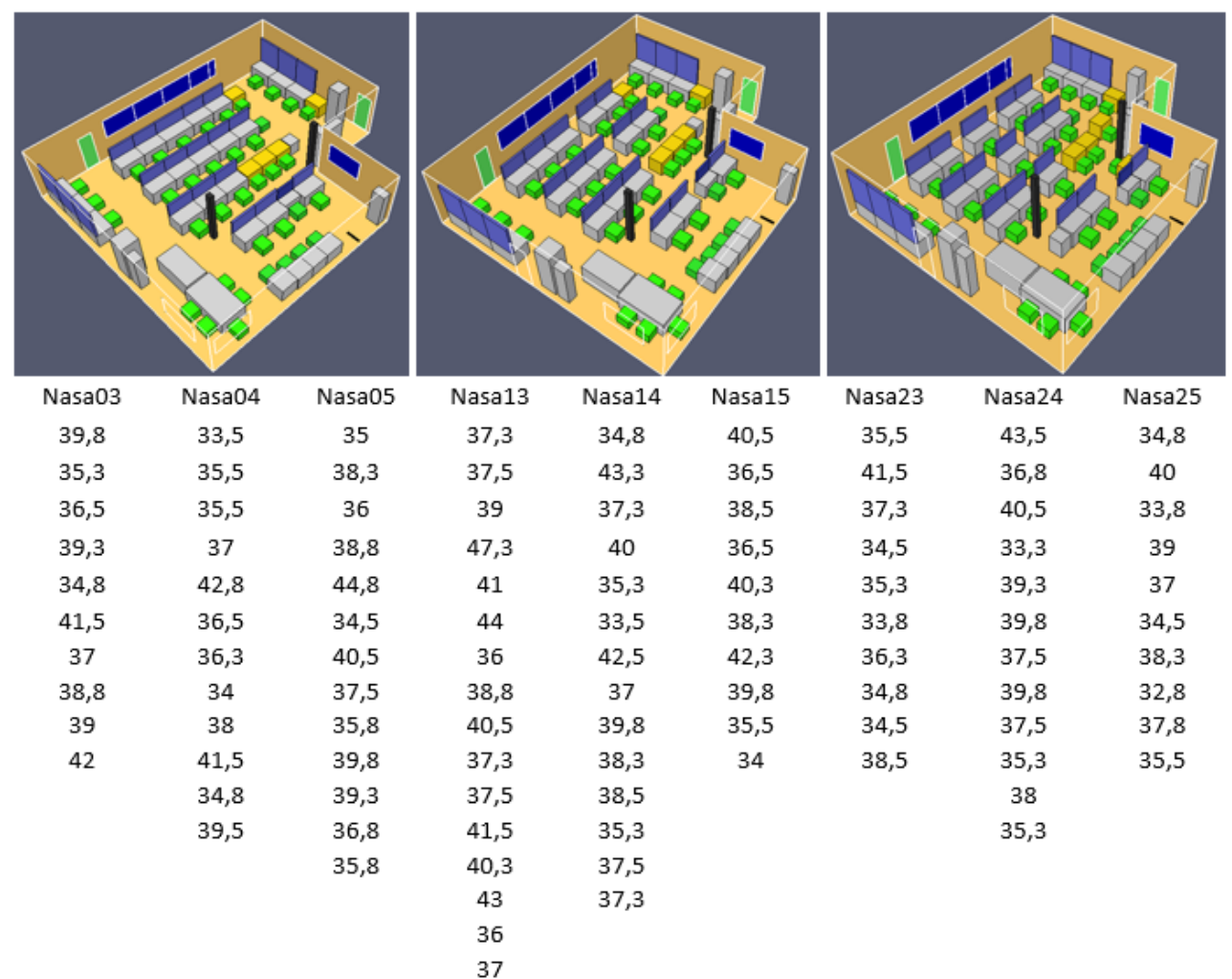

Tabla 3-6 Tiempos de evacuación del experimento del CIC tipo NASA (Elaboración propia) 

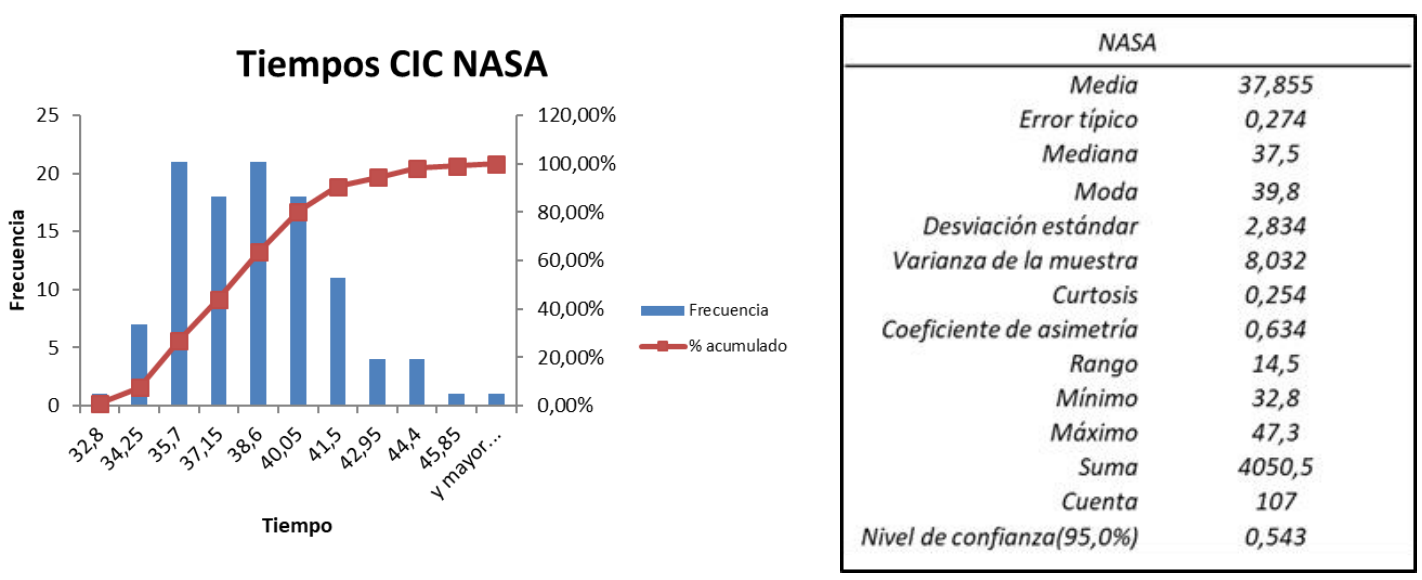

Figura 3-33 Estadísticas del DEE del CIC tipo NASA

Es interesante destacar que esta disposición NASA resultó ser la de mayor prioridad en el multicriterio subjetivo. El promedio del tiempo de evacuación en este modelo es el mayor de los tres, si bien, la diferencia entre todas ellos es menor de un segundo.

Se realizó un contraste de hipótesis para valorar si existen diferencias significativas entre las medias poblacionales de los tres experimentos, resultando que sí se puede rechazar la hipótesis nula en favor de la alternativa, con un nivel se significación de $\alpha=0,05$ (ver A.8), esto permite afirmar que no todos los tiempos de evacuación pertenecen a la misma población.

Independientemente a la medición de los tiempos, se realizó un análisis minucioso de los posibles cuellos de botella y de las gráficas obtenidas del Pathfinder poniéndose un especial énfasis en el modelo NASA. No se apreciaron diferencias significativas entre las distintas disposiciones. En el A.9 se adjuntan algunos ejemplos de imágenes de los vídeos y de las gráficas sobre los cuales se materializó el análisis comentado.

\subsection{Validación de la simulación}

“Un proceso de validación consiste en realizar la comparación entre el resultado obtenido con el modelo que se pretende validar con el fenómeno en la realidad, ya sea un fenómeno físico o de cualquier otra índole, constatando que el resultado de dicha comparación determina un rango satisfactorio en lo que respecta a la precisión de lo obtenido en la simulación frente a la realidad que se ha pretendido simular" [161]. 
En consecuencia, con la validación se buscó comprobar que: El modelo utilizado en la simulación con el Pathfinder supone una aproximación adecuada de la realidad para los objetivos particulares de este estudio.

Para ello, se realizó el experimento de evacuación real sobre dos modelos de CIC. EI primer experimento se ejecutó sobre un CIC tipo CENTRO04 (Figura 3-34), este era el prototipo original trazado en los planos del astillero, por tanto, se consideró que era interesante experimentarlo. El segundo experimento se ejecutó sobre un $\mathrm{CIC}$ tipo NASA04, justificado en que el diseño NASA resultó el mejor valorado en la resolución de la decisión multicriterio subjetiva.

Previamente a la realización de los experimentos se realizaron las mediciones de las dimensiones físicas y se marcaron las dos disposiciones sobre el escenario sobre el que se ensamblaron los CIC artificiales (patio de aulas Álvaro de Bazán de la Escuela Naval Militar de Marín). Se contó con la imprescindible colaboración de 40 individuos (alumnos de la ENM) y del mobiliario necesario en la simulación de consolas y perímetro del CIC. (ver A.10).

Una vez dispuesto el CIC, el día de la prueba, se actuó de la siguiente manera:

- Por causa de la escasez de tiempo disponible se realizaron únicamente 6 réplicas de evacuación para cada disposición de CIC.

- Los 40 participantes ocuparon los puestos de manera aleatoria en cada réplica.

- A cada participante se le proporcionó una hoja que, en función del número de réplica que se estuviese ejecutando, le indicaba el "delay time", es decir el tiempo de espera en su puesto antes de proceder a la evacuación, representando con ello, la destrucción de equipos. Estos tiempos se generaron a partir de una distribución Normal $N(20,6)$ [min. 10; max. 60] seg. (A.11). Los tiempos de espera los contabilizó cada ocupante de manera individual. Esta misma variabilidad es con la que se había programado el Pathfinder. 


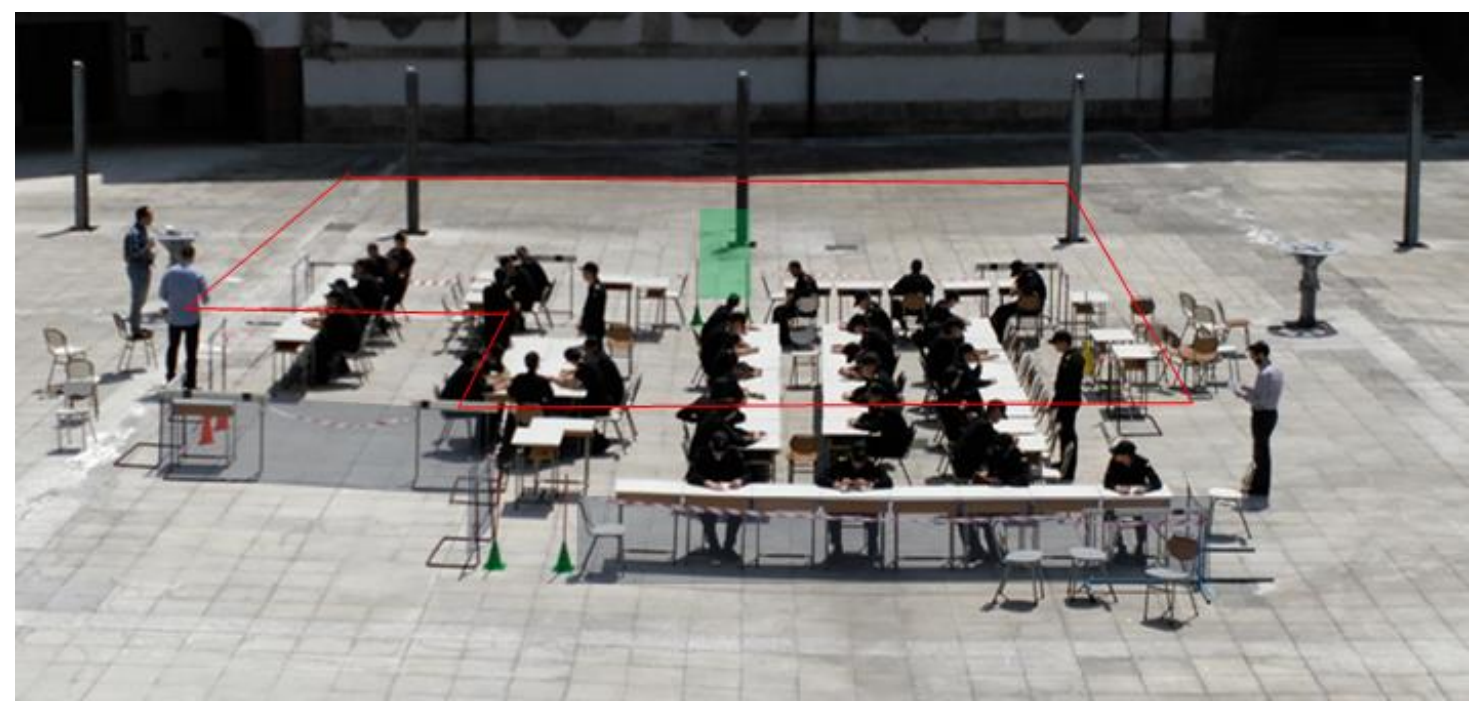

Figura 3-34. Fotografía de una representación del CIC tipo “Centro04” para la experimentación real. La línea roja simboliza el perímetro y los conos verdes las puertas de salida (José M. Núñez)

\section{CENTRO}

Las estadísticas obtenidas en esta experimentación se pueden observar en la Tabla 3-7. El promedio de los tiempos de evacuación de las seis réplicas (registrado por tres cronometradores), es de 35,95 segundos.

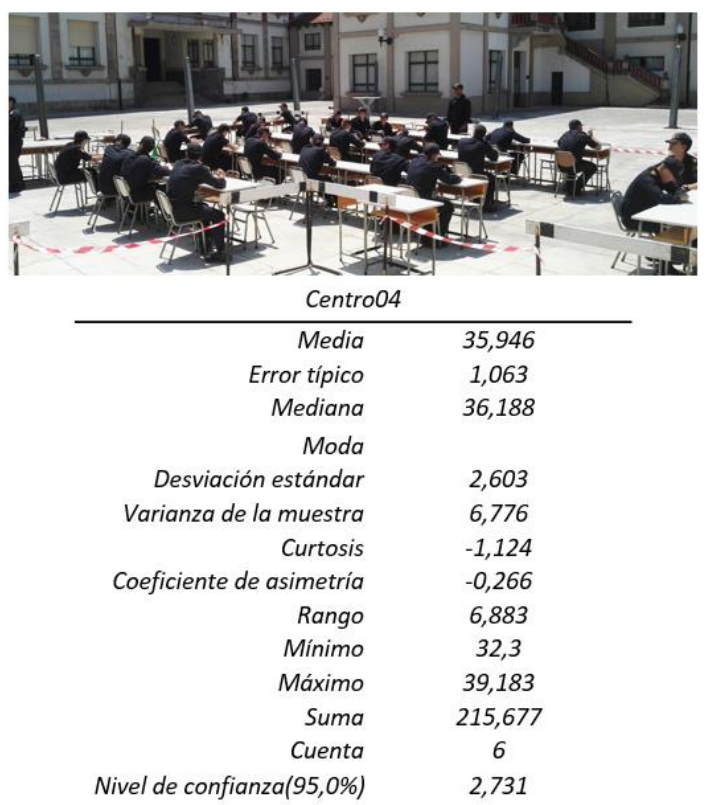

Tabla 3-7. Estadísticas descriptivas de los tiempos de evacuación reales del experimento "Centro04” (Elaboración propia)

Se realizó un contraste de hipótesis entre estos resultados y los obtenidos en la simulación para esta disposición de CIC, resultando que no se rechazaba la hipótesis nula 
de igualdad de medias. Es decir, a un nivel de significación de $\alpha=0,05$ no había evidencias estadísticas suficientes para asumir que la media de la experimentación real fuese distinta de la media de la simulación por ordenador (ver A.12).

NASA

Las estadísticas obtenidas en esta experimentación se pueden observar en la Tabla 3-8.

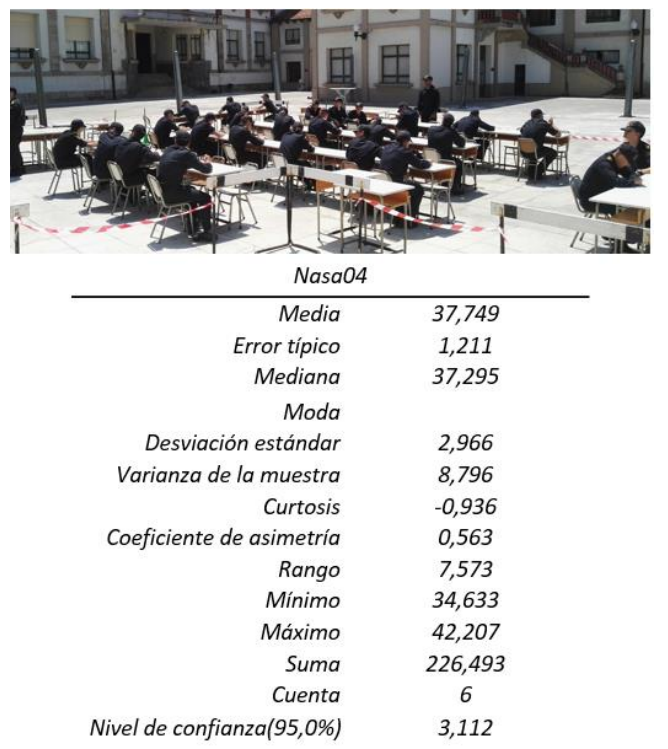

Tabla 3-8. Estadísticas descriptivas de los tiempos de evacuación reales del experimento “Nasa04” (Elaboración propia)

El promedio de los tiempos de evacuación de las seis réplicas es de 37,7 segundos.

Se realizó un contraste de hipótesis entre estos resultados y los obtenidos en la simulación para esta disposición de CIC, resultando que no se rechazaba la hipótesis nula de igualdad de medias. Es decir, a un nivel de significación de $\alpha=0,05$ no había evidencias estadísticas suficientes para asumir que la media de la experimentación real fuese distinta de la media de la simulación por ordenador (ver A.13).

\subsection{Otros Experimentos}

Aprovechando la valiosísima oportunidad de la realización de experimentaciones reales, se decidió sustituir cuatro réplicas de las diez previstas en cada tipo de CIC por unos nuevos experimentos. 
Con el objetivo de valorar si se producían cuellos de botella se realizaron: Dos evacuaciones con el mismo tiempo de espera inicial, 10 segundos para todos los ocupantes; dos evacuaciones diferenciando dos zonas, consolas de proa y consolas de popa, se les asignó tiempos de espera inicial ligeramente diferentes, 12 segundos para los ocupantes ubicados en la zona de proa y 10 segundos para los ocupantes ubicados en la zona de popa. En todas las réplicas no se observó ningún tipo de aglomeración, ni cuello de botella de tiempo superior al 10\% del tiempo total de evacuación. Los resultados se pueden observar en la tabla de la Tabla 3-9.

\begin{tabular}{|c|c|c|c|c|}
\hline CENTROO4 & Tiempo & & NASA04 & Tiempo \\
\hline Réplica 7 & 18,04 & \multirow{2}{*}{ todos 10 seg delay } & Réplica 7 & 18,69 \\
\hline Réplica 8 & 19,26 & & Réplica 8 & 18,45 \\
\hline Réplica 9 & 20,92 & \multirow{2}{*}{$\begin{array}{c}\text { consolas proa } 12 \text { seg } \\
\text { delay. Consolas popa } 10 \\
\text { seg delay }\end{array}$} & Réplica 9 & 21,29 \\
\hline Réplica 10 & 20,26 & & Réplica 10 & 20,19 \\
\hline A ciegas & 50,64 & & A ciegas & 45,88 \\
\hline
\end{tabular}

Tabla 3-9. Tiempos de evacuación de los otros experimentos

Para este experimento es necesario matizar que, aunque los tiempos de evacuación son más reducidos respecto a los anteriores, no se puede demostrar una disminución verdadera del tiempo de evacuación, simplemente, se explica porque no existió la aleatoriedad programada anteriormente en la variable "delay time", que se correspondía con una distribución Normal $N(20,6)[\min .10 ; \max .60] \mathrm{seg}$.

Como último experimento, también para cada tipo de $\mathrm{CIC}$ (Centro04 y Nasa04), se realizaron dos evacuaciones a ciegas, es decir, sin visibilidad (el CIC no dispone de entradas de luz natural). Con esto, se pretendió simular la presencia de humo o una posible falta de alimentación eléctrica que conlleva la pérdida de visibilidad dentro del compartimento. Se estableció el mismo tiempo de espera inicial de 10 segundos para todos los ocupantes. Los resultados se pueden observar en la Tabla 3-9.

De la experimentación real se pueden extraer dos conclusiones: 
- Se puede considerar que el modelo de simulación realizado en el Pathfinder queda validado en el sentido de ser una aproximación adecuada al marco experimental del problema.

- La evacuación a ciegas resultó sorprendentemente fluida y rápida. Los experimentos a ciegas fueron los últimos en realizarse $y$, probablemente, eso contribuyó de forma considerable a la mejora de la orientación de los ocupantes. Esto, se juzga que pudiera ser una aproximación razonable a la realidad de un buque de guerra, pues el personal del destino del $\mathrm{CIC}$ conoce el compartimento y está perfectamente adiestrado en la evacuación del compartimento.

\subsubsection{Jerarquización de las Alternativas}

Con los promedios de los tiempos obtenidos en la simulación con en el software, se procedió a resolver un nuevo problema multicriterio denominado "objetivo". Sobre el programa ADLA, se sustituyeron las valoraciones de las contribuciones de las alternativas al subcriterio de Evacuación, que habían enjuiciado subjetivamente los expertos mediante matrices de comparación por parejas, por los tiempos de evacuación de las tres disposiciones calculados en el Pathfinder.

\section{Subcriterio Evacuación}

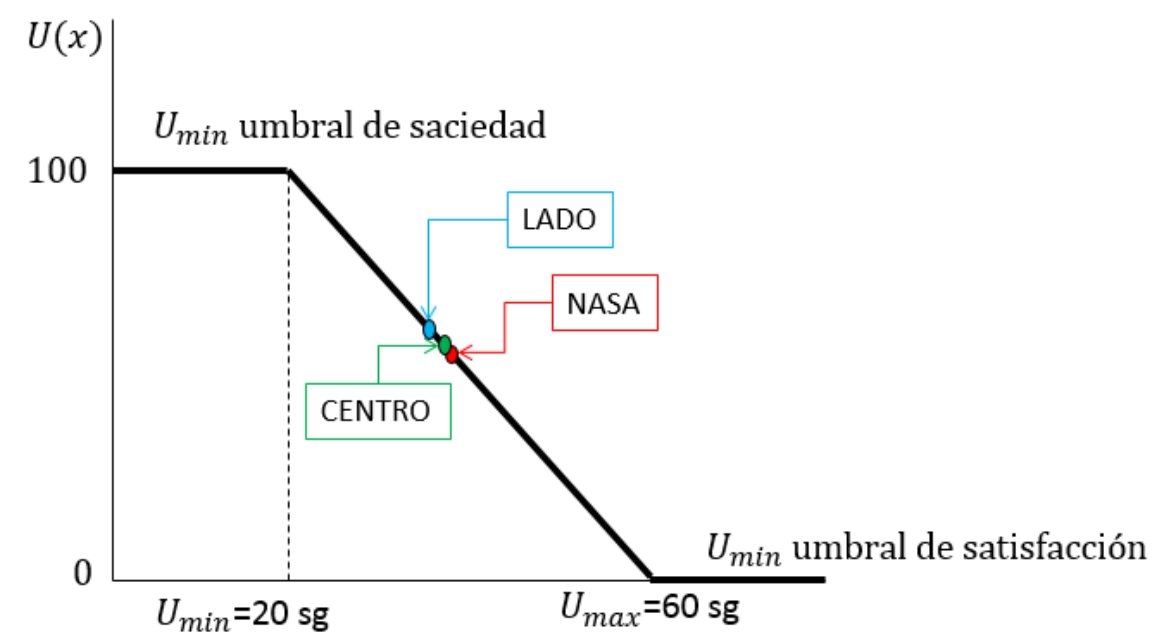

Figura 3-35 Utilidad del subcriterio de Evacuación basado en una función de utilidad. (Elaboración propia)

Estos tiempos se agregaron valiéndose de una función de utilidad (Figura 3-35). 
La función seleccionada ha sido una función lineal en la que, consensuado con los expertos, el $100 \%$ de utilidad se determinado para tiempos de evacuación por debajo de 20 segundos (se estimó que no se producirían apenas bajas en ese tiempo de evacuación y un tiempo menor no sería factible), y el $0 \%$ de utilidad se determinó para tiempos superiores a los 60 segundos (más de un minuto de tiempo en la evacuación fue considerado como inaceptable por el previsible alto porcentaje de bajas que se produciría). Estos tiempos están basados en datos reales que maneja la Armada, y que por ser confidenciales se han modificado.

\section{$\underline{\text { Resolución en programa ADLA }}$}

Los resultados obtenidos de la valoración de las alternativas con la nueva metodología se pueden observar en la Figura 3-36, en la que se aprecia que la alternativa NASA ha vuelto a resultar la mejor valorada con un $44,75 \%$.

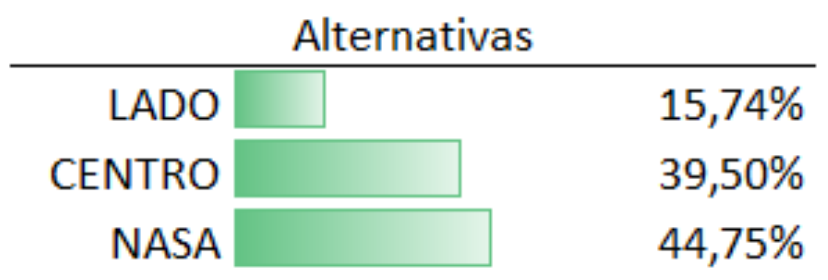

Figura 3-36 Valoración global de los CIC con el multicriterio objetivo (Elaboración propia)

En la Tabla 3-10, se visualizan los cálculos intermedios realizados para evaluar la valoración final de las alternativas. En la primera fila de la tabla aparecen los criterios con sus pesos que, lógicamente, no varían respecto al multicriterio subjetivo. En las columnas, debajo de los criterios, aparecen los porcentajes con los que cada criterio contribuye a las distintas alternativas. Se puede observar que el criterio MANDO Y CONTROL, puesto que no se ha modificado, contribuye exactamente igual que en el multicriterio subjetivo. Por contra, la contribución del criterio MOVILIDAD Y ACCESIBILIDAD ha variado respecto a las alternativas, y la alternativa NASA se ha visto reforzada alcanzando una contribución más alta, ahora del 26,22\% (en el multicriterio subjetivo era del $17,22 \%)$. 


\begin{tabular}{|c|c|c|}
\cline { 2 - 3 } \multicolumn{1}{c|}{} & MANDO Y CONTROL (87,5\%) & MOVILIDAD Y ACCESIBILIDAD (12,5\%) \\
\hline LADO (15,74\%) & $11,45 \%$ & $45,78 \%$ \\
\hline CENTRO $(39,5 \%)$ & $41,15 \%$ & $28,00 \%$ \\
\hline NASA $(44,75 \%)$ & $47,40 \%$ & $26,22 \%$ \\
\hline
\end{tabular}

Tabla 3-10 Matriz decisional multicriterio objetivo (Elaboración propia)

Sobre la Figura 3-37 se puede observar de forma gráfica las contribuciones de la matriz decisional del multicriterio objetivo.

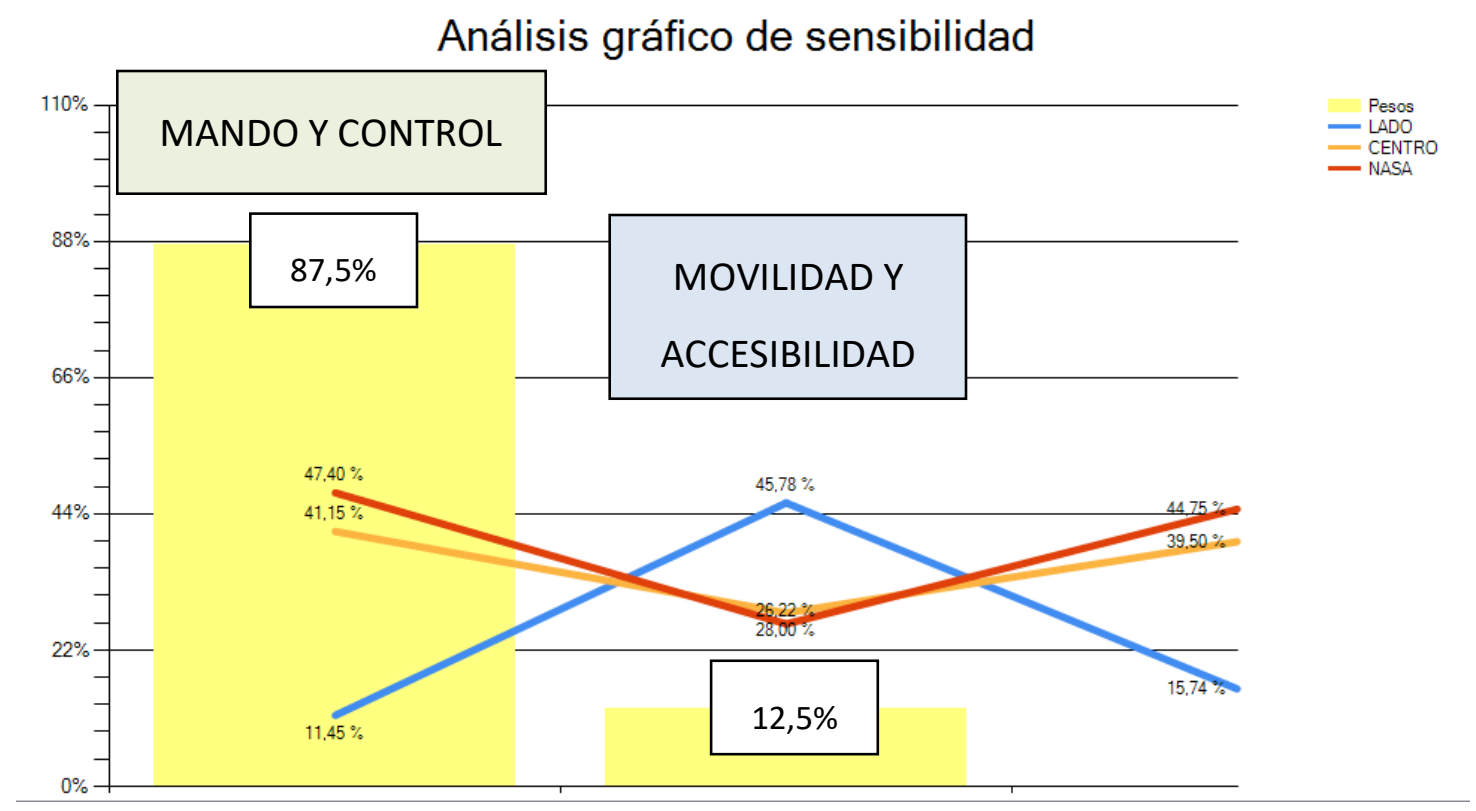

Figura 3-37 Gráfica de análisis gráfico de sensibilidad, resultado del multicriterio objetivo (ADLA)

\subsubsection{Análisis de Sensibilidad y Robustez}

Sobre la Figura 3-38 se exponen los resultados de los pesos asignados al criterio de MANDO Y CONTROL $(87,5 \%)$ y al criterio de MOVILIDAD Y ACCESIBILIDAD (12,5\%), sobre el gráfico de barras (azul), y las valoraciones de las alternativas sobre el otro gráfico de barras (naranja). 


\section{Análisis dinámico de sensibilidad}
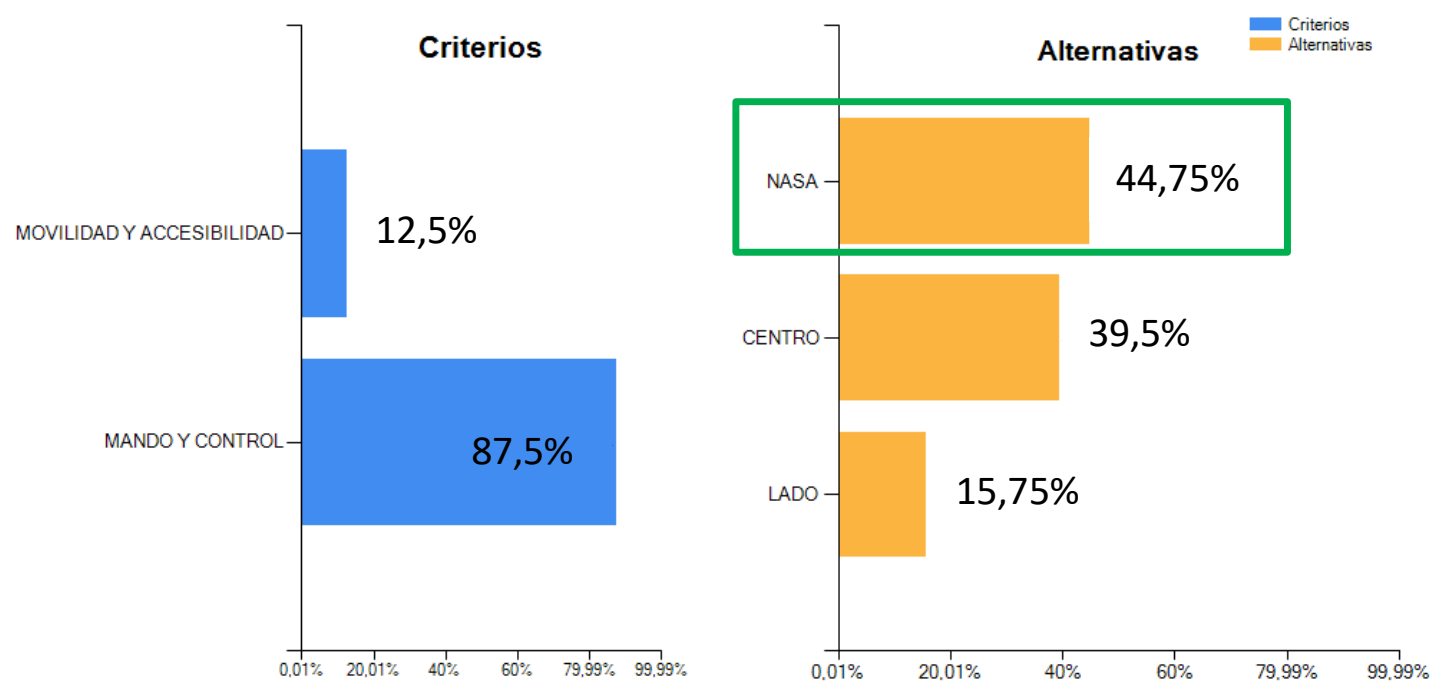

Figura 3-38 Gráfica de barras para el análisis dinámico de sensibilidad que se ha obtenido como resultado del multicriterio objetivo (ADLA)

Sobre la Figura 3-39 se puede observar el gráfico del análisis dinámico de sensibilidad que proporciona ADLA, esta señala que para que se produjese un cambio en el resultado final, es decir, en la valoración final de las alternativas, el decisor tendría que cambiar los pesos asignados a los criterios en más de un 52\% a favor del criterio de MOVILIDAD Y ACCESIBILIDAD, en ese caso, la alternativa elegida sería la disposición tipo LADO, por un escaso margen de 1 punto respecto a CENTRO. Por tanto, se puede afirmar que el resultado del multicriterio objetivo es mucho más robusto que el del multicriterio subjetivo. 


\section{Análisis dinámico de sensibilidad}

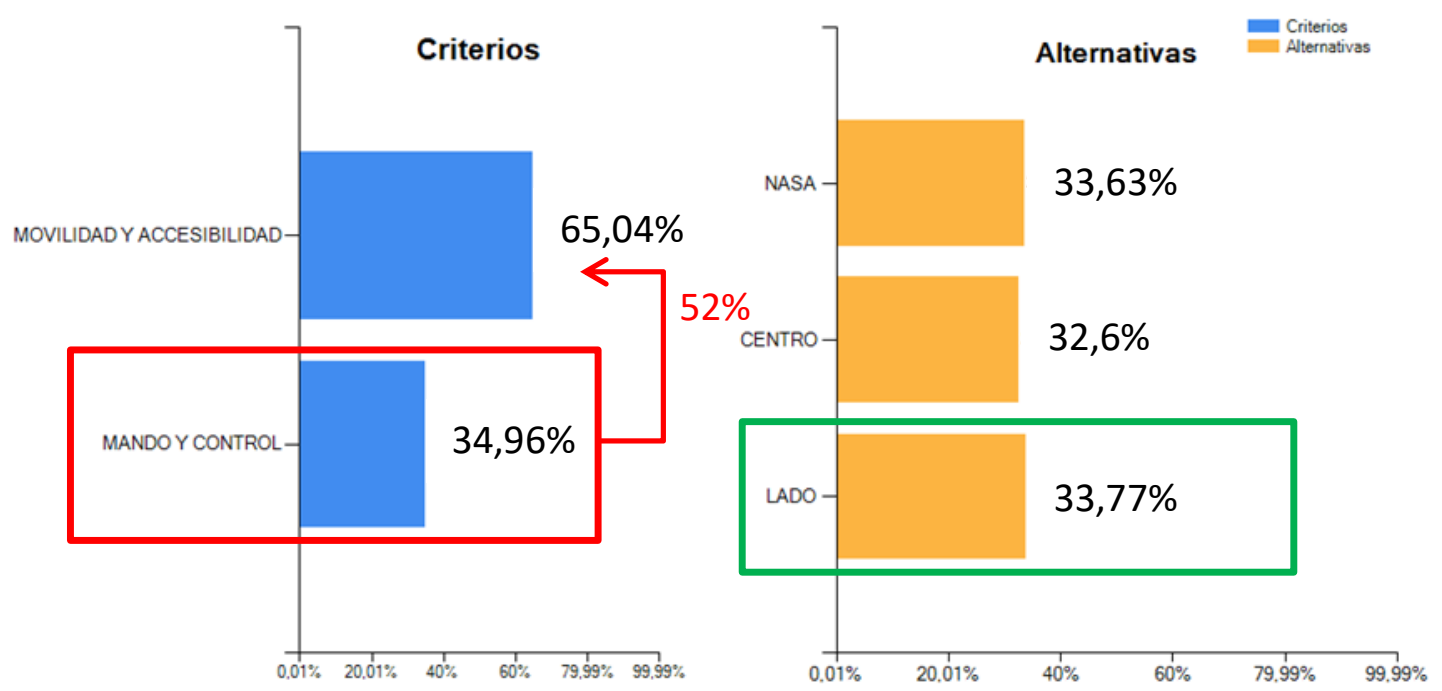

Figura 3-39 Gráfica de reasignación de pesos para conmutación de alternativas. La flecha y la cifra en rojo indican el \% en que ha sido necesario disminuir el peso del criterio de Mando y Control para que se produzca la conmutación en el resultado de NASA a LADO (barras naranjas) (ADLA)

En el multicriterio objetivo la alternativa tipo CENTRO, independientemente de los cambios de pesos a los criterios, no saldría elegida nunca. Para que pudiese ser elegida sería necesario un cambio en las matrices de valoración de las alternativas para los subcriterios.

\subsubsection{Análisis Comparativo}

En el comienzo del análisis comparativo entre el multicriterio subjetivo y el objetivo, se debe destacar que, en ambos multicriterios resultó mejor valorada la alternativa NASA; en el multicriterio subjetivo por 3,4 puntos respecto a la alternativa CENTRO y en el multicriterio objetivo por 6,2 puntos, también, respecto a la alternativa CENTRO.

Como factor diferencial entre uno y otro resultado destaca primordialmente la robustez de la decisión. Si bien, el multicriterio subjetivo resultó bastante robusto, al aplicar la objetividad de los tiempos de evacuación, la decisión, resultado del multicriterio objetivo, se podría calificar de inapelable (ver Figura 3-40). 

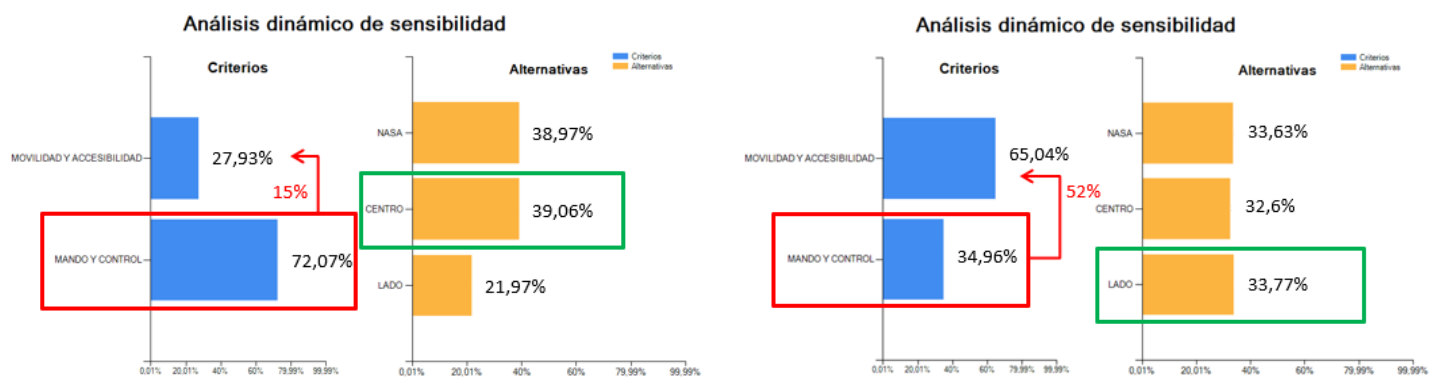

Figura 3-40 Gráficas de reasignación de pesos para conmutación de alternativas. A la izquierda el multicriterio subjetivo (variación de opinión del 15\%), a la derecha el multicriterio objetivo (variación de opinión del 52\%)

(ADLA)

\subsubsection{Conclusiones de los Resultados y Líneas Futuras}

Este trabajo ha sido la primera puesta en práctica de la nueva metodología ideada en esta tesis. Se considera que ha resultado una buena contribución a los objetivos principal y secundarios que se persiguen en la tesis, pues ha aportado una valiosa ayuda a la decisión del EMA acerca de la mejor disposición del CIC de las fragatas F-110 y, a su vez, ha rebajado la subjetividad en los problemas de decisión multicriterio y ha permitido el empleo de un software en la simulación de las contribuciones de las alternativas a un subcriterio.

De las alternativas que se consideraron a estudio se ha determinado que, a la vista de los criterios y juicios aportados por los expertos y de la contribución de la nueva metodología, la mejor disposición es la denominada tipo NASA.

El proceso de trabajo se realizó conforme a la metodología planteada en esta tesis que se puede resumir en las siguientes fases:

- Fase 1. Representación del Problema. Se ha modelado, en colaboración con los expertos del EMA, una estructura jerárquica de criterios de evaluación en la que han quedado representados todos los aspectos considerados relevantes en el proceso de la decisión. Se han definido los criterios y las alternativas.

- Fase 2. Evaluación de los criterios y alternativas. Inicialmente, con el objetivo de realizar una comparativa entre las dos metodologías, se aplicó la metodología AHP clásica completa. Conforme a los juicios subjetivos de los expertos, se valoraron las denominadas matrices de comparación por pares asignando pesos 
a los criterios. Se priorizaron las alternativas y se efectuó un análisis de sensibilidad para valorar la robustez de la decisión.

- Fase 3. Contribución de las alternativas. Con el propósito de aplicar objetividad al multicriterio subjetivo del paso anterior, sobre el subcriterio Evacuación, se ha realizado un Diseño Estadístico de Experimentos (DEE) y una simulación mediante ordenador para investigar la influencia de las tres alternativas (LADO, CENTRO, NASA) sobre la variable "tiempo de evacuación". Se validaron los datos de la simulación mediante una experimentación real.

- Fase 4. Jerarquización de las alternativas. Se incorporaron los datos obtenidos en la simulación a un nuevo problema de decisión multicriterio que se ha denominado "objetivo", se obtuvo el resultado de la alternativa NASA como mejor valorada.

- Fase 5. Análisis de sensibilidad. Si bien es cierto que la reducción de subjetividad del problema tan solo alcanza un 5\% del mismo, el análisis de sensibilidad sobre el problema "objetivo", demuestra que la resolución del problema ahora es mucho más robusta.

Como ya se había mencionado en el punto $\underline{3.1}$, las fases del proceso de toma de decisiones forman un ciclo cerrado, pues en la mayoría de los procesos reales de decisión el proceso no concluye, sino que se realimenta e invita a una reconsideración de todos los elementos decisionales. Por ello, como líneas futuras que pudieran tener interés en el análisis y repercusión en otros futuros buques o para modificaciones de los actuales, se propuso seguir investigando otros aspectos definidos en los subcriterios que fuesen susceptibles de ser valorados objetivamente. Se plantearon fundamentalmente líneas futuras que están recogidas en la propuesta del punto $\underline{3.2 .3}$ (Estudio 2); son las siguientes:

- Con la finalidad de conocer el impacto de la disposición de las consolas en el Mando y Control, la "Situational awareness", la Diseminación y Presentación de la información, las comunicaciones entre los diferentes puestos operativos, etc., se podría virtualizar el CIC mediante ordenadores del tipo PC simulando las distintas consolas. Sobre estas, mediante una aplicación elaborada ad hoc, realizar experimentos con personal real que ocupe los puestos. 
Para efectuar esta virtualización, y permitir adoptar las distintas posibles configuraciones sería necesario disponer de un local con dimensiones similares al CIC de las fragatas F-110. La aplicación debería poder monitorizar las comunicaciones entre puestos, ordenar acciones a diferentes puestos, ejecutar estas acciones y almacenar una serie de datos que serían analizados posteriormente mediante estudios estadísticos.

- Realizar nuevas simulaciones mediante software para valorar cómo es el comportamiento de las alternativas para los subcriterios de:

- Libertad de movimiento en operación.

- Libertad de movimiento en relevos.

- Mediante una encuesta ampliar la población de expertos que puedan aportar ideas, sugerencias y permitir así abrir nuevas líneas de investigación en relación con las disposiciones de consolas y equipos del $\mathrm{CIC}$. 


\subsection{Estudio de la Decisión del Comedor Óptimo en la Fragata F-110}

En este punto, primero se explicará brevemente qué es y cómo se organiza el comedor de dotación (o marinería) en un buque de guerra y, posteriormente, se mostrará cómo se aplicó la metodología ideada en esta tesis al problema de decisión del EMA acerca de: ¿Cuál comedor de marinería está mejor diseñado para permitir un flujo fluido de personal durante las comidas?

\section{El Comedor de Dotación [162]}

La vida a bordo de un buque de guerra no es cómoda. Largos períodos de tiempo navegando, condiciones meteorológicas adversas, jornadas de trabajo de más de 12 horas, alejado de la familia y amigos, etc., todo esto, no lo convierte en un sitio idílico. Las condiciones de vida en un barco de guerra implican todo tipo de privaciones y es entonces, bajo esas intrínsecas circunstancias del transcurrir diario, cuando las necesidades y hábitos más cotidianos del ser humano adquieren otra dimensión en importancia. La comida en un buque de guerra no es un asunto menor en absoluto. El comedor de dotación no descansa y su batalla diaria es dar de comer y tratar de contentar a toda la dotación.

El servicio de aprovisionamiento dirige la obtención y distribución interior de los pertrechos, víveres y efectos de consumo (ver organigrama de Figura 3-41). Regenta el almacenamiento y control de todos los repuestos. Es responsable de la habitabilidad, elaboración de comidas y policía de cocinas y comedores. Le corresponde la preparación y el adiestramiento de pañoles de respetos, cocineros, despenseros, rancheros, reposteros y lavanderos. 


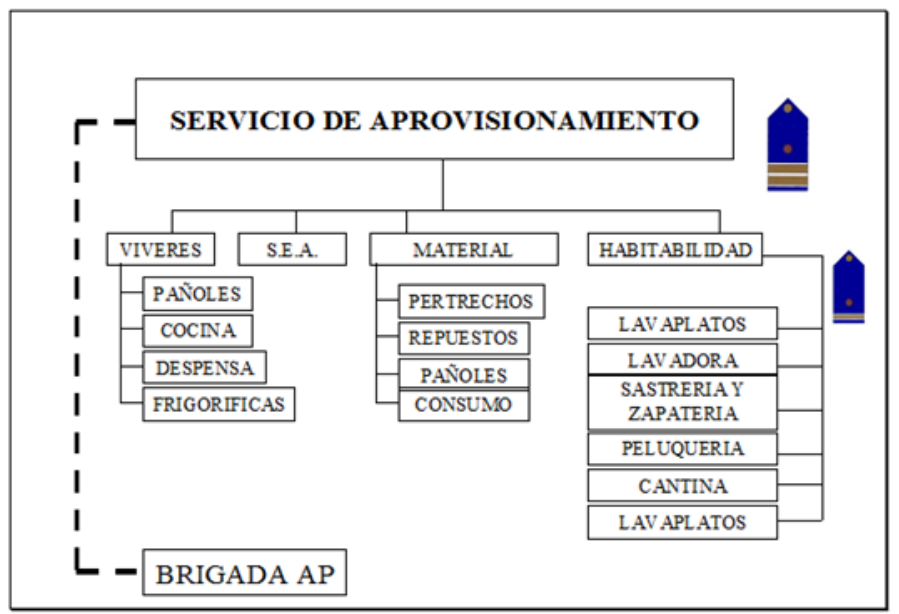

Figura 3-41 Servicio de aprovisionamiento (Organigrama extraído de [81])

De las tres comidas habituales que se reparten en el comedor: desayuno, comida y cena (a partir de aquí se denominarán así); por experiencia, se sabe que la hora de la comida es cuando se produce la mayor "tasa de afluencia" (está constatado que hay más personal que, regularmente, no acude a los desayunos y/o cenas), además, el tiempo de permanencia en el comedor durante la ingesta de la comida también es el mayor. Por ello, aunque se realizó un análisis del comportamiento en las tres comidas, este trabajo se centró en el estudio del comedor durante el horario de la comida (ver Figura 3-42).

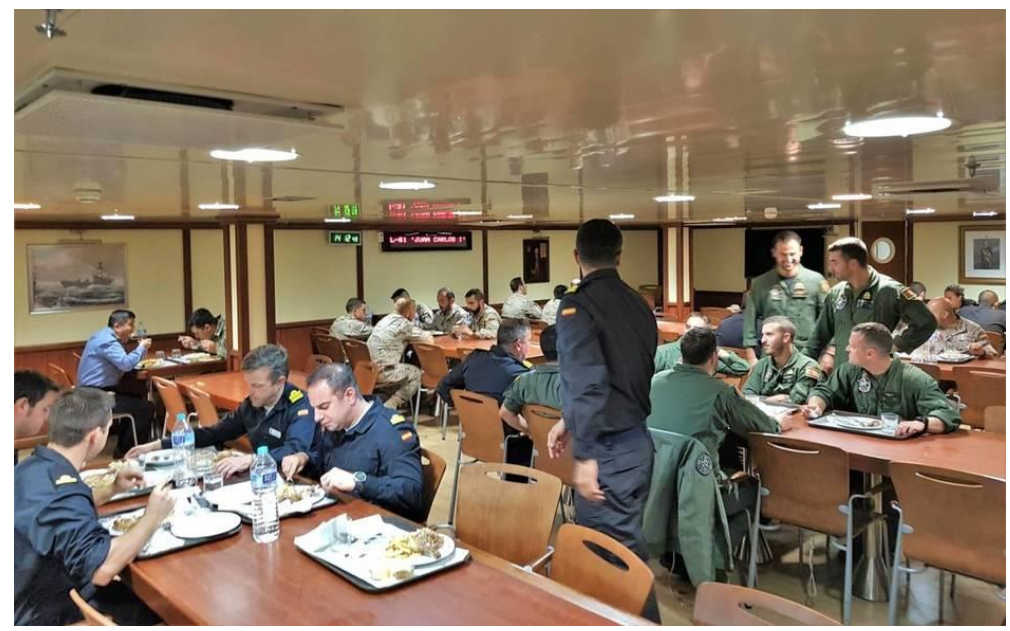

Figura 3-42 Comedor de oficiales a bordo del Juan Carlos I durante el reparto de la comida (Foto: Juanjo Fernández)

La capacidad del comedor no permite comer a la vez a toda la dotación, por lo que hay turnos establecidos y, a pesar de ello, a veces hay que hacer cola. La organización del buque a tres vigilancias (grado de alistamiento habitual en navegación) supone que aproximadamente $1 / 3$ de la dotación del buque está de guardia y los 2/3 restantes están 
en otras tareas (trabajos, descanso, comidas, etc.). Esta organización implica que, en el primer turno de comida que comienza a las 13:00 horas, al comedor de dotación acudan 2/3 de la marinería; en el caso de la fragata F-110 supondrán aproximadamente 60 personas.

\subsubsection{Representación del Problema y Selección de Criterios}

Para la elaboración del multicriterio que diese respuesta a las cuestiones planteadas por la Sección de Planes de Definición de Capacidades de la División de Planes del EMA se requirió la colaboración de oficiales de Intendencia de la Armada con amplia experiencia de embarque en fragatas desempeñando la Jefatura del Servicio de Aprovisionamiento. Como ya se ha comentado en el punto anterior, esta Jefatura incluye el destino encargado de la gestión de cocina y comedores.

En una reunión inicial se les explicó a los expertos el método del proceso de análisis jerárquico (AHP), en el que se requería la descomposición del problema en una estructura jerárquica con al menos tres niveles básicos (objetivo, criterios y alternativas) y de esta manera se conseguiría una visión general del problema.

Se concluyó que el objetivo era escoger el comedor de marinería "óptimo" que diese una mejor respuesta a las cuestiones y dudas que se planteaba el EMA: ¿Está el comedor de marinería bien diseñado para permitir un flujo fluido de personal durante las comidas? ¿Se puede estimar el tiempo de espera en cola y cuánto tiempo tardaría un turno en comer? En determinadas misiones que desarrollará el barco el aumento de dotación previsto es de 18 personas ¿el flujo seguirá siendo fluido? ¿Qué grado de organización de la cocina-comedor-lavaplatos es el mejor?

Como hipótesis del problema se plantearon los siguientes puntos:

- El conjunto de cocina y comedor debe permitir una manipulación higiénica correcta de alimentos.

- La disposición de equipos de la cocina y comedor debe evitar los cruces de productos (materias primas, productos cocinados y basuras).

- Se debe observar la adecuada ubicación de las cámaras frigoríficas y de la panadería. 
- Los accesos deben ser apropiados para generar la mayor fluidez de entrada y salida.

- La distribución, número de asientos, mesas y mesas calientes de reparto debe ser suficiente para proporcionar los servicios de comidas sin grandes tiempos de espera.

\subsubsection{Las Alternativas}

Es necesario añadir, que en el momento de la realización de este trabajo al astillero Navantia le urgía la respuesta, puesto que la elección de una u otra alternativa implica la remodelación y rediseño de otros compartimentos adyacentes, lo cual, genera muchas horas de ingeniería.

Para el problema de la decisión el astillero definió las tres alternativas factibles con las siguientes denominaciones:

- Comedor versión 4 Optimizado (Alt4Opt)

- Comedor versión 5 (Alt5)

- Comedor versión 6 (Alt6)

\subsection{Alternativa 4 Optimizada}

Este comedor de marinería se sitúa sobre la segunda cubierta (recuadro en rojo en Figura 3-43), el comedor de suboficiales es adyacente. El comedor de oficiales está situado en la cubierta superior y dispone de un montaplatos que comunica la cocina y la repostería de oficiales (cuadrado azul). Dispone de un pañol de provisiones de uso diario. La línea de autoservicio está frente a la entrada del comedor y dispone de una ventana de acceso directo al lavaplatos. Dispone de zona de basura con tres contenedores. Esta disposición permite dos formas de dejar las bandejas sucias en los comedores de suboficiales y marinería, por medio de los bandejeros situados en cada comedor o por las ventanas de servicio directamente al área del lavaplatos. El local de la panadería es independiente. Dispone de 62 asientos, una única vía de acceso (flecha verde) y su tamaño aproximado es de $73 \mathrm{~m}^{2}$. 


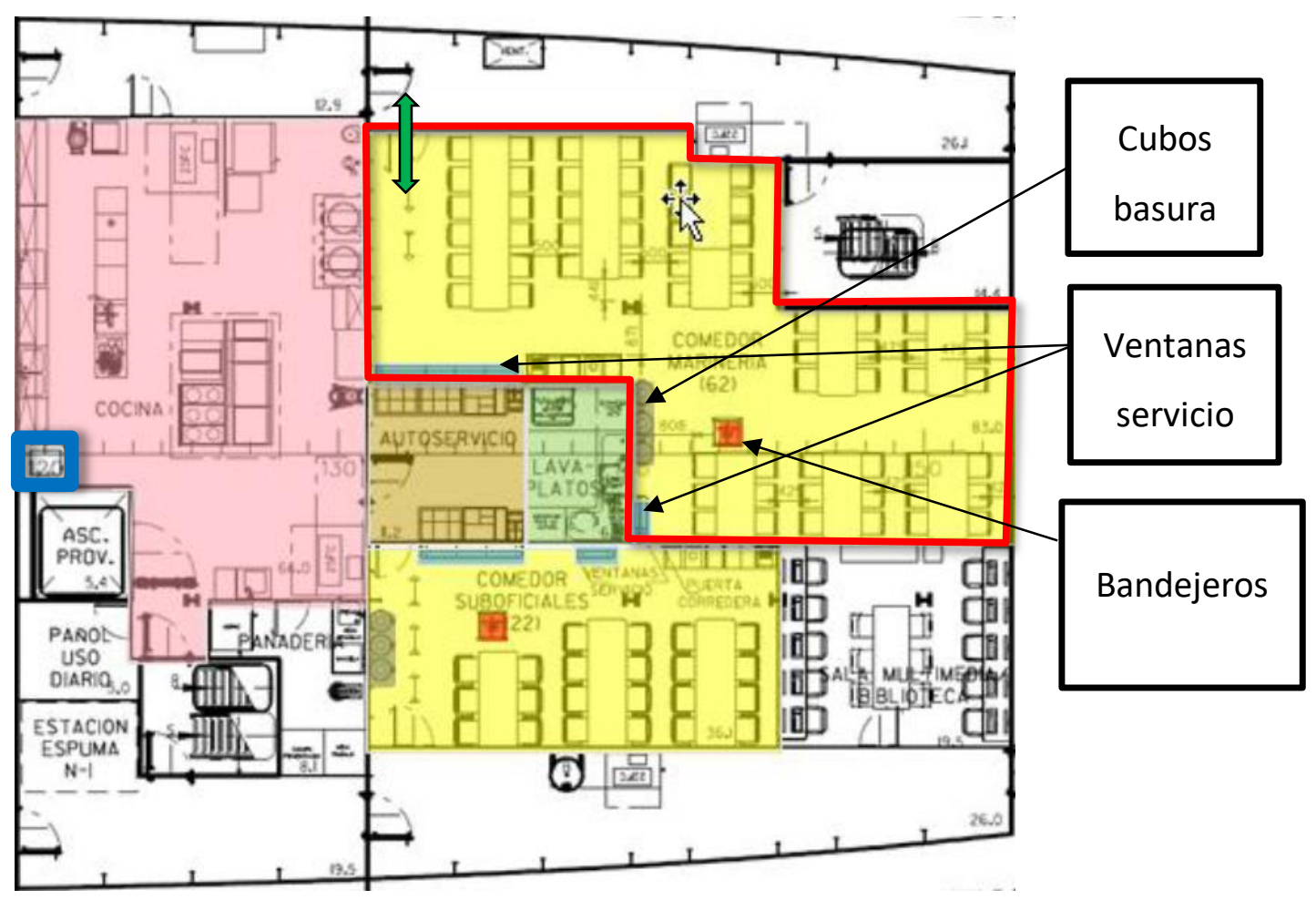

Figura 3-43 Alternativa 4 Optimizada (Navantia)

\subsection{Alternativa 5}

También este comedor de marinería se sitúa sobre la segunda cubierta (recuadro en rojo en Figura 3-44). Adyacente, está el comedor de suboficiales y, a este, el de oficiales. No dispone de pañol de provisiones de uso diario dentro del área de cocina. Dispone de zona de basura con tres contenedores. Solo permite dejar las bandejas sucias en los bandejeros situados en cada comedor. El paso de los bandejeros sucios es a través del área de autoservicio o a través de los pasillos situados a cada banda. La panadería es un espacio unificado con la cocina. Dispone de 64 asientos, una única vía de acceso, que en este caso es a través de un tronco que da servicio a varias cubiertas. Su tamaño aproximado es de $75 \mathrm{~m}^{2}$. 


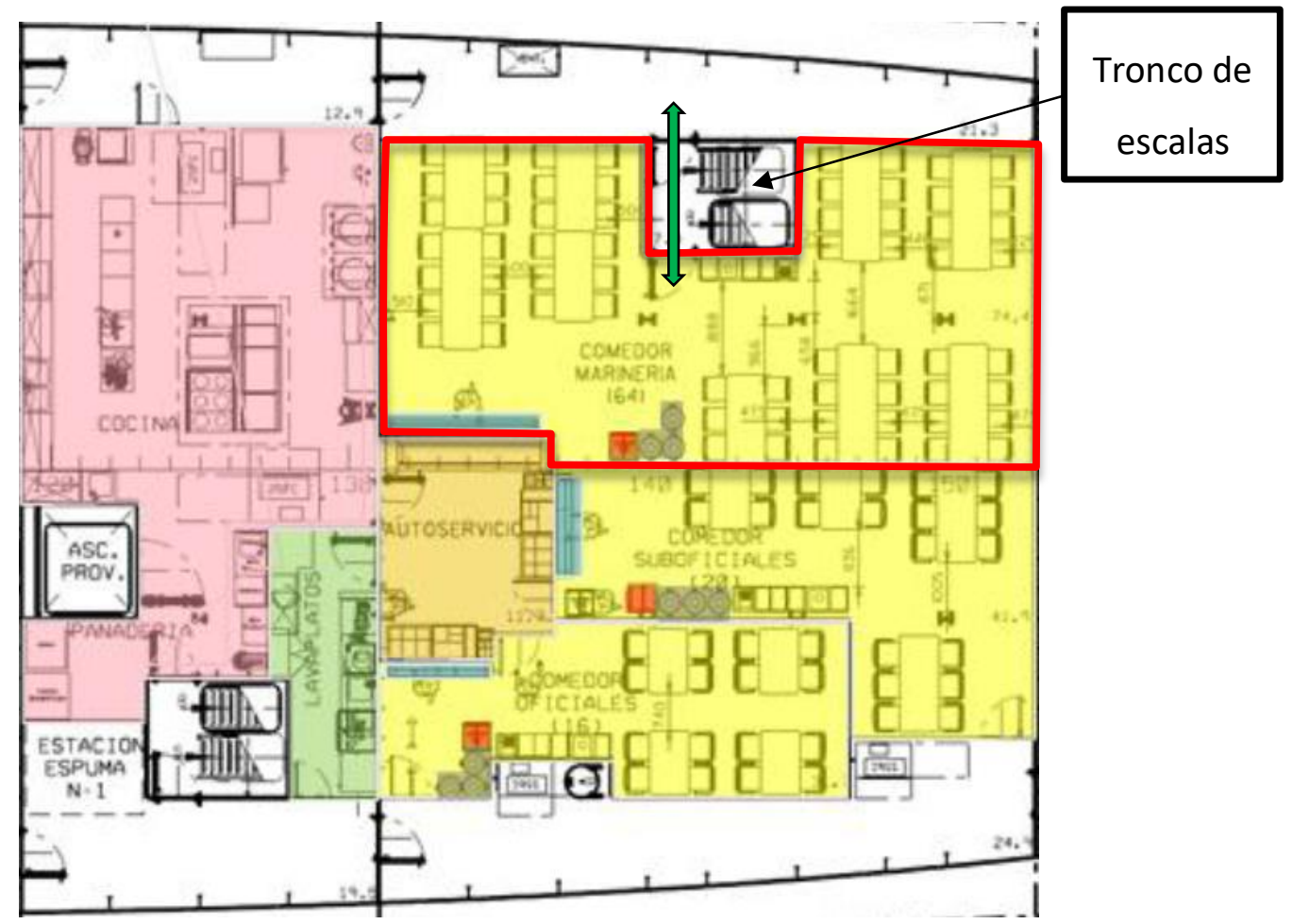

Figura 3-44 Alternativa 5 (Navantia)

\subsection{Alternativa 6}

Este comedor de marinería también se sitúa sobre la segunda cubierta (recuadro en rojo en Figura 3-45), con el comedor de suboficiales adyacente. No dispone de pañol de provisiones de uso diario dentro del área de cocina. Dispone de zona de basura con tres contenedores. El paso de los bandejeros sucios es a través del área de autoservicio o a través de los pasillos situados a cada banda. La panadería es un espacio unificado con la cocina. Dispone de 62 asientos, dos vías de acceso (flechas verdes), y su tamaño aproximado es de $68 \mathrm{~m}^{2}$. 


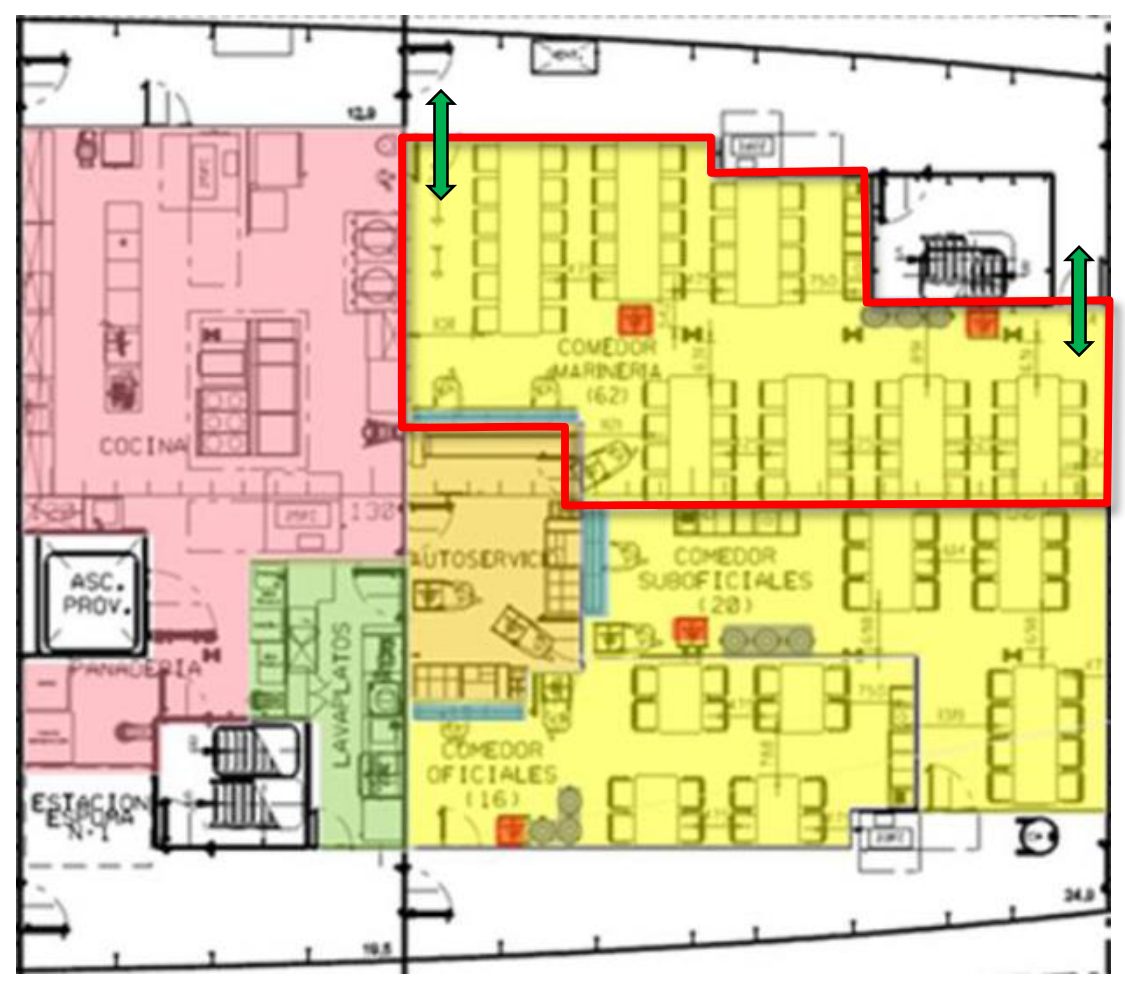

Figura 3-45 Alternativa 6 (Navantia)

\subsubsection{Definición de Criterios}

En la reunión con los expertos y empleando como referencia las cuestiones y las alternativas expuestas, se confeccionó el problema de decisión que se observa en la Figura 3-46.

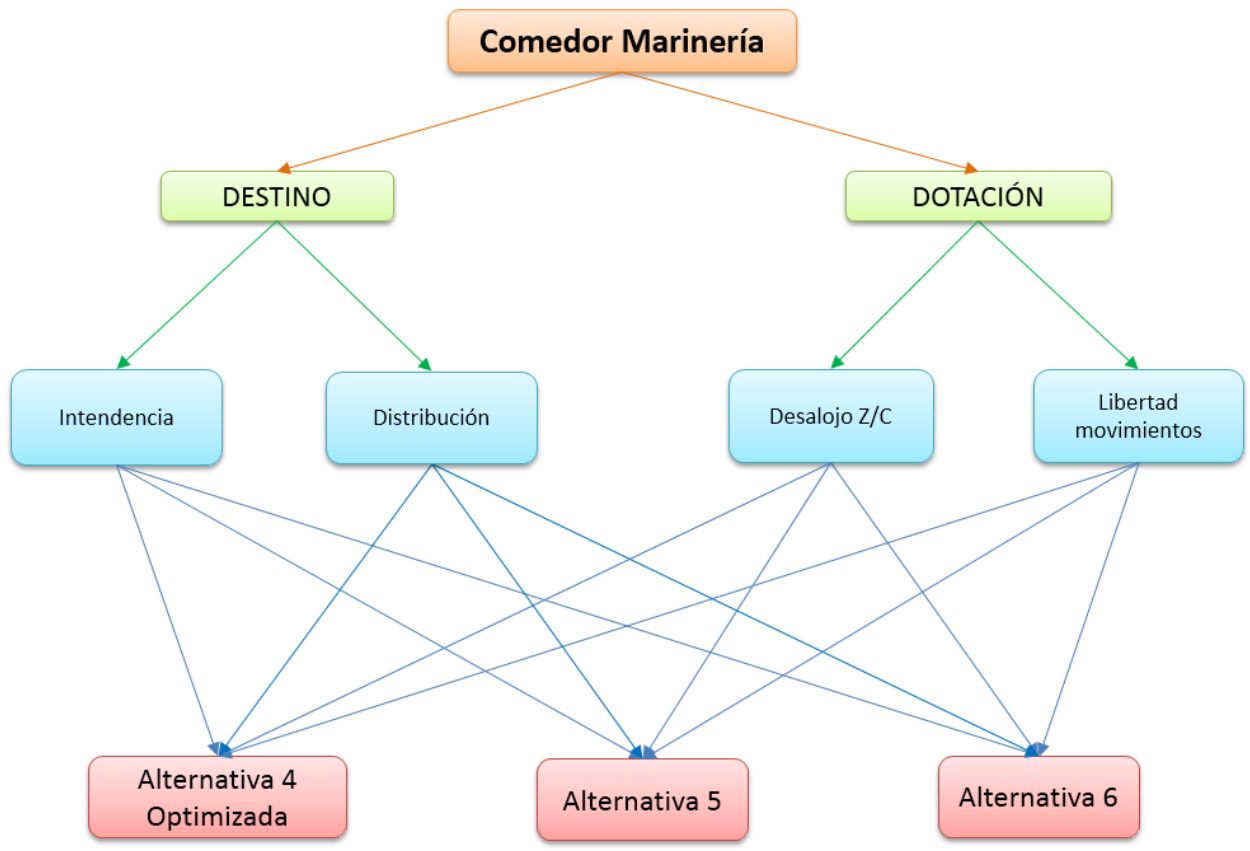

Figura 3-46 Modelo AHP confeccionado con los expertos para el problema del comedor (Elaboración propia) 
El modelo definido por los expertos contempló:

- 2 criterios

- 4 subcriterios

- 3 alternativas

Este modelo genera un total de tres MCP para la asignación de pesos de evaluación a los criterios y subcriterios y cuatro MCP para valorar las contribuciones de las alternativas a los diferentes criterios, de las cuales, dos se resolvieron mediante MCP y otras dos se sustituyeron por funciones de utilidad.

Previo al relleno de las matrices de comparación, y con el objetivo de poder servirse de este modelo con otros expertos ajenos a este modelo, se hizo una breve descripción de qué significado tienen los criterios y subcriterios.

\section{Criterio DESTINO}

Este criterio se abordó desde la perspectiva del personal del servicio de aprovisionamiento con destino en la cocina y el comedor (cocineros y reposteros), se divide en dos subcriterios:

- Subcriterio Intendencia. Comprende todos los aspectos relacionados con el funcionamiento de la cocina, la mesa caliente, el lavaplatos y la panadería como, por ejemplo:

- Transporte de alimentos entre refrigerador, congelador o pañol de víveres de forma ordenada y sin mezclar los productos que serán cocinados de los que se servirán sin cocinar.

- Preparación de forma higiénica de alimentos.

- Dimensiones y diseño de cocina que permitan unas adecuadas prácticas de manipulación, de forma que no se produzcan contaminaciones cruzadas entre alimentos.

- Transporte de comida de consumo desde la cocina hasta la línea de servicio.

- Evitar cruces de productos (materias primas, productos cocinados y basuras). 
- Limpieza de los recipientes y útiles de trabajo (lavavajillas) al finalizar su cometido y/o antes de ser utilizados de nuevo.

- Panadería debidamente aislada que evite alteraciones en el producto.

- Subcriterio Distribución. Comprende todos los aspectos relacionados con la prestación de un servicio en un comedor colectivo como, por ejemplo:

- Puntos de recogida de los desperdicios generados durante el servicio de comida en cubos de basura apropiados.

- Facilidad de transporte de bandejas al lavaplatos.

- Limpieza del compartimento.

\section{Criterio DOTACIÓN}

Este criterio se abordó desde la perspectiva del usuario del comedor, se divide en dos subcriterios (Esta parte del problema de decisión se afrontó aplicando la nueva metodología tratando de aportar al criterio Dotación el 100\% de objetividad):

- Subcriterio Desalojo Z/C. Comprende el supuesto en el que el comedor de marinería se encontrase al $100 \%$ de ocupación y se tocase Zafarrancho de Combate. Trata de dar respuesta a ¿Cuál comedor desaloja al personal en el menor tiempo?

- Subcriterio Libertad de movimientos. Este subcriterio trata de dar respuesta a ¿Cuánto tiempo es la espera en la cola? ¿Cuál es el comedor menos congestionado? ¿En cuánto tiempo se consigue prestar el servicio de comida a toda la marinería?

3.3.2. Evaluación de los Criterios. Evaluación Subjetiva de las Alternativas

Se elaboró una tabla de Excel con las tres matrices, y se envió a los expertos para su relleno conforme a la escala de Saaty que, por sencillez, se restringió a los números impares. Se les solicitó que el relleno fuese independiente (Figura 3-47). 

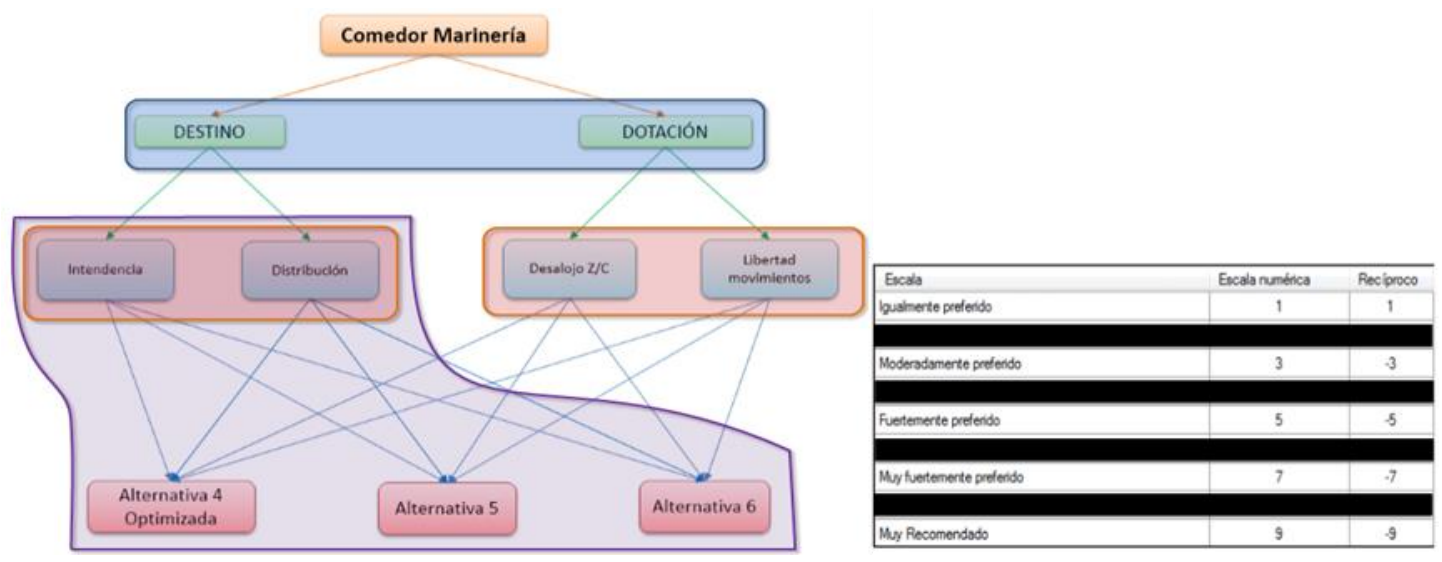

Figura 3-47 Diagrama de matrices y escala de Saaty (Elaboración propia)

Los expertos, a la hora de enjuiciar las matrices, dispusieron de los planos de comedor facilitados por el astillero (Figura 3-43, Figura 3-44 y Figura 3-45) y de las definiciones de criterios del punto 3.3.1.2. Estas referencias son necesarias para hacerse una composición de lugar, poder evaluar y decidir en las comparativas entre criterios y alternativas.

\subsubsection{Asignación de Pesos a los Criterios}

Las matrices con las respuestas consolidadas se pueden ver sobre la Tabla 3-11.

\begin{tabular}{|r|c|c|}
\hline Matriz 1: Criterios & DESTINO & DOTACION \\
\hline DESTINO & & $\mathbf{3}$ \\
\hline DOTACION & & \\
\hline
\end{tabular}

\begin{tabular}{|r|c|c|}
\hline Matriz 2: DESTINO & Intendencia & Distribución \\
\hline Intendencia & & 5 \\
\hline Distribución & & \\
\hline
\end{tabular}

\begin{tabular}{|r|c|c|}
\hline Matriz 3: DOTACION & Desalojo Z/C & Libertad Moviminentos \\
\hline Desalojo Z/C & & -3 \\
\hline Libertad Moviminentos & & \\
\hline
\end{tabular}

Tabla 3-11 Matrices consolidadas por los expertos para asignación de pesos

Se observa que el criterio DESTINO es moderadamente preferido sobre el criterio DOTACION. A su vez, dentro del criterio DESTINO lo referente al subcriterio Intendencia es fuertemente preferido respecto a Distribución. Dentro del criterio DOTACION, el subcriterio Libertad de Movimientos es moderadamente preferido al de Desalojo Z/C. 


\subsubsection{Evaluación Subjetiva de las Alternativas}

Las matrices consolidadas de respuesta a la contribución de las alternativas a los subcriterios de DESTINO se pueden observar en la Tabla 3-12.

\begin{tabular}{|r|c|c|c|}
\hline Matriz 4: Intendencia & Alt4 Opt & Alt 5 & Alt 6 \\
\hline Alt4 Opt & & -3 & -3 \\
\hline Alt 5 & & & 1 \\
\hline Alt 6 & & & \\
\hline
\end{tabular}

\begin{tabular}{|r|c|c|c|}
\hline Matriz 5: Distribución & Alt4 Opt & Alt 5 & Alt 6 \\
\hline Alt4 Opt & & 3 & 3 \\
\hline Alt 5 & & & 1 \\
\hline Alt 6 & & & \\
\hline
\end{tabular}

Tabla 3-12 MCP subjetivas para valoración de la contribución de las alternativas. Problema del comedor

Referente al subcriterio Intendencia los expertos prefieren por igual las Alt5 y Alt6. Vinculado al subcriterio Distribución, la Alt4Opt es moderadamente preferida, es decir, es la mejor valorada.

Hasta aquí, se han resuelto los pasos conforme a la metodología AHP clásica. En la siguiente fase es donde se emplean técnicas para reducir la subjetividad, valorando cómo contribuyen las alternativas a los subcriterios Desalojo Z/C y Libertad de Movimientos.

\subsubsection{Contribución de las Alternativas. Problema Objetivo}

En esta fase se explica cómo se tomaron las decisiones para realizar las simulaciones, la toma de datos, su tratamiento estadístico y el diseño de funciones de utilidad. Todo ello, para obtener la mayor objetividad en el cálculo de las contribuciones de las alternativas. Como ya se ha mencionado, esta fase es crítica por su transcendencia en los resultados del problema.

En un trabajo conjunto con los expertos se acordó realizar dos estudios:

- Estudio 1. Simulación con ordenador para determinar diferencias en los tiempos de evacuación del comedor.

Objeto: Modelar en ordenador el comedor de dotación de las fragatas F-110.

Técnicas: Simulación Montecarlo, Técnicas de muestreo y Análisis estadístico inferencial. 
Variables a analizar: Disposición de puertas de salida y tiempos de evacuación.

- Estudio 2. Simulación con ordenador para determinar diferencias en los tiempos de servicio del comedor.

Objeto: Representar en ordenador el funcionamiento del comedor durante el servicio de la Comida.

Técnicas: Simulación Montecarlo, Técnicas de muestreo y Análisis estadístico descriptivo e inferencial.

Variables a analizar: Tiempo de ocupación del comedor, tiempo empleado en comer, tiempo en la cola y velocidad de movimiento de los individuos dentro del comedor.

\subsubsection{La Evacuación del Comedor. Subcriterio Desalojo Z/C}

Para el análisis de las contribuciones de las alternativas al subcriterio de "Desalojo Z/C", se efectúa sobre el software de simulación de evacuaciones Pathfinder (ver punto 3.2.3.3.1), la medición de los tiempos que se tardaría en desalojar el comedor ante una orden de Zafarrancho de Combate, en el supuesto del 100\% de ocupación de asientos (Figura 3-48).

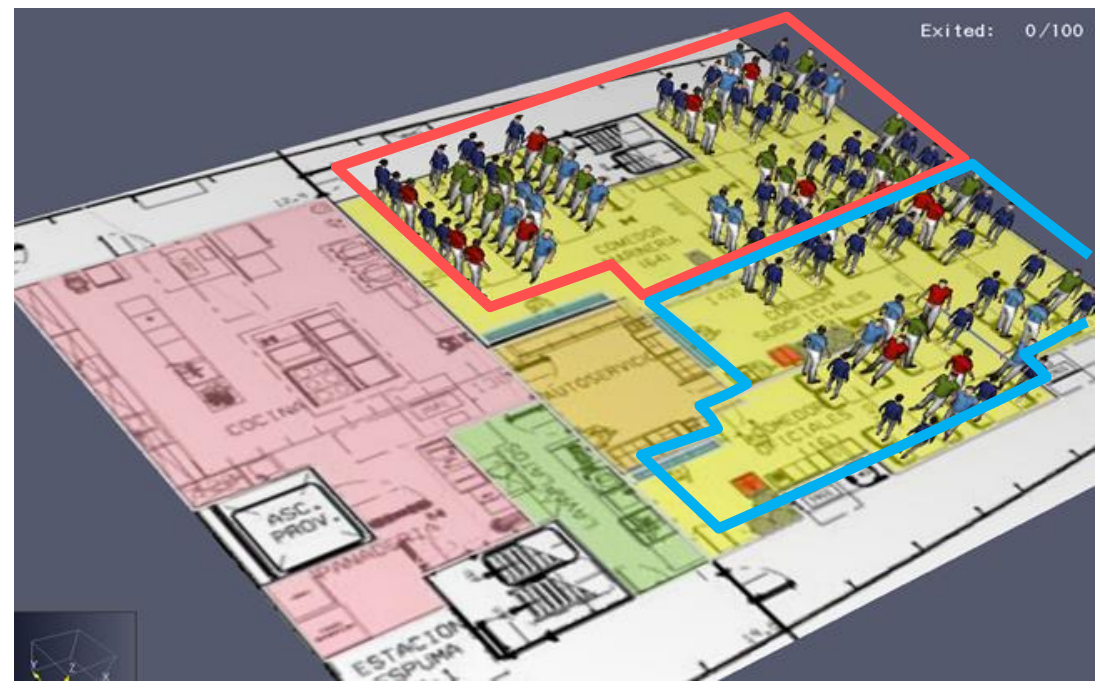

Figura 3-48 Imagen del comedor Alt5 con el 100\% de ocupación de asientos (recuadro rojo indica el perímetro). El comedor de oficiales y suboficiales (en estribor recuadro azul) también está completo, pero no ha sido objeto de este estudio.

El Z/C es el grado máximo de alistamiento del buque para combatir y requiere, de cada uno de los miembros de la dotación, la ocupación de un puesto en su compartimento 
asignado en el Plan de Combate. Esta orden, anunciada por "órdenes generales" (altavoces), obliga a dejar inmediatamente cualquier tarea o actividad y dirigirse en el menor tiempo posible a su puesto. En este estudio se empleó como referencia una aproximación del tiempo real que emplea un buque, tipo fragata, en que toda la dotación ocupe su puesto en $\mathrm{Z} / \mathrm{C}$ y da la novedad al Comandante, este fue de 3 minutos (por confidencialidad no se pueden mostrar los datos reales).

En todos los experimentos se utilizaron los mismos parámetros de comportamiento del personal durante el desalojo del comedor. El programa, como ya se ha comentado, admite varias configuraciones de comportamiento, no obstante, se escogió la configuración por defecto con excepción de la variable de velocidad de los individuos, el conocimiento de tiempo real de desalojo no estaba entre los objetivos que se perseguían con la simulación sino la comparativa entre alternativas.

El programa Pathfinder, también se ha comentado, es determinista en cuanto a resultados. Por ello, para darle la necesaria estocasticidad a los resultados, se configuró el siguiente comportamiento genérico de variables de entorno:

- Velocidad del personal: Distribución Uniforme, $U[2,04 ; 2,17] \mathrm{m} / \mathrm{s}$. Esta velocidad está basada en datos reales de medición de evacuación en buques de la Armada española.

- Door choice (variable que afecta únicamente a la Alternativa 6): Distribución Uniforme, $U[15 ; 100] \%$. Esta variable, como ya se comentó, mide el nivel de determinación de un individuo para dirigirse a la puerta más cercana o a otra, en caso de congestión (ver punto $\underline{3.2 .3 .3 .2}$ ).

- Initial delay: Distribución Uniforme,U[1; 5$]$ seg. Esta variable asigna a cada individuo un tiempo de retardo antes de comenzar el desalojo. Con este tiempo se simula la reacción del individuo al toque de Z/C, que consiste en escuchar la orden y proceder a su puesto.

Se procedió de la misma forma que en el experimento de evacuación del CIC tanto en la aleatoriedad como en el número de réplicas de cada simulación (ver A.2).

Se consideró que son de aplicación los mismos argumentos expuestos para los experimentos de evacuación del CIC y, por consiguiente, se consideró que la distribución 
Normal es la que mejor se ajustaba a los resultados de los tiempos obtenidos en esta simulación (ver punto $\underline{3.2 .3 .3 .2}$ ). No se realizaron pruebas de bondad de ajuste.

\subsection{Experimento Evacuación. Alternativa 4 Optimizada}

Sobre la Figura 3-49 se pueden observar las estadísticas descriptivas de los resultados obtenidos para la Alt4Opt. El comedor está en su máxima capacidad de personal sentado (62 personas). Este comedor dispone de una única puerta de acceso y salida, situada en popa babor. El promedio de tiempo en realizar el desalojo es de 63,79 segundos.

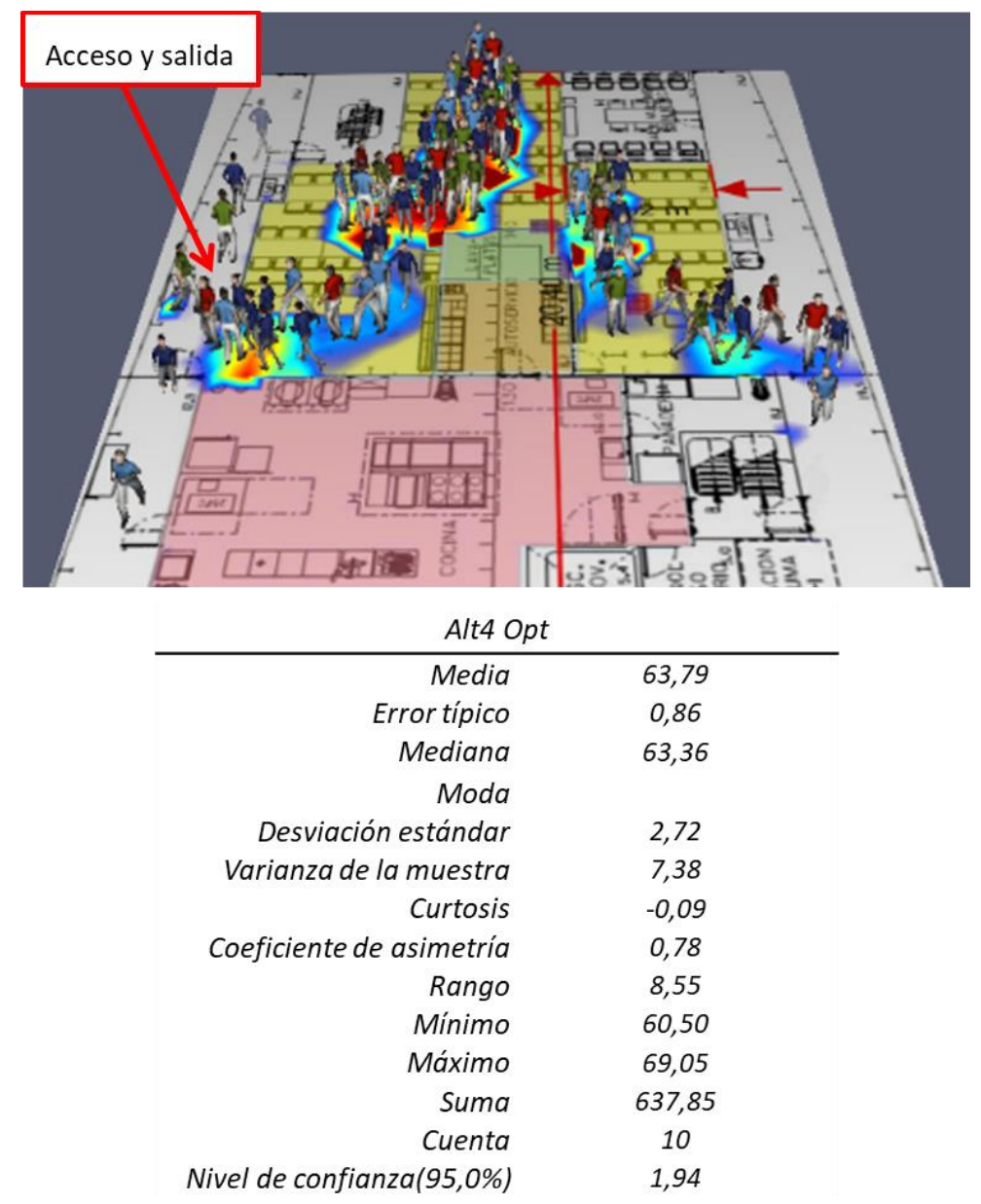

Figura 3-49 Estadísticas del experimento de tiempo en desalojar el comedor Alt.40pt (Elaboración propia)

\subsection{Experimento Evacuación. Alternativa 5}

Sobre la Figura 3-50 se pueden observar las estadísticas descriptivas de los resultados obtenidos para la Alt5. El comedor está en su máxima capacidad de personal sentado (64 personas). El personal desaloja el comedor por la única puerta de acceso y salida, situada en el centro babor. Este acceso comunica con un "tronco de escalas" que atiende 
varios espacios, como por ejemplo el sollado de marinería en la cubierta inferior. Esto explica el aumento del tiempo de desalojo ya que se produce un cuello de botella en el estrechamiento del tronco (ver Figura 3-51). El promedio de tiempo en realizar el desalojo es de 82,69 segundos.

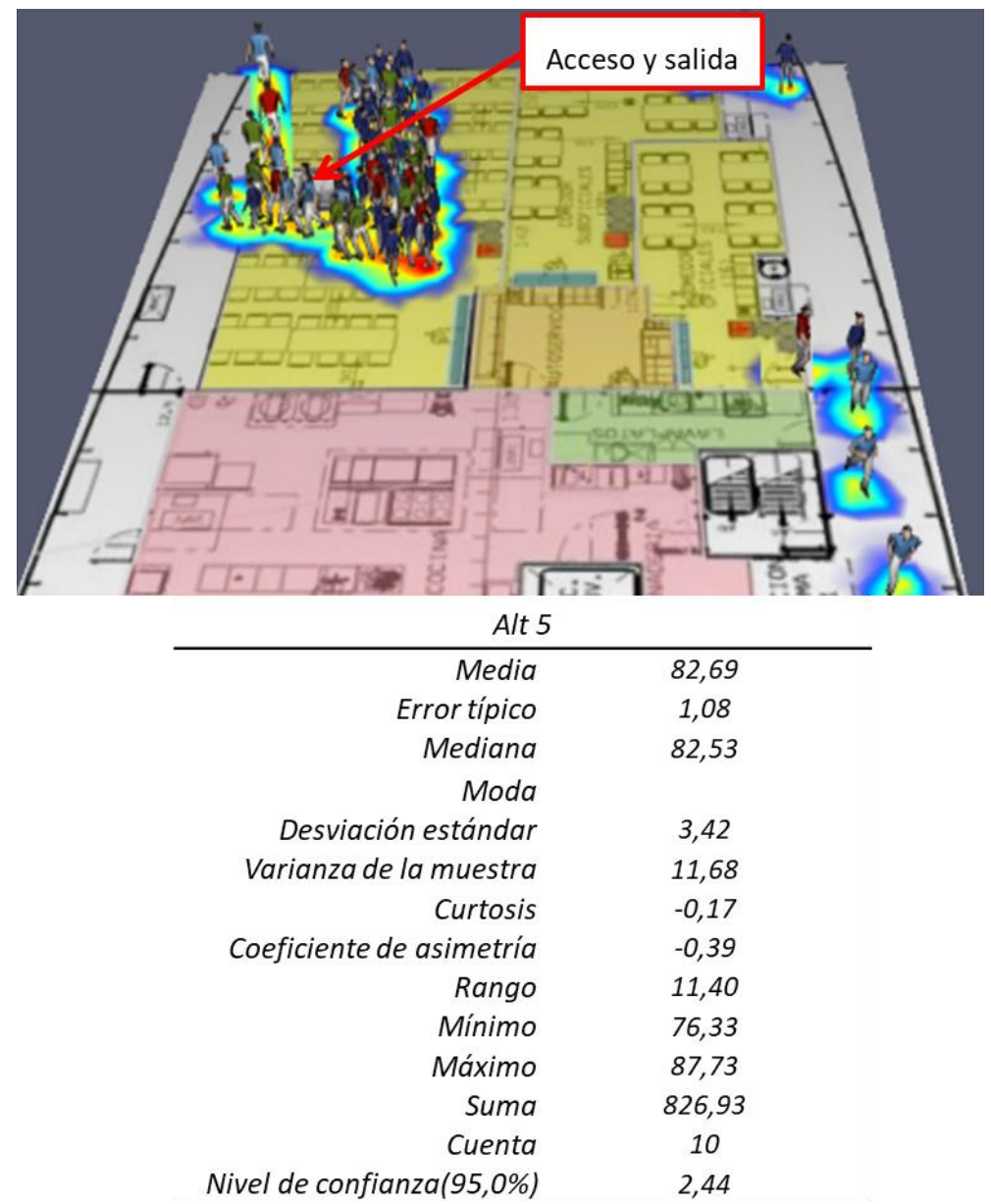

Figura 3-50 Estadísticas del experimento de tiempo en desalojar el comedor Alt5 (Elaboración propia) 


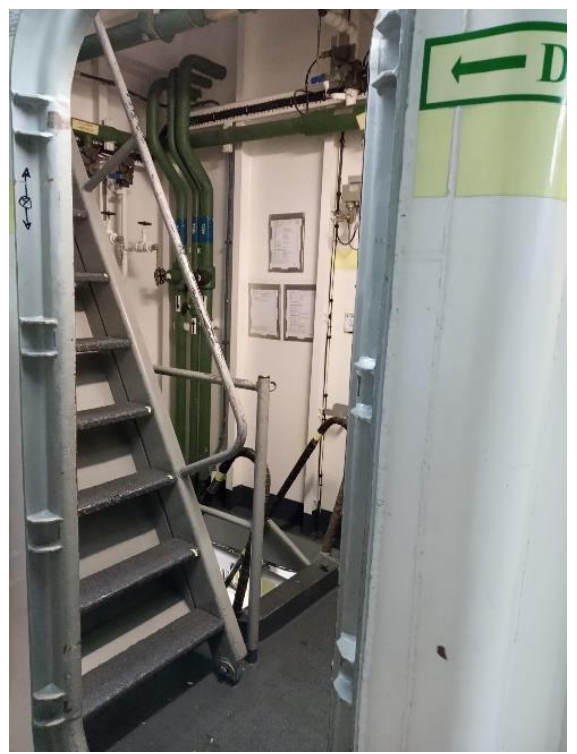

Figura 3-51 Imagen de un tronco de escalas tomada en la F-102 (Gonzalo Leira)

\subsection{Experimento Evacuación. Alternativa 6}

Sobre la Figura 3-52 se pueden observar las estadísticas descriptivas de los resultados obtenidos para la Alt6. El comedor está en su máxima capacidad de personal sentado (62 personas). El personal desaloja el comedor por dos puertas de acceso situada en el popa y proa babor. El disponer de dos puertas en el compartimento explica claramente la disminución del tiempo. El promedio de tiempo en realizar el desalojo es de 35,63 segundos. 


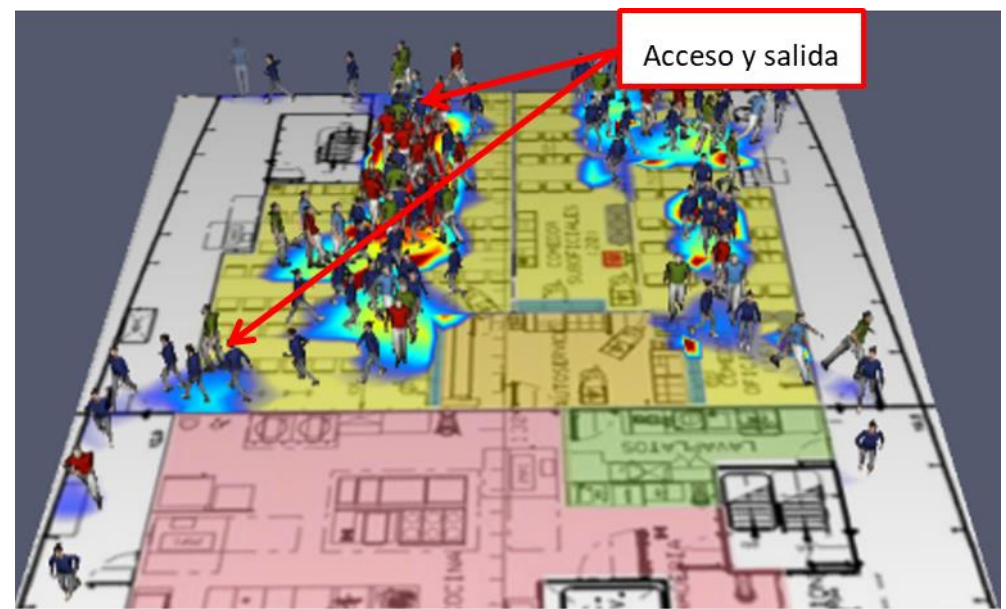

\begin{tabular}{rc} 
Alt 6 & \\
\hline Media & 35,63 \\
Error típico & 0,37 \\
Mediana & 35,48 \\
Moda & \\
Desviación estándar & 1,17 \\
Varianza de la muestra & 1,37 \\
Curtosis & $-1,23$ \\
Coeficiente de asimetría & 0,07 \\
Rango & 3,38 \\
Mínimo & 33,9 \\
Máximo & 37,28 \\
Suma & 356,3 \\
Cuenta & 10 \\
Nivel de confianza(95,0\%) & 0,84
\end{tabular}

Figura 3-52 Estadísticas del experimento de tiempo en desalojar el comedor Alt6 (Elaboración propia)

\section{ANOVA Desalojo Z/C}

Sobre los resultados obtenidos en los tres experimentos de desalojo del comedor se realizó un contraste de hipótesis para valorar si existen diferencias significativas entre las medias poblacionales de las muestras, resultando que sí se rechazaba la hipótesis nula en favor de la alternativa con un nivel se significación $\alpha=0,05$ (Figura 3-53). Esto significa que sí tenemos evidencias estadísticas de que los tiempos de desalojo tienen medias poblacionales distintas (A.14). 


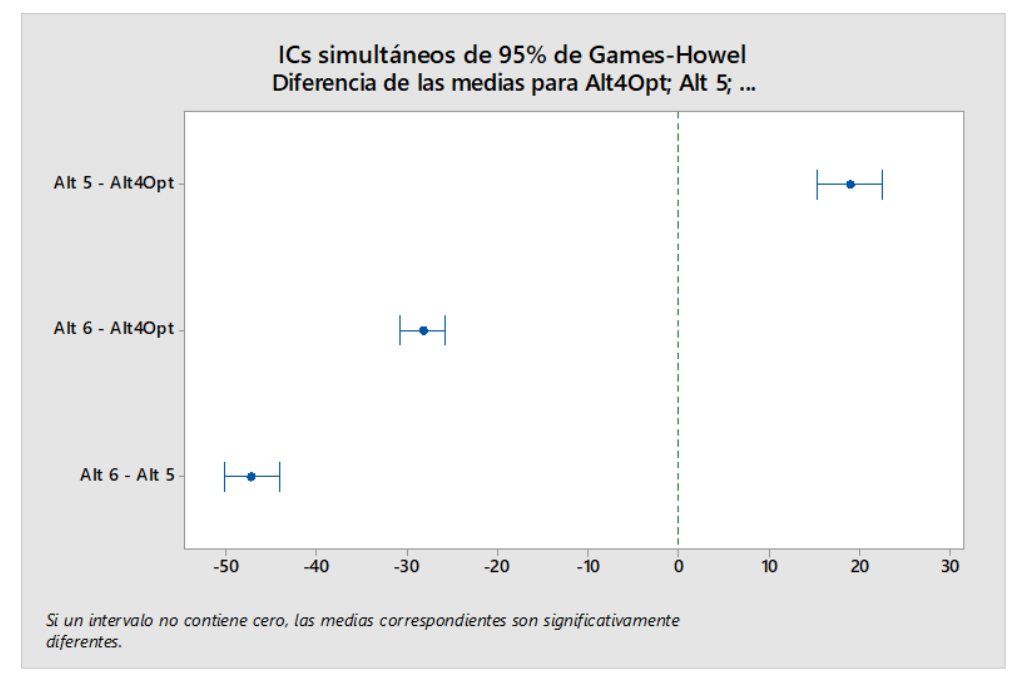

Figura 3-53 ANOVA: Alt4Opt; Alt5; Alt6

\subsubsection{El Servicio de la Comida. Subcriterio Libertad de} Movimientos

Conforme a lo que se acordó con los expertos, para la realización de este estudio de simulación con ordenador, con el objetivo de determinar diferencias en los tiempos de servicio del comedor, fue necesario recopilar datos reales sobre el comportamiento de la dotación y los tiempos empleados en comer.

Posteriormente, se planearon sobre el software AnyLogic las réplicas del experimento de reparto de la Comida.

\subsection{Recopilación de datos}

Para la realización de este trabajo se contó con la valiosísima colaboración de tres buques: las Fragatas F-100 "Blas de Lezo" y “Cristóbal Colón", y el portaaviones "Juan Carlos I".

La fragata "Blas de Lezo" (F-103) se encontraba navegando por aguas españolas participando en unos ejercicios nacionales $y$, en consecuencia, contaba a bordo únicamente con la dotación propia, es decir, el número de personas que se corresponden con la plantilla del buque.

La fragata "Cristóbal Colón" (F-105) estaba desplegada y navegando en aguas australianas dentro del "Acuerdo de proyecto entre la Armada Española y la Marina Real Australiana (RAN) sobre la utilización de buques". Consiguientemente, los días de la 
toma de datos contaba con una plantilla extra de personal perteneciente a la Armada Australiana y el número de personas a las que prestar el servicio de comedor excedía en aproximadamente un $170 \%$.

El portaviones "Juan Carlos I" estaba navegando en el denominado "Embarque de fin de curso de los alumnos de la ENM" y contaba, por consiguiente, con el aumento a su dotación habitual de los alumnos (73 personas).

A las fragatas se les envió una tabla Excel para la toma de datos con los que obtener las distribuciones adecuadas para la simulación:

- En la primera hoja de la tabla se anotó el número de personas que, a partir de la hora de comienzo del reparto de la comida, llegaban al comedor de marinería en tramos de 5 en 5 minutos. El registro de datos se prolongó durante un periodo tres días de navegación en las tres comidas, con esta información se pretendía conocer la tasa de llegada de la dotación al comedor.

- En la segunda hoja se anotó el tiempo que tardaba en ser servido un individuo en la línea de servicio. Se escogieron personas 30 personas al azar cada día. El registro de datos se prolongó durante un periodo tres días de navegación registrando datos para las tres comidas, con esta información se pretendía conocer el tiempo empleado en servir las distintas comidas.

- En la tercera hoja se anotó el tiempo que tardaban personas escogidas al azar en desayunar/comer/cenar, es decir, el tiempo transcurrido entre el instante en el que se sentaban y el instante en el que dejaban el asiento libre. Se escogieron personas 30 personas al azar cada día. El registro de datos se prolongó durante un periodo tres días de navegación registrando datos para las tres comidas. Con esto, se pretendía conocer el tiempo de ocupación de asientos en el comedor durante las diferentes comidas.

A los alumnos embarcados en el portaviones se les solicitó que rellenasen para los días 5 y 6 de junio (dos días), las horas de: llegada al comedor (incorporación a la cola); sentarse en la mesa y finalización de la comida. Con estos datos se pretendía conocer la distribución de llegada al comedor y la duración del tiempo empleado en la ingesta. 
En el Apéndice B se puede observar un extracto de los datos obtenidos de todos los buques.

\subsection{Análisis Estadístico de los Datos}

La siguiente tabla resume el tipo de datos recopilado y el tipo de análisis que se ha realizado (ver Tabla 3-13). Posteriormente, se explicarán las decisiones tomadas para seleccionar las distribuciones de probabilidad para su empleo en el programa de simulación AnyLogic.

\begin{tabular}{|c|c|c|c|c|}
\cline { 2 - 5 } \multicolumn{1}{c|}{} & JCI & F-103 & F-105 & ANÁLISIS \\
\hline $\begin{array}{c}\text { Tiempo de } \\
\text { llegada }\end{array}$ & $\boldsymbol{X}$ & $\boldsymbol{X}$ & $\boldsymbol{X}$ & Gráfico, descriptivo e inferencial. \\
\hline $\begin{array}{c}\text { Tasa de } \\
\text { Ilegada }\end{array}$ & $\boldsymbol{X}$ & $\boldsymbol{X}$ & $\begin{array}{c}\text { Gráfico, descriptivo e inferencial. } \\
\text { U Mann-Whitney. } \text {-Student. }\end{array}$ \\
\hline $\begin{array}{c}\text { Tiempo en } \\
\text { la línea }\end{array}$ & $\boldsymbol{X}$ & $\boldsymbol{X}$ & $\begin{array}{c}\text { Gráfico, descriptivo e inferencial. } \\
\text { H kruskal-Wallis. ANOVA. }\end{array}$ \\
\hline $\begin{array}{c}\text { Tiempo de } \\
\text { desayuno }\end{array}$ & $\boldsymbol{X}$ & $\boldsymbol{X}$ & $\boldsymbol{X}$ & $\begin{array}{c}\text { Gráfico, descriptivo e inferencial. } \\
\text { H kruskal-Wallis. ANOVA. }\end{array}$ \\
\hline $\begin{array}{c}\text { Tiempo de } \\
\text { comida }\end{array}$ & $\boldsymbol{X}$ & $\boldsymbol{X}$ & $\boldsymbol{X}$ & $\begin{array}{c}\text { Gráfico, descriptivo e inferencial. } \\
\text { H kruskal-Wallis. ANOVA. }\end{array}$ \\
\hline $\begin{array}{c}\text { Tiempo de } \\
\text { cena }\end{array}$ & & & &
\end{tabular}

Tabla 3-13 Tabla resumen de los análisis realizados a los datos

\subsection{Tiempos de Llegada al Comedor}

Como se puede intuir sobre la información reflejada en la Tabla 3-13 los datos recogidos de la llegada al comedor del personal de las fragatas y del portaaviones son diferentes. Inicialmente, se enviaron las tablas de recogida de datos a las fragatas y se recogió la información del número de personas que llegan al comedor en intervalos de 5 minutos (datos agrupados); al observar que este tipo de recogida de datos no proporcionaba información suficiente, se decidió, que en el portaaviones se recogiesen las horas exactas de llegada de cada individuo.

$\underline{\text { Tiempos de las Fragatas }}$ 
En las siguientes gráficas (ver Figura 3-54 y Figura 3-55) se aprecia la distribución de llegada al comedor en el desayuno durante tres días en las dos fragatas. Se puede considerar que el comportamiento dentro de la F-103 es muy similar todos los días, mientras que en la F-105 existe más variabilidad. Entre las dos fragatas los comportamientos de los individuos son manifiestamente diferentes. Una explicación plausible pudiera ser debida a los desiguales tipos de operaciones y grados de alistamiento entre los dos buques. La F-105 transportaba un extra de personal (personal de la armada australiana) y estaba desarrollando otro tipo de misiones diferentes, las cuales siempre tienen una influencia directa en los hábitos de abordo (Guardias, operaciones de vuelo, aprovisionamientos, zafarranchos de combate, etc.).

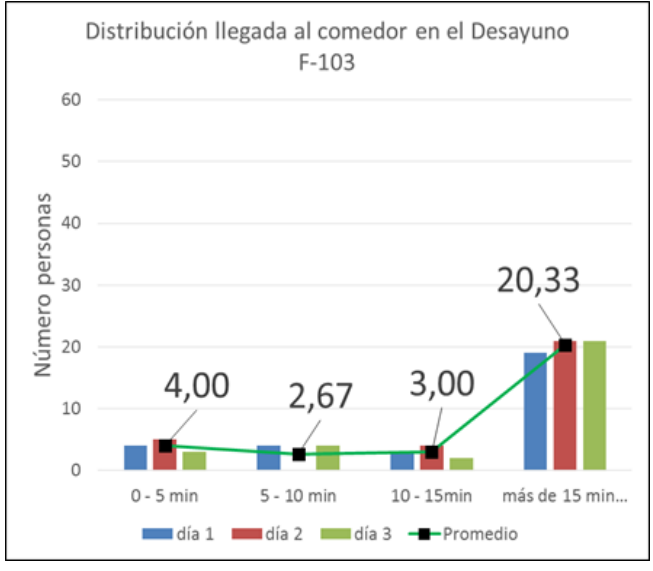

Figura 3-54 Distribución de llegada de personas al comedor en el desayuno en la F-103

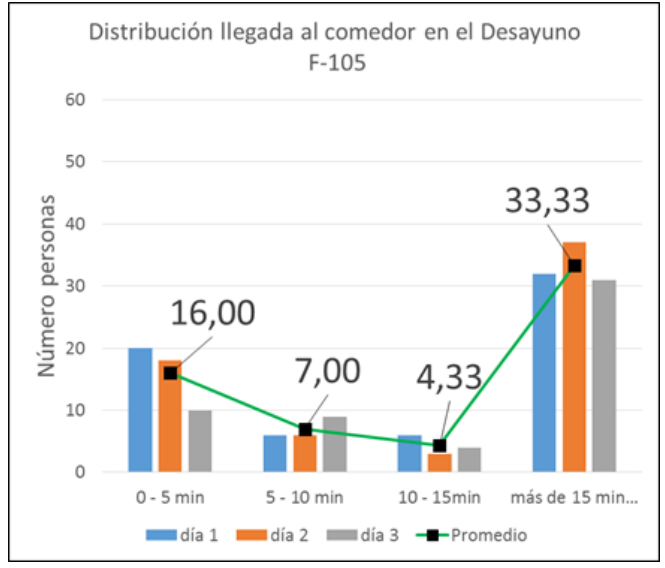

Figura 3-55 Distribución de llegada de personas al comedor en el desayuno en la F-105

En las siguientes gráficas (ver Figura 3-56 y Figura 3-57) se observa la distribución de llegada al comedor a la hora de la comida, en las dos fragatas, durante tres días. Se aprecia que el comportamiento dentro de la F-103, a diferencia del desayuno, es más variable, mientras que en la F-105 por el contrario, tiene un comportamiento muy similar todos los días. En el análisis visual de estas gráficas, especialmente sobre la de la F-105, es cuando se detectó que la información proporcionada no es suficiente, puesto que se desconoce la distribución de llegada de aproximadamente el 50\% del personal que llegan más tarde de los 15 minutos desde la apertura de la línea del comedor (de promedio llegan más de 48 personas a comer transcurridos los de 15 minutos de apertura del comedor). 


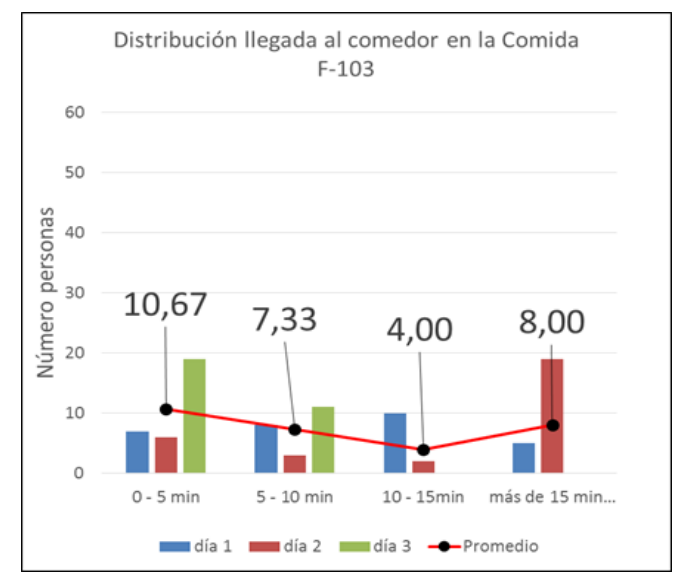

Figura 3-56 Distribución de llegada de personas al comedor en la comida en la F-103

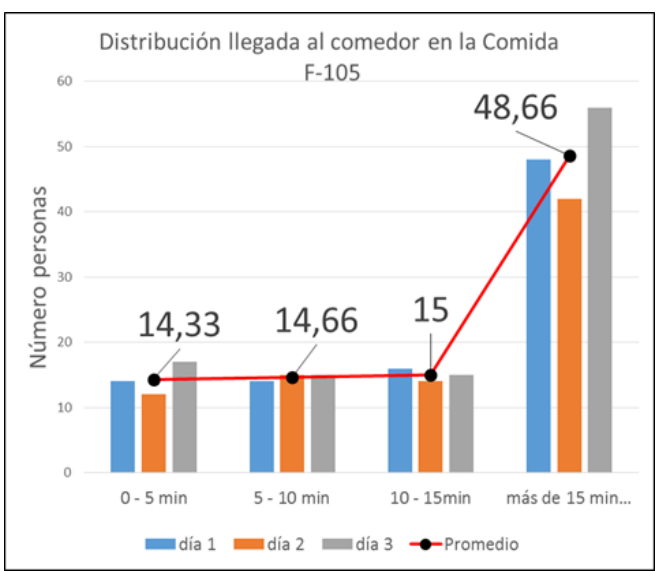

Figura 3-57 Distribución de llegada de personas al comedor en la comida en la F-105

En las siguientes gráficas (ver Figura 3-58 y Figura 3-59) se puede observar la distribución de llegada de personas al comedor durante la cena. Se vuelve a apreciar que el comportamiento dentro de la F-103 es más variable, mientras que en la F-105 es muy similar todos los días. Nuevamente, en la F-105 se desconoce la distribución de llegada de más del $50 \%$ de personas que llegan más tarde de los 15 minutos desde la apertura de la línea del comedor.

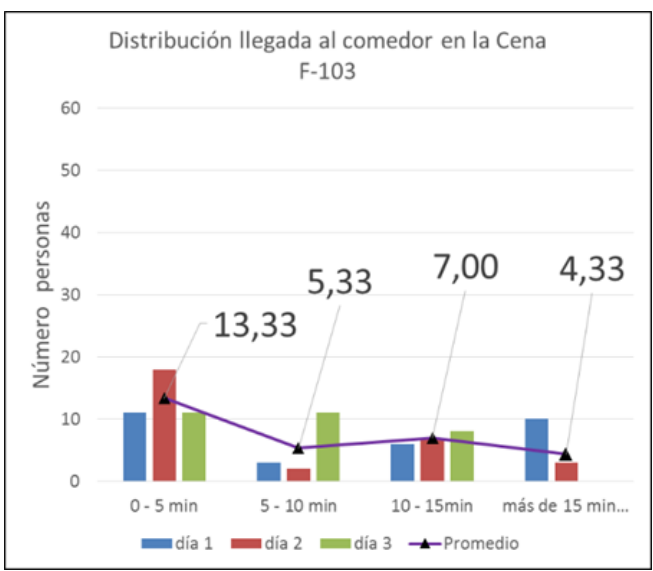

Figura 3-58 Distribución de llegada de personas al comedor en la cena en la F-103

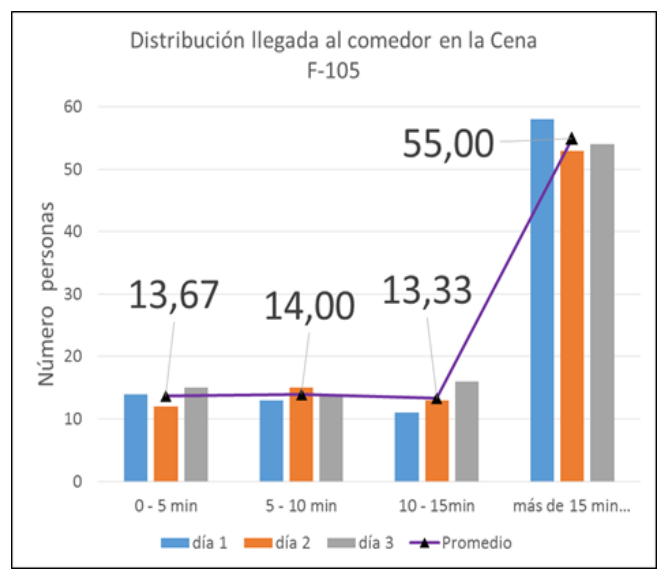

Figura 3-59 Distribución de llegada de personas al comedor en la cena en la F-105

Otro desacierto que se detectó en la toma de datos tiene relación con las características de diseño del comedor en estas fragatas. Los datos registrados reflejan el número de personas "que entran" en el comedor no cuándo se incorporan a la cola. Se da la circunstancia, que la entrada al comedor coincide con el comienzo de la línea de servicio, 
en consecuencia, la cola está formada fuera del comedor y no se tienen datos de incorporación a ella (ver Figura 3-60).

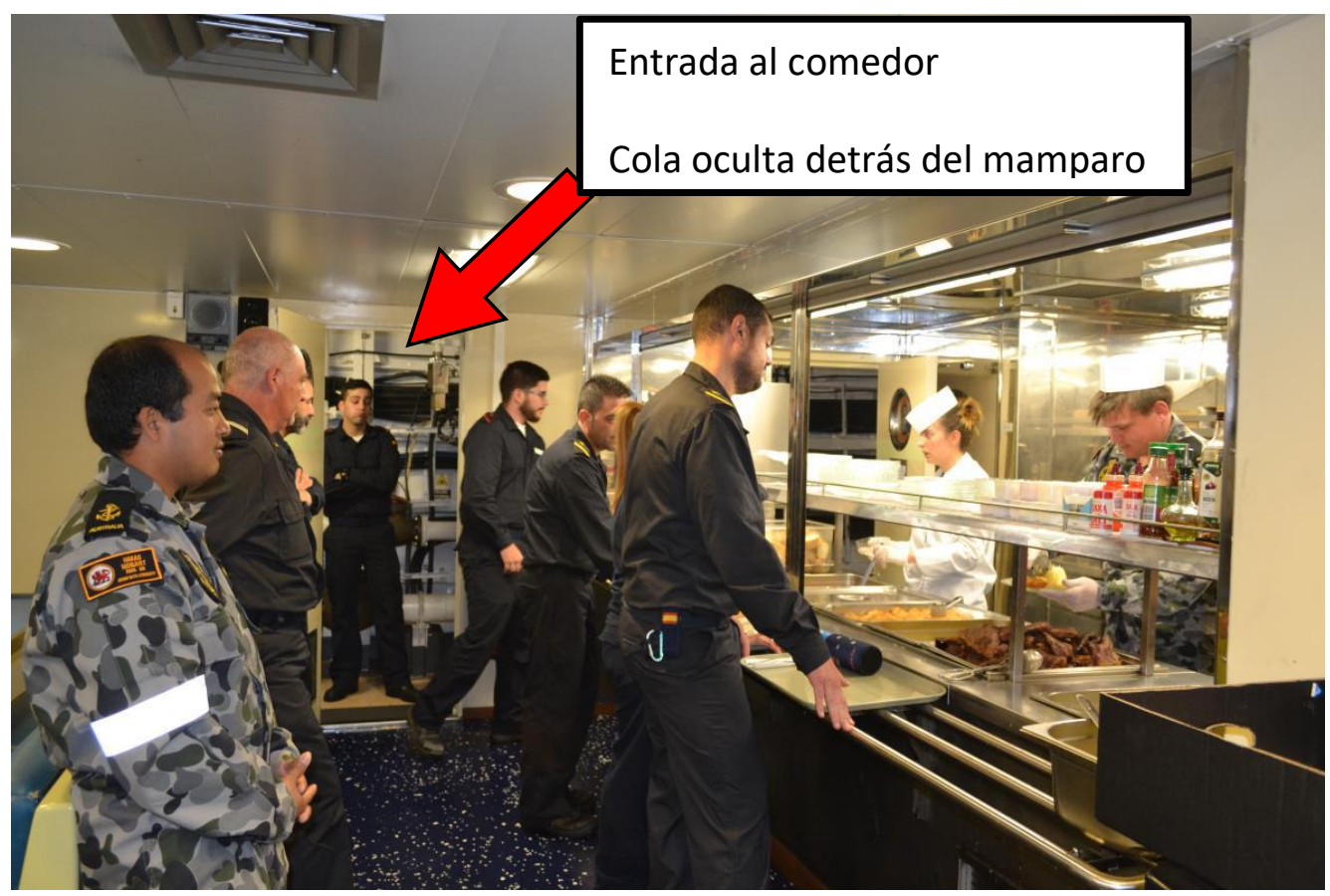

Figura 3-60 Imagen de la línea de servicio en el comedor de la F-105 ("Cristóbal Colón")

En conclusión, tal como se ha podido apreciar sobre las gráficas anteriores y estudiando los pormenores de la toma de datos, la información extraíble del análisis de los datos no es válida en el sentido de extrapolar una distribución común de probabilidad de llegada plausible.

\section{$\underline{\text { Tiempos del Portaviones }}$}

Con los datos del portaviones de horas de llegada al comedor en el desayuno y comida (los datos obtenidos de hora de llegada para la cena no resultaron válidos), se realizó la agrupación en intervalos de 5 minutos. En la gráfica de la Figura 3-61 se observa la distribución de llegada al comedor para el desayuno. En ambos días, el comportamiento de la tasa de llegada ha sido desigual dando, incluso, una apariencia de bimodalidad, que difícilmente se puede explicar sin haber estado presente en la toma de datos. 


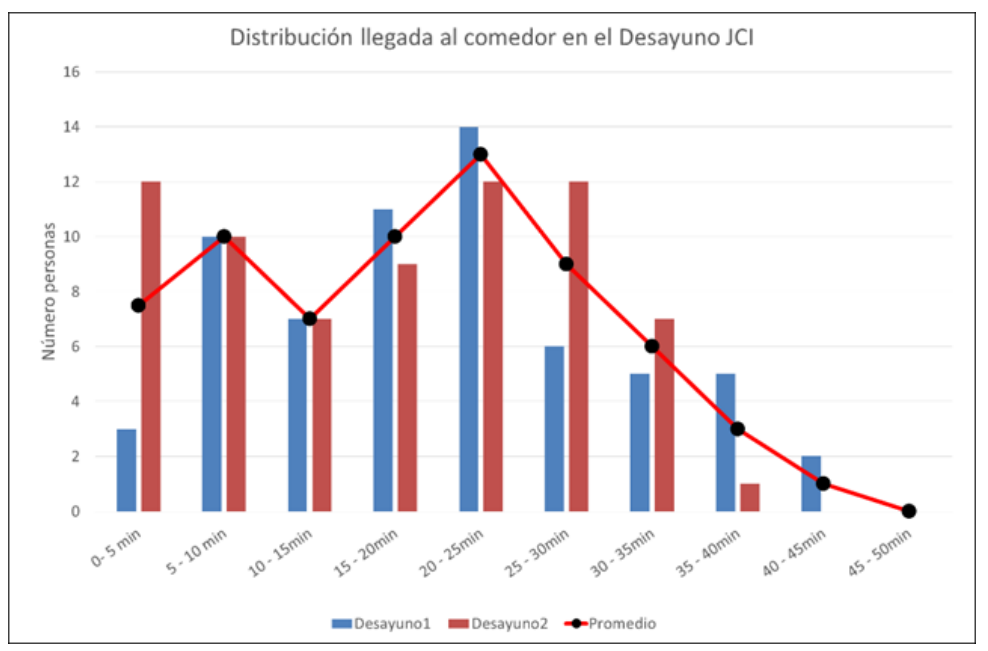

Figura 3-61 Distribución de llegada de alumnos al comedor en el desayuno en el portaviones

Tras consultar con los responsables de la recopilación de datos en el buque (alumnos de la ENM), se averiguó que estaban regidos por un horario especial sin guardias ni servicios, por lo que de estos datos no se pudo inferir una tasa de llegada plausible para el estudio que se pretendía realizar.

En la gráfica de la Figura 3-62 se puede observar las llegadas al comedor para realizar la comida, se aprecia que los alumnos han sido divididos en dos turnos y se observa una gran aleatoriedad de comportamientos, que puede perfectamente justificarse por dos motivos: los alumnos estuvieron exentos de montar guardias en la mar, y el "despiste" congénito de alumno, es decir, que tanto el régimen de vida a bordo como el propio buque en sí, les resultó desconocido o poco familiar. Esto evidencia que la extrapolación del comportamiento de un alumno sobre un miembro de la dotación hubiese sido un error.

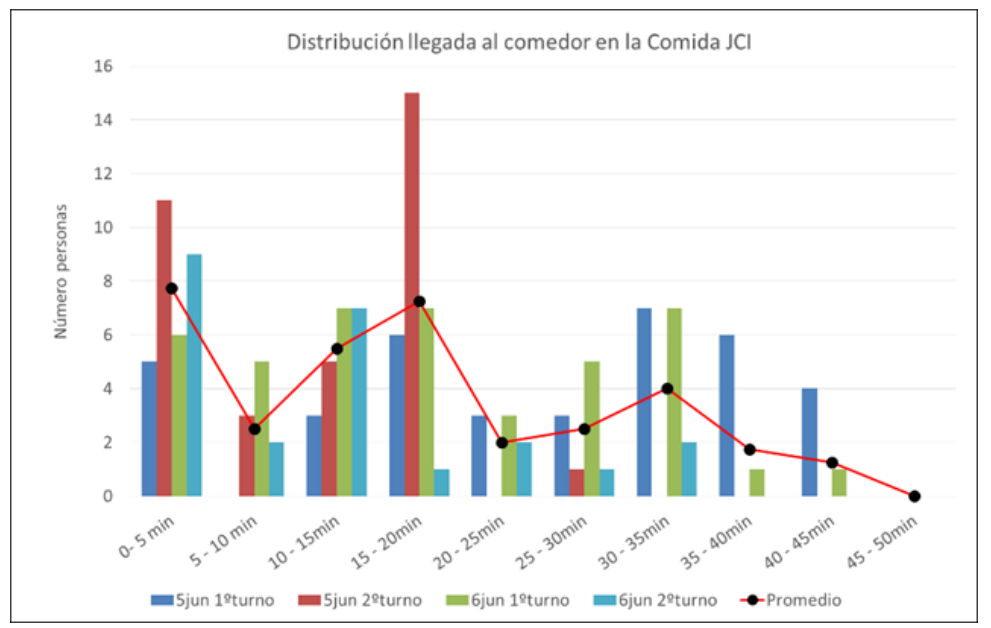

Figura 3-62 Distribución de llegada de alumnos al comedor en la comida en el portaviones 
Gracias a los análisis efectuados a los datos recogidos y en colaboración con los expertos se pudo concluir que:

- No se puede inferir una distribución única plausible para la realización del estudio.

- Las tasas de llegada al comedor están muy correlacionadas con el tipo de actividades que esté desarrollando el buque.

- Los alumnos de la ENM tienen un comportamiento más errático que el personal de dotación, que está sometida a guardias y servicios e implica un horario más constreñido.

Con los expertos se consideró que, siendo el propósito del EMA conocer si alguna de las alternativas de comedor se saturaría cuando hubiese un aumento de dotación (se calcula que son 80 personas), se determinó que se experimentase en el AnyLogic con varias distribuciones de llegada.

Por experiencia, se sabe que el comportamiento estándar de la dotación es la de acudir en los primeros minutos a la comida, por ello, se tomó la decisión de simular con tasas de llegada que respondiesen a unas distribuciones exponenciales en las que: en 15 minutos acude toda la marinería del turno de comida, Exp. (320); otra tasa en la que acuden en 30 minutos, Exp.(160); y una tercera en la que acuden en 60 minutos, $\operatorname{Exp} .(80)$.

\subsection{Tiempo en Línea de Servicio}

Se entiende por "tiempo en línea de servicio" como el tiempo transcurrido desde que un individuo empieza a ser servido (el cocinero le empieza a servir la primera porción de comida en la bandeja) hasta que una vez servido sale de la mesa caliente (línea) para dirigirse a un asiento.

\section{$\underline{\mathrm{F}-103}$}

En la gráfica de la Figura 3-63 se muestra el informe de resumen de los tiempos de servicio en la línea durante el desayuno. El promedio son 167,8 segundos. Estos datos 
no superan las pruebas de bondad de ajuste a una distribución Normal ( $p_{-}$valor $<$ 0,005 ) (ver pruebas de bondad de ajuste en B.2).

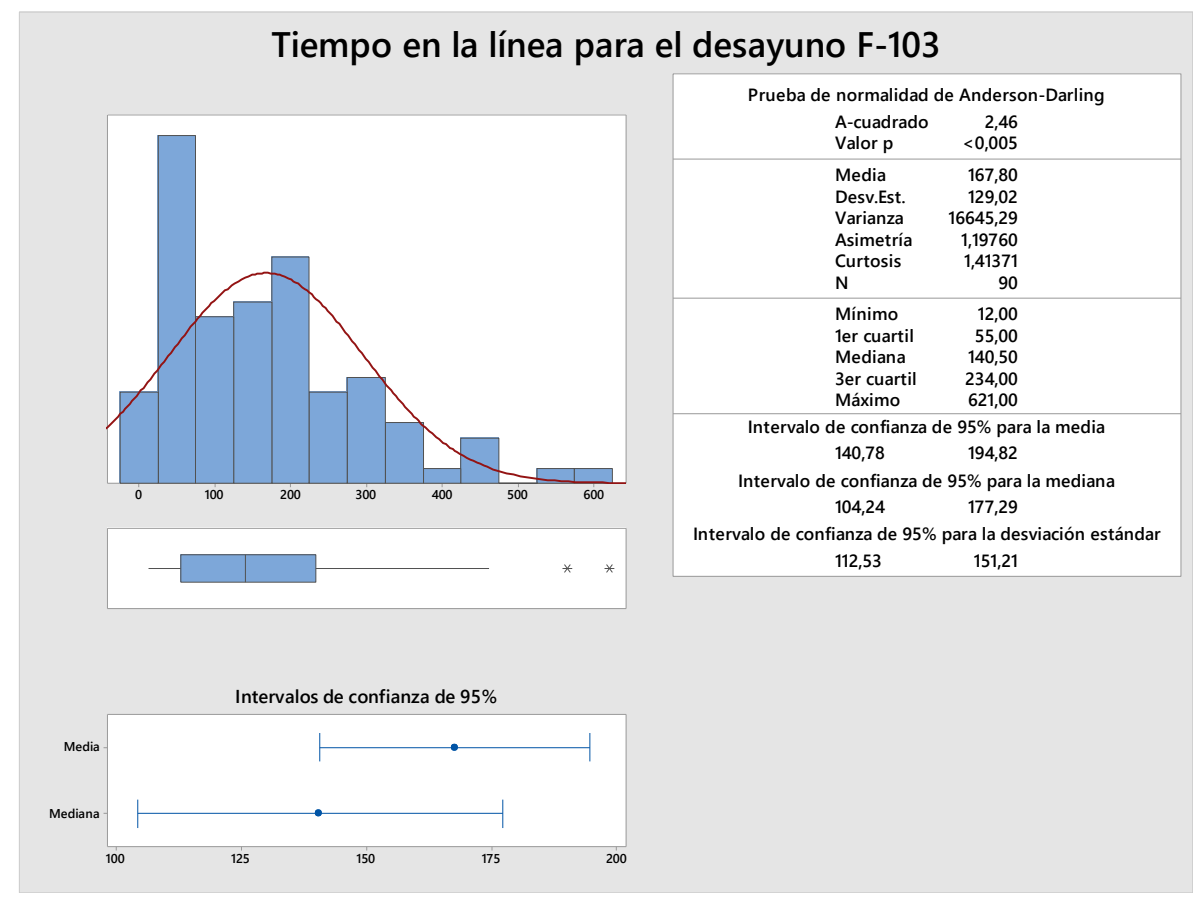

Figura 3-63 Informe de resumen del tiempo en la línea durante el desayuno en la F-103

Se aprecia que es positivamente sesgada, destacando un número importante de personas que permanece más de 2 minutos (mediana =140 segundos), incluso algunos superan los 5 minutos en la línea. Este hecho es difícil de explicar sin haber estado presente en la toma de datos. Quizás, su justificación pudiera ser que el desayuno no estuviese asistido desde la mesa caliente, es decir, que el funcionamiento fuese de autoservicio con las particularidades propias del desayuno: tostadora, zumos, máquina de café, etc. Lo anterior, confirma la importancia de la teoría de que, siempre que sea posible, el analista esté presente en el momento de la toma de datos.

En la gráfica de la Figura 3-64 se muestra el informe de resumen de los tiempos de servicio en la línea durante la comida. El promedio son 36,5 segundos. Estos datos superan las pruebas de bondad de ajuste a una distribución Normal ( $p_{-}$valor $\left.=0,116\right)$, se ajustan a una distribución Normal, $N(36,5 ; 13,1)$ segundos. 


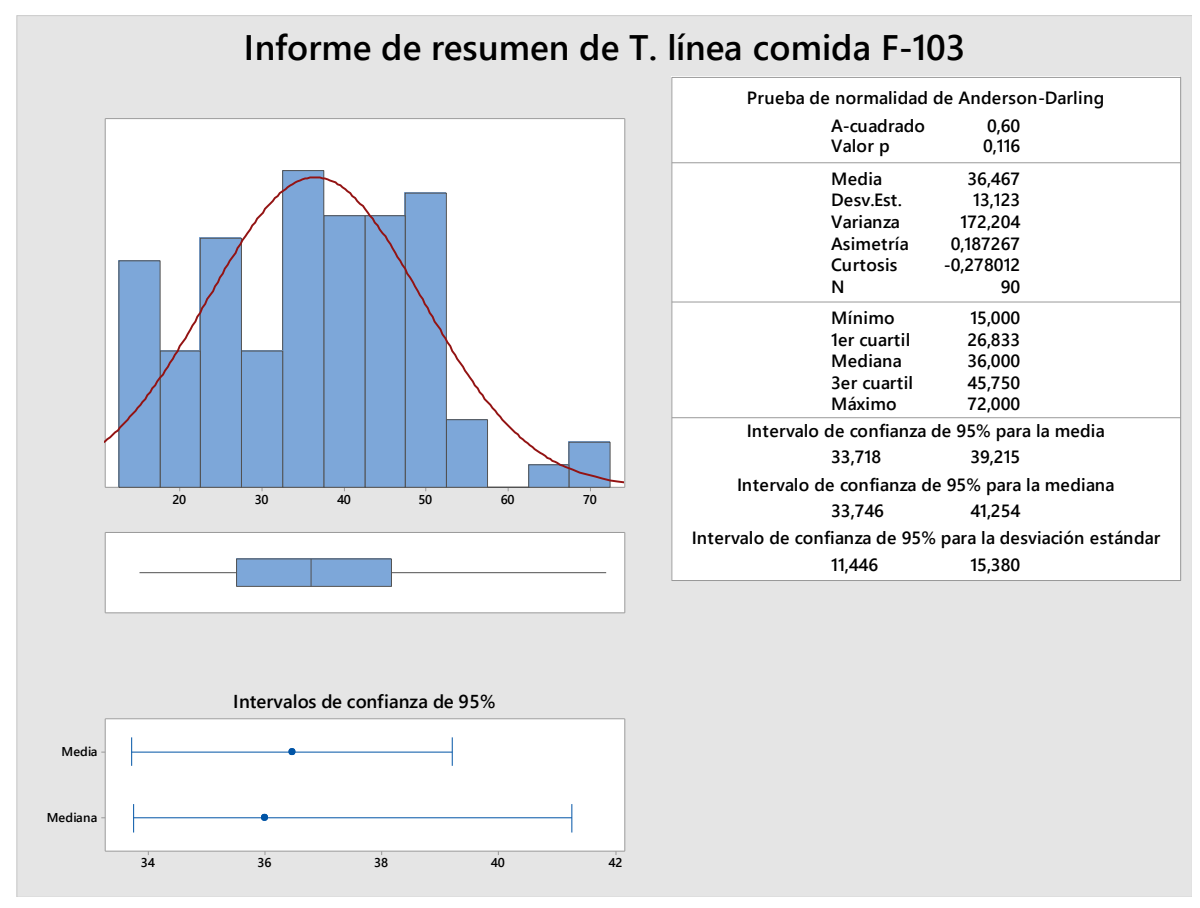

Figura 3-64 Informe de resumen del tiempo en la línea durante la comida en la F-103

En la gráfica de la Figura 3-65 se muestra el informe de resumen de los tiempos de servicio en la línea durante la cena. El promedio son 44,7 segundos. Estos datos no superan las pruebas de bondad de ajuste a una distribución Normal ( $p_{-} v a l o r<0,005$ ). Sobre el box-plot de la Figura 3-65 se observa la presencia de un dato atípico (círculo rojo) de un tiempo en la línea superior a los 2 minutos y medio. Eliminado este dato, se ha vuelto a realizar la prueba de bondad de ajuste a una Normal, pudiéndose afirmar que estadísticamente se ajusta a una distribución Normal, $N(43,5 ; 12,9)$ segundos $\left(p_{\_}\right.$valor $\left.=0,711\right)$ (ver Figura 3-66). 


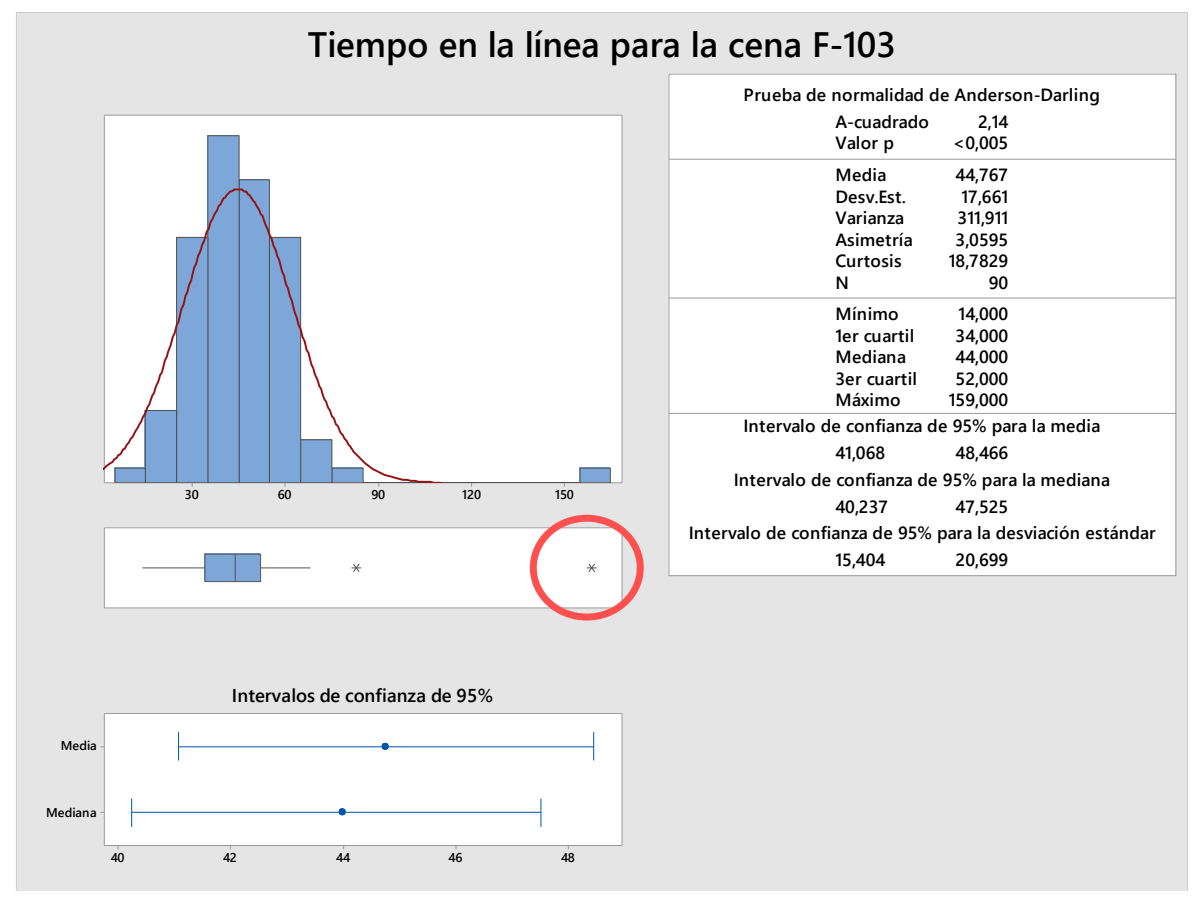

Figura 3-65 Informe de resumen del tiempo en la línea durante la cena en la F-103

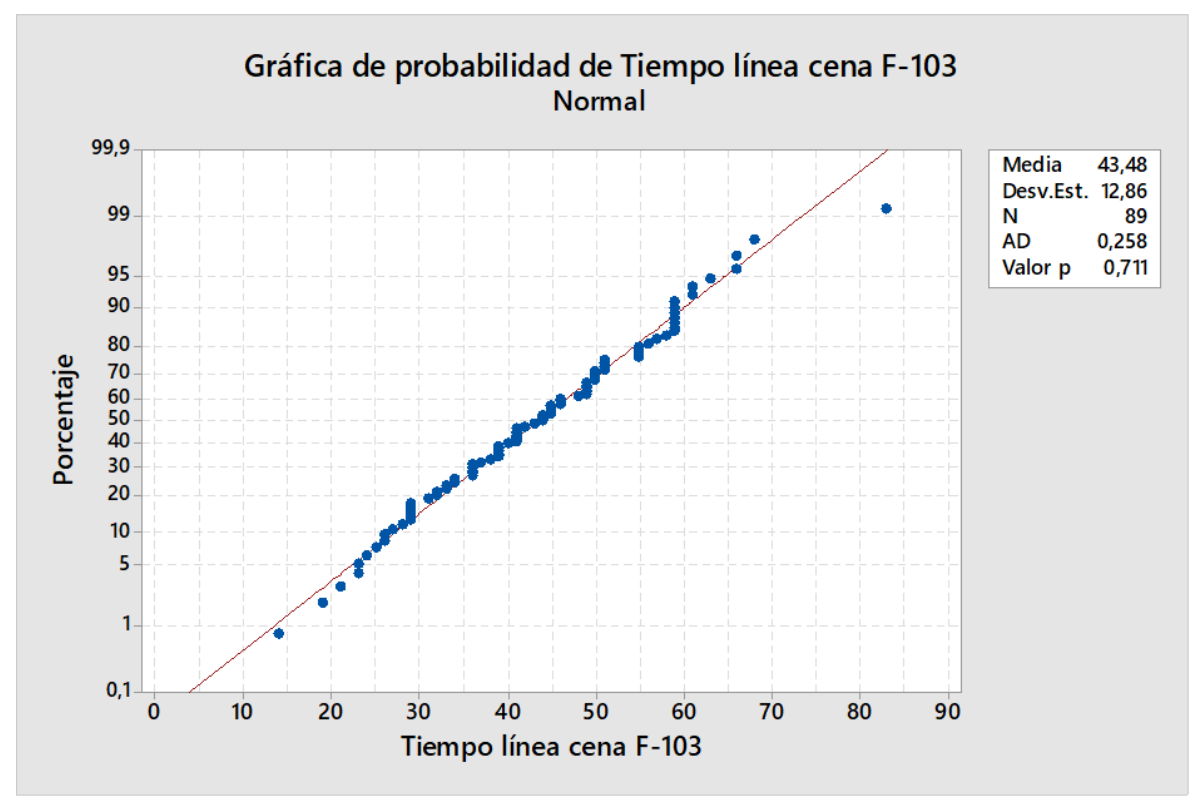

Figura 3-66 Prueba de bondad de ajuste a una Normal de los tiempos en línea para la cena en la F-103 (eliminados los datos atípicos)

\section{$\underline{\mathrm{F}-105}$}

En la gráfica de la Figura 3-67 se muestra el informe de resumen de los tiempos de servicio en la línea durante el desayuno. El promedio son 102,7 segundos. Estos datos no superan las pruebas de bondad de ajuste a una distribución Normal ( $p_{-}$valor $<$ 
0,005 ) (ver pruebas de bondad de ajuste en B.3). Positivamente sesgada, es reseñable el número de personas que permanece más de 2 minutos en la línea (tercer cuartil 130 seg.), en cualquier caso, el tiempo en la línea de este buque es aparentemente menor que en la F-103. La desviación típica es grande (64 seg.), por lo que también pudiera ser que el desayuno no estuviese asistido.

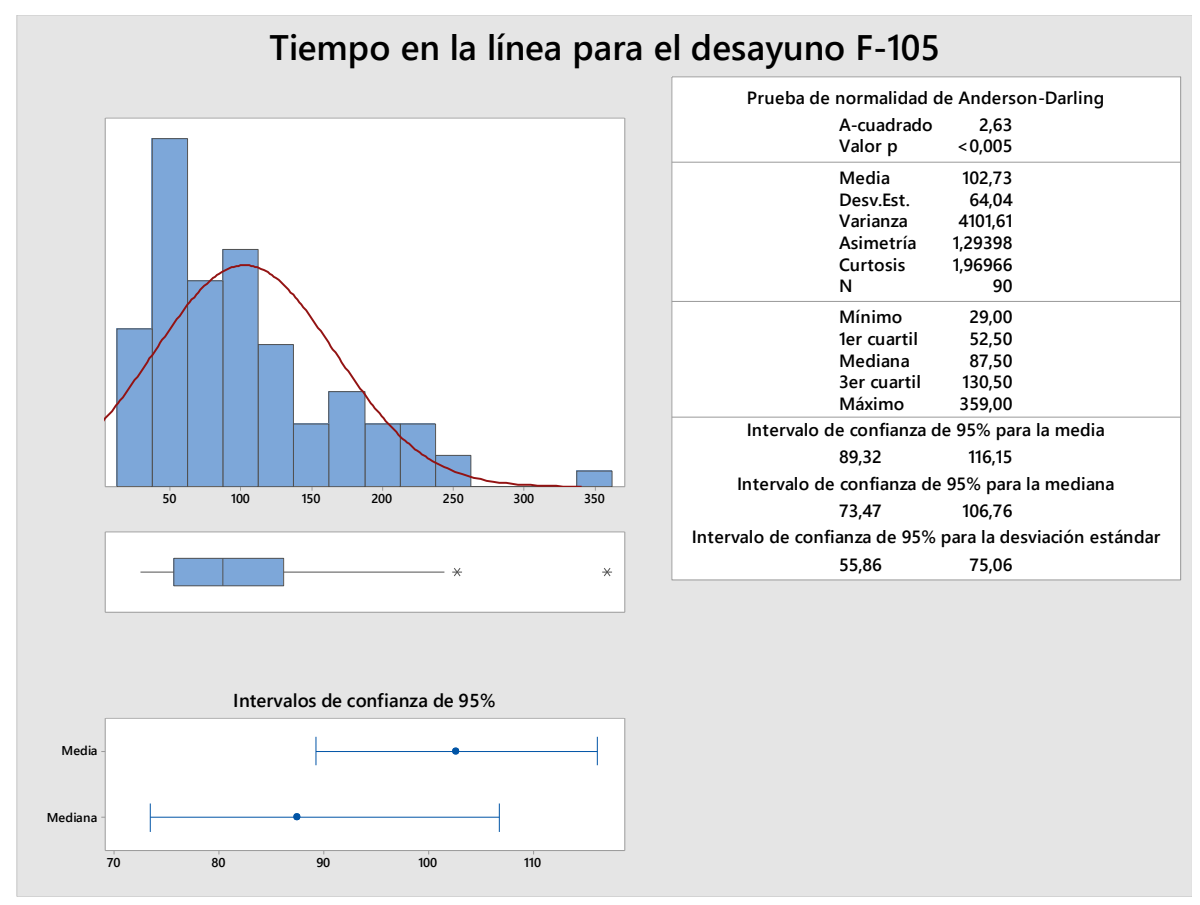

Figura 3-67 Informe de resumen del tiempo en la línea durante el desayuno en la F-105

En la gráfica de la Figura 3-68 se muestra el informe de resumen de los tiempos de servicio en la línea durante la comida de la F-105. El promedio son 57,8 segundos, que son más de 20 segundos con respecto a la media de la F-103 (36,4 seg.). Estos datos sí superan las pruebas de bondad de ajuste a una distribución Normal ( $p_{-}$valor $=0,369$ ); Normal, $N(57,8 ; 18,8)$ segundos. 


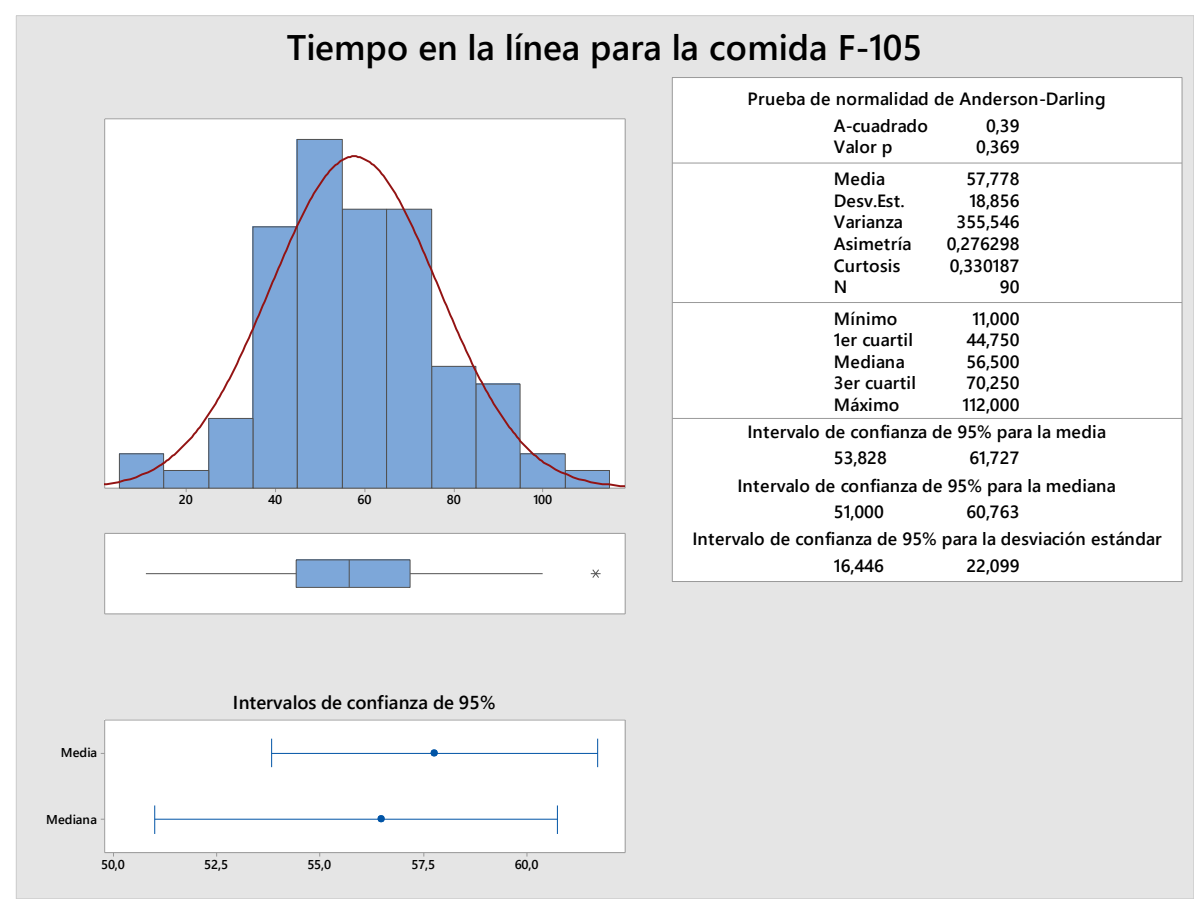

Figura 3-68 Informe de resumen del tiempo en la línea durante la comida en la F-105

En la gráfica de la Figura 3-69 se muestra el informe de resumen de los tiempos de servicio en la línea durante la cena de la F-105. El promedio son 81,8 segundos y no supera la prueba de bondad de ajuste a una distribución Normal ( $p_{-}$valor $=0,028$ ). Al igual que ocurrió con los datos de la F-103, el box-plot exterioriza una apariencia de distribución Normal y, a su vez, muestra la presencia de tres datos atípicos (círculo rojo) de un tiempo en la línea superior a los 2 minutos. Eliminados estos datos atípicos, se ha vuelto a realizar la prueba de bondad de ajuste a una Normal, pudiéndose afirmar que estadísticamente se ajusta a una distribución Normal, $N(79,65 ; 20,2)$ segundos $\left(p_{\text {_valor }}=0,207\right)$ (ver Figura 3-70). 


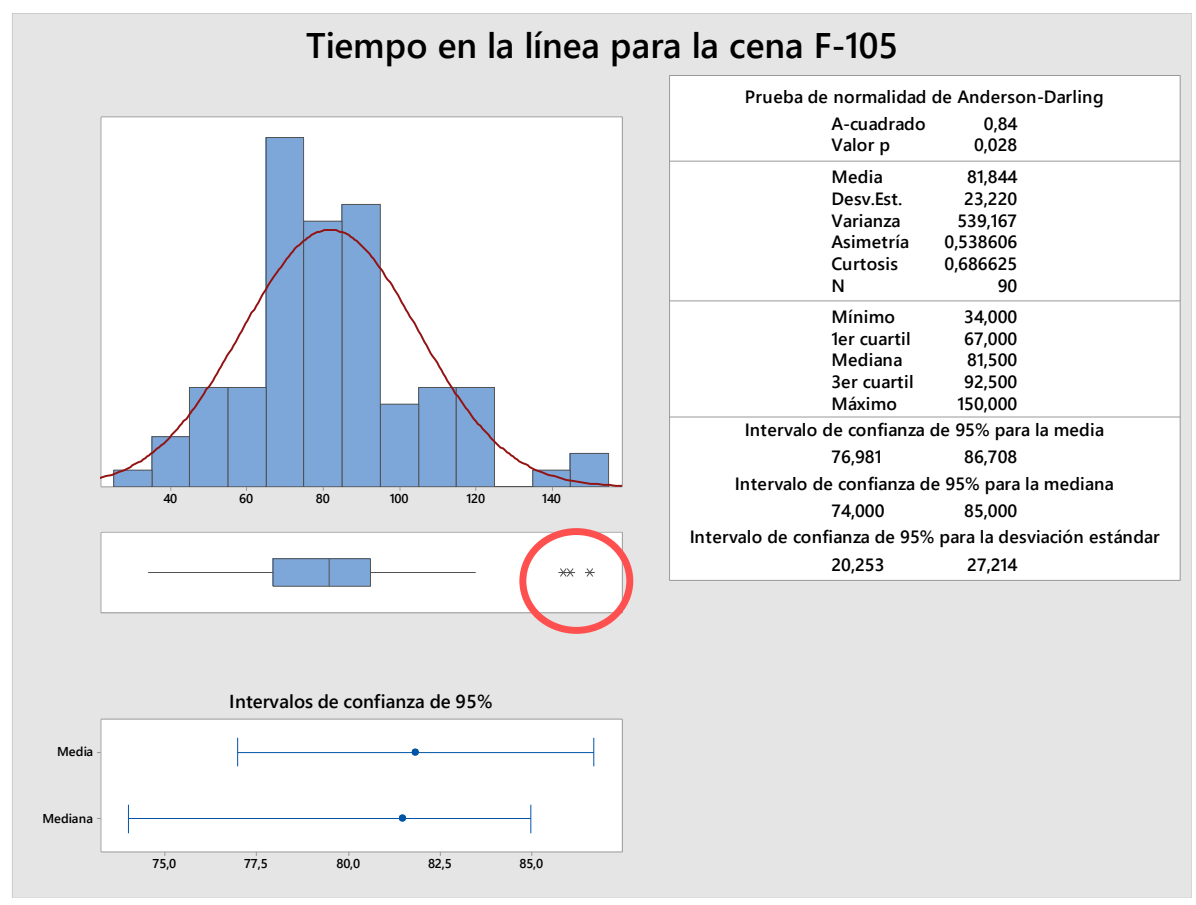

Figura 3-69 Informe de resumen del tiempo en la línea durante la cena en la F-105

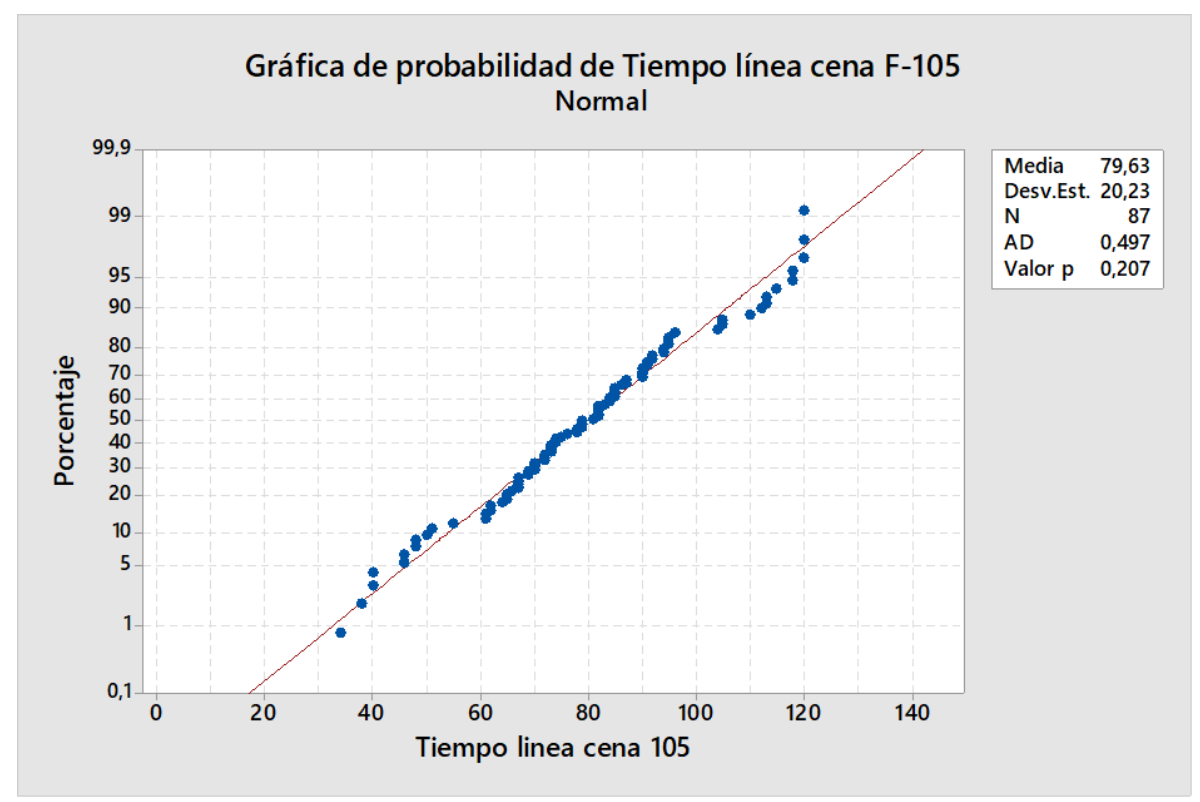

Figura 3-70 Prueba de bondad de ajuste a una Normal de los tiempos en línea para la cena en la F-105

(eliminados los datos atípicos)

Previo a la realización de pruebas para dar respuesta a la cuestión: ¿̇los tiempos en la línea para las distintas comidas de las dos fragatas pertenecen a la misma población?; se representó la gráfica Box-Plot un análisis visual en el que, aparentemente, se aprecia que no pertenecen a la misma población en ningún caso (ver Figura 3-71). 


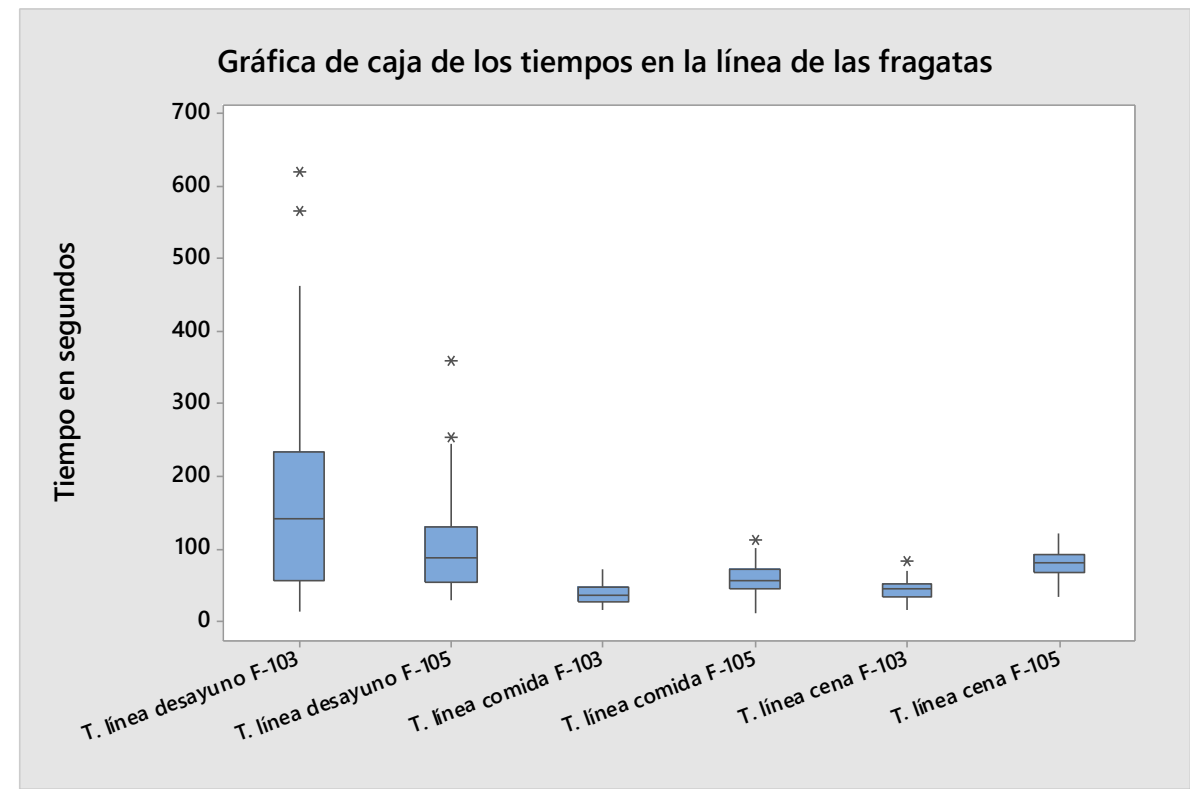

Figura 3-71 Gráfica de caja de los tiempos en la línea de las fragatas (los datos atípicos de las cenas se han eliminado)

Para los tiempos en la línea en el desayuno, al no cumplirse los criterios de normalidad necesarios para realizar una prueba paramétrica, se realiza la prueba no paramétrica de U Mann-Whitney [163]. Esta es una muy buena alternativa a la prueba t (sobre igualdad de medias) cuando no se cumplen algunos de los supuestos en los que se basa la prueba t (normalidad y homocedasticidad) [164], si bien, la sensibilidad respecto a la violación de hipótesis es menos restrictiva [165]. Con los tiempos de línea de la comida y cena (sin datos atípicos) la paramétrica t-Student [166]. 
Los resultados resumidos de las pruebas se pueden observar en la Tabla 3-14 (resultados en B.4).

\begin{tabular}{|c|c|c|c|c|}
\cline { 2 - 5 } \multicolumn{1}{c|}{} & Hipótesis & Prueba & p-valor & Decisión \\
\hline $\begin{array}{c}\text { La distribución de } \\
\text { los tiempos en la } \\
\text { línea para el } \\
\text { desayuno es la } \\
\text { misma en las dos } \\
\text { fragatas. }\end{array}$ & $\begin{array}{c}H_{0}: \eta_{1}=\eta_{2} \text { versus } H_{1}: \eta_{1} \neq \eta_{2} \\
\text { donde } \eta \text { es la mediana de la población }\end{array}$ & $\begin{array}{c}\text { Ude Mann- } \\
\text { muestras } \\
\text { independientes }\end{array}$ & 0,0011 & $\begin{array}{c}\text { Rechazar la } \\
\text { hipótesis } \\
\text { nula }\end{array}$ \\
\hline $\begin{array}{c}\text { La distribución de } \\
\text { los tiempos en la } \\
\text { línea para la } \\
\text { comida es la } \\
\text { misma en las dos } \\
\text { fragatas. }\end{array}$ & $H_{0}: \mu_{1}=\mu_{2}$ versus $H_{1}: \mu_{1} \neq \mu_{2}$ & $\begin{array}{c}\text { t de Student } \\
\text { para } 2 \text { muestras } \\
\text { independientes }\end{array}$ & 0,000 & $\begin{array}{c}\text { Rechazar la } \\
\text { hipótesis } \\
\text { nula }\end{array}$ \\
\hline $\begin{array}{c}\text { La distribución de } \\
\text { los tiempos en la } \\
\text { línea para la } \\
\text { cena es la misma } \\
\text { en las dos } \\
\text { fragatas. }\end{array}$ & donde la población $\mu$ es la media de la población & $\begin{array}{c}\text { para } 2 \text { muestras } \\
\text { independientes }\end{array}$ & 0,000 & $\begin{array}{c}\text { Rechazar la } \\
\text { hipótesis } \\
\text { nula }\end{array}$ \\
\hline
\end{tabular}

Tabla 3-14 Tabla resumen de resultados de contrastes de hipótesis de los tiempos en la línea (Elaboración propia)

Con los análisis efectuados a los tiempos en la línea del comedor, se puede concluir que:

- Los tiempos de servicio en la línea de ambas fragatas son diferentes.

- Los tiempos de servicio en la línea dentro de cada fragata son diferentes entre las distintas comidas.

- Con los datos disponibles no se puede inferir una única distribución poblacional.

Con los expertos se consideró que, siendo el propósito del EMA conocer si alguna de las alternativas de comedor se saturaría cuando hubiese un aumento de dotación y, como ya se comentó, por experiencia la comida es el reparto con mayor afluencia de personal, se decidió que en el software AnyLogic se simulará con la distribución de tiempo en la línea de la comida de la F-105; Normal, $N(57,8 ; 18,8)$ segundos por ser la que tiene mayor promedio.

Como se adelantó en la información reflejada en la tabla resumen de los análisis efectuados a los datos (Tabla 3-13), no se pudieron obtener datos del tiempo de servicio en la línea del portaaviones $\mathrm{JCl}$. Se tomaron las horas de incorporación a la cola y las horas de sentarse a la mesa, con esto, se tiene información de la suma del tiempo en cola más el tiempo de servicio en la línea. En la Figura 3-72 se puede ver como se graficó, 
sobre un diagrama de dispersión, las horas de incorporación a la cola con el tiempo de cola más línea (hora llegada: tiempo en la cola + tiempo en la línea).

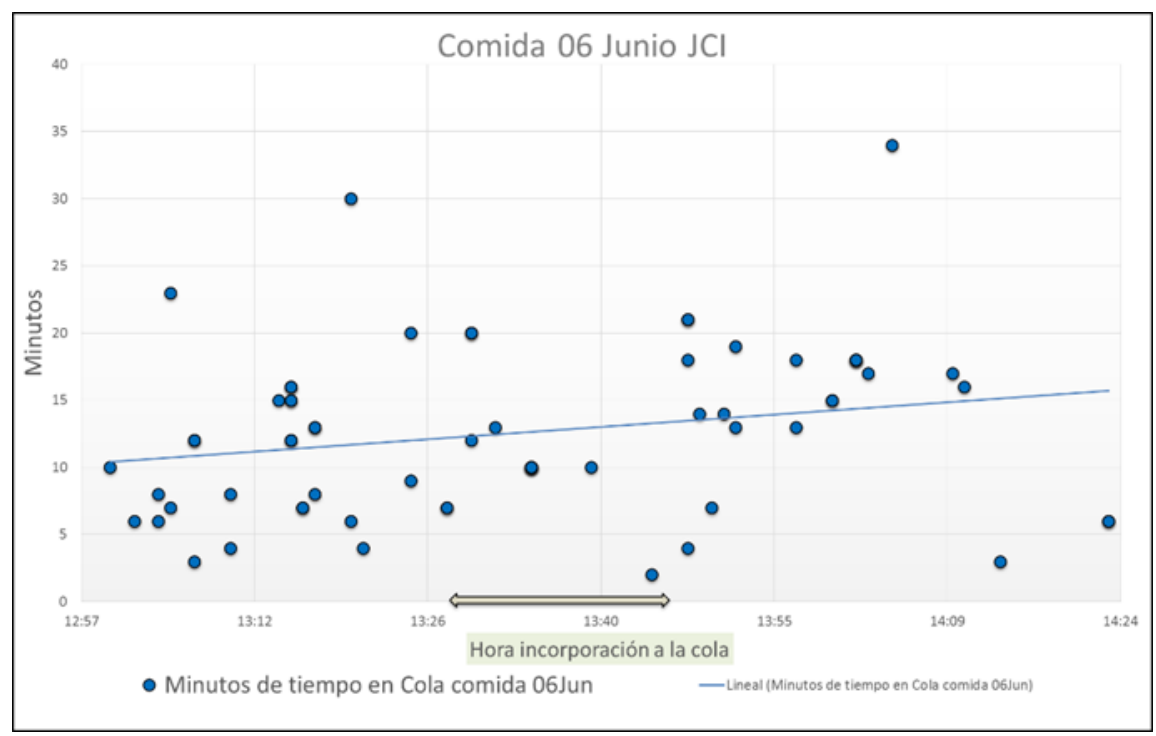

Figura 3-72 Gráfica de dispersión en el eje de abscisas: hora incorporación a la cola; en el eje de ordenadas: tiempo en sentarse a la mesa

Se aprecia que no existe correlación, por lo que no se puede inferir el tiempo de espera en función de la hora de llegada al comedor. Esto es consecuencia, entre otras, de la política de cola en los buques en la que existen prioridades por rango y por actividades previstas (ver B.5).

\subsection{Tiempo en Desayuno, Comida y Cena.}

Se entiende por tiempo en desayuno, comida y cena como el tiempo desde que un individuo se sienta para ingerir los alimentos hasta que se levanta una vez finalizada la ingesta. En la gráfica de la Figura 3-73, se puede observar las distribuciones de los tiempos de duración de las comidas en los tres buques. 


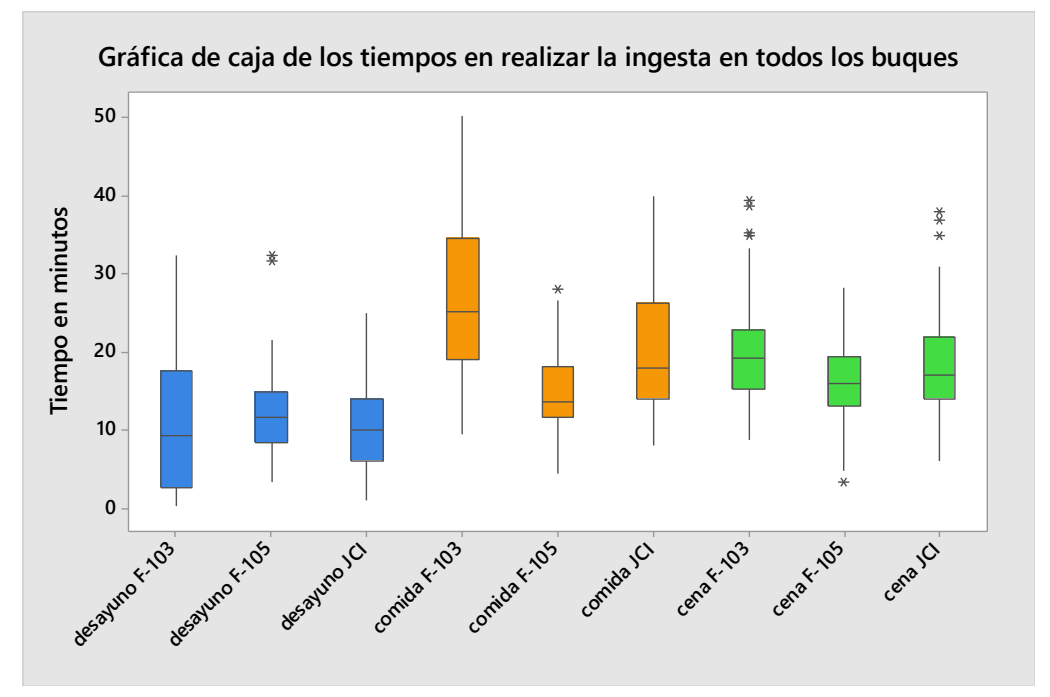

Figura 3-73 Gráfica Box-Plot de los tiempos en realizar la ingesta en todos los buques

En las gráficas de Figura 3-74 se observan las distribuciones de los tiempos en realizar las comidas de la fragata F-103. El desayuno (azul) es el que tiene duraciones menores, es una distribución positivamente sesgada. En la comida (naranja) se aprecia una bimodalidad que, en un análisis más detallado, se apreció que fue debido al grupo que comió el segundo día de recogida de datos, desconociéndose la razón del aumento del tiempo de ingesta (ver Figura 3-75). La cena (verde) muestra más simetría y curtosis.

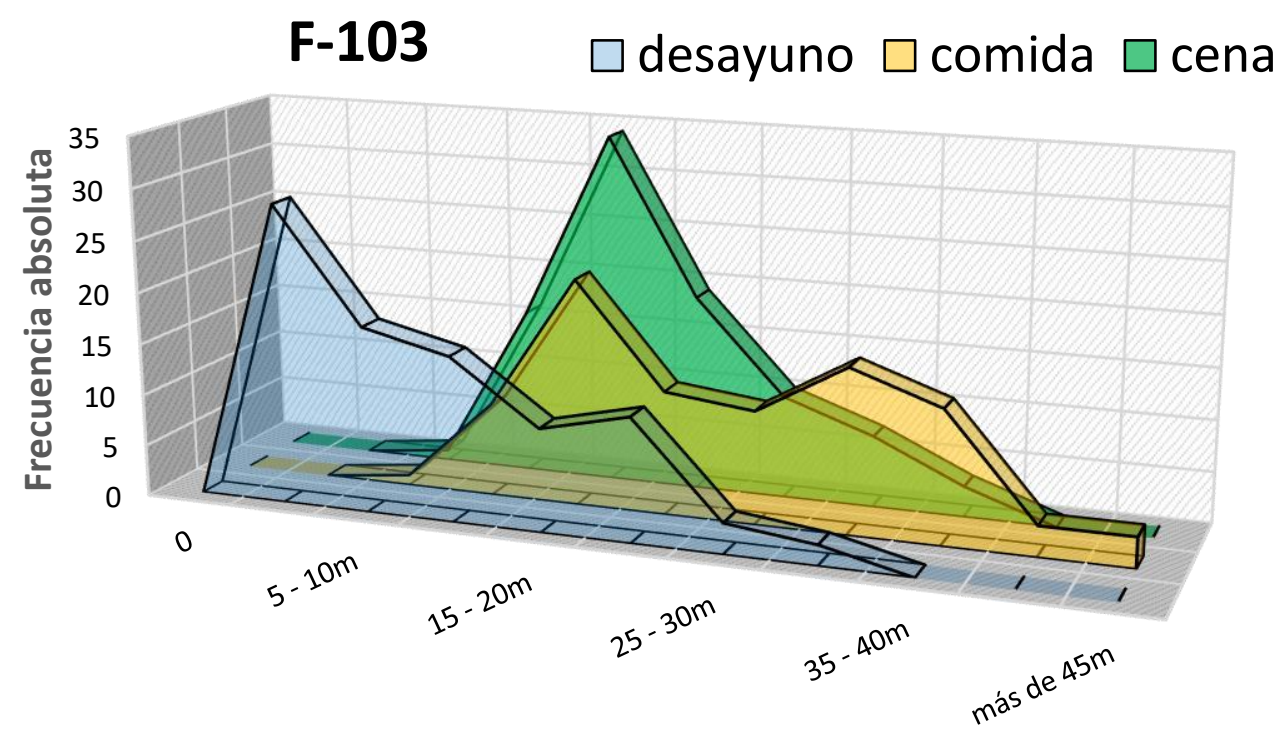

Tiempo empleado en realizar la ingesta F-103

\begin{tabular}{|c|c|c|c|c|c|c|c|c|c|c|c|}
\hline & 0 & $<5 \mathrm{~m}$ & $5-10 m$ & $\begin{array}{l}10- \\
15 \mathrm{~m}\end{array}$ & $\begin{array}{l}15- \\
20 m\end{array}$ & $\begin{array}{l}20- \\
25 \mathrm{~m}\end{array}$ & $\begin{array}{l}25- \\
30 \mathrm{~m}\end{array}$ & $\begin{array}{l}30- \\
35 m\end{array}$ & $\begin{array}{l}35- \\
40 m\end{array}$ & $\begin{array}{l}40- \\
45 \mathrm{~m}\end{array}$ & $\begin{array}{c}\text { más de } \\
45 \mathrm{~m}\end{array}$ \\
\hline$\square$ desayuno & 0 & 29 & 18 & 16 & 10 & 12 & 3 & 2 & 0 & 0 & 0 \\
\hline$\square$ comida & 0 & 0 & 1 & 9 & 22 & 12 & 11 & 16 & 13 & 3 & 3 \\
\hline 口cena & 0 & 0 & 1 & 16 & 34 & 19 & 10 & 7 & 3 & 0 & 0 \\
\hline
\end{tabular}




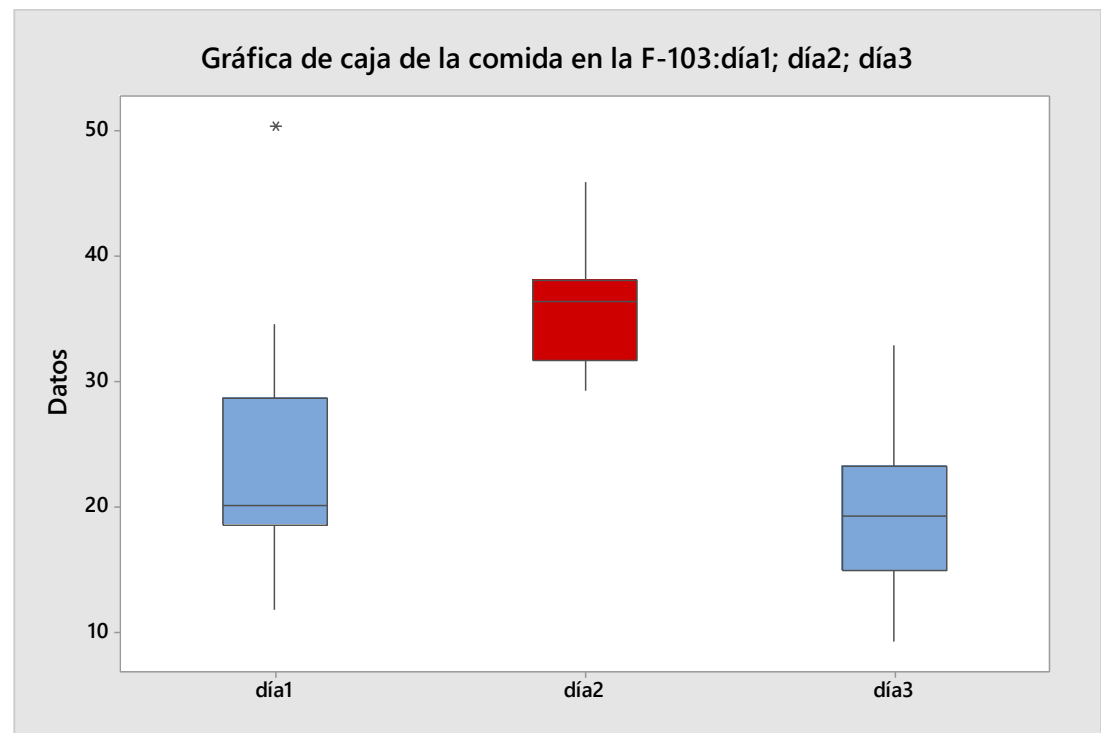

Figura 3-75 Gráfica de caja de la duración de las comidas en la F-103

En las gráficas de Figura 3-76 se observan las distribuciones de los tiempos en realizar las comidas de la fragata F-105. El desayuno tiene una distribución más platicúrtica y simétrica que en la F-103, también está ligeramente sesgada a la derecha. La comida es más leptocúrtica que en la F-103 y con sesgo positivo. La cena se muestra más platicúrtica que en la F-103 y es bastante simétrica.

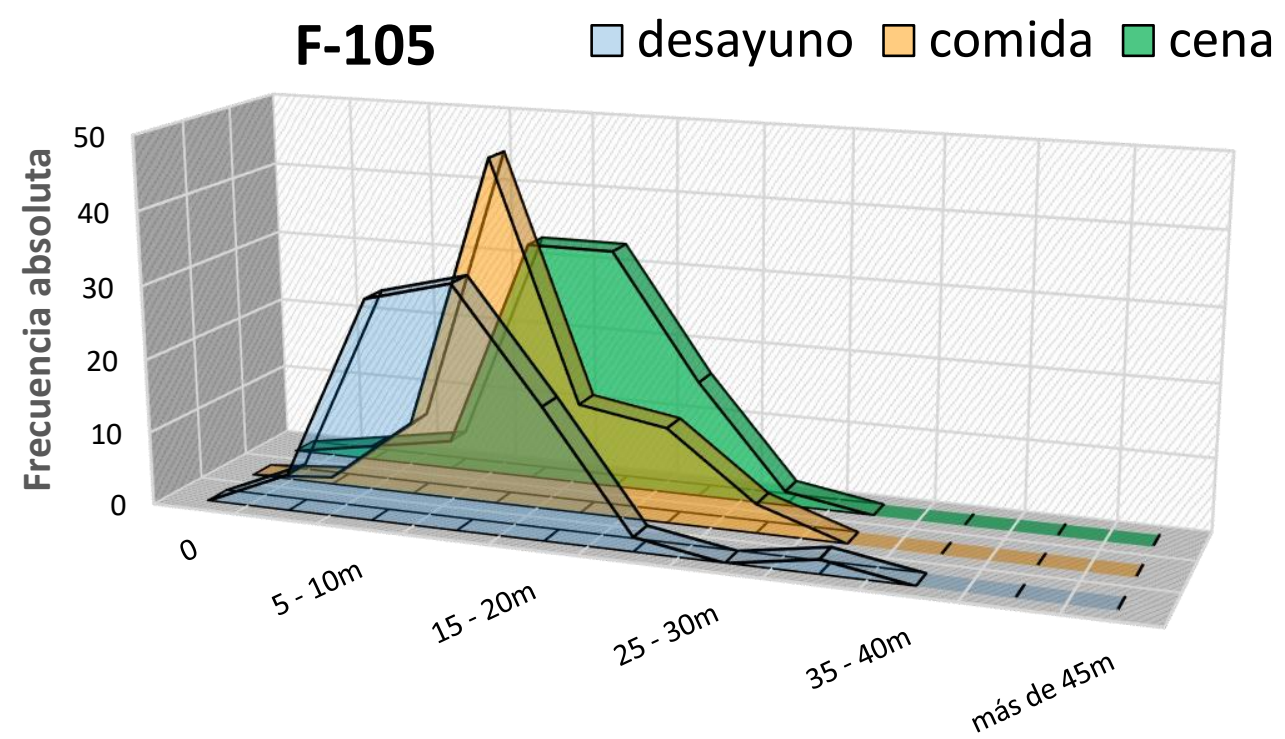

Tiempo empleado en realizar la ingesta F-105

\begin{tabular}{|c|c|c|c|c|c|c|c|c|c|c|c|}
\hline & 0 & $<5 \mathrm{~m}$ & $5-10 m$ & $\begin{array}{l}10- \\
15 \mathrm{~m}\end{array}$ & $\begin{array}{l}15- \\
20 \mathrm{~m}\end{array}$ & $\begin{array}{l}20- \\
25 \mathrm{~m}\end{array}$ & $\begin{array}{l}25- \\
30 m\end{array}$ & $\begin{array}{l}30- \\
35 \mathrm{~m}\end{array}$ & $\begin{array}{l}35- \\
40 \mathrm{~m}\end{array}$ & $\begin{array}{l}40- \\
45 m\end{array}$ & $\begin{array}{c}\text { más de } \\
45 \mathrm{~m}\end{array}$ \\
\hline$\square$ desayuno & 0 & 5 & 30 & 33 & 18 & 2 & 0 & 2 & 0 & 0 & 0 \\
\hline 口comida & 0 & 1 & 10 & 47 & 15 & 13 & 4 & 0 & 0 & 0 & 0 \\
\hline 口cena & 0 & 2 & 4 & 33 & 33 & 16 & 2 & 0 & 0 & 0 & 0 \\
\hline
\end{tabular}

Figura 3-76 Tiempos empleados en la ingesta F-105 
En las gráficas de la Figura 3-77 se observan las distribuciones de los tiempos empleados por los alumnos en realizar las comidas en el portaaviones $\mathrm{JCl}$. El desayuno muestra bastante simetría y un pequeño sesgo positivo. En la comida se distinguen dos modas que están relacionadas con los dos días de toma de datos en los que, por circunstancias desconocidas, el comportamiento fue diferente. Los datos de la cena solo se registraron un día, presentan un comportamiento parecido a los otros buques, el rasgo más característico es su claro sesgo positivo.

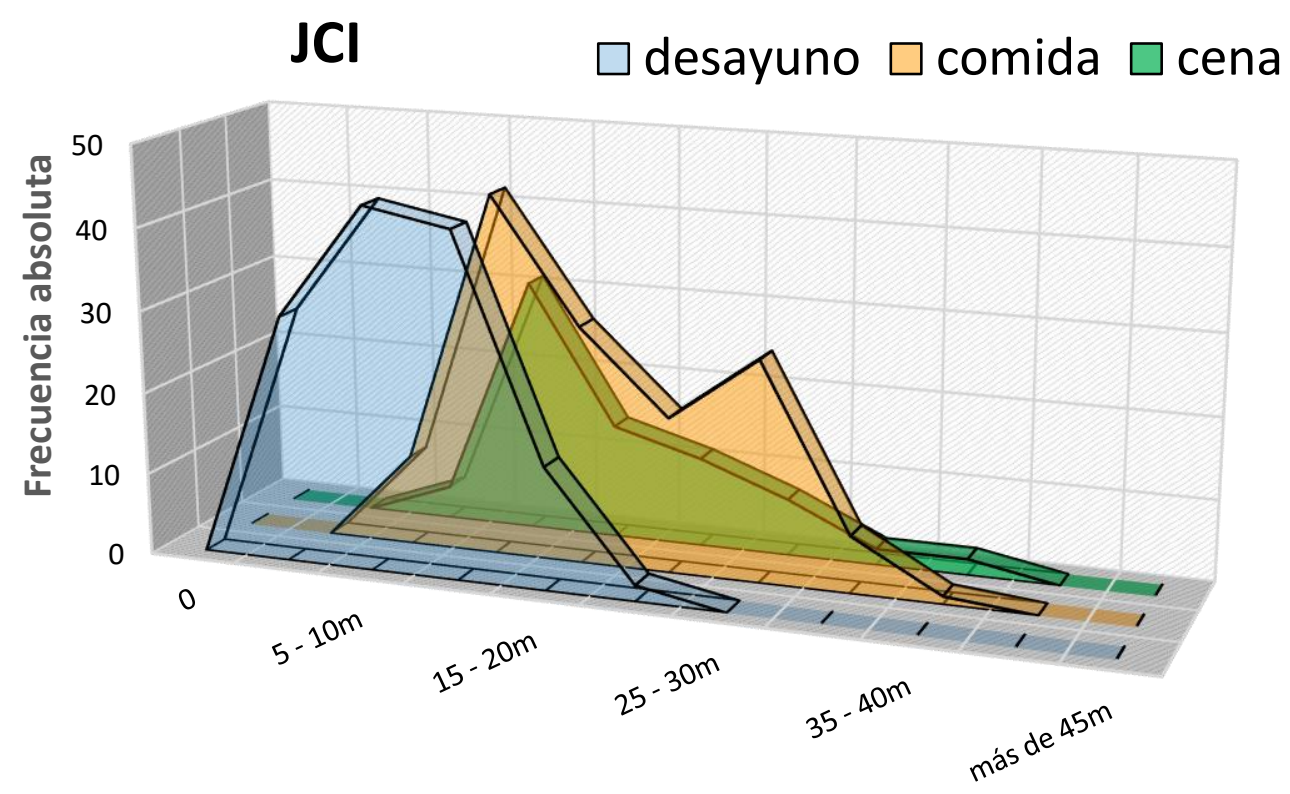

Tiempo empleado en realizar la ingesta $\mathrm{JCl}$

\begin{tabular}{|c|c|c|c|c|c|c|c|c|c|c|c|}
\hline & 0 & $<5 m$ & $5-10 m$ & $\begin{array}{l}10- \\
15 \mathrm{~m}\end{array}$ & $\begin{array}{l}15- \\
20 \mathrm{~m}\end{array}$ & $\begin{array}{l}20- \\
25 \mathrm{~m}\end{array}$ & $\begin{array}{l}25- \\
30 \mathrm{~m}\end{array}$ & $\begin{array}{l}30- \\
35 \mathrm{~m}\end{array}$ & $\begin{array}{l}35- \\
40 \mathrm{~m}\end{array}$ & $\begin{array}{l}40- \\
45 \mathrm{~m}\end{array}$ & $\begin{array}{l}\text { más de } \\
45 \mathrm{~m}\end{array}$ \\
\hline Ddesayuno & 0 & 30 & 44 & 42 & 15 & 2 & 0 & 0 & 0 & 0 & 0 \\
\hline$\square$ comida & 0 & 0 & 11 & 44 & 29 & 19 & 27 & 7 & 1 & 0 & 0 \\
\hline 口cena & 0 & 0 & 4 & 31 & 14 & 11 & 7 & 2 & 2 & 0 & 0 \\
\hline
\end{tabular}

Figura 3-77 Tiempos empleados en la ingesta JCl

Se realizaron las pruebas de bondad de ajuste a una Normal a todas las distribuciones, resultando que, con un $95 \%$ de confianza, se rechazaban las hipótesis nulas de normalidad, excepto para los tiempos del desayuno (eliminando los datos atípicos) y la cena de la F-105 (ver B.6).

Ante la ausencia de normalidad de las distribuciones se realiza la prueba no paramétrica de Kruskal-Wallis para comprobar si los tiempos empleados en las distintas ingestas pertenecen a la misma población [167]. En la Tabla 3-15 se observa que al 95\% de 
confianza se puede rechazar la hipótesis nula sobre igualdad de distribuciones entre los tres buques para las tres pruebas realizadas (ver B.7).

\begin{tabular}{|c|c|c|c|c|}
\cline { 2 - 5 } \multicolumn{1}{c|}{} & Hipótesis & Prueba & p-valor & Decisión \\
\hline $\begin{array}{c}\text { La distribución de } \\
\text { los tiempos en } \\
\text { ingerir el } \\
\text { desayuno es la } \\
\text { misma en los tres } \\
\text { buques. }\end{array}$ & $\begin{array}{c}H_{0}: \eta_{1}=\eta_{2}=\eta_{3} \text { versus medianas no son todas iguales } \\
\text { donde } \eta \text { es la mediana de la población }\end{array}$ & $\begin{array}{c}\text { H de Kruskal- } \\
\text { Wallis para } \\
\text { muestras } \\
\text { independientes }\end{array}$ & 0,02 & $\begin{array}{c}\text { Rechazar la } \\
\text { hipótesis } \\
\text { nula }\end{array}$ \\
\hline $\begin{array}{c}\text { La distribución de } \\
\text { los tiempos en } \\
\text { ingerir la comida } \\
\text { es la misma en } \\
\text { los tres buques. }\end{array}$ & $\begin{array}{c}H_{1}: \text { las medianas no son todas iguales } \\
\text { donde } \eta \text { es la mediana de la población }\end{array}$ & $\begin{array}{c}\text { H de Kruskal- } \\
\text { Wallis para } \\
\text { muestras }\end{array}$ & 0,000 & $\begin{array}{c}\text { Rechazar la la } \\
\text { hipótesis } \\
\text { nula }\end{array}$ \\
\hline $\begin{array}{c}\text { La distribución de } \\
\text { los tiempos en } \\
\text { ingerir la cena es } \\
\text { la misma en los } \\
\text { tres buques. }\end{array}$ & $\begin{array}{c}H_{1}: \text { las medianas no son todas iguales } \\
\text { donde } \eta \text { es la mediana de la población }\end{array}$ & $\begin{array}{c}\text { Wallis para } \\
\text { muestras } \\
\text { independientes }\end{array}$ & 0,000 & $\begin{array}{c}\text { Rechazar la } \\
\text { hipótesis } \\
\text { nula }\end{array}$ \\
\hline
\end{tabular}

Tabla 3-15 Tabla resumen de resultados de contrastes de hipótesis de los tiempos de las comidas (Elaboración

$$
\text { propia) }
$$

Se realizó posteriormente la prueba ANOVA con comparaciones en parejas de Fisher, para la comprobación de igualdad de medias dos a dos, resultando que, aunque las distribuciones sean distintas: no se puede rechazar la hipótesis de igualdad de medias de los tiempos empleados en el desayuno en los tres buques; y sí se puede rechazar estadísticamente la hipótesis de igualdad de medias de los tiempos empleados en la comida y la cena en los tres buques (ver B.7).

Con los análisis efectuados a los tiempos de la ingesta, se puede concluir que:

- Las distribuciones de los tiempos empleados en el desayuno, comida y cena son distintas entre los buques.

- El promedio de tiempo empleado en el desayuno es el mismo en los tres buques.

- Los promedios de tiempo empleado en la comida y la cena son diferentes en los tres buques.

- Las distribuciones de los tiempos de la comida, en los tres días de toma de datos, en la F-103 han sido muy diferentes.

- Del análisis de los datos no se puede inferir una única distribución plausible. 
Con los expertos se acordó seleccionar la distribución que en promedio tarde más en realizar la ingesta de la comida. La que promedia un tiempo mayor es la F-103, esto implica, que el personal ocupa durante más tiempo un asiento en el comedor.

En la siguiente Tabla 3-16 se muestran los promedios de la duración de las comidas en la F-103.

\begin{tabular}{|c|c|c|c|}
\hline Factor & $N$ & Media & Desv. Est. \\
\hline día1 & 30 & 23,47 minutos & 7,74 \\
\hline día2 & 30 & 36,07 minutos & 4,19 \\
\hline Día3 & 30 & 19,43 minutos & 5,49 \\
\hline
\end{tabular}

Tabla 3-16 Promedios de duración de las comidas en la F-103 (Elaboración propia)

Con los tiempos de los tres días de la comida en la F-103, se efectúa una prueba de bondad de ajuste (ver B.8). Para la comprobación de igualdad de medias dos a dos, se efectuó una ANOVA con comparaciones en parejas de Fisher, resultando que sí se puede rechazar la hipótesis de igualdad de medias (ver B.9).

En consecuencia, se determinó simular en el AnyLogic con la distribución de tiempo de la comida de la F-103 del día 2, la Normal, $N(36,1 ; 4,2)$ minutos, por ser la de mayor promedio de ocupación del comedor.

\subsection{El software AnyLogic}

Se consideraron diferentes métodos de modelación para este estudio; entre ellas se encuentra la teoría de las colas analítica, que es efectiva para este tipo de análisis, pero sólo cuando las relaciones de los proveedores de servicios y los destinatarios son estáticas como, por ejemplo, las ventanillas de los bancos [168].

Finalmente, se decidió utilizar AnyLogic, que permite simular los comportamientos sociales de los individuos y tener en cuenta la geometría de los compartimentos, cuestiones difícilmente modelables en un estudio analítico.

El software AnyLogic es una herramienta de simulación que soporta los tres métodos de modelo: dinámica del sistema, eventos discretos y basado en agentes [113]. 
La simulación de tráfico peatonal es una parte importante en sectores de: construcción, diseño de instalaciones, aeropuertos, estaciones de ferrocarril, buques, etc. Estos análisis pueden ayudar, por ejemplo, a los arquitectos e ingenieros a mejorar sus diseños, a los propietarios de instalaciones revisar un posible cambio en el edificio y a las autoridades civiles simular posibles rutas de evacuación de un colegio.

Los flujos peatonales son complejos y requieren de una simulación de baja abstracción altamente detallada. Los peatones siguen reglas básicas que han sido determinadas por estudios teóricos detallados; se mueven a velocidades predeterminadas, evitan espacios físicos tales como paredes, así como a otras personas y usan información sobre las multitudes que los rodean para ajustar su distancia y velocidad. Los resultados han sido probados muchas veces en estudios de campo [169].

AnyLogic, por ejemplo, puede resolver estos problemas de tráfico peatonal:

- Cálculo de tiempos y rendimiento en una instalación de grandes dimensiones. Por ejemplo, un aeropuerto, si el objetivo es crear un diseño que minimice el tiempo de viaje y garantice que los flujos peatonales no interfieran entre sí, una simulación AnyLogic puede probar fácilmente las condiciones normales, especiales o de volumen máximo [170].

- Análisis de impacto de tráfico peatonal en un parque temático o en un museo. Se puede realizar una simulación para entender como los cambios de ubicación de un quiosco o un panel de publicidad pueden afectar a la experiencia del cliente y a los flujos dentro del recinto.

- Análisis de evacuación. El modelado de eventos de emergencia puede ayudar a desarrollar planes de evacuación eficaces que salvan vidas.

En este trabajo se empleará AnyLogic para simular la fluidez y los tiempos de servicio en los tres diseños/alternativas del comedor de marinería de la fragata F-110.

\subsection{Experimentos del Comedor}

Con las conclusiones de los análisis estadísticos de los datos recopilados, se realizaron las simulaciones con el software AnyLogic (Figura 3-78).

Los experimentos se diseñaron de la siguiente manera: 
- En todas las réplicas se utilizaron las mismas variables de comportamiento del personal durante el reparto de la Comida. El programa admite varias configuraciones de comportamiento, pero como entre los objetivos que se persiguen con la experimentación no estaba el conocimiento de los tiempos reales sino la comparativa entre alternativas, se optó por la configuración por defecto del programa.

- La simulación consistió en una recreación de la comida en las tres alternativas de comedor, para aproximadamente $2 / 3$ de la marinería, más un grupo de 18 personas de refuerzo que pudiese llevar el buque.

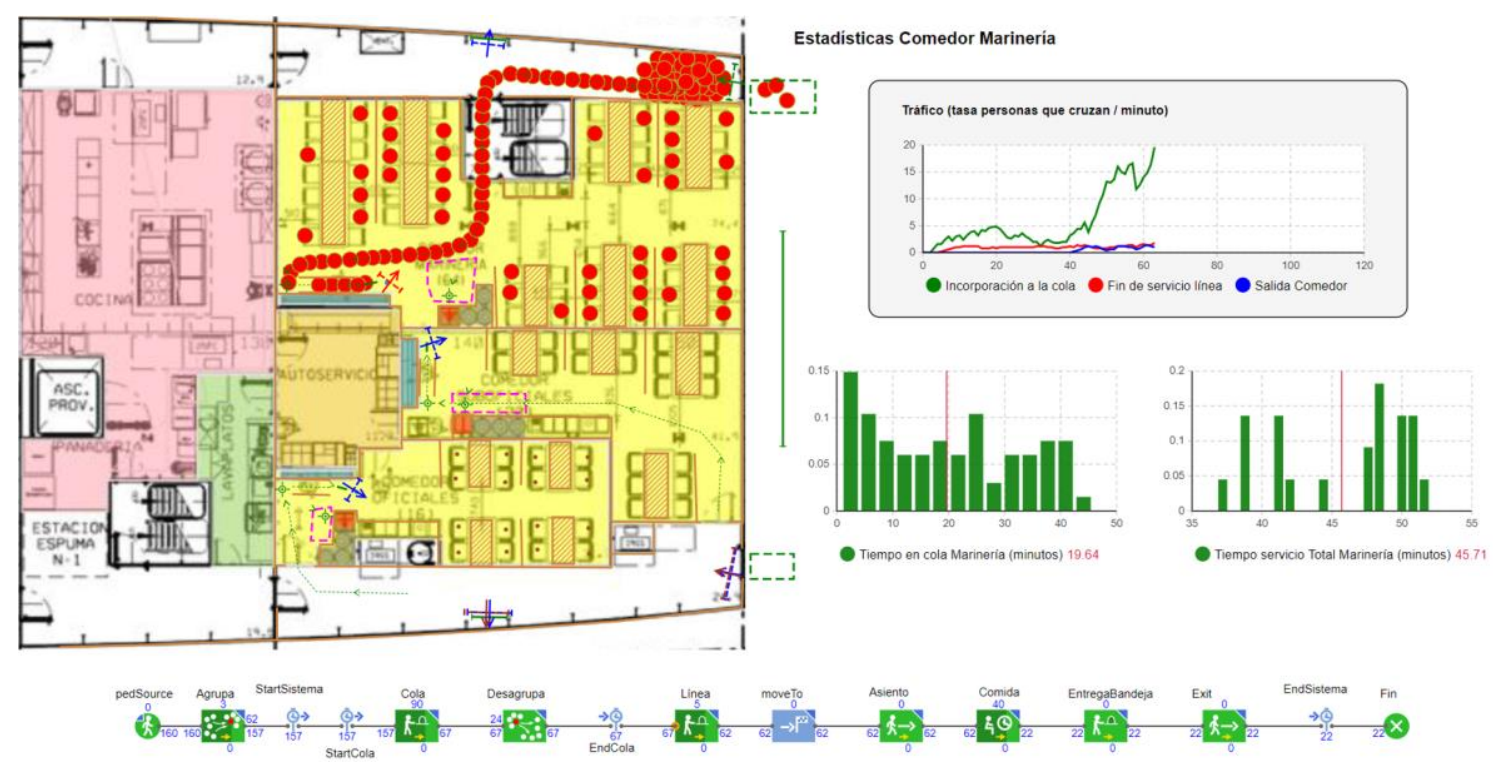

Figura 3-78 Ejemplo de una simulación de saturación con 160 personas (Alt5), tasa de llegada Exp(320). En la imagen, sobre la fila de procesos, se observa que: las 160 personas han acudido al comedor, 3 no han podido incorporarse al pasillo del comedor por culpa del tumulto, 90 están en la cola, 5 en la línea, 40 están comiendo y 22 ya lo han abandonado

El esquema de la simulación consistió en un conjunto seriado de procesos por los que trascurre cada persona de forma individual (ver Figura 3-79).

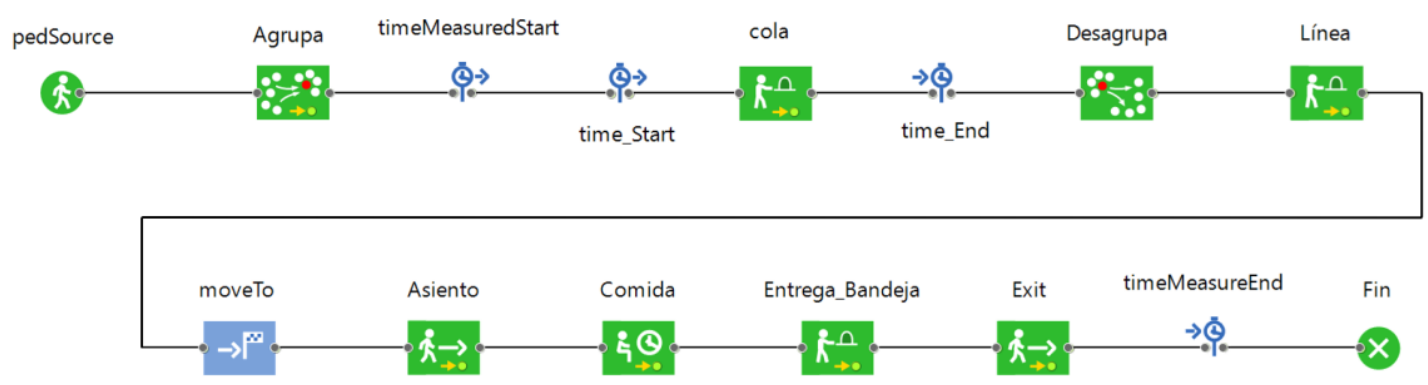

Figura 3-79 Esquema de los procesos en la simulación en AnyLogic (Elaboración propia) 


\begin{tabular}{|c|c|}
\hline pedSource & $\begin{array}{l}\text { Este proceso genera la aparción de individuos que acuden al comedor conforme } \\
\text { a una distribución. Se programó la simulación con tres tasas de llegada, para } \\
\text { cada alternativa ( } 9 \text { experimentos). Exp(80), Exp(160) y Exp(320) (Siendo la } \\
\text { unidad de tiempo } 1 \text { hora). Con esto se pretende estudiar el comportamiento del } \\
\text { comedor desde, cuando todo el personal acude prácticamente a la vez, hasta, } \\
\text { cuando llega más espaciado en el tiempo. }\end{array}$ \\
\hline & $\begin{array}{l}\text { Permite agrupar al personal aleatoriamente, siendo así un comportamiento } \\
\text { similar al real. Se programó una distribución Uniforme, } U(1,4) \text { personas. } \\
\text { Cuando se genera un individuo en el proceso (pedSource), se le asigna } \\
\text { aleatoriamente un número de agrupamiento que obliga al individuo a esperar } \\
\text { hasta formar el grupo y, después, se realiza la entrada grupal por el acceso de } \\
\text { proa babor para dirigirse al comedor. }\end{array}$ \\
\hline $\begin{array}{c}\text { timeMeasuredStart } \\
\longrightarrow\end{array}$ & $\begin{array}{l}\text { Permite medir el tiempo individualmente desde que acude al comedor hasta que } \\
\text { sale. }\end{array}$ \\
\hline & Permite medir el tiempo que permanecen los individuos en al cola. \\
\hline 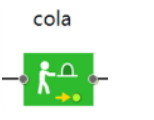 & $\begin{array}{l}\text { Este proceso permite ordenar la cola y dirigirla a un punto de servicio donde } \\
\text { comienza la línea de reparto. Se seleccionó la política FIFO. }\end{array}$ \\
\hline & $\begin{array}{l}\text { Este proceso desagrupa el grupo que se hubiese formado anteriormente. Esto } \\
\text { es necesario para evitar comportamientos grupales dentro del comedor que } \\
\text { impen la asignación individual de asientos. }\end{array}$ \\
\hline$k_{\rightarrow 0}^{n}-$ & $\begin{array}{l}\text { Este proceso permite simular el tiempo que tarda un individuo en ser atendido. } \\
\text { Como ya se ha mencionado anteriormente, se decidió experimentar con la } \\
\text { distribución del tiempo de Línea de media más elevada, Línea comida de la F- } \\
105, \text { Normal, } N(57,8 ; 18,8) \text { segundos. Se seleccionó la política FIFO. }\end{array}$ \\
\hline $\begin{array}{l}\text { moveTo } \\
-\rightarrow T^{m} .\end{array}$ & $\begin{array}{l}\text { Este recurso permite a cada individuo que, una vez atendido en la línea, primero } \\
\text { se dirija a un punto al final de la línea, después se ejecuta una función Java que } \\
\text { permite escojer aleatoriamente un asiento entre los que estén libres, en caso } \\
\text { de estar todo ocupado permenece en espera. }\end{array}$ \\
\hline $\begin{array}{l}\text { Asiento } \\
-\sum_{i \rightarrow 0} \rightarrow-\end{array}$ & $\begin{array}{l}\text { Este proceso obliga al individuo a dirigirse y alcanzar el asiento asignado en el } \\
\text { comedor. Los asientos están definidos por (coordenadas }(x, y)) \text {. La definición } \\
\text { de asientos (tipo bancada con respaldo y fijos al suelo) ralentiza el sentarse si } \\
\text { las sillas adyacentes están ocupadas. }\end{array}$ \\
\hline
\end{tabular}


Comida Este proceso permite al individuo una vez que alcanza su asiento, realizar un : tiempo de espera que simula la ingesta. Como ya se mencionó, se experimentó con la distribución del tiempo comida de promedio más elevadoa. Distribución Norma, $N(36 ; 4,15)$ minutos. Cuando finaliza, se ejecuta una función Java específica que "devuelve" la silla a la lista de asientos libres.

Entrega_Bandeja Este proceso lleva al individuo a la zona de los cubos de basura para tirar los - desperdicios y depositar la bandeja en el bandejero. De este proceso no se obtuvieron datos sobre el tiempo que conlleva, por tanto, se escogió una distribución Uniforme, $U(5 ; 25)$ segundos. Se seleccionó la política de cola FIFO.

Exit Este proceso dirige al individuo a la salida habilitada que se encuentra en el pasillo adyacente al comedor.

Fin

Este proceso hace desaparecer al individuo.

La licencia gratuita de AnyLogic no permitió aplicar el método de simulación de Montecarlo ni almacenar los datos del experimento, por lo que inicialmente se proyectó un tamaño muestral de 10 réplicas para cada alternativa y cada tasa de llegada (90 réplicas). Mediante el estadístico del $\quad$ A.2, se comprobó si el número de réplicas era suficiente para una estimación de la media poblacional dentro de un intervalo de 3 minutos. 


\subsection{Resultados de los Experimentos}

Los resultados obtenidos en la simulación con AnyLogic se pueden observar en la Tabla 3-17.

Exponencial 80

Exponencial 160

Exponencial 320

\begin{tabular}{|c|c|c|c|c|c|c|c|c|c|}
\hline $\begin{array}{l}\text { Promedio } \\
\text { (Tiempo en } \\
\text { minutos) }\end{array}$ & Alt40pt & Alt5 & Alt6 & Alt4Opt & Alt5 & Alt6 & Alt4Opt & Alt5 & Alt6 \\
\hline $\begin{array}{r}\text { Tiempo de } \\
\text { ocupación del } \\
\text { comedor }\end{array}$ & 125 & 125,3 & 125,7 & 125 & 124,8 & 124 & 120 & 123 & 122,2 \\
\hline $\begin{array}{r}\text { Tiempo } \\
\text { empleado en } \\
\text { comer }\end{array}$ & 48,9 & 50,7 & 49,4 & 64,7 & 64,9 & 64,8 & 71 & 70,4 & 70,6 \\
\hline Tiempo en cola & 6,5 & 8,6 & 6,6 & 22 & 22 & 21,9 & 28,3 & 28,2 & 28,1 \\
\hline Velocidad $(\mathrm{m} / \mathrm{s})$ & 0,562 & 0,556 & 0,557 & 0,548 & 0,548 & 0,527 & 0,522 & 0,507 & 0,467 \\
\hline
\end{tabular}

Tiempo de ocupación del comedor (ver Figura 3-80)

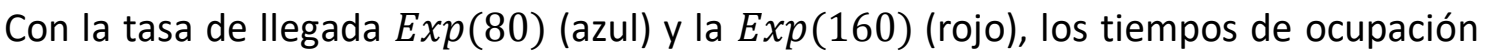
del comedor son muy similares, las diferencias máximas son de tan solo un minuto. Cuando el ritmo de llegada es más elevado, $\operatorname{Exp}(320)$ (verde), se aprecian unas ligeras diferencias que alcanzan los 3 minutos en promedio. La Alt4Opt tiene el menor tiempo de ocupación del comedor con 120 minutos y la alternativa con más promedio es la Alt5 con 123 minutos.

TIEMPO OCUPACIÓN COMEDOR

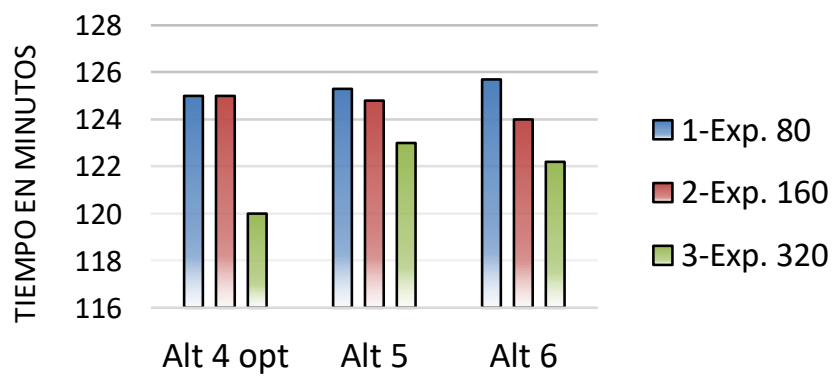

Figura 3-80 Gráfica de barras con los promedios de tiempo de ocupación del comedor 


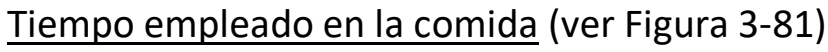

Los resultados para las distintas tasas de llegada en los tres comedores son muy similares, con una diferencia máxima con la tasa de llegada $\operatorname{Exp}(80)$, cuando el promedio de los tiempos empleados por los 80 individuos en comer (cola + servicio en la línea + comida + entrega de bandeja) entre el más rápido, Alt40pt con 48,9, y el más lento, Alt5 con 50,7 , es de 1,8 minutos.

Conforme se aumenta la tasa de llegada $(\operatorname{Exp}(160)$ y $\operatorname{Exp}(320))$, se aprecia un aumento del promedio de tiempo que emplean en comer muy semejante para las tres alternativas. Este acrecentamiento del tiempo es debido a la dilatación del tiempo en cola (se verá en el siguiente análisis), que aumenta de manera ostensible por llegar los individuos menos espaciados en el tiempo.

TIEMPO EMPLEADO EN LA COMIDA

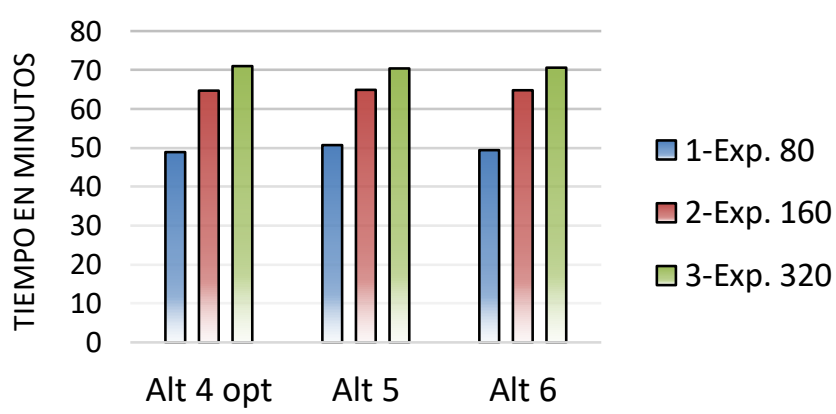

Figura 3-81 Gráfica de barras con los promedios del tiempo empleado en la comida

Tiempo en la cola (ver Figura 3-82)

Los resultados del tiempo en la cola, para las distintas tasas de llegada en los tres comedores, son muy parejos. La máxima diferencia ocurre con la tasa de llegada $\operatorname{Exp}(80)$, cuando el promedio de espera en la cola es menor en la Alt4Opt, 6,5 minutos, y el mayor es en la Alt5 con 8,6 minutos.

Conforme se aumenta la tasa de llegada $(\operatorname{Exp}(160)$ y $\operatorname{Exp}(320))$, se aprecia un abultado crecimiento del tiempo en la cola muy similar para las tres alternativas, en promedio es superior al $300 \%$. 


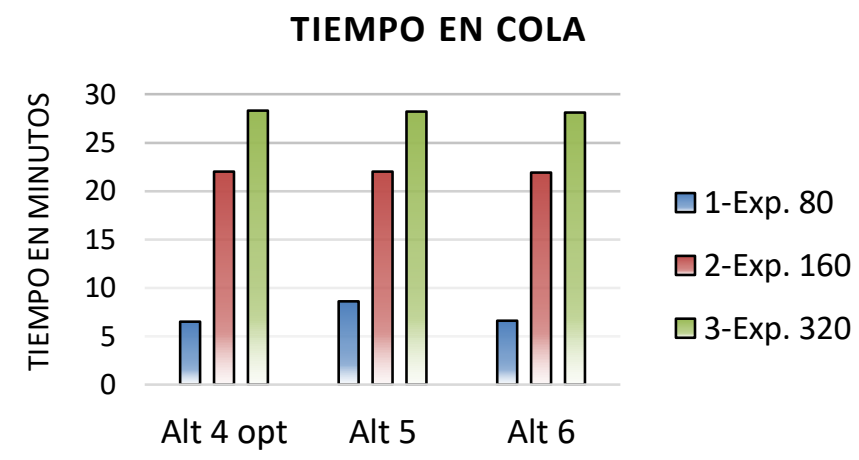

Figura 3-82 Gráfica de barras con los promedios del tiempo en cola

\section{Velocidad desplazamiento (ver Figura 3-83)}

Por último, la velocidad media a la que se han desplazado los individuos durante los procesos se interpretó como un indicador correlacionado con la fluidez de movimientos dentro del comedor que exterioriza el grado de muchedumbre.

Nuevamente, los resultados fueron bastante análogos. La Alt4Opt resultó el comedor más "despejado" para las distintas tasas de llegada. Las velocidades decrecieron conforme aumentaba la tasa de llegada, a la vez que ascendían las diferencias en promedio entre alternativas. La máxima diferencia se produjo con la tasa $\operatorname{Exp}(320)$, donde la Alt4Opt obtuvo una velocidad media de movimiento de 0,522 m/s, mejorando en 55 centésimas a la alternativa más lenta, la Alt6, que redujo su velocidad en casi un $20 \%$ respecto a la tasa $\operatorname{Exp}(80)$.

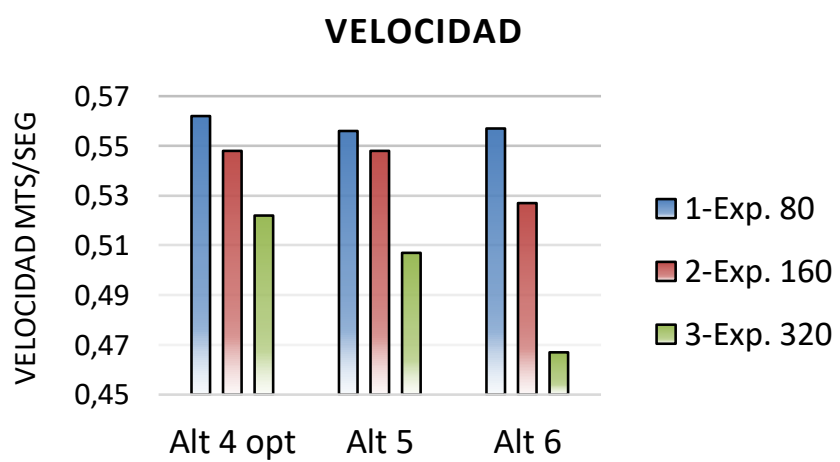

Figura 3-83 Gráfica de barras con los promedios de la velocidad de movimiento en los comedores

Sobre los resultados obtenidos se realizó un contraste de hipótesis para valorar si existían diferencias significativas entre las medias poblacionales de las muestras 
(Contraste ANOVA), obteniéndose con un nivel de confianza del 95\% los resultados de siguientes (Tabla 3-18):

\begin{tabular}{|c|c|c|c|c|c|c|c|c|c|}
\hline \multirow[b]{2}{*}{ Hipótesis nula } & \multicolumn{3}{|c|}{ Exponencial 80} & \multicolumn{3}{|c|}{ Exponencial 160} & \multicolumn{3}{|c|}{ Exponencial 320} \\
\hline & Prueba & Sig. & decisión & Prueba & Sig. & Decisión & Prueba & Sig. & Decisión \\
\hline $\begin{array}{l}\text { Las medias de } \\
\text { tiempo de ocupación } \\
\text { del comedor son } \\
\text { iguales entre las } \\
\text { alternativas. }\end{array}$ & ANOVA & 0,91 & $\begin{array}{c}\text { Conserve } \\
\text { la hipótesis } \\
\text { nula }\end{array}$ & ANOVA & 0,90 & $\begin{array}{c}\text { Conserve } \\
\text { la hipótesis } \\
\text { nula }\end{array}$ & ANOVA & 0,24 & $\begin{array}{c}\text { Conserve } \\
\text { la hipótesis } \\
\text { nula }\end{array}$ \\
\hline $\begin{array}{l}\text { Las medias de } \\
\text { tiempo empleado en } \\
\text { comer son iguales } \\
\text { entre las } \\
\text { alternativas. }\end{array}$ & ANOVA & 0,54 & $\begin{array}{c}\text { Conserve } \\
\text { la hipótesis } \\
\text { nula }\end{array}$ & ANOVA & 0,98 & $\begin{array}{c}\text { Conserve } \\
\text { la hipótesis } \\
\text { nula }\end{array}$ & ANOVA & 0,78 & $\begin{array}{c}\text { Conserve } \\
\text { la hipótesis } \\
\text { nula }\end{array}$ \\
\hline $\begin{array}{l}\text { Las medias de } \\
\text { tiempo en cola son } \\
\text { iguales entre las } \\
\text { alternativas. }\end{array}$ & ANOVA & 0,34 & $\begin{array}{l}\text { Conserve } \\
\text { la hipótesis } \\
\text { nula }\end{array}$ & ANOVA & 0,99 & $\begin{array}{l}\text { Conserve } \\
\text { la hipótesis } \\
\text { nula }\end{array}$ & ANOVA & 0,97 & $\begin{array}{c}\text { Consene } \\
\text { la hipótesis } \\
\text { nula }\end{array}$ \\
\hline $\begin{array}{l}\text { Las medias de } \\
\text { velocidad de los } \\
\text { individuos son } \\
\text { iguales entre las } \\
\text { alternativas. }\end{array}$ & ANOVA & 0,29 & $\begin{array}{c}\text { Conserve } \\
\text { la hipótesis } \\
\text { nula }\end{array}$ & ANOVA & 0,01 & $\begin{array}{c}\text { Rechace la } \\
\text { hipótesis } \\
\text { nula }\end{array}$ & ANOVA & 0,02 & $\begin{array}{c}\text { Rechace la } \\
\text { hipótesis } \\
\text { nula }\end{array}$ \\
\hline
\end{tabular}

Tabla 3-18 Resumen de los resultados ANOVA de los experimentos con AnyLogic (Elaboración propia)

Únicamente se puede rechazar la hipótesis nula sobre igualdad de medias para la velocidad de los individuos, resultando ser la media más lenta la del comedor Alt6. Este resultado pudiera estar justificado por ser el comedor de menores dimensiones y este hecho acentúa la saturación cuando los individuos acuden en un intervalo de tiempo corto $(\operatorname{Exp}(160)$ y $\operatorname{Exp}(320))$.

Los resultados de los contrastes se pueden consultar en los B.10, B.11 y B.12

\subsubsection{Jerarquización de las Alternativas}

Con los resultados de la simulación se procedió, sobre el programa ADLA, a dar valoraciones de las contribuciones de las alternativas a los subcriterios Desalojo Z/C y Libertad de Movimientos. 


\section{Subcriterio Desalojo Z/C}

Como ya se ha comentado, se estimó en 3 minutos el tiempo límite admisible para que toda la dotación su puesto en Z/C y dar la novedad al Comandante. Por consiguiente, en convenio con los expertos, se tomó la decisión de emplear los tiempos valiéndose de una función de utilidad lineal en la que el 100\% de utilidad, es decir, la máxima utilidad, estuviera determinada por el tiempo menor de desalojo (Alt6 $=35,63 \mathrm{~s}$ ), y el $0 \%$ de utilidad estuviera determinado para tiempos superiores a los 3 minutos, situación en la que sería inaceptable que hubiese alguien en el comedor (ver Figura 3-84).

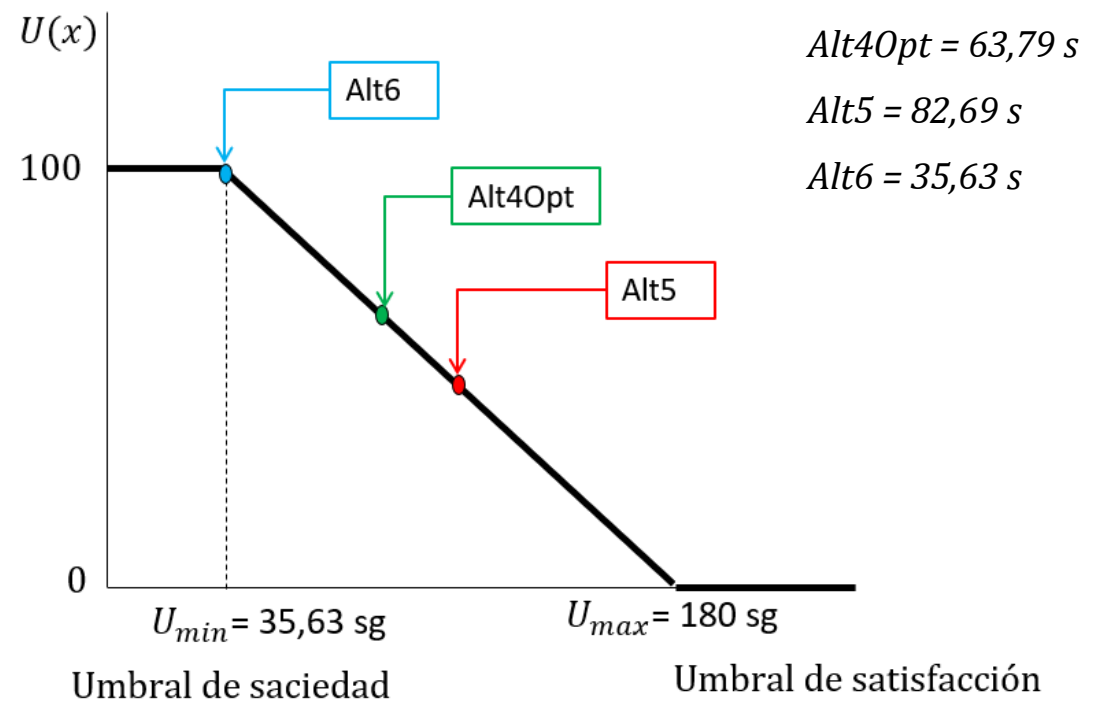

Figura 3-84 Utilidad del subcriterio de Desalojo Z/C basado en una función (gráfica sin escala) (Elaboración propia)

\section{$\underline{\text { Subcriterio Libertad de movimientos }}$}

Como se ha demostrado estadísticamente, con los resultados del contraste ANOVA, solo existen diferencias entre las alternativas para la variable velocidad de los individuos, que difieren cuando la tasa de llegada es $\operatorname{Exp}(160)$ o $\operatorname{Exp}(320)$.

Las velocidades menores resultaron cuando la tasa de llegada es $\operatorname{Exp}(320)$, pudiéndose derivar con ello, que esta tasa es la que genera mayores congestiones en los comedores. Consiguientemente, se tomó la decisión de emplear esas velocidades en una función de utilidad lineal. El $100 \%$ de utilidad y, por tanto, umbral de satisfacción, estuvo determinado por la velocidad media de los individuos en tránsito, esto es, la media de la velocidad que asignó AnyLogic por defecto que es de $0,75 \mathrm{~m} / \mathrm{s}$ (velocidad cómoda, Uniforme, $U[0,5 ; 1,0] \mathrm{m} / \mathrm{s})$. El $0 \%$ de utilidad estuvo determinado para la velocidad 
cero, que implicaría que no existió la posibilidad de moverse por culpa de la muchedumbre (ver Figura 3-85).

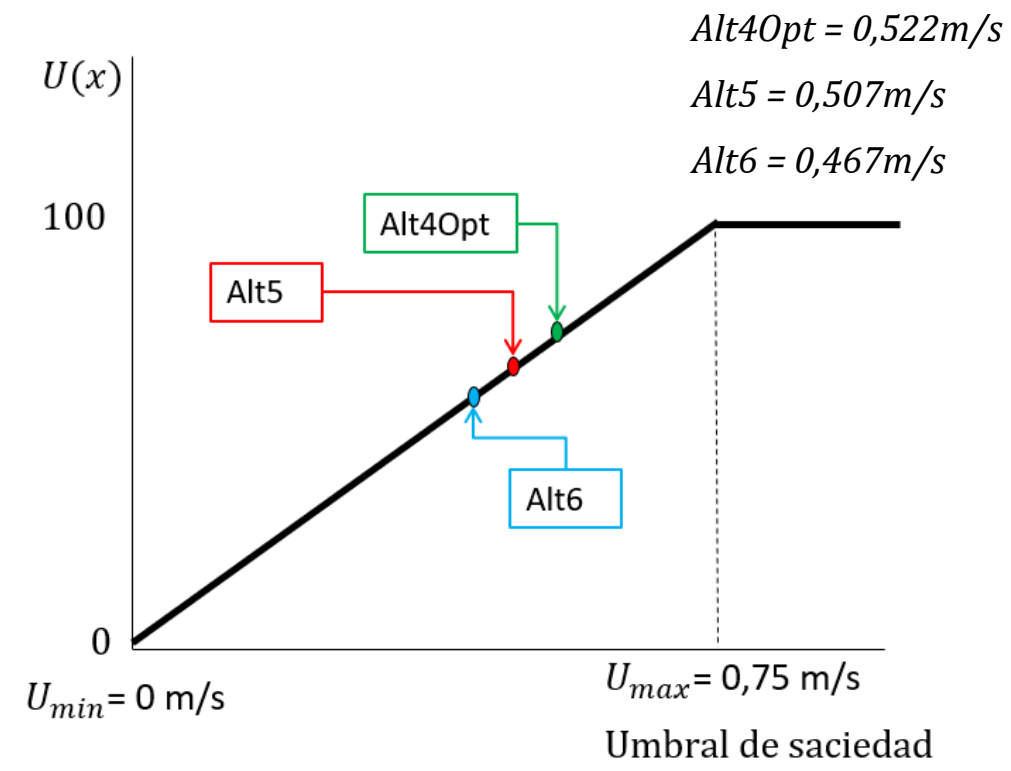

Figura 3-85 Utilidad del subcriterio de Libertad de movimientos basado en una función (gráfica sin escala)

(Elaboración propia)

\section{Resolución en programa ADLA}

Sobre el programa ADLA se han aplicado al criterio DESTINO los resultados de las matrices de comparación por parejas, producto de la valoración subjetiva de los expertos, y al criterio DOTACIÓN los resultados obtenidos en las simulaciones.

Una vez rellenas los datos de las matrices de comparación y aplicadas las funciones de utilidad, los pesos asignados han resultado los que se pueden apreciar en la Tabla 3-19.

\begin{tabular}{|c|c|c|c|}
\hline Criterios & & subcriterios & \\
\hline \multirow[t]{3}{*}{ DESTINO } & $75 \%$ & & \\
\hline & & Intendencia & $83,33 \%$ \\
\hline & & Distribución & $16,67 \%$ \\
\hline \multirow[t]{3}{*}{ DOTACION } & $25 \%$ & & \\
\hline & & Desalojo Z/C & $25 \%$ \\
\hline & & Libertad movimientos & $75 \%$ \\
\hline
\end{tabular}

Tabla 3-19 Pesos de criterios/subcriterios (Elaboración propia) 
El comedor que resultó mejor valorado es la Alt6, con un $37,66 \%$, seguido de la Alt5 con un 37,34\% (ver Tabla 3-20).

\begin{tabular}{rr}
\multicolumn{2}{c}{ Alternativas } \\
\hline Alt4Opt & $25 \%$ \\
Alt5 & $37,34 \%$ \\
Alt6 & $37,66 \%$
\end{tabular}

Tabla 3-20 Valoración global de los comedores con el multicriterio objetivo (Elaboración propia)

Sobre la Figura 3-86, donde el problema decisional se dispone en árbol, se observa que el criterio subjetivo DESTINO, que pesa un $75 \%$, fruto de las preferencias de los expertos, contribuye con el mismo porcentaje a las Alt5 y Alt6 (39,05\%), y tan solo con el 21,9\% a la Alt4Opt. El criterio objetivo DOTACIÓN, que contribuye de manera muy paritaria a las tres alternativas, rompe el empate entre Alt5 $(32,22 \%)$ y Alt6 $(33,5 \%)$, contribuyendo con tan solo 1,3 puntos más a la Alt6.

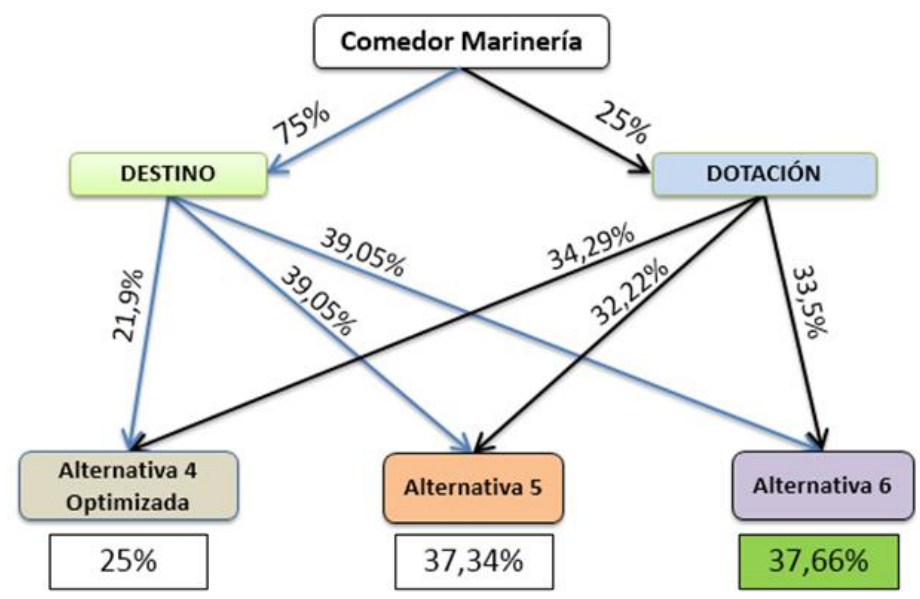

Figura 3-86 Problema decisional en árbol (Elaboración propia)

En la siguiente Tabla 3-21 se observa el desglose del criterio DESTINO en sus dos subcriterios y como contribuyen a la elección de las alternativas, mediante la valoración subjetiva de los expertos (matrices de comparación por parejas). Se observa que para 
los expertos es igualmente preferido las alternativas Alt5 y Alt6 en su valoración de los subcriterios.

\begin{tabular}{|c|c|c|c|c|c|c|}
\hline & \multicolumn{6}{|c|}{ Matriz comparación parejas } \\
\hline & & $\begin{array}{l}\text { INO } \rightarrow \\
5 \%)\end{array}$ & & $\begin{array}{c}\text { tendencia } \\
(83,3 \%) \\
\downarrow\end{array}$ & & $\begin{array}{c}\text { istribución } \\
(16,7 \%) \\
\downarrow\end{array}$ \\
\hline Alt40pt & $\leftarrow$ & $21,9 \%$ & $\leftarrow$ & $14,29 \%$ & $\leftarrow$ & $60 \%$ \\
\hline Alt5 & $\leftarrow$ & $39,05 \%$ & $\leftarrow$ & $42,86 \%$ & $\leftarrow$ & $20 \%$ \\
\hline Alt6 & $\leftarrow$ & $39,05 \%$ & $\leftarrow$ & $42,86 \%$ & $\leftarrow$ & $20 \%$ \\
\hline
\end{tabular}

Tabla 3-21 Sub-matriz para DESTINO (Elaboración propia)

En la siguiente Tabla 3-22 se observa el desglose del criterio DOTACIÓN en sus dos subcriterios y como, mediante las funciones lineales planeadas, contribuyen en la elección de las alternativas. Sobre la tabla se puede observar que la mayor diferencia se encuentra en el subcriterio Desalojo Z/C que, para la Alt6, pesa un 40,34\%.

\begin{tabular}{|c|c|c|c|c|c|c|}
\hline & \multicolumn{6}{|c|}{ Funciones lineales } \\
\hline & & $\begin{array}{l}\text { ACIÓN } \rightarrow \\
(25 \%)\end{array}$ & & $\begin{array}{c}\text { Desalojo Z/C } \\
\text { (25\%) } \\
\downarrow\end{array}$ & & $\begin{array}{l}\text { Libertad } \\
\text { novimientos } \\
(75 \%) \\
\downarrow\end{array}$ \\
\hline Alt4Opt & $\leftarrow$ & $34,29 \%$ & $\leftarrow$ & $32,47 \%$ & $\leftarrow$ & $34,89 \%$ \\
\hline Alt5 & $\leftarrow$ & $32,22 \%$ & $\leftarrow$ & $27,19 \%$ & $\leftarrow$ & $33,89 \%$ \\
\hline Alt6 & $\leftarrow$ & $33,5 \%$ & $\leftarrow$ & $40,34 \%$ & $\leftarrow$ & $31,22 \%$ \\
\hline
\end{tabular}

Tabla 3-22 Sub-matriz para DOTACIÓN (Elaboración propia)

\subsubsection{Análisis de Sensibilidad y Robustez}

Como ya se ha comentado en el punto 3.2.2.1, La ordenación de las alternativas depende de todas las evaluaciones, pesos y procedimientos del método. Estos, se han ido efectuando hasta la obtención de la ordenación y queda comprobar si las decisiones son lo suficientemente robustas y no se ven afectadas por ligeros cambios en los pesos o si, por el contrario, algún pequeño cambio en la subjetividad del decisor cambia el resultado.

En la Figura 3-87 se muestran los resultados de los pesos asignados a los criterios (barras azules) y las valoraciones de las alternativas (barras naranjas). Como se puede observar, la Alt6 resulta la mejor valorada, pero tan solo por un $0,3 \%$ respecto a la Alt5, este 
"empate técnico" obliga a realizar un análisis de sensibilidad, que en esta situación se convierte en trascendental.

\section{Análisis dinámico de sensibilidad}

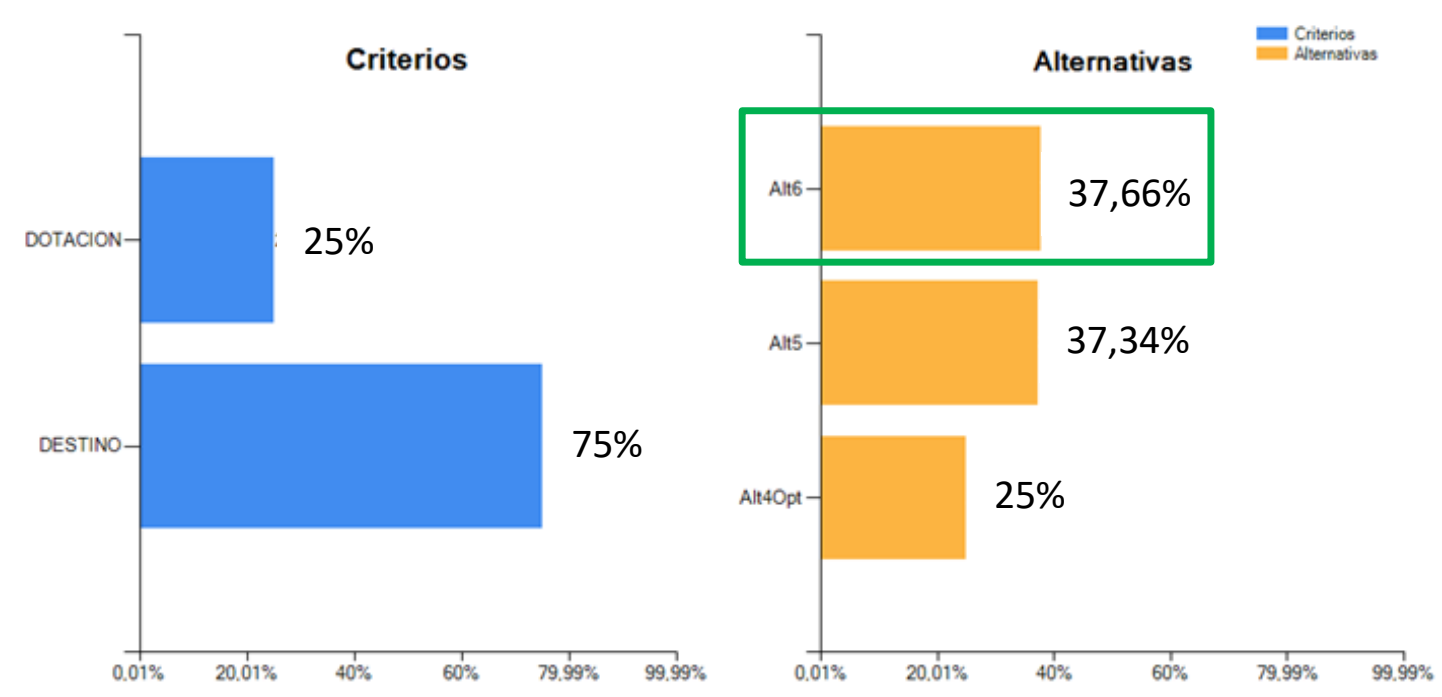

Figura 3-87 Gráfica de barras para el análisis dinámico de sensibilidad que se ha obtenido como resultado del multicriterio subjetivo (ADLA)

En la Figura 3-88 se puede observar que se necesita disminuir el peso del criterio DESTINO hasta un 4,32\% (más de 70 puntos), para que el resultado conmute a favor de la Alt4Opt. Una diferencia de cambio de criterio tan grande es muy improbable, lo que demuestra que la decisión, a pesar de la escasa diferencia del resultado entre Alt5 y Alt6, es muy robusta. Además, se puede afirmar que es fruto de valoraciones "objetivas". 


\section{Análisis dinámico de sensibilidad}

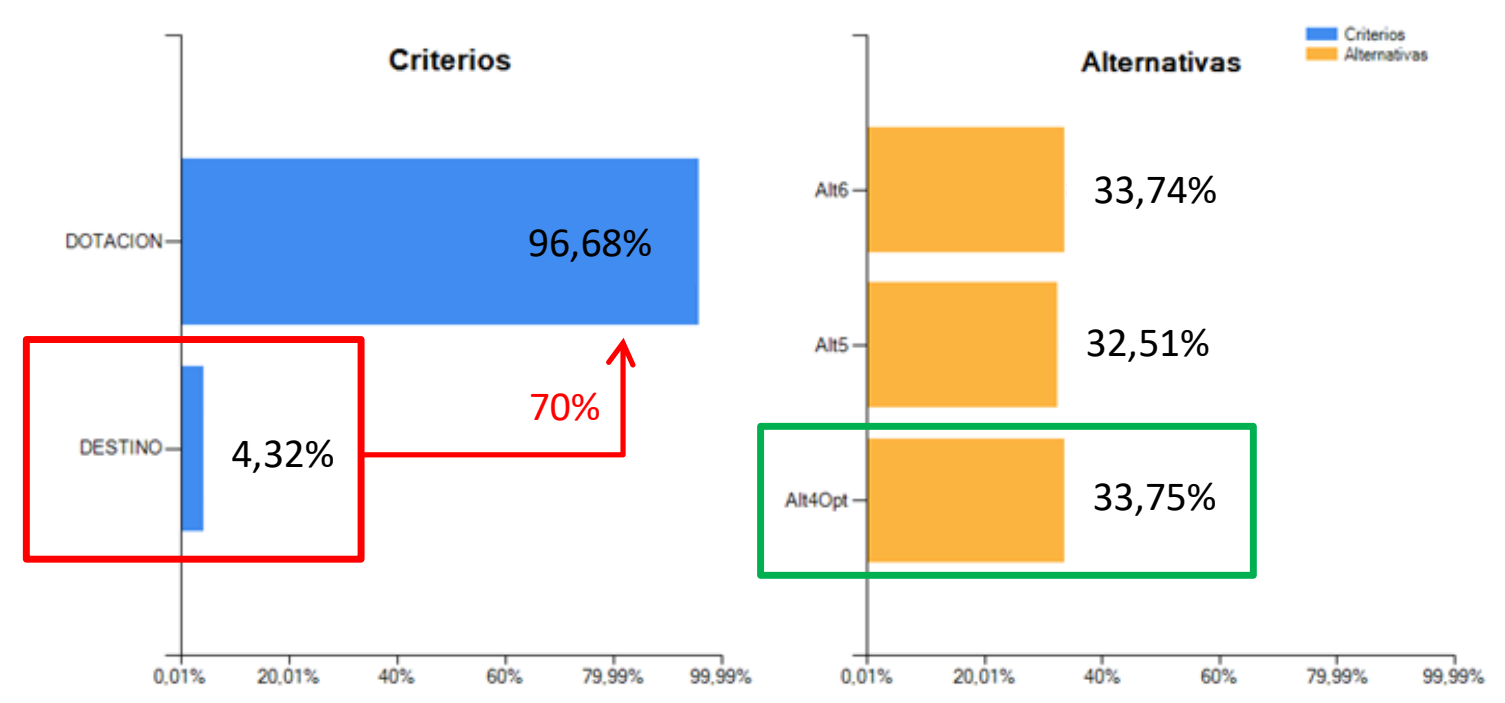

Figura 3-88 Gráfica de reasignación de pesos para conmutación de alternativas. La flecha y la cifra en rojo indican el \% en que ha sido necesario disminuir el peso del criterio DESTINO para que se produzca la conmutación en el resultado de la Alt6 a la Alt40pt (ADLA)

\subsubsection{Conclusiones de los resultados y Líneas Futuras}

Este trabajo ha sido la segunda puesta en práctica de la nueva metodología concebida en esta tesis. Se concluye que ha resultado una valiosa contribución a los objetivos principal y secundarios que se persiguen. Ha aportado una importante ayuda acerca de la mejor disposición del comedor de las fragatas F-110 y, a su vez, ha rebajado la subjetividad de la decisión y ha permitido el empleo de softwares en la simulación de las contribuciones de las alternativas a varios criterios.

De las tres alternativas propuestas por el astillero resultó mejor valorada la Alt6. El proceso de trabajo se realizó conforme a la metodología planteada en esta tesis que se resume en las siguientes fases:

- Fase 1. Representación del Problema. Se ha formado, en colaboración con oficiales de intendencia con amplia experiencia, una estructura jerárquica de criterios de evaluación en la que han quedado representados todos los aspectos considerados relevantes en el proceso de la decisión. Se han definido los criterios y las alternativas. 
- Fase 2. Evaluación de los criterios y alternativas. Los expertos, mediante matrices de comparación por pares y de manera individual y anónima, evaluaron los criterios asignándoles unos pesos. Posteriormente realizaron una valoración de las contribuciones de las tres alternativas al criterio subjetivo DESTINO.

- Fase 3. Contribución de las alternativas. Sobre el criterio objetivo DOTACIÓN, y con la intención de dar respuesta y reducir la subjetividad sobre las cuestiones planteadas por el EMA, se realizó lo siguiente:

- Simulación de los tiempos de desalojo del comedor. Los datos obtenidos se han analizado estadísticamente y se ha diseñado una función de utilidad para valorar las contribuciones de las alternativas al subcriterio Desalojo Z/C.

- Recopilación de datos reales de hábitos en los comedores de varios buques. Se analizaron estadísticamente y se emplearon en un software de simulación. Los resultados obtenidos se han aplicado en una función de utilidad para valorar las contribuciones de las alternativas al subcriterio Libertad de movimientos.

- Fase 4. Jerarquización de las alternativas. Con la ayuda del programa ADLA, que implementa el algoritmo de Saaty, se jerarquizaron las alternativas de cara a la decisión final. La Alt6 resultó la mejor valorada.

- Fase 5. Análisis Sensibilidad. Se ha realizado un análisis profundo de la robustez del modelo, comprobándose que, efectivamente, es muy robusto a los cambios de criterio.

Como líneas futuras de interés se propuso seguir investigando otros aspectos definidos en los subcriterios que fuesen susceptibles de ser valorados objetivamente y que contribuyan a un mejor conocimiento del funcionamiento del servicio de aprovisionamiento. Concretamente, se propuso:

- Como línea futura inmediata, se propuso realizar un nuevo multicriterio incluyendo expertos en otros ámbitos que añadan criterios de ingeniería y económicos.

- Con la presencia de un analista a bordo, recoger más datos sobre los hábitos del personal y el funcionamiento de la cocina. 
- Realizar las simulaciones de los tres comedores (marinería, suboficiales y oficiales) y cocina simultáneamente, incluyendo en la simulación los procesos propios de la cocina (repartidor en área de autoservicio, recogida de bandejas, tránsito de las marmitas con comida, etc.) 


\subsection{Estudio de la Decisión del Posicionamiento Óptimo de las} Ametralladoras en la Fragata F-110

En este punto se explicará cómo se utilizó la metodología planteada en esta tesis, para abordar el problema de decisión multicriterio que diese respuesta a la siguiente cuestión planteada por el EMA: Entendiendo por eficacia de un arma como su capacidad para neutralizar amenazas ¿Cuál sería la disposición óptima de la artillería secundaria de la fragata F-110, en función de su eficacia contra la guerra asimétrica?

Antes de explicar la metodología es preciso exponer escuetamente unas pinceladas sobre qué es la amenaza asimétrica y qué tipo de armas son las que conforman la artillería secundaria de un buque de guerra.

\section{$\underline{\text { La amenaza asimétrica }}$}

El día 12 de octubre del 2000 el destructor de la marina estadounidense "USS Cole" mientras se encontraba atracado en el puerto yemení de Adén, fue atacado por una lancha suicida. Las dramáticas consecuencias del ataque fueron la muerte de 17 tripulantes además de 39 heridos de diversa consideración (ver Figura 3-89).

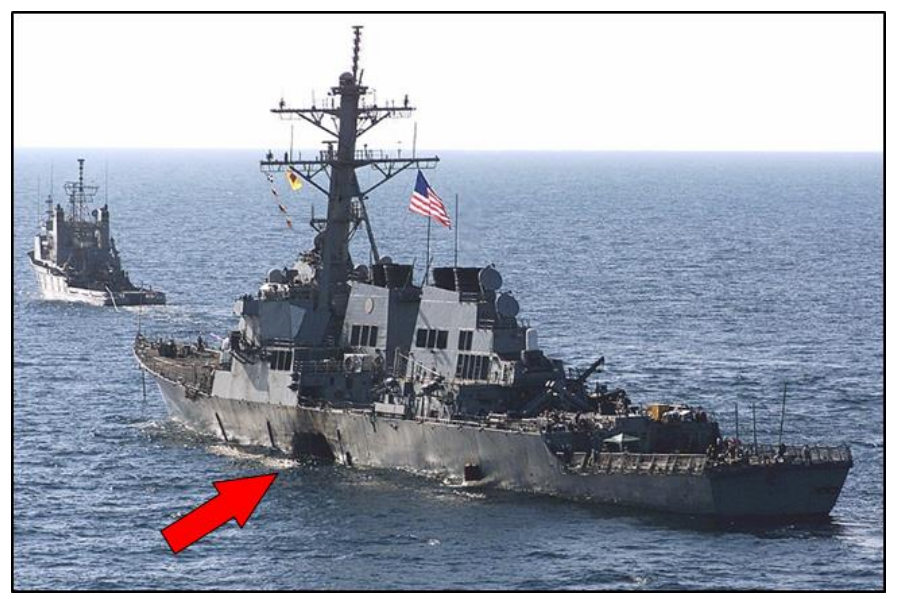

Figura 3-89 El USS Cole siendo remolcado tras sufrir el ataque en su costado de babor (Don L. Maes)

Dos años después, en el 2002 los yihadistas atacaron, también en aguas yemeníes, al petrolero francés "Limburg" mostrando al mundo la determinación de los terroristas y sus capacidades en el medio marítimo [171] (ver Figura 3-90). 


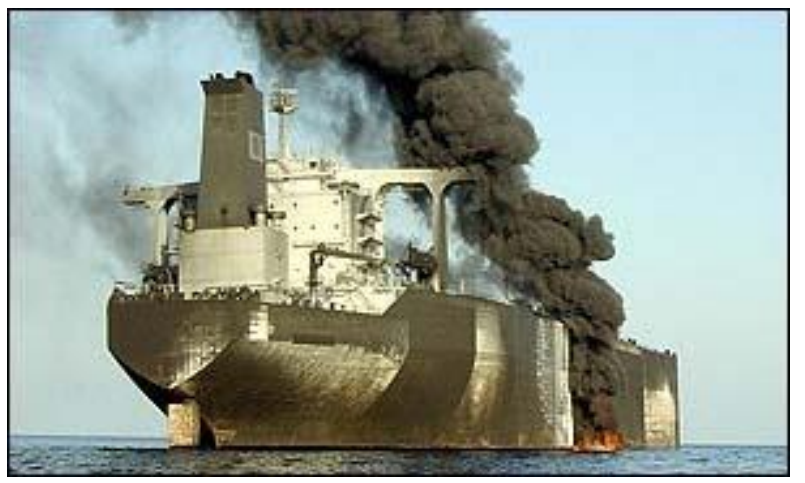

Figura 3-90 Tanquero Limburg en llamas tras el ataque por su costado de estribor (BBC)

En esta década se puede afirmar que la situación no ha mejorado. El atentado suicida contra el petrolero japonés "M. Star", ejecutado por Al Qaida en el Estrecho de Ormuz el 28 de julio de 2010, aunque tuvo escasas consecuencias (un herido leve y daños en el buque) puso de actualidad a los estrechos como zonas de fijación por parte de los terroristas. Se debe subrayar que por Ormuz transita el $40 \%$ del petróleo consumido en el mundo y por el Golfo de Adén circulan más de 16.000 mercantes al año, representando el $20 \%$ del comercio marítimo mundial.

Por otro lado, y haciendo una obligada mención a otro estrecho de importancia estratégica para España, conviene recordar que en 2002 fue desarticulada por Marruecos una célula yihadista salafista formada por elementos locales y extranjeros, en concreto por saudíes vinculados a Al Qaida, que pretendía atentar en el Estrecho de Gibraltar contra unidades navales de la operación "Active Endeavour" de la OTAN en el Mediterráneo.

Como se menciona en [171], el Estrecho de Bab El Mandeb (Figura 3-91), que separa Somalia de Yemen, linda con dos países con escenarios de una actividad inusitada por parte de grupos terroristas. Desde hace unos pocos años se han multiplicado los ataques armados contra los buques que transitan por él. Esta zona de paso, una franja de apenas 12 kilómetros de anchura es uno de los puntos marítimos más estratégicos de todo el mundo. 


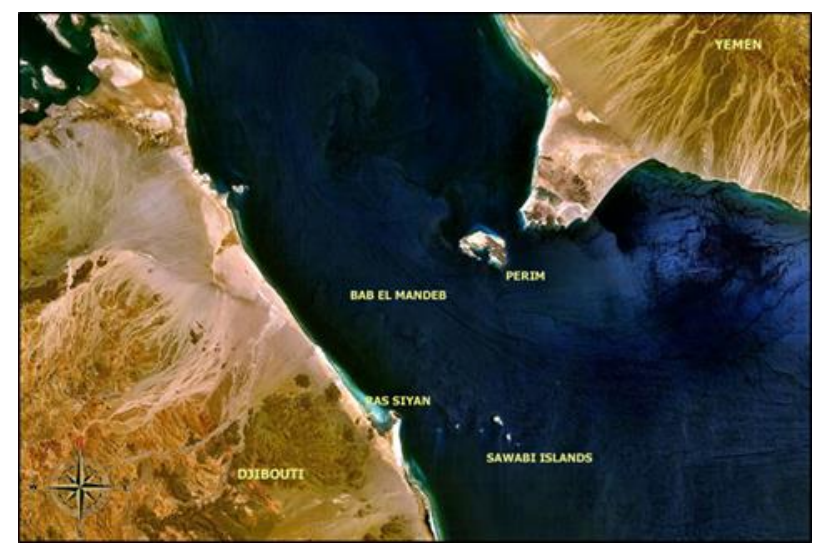

Figura 3-91 Imagen satélite del estrecho de Bab El Mandeb (Google)

Más recientemente, en febrero de 2017 una fragata de la Royal Saudi Navy sufrió un ataque perpetrado por terroristas Yemenies, que provocó la muerte a 2 de sus tripulantes y dejaron 3 heridos. El ataque simultáneo de embarcaciones suicidas cargadas de explosivos que, posteriormente tras la investigación se demostró que eran embarcaciones rápidas teledirigidas, consiguió alcanzar el buque provocando una gran explosión (Figura 3-92).

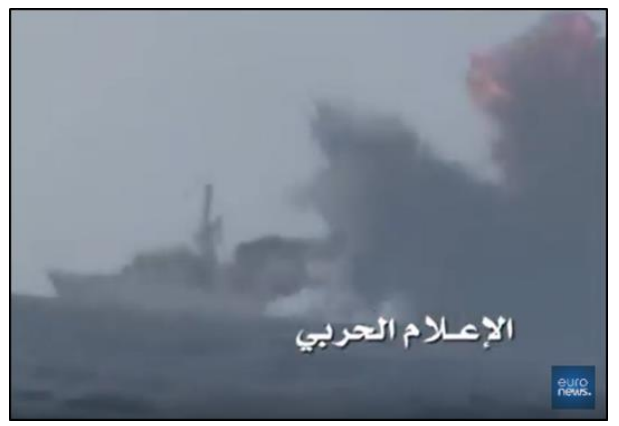

Figura 3-92 Ataque a la fragata saudí de la clase Al Madinah (Euronews)

Todas estas clases de ataque se encuadran en lo que se denomina: guerra asimétrica.

Entre otras particularidades, la guerra asimétrica se caracteriza porque el tiempo de reacción es escaso. Las embarcaciones atacantes son pequeñas, rápidas y en muchas ocasiones la cercanía de costa las convierte en difíciles de detectar. Otras veces las lanchas se enmascaran entre otros buques o embarcaciones similares, pues procuran realizar sus ataques en zonas de mucha densidad de tráfico marítimo. Contra este tipo de ataques los cañones de gran calibre y los misiles son ineficaces. Los terroristas pueden conseguir mediante una escasa inversión económica y tecnológica, ocasionar pérdidas de vidas humanas y de millones de euros en reparaciones. 
En un futuro muy cercano, a la amenaza asimétrica también se incorporarán ataques de drones. Recientemente en Yemen se incautaron siete drones de tamaño medio que habían sido manipulados para albergar explosivos en su interior. Estos drones tendrían una estructura muy similar a la de los "Ababil-T" fabricados por Irán. Tienen un radio de acción de 100 kilómetros y se operan con cargas explosivas en su interior. Este tipo de armamento supone una evolución en las tácticas de combate de los terroristas que complicará, aún más, la seguridad ante posibles futuros ataques.

Contra este tipo de amenaza, las ametralladoras de defensa de punto se muestran como el remedio más eficaz.

\section{$\underline{\text { Las ametralladoras }}$}

La compra de los modelos de artillería secundaria de la F-110, aunque todavía están en fase de decisión, presumiblemente la compondrán dos montajes de $25 \mathrm{~mm}$ (Mk-38) y dos/cuatro ametralladoras de $12,7 \mathrm{~mm}$ situadas en afustes operados remotamente (RWS). A continuación, se exponen las dos ametralladoras sobre las que la Armada ha mostrado más interés conforme a lo transmitido por los responsables del EMA.

- La ametralladora Mk-38 (ver Figura 3-93)

La ametralladora Mk-38 (Machine Gun System - MGS) está diseñada para la defensa del buque frente a las amenazas de superficie del tipo FIAC (Fast Inshore Attack Craft), que se caracterizan por ser pequeñas y rápidas. En realidad, la ametralladora es todo un sistema de armas de autodefensa, en la que destaca su sensor avanzado electroóptico/infrarrojo (EO/IR) que le proporciona una gran capacidad de vigilancia y detección. Este sistema sensor está integrado con un avanzado y potente sistema de disparo de $25 \mathrm{~mm}$ de calibre, pero que, a su vez puede moverse por separado del sistema de armas eludiendo con ello, que las amenazas atacantes sepan que han sido detectadas y que están en seguimiento por parte del sensor. La Mk-38 tiene un alcance aproximado de 2,5 kilómetros y los métodos de disparo puede ser: "tiro a tiro" o en ráfaga (180 disparos por minuto) [172].

Esta ametralladora se maneja en remoto mediante una consola ubicada en el $\mathrm{CIC}$, lo que evita que haya personal en exteriores y asegura que el operador permanezca fuera de peligro. Está instalada a bordo de diferentes de buques de la Armada de los EE.UU. y 
también en otros muchos buques de la OTAN, entre los que se encuentran los buques de acción marítima españoles (BAM) y la fragata F-100 más moderna: la "Cristóbal Colón".

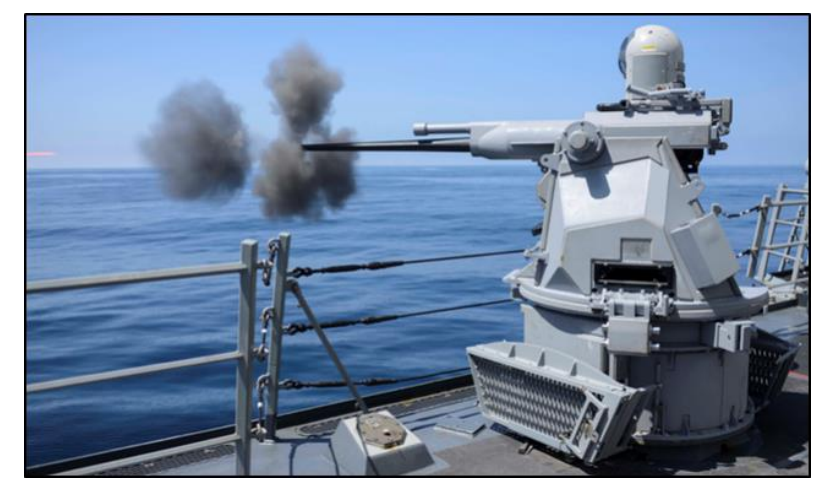

Figura 3-93 Ametralladora Mk-38 (Bae Systems)

- La ametralladora de 12,7mm RWS (ver Figura 3-94)

Las principales diferencias entre la ametralladora Mk-38 y una ametralladora de 12,7mm son: el menor calibre, sensores de prestaciones inferiores, una precisión y alcance menor; por el contrario, son de adquisición más económica y tienen menor peso y volumen, aspectos transcendentales en un buque.

En el comienzo de este trabajo no estaba definido a qué empresa se le comprará el arma, pero a efectos de este trabajo es una cuestión irrelevante, ya que el propósito del EMA era conocer la mejor ubicación de las armas, no un estudio comparativo entre ellas.

A continuación, se describe someramente la ametralladora italiana HITROLE [173] que es una de las firmes candidatas a ser instalada en la F-110.

La torreta naval HITROLE es un sistema moderno completamente controlado desde una consola de control remoto (RWS) que permite al artillero operar desde una posición protegida dentro de la estructura del barco: cualquier operación, incluyendo carga y recuperación, puede realizarse con la máxima seguridad.

Su bajo peso y su alto nivel de flexibilidad hacen que esta torreta sea especialmente adecuada para su instalación como armamento secundario en buques para la autoprotección en el rol antiterrorista. 


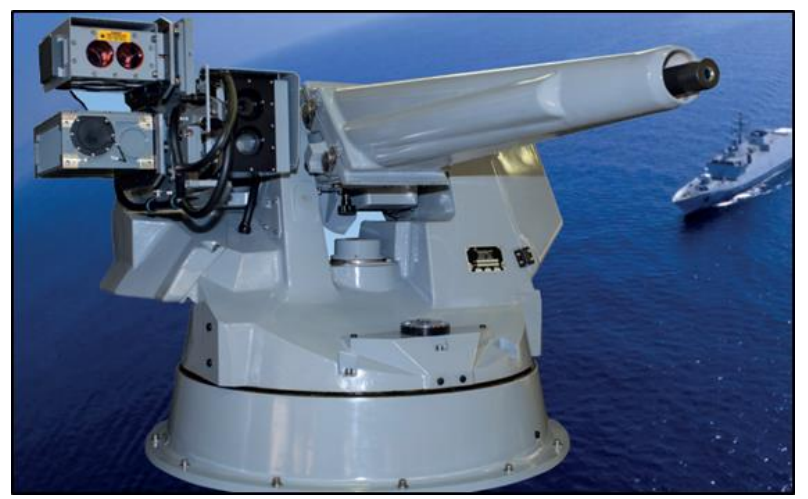

Figura 3-94 Ametralladora 12,7 mm RWS HITROLE (LEONARDO)

Las acciones de vigilancia, detección y seguimiento se realizan mediante una cámara de TV diurna de altas prestaciones y como una opción adicional incluye la posibilidad de instalar un sensor IR para el funcionamiento nocturno, así como un telémetro láser.

Tiene un sistema independiente de estabilización giroscópica y, por tanto, no requiere una señal externa de otros sistemas de estabilización de buque, al igual que ocurre con la Mk-38.

\subsubsection{Representación del Problema y Selección de Criterios}

Para la representación del problema se conformó un equipo de expertos especialistas en artillería, estos contaban con una amplia experiencia de embarque en fragatas desempeñando la Jefatura de Armas. Así, se comenzó a trabajar en la elaboración del multicriterio que, siguiendo con la metodología planteada en la tesis, en una reunión inicial se les explicó el método del proceso de análisis jerárquico (AHP), en el que se requería la descomposición del problema en una estructura jerárquica con al menos tres niveles básicos (objetivo, criterios y alternativas) y de esta manera se conseguiría una visión general del problema.

Se puso de manifiesto que el objetivo era determinar la opción óptima de la disposición de ametralladoras en la F-110 en función de su eficacia, es decir, en función de la capacidad para neutralizar las amenazas de guerra asimétrica que puedan atacar al buque.

Como hipótesis del problema se plantearon los siguientes puntos: 
- La ubicación de las ametralladoras debe permitir el acceso a ellas de manera fácil y segura.

- Se debe poder ubicar, próximas a las ametralladoras, las cajas de urgencia.

- Los sectores de fuego deben de carecer de zonas ciegas. Especialmente zonas ciegas por cercanía².

- Se debe poder hacer frente, de manera eficaz, a una amenaza múltiple que ataque el buque de manera sorpresiva, a una corta distancia, desde diferentes direcciones y a una gran velocidad.

\subsubsection{Las Alternativas}

Las alternativas fueron definidas por el EMA. Se tenía interés en comparar diferentes disposiciones en las que el número de armas fuese diferente e incluso que las armas no estuviesen dispuestas simétricamente respecto al eje longitudinal. Así, el EMA definió seis alternativas:

- Opción A

- Opción B

- Opción C
- Opción D

- Opción E

- Opción F

\subsection{Opción A}

Esta alternativa cuenta con la siguiente configuración de ametralladoras: cuatro de $12,7 \mathrm{~mm}$ y dos Mk-38 (ver Figura 3-95).

Las cuatro de $12.7 \mathrm{~mm}$ están simétricamente situadas en ambas bandas, dos a popa del mástil integrado en la cubierta núm. 03, numeradas №1 y №2 y representadas por dos puntos azules sobre la Figura 3-95, sus sectores de fuego son aproximadamente entre las marcaciones $15^{\circ}$ Babor/Estribor $(\mathrm{Br} / \mathrm{Er})$ y los $165^{\circ} \mathrm{Br} / \mathrm{Er}$. Las otras dos

\footnotetext{
${ }^{2}$ Por razones de confidencialidad los datos de los sectores de fuego aquí expuestos no son los reales. Se han mostrado los mismos sectores en todas las simulaciones, que están basados en una alteración de los verdaderos, definidos sobre plano del astillero.
} 
ametralladoras de $12.7 \mathrm{~mm}$ están situadas a media eslora en la cubierta núm. 02, numeradas №3 y №4, y sus sectores de fuego son aproximadamente entre las marcaciones $10^{\circ} \mathrm{Br} / \mathrm{Er}$ y los $170^{\circ} \mathrm{Br} / \mathrm{Er}$.

Las dos ametralladoras Mk-38, denominadas en la imagen №5 y №6 y representadas por dos puntos rojos, están situadas simétricamente a popa sobre el hangar del helicóptero en la cubierta núm. 02, su sector fuego aproximado es entre las marcaciones $10^{\circ} \mathrm{Br} / \mathrm{Er}$ y los $180^{\circ} \mathrm{Br} / \mathrm{Er}$.

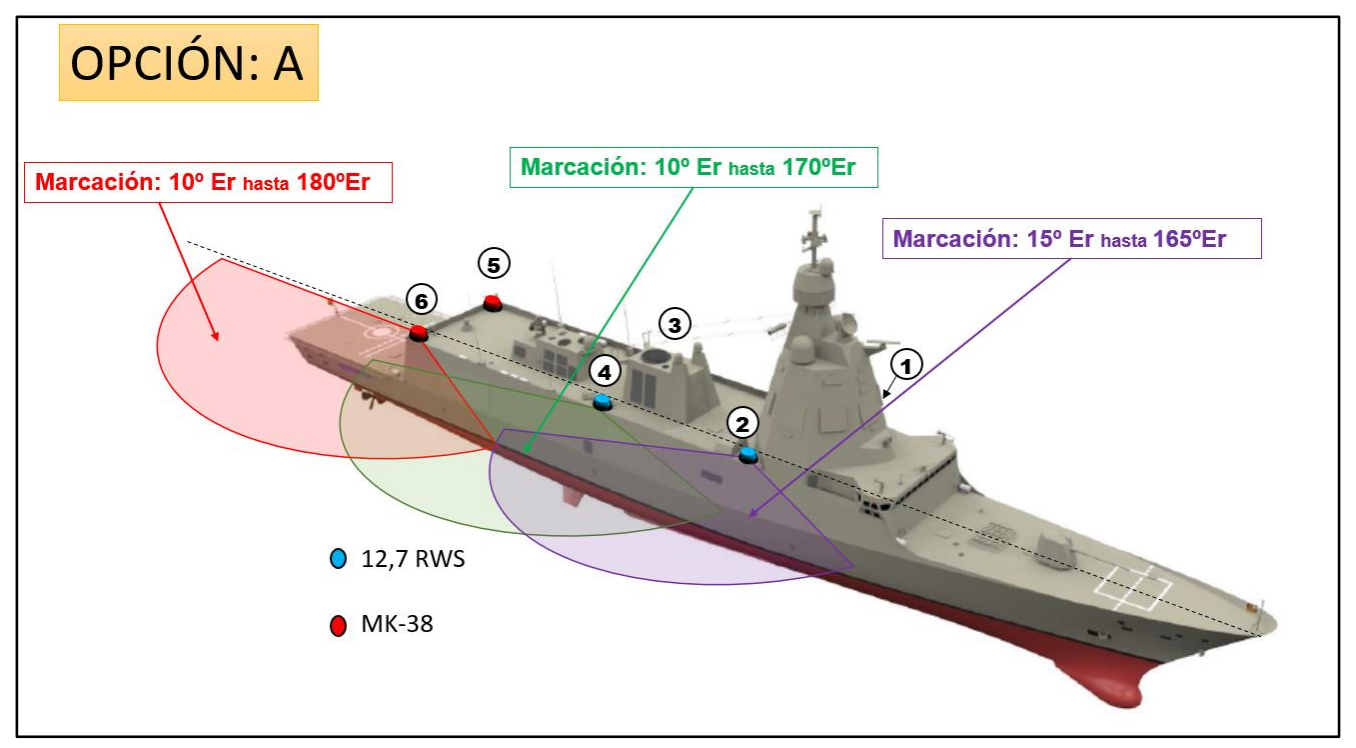

Figura 3-95 Opción A (Elaboración propia sobre imagen de F-110 de DGAM)

\subsection{Opción B}

Esta alternativa cuenta con la siguiente configuración de ametralladoras: cuatro de $12,7 \mathrm{~mm}$ y dos Mk-38 (ver Figura 3-96).

Las cuatro de $12.7 \mathrm{~mm}$ se situarían simétricamente en ambas bandas, dos sobre el puente alto en la cubierta núm. 03, numeradas №1 y №2, con sectores de fuego aproximados entre las marcaciones $00^{\circ} \mathrm{Br} / \mathrm{Er}$ y los $165^{\circ} \mathrm{Br} / \mathrm{Er}$. Las otras dos de $12.7 \mathrm{~mm}$ están situadas a media eslora en la cubierta núm. 02, numeradas №3 y №4, y sus sectores de fuego son aproximadamente entre las marcaciones $10^{\circ} \mathrm{Br} / \mathrm{Er}$ y los $170^{\circ}$ $\mathrm{Br} / \mathrm{Er}$.

Las dos ametralladoras Mk-38, denominadas №5 y №6 y representadas por dos puntos rojos, están situadas simétricamente a popa sobre el hangar del helicóptero en la 
cubierta núm. 02 , su sector fuego aproximado es entre las marcaciones $10^{\circ} \mathrm{Br} / \mathrm{Er}$ y los $180^{\circ} \mathrm{Br} / \mathrm{Er}$.

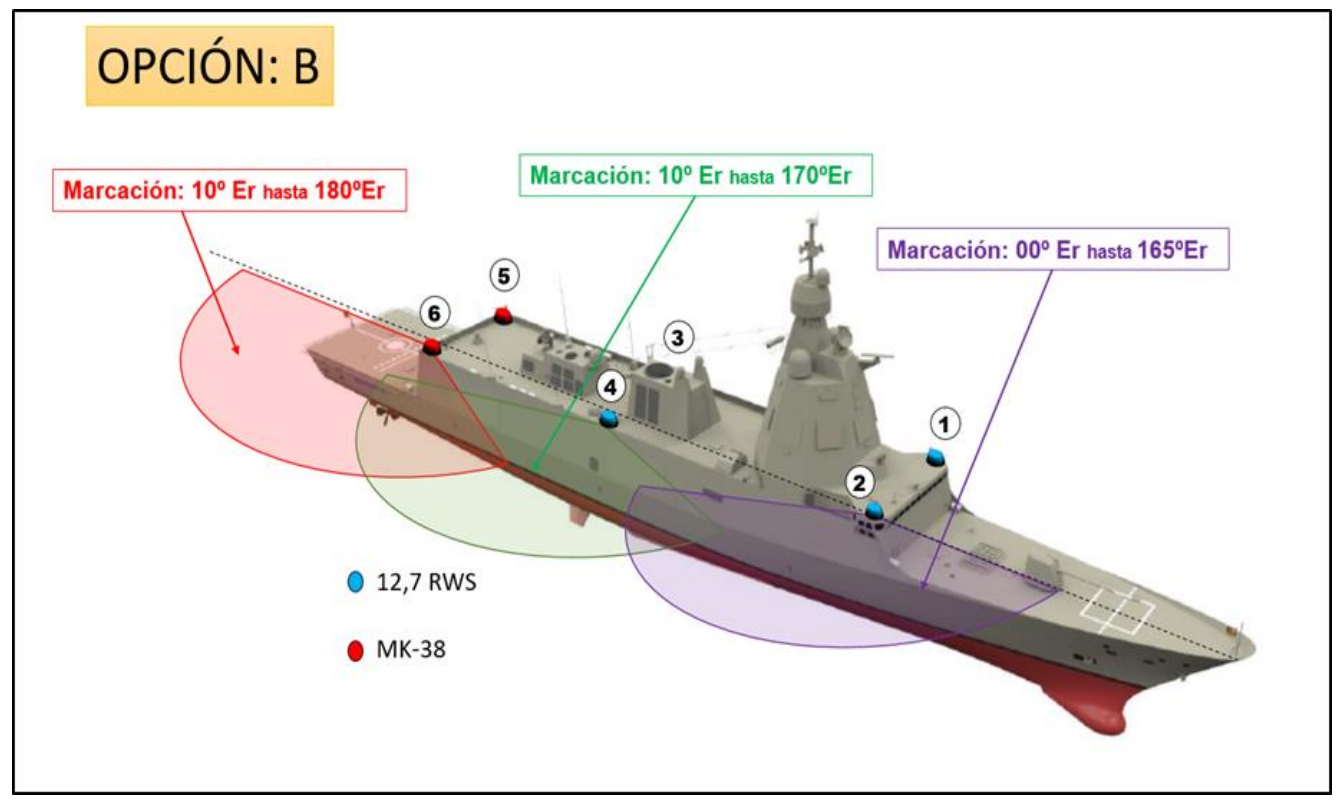

Figura 3-96 Opción B (Elaboración propia sobre imagen de F-110 de DGAM)

\subsection{Opción C}

Esta alternativa cuenta con la siguiente configuración de ametralladoras: cuatro de $12,7 \mathrm{~mm}$ y dos Mk-38 (ver Figura 3-97).

Esta alternativa se diferencia de las otras dos alternativas anteriores $A$ y $B$, en que las dos ametralladoras de $12,7 \mathrm{~mm}$ de proa están situadas en los alerones del puente y, por tanto, están en la cubierta núm. 02. Sus sectores de fuego son similares a los de la Opción A y están aproximadamente entre las marcaciones $15^{\circ} \mathrm{Br} / \mathrm{Er}$ y los $165^{\circ} \mathrm{Br} / \mathrm{Er}$.

Las otras cuatro ametralladoras están dispuestas de la misma forma que en las dos opciones anteriores. 


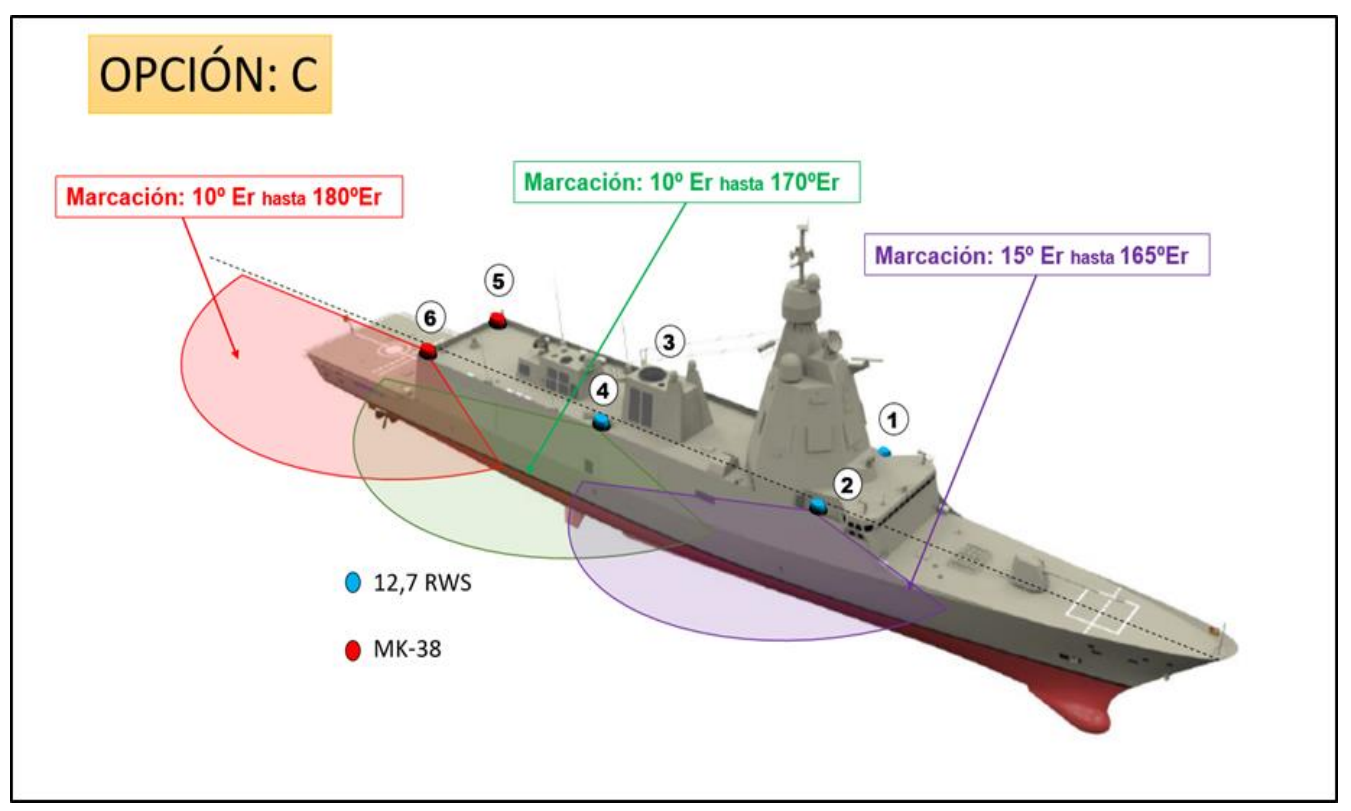

Figura 3-97 Opción C (Elaboración propia sobre imagen de F-110 de DGAM)

\subsection{Opción D}

Esta alternativa cuenta con la siguiente configuración de ametralladoras: dos de $12,7 \mathrm{~mm}$ y dos Mk-38 (ver Figura 3-98).

Las dos de $12.7 \mathrm{~mm}$ están situadas a popa del mástil integrado en la cubierta núm. 02, numeradas №1 y №2, sus sectores de fuego iguales a la Opción A.

Las Mk-38 están dispuestas de la misma forma que en las tres opciones anteriores.

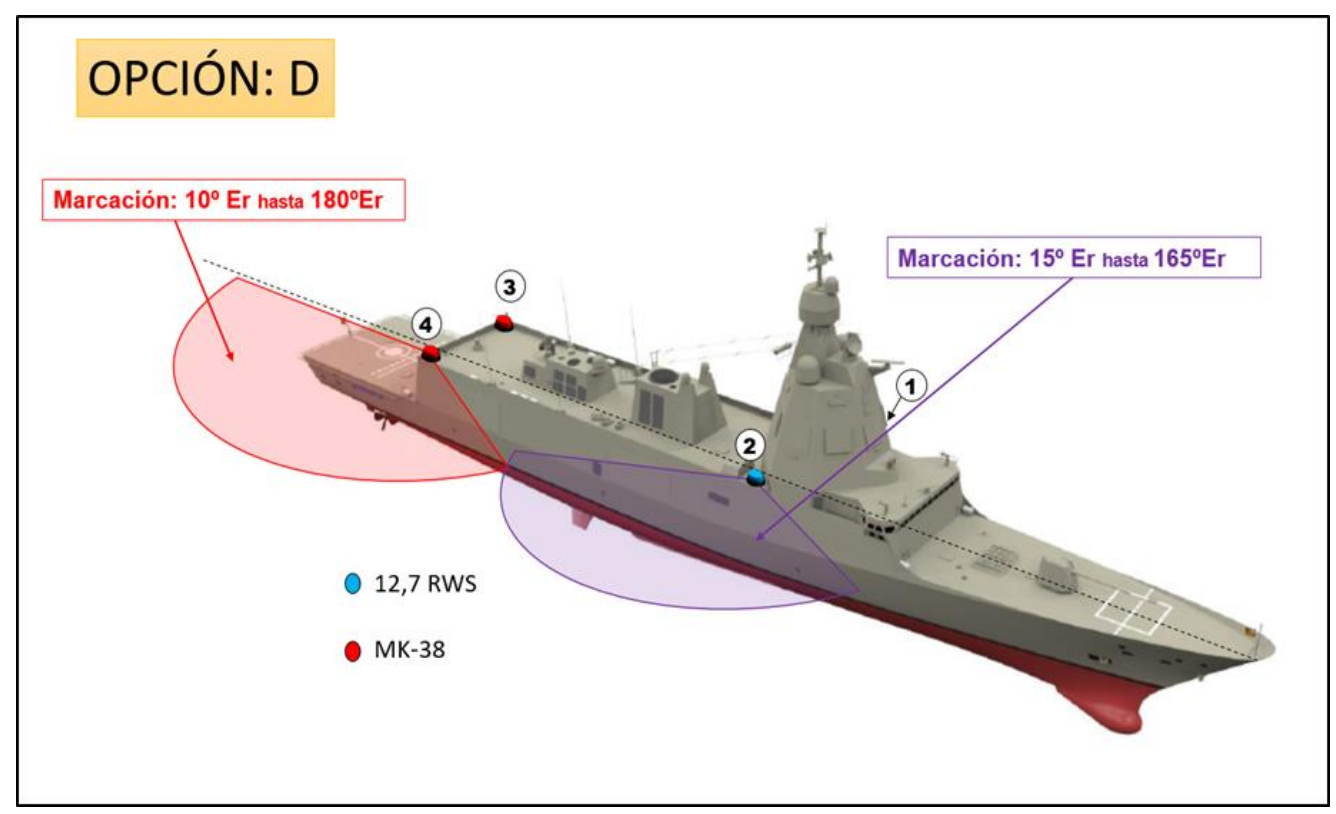

Figura 3-98 Opción D (Elaboración propia sobre imagen de F-110 de DGAM) 


\subsection{Opción E}

Esta alternativa cuenta con la siguiente configuración de ametralladoras: dos de $12,7 \mathrm{~mm}$ y dos Mk-38 (ver Figura 3-99).

Esta opción sitúa las ametralladoras de forma asimétrica. En el puente alto, cubierta núm. 03, en babor se instala una Mk-38 y en estribor una de $12,7 \mathrm{~mm}$, los sectores de fuego son similares a la Opción B, entre marcaciones $00^{\circ} \mathrm{Br} / \mathrm{Er}$ y los $165^{\circ} \mathrm{Br} / \mathrm{Er}$. En popa sobre el hangar, en la cubierta núm. 02 , se sitúan de forma asimétrica, una Mk-38 en la banda de estribor y una de $12,7 \mathrm{~mm}$ en la banda de babor. Los sectores son similares a las otras opciones anteriores.

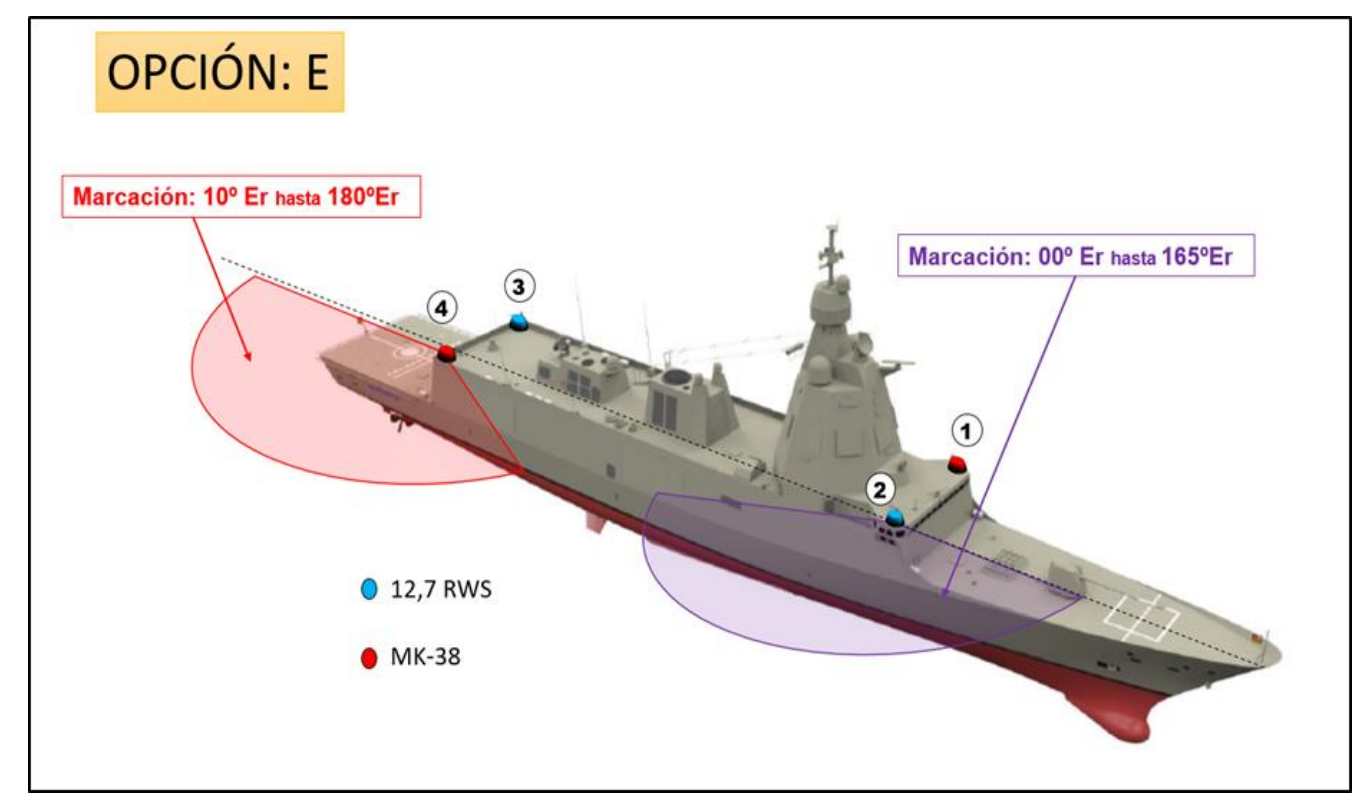

Figura 3-99 Opción E (Elaboración propia sobre imagen de F-110 de DGAM)

\subsection{Opción F}

Esta alternativa cuenta con la siguiente configuración de ametralladoras: cuatro de $12,7 \mathrm{~mm}$ y dos Mk-38 (ver Figura 3-100).

Las ametralladoras están situadas de manera asimétrica con una disposición es similar a la Opción E, con la diferencia de que cuenta con dos de $12,7 \mathrm{~mm}$ más, situadas en los costados a media eslora (№3 y №4). 


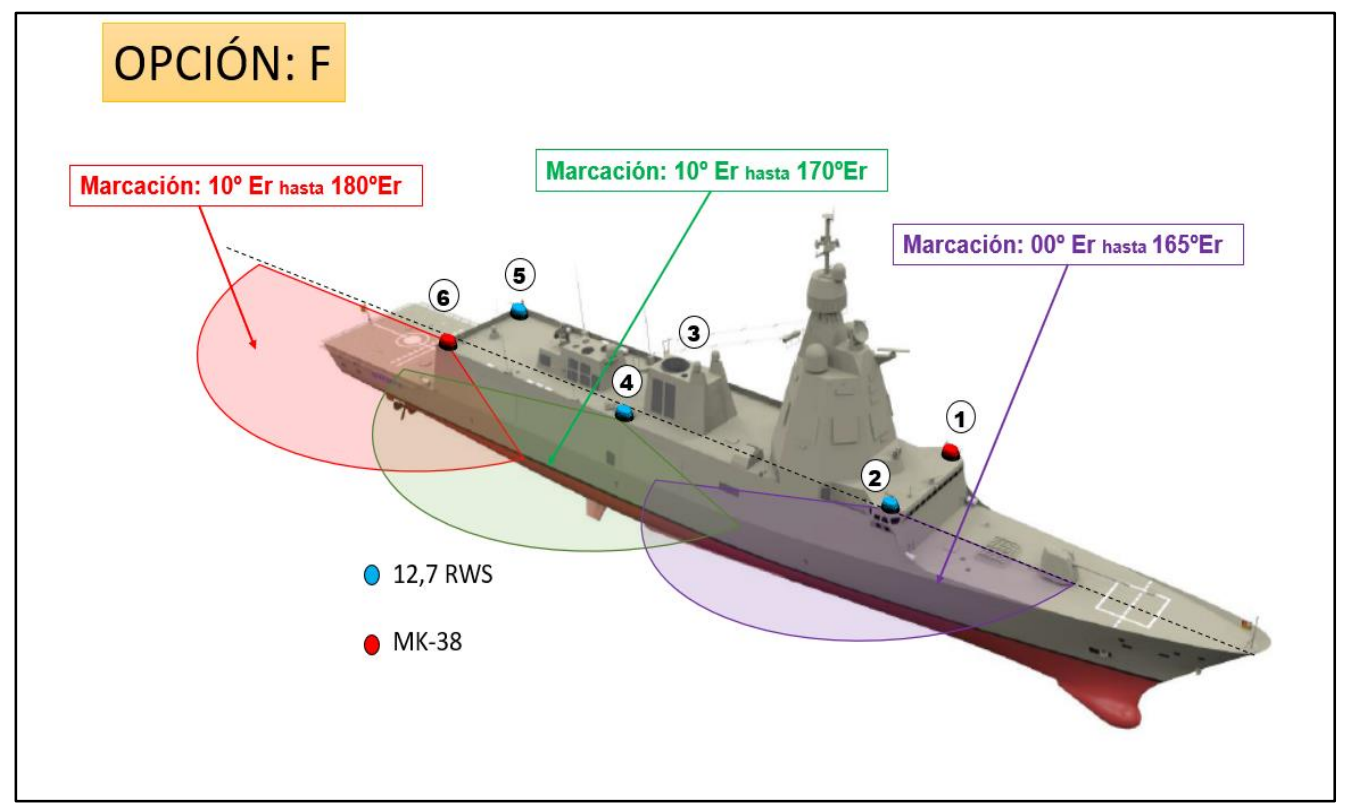

Figura 3-100 Opción F (Elaboración propia sobre imagen de F-110 de DGAM)

\subsubsection{Definición de Criterios}

Con las cuestiones planteadas por el EMA y las alternativas mostradas en el punto anterior como referencia, en una reunión con los expertos se confeccionó el problema de decisión que se aprecia en la Figura 3-101.

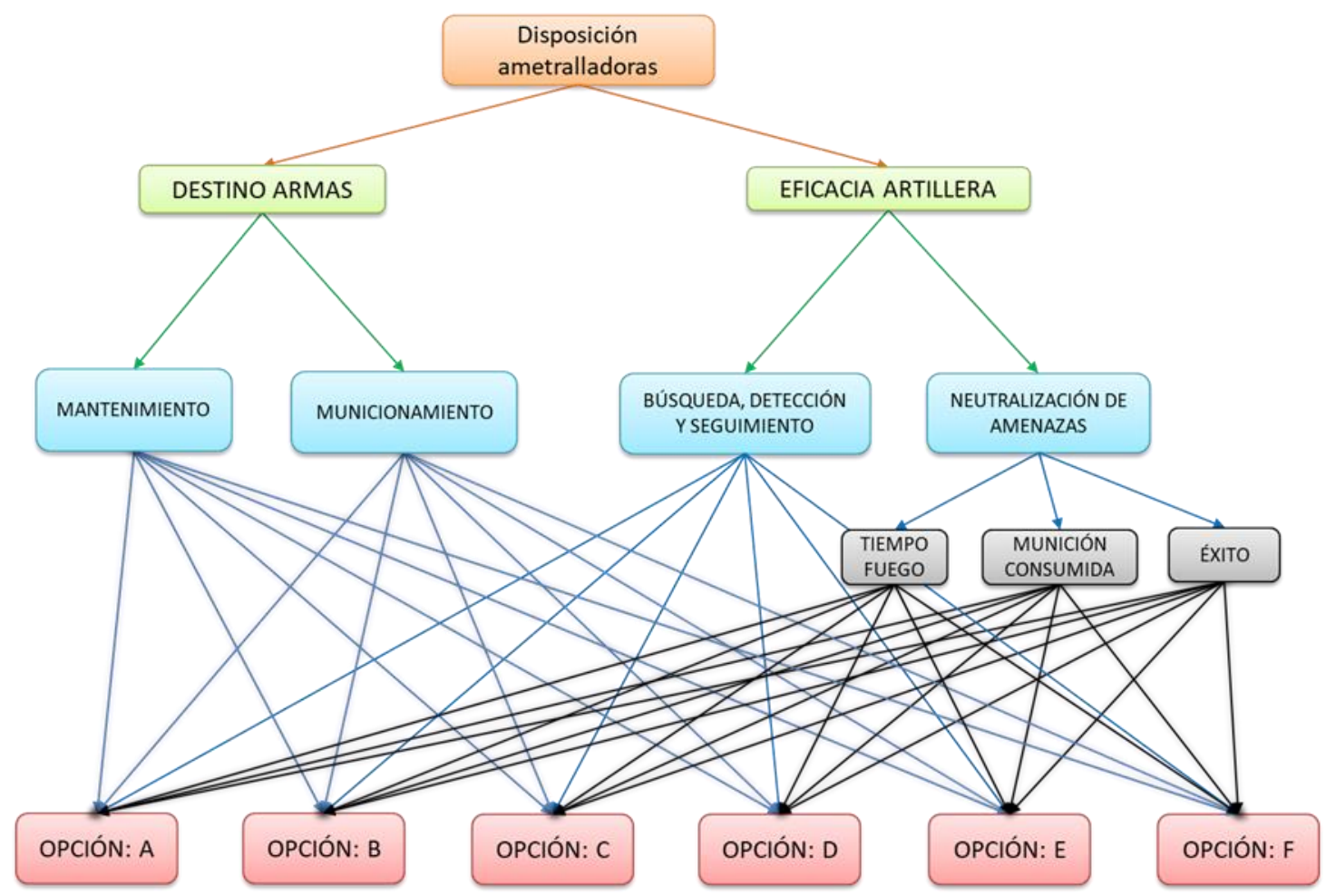

Figura 3-101 Modelo AHP confeccionado con los expertos para el problema de las ametralladoras (Elaboración propia) 
Este modelo definido por los expertos consideró:

- 2 criterios

- 4 subcriterios

- 3 sub-subcriterios

- 6 alternativas

Con este modelo se generan un total de cuatro MCP para la asignación de pesos de evaluación a los criterios, subcriterios y sub-subcriterios, y se generarían seis MCP para la valoración de las contribuciones de las alternativas a los diferentes criterios, de estas, tres se resolvieron mediante MCP y las otras tres mediante funciones de utilidad.

Con anterioridad al relleno de las MCP, y con el objetivo de poder servirse de este modelo con otros expertos ajenos a la confección de este problema, se definieron los conceptos que envuelven a los criterios, subcriterios y sub-subcriterios.

\section{Criterio DESTINO ARMAS}

Este criterio comprende todos los trabajos y acciones encaminadas a la gestión de las ametralladoras por parte del personal destinado en el Servicio de Armas.

- Subcriterio Mantenimiento. El mantenimiento del primer escalón se podría definir como: conjunto de acciones de sostenimiento llevadas a cabo por la dotación de la unidad bajo la responsabilidad directa de su comandante. Este subcriterio comprende los aspectos relacionados con el mantenimiento del primer escalón las ametralladoras, entendiéndose como el conjunto de actividades encaminadas a conseguir un determinado nivel de disponibilidad en condiciones de empleo aceptable, al mínimo coste, con oportunidad y con el máximo de seguridad para el personal que lo utiliza y lo mantiene.

- Subcriterio Municionamiento. Este subcriterio propone analizar los discernimientos relativos a la munición disponible para las ametralladoras, es decir, la cantidad de munición utilizable en las cajas de urgencia, que el arma pueda ser recargada con rapidez y orientada en condiciones de ser disparada a voluntad del operador. 


\section{Criterio EFICACIA ARTILLERA}

La eficacia artillera comprende todas las acciones que resulten del empleo operativo de las ametralladoras por parte de un individuo adiestrado.

- Subcriterio Búsqueda Detección Seguimiento. Este subcriterio comprende los conceptos de observación, exploración de la superficie, seguimiento y designación de armas, desde los sensores de las ametralladoras que están limitados en su capacidad por las superestructuras del buque.

- Subcriterio Neutralización Amenazas. Este subcriterio está relacionado con la pregunta de ¿cómo serán de eficaces las ametralladoras frente a un ataque coordinado de tres lanchas suicidas cargadas de explosivos?, poniendo en valor que la respuesta sea rápida y capaz de neutralizarlas antes de un acercamiento peligroso para la fragata.

- Sub-subcriterio Éxito. Este se restringe a la capacidad de triunfo frente a las amenazas encuadradas en la denominada guerra asimétrica.

- Sub-subcriterio Tiempo Fuego. Está relacionado con la duración de la acción en repeler las amenazas.

- Sub-subcriterio Munición Consumida. Se corresponde con la cantidad de disparos que se necesitan para la neutralización de las amenazas.

\subsubsection{Evaluación de los Criterios. Evaluación Subjetiva de las} Alternativas

Se elaboró una tabla de Excel con las siete matrices y se envió a los expertos para su relleno conforme a la escala de Saaty que, nuevamente por sencillez, se restringió a los números impares (Figura 3-102). Con el objetivo de evitar sesgos, se les requirió un relleno individual e independiente. 


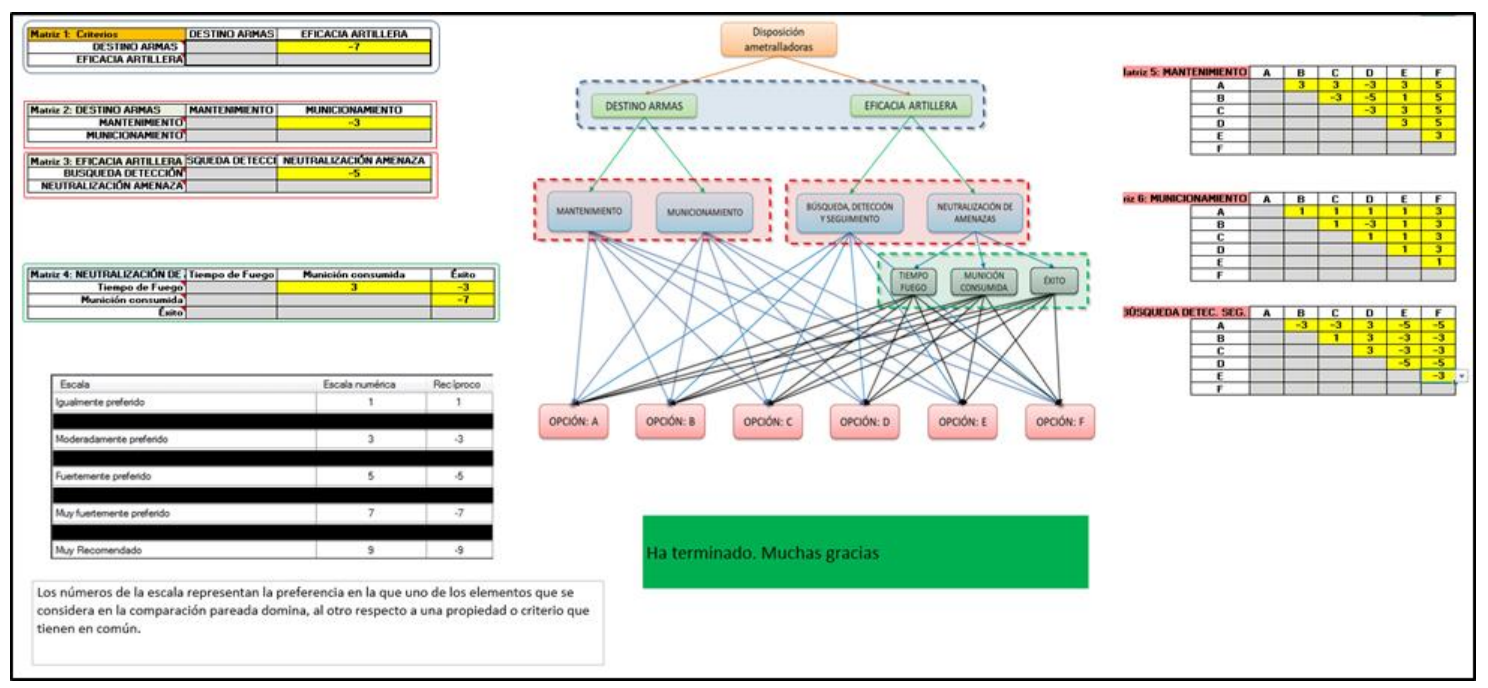

Figura 3-102 Hoja Excel enviada a los expertos para el relleno de MCP en el problema de las ametralladoras

(Elaboración propia)

Los expertos, a la hora de enjuiciar las matrices, dispusieron de las figuras que se elaboraron para la definición de las opciones (punto 3.4.1.1) y de las explicaciones de criterios (punto 3.4.1.2). Estas referencias son necesarias para meditar sobre las circunstancias del problema, poder evaluar y decidir en las comparativas entre criterios y alternativas.

\subsubsection{Asignación de Pesos a los Criterios}

La respuesta obtenida del relleno de las MCP por los expertos se puede observar en la Tabla 3-23.

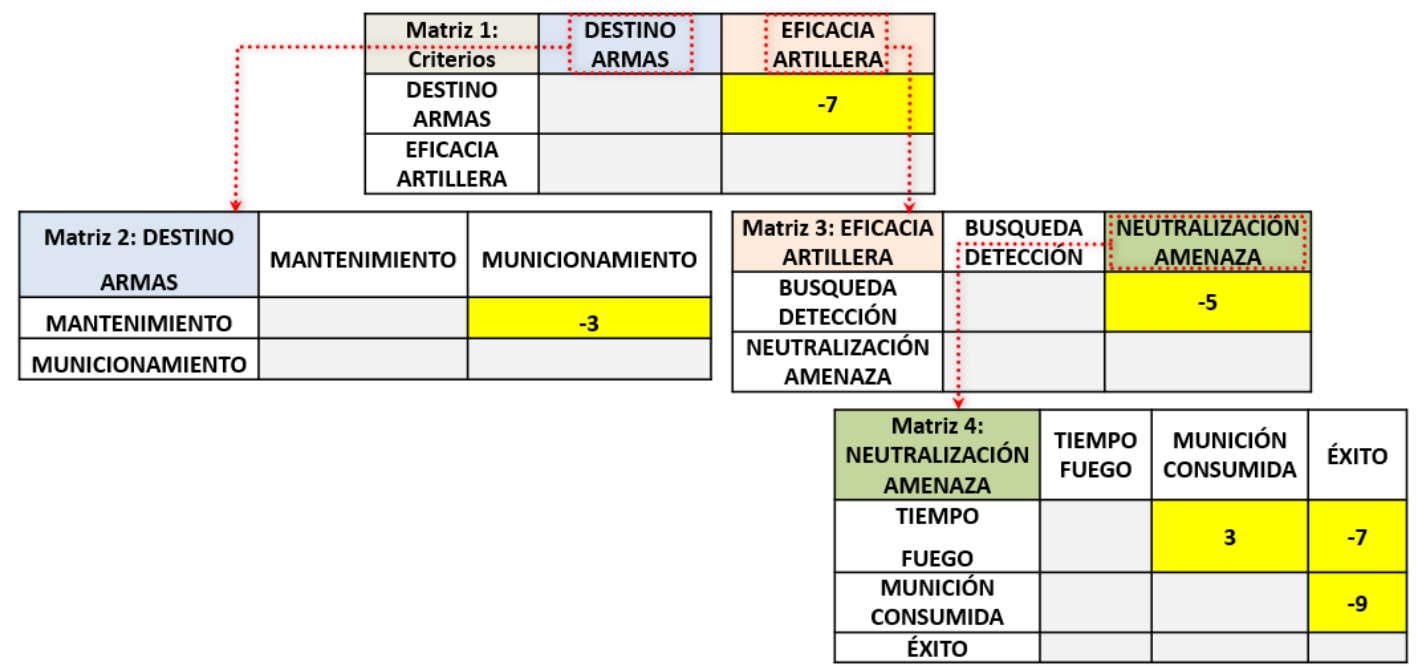

Tabla 3-23 MCP consolidadas con las respuestas de los expertos. Problema de las ametralladoras 
Se observa que el criterio EFICACIA ARTILLERA es "muy fuertemente preferido" frente a DESTINO ARMAS (Matriz 1). El subcriterio Municionamiento es "moderadamente preferido" frente a Mantenimiento (Matriz 2); Neutralización Amenaza es "fuertemente preferido" frente a Búsqueda Detección (Matriz 3). Y finalmente el sub-subcriterio Éxito es entre "Muy fuertemente preferido" y "Muy recomendado" frente a los otros dos subsubcriterios (Matriz 4).

\subsubsection{Evaluación Subjetiva de las Alternativas}

Previo a la deliberación, con el objetivo de establecer el nivel de prioridad de una alternativa sobre otra tomando como base de comparación el grado de cumplimiento o satisfacción de cada subcriterio, se les envió a los expertos algunas preguntas esenciales de ayuda a la reflexión.

Subcriterio de Mantenimiento:

- Bajo cualquier condición meteorológica en la mar, durante el día y/o la noche, ¿qué alternativa cree usted que ofrece una mejor disposición para realizar acciones preventivas simples como: limpieza, inspección, lubricación, etc.?

- Teniendo en cuenta los tiempos de reparación de los fallos y averías más habituales de estas ametralladoras, ¿cree usted que existe alguna alternativa con una disposición de las ametralladoras que facilita esta tarea de reparación?

- ¿Cree usted que alguna de las alternativas ofrece una disposición de las ametralladoras que está menos protegida de las inclemencias de la mar y, por tanto, se pueden producir más averías?

Subcriterio de Municionamiento:

- En su opinión, ¿existe alguna alternativa que por su disposición de las armas dificulte una rápida recarga de munición?

- ¿Cree usted que alguna alternativa no ofrece rapidez o seguridad en la reposición de la munición en las cajas de urgencia?

- ¿Cree usted que alguna alternativa sitúa las ametralladoras en zonas de excesiva cercanía a fuentes de radiación y podría generar problemas con algún tipo de munición, por ejemplo, las de espoleta del tipo VT-RF (tiempo variable radiofrecuencia)? 
Subcriterio de Búsqueda Detección Seguimiento:

- En su opinión, ¿̇existe alguna alternativa que por la disposición de las armas disminuya las capacidades de búsqueda, detección y seguimiento? (altura de las armas, obstaculización de las superestructuras, etc.)

- ¿Cree usted que alguna alternativa sitúa las ametralladoras en zonas de excesiva cercanía a fuentes de radiación que puedan interferir con sus sensores de exploración?

Las MCP consolidadas de las respuestas de las contribuciones de las alternativas a los subcriterios Mantenimiento, Municionamiento y Búsqueda Detección Seguimiento, se pueden observar en la Tabla 3-24.

Matriz 5: MANTENIMIENTO

\begin{tabular}{|l|l|l|l|l|l|l|}
\hline & A & B & C & D & E & F \\
\hline A & & 3 & 3 & -3 & 3 & 5 \\
\hline B & & & -3 & -5 & 1 & 5 \\
\hline C & & & & -3 & 3 & 5 \\
\hline D & & & & & 3 & 5 \\
\hline E & & & & & & 3 \\
\hline F & & & & & & \\
\hline
\end{tabular}

Matriz 6: MUNICIONAMIENTO

\begin{tabular}{|l|l|l|l|l|l|l|}
\hline & A & B & C & D & E & F \\
\hline A & & 1 & 1 & 1 & 1 & 3 \\
\hline B & & & 1 & -3 & 1 & 3 \\
\hline C & & & & 1 & 1 & 3 \\
\hline D & & & & & 1 & 3 \\
\hline E & & & & & & 1 \\
\hline F & & & & & & \\
\hline
\end{tabular}

Matriz 7: BÚSQUEDA DETEC. SEG.

\begin{tabular}{|c|c|c|c|c|c|c|}
\hline & A & B & C & D & E & F \\
\hline A & & -3 & -3 & 3 & -5 & -5 \\
\hline B & & & 1 & 3 & -3 & -3 \\
\hline C & & & & 3 & -3 & -3 \\
\hline D & & & & & -5 & -5 \\
\hline E & & & & & & -3 \\
\hline F & & & & & & \\
\hline
\end{tabular}

Tabla 3-24 MCP subjetivas para la valoración de la contribución de las alternativas. Problema de las ametralladoras

Referente al subcriterio Mantenimiento (Matriz 5), la Opción D resultó entre moderada y fuertemente preferida al resto de opciones. Y, por el contrario, La Opción F, posiblemente por su novedosa disposición asimétrica de las armas inexistente en buques en la actualidad, fue claramente la menos preferida respecto a las demás.

Concerniente al subcriterio Municionamiento (Matriz 6), se reflejó que prácticamente todas las opciones son igualmente preferidas, excepto la Opción F que fue, nuevamente, la menos preferida prácticamente respecto a todas las demás.

Respecto al subcriterio Búsqueda Detección Seguimiento (Matriz 7), los expertos respondieron para las Opciones E y F, entre moderada y fuertemente preferidas. Este juicio se debe a que en estas opciones se sitúa una Mk-38 en proa babor, ganándose 
para el sector proel unos sensores electro-óptico/infrarrojos muy superiores a los de la ametralladora de $12,7 \mathrm{~mm}$.

De nuevo, hasta aquí, se han resuelto los pasos conforme a la metodología AHP clásica. En la siguiente fase se buscó reducir la subjetividad valorándose el cómo contribuyen las alternativas a los sub-subcriterios: Tiempo Fuego, Munición Consumida y Éxito.

\subsubsection{Contribución de las Alternativas. Problema Objetivo}

En esta fase trascendente se explicará cómo mediante código matemático en Matlab, con la técnica de simulación Montecarlo, se representó el ataque múltiple de tres FIACs, buscando la analogía con el ataque que sufrió la fragata saudí en 2017.

En un trabajo conjunto con los expertos se acordó realizar el siguiente estudio:

- Estudio 1. Simulación con ordenador para determinar si existen diferencias entre los sub-subcriterios para las distintas disposiciones de ametralladoras.

Objeto: Escribir un script que recree un ataque simultáneo de tres FIACs y una respuesta con la artillería secundaria para repelerlo.

Técnicas: Simulación Montecarlo, Análisis estadístico descriptivo e inferencial y Programación con Matlab.

Variables a analizar: Tiempo de duración de las acciones de repeler los ataques, consumo de munición y porcentaje de éxito.

\subsubsection{Simulación Matlab. Subcriterios Tiempo Fuego, Munición} Consumida y Éxito

Como ya se ha comentado en el punto anterior, para confrontar cómo contribuyen las alternativas a los sub-subcriterios de Tiempo Fuego, Munición Consumida y Éxito, se simulará un ataque simultáneo de tres lanchas, mediante código matemático en Matlab con metodología Montecarlo.

Acorde a lo recomendado por los expertos, el escenario de la simulación consistió en una fragata F-110 navegando a rumbo Este (090) a 12 nudos (nudo = milla náutica por hora) de velocidad. La zona de navegación es un estrecho de aguas restringidas donde 
las caídas de rumbo no son posibles y, por tanto, no se puede maniobrar el buque para ofrecer un mejor aspecto artillero frente a la amenaza (ver Figura 3-103).

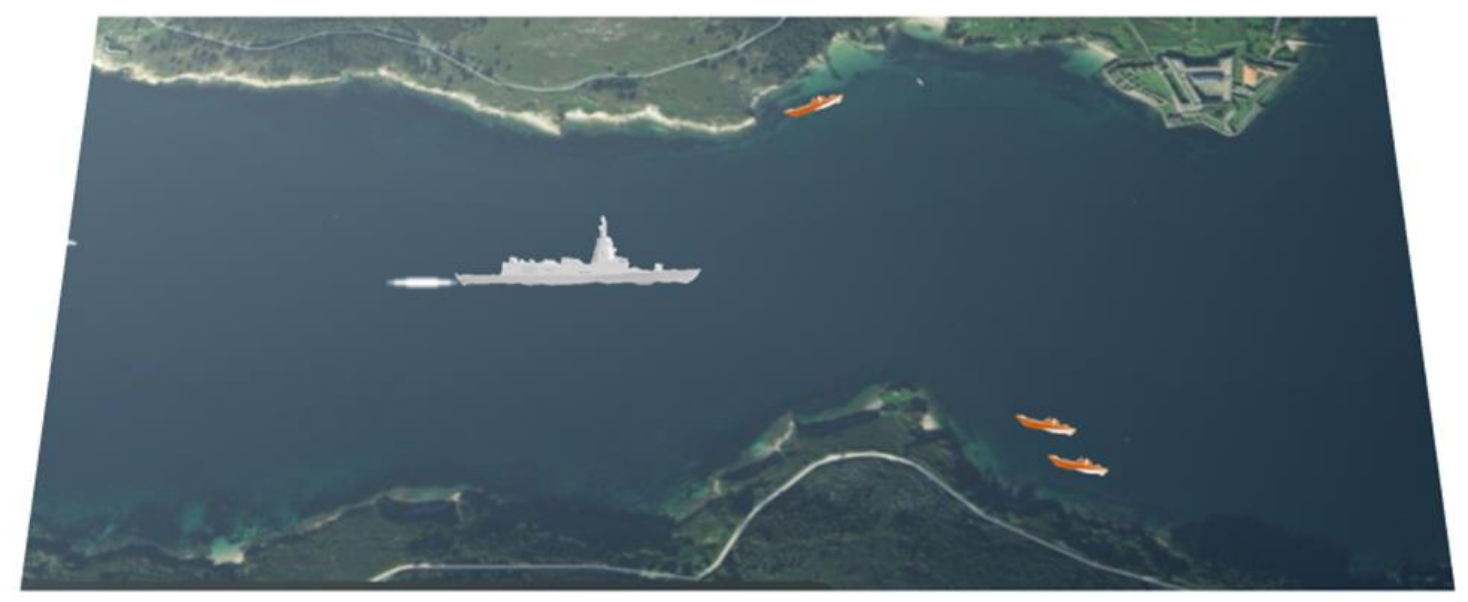

Figura 3-103 Recreación de un ataque simultáneo de tres FIACs (embarcaciones naranjas) a una F-110

(Elaboración propia sobre imagen de Google Maps)

La densidad de tráfico en la zona será grande y podrán existir accidentes geográficos que permitan permanecer a los atacantes ocultos hasta que la fragata se encuentra a una corta distancia de ellos.

Todas estas circunstancias del escenario concebido se han simulado en Matlab del siguiente modo:

- La fragata no ha realizado caídas de rumbo.

- En cada réplica los atacantes aparecen a una corta distancia, alta velocidad y en cualquier marcación, siempre de manera aleatoria.

- La simulación del ataque asimétrico es el de "lanchas suicidas con explosivos" que detonan por impacto con el buque, por tanto, las tres lanchas llevan en todo momento un rumbo de colisión con la fragata.

Es importante destacar que en la simulación se entendió que, en todo momento, las fases previas al comienzo de la acción ya han sucedido y, por tanto, se evaluó únicamente la capacidad artillera de respuesta frente a la amenaza. No se ha pretendido, en ningún caso, simular ni evaluar los sensores de detección y seguimiento de las armas.

Para determinar el número de réplicas, en la simulación Montecarlo, se tuvo en cuenta lo siguiente: La marcación es el ángulo medido desde la proa del buque, en sentido 
horario, hasta la visual al objeto en cuestión, en nuestro caso las lanchas, en consecuencia, la variación en marcación de una sola lancha puede ser desde los $0^{\circ}$ hasta $359^{\circ}$. Esta variabilidad sumada a las otras dos lanchas genera una combinación sin repetición de 360 elementos tomados de 3 en 3

$$
C_{m}^{n}=\frac{m !}{n !(m-n) !}=7711320
$$

a esta combinación de la variabilidad en marcaciones habría que sumarle la variabilidad de las lanchas en distancia y velocidad. Ante y la imposibilidad de alcanzar semejante número de experimentos, se optó por realizar $360 \times 60=21600$ réplicas estocásticas para cada alternativa y posteriormente analizar los resultados para conocer si el número de réplicas era suficiente. En total se realizaron 129600 réplicas.

Las variables de entorno, consensuadas con los expertos, fueron las siguientes:

- Marcación de las lanchas: En cada réplica, cada lancha aparece en una marcación aleatoria conforme a una distribución Uniforme, $U\left[0^{\circ}, 359^{\circ}\right]$

- Velocidad de las lanchas: En cada réplica, cada lancha surge a una velocidad aleatoria conforme a una distribución Uniforme, $U[25,50]$ nudos

- Distancia de las lanchas: En cada réplica, cada lancha aparece a una distancia conforme a una distribución Uniforme, $U[300,800]$ metros

\section{El método de fuego y la probabilidad de impacto ${ }^{3}$}

El algoritmo de apertura de fuego para repeler los ataques en Matlab se estableció en dos modos de funcionamiento:

- Modo "tiro a tiro". Un disparo en 1 segundo con descanso de 1 segundo.

- Modo ráfaga. Cinco disparos continuados en 5 segundos con descanso de 1 segundo.

\footnotetext{
${ }^{3}$ Por confidencialidad toda la información expuesta en este punto procede de datos reales alterados.
} 
Se consideraron las siguientes zonas de distancias de apertura de fuego:

- Zona D1: más de 300 metros de distancia al buque.

- Zona D2: menos de 300 metros de distancia al buque.

La selección del modo de apertura de fuego vino determinada por la distancia de los atacantes. Cuando los tres atacantes se encuentren en la zona D1, el fuego de todas las ametralladoras es en Modo "tiro a tiro" y se conmuta al Modo ráfaga, también para todas las ametralladoras, en cuanto una sola FIAC entra en la zona D2.

Cuando en una réplica de la simulación se consiguió abatir las tres FIAC se consideró y contabilizó como un éxito (ver Figura 3-104). Por el contrario, cuando al menos una lancha alcanzaba los 50 metros de distancia a la fragata sin ser neutralizada se consideró un fracaso; se estimó que la distancia ciega aproximada de las armas es de 50 metros (ver Figura 3-105).

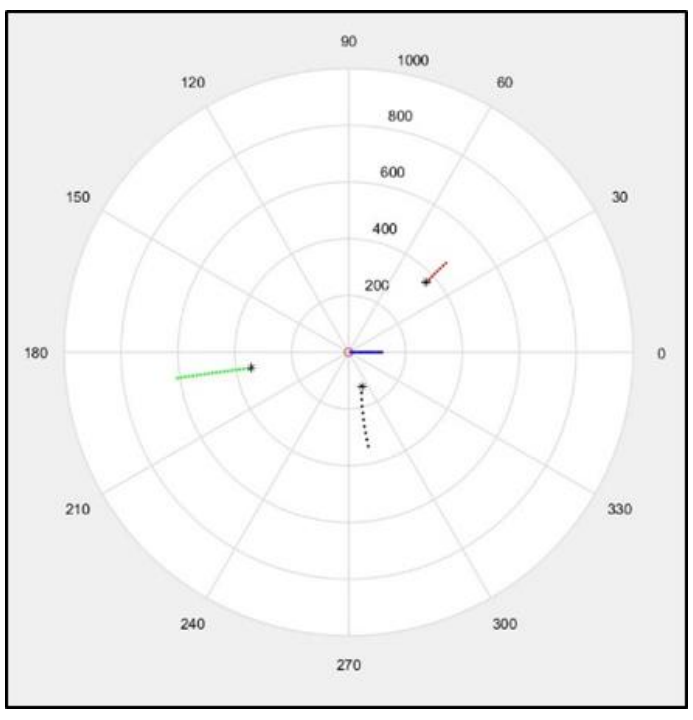

Figura 3-104 Ejemplo de Matlab de un ataque con el resultado de: Éxito. Se neutralizan las tres lanchas quedando reflejado por los asteriscos

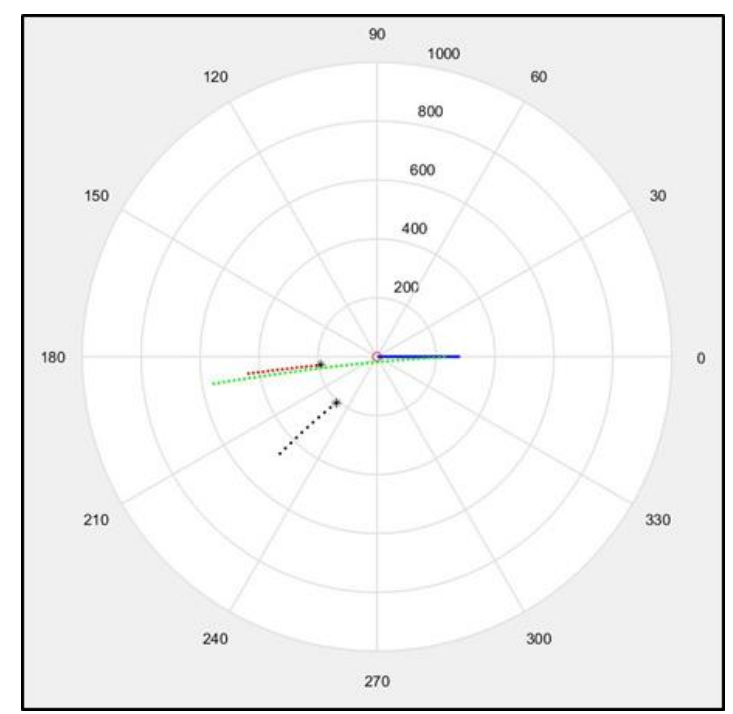

Figura 3-105 Ejemplo de Matlab de un ataque con el resultado de: Fracaso. Se neutralizan dos lanchas y la tercera (trayectoria verde) consigue alcanzar el buque (trayectoria azul)

El script de Matlab tiene un funcionamiento en bucle en el que, en cada iteración de un segundo de tiempo, se actualiza una matriz de visibilidad de los atacantes para cada arma, es decir, se actualiza si están o no, dentro del sector de fuego de cada arma. También se actualizan las distancias de los atacantes y el número de impactos recibidos. 
Para establecer una lancha como "neutralizada" se consideró que debía haber recibido cinco impactos de cualquier calibre.

\section{Algoritmo de Fuego}

El algoritmo de selección de "qué arma dispara y a qué FIAC", trabaja con una lógica que responde a las siguientes prioridades resumidas:

- Si una lancha está dentro del sector de una única arma, esa ametralladora, aunque dentro de su sector observe más lanchas, prioriza el fuego sobre esa lancha.

- Si las lanchas atacan desde varias marcaciones diferentes, se prioriza el fuego del máximo número de armas sobre las más cercanas.

- Si las tres lanchas atacan por el mismo costado, las tres/dos ametralladoras disponibles por esa banda pueden actuar simultáneamente.

- Cuando queda una última lancha por neutralizar, todas las armas disponibles se concentran sobre ese blanco.

- Cuando un arma neutraliza una lancha, antes de poder "engancharse" a una nueva FIAC, se origina un tiempo de retardo que simula el trabajo del operador de la consola. El retardo sigue una distribución Uniforme, $U[10,30] \mathrm{seg}$.

- En las alternativas que disponen de 6 ametralladoras, nunca puede dispararse con las seis simultáneamente por falta de consolas que las operen. Las dos Mk38 disponen de consola propia y para las 4 ametralladoras de $12,7 \mathrm{~mm}$ se dispone de solo 2 consolas (sistema de 2 consolas para 4 armas).

- Cuando solo se dispone de una consola para las dos de $12,7 \mathrm{~mm}$ de una misma banda y coincide que las dos de $12,7 \mathrm{~mm}$ tienen las mismas lanchas dentro de sus sectores, se prioriza el uso de las $12,7 \mathrm{~mm}$ números 1 y 2 , es decir, las ubicadas más a proa o más a popa, según la alternativa que estemos simulando. 
Las probabilidades de impacto se simularon mediante cuatro funciones ${ }^{4}$ que, en función de la distancia y el arma seleccionada, se seleccionaba una de ellas.

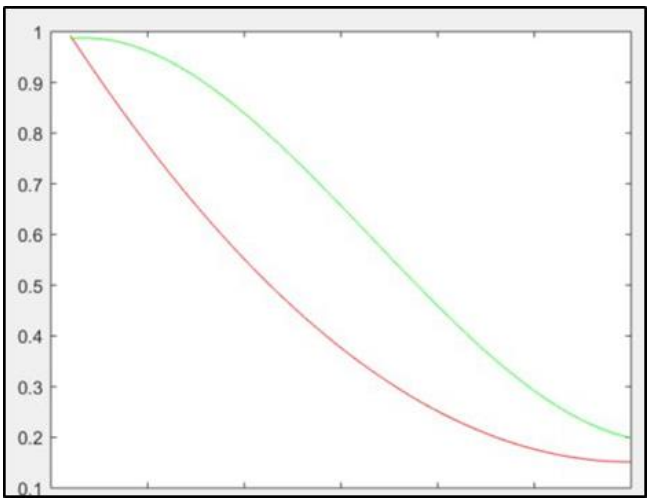

Figura 3-106 Ejemplo de la gráfica de probabilidad de impacto de la ametralladora Mk-38. En verde la curva de disparo en Modo ráfaga y en rojo en Modo "tiro a tiro"

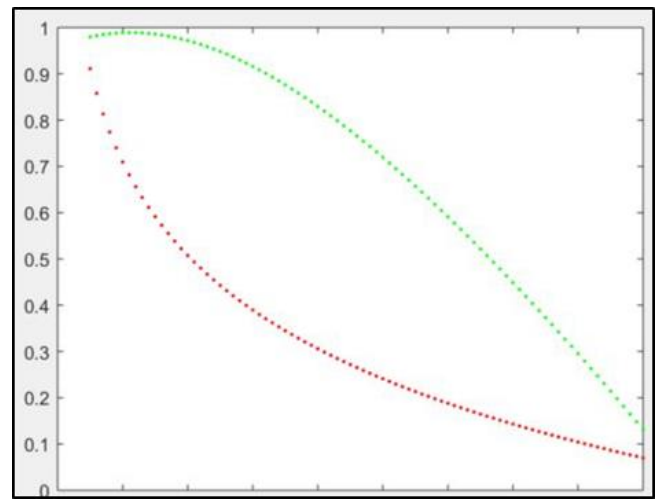

Figura 3-107 Ejemplo de gráfica de probabilidad de impacto de la ametralladora de $12,7 \mathrm{~mm}$. En verde la curva de disparo en Modo ráfaga y en rojo en Modo "tiro a tiro"

Sobre las Figura 3-106 y Figura 3-107, aparecen dibujadas unos ejemplos de curvas de probabilidad de impacto, a la izquierda la de la ametralladora Mk-38 y a la derecha la de $12,7 \mathrm{~mm}$. Las curvas en color verde representan la probabilidad cuando se dispara en Modo ráfaga y en rojo cuando se dispara en Modo "tiro a tiro" (las curvas no están en la misma escala). La ametralladora Mk-38 para la misma distancia de tiro tiene una mayor probabilidad de impacto, a la vez que también tiene mayor poder destructivo, aunque, en este trabajo esta circunstancia no se ha tenido en cuenta por falta de datos fiables que diferencien la capacidad de destrucción entre los dos tipos de calibres.

En cada iteración se extrajo un aleatorio $(U[0,1])$ para cada dupla de [FIACAmetralladora que estuviese enganchada sobre ella], y se comparó con el número que arrojaba la curva de probabilidad de impacto correspondiente.

En el supuesto de que el número aleatorio generado fuese mayor que

$$
\left[1-P_{i}\right]
$$

\footnotetext{
4 Se recuerda que por confidencialidad: las curvas de probabilidad no son reales y no se puede proporcionar el dato de la distancia (eje de abscisas).
} 
donde $P_{i}$ es la Probabilidad de impacto del arma

se consideró que la lancha habría recibido un impacto.

Así, con la simulación en Matlab se tomaron para cada alternativa las siguientes variables conforme a la propuesta del estudio del punto $\underline{3.4 .3}$ :

- Munición Consumida. Se midieron los consumos del número de disparos que realizaron las ametralladoras durante la acción de repeler la amenaza, en el concepto de: Menor munición consumida $\Rightarrow$ Mayor eficacia.

- Tiempo de fuego. Se tomaron los tiempos de duración de la acción, independientemente de si había sido un éxito o un fracaso. Esta información permite distinguir la rapidez de neutralización de FIACs y, por tanto, es un índice de la eficacia de cada alternativa. Menor tiempo $\Rightarrow$ Mayor eficacia.

- Éxito. Como ya se ha comentado, se contabilizó como éxito la neutralización de las tres FIACs, lo contrario se consideró un fracaso. Mayor \% éxito $\Rightarrow$ Mayor eficacia.

\subsection{Experimento en Matlab. Opción A}

Los datos obtenidos en la simulación para esta alternativa arrojan un porcentaje de Éxito del 73,48\% (ver Figura 3-108).

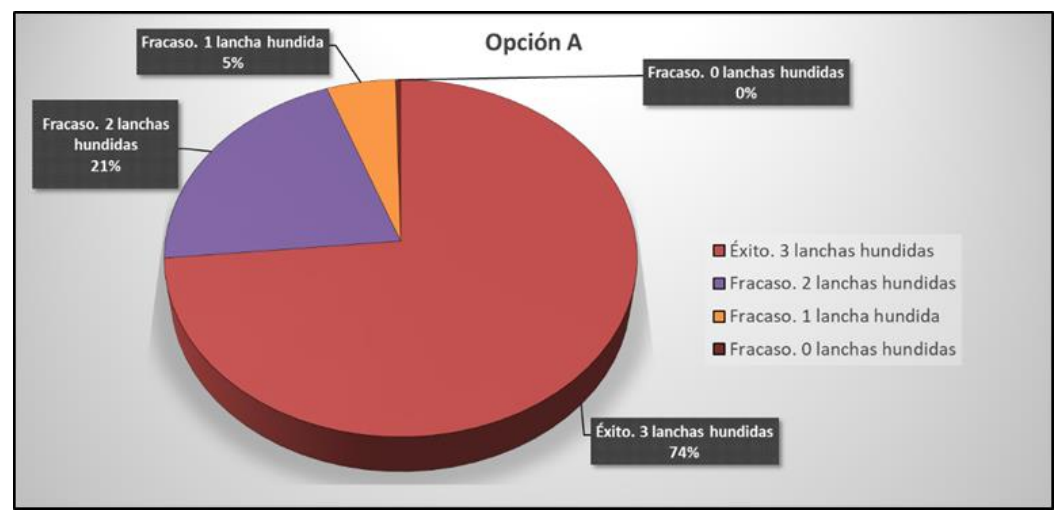

Figura 3-108 Gráfico de los porcentajes de lanchas neutralizadas. Opción A

El tiempo promedio de duración de la acción es de 21,38 segundos. La distribución de los tiempos se puede apreciar en el histograma con los estadísticos descriptivos de la Figura 3-109. 
El promedio de duración de la acción, cuando el resultado es éxito, es de 20,64 segundos que es aproximadamente un segundo menor al total.

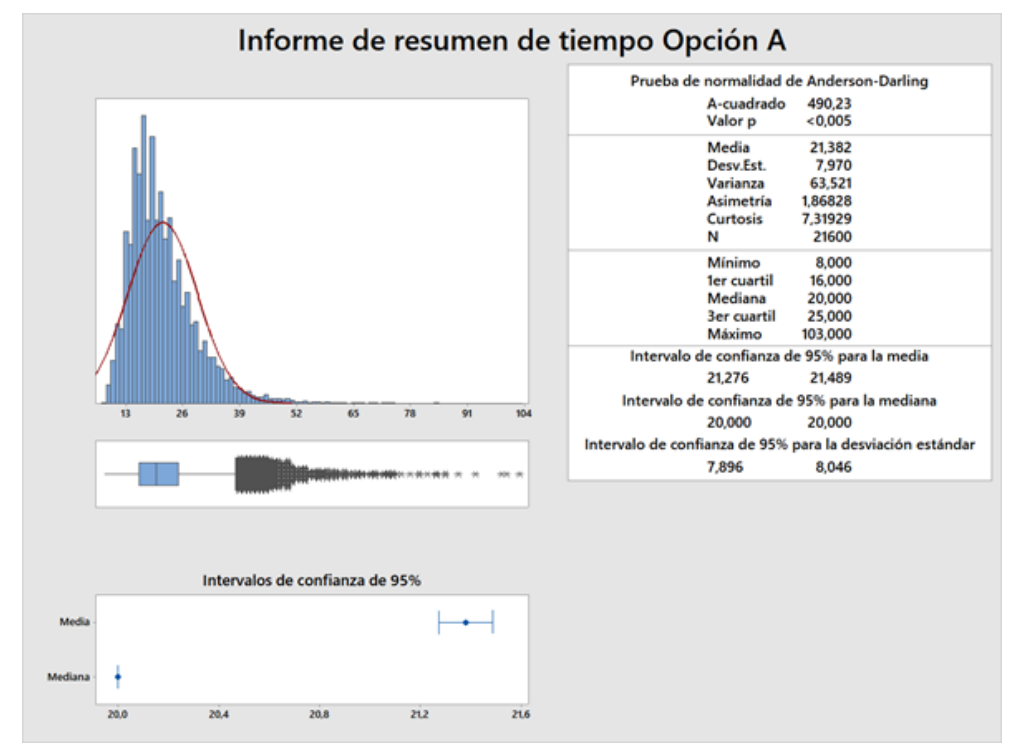

Figura 3-109 Informe de resumen de tiempo. Opción A

Las distribuciones de la munición consumida por cada una de las seis ametralladoras se pueden observar en la gráfica de la Figura 3-110.

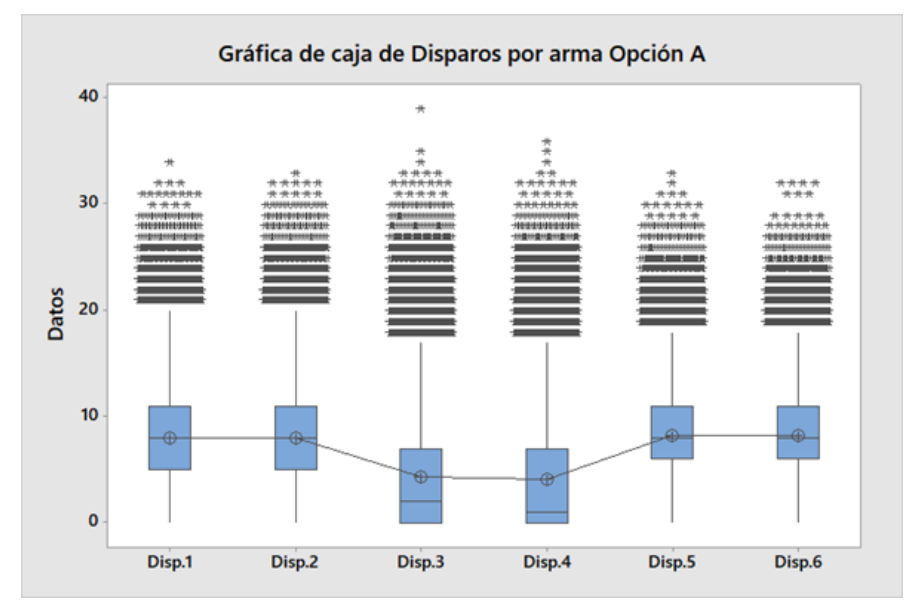

Figura 3-110 Box-Plot de disparos por arma. Opción A

Los promedios de disparos por arma son los reflejadas en la Tabla 3-25 y Figura 3-111.

Promedio de disparos por arma. Opción A

\begin{tabular}{|c|c|c|c|c|c|}
\hline $\begin{array}{c}\text { Ametralladora 1 } \\
12.7 \mathrm{~mm}\end{array}$ & $\begin{array}{c}\text { Ametralladora 2 } \\
12.7 \mathrm{~mm}\end{array}$ & $\begin{array}{c}\text { Ametralladora 3 } \\
12.7 \mathrm{~mm}\end{array}$ & $\begin{array}{c}\text { Ametralladora 4 } \\
12.7 \mathrm{~mm}\end{array}$ & $\begin{array}{c}\text { Ametralladora 5 } \\
\text { Mk-38 }\end{array}$ & $\begin{array}{c}\text { Ametralladora 6 } \\
\text { Mk-38 }\end{array}$ \\
\hline 7.98 & 7.95 & 4.26 & 4.02 & 8.23 & 8.24 \\
\hline
\end{tabular}

Tabla 3-25 Promedio de disparos por ametralladora. Opción A 


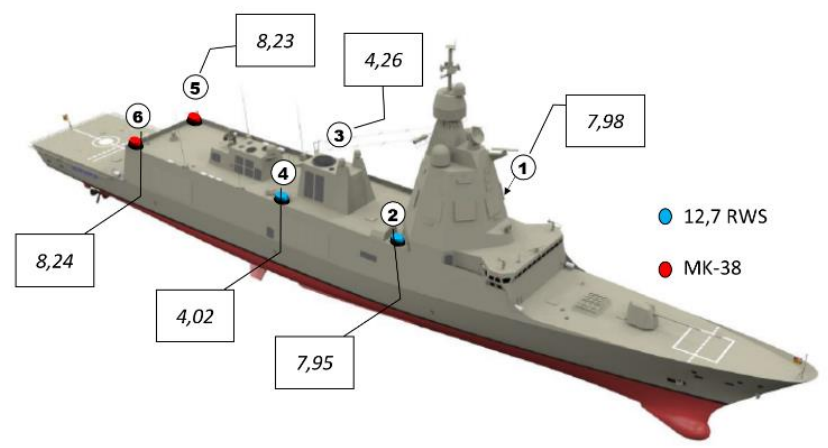

Figura 3-111 Promedio de disparos por ametralladora. Opción A (Elaboración propia sobre imagen de F-110 de DGAM)

Como se puede apreciar los consumos de munición son distintos. Las ametralladoras de $12,7 \mathrm{~mm}$ de proa (núm. 1 y 2) tienen de promedio más de 3 disparos por arma respecto a las situadas a media eslora (núm. 3 y 4). Esta diferencia es debida a lo que se explicó en el algoritmo de fuego, que prioriza a las ametralladoras №1 y №2 en caso de disponer de una sola consola para las dos armas del mismo costado. Las ametralladoras de proa de $12,7 \mathrm{~mm}$ núm. 1 y 2 tienen un consumo menor que las de popa núm. 5 y 6. Aparentemente, el consumo es el mismo entre ambas bandas.

Se realizó un contraste de hipótesis ANOVA para comprobación de si las medias de disparo de todas las armas eran iguales, resultando que únicamente los son para las duplas [Arma 1, Arma 2] y [Arma 5, Arma 6] (ver Figura en Apéndice C-1).

El promedio del consumo global de disparos es de 6,78 disparos por ametralladora.

\subsection{Experimento en Matlab. Opción B}

Los datos obtenidos en la simulación para esta alternativa arrojan un porcentaje de éxito del $81,37 \%$. Los resultados del conjunto de las réplicas se pueden apreciar sobre el gráfico de la Figura 3-112. 


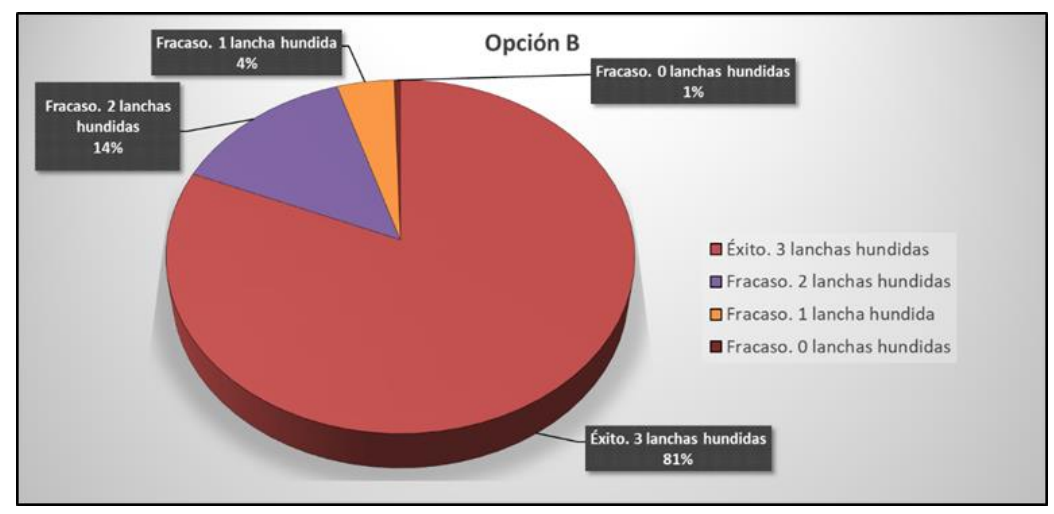

Figura 3-112 Gráfico de los porcentajes de lanchas neutralizadas. Opción B

El tiempo promedio de duración de la acción es de 21,12 segundos. La distribución de los tiempos se puede apreciar en el histograma con los estadísticos descriptivos de la Figura 3-113.

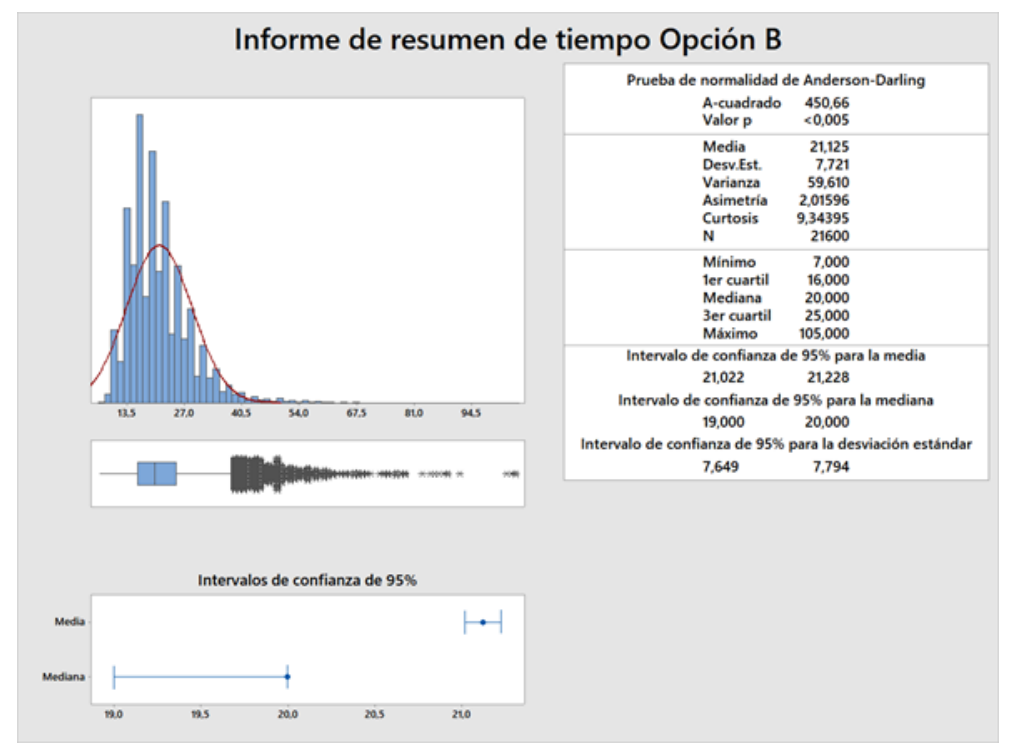

Figura 3-113 Informe de resumen de tiempo. Opción B

El promedio de duración de la acción, cuando se ha tenido éxito, es de 20,55 segundos, que es ligeramente menor al global.

Las distribuciones de la munición consumida por cada una de las seis ametralladoras se pueden observar en la gráfica de la Figura 3-114. 


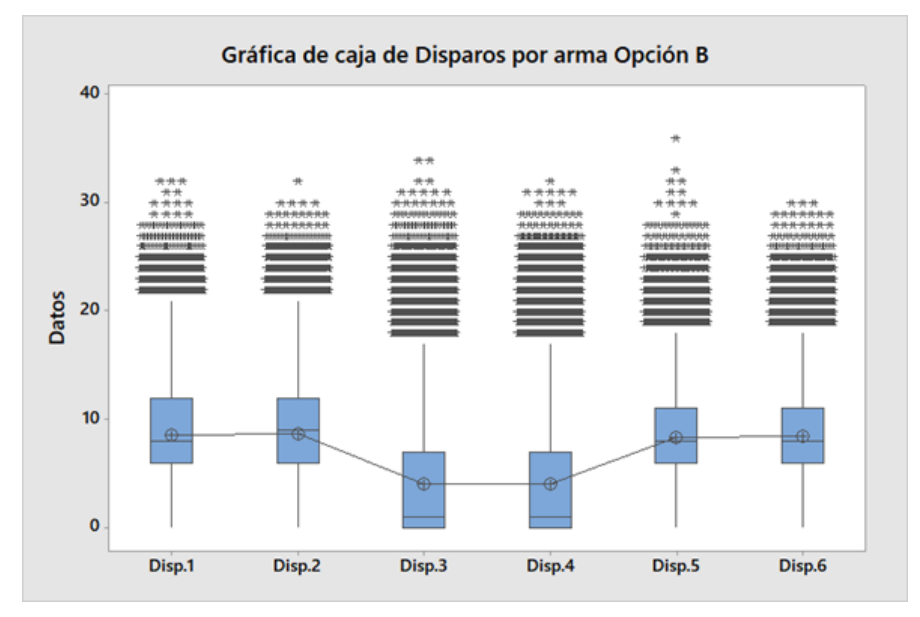

Figura 3-114 Box-Plot de disparos por arma. Opción B

Los promedios de disparos por arma son los reflejadas en la Tabla 3-26 y Figura 3-115.

Promedio de disparos por arma. Opción B

\begin{tabular}{|c|c|c|c|c|c|}
\hline $\begin{array}{c}\text { Ametralladora 1 } \\
12.7 \mathrm{~mm}\end{array}$ & $\begin{array}{c}\text { Ametralladora 2 } \\
12.7 \mathrm{~mm}\end{array}$ & $\begin{array}{c}\text { Ametralladora 3 } \\
12.7 \mathrm{~mm}\end{array}$ & $\begin{array}{c}\text { Ametralladora 4 } \\
12.7 \mathrm{~mm}\end{array}$ & $\begin{array}{c}\text { Ametralladora 5 } \\
\text { Mk-38 }\end{array}$ & $\begin{array}{c}\text { Ametralladora 6 } \\
\text { Mk-38 }\end{array}$ \\
\hline 8.55 & 8.66 & 4.04 & 4.06 & 8.37 & 8.42 \\
\hline
\end{tabular}

Tabla 3-26 Promedio de disparos por ametralladora. Opción B

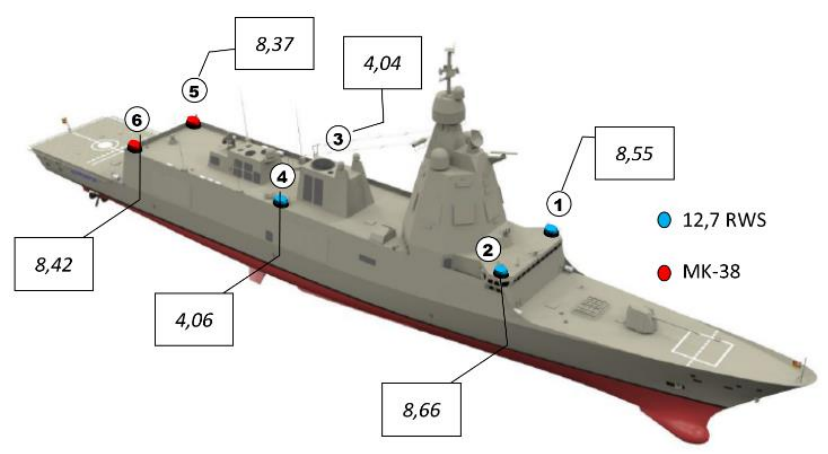

Figura 3-115 Promedio de disparos por ametralladora. Opción B (Elaboración propia sobre imagen de F-110 de DGAM)

Supuestamente, se puede estimar que los consumos de munición son distintos. Las ametralladoras de $12,7 \mathrm{~mm}$ de proa (núm. 1 y 2 ) tienen de promedio más de 4 disparos por arma respecto a las situadas a media eslora (núm. 3 y 4). Esta diferencia es debida al algoritmo de fuego. Las ametralladoras núm. 1 y 2, en esta opción, a diferencia de la opción A, tienen un ligero mayor consumo que las núm. 5 y 6 . En apariencia, simétricamente respecto al plano longitudinal todas tienen el mismo consumo por banda. 
Se realizó un contraste de hipótesis ANOVA para comprobación de si las medias de disparo de todas las armas eran iguales, resultando que estadísticamente no se puede rechazar la igualdad de medias entre el [Arma 1, Arma 2], [Arma 3 , Arma 4] y [Arma 5 , Arma 6] (ver Figura en Apéndice C-2).

El promedio total de disparos es de 7,02 disparos por arma, que es algo mayor que en la opción A. Este aumento del porcentaje de éxito y del promedio de número de disparos por arma, pudiera deberse a que las ametralladoras 1 y 2 están situadas más a proa generando un cono ciego algo menor hacia proa y, por tanto, abarcan un sector de fuego mayor.

\subsection{Experimento en Matlab. Opción C}

Los resultados obtenidos en la simulación para esta alternativa arrojan un porcentaje de éxito del 73,62\%. Los porcentajes del conjunto de las réplicas se pueden apreciar sobre el gráfico de la Figura 3-116.

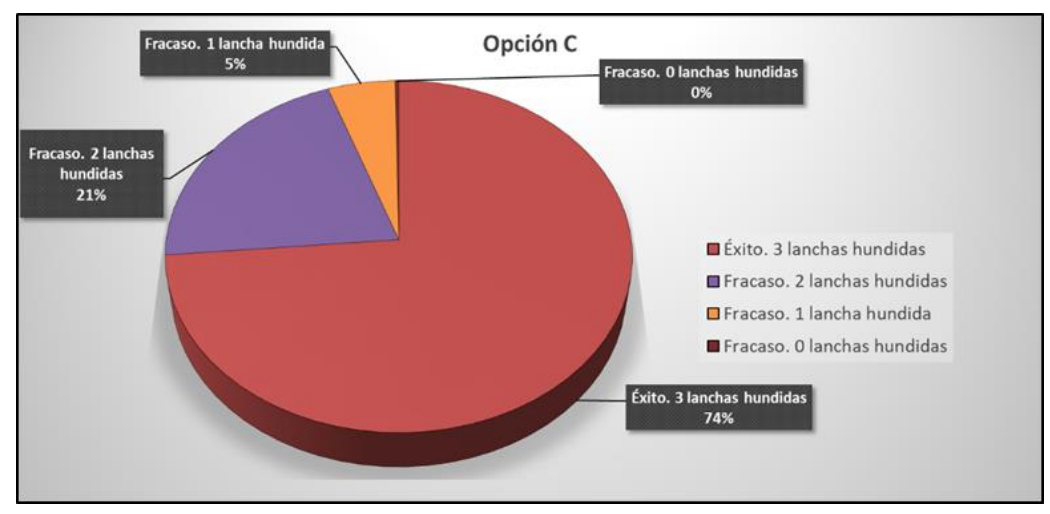

Figura 3-116 Gráfico de los porcentajes de lanchas neutralizadas. Opción C

El tiempo promedio de duración de la acción es de 21,47 segundos. La distribución de los tiempos se puede apreciar en el histograma con los estadísticos descriptivos de la Figura 3-117.

El promedio de duración de la acción, cuando se ha tenido éxito, es de 21,47 segundos, que es muy parejo al de la opción A. 


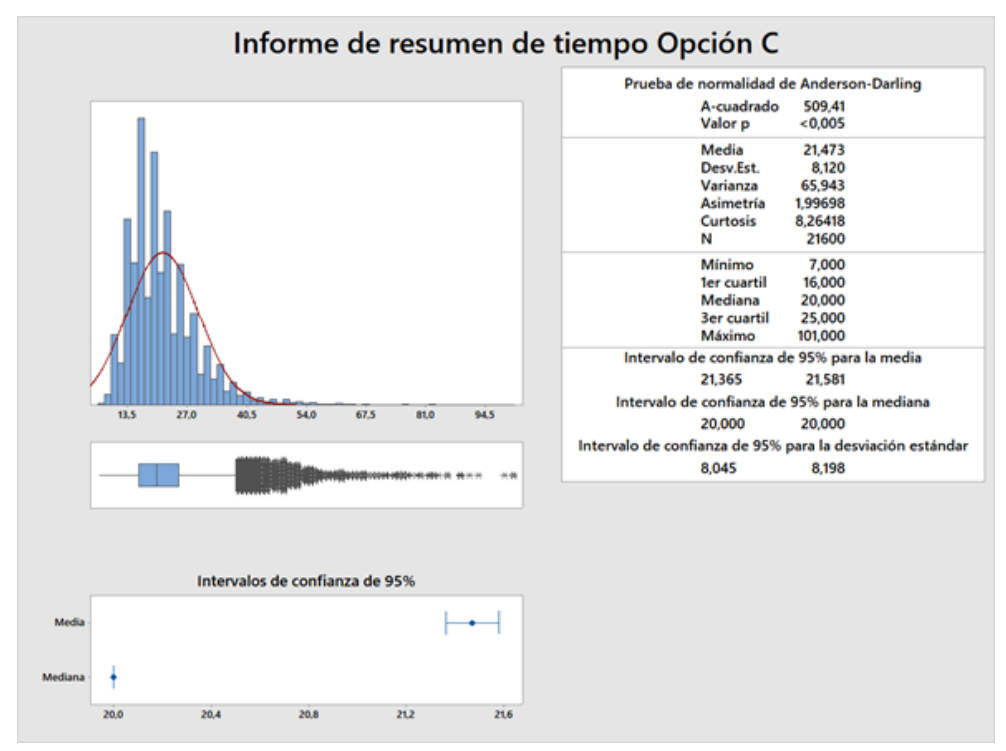

Figura 3-117 Informe de resumen de tiempo. Opción C

Las distribuciones de la munición consumida por cada ametralladora se pueden observar en la gráfica de la Figura 3-118 .

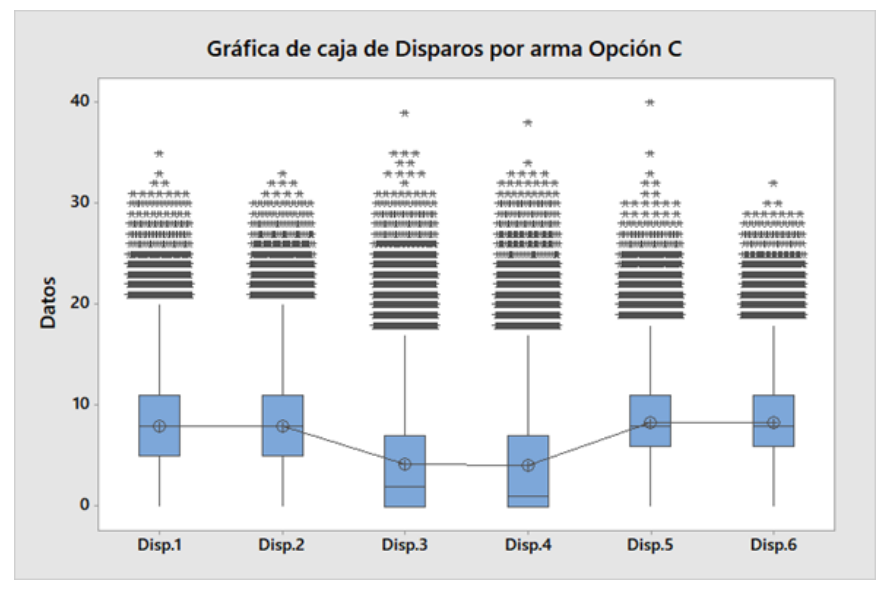

Figura 3-118 Box-Plot de disparos por arma. Opción C

Los promedios de disparos por arma son los reflejadas en la Tabla 3-27 y Figura 3-119.

Promedio de disparos por arma. Opción C

\begin{tabular}{|c|c|c|c|c|c|}
\hline $\begin{array}{c}\text { Ametralladora 1 } \\
12.7 \mathrm{~mm}\end{array}$ & $\begin{array}{c}\text { Ametralladora 2 } \\
12.7 \mathrm{~mm}\end{array}$ & $\begin{array}{c}\text { Ametralladora 3 } \\
12.7 \mathrm{~mm}\end{array}$ & $\begin{array}{c}\text { Ametralladora 4 } \\
12.7 \mathrm{~mm}\end{array}$ & $\begin{array}{c}\text { Ametralladora 5 } \\
\text { Mk-38 }\end{array}$ & $\begin{array}{c}\text { Ametralladora 6 } \\
\text { Mk-38 }\end{array}$ \\
\hline 7.98 & 7.99 & 4.24 & 4.02 & 8.27 & 8.27 \\
\hline
\end{tabular}

Tabla 3-27 Promedio de disparos por ametralladora. Opción C 


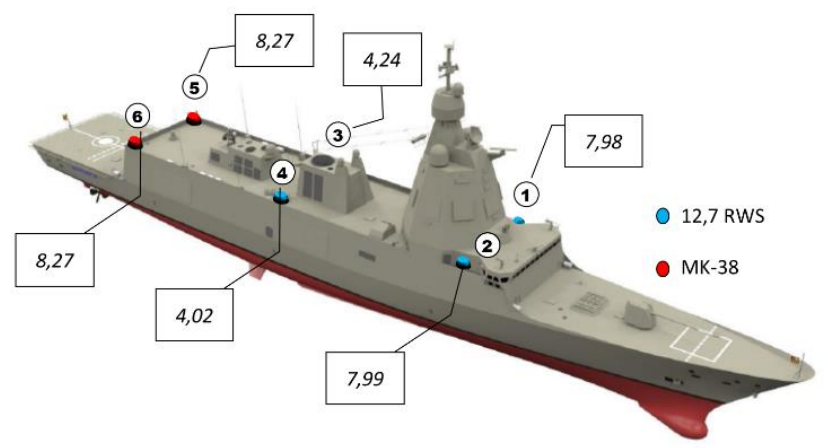

Figura 3-119 Promedio de disparos por ametralladora. Opción C (Elaboración propia sobre imagen de F-110 de DGAM)

Se puede considerar que los consumos de munición por arma son muy similares a los de la Opción A. Las ametralladoras de 12,7mm de proa núm. 1 y 2 tienen de promedio más de 3 disparos por arma respecto a las situadas a media eslora núm. 3 y 4 y, a su vez, un ligero menor consumo que las núm. 5 y 6.

Se realizó un contraste de hipótesis ANOVA para comprobación de si las medias de disparo de todas las armas eran iguales, resultando que no se puede rechazar la hipótesis de igualdad para las duplas [Arma 1, Arma 2] y [Arma 5 , Arma 6] (ver Figura en Apéndice C-3).

El promedio global de disparos es de 6,79 disparos por ametralladora, que es semejante al resultado de la Opción A. En general, se puede afirmar que los resultados obtenidos son muy similares a la Opción A en las tres variables objeto de la simulación.

\subsection{Experimento en Matlab. Opción D}

Los datos obtenidos en la simulación para esta alternativa arrojan un porcentaje de éxito del $52,1 \%$, que es bastante inferior a las opciones anteriores que cuentan con 6 ametralladoras. Los resultados del conjunto de las réplicas se pueden apreciar sobre el gráfico de la Figura 3-120. 


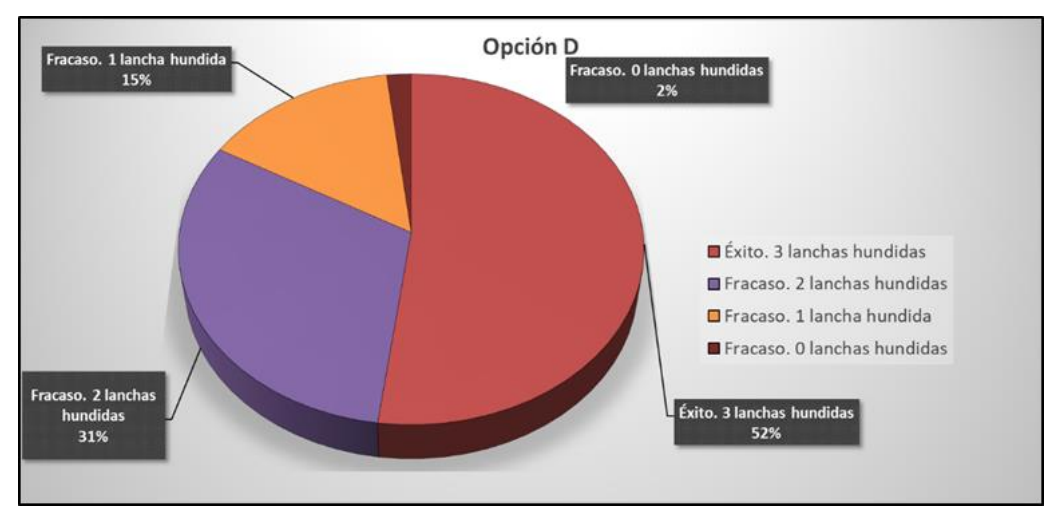

Figura 3-120 Gráfico de los porcentajes de lanchas neutralizadas. Opción D

El tiempo promedio de duración de la acción es de 24,88 segundos. La distribución de los tiempos se puede apreciar en el histograma con los estadísticos descriptivos de la Figura 3-121.

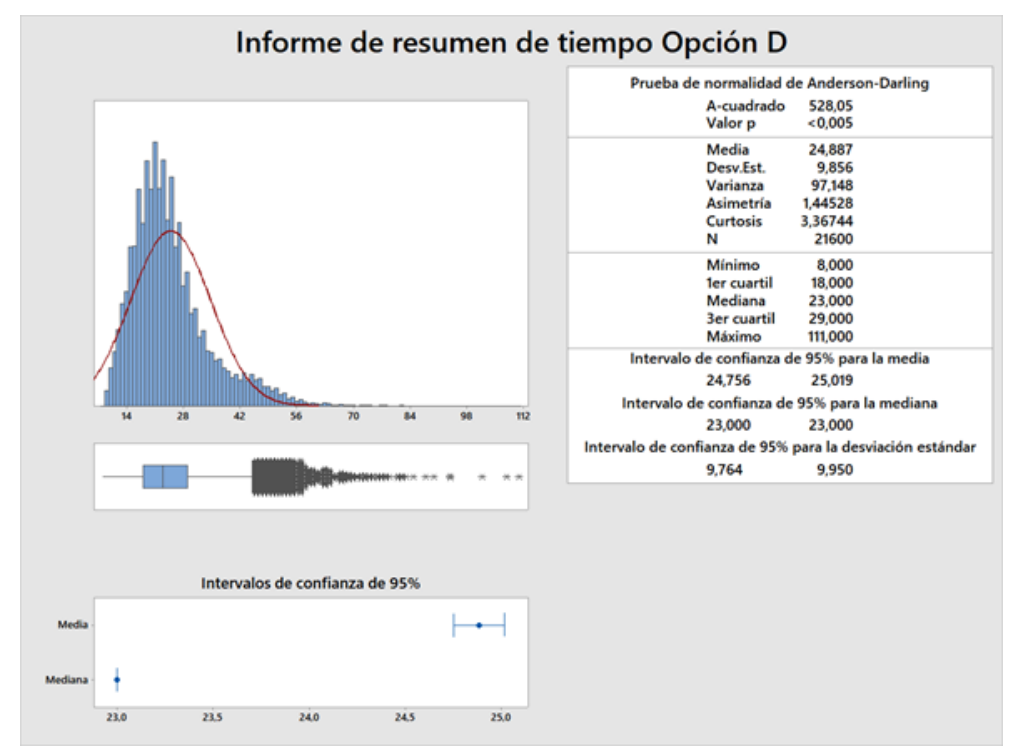

Figura 3-121 Informe de resumen de tiempo. Opción D

El promedio de duración de la acción, cuando se ha tenido éxito, es de 24,7 segundos.

Las distribuciones de la munición consumida por cada ametralladora se pueden observar en la gráfica de la Figura 3-122. 


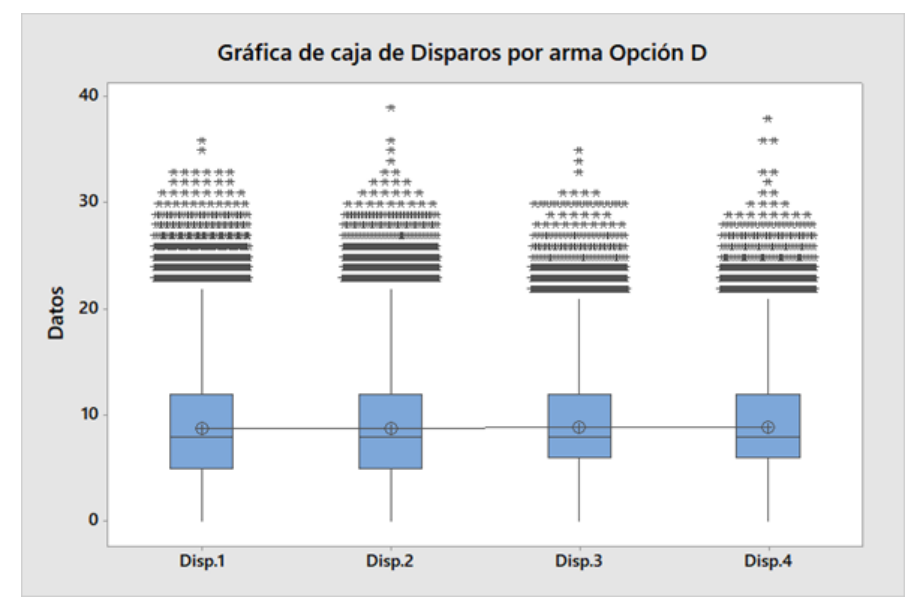

Figura 3-122 Box-Plot de disparos por arma. Opción D

Los promedios de disparos por arma son los reflejadas en la Tabla 3-28 y Figura 3-123.

Promedio de disparos por arma. Opción D

\begin{tabular}{|c|c|c|c|}
\hline $\begin{array}{c}\text { Ametralladora 1 } \\
12.7 \mathrm{~mm}\end{array}$ & $\begin{array}{c}\text { Ametralladora 2 } \\
12.7 \mathrm{~mm}\end{array}$ & $\begin{array}{c}\text { Ametralladora 3 } \\
\text { Mk-38 }\end{array}$ & $\begin{array}{c}\text { Ametralladora 4 } \\
\text { Mk-38 }\end{array}$ \\
\hline 8,81 & 8,83 & 8,9 & 8,87 \\
\hline \multicolumn{2}{|r|}{ Tabla 3-28 Promedio de disparos por arma. Opción D } \\
\hline
\end{tabular}

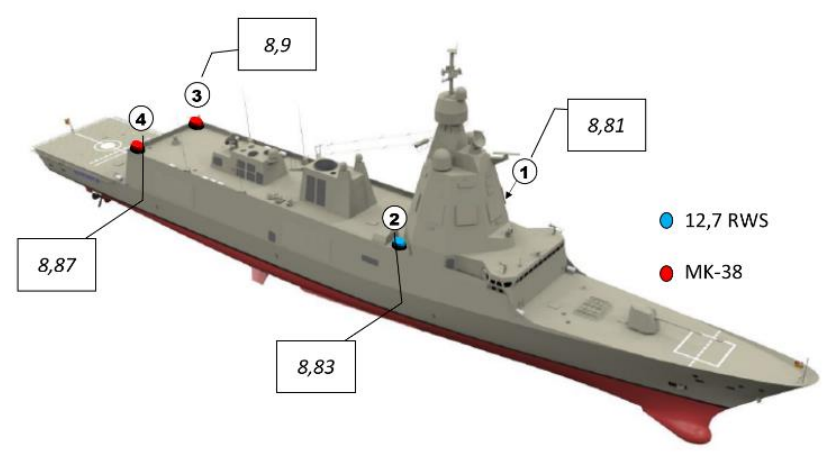

Figura 3-123 Promedio de disparos por ametralladora. Opción D (Elaboración propia sobre imagen de F-110 de DGAM)

Los consumos de munición por arma son muy similares entre las cuatro ametralladoras. Se realizó un contraste de hipótesis ANOVA para comprobación de si las medias de consumo de las armas son iguales, resultando que no se puede rechazar la hipótesis de igualdad de medias entre las cuatro ametralladoras (ver Figura en Apéndice C-4).

El promedio global de disparos por ametralladora es de 8,88. Lógicamente, es más elevado que en las opciones anteriores que contaban con seis ametralladoras. Esta 
opción se muestra menos eficaz en todas las variables respecto de las opciones anteriores.

\subsection{Experimento en Matlab. Opción E}

Los datos obtenidos en la simulación para esta alternativa arrojan un porcentaje de éxito del 58,76\%, que es algo mayor que la Opción D. Los resultados del conjunto de las réplicas se pueden apreciar sobre el gráfico de la Figura 3-124.

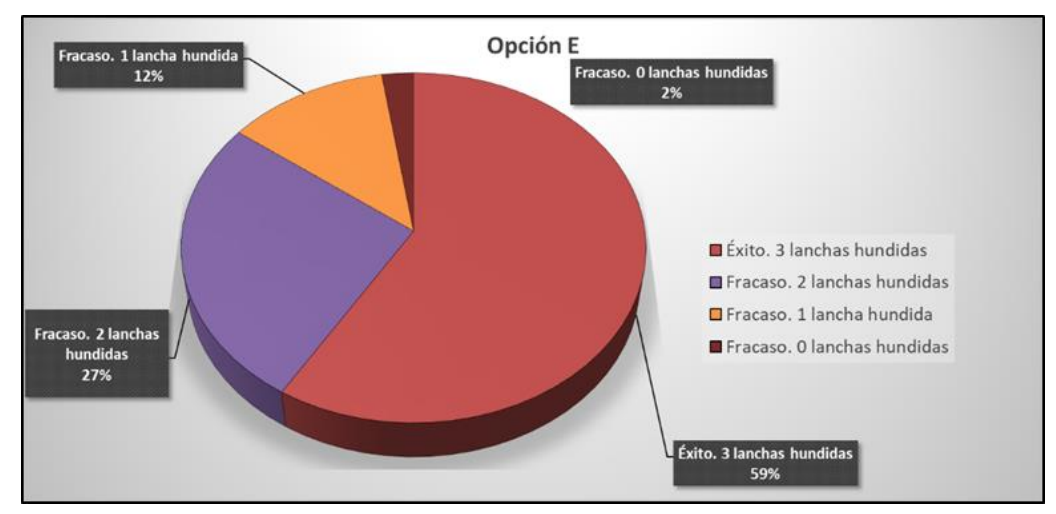

Figura 3-124 Gráfico de los porcentajes de lanchas neutralizadas. Opción E

El tiempo promedio de duración de la acción es de 25,18 segundos. La distribución de los tiempos se puede apreciar en el histograma con los estadísticos descriptivos de la Figura 3-125.

El promedio de duración de la acción, cuando se ha tenido éxito, es de 24,5 segundos.

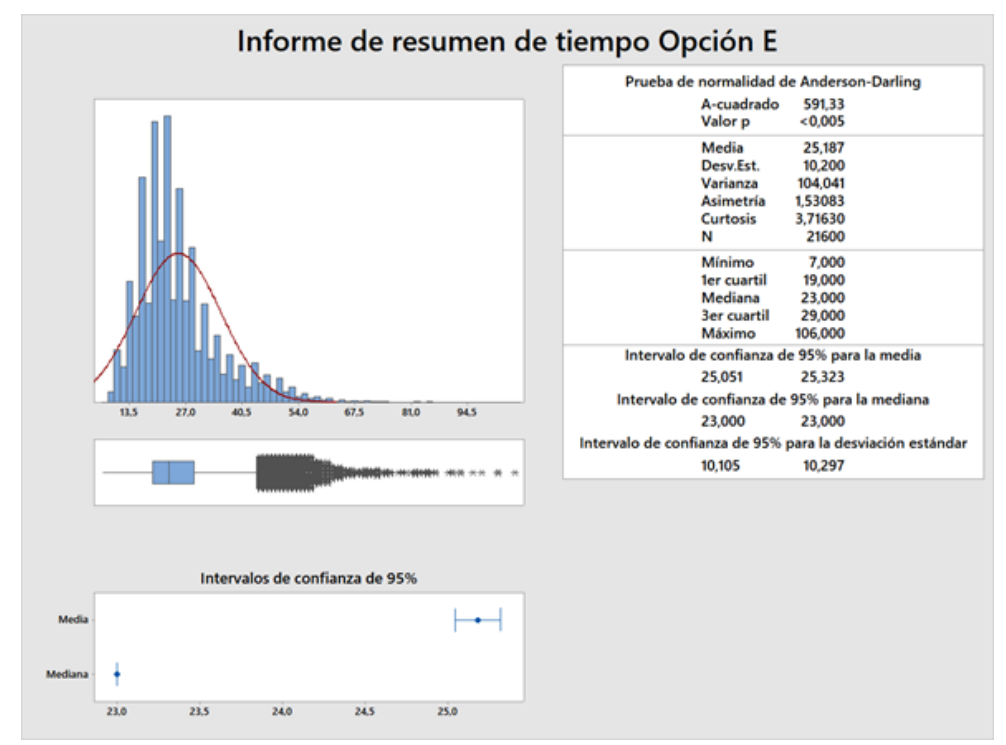

Figura 3-125 Informe de resumen de tiempo. Opción E 
Las distribuciones de la munición consumida por cada ametralladora se pueden observar en la gráfica de la Figura 3-126.

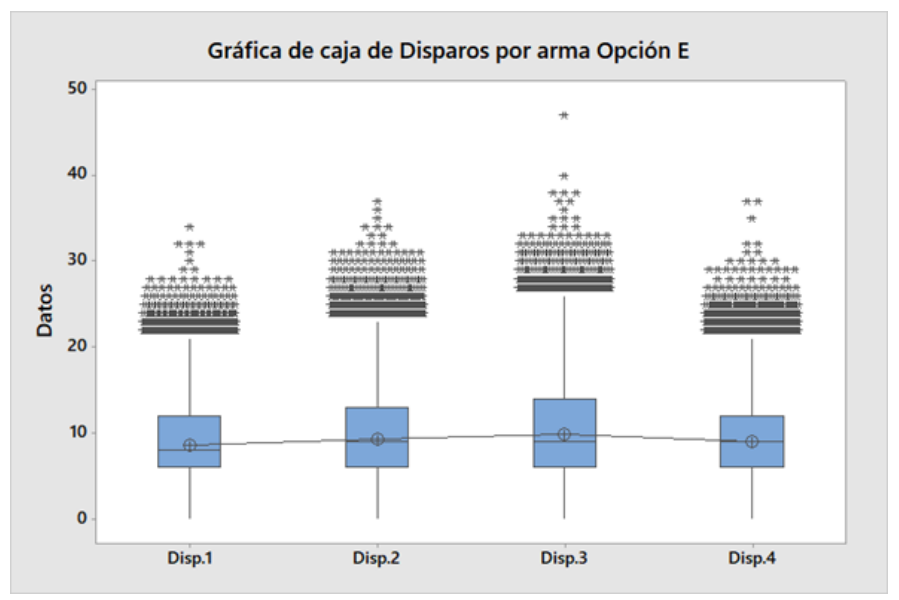

Figura 3-126 Box-Plot de disparos por arma. Opción E

Los promedios de disparos por arma son los reflejadas en la Tabla 3-29 y Figura 3-127.

Promedio de disparos por arma. Opción E

\begin{tabular}{|c|c|c|c|}
\hline $\begin{array}{c}\text { Ametralladora 1 } \\
12.7 \mathrm{~mm}\end{array}$ & $\begin{array}{c}\text { Ametralladora 2 } \\
12.7 \mathrm{~mm}\end{array}$ & $\begin{array}{c}\text { Ametralladora 3 } \\
\text { Mk-38 }\end{array}$ & $\begin{array}{c}\text { Ametralladora 4 } \\
\text { Mk-38 }\end{array}$ \\
\hline 8.6 & 9.34 & 9.92 & 9.05 \\
\hline
\end{tabular}

Tabla 3-29 Promedio de disparos por arma. Opción E

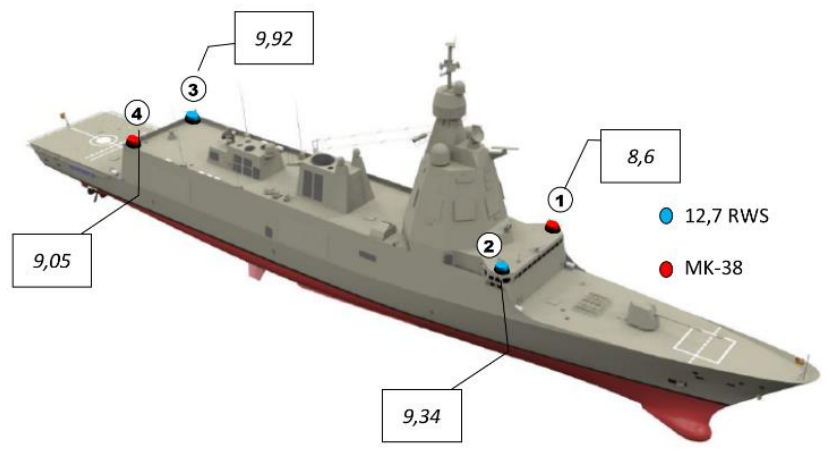

Figura 3-127 Promedio de disparos por ametralladora. Opción E (Elaboración propia sobre imagen de F-110 de DGAM)

Los consumos de munición por arma son ligeramente diferentes entre las cuatro ametralladoras y levemente más alto que en la opción D.

Se realizó un contraste de hipótesis ANOVA para comprobación de si las medias de las armas difieren, resultando que si se puede rechazar la hipótesis de igualdad de medias entre las cuatro ametralladoras (ver Figura en Apéndice C-5). 
El promedio global de disparos es de 9,23 por ametralladora. Este consumo, indudablemente, es más elevado que en las opciones que cuentan con seis armas, pero también lo es con respecto a la opción D. Esta opción se muestra con un porcentaje de acierto mejor que la otra opción de cuatro ametralladoras, posiblemente por una mejor disposición de ametralladoras, que al estar las de proa ubicadas en el puente alto mejora el sector de fuego. La asimetría en la disposición de las armas no parece ser especialmente relevante.

\subsection{Experimento en Matlab. Opción F}

Los datos obtenidos en la simulación para esta alternativa arrojan un porcentaje de éxito del $80,41 \%$. Los resultados del conjunto de las réplicas se pueden apreciar sobre el gráfico de la Figura 3-128.

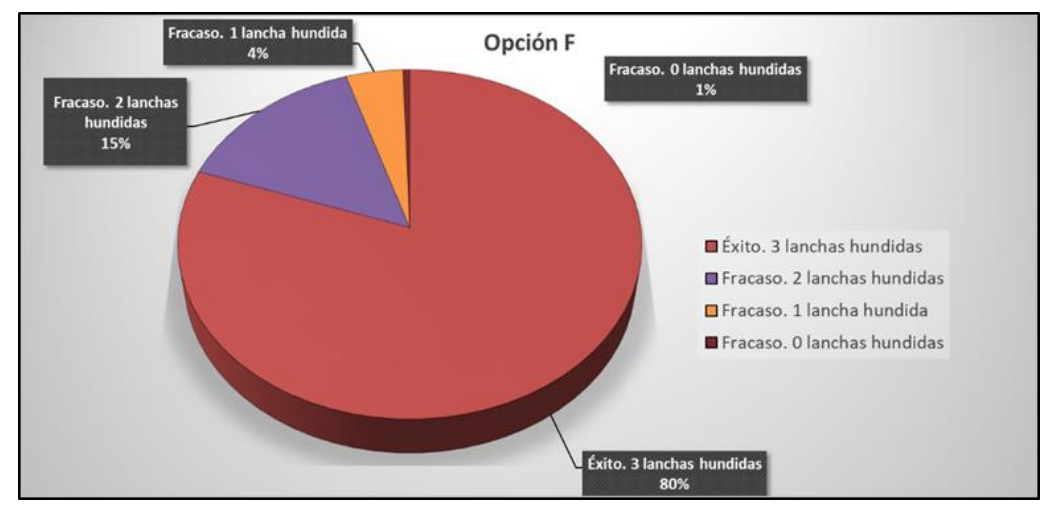

Figura 3-128 Gráfico de los porcentajes de lanchas neutralizadas. Opción F

El tiempo promedio de duración de la acción es de 21,7 segundos. La distribución de los tiempos se puede apreciar en el histograma con los estadísticos descriptivos de la Figura 3-129.

El promedio de duración de la acción, cuando se ha tenido éxito, es de 20,8 segundos. 


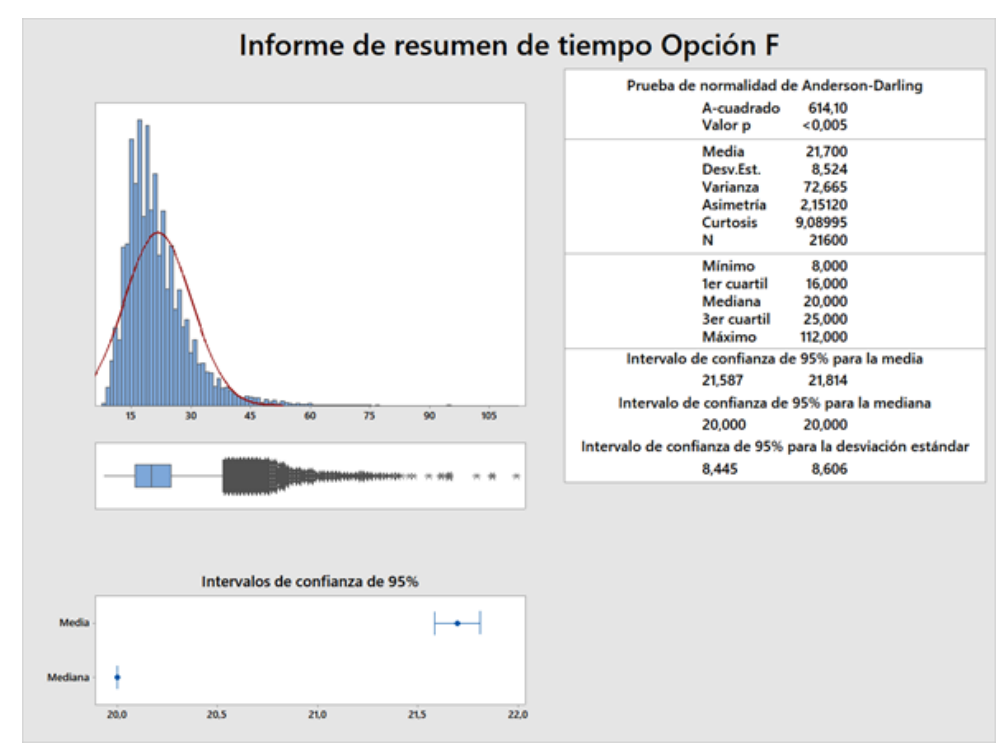

Figura 3-129 Informe de resumen de tiempo. Opción F

Las distribuciones de la munición consumida por cada ametralladora se pueden observar en la gráfica de la Figura 3-130.

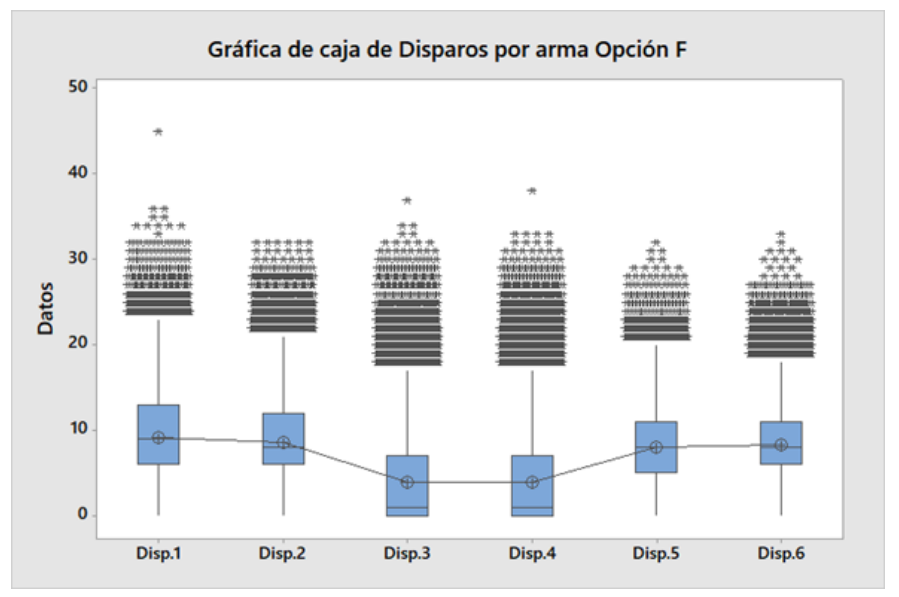

Figura 3-130 Box-Plot de disparos por arma. Opción F

Los promedios de disparos por arma son los reflejadas en la Tabla 3-30 y Figura 3-131.

Promedio de disparos por arma. Opción F

\begin{tabular}{|c|c|c|c|c|c|}
\hline $\begin{array}{c}\text { Ametralladora 1 } \\
\text { Mk-38 }\end{array}$ & $\begin{array}{c}\text { Ametralladora 2 } \\
12.7 \mathrm{~mm}\end{array}$ & $\begin{array}{c}\text { Ametralladora 3 } \\
12.7 \mathrm{~mm}\end{array}$ & $\begin{array}{c}\text { Ametralladora 4 } \\
12.7 \mathrm{~mm}\end{array}$ & $\begin{array}{c}\text { Ametralladora 5 } \\
12.7 \mathrm{~mm}\end{array}$ & $\begin{array}{c}\text { Ametralladora 6 } \\
\text { Mk-38 }\end{array}$ \\
\hline 9.15 & 8.64 & 3.88 & 3.93 & 7.98 & 8.33 \\
\hline
\end{tabular}

Tabla 3-30 Promedio de disparos por arma. Opción F 


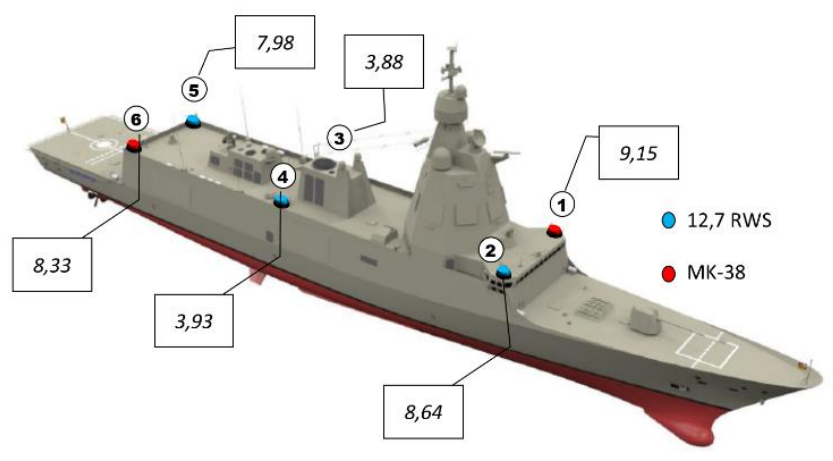

Figura 3-131 Promedio de disparos por ametralladora. Opción F (Elaboración propia sobre imagen de F-110 de DGAM)

Se observa que los consumos de munición por arma son ligeramente diferentes entre las seis ametralladoras, al igual que ocurría en la opción anterior, que también tiene una disposición de armas asimétrica.

Se realizó un contraste de hipótesis ANOVA para comprobación de si las medias de las armas difieren, resultando que se rechaza la hipótesis de igualdad de medias (ver Figura en Apéndice C-6 )

El promedio total de disparos es de 6,99 por arma, que es ligeramente inferior a la opción B $(7,01)$.

Se puede concluir que esta opción es muy pareja en cuanto al porcentaje de éxito a la Opción B, causado probablemente a que comparten la misma disposición física y, en consecuencia, tienen los mismos sectores de fuego y, quizás, no tanto por la asimetría en la disposición de las armas.

\section{Contrastes de hipótesis entre Opciones B y F}

Para las dos opciones que muestran una proporción de acierto más alto, la Opción B $(81,37 \%)$ y la Opción $F(80,41 \%)$, se realizó un contraste de hipótesis sobre igualdad de los porcentajes de éxito, resultando un $p_{-}$valor $=0,012$, lo que permite rechazar la hipótesis nula sobre la igualdad entre estas proporciones (ver C.2).

Una vez comprobado que existe diferencia entre estas dos opciones, con el objeto de indagar más sobre las diferencias entre ellas, se realizó un contraste de hipótesis diferenciando los ataques por sectores. Los expertos consideraron interesante comprobar si existían diferencias entre los porcentajes de éxito, cuando coincide que 
las tres lanchas atacan al buque entrando por el mismo sector (ver Figura 3-132), especialmente en lo referente a los sectores proel y popel.

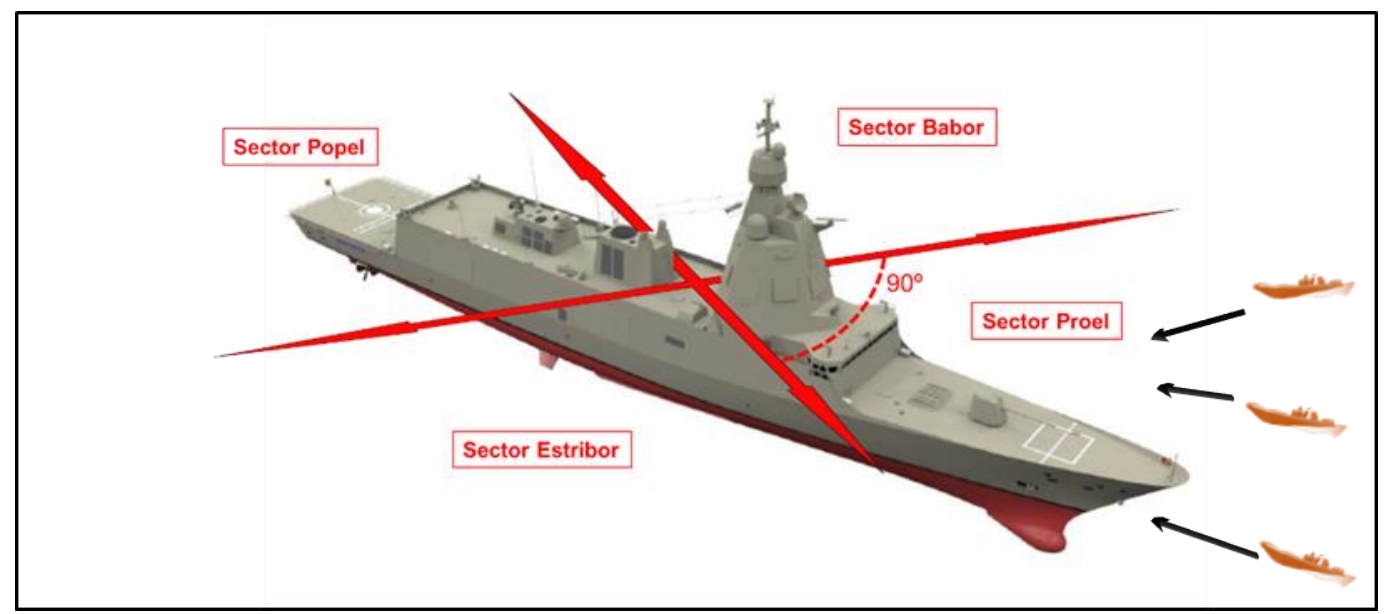

Figura 3-132 Sectores de ataque. Las flechas negras marcan un ejemplo de ataque de tres lanchas por el sector proel (Elaboración propia sobre imagen de F-110 de DGAM)

Es necesario recordar que la Opción B monta las dos ametralladoras Mk-38 en popa y, por tanto, es interesante comprobar si, al intercambiar la Mk-38 de babor por una de 12,7mm (Opción F), el porcentaje de éxito, precisamente cuando el ataque está concentrado desde ese sector popel, pierde puntos porcentuales o no. Esta misma reflexión se puede plantear para el sector proel, puesto que la Opción F "gana" una Mk38 en proa $\mathrm{Br}$.

Así, una de las preguntas planteadas por los expertos fue la siguiente: Si los tres atacantes provienen por el sector proel cla Opción F tiene mejor porcentaje de éxito respecto a la Opción B?

En la siguiente Tabla 3-31, se pueden observar los datos filtrados por sectores y los p_valores del contraste de hipótesis, en los que se aprecia que en ningún caso se puede rechazar la hipótesis nula sobre igualdad de proporciones, dicho de otra forma, no existen evidencias estadísticas suficientes para admitir que los porcentajes de éxito, cuando las tres lanchas atacan por el mismo sector, sean distintos (ver C.2). 


\begin{tabular}{|c|c|c|c|}
\hline & Opción B & Opción F & \\
\hline$N^{0}$ casos que las tres lanchas vienen por el sector Proel & 332 & 346 & \multirow{2}{*}{ p_valor $=0,93$} \\
\hline$N^{0}$ Éxitos (Sector Proel) & 192 & 202 & \\
\hline$N^{0}$ casos que las tres lanchas vienen por el sector Popel & 317 & 331 & \multirow{2}{*}{ p_valor $=0,87$} \\
\hline$N^{0}$ Éxitos (Sector Popel) & 207 & 214 & \\
\hline$N^{\circ}$ casos que las tres lanchas vienen por el sector Banda $\mathrm{Er}$ & 324 & 334 & \multirow{2}{*}{$p \_$valor $=0,56$} \\
\hline$N^{0}$ Éxitos (Sector Banda Er) & 280 & 294 & \\
\hline$N^{0}$ casos que las tres lanchas vienen por el sector Banda $\mathrm{Br}$ & 287 & 313 & \multirow{2}{*}{$p \_$valor $=0,61$} \\
\hline$N^{0}$ Éxitos (Sector Banda Br) & 256 & 274 & \\
\hline
\end{tabular}

Tabla 3-31 Resultados de ataques filtrados por sectores

En el C.3 se muestran las distribuciones e informes estadísticos resumidos de los consumos de munición por arma para las opciones B y F. Sobre las Figura en Apéndice C-7 y Figura en Apéndice C-11, se puede apreciar los pequeños cambios de consumo de munición para las ametralladoras Mk-38 y de 12,7mm que intercambian sus posiciones, se observa un ligero mayor consumo cuando las armas están ubicadas en popa.

\section{$\underline{\text { Resumen de los resultados }}$}

Con el objetivo de averiguar cómo contribuyen las alternativas a los tres subsubcriterios, se ha resumido en tabla (ver Tabla 3-32) y gráficamente los datos obtenidos en la simulación para su empleo en las funciones de utilidad que aportarán objetividad al proceso de decisión.

\begin{tabular}{|c|c|c|c|c|c|c|}
\cline { 2 - 7 } \multicolumn{1}{c|}{} & Opción A & Opción B & Opción C & Opción D & Opción E & Opción F \\
\hline Éxito & $73,48 \%$ & $81,37 \%$ & $73,62 \%$ & $52,10 \%$ & $58,76 \%$ & $80,41 \%$ \\
\hline Tiempo & 21,382 & 21,124 & 21,472 & 24,887 & 25,186 & 21,7 \\
\hline Munición & 6,78 & 7,02 & 6,80 & 8,89 & 9,23 & 6,99 \\
\hline
\end{tabular}

Tabla 3-32 Datos resumidos para aplicar en las funciones de utilidad

En la Figura 3-133 se pueden observar las gráficas de barras de las variables objeto del estudio con las opciones ordenadas de "mejor" a "peor" sobre el eje de abscisas. 


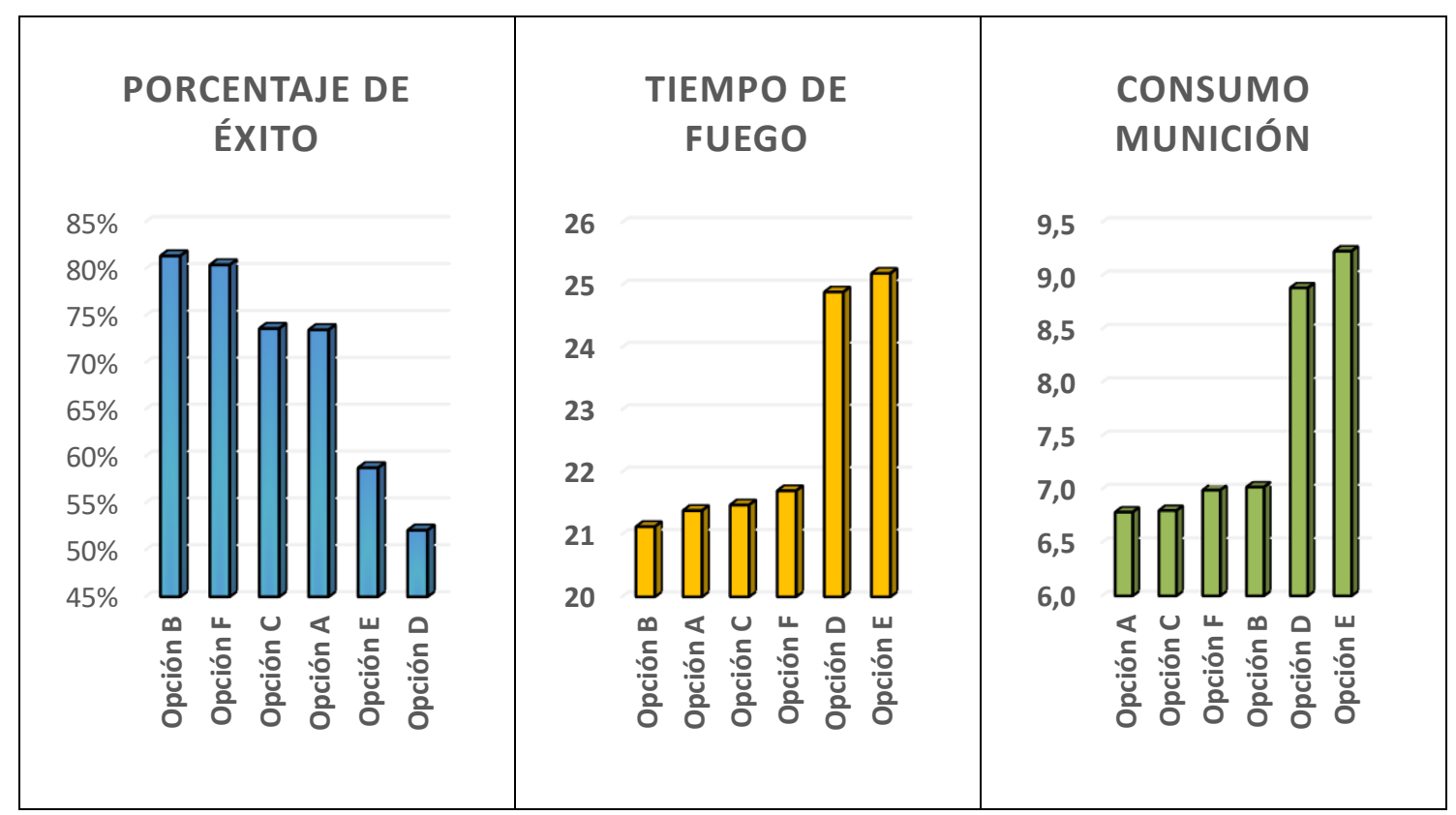

Figura 3-133 Gráficas comparativas de las variables objeto de la simulación

\subsubsection{Jerarquización de las Alternativas}

Con los resultados conseguidos se procedió sobre el programa ADLA, en consenso con los expertos, a dar valoraciones de las contribuciones de las alternativas a los subsubcriterios: Éxito, Tiempo Fuego y Munición Consumida.

\section{Sub-subcriterio Éxito}

De los resultados obtenidos en la simulación numérica con Matlab se ha observado que se obtienen unos porcentajes de éxito distintos para cada alternativa, además, en las dos alternativas que obtuvieron los porcentajes más altos y parejos, se ha realizado un contraste de hipótesis que confirmó la diferencia de promedios. Por consiguiente, para la valoración de la contribución de las alternativas al sub-subcriterio Éxito se empleó una función de utilidad lineal $\left(U_{e}\right)$ en la que se utilizó directamente los porcentajes conseguidos que aparecen reflejados en la Tabla 3-32

$$
U_{e}=\% \text { éxito }
$$

el $100 \%$ de utilidad y, por tanto, umbral de satisfacción, estaría determinado por el $100 \%$ de éxito en repeler los ataques. El $0 \%$ de utilidad estaría determinado por el $0 \%$ de éxito (ver Figura 3-134). 


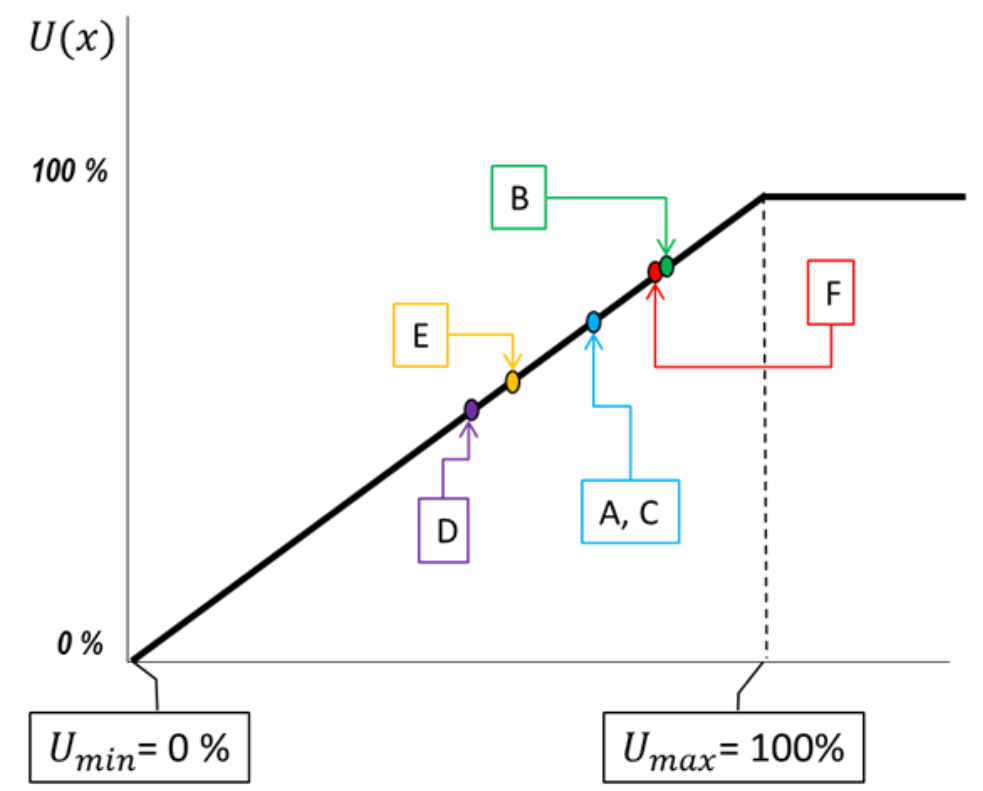

Umbral de saciedad

Figura 3-134 Utilidad del sub-subcriterio Éxito (gráfica sin escala) (Elaboración propia)

\section{Sub-subcriterio Tiempo Fuego}

La velocidad promedio de las lanchas atacantes en la simulación es de 37,5 nudos y su distancia promedio de comienzo del ataque es 550 metros (reflejado en las variables de entorno en el punto $\underline{3.4 .3 .1}$ ). Si supusiésemos el buque parado, el tiempo promedio de una lancha en alcanzar la zona ciega, estimada en 50 metros, es de

$$
t=\frac{550 \mathrm{mts}-50 \mathrm{mts}}{37,5 \cdot \frac{1852 \mathrm{mts}}{3600 \mathrm{seg}}}=25,9 \text { segundos }
$$

por consiguiente, para la valoración de la contribución de las alternativas al subsubcriterio Tiempo Fuego, se empleó una función de utilidad lineal en la que el 0\% de utilidad estuvo determinado por el cálculo anterior de 25,9 segundos y el 100\% de utilidad y, por tanto, umbral de satisfacción, estuvo determinado por el menor tiempo posible en el que, mediante el algoritmo creado, se pueden conseguir 5 impactos $y$ neutralizar en Modo "tiro a tiro" una FIAC, que son 9 segundos (ver Figura 3-135).

La función de utilidad del tiempo $\left(U_{t}\right)$ se definió mediante la fórmula

$$
U_{t}=1-\frac{t-t . \operatorname{mín}}{t . m a ́ x-t . \operatorname{mín}}=1-\frac{t-9}{25,9-9}
$$




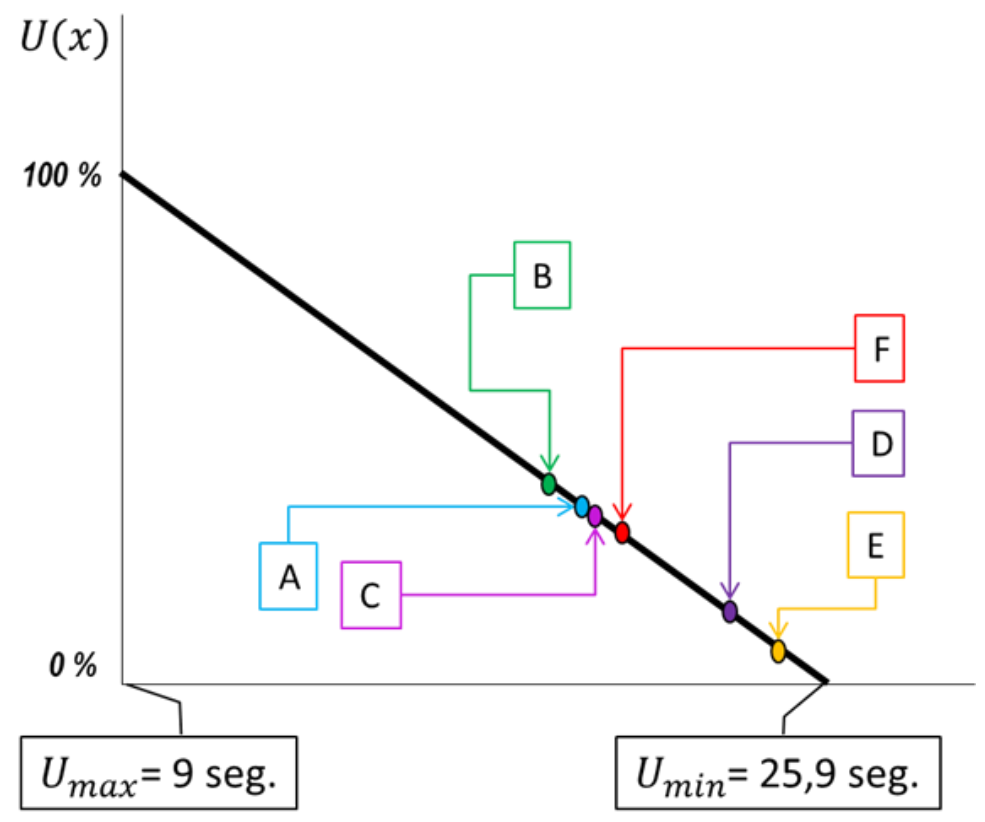

Umbral de saciedad

Figura 3-135 Utilidad del sub-subcriterio Tiempo de Fuego (gráfica sin escala) (Elaboración propia)

\section{Sub-subcriterio Munición Consumida}

Los cargadores de las ametralladoras tienen de promedio aproximadamente una capacidad de 225 disparos. Lógicamente, es muy recomendable terminar la acción de neutralización de la amenaza sin alcanzar ese consumo de munición, puesto que los tiempos de recarga suponen un lapso en la utilización del arma, que puede costar muy caro.

Nuevamente, es necesario recordar que la cifra de consumo obtenida en la simulación no es real. Por confidencialidad de los datos no está simulada la cadencia de fuego real de las ametralladoras, pero aun así y con el visto bueno de los expertos, se puede afirmar que la simulación guardaba una relación de proporcionalidad promedio próxima al 1: 5 , por lo que para la valoración de la contribución de las alternativas al sub-subcriterio Munición Consumida, se empleó una función de utilidad lineal en la que el umbral de satisfacción con el 100\% de utilidad estuvo determinado por un consumo de 1 disparo (equivalente a 5 disparos aprox.) y el $0 \%$ de utilidad estuvo determinado por la máxima capacidad del cargador 225/5 = 45 disparos (ver Figura 3-136).

La función de utilidad de la munición $\left(U_{m}\right)$ quedó definida por la fórmula 


$$
U_{m}=1-\frac{C_{o}-C_{o} \operatorname{mín}}{C_{o} \operatorname{má} x-C_{o} \operatorname{mín}}=1-\frac{C_{o}-1}{45-1}
$$

donde $C_{o}$ es consumo de munición.

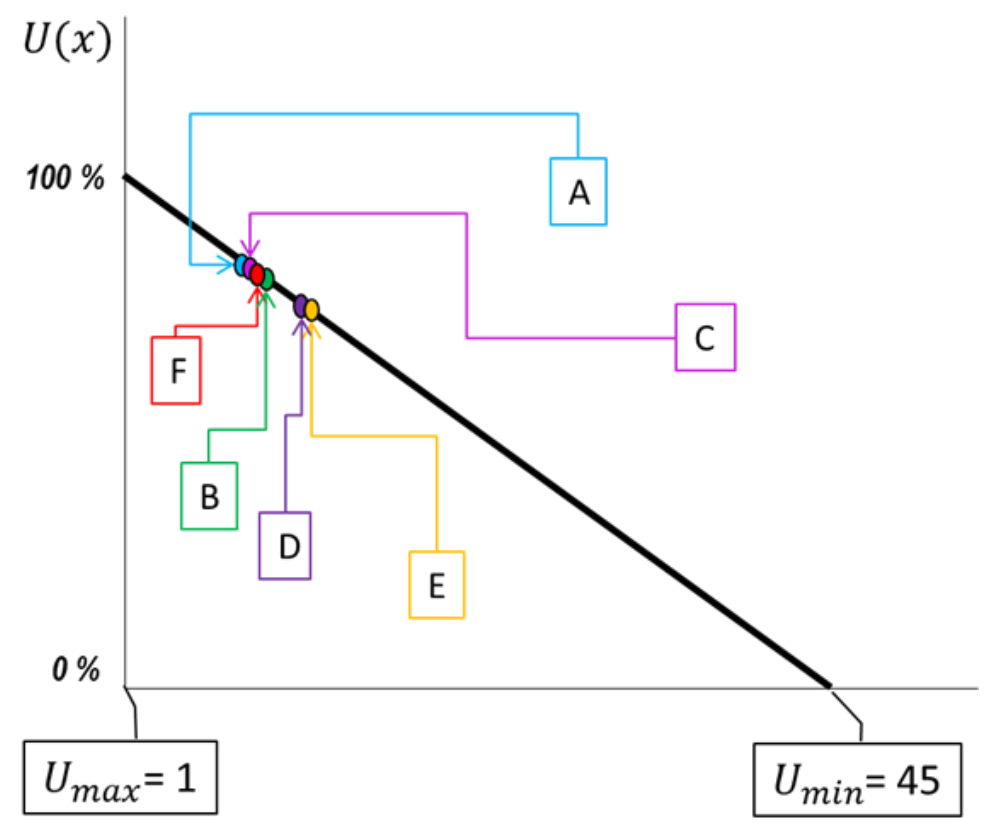

Umbral de saciedad

Figura 3-136 Utilidad del sub-subcriterio Munición Consumida (gráfica sin escala) (Elaboración propia)

\section{$\underline{\text { Resolución en programa ADLA }}$}

Sobre el programa ADLA, se aplicaron los resultados de las matrices de comparación por parejas, producto de la valoración subjetiva de los expertos, y mediante las funciones de utilidad, los resultados obtenidos en las simulaciones.

Una vez rellenas las MCP y aplicadas las funciones de utilidad, los pesos asignados han resultado los que se pueden apreciar en la Tabla 3-33. 


\begin{tabular}{|c|c|c|c|c|c|}
\hline Criterios & (pesos) & subcriterios & (pesos) & sub-subcriterios & (pesos) \\
\hline \multicolumn{6}{|l|}{ EFICACIA } \\
\hline \multirow[t]{7}{*}{ ARTILLERA } & $87,5 \%$ & & & & \\
\hline & & Búsqueda Detección & & & \\
\hline & & Seguimiento & $16,7 \%$ & & \\
\hline & & Neutralización Amenazas & $83,3 \%$ & & \\
\hline & & & & Tiempo Fuego & $15,5 \%$ \\
\hline & & & & Munición Consumida & $6,9 \%$ \\
\hline & & & & Éxito & $77,7 \%$ \\
\hline
\end{tabular}

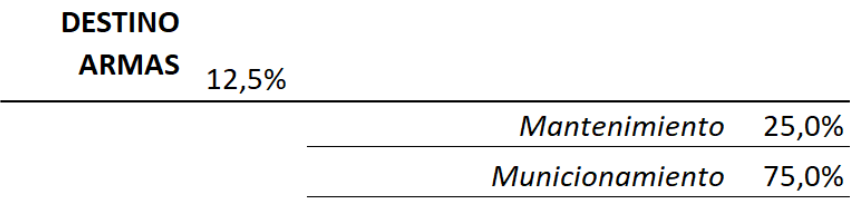

Tabla 3-33 Tabla de pesos de criterios/subcriterios/sub-subcriterios (Elaboración propia)

En la valoración global de las seis alternativas (ver Figura 3-137) ha resultado la mejor valorada la alternativa Opción F con un 20,4\%, seguida de la Opción B con un 18,2\%.

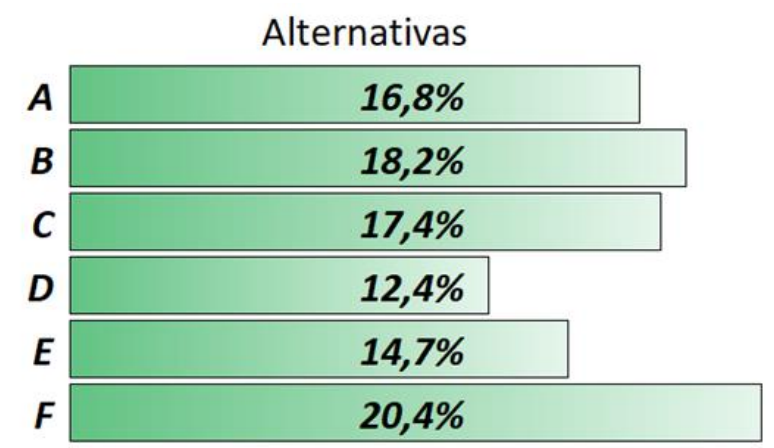

Figura 3-137 Valoración global de las alternativas (Elaboración propia)

En la Figura 3-138, se visualizan las utilidades de las alternativas para el criterio DESTINO ARMAS, se puede observar que la Opción D resultó la mejor evaluada por los expertos mediante sus valoraciones subjetivas con un $26,5 \%$. Por el contrario, la opción $\mathrm{F}$ es la peor valorada con un $7 \%$.

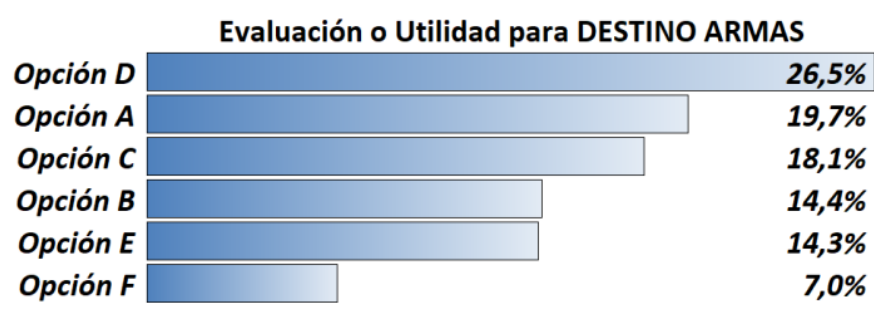

Figura 3-138 Utilidad de las alternativas para DESTINO ARMAS (ADLA) 
En el diagrama de barras de la Figura 3-139, se visualizan las utilidades de las alternativas para el criterio EFICACIA ARTILLERA, donde se puede observar que la Opción F resultó la mejor evaluada con un 22,4\% y la Opción B resulto ser la segunda opción mejor valorada con un $18,8 \%$, la opción $D$ resulta la peor valorada con una utilidad del $10,4 \%$. Esta valoración es producto de la combinación de las apreciaciones subjetivas de los expertos sobre el subcriterio Búsqueda Detección Seguimiento, que pesa únicamente un 16,7\%, y de los resultados de la simulación en Matlab sobre el subcriterio Neutralización Amenazas, que pesa un $83,3 \%$. Se podría afirmar, por consiguiente, que se ha restado subjetividad al proceso AHP en una proporción cercana al 73\% $(87,5 \% \times 83,3 \%)$.

\begin{tabular}{l|r|r|}
\multicolumn{1}{c|}{} & Evaluación o Utilidad para EFICACIA ARTILLERA \\
\hline Opción F & $22,4 \%$ \\
\hline Opción B & $18,8 \%$ \\
Opción C & $17,3 \%$ \\
Opción A & $16,4 \%$ \\
Opción E & $14,8 \%$ \\
Opción D & $10,4 \%$
\end{tabular}

Figura 3-139 Utilidad de las alternativas para EFICACIA ARTILLERA (ADLA)

La Opción F respecto al subcriterio Neutralización de Amenazas tiene una valoración muy cercana e inferior a la Opción $B$, pero para el subcriterio Búsqueda Detección Seguimiento (Matriz 7 de Tabla 3-24), los expertos manifestaron hacia la Opción F como moderadamente preferida respecto de la Opción B. Este juicio se debía a que se sitúa una Mk-38 en proa babor, ganándose para el sector proel unos sensores superiores a los de la ametralladora de $12,7 \mathrm{~mm}$.

\subsubsection{Análisis de Sensibilidad y Robustez}

Como ya se ha explicado, en esta fase se realiza un análisis de sensibilidad que nos indicará la robustez del modelo. Esta información es vital para los expertos decisores, puesto que, les permite comprobar si pequeñas diferenciaciones en la valoración de criterios producen o no, conmutaciones en la jerarquización de las alternativas. Una vez analizada la robustez y retroalimentado el modelo, en caso de ser necesario, se define la jerarquización final, esto es, la decisión que proporciona la analista argumentada con los análisis realizados. 
En la Figura 3-140 se muestran los resultados de los pesos asignados a los criterios (barras azules) y las valoraciones de las alternativas (barras naranjas). La Opción F resulta la mejor valorada con un $20,4 \%$, tan solo supera a la Opción B en 2,2 puntos. La robustez de esta diferencia, que se podría calificar de pequeña, se comprobará mediante un análisis de sensibilidad.

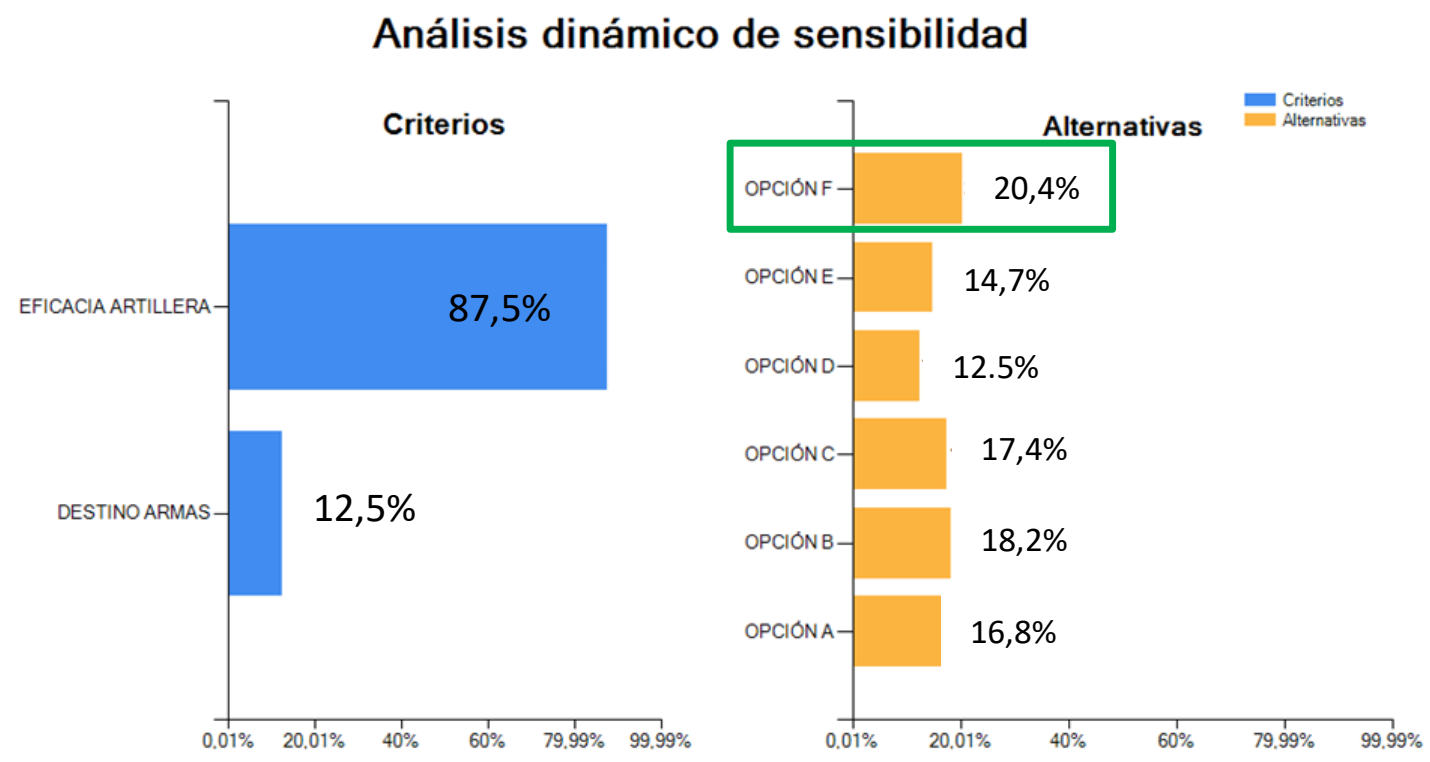

Figura 3-140 Gráfica de barras para el análisis dinámico de sensibilidad (ADLA)

El resultado del análisis de sensibilidad se puede observar en la Figura 3-141, donde se muestra que sería necesario rebajar el peso del criterio EFICACIA ARTILLERA en 19 puntos para que el resultado conmutase a favor de la Opción C. Esta diferencia significativa de cambio de juicio de los expertos se cree improbable. Por tanto, se puede afirmar que la decisión es bastante robusta. 
Análisis dinámico de sensibilidad
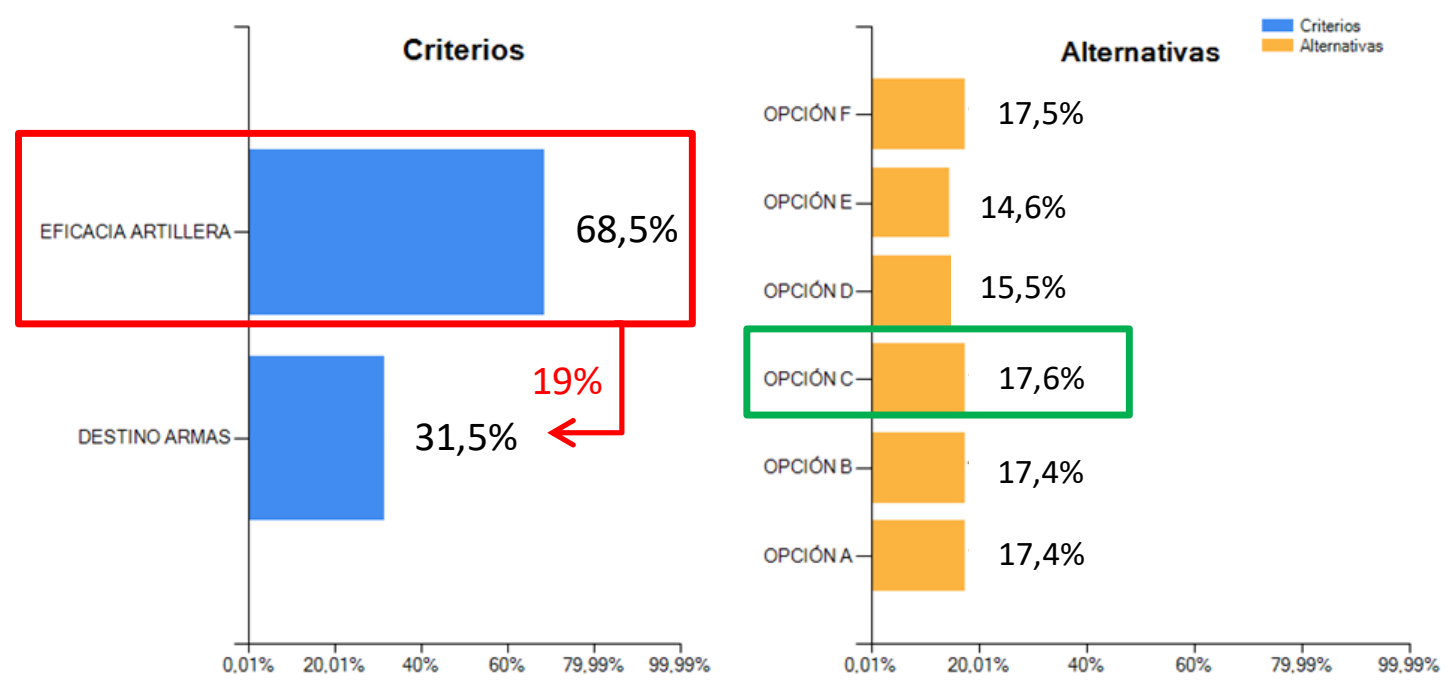

Figura 3-141 Gráfica de reasignación de pesos para conmutación de alternativas. La flecha y la cifra en rojo indican el \% en que ha sido necesario disminuir el peso del criterio DESTINO ARMAS para que se produzca la conmutación en el resultado de la Opción F a la Opción C (ADLA)

\subsubsection{Conclusiones de los resultados y Líneas Futuras}

Este trabajo ha sido el tercer ensayo de la nueva metodología discurrida en esta tesis. Se concluye que ha resultado una valiosa contribución a los objetivos principal y secundarios que se persiguen. Ha aportado una importante ayuda acerca de la mejor disposición de las ametralladoras en las fragatas F-110 y, al mismo tiempo, ha rebajado la subjetividad de la decisión (73\% aproximadamente) y obligado al diseño de un software específico que permitiese la evaluación de las contribuciones de las alternativas a varios criterios.

De las seis alternativas sujetas a este estudio ha resultado mejor valorada la Opción F.

El proceso de trabajo se realizó conforme a la metodología planteada, reflejada en el esquema elaborado para la consecución de los objetivos. Puede resumirse en los siguientes pasos:

- Fase 1. Representación del Problema. Se ha modelado, en colaboración con especialistas en artillería, una estructura jerárquica de criterios de evaluación en la que han quedado representados todos los aspectos considerados relevantes en el proceso de la decisión. Se han definido los criterios y las alternativas. 
- Fase 2. Evaluación de los criterios y alternativas. De manera subjetiva y basándose en sus conocimientos y experiencia, los expertos rellenaron las MCP de forma individual y anónima, para la asignación de pesos a los criterios. Posteriormente, han realizado una valoración de las contribuciones de las seis alternativas a los subcriterios Mantenimiento, Municionamiento y Búsqueda Detección Seguimiento.

- Fase 3. Contribución de las alternativas. Sobre los sub-subcriterios "objetivos": Éxito, Tiempo Fuego y Munición Consumida; se realizó una simulación mediante código matemático en Matlab con metodología Montecarlo. Los resultados obtenidos se han tratado estadísticamente y se han diseñado tres funciones de utilidad para valorar las contribuciones de las alternativas los sub-subcriterios.

- Fase 4. Jerarquización de las alternativas. Con la ayuda del programa ADLA, que implementa el algoritmo de Saaty, se jerarquizaron las alternativas de cara a la decisión final. La Opción F resultó la mejor valorada.

- Fase 5. Análisis Sensibilidad. Se ha realizado un análisis acerca de la robustez del modelo, comprobándose que, efectivamente, es bastante robusto a los cambios de criterio.

Es importante recordar que esta valoración proviene de la opinión de expertos en artillería, afines a los que en el futuro embarcarán en la F-110 y tendrán que dirigir la defensa del buque frente a la amenaza asimétrica. Con esto, se pretende explicar que en la resolución del problema no se exigió tener en cuenta otros posibles criterios, como los relacionados con la ingeniería naval o económicos, por ejemplo.

Líneas futuras

Como líneas futuras para decisiones similares relativas a la artillería secundaria, se considera que en este trabajo el modelo matemático creado en Matlab tiene un nivel alto de abstracción, por ello, podría ser interesante implementar una simulación con un nuevo modelo de un nivel de abstracción intermedio, para lo que sería necesario disponer de:

- Información completa de todas las características de las armas que finalmente se vayan a montar, incluidas las tasas de fallo de fuego. 
- Mediante técnicas de Machine Learning generar un nuevo algoritmo de enfrentamiento de las armas contra todo tipo de amenazas de guerra asimétrica, incluyendo, por supuesto, los drones.

- Simular con los distintos tipos de munición especial que pueden disparar las ametralladoras. 



\section{Capítulo 4. Conclusiones y Líneas Futuras de Investigación}

\subsection{Conclusiones}

En este punto se expondrán las conclusiones derivadas del trabajo realizado, tratando, con ello, de verificar el grado de cumplimiento de los objetivos principal y secundarios. Se planteó como objetivo principal de esta tesis (01) el diseño de un método analítico que repercutiese como una ayuda en los procesos de trabajo que se generan para la toma de decisiones multicriterio; como objetivos secundarios se planearon, el análisis de herramientas de simulación actuales (OS1), el desarrollo de software específico en problemas donde no se encontrasen herramientas de simulación convenientes (OS2) y, por último, la reducción de la subjetividad (OS3).

Para la consecución de los objetivos se realizaron los siguientes trabajos:

1. Se comenzó con una investigación sobre la historia y evolución de los distintos métodos de decisión multicriterio (MCDM). Sobre la sistemática de los procesos científicos de toma de decisiones basados en la investigación operativa se estableció, dentro de la envoltura y apoyándose en los cimientos que proporciona el rigor científico del método AHP, una nueva metodología adaptable a las particularidades de cada problema. Por consiguiente, con esta tesis, no se persiguió una aportación acotada a la teoría general de la toma de decisiones, es decir, no se buscó una metodología única y exclusiva, sino, enunciar un planteamiento flexible que se adapte a la particularidad de cada 
problema. Esta nueva metodología se descompone en distintas fases que comienzan con la definición del problema, para seguidamente comenzar la fase de evaluación de criterios, evaluación de las contribuciones de las alternativas, resolución de la jerarquización de las alternativas, análisis de sensibilidad y, con los resultados obtenidos, la última fase, proporcionar la ayuda a la decisión. De todas estas fases, la que requiere mayor atención es la de evaluación de las contribuciones de las alternativas, siendo el núcleo de esta metodología. Una adecuada planificación de esta fase exige una correcta búsqueda y aplicación de las técnicas ad hoc que mejor se puedan adecuar al problema, lo que redundará en una mayor reducción de la subjetividad y de los sesgos de pensamiento grupal implícitos a toda decisión humana. En esta fase el empleo de técnicas estadísticas se antoja imprescindible para el tratamiento y análisis de la información generada.

2. Se efectuó un primer estudio aplicando la nueva metodología sobre un problema real de decisión referente al CIC de las fragatas F-110. En colaboración con expertos, se discurrió una estructura jerárquica. Se definieron los criterios y las alternativas. Se resolvió, inicialmente, la metodología AHP clásica completa, en el sentido de que todos los juicios de las matrices de comparación por pares para valoración de los criterios en los distintos niveles y para valoración de las contribuciones de las alternativas, se realizaron de forma subjetiva. Se completó la jerarquización de alternativas y se efectuó un análisis de sensibilidad. Posteriormente, se aplicó la nueva metodología; se enjuiciaron las contribuciones de las alternativas al subcriterio Evacuación mediante un software de modelado 3D, otro de simulación de evacuaciones y la aplicación de técnicas estadísticas, posteriormente, se validaron los resultados a través de una experimentación real. Se jerarquizaron las alternativas y el nuevo análisis de sensibilidad resultó más robusto, con el añadido de ser un dictamen más objetivo.

3. Se efectuó un segundo estudio aplicando la nueva metodología sobre un problema real de decisión acerca del comedor de las fragatas F-110. Con los expertos se diseñó y se definió una representación del problema en una estructura jerárquica de objetivo, criterios y alternativas. Se evaluaron los 
criterios y se realizó una valoración de las contribuciones de las alternativas a un criterio subjetivo. Para la fase objetiva de valoración de las contribuciones de las alternativas, se recopilaron datos reales de comportamientos del comedor en tres buques navegando. Mediante softwares de simulación, técnicas estadísticas y funciones de utilidad, se enjuiciaron las contribuciones a los subcriterios de Desalojo Z/C y Libertad Movimientos. Ambas contribuciones difícilmente podrían haber sido enjuiciadas de manera subjetiva por los expertos. Se jerarquizaron las alternativas y, finalmente, se realizó un análisis profundo de la robustez del modelo, concluyendo que, efectivamente, era muy robusto a los cambios de criterio.

4. Se efectuó un tercer estudio aplicando la nueva metodología sobre un problema real de decisión acerca de la disposición de la artillería secundaria de las fragatas F-110. Se modeló, en colaboración con especialistas en artillería, una estructura jerárquica. Se definieron, los criterios y las alternativas. Los expertos rellenaron las MCP para la asignación de pesos a los criterios subjetivos y para la valoración de las contribuciones de las alternativas a distintos criterios. La evaluación de las contribuciones de las alternativas a los criterios objetivos se realizó con la ayuda de código matemático creado ad hoc en Matlab con metodología Montecarlo, sobre las curvas de probabilidad de impacto de las armas proporcionadas por el EMA. Los resultados obtenidos se han tratado estadísticamente y por medio de tres funciones de utilidad se integraron en la jerarquizaron de las alternativas de cara a la decisión final. El análisis de sensibilidad mostró una gran robustez del modelo, a los eventuales cambios de criterio de los decisores.

Por todo lo anteriormente expuesto se puede concluir que para los objetivos planteados se han alcanzado los siguientes resultados:

- Objetivo principal (01). Proporcionar un método analítico de ayuda en los procesos de trabajo que se generan para la toma de decisiones multicriterio. Se ha alcanzado el $100 \%$ del objetivo, porque se ha diseñado una metodología que se sobrepone sobre los pasos y etapas que conforman los procesos científicos de toma de decisiones basados en la investigación operativa. La ciencia de este nuevo método ha sido explicada y esquematizada en distintas 
fases, entre las cuales, el núcleo de este conjunto de métodos está en la fase de la evaluación de las contribuciones de las alternativas de una forma menos subjetiva que en los métodos clásicos. Finalmente, la metodología se ha ensayado con éxito en tres estudios reales de cierta transcendencia.

- Objetivo secundario primero (OS1). Analizar herramientas de simulación actuales.

Se ha alcanzado el $90 \%$ del objetivo, porque se han empleado varios softwares de simulación que se han mostrado muy válidos para su aplicación en el decisor analítico ideado en esta tesis. No se puede concluir que se haya alcanzado el $100 \%$ del objetivo porque, los softwares fueron utilizados en su versión libre sin necesidad de pago de la licencia y, por consiguiente, no se pudieron emplear en todo su potencial. No obstante, y como se ha comentado anteriormente, sí se puede concluir que son acordes con el marco experimental del problema de la decisión.

- Objetivo secundario segundo (OS2). Desarrollo ad hoc de software en problemas donde no se encuentren herramientas de simulación adecuadas.

Se ha alcanzado el $100 \%$ del objetivo, porque se ha diseñado un script en Matlab con metodología Montecarlo, que ha permitido recrear un algoritmo de selección de fuego con la artillería secundaria de la F-110, que resulta imposible de encontrar en un software de simulación comercial. Este script ha resultado eficaz y eficiente para los fines, de valoración de las contribuciones de las alternativas, que se perseguían.

- Objetivo secundario tercero (OS3). Reducción de la subjetividad en las decisiones multicriterio.

Se ha alcanzado el $90 \%$ del objetivo, porque se ha conseguido restar subjetividad en todos los ensayos de estudio realizados. Es indudable que nunca se puede alcanzar la objetividad completa y que el término "objetivo" es un concepto relativo, sin embargo, sí puede afirmarse que se puede substraer subjetividad. En los estudios realizados se puede concluir que se ha restado un $5 \%$ en el trabajo del $\mathrm{CIC}$, un $25 \%$ en el trabajo del comedor y un $73 \%$ en el trabajo de la artillería secundaria. 


\subsection{Líneas Futuras de Investigación}

Como resultado de esta investigación, algunos objetivos se han alcanzado por completo mientras que otros se han quedado ligeramente inconclusos. Sería interesante, con el fin de complementar o dar continuidad a este trabajo, seguir la investigación sobre las siguientes líneas:

- Línea Futura 1 (LF1). Ahondar en los análisis y empleo de herramientas de simulación actuales.

Como ya se ha comentado, aunque los softwares de simulación se han mostrado muy válidos, tanto el Pathfinder, Pyrosim y AnyLogic se han utilizado en su versión libre. Esta circunstancia no permitió emplear todo el potencial que ofrecen estos programas, especialmente en lo referente a la metodología Montecarlo, viéndose el trabajo limitado a un número de replicas inferior al que hubiera gustado. Otra privación fue que, para simular las evacuaciones, el EXODUS permite un nivel de abstracción más bajo por disponer de una versión marítima orientada expresamente a la evacuación de buques. Una futura investigación podría emplear estos u otros programas descendiendo en el nivel de abstracción y permitiendo el empleo de técnicas Montecarlo.

- Línea Futura 2 (LF2). Investigar y darle continuidad a la reducción de la subjetividad e implementar nuevas funciones de utilidad.

Si bien, nunca se podrá afirmar que se ha alcanzado un $100 \%$ de objetividad, durante la fase de definición del problema de la decisión se puede tratar de añadir más criterios que sean susceptibles de ser evaluados en términos más objetivos. Por ejemplo, los criterios económicos tanto de costes como de tiempo. Asimismo, sería interesante investigar nuevas funciones de utilidad no lineales que se pudieran adaptar a una mejor valoración de las contribuciones de las alternativas (en este trabajo, consensuado con los expertos, solo se emplearon funciones de utilidad lineales).

- Línea Futura 3 (LF3). Empleo de la metodología en otros ámbitos.

Actualmente, esta metodología se está empleando en un problema de decisión de otro organismo dependiente del Ministerio de Defensa: la DGAM. El problema planteado es acerca de cuál es la mejor estructura organizacional para 
compra de material (ver Figura 4-1). Al presente, se está trabajando en la fase crucial del método, la fase 3 . Un grupo de analistas con expertos de la DGAM están en el proceso de averiguación y análisis de qué técnicas estadísticas, de simulación, evaluación de datos históricos, valoración de riesgos y funciones de utilidad, son las que mejor se pueden adaptar al problema.

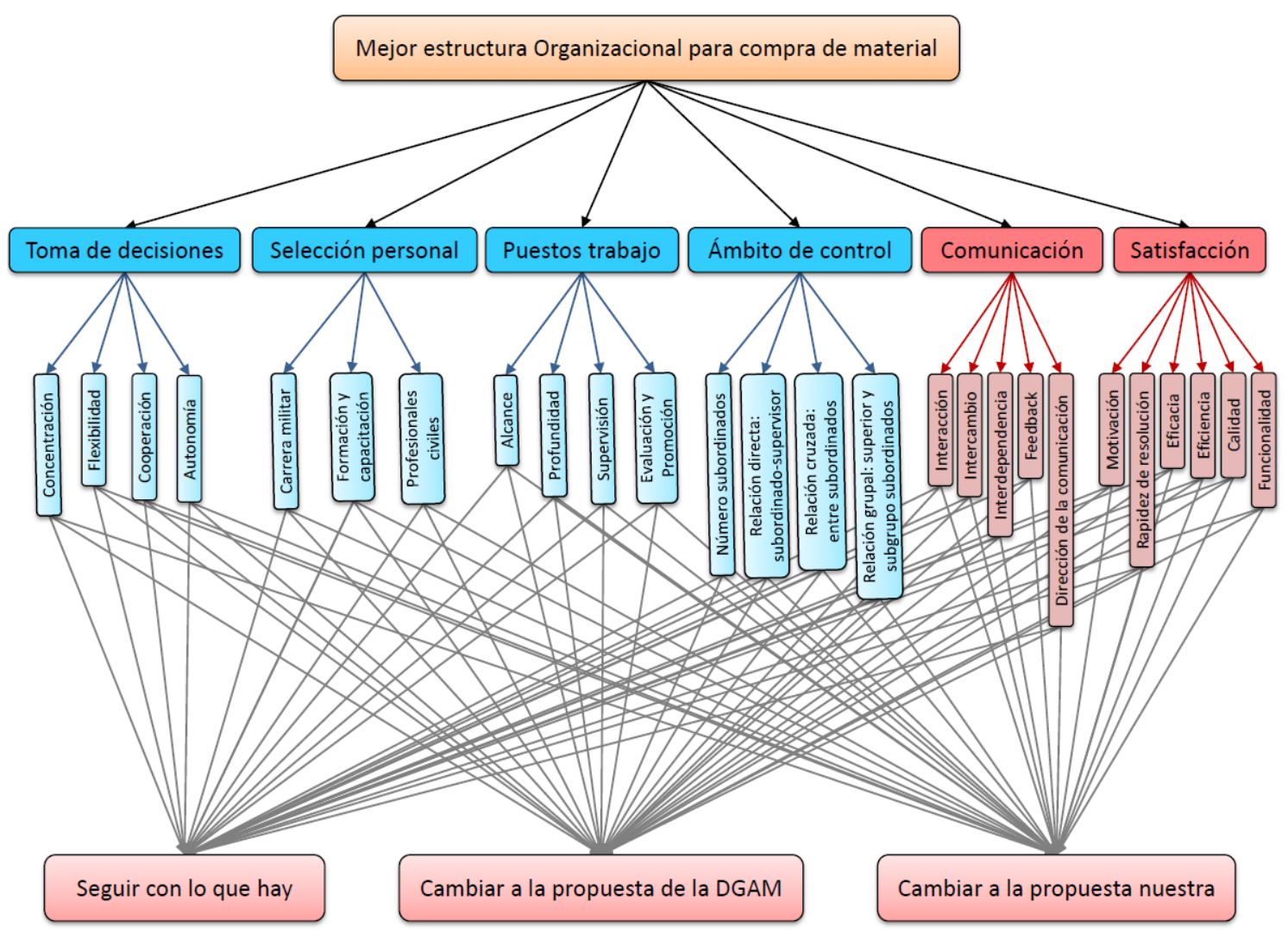

Figura 4-1 Problema de la decisión multicriterio de la DGAM (Elaboración propia)

Como propuesta de continuidad en esta línea de investigación, también sería muy interesante probar la metodología en otros ámbitos corporativos diferentes al Ministerio de Defensa. 


\section{Bibliografía}

[1] "Armada Española," [Online]. Available: http://www.armada.mde.es/ArmadaPortal/page/Portal/ArmadaEspannola/c onocenosajema/preflang-es/.

[2] T. Saaty, "A Scaling Method for Priorities in Hierarchical Structures, Journal of Mathematical Psychology," Journal of Mathematical Psychology, 1977.

[3] T. Gal, T. Stewart and T. Hanne, Multicriteria Decision Making: Advances in MCDM Models, Algorithms, Theory, and Applications, Norwell: Kluwer Academic Publishers, 1999.

[4] M. López, Análisis y Adopción de Decisiones, Madrid: PIRAMIDE, 1989.

[5] S. Ríos, Análisis de Decisiones, Madrid: ICE, 1976.

[6] C. Romero, Teoría de la Decisión Multicriterio: Conceptos, técnicas y aplicaciones, Madrid: Alianza Editorial, 1993.

[7] E. Weber, Handwörterbuch Physiol, 1846.

[8] G. Fechner, Elemente der Psychophysik, 1860.

[9] J. M. Franquet, EL Estudio Operativo de la Psicología. Una Aproximación Matemática, UNED, 2008.

[10] G. Miller, "The Magical Number Seven Plus or Minus Two: Some Limits on Our Capacity for Processing Information," Psychological Review, pp. 81-97, 1956. 
[11] E. Triantaphyllou, F. Lootsma, P. Pardalos and S. Mann, On the Evaluation and Application of Different Scales For Quantifying Pairwise Comparisons in Fuzzy Sets, 1994.

[12] T. Saaty, The Analytic Hierarchy Process, McGraw-Hill, 1980.

[13] E. Nanson, "Methods of Elections," in Transactions \& Proceedings of the Royal Society of Victoria, 1882.

[14] K. Arrow, Social Choice and Individual Values, John Wiley \& Sons, 1951.

[15] A. Sen, Elección Colectiva y Bienestar Social, Madrid: Alianza Editorial, 1976.

[16] F. H. Allport, Social Psychology, Boston: Houghton Mifflin, 1924.

[17] I. Janis, "Groupthink," Phychology Today, no. November, 1971.

[18] M. Köksalan, J. Wallenius and S. Zionts, Multiple Criteria Decision Making. From Early to the 21st Century, Word Scientific, 2011.

[19] F. R. d. I. Rúa, Lección Inaugural del Curso Académico 2018-2019, Málaga: Universidad de Málaga, 2018.

[20] International Society on MCDM, "International Society on MCM," [Online]. Available: http://www.mcdmsociety.org/.

[21] K. MacCrimmon, "An Overview of Multiple Objective Decision Making," in Multiple Crietria Decision Making, Columbia, University of South Carolina Press, 1973, pp. 18-43.

[22] P. Fortemps and R. Slowinski, "A graded quadrivalent logic for preference modelling: Loyola-like approach," Fuzzy Optimization and Decision Making, vol. 1, pp. 93-111, 2002.

[23] Condorcet, Essai sur l'application de l'analyse à la probabilité des décisions rendues à la pluralité des voix, 1785.

[24] F. Y. Edgeworth, Mathematical Psychics: An Essay on the Application of Mathematics to the Moral Sciences, 1881. 
[25] W. Pareto, Cours d'économie politique, 1897.

[26] W. Pareto, Manual of Political Economy, 1906.

[27] F. P. Ramsey, "Truth and Probability," in The Foundations of Mathematics and other Logical Essays, 1926, pp. 156-198.

[28] L. Savage, The Foundations of Statistics, New York: Dover Publications, 1954.

[29] J. Neumann and O. Morgenstern, Theory of Games and Economic Behavior, Princeton: Priceton University Press, 1944.

[30] J. F. Nash, "Equilibrium Points in n-Person Games," Proceedings of the National Academy of Sciences of the United States of America, vol. 36, no. 1, pp. 48-49, 1950.

[31] J. F. Nash, "The Bargaining Problem," Econometrica, vol. 18, no. 2, pp. 155-162, 1950.

[32] G. Debreu, Theory of Value. An Axiomatic Analysis of Economic Equilibrium, New Haven: Yale University Press, 1959.

[33] G. Debreu, "Topological methods in cardinal utility theory," Mathematical Methods in the Social Sciences, Stanford University Press, pp. 16-26, 1960.

[34] P. Samuelson, "A Note on the Pure Theory of Consumer's Behavior," Economica, vol. 5, no. 17, pp. 61-71, 1938.

[35] W. Edwards, "The Theory of Decision Making," Psychological Bulletin, vol. 51, no. 4, pp. 380-411, 1954.

[36] W. Edwards, "Behavioral Decision Theory," Annual Review of Psychology, vol. 12, pp. 473-498, 1961.

[37] H. A. Simon, "A Behavioral Model of Rational Choice," The Quarterly Journal of Economics, vol. 69, no. 1, pp. 99-118, 1955.

[38] R. D. Luce and H. Raiffa, Games and Decisions: Introduction and Critical Survey, New York: Wiley, 1957. 
[39] R. Howard and G. Kimball, "Sequential Decision Processes," in Notes on Operations Research, 1959.

[40] H. Raiffa and R. Schlaifer, Applied Statistical Decision Theory, New York: Wiley, 1961.

[41] H. Raiffa, Decision analysis; introductory lectures on choices under uncertainty, Reading, Mass., Addison-Wesley, 1968.

[42] R. Frisch, "Numerical Determination of a Quadratic Preference Function for Use in Macroeconomic Programming," Giornale degli Economisti e Annali di Economia, vol. 20, pp. 43-83, 1961.

[43] P. C. Fishburn, Decision and Value Theory, Wiley, 1964.

[44] P. C. Fishburn, Utility Theory for Decision Making, Wiley, 1970.

[45] B. Roy, "Classement et choix en présence de points de vue multiples: la méthode ELECTRE," Révue Francaise D'Informatique et de Recherche opérationnelle, vol. 2, pp. 57-75, 1968.

[46] Barba-Romero, "Panorámica Actual de la decisión Multicriterio Discreta," Investigaciones Económicas, vol. 11, no. 2, pp. 279-308, 1987.

[47] G. B. Dantzig, "Programming in a Linear Structure," Econometrica, vol. 17, pp. 73-74, 1948.

[48] L. Kantorovich, "Mathematical Methods of Organizing and Planning Production," Leningrad State University, 1939.

[49] S. I. Gass, Linear Programming. Methods and Applications, New York: McGrawHill, 1958.

[50] H. W. Kuhn and A. W. Tucker, "Nonlinear Programming," in Second Berkeley Symposium, 1951.

[51] G. Zoutendijk, Methods of Feasible Directions : a Study in Linear and Nonlinear Programming, Elsevier, 1960. 
[52] T. Koopmans, "An analysis of production as an efficient combination of activities," in Activity Analysis of Production and Allocation, Proceeding of a Conference, London, 1951.

[53] T. Saaty and S. Gass, "Parametric Objective Function (Part 1)," Operations Research, vol. 2, no. 3, pp. 316-319, 1954.

[54] S. Gass and T. Saaty, "Parametric Objective Function (Part 2)," Operations Research, vol. 3, no. 4, pp. 395-401, 1955.

[55] A. Charnes, W. Cooper and R. Ferguson, "Optimal Estimation of Executive Compensation by Linear Programming," Management Science, vol. 1, no. 2, pp. 138-151, 1955.

[56] A. Charnes and W. W. Cooper, Management Models and Industrial Applications of Linear Programming, Wiley, 1961.

[57] B. Contini and S. Zionts, "Restricted Bargaining for Organizations with Multiple Objectives," Econometrica, vol. 36, no. 2, pp. 397-414, 1968.

[58] I. Yuji, Management Goals and Accounting for Control, Amsterdam: Rand McNally and Co, 1965.

[59] S. Lee, "Goal Programming for Decision Analysis," Philadelphia, Auerbach Publishers, pp. 298-319.

[60] A. M. Geoffrion, "Solving Bicriterion Mathematical Programs," Operations Research, vol. 15, no. 1, pp. 39-54, 1967.

[61] A. M. Geoffrion, "Proper Efficiency and the Theory of Vector Maximization," Journal of Mathematical Analysis and Applications, vol. 22, no. 3, pp. 618-630, 1968.

[62] L. Zadeh, "Fuzzy Sets," Information and control, vol. 8, pp. 338-353, 1965.

[63] J. L. Cohon, Multiobjective Programming and Planning, New York: Dover Publications, 1978. 
[64] R. Bolado, J. Ibáñez and A. Lantarón, El Juicio de Expertos, Madrid: Consejo de Seguridad Nuclear, 1998.

[65] N. Hayes, Dirección de Equipos: una Estrategia para el Éxito, Paraninfo, 2002.

[66] M. Shaw, Group Composition and Group Cohesiveness, Cathcart, 1988.

[67] I. Janis and L. Mann, Decision Making, Free Press, 1979.

[68] G. Orwell, 1984, 1949.

[69] "Armada Española," [Online]. Available: http://www.armada.mde.es/ArmadaPortal/page/Portal/ArmadaEspannola/b uquessuperficie/preflang-es/.

[70] Secretario Estado Defensa, Proceso de Obtención de Recursos Materiales, 2011.

[71] J. González-Aller Lacalle, "Fragata F-110. Nuestro Futuro," Revista General de Marina, 2014.

[72] F. Antón Brage, "Programas de Adquisición: La Gestión de Requisitos," Revista General de Marina, 2014.

[73] J. Caprace and P. Rigo, "A Complexity Metric for Practical Ship Design," in Proceedings, 11th International Symposium on Practical Design of Ships and Other Floating Structures, Rio de Janeiro, 2010.

[74] R. Pawling, V. Percival and D. Andrews, "A Study into the Validity of the Ship Design Spiral in Early Stage," Journal of Ship Production and Design, no. 33, pp. 81-100, 2017.

[75] "The Fallacy of Using a Parent Design: The Design is Nature," SNAME Transactions, no. 121, pp. 91-122, 2013.

[76] NAVANTIA, "Navantia," [Online]. Available: https://www.navantia.es/es/.

[77] INDRA, “Indra," [Online]. Available: https://www.indracompany.com/. 
[78] M. Defensa, “http://www.defensa.gob.es/Galerias/dgamdocs/programaF110.pdf," [Online]. [Accessed 2019].

[79] Armada Española. Ministerio de Defensa, Concepto de Operaciones Navales, 2015.

[80] A. González del Tánago, "La Fragata F-110 una Apuesta de Presente y Futuro," Revista General de Marina, 2018.

[81] Armada Española. Ministerio de Defensa, Cultura y Arte Naval.

[82] J. Margling, Public Investment Criteria, MIT Press, 1967.

[83] L. Zadeh, “Optimality and Non-scalar- Valued Performance Criteria,” 1963.

[84] P. Yu, "A Class of Solutions for Group Decision Problems," Management Science, vol. 19, pp. 936-946, 1973.

[85] M. Zeleny, Compromise Programming, Columbia: University of South Carolina Press, 1973.

[86] M. Zeleny, "A Concept of Compromise Solutions and the Method of the Displaced Ideal," Computers and Operations Research, vol. 1, pp. 479-496, 1974.

[87] H. Simon, "A Behavioral Model of Rational Choice," The Quarterly Journal of Economics, vol. 69, no. 1, pp. 99-118, 1955.

[88] C. Romero, Análisis de las Decisiones Multicriterio, Madrid: Isdefe, 1996.

[89] A. Charnes, W. Cooper and R. Ferguson, "Optimal Estimation of Executive Compensation by Linear Programming," Management Science, pp. 138-151, 1955.

[90] S. Lee, Goal Programming for Decision Analysis, Filadelfia, 1972.

[91] J. Ignizio, Goal Programming and Extensions, Massachustts, 1976. 
[92] J. P. Ignizio, "Generalized Goal Programming. An Overview," Computer and Operations Research, vol. 10, pp. 277-289, 1983.

[93] J. Pomerol and S. Barba-Romero, Multicriterion Decision in Management: Principles and Practice, Kluwer Academic Publishers, 2000.

[94] B. Roy, "ELECTRE III: Un algorithme de rangement fondé sur une représentation floue des préférences en présence de critères multiples.," Cahiers du Centre d'études de recherche operationnelle, vol. 20, pp. 3-24, 1978.

[95] J. Brans, B. Mareschal and P. Vincke, "PROMETHEE: A new family of outranking methods in multicriteria analysis.," Operational Research, pp. 408-421, 1984.

[96] R. Keeney and H. Raiffa, Decisions with Multiple Objectives: Preferences and Value Tradeoffs, Wiley, 1976.

[97] C. Bana E Costa and J. Vansnick, "Applications of the MACBETH approach in the framework of an additive aggregation model.," Journal of Multicriteria Decision Analysis, vol. 6, pp. 107-114, 1997.

[98] H. Linstone and M. Turof, Delphi Method: Techniques and Applications, Addison-Wesley , 1975.

[99] R. Touza, Análisis de Decisiones Multicriterio, Armada Española, 2016.

[100] V. Belton and T. Gear, On a short-coming of Saaty's Method of Analytic Hierarchies, Omega, 1983, pp. 228-230.

[101] A. Tversky, "Intransitivity of Preferences," Psychological Review, pp. 31-48, 1969.

[102] J. Dyer and R. Wendell, "A Critique of the AHP," University of Texas, Austin, 1985.

[103] T. Saaty, "Axiomatic Foundations of the Analytic Hierarchy Process," Management Science, pp. 841-855, 1983. 
[104] T. Saaty, "An Exposition of the AHP in Reply to the Paper "Remarks on the AHP"," Management Science, pp. 259-268, 1990.

[105] J. Dyer, "Remarks on the AHP," Management Science, pp. 249-258, 1990.

[106] T. Saaty, Fundamentals of Decision Making and Priority Theory with the AHP, RWS, 1994.

[107] Expert Choice Software, Pittsburgh, 1990.

[108] "International Society on MCDM," [Online]. Available: https://www.mcdmsociety.org/content/software-related-mcdm.

[109] "GMV Innovating Solutions," [Online]. Available: https://www.gmv.com/es/.

[110] GMV Aeroespace and Defence, Manual de Ususario ADLA, Madrid, 2014.

[111] GMV, Manual de Usuario ADLA, 2014.

[112] B. Khoshnevis, Ciscrete Systems Simulation, McGraw-Hill, 1994.

[113] I. Grigoryev, AnyLogic in Three Days, 2016.

[114] A. Urquía, Métodos de Simulación y Modelado, UNED, 2016.

[115] D. Pedgen, R. Shanon and R. Sadowski, Introduction to Simulation using SIMAN, 1995.

[116] F. Budnick, D. McLeavey and R. Mojena, Principles of Operations Research for Management, illinois: Irwin, 1988.

[117] G. González-Cela, R. Bellas, J. T. Martínez and R. Carreño, “Optimal Design of Spanish Navy F-110 Frigates Combat Information Center," Naval Engineer Journal, vol. 130, no. 1, pp. 121-132, 2018.

[118] “Diseño ergonómico de los centros de control. Parte 1: Principios para el diseño de los centros de control. (ISO 11064-1)," 2001. [Online]. Available: https://www.une.org/encuentra-tu-norma/busca-tunorma/norma?c=N0025544. 
[119] “Diseño ergonómico de los centros de control. Parte 2: Principios para la ordenación de las salas de control y sus anexos. (ISO 11064-2)," 2001. [Online]. Available: $\quad$ https://www.une.org/encuentra-tu-norma/busca-tunorma/norma?c=N0025545.

[120] “Diseño ergonómico de los centros de control. Parte 3: Disposición de las salas de control. (ISO 11064-3)," 2018. [Online]. Available: https://www.une.org/encuentra-tu-norma/busca-tunorma/norma/?c=N0024251.

[121] “Diseño ergonómico de los centros de control. Parte 4: Diseño y dimensiones de las estaciones de trabajo (ISO 11064-4)," 2013. [Online]. Available: https://www.une.org/encuentra-tu-norma/busca-tunorma/norma?c=N0054599.

[122] “Diseño ergonómico de los centros de control. Parte 5: Dispositivos de visualización y comandos (ISO 11064-5)," 2008. [Online]. Available: https://www.une.org/encuentra-tu-norma/busca-tunorma/norma/?c=N0044187.

[123] “Diseño ergonómico de centros de control. Parte 6: Requisitos ambientales para centros de control (ISO 11064-6)," 2006. [Online]. Available: https://www.une.org/encuentra-tu-norma/busca-tunorma/norma/?c=N0035334.

[124] “Diseño ergonómico de centros de control. Parte 7: Principios para la evaluación de centros de control (ISO 11064-7)," 2006. [Online]. Available: https://www.une.org/encuentra-tu-norma/busca-tunorma/norma/?c=N0037467.

[125] The US Navy, [Online]. Available: https://www.navy.mil/navydata/fact_display.asp?cid=4200\&tid=900\&ct=4.

[126] Thunderhead Engineering, "Pyrosim," [Online]. Available: https://www.thunderheadeng.com/pyrosim/. 
[127] Navy, Royal Netherlands, [Online]. Available: https://www.defensie.nl/organisatie/marine/materieel/schepen/luchtverded igings--en-commandofregatten-Icf.

[128] R. Scott, "Command View: Rethinking Interactions in the Operations Room," IHS Jane's Navy International, 2016.

[129] "SAAB," [Online]. Available: https://saab.com/naval/decisionsuperiority/combat-management-systems/9lv-cms/.

[130] Royal Navy, [Online]. Available: https://www.royalnavy.mod.uk/type45.

[131] Marina Militare, [Online]. Available: http://www.marina.difesa.it/Pagine/default.aspx. "SPSS an IBM Company," [Online]. Available: http://www.spss.com.hk/software/data-collection/.

[133] IMO, [Online]. Available: http://www.imo.org.

[134] INSA, "Naval Ship Code," [Online]. Available: http://www.navalshipcode.org/naval-ship-code/.

[135] Touza, R., Aplicación de la Normativa de la OMI, a la Evacuación de los Buques de Guerra. Análisis Estadístico del Movimiento de Personal y Simulación, 2011.

[136] IMO Maritime Safety Commite Circ 1033, "Directrices para el análisis de la evacuación de los buques de pasaje," 2002.

[137] Thunderhead Engineering, "Pathfinder," [Online]. Available: https://www.thunderheadeng.com/pathfinder/.

[138] Thunderhead Engineering, "Thunderhead Engineering," [Online]. Available: http://www.thunderheadeng.com/.

[139] Fire Safety Engineering Group, "EXODUS," [Online]. Available: http://fseg.gre.ac.uk/index.html. 
[140] DNV

$\mathrm{GL}$,

"AENEAS,"

[Online].

Available:

https://www.dnvgl.com/services/aeneas-the-standard-in-passengerevacuation-analysis-48508.

[141] Traffgo-ht, "PedGo," [Online]. Available: https://www.traffgoht.com/en/pedestrians/products/pedgo/index.html.

[142] Brookes

Bell, "EVI," [Online].

Available:

http://www.brookesbell.com/service/software/evi-escape-evacuation-

analysis.

[143] INCONTROL Simulation Software, "INCONTROL," [Online]. Available: https://www.incontrolsim.com/.

[144] AnyLogic, "AnyLogic," [Online]. Available: https://www.anylogic.com/.

[145] Thunderhead Engineering, Pathfinder Manual.

[146] National Institute of Standards and Technology, "NIST," [Online]. Available: https://www.nist.gov/.

[147] D. Helbing and P. Molnar, "Social Force Model for Pedestrian Dynamics," Physical Review, 1998.

[148] E. Uriarte, "Análisis comparativo de los criterios tradicionales de evacuación de buques frente a los que incluyen la presencia de fuego y humo.," 2014.

[149] IMO, "Guidelines for Evacuation Analysis for New and Existing Passenger Ships," [Online].

Available: http://www.imo.org/blast/blastDataHelper.asp?data_id=20573\&filename=1 238.pdf.

[150] F. Pérez, La Evacuación del Buque de Guerra. Estudio del Movimiento de Personal en Situaciones de Emergencia, 2008.

[151] S. Casadesus and F. Garriga-Garzón, “Procedimientos Gráficos y Analíticos para Validar los Modelos Utilizados en el Estudio de la Evacuación de Edificios," in 
Proceedings, International Conference on Industrial Engineering and Industrial Management (IEEM), Barcelona, 2009.

[152] T. Meyer-König, P. Valanto and D. Povel, "Implementing Ship Motion in AENEAS - Model Development and First Results, in Pedestrian and Evacuation Dynamics 2005," 2005, pp. 429-441.

[153] E. R. Galea, "A General Approach to Validating Evacuation Models with an Application to EXODUS," Journal of Fire Sciences, no. 16, pp. 414-436, 1998.

[154] Minitab, “Minitab,” [Online]. Available: https://www.minitab.com/es-mx/.

[155] H. Levene, "Contributions to Probability and Statistics," Stanford University Press, 1960.

[156] M. Brown and A. Forsythe, "Robust Tests for the Equality of Variance," Journal of the American Statistical Association, pp. 364-367, 1974.

[157] Y. Hochberg, G. Weiss and S. Hart, "On graphical Procedure for Multiple Comparisons," Journal of the American Statistical Association, vol. 77, no. 380, pp. 767-772.

[158] R. Wilcox, New Statistical Procedures for the Social Sciences, Hillsdale: LEA, 1987.

[159] J. Tukey, The Problem of Multiple Comparisons, Princeton University, 1953.

[160] R. Fisher, The Design of Experiments, Edinburgh: Oliver\&Boyd, 1935.

[161] E. Péter, Modelo Híbrido para la Ayuda al Capitán, Universidad Politécnica de Madrid, 2014.

[162] G. González-Cela, R. Bellas, R. Carreño, J. Martínez, R. Touza, A. González-Gil, M. Gómez and D. González, "A framework for integrating human factors in the early stages of ship design: Application to the mess halls of a surface combatant," Journal of Ship and Design , 2019. 
[163] H. Mann and D. Whitney, "On a test of whether one of two random variables is stochastically larger than the other," Annals Mathematical Statistics, no. 18, pp. 50-60, 1947.

[164] R. Villacampa, Introducción a la Estadística: Descriptiva, Inferencia Paramétrica, 2015.

[165] J. Bradley, Distribution-free statistical tests, Prentice-Hall, 1968.

[166] Student, "The Probable Error of a Mean," Biometrika, vol. 6, no. 1-25, 1908.

[167] W. Kruskal and A. Wallis, "Use of Ranks in One-Criterion Variance Analysis," Journal of the American Statistical Association, no. 47, pp. 583-621, 1952.

[168] T. Tanizaki and T. Shimura, "Modeling and Analysis Method of Restaurant Service Process," in Proceedings, 10th CIRP Conference on Intelligent Computation in Manufacturing Engineering, Ischia, 2016.

[169] A. Borshchev, The Big Book of Simulation Modeling: Multimethod Modeling with AnyLogic, Chicago: AnyLogic North America, 2013.

[170] AnyLogic,

"AnyLogic,"

[Online].

Available:

https://cloud.anylogic.com/model/d5a74028-b504-42f6-9e331ca2d554604e?mode=SETTINGS.

[171] C. Echeverría, "EL Estrecho de BAB EL MANDEB Como Escenario Potencial de Desestabilización ante el Creciente Activismo Terrorista en YEMEN Y SOMALIA," 2010.

[172] Bae "Bystems, "Bae Systems," [Online]. Available: https://www.baesystems.com/en-us/home.

[173] Leonardo, “Leonardo," [Online]. Available: http://www.leonardocompany.com. 
APÉNDICES 



\section{Apéndice A. Estudio del CIC}

\section{A.1. Diseño CIC. Matrices de comparación por pares}

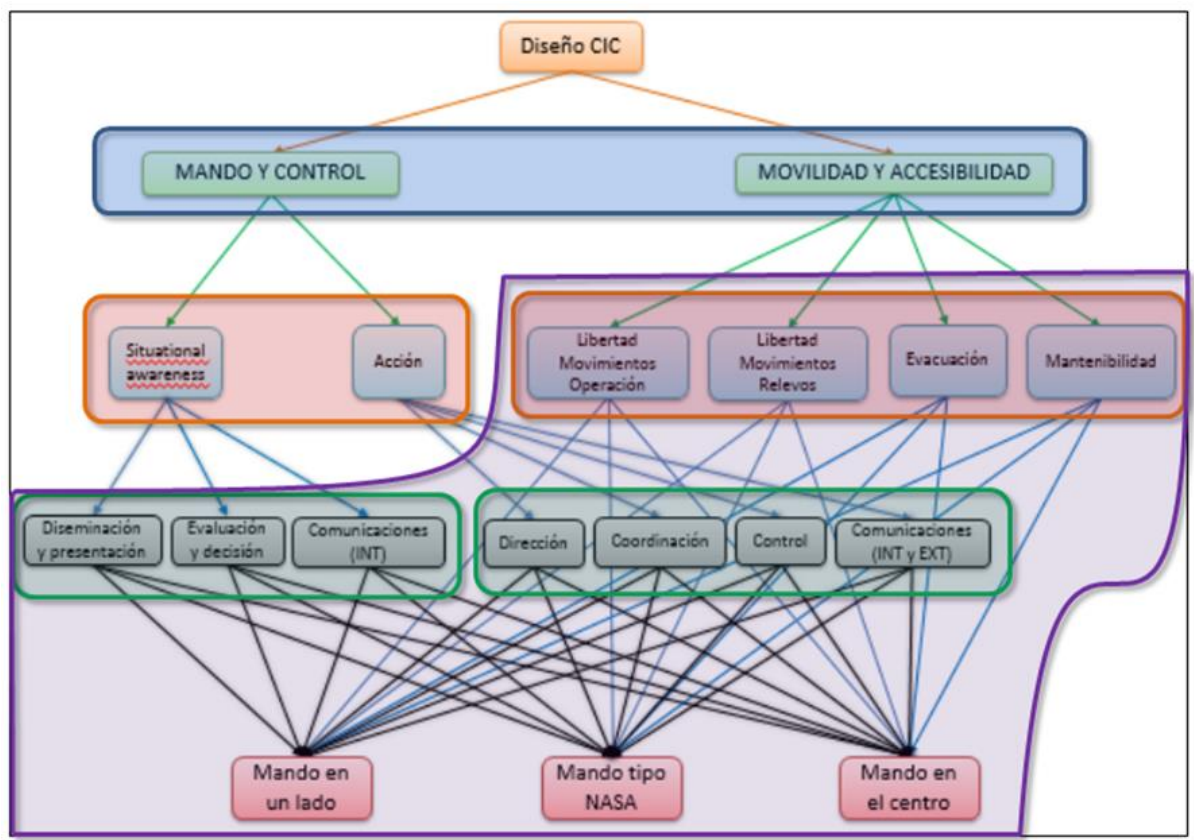

Figura en Apéndice A-1 Esquema de ayuda enviado a los expertos (Elaboración propia)

\begin{tabular}{|l|c|c|}
\hline Escala & Escala numérica & Recíproco \\
\hline Igualmente preferido & 1 & 1 \\
\hline Moderadamente preferido & 3 & -3 \\
\hline & & -5 \\
\hline Fuertemente preferido & 5 & \\
\hline & & -7 \\
\hline Muy fuertemente preferido & 7 & \\
\hline & & -9 \\
\hline Muy Recomendado & 9 & \\
\hline
\end{tabular}

Figura en Apéndice A-2 Escala de Saaty facilitada a los expertos 
Apéndice A. Estudio del $\mathrm{CIC}$

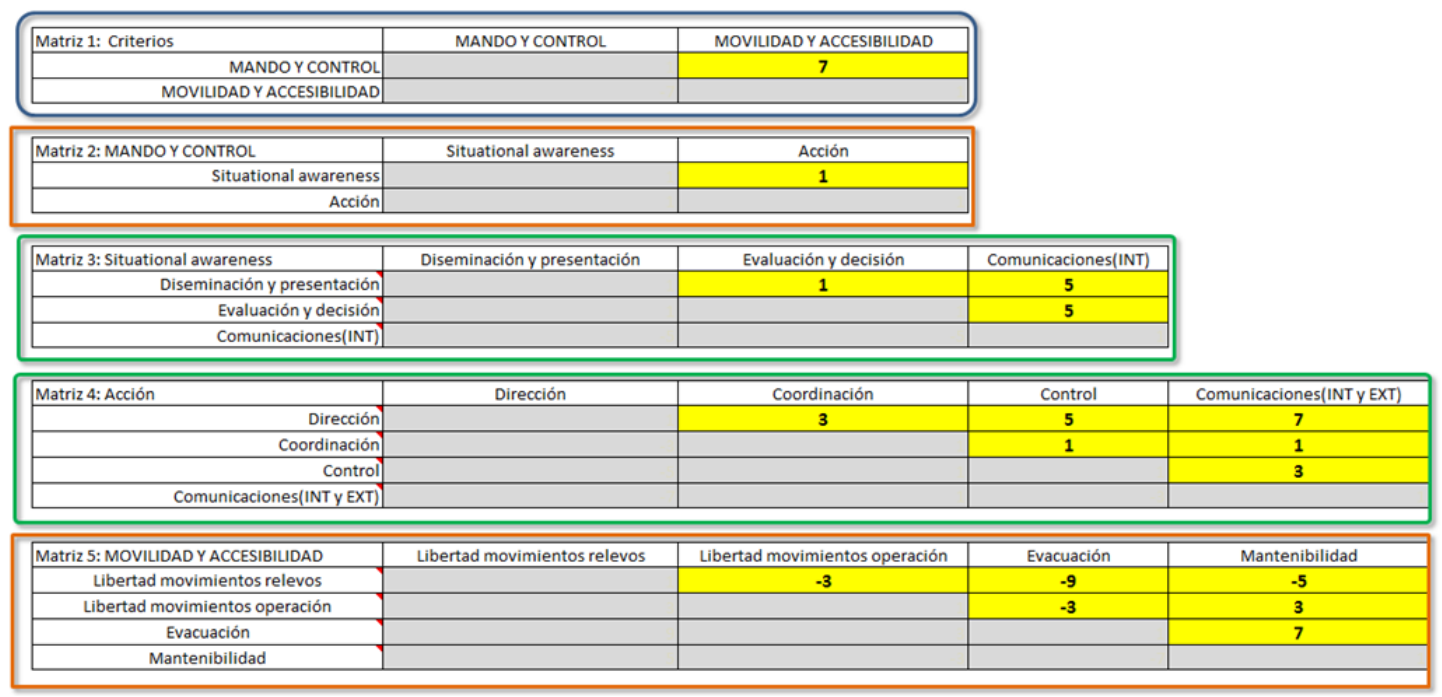

Figura en Apéndice A-3 Matrices de asignación de pesos a los criterios 


\begin{tabular}{|c|c|c|c|}
\hline Matriz 6: Diseminación y presentación & Lado & Centro & NASA \\
\hline Lado & & 1 & -3 \\
\hline Centro & & & -3 \\
\hline NASA & & & \\
\hline Matriz 7: Evaluación y decisión & Lado & Centro & NASA \\
\hline Lado & & -5 & -3 \\
\hline Centro & & & 3 \\
\hline NASA & & & \\
\hline Matriz 8: Comunicaciones(INT) & Lado & Centro & NASA \\
\hline Lado & & -3 & 1 \\
\hline Centro & & & 3 \\
\hline NASA & & & \\
\hline Matriz 9: Dirección & Lado & Centro & NASA \\
\hline Lado & & -3 & 1 \\
\hline Centro & & & 3 \\
\hline NASA & & & \\
\hline Matriz 10: Coordinación & Lado & Centro & NASA \\
\hline Lado & & -3 & 1 \\
\hline Centro & & & 3 \\
\hline NASA & & & \\
\hline Matriz 11: Control & Lado & Centro & NASA \\
\hline Lado & & 1 & -3 \\
\hline Centro & & & -3 \\
\hline NASA & & & \\
\hline Matriz 12: Comunicaciones (INT Y EXT) & Lado & Centro & NASA \\
\hline Lado & & -3 & 1 \\
\hline Centro & & & 3 \\
\hline NASA & & & \\
\hline Matriz 13: Libertad movimientos operación & Lado & Centro & NASA \\
\hline Lado & & 3 & 3 \\
\hline Centro & & & 1 \\
\hline NASA & & & \\
\hline Matriz 14: Libertad movimientos relevos & Lado & Centro & NASA \\
\hline Lado & & 3 & 3 \\
\hline Centro & & & 1 \\
\hline NASA & & & \\
\hline Matriz 15: Evacuación & Lado & Centro & NASA \\
\hline Lado & & -3 & 1 \\
\hline Centro & & & 5 \\
\hline NASA & & & \\
\hline Matriz 16: Mantenibilidad & Lado & Centro & NASA \\
\hline Lado & & 3 & 3 \\
\hline Centro & & & 1 \\
\hline NASA & & & \\
\hline
\end{tabular}

Figura en Apéndice A-4 Matrices para la valoración de las alternativas 



\section{A.2. Estadístico para el cálculo de réplicas}

Se ha utilizado el estadístico: $\quad n \cong t_{n-1,1-\frac{\alpha}{2}}^{2} \frac{\left(n_{0}\right)}{h^{2}} ; h=$ error $=2$ seg.; Confianza $=$ 0.95

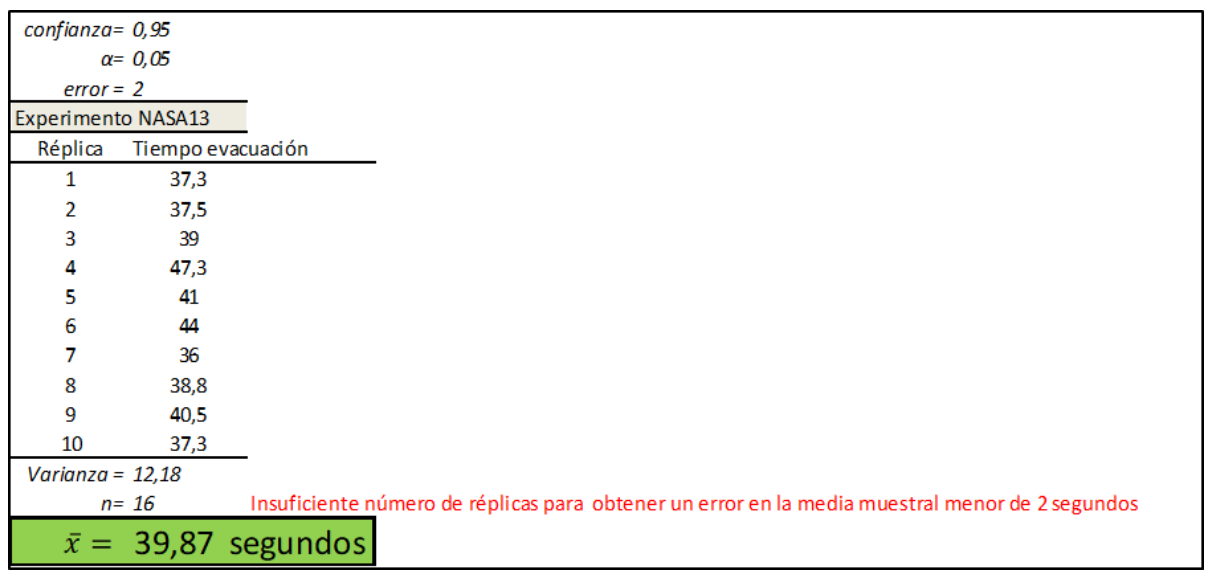

Figura en Apéndice A-5 Imagen ejemplo de un experimento de 10 réplicas que resulta insuficiente

\begin{tabular}{|c|c|c|c|}
\hline & B & C & D \\
\hline 2 & confianza $=$ & 0,95 & \\
\hline 3 & $\alpha=$ & 0,05 & \\
\hline 4 & error $=$ & 2 & \\
\hline 5 & Experimento NASA13 & & \\
\hline 6 & Réplica & Tiempo evacuación & \\
\hline 7 & 1 & 37,3 & \\
\hline 8 & 2 & 37,5 & \\
\hline 9 & 3 & 39 & \\
\hline 10 & 4 & 47,3 & \\
\hline 11 & 5 & 41 & \\
\hline 12 & 6 & 44 & \\
\hline 13 & 7 & 36 & \\
\hline 14 & 8 & 38,8 & \\
\hline 15 & 9 & 40,5 & \\
\hline 16 & 10 & 37,3 & \\
\hline 17 & Varianza $=$ & $=V A R \cdot S(C 7: C 16)$ & $\begin{array}{l}\text { =SI (C18<10;"Número de réplicas } \\
\text { suficiente para obtener un error en la }\end{array}$ \\
\hline 18 & $n=$ & $=$ POTENCIA $($ INV.T.2C(0,05;9);2)*C17/(C4^2) & $\begin{array}{c}\text { media muestral menor de } 2 \text { segundos"; } \\
\text { "Insuficiente número de réplicas para } \\
\text { obtener un error en la media muestral } \\
\text { menor de } 2 \text { segundos") }\end{array}$ \\
\hline 19 & & \multicolumn{2}{|c|}{$=$ CONCATENAR(PROMEDIO (C7:C16);" segundos") } \\
\hline
\end{tabular}

Tabla en Apéndice A-1 Tabla Excel elaborada para aplicación del estimador del número de réplicas. Datos de 10 



\section{A.3. Modelos de CIC}

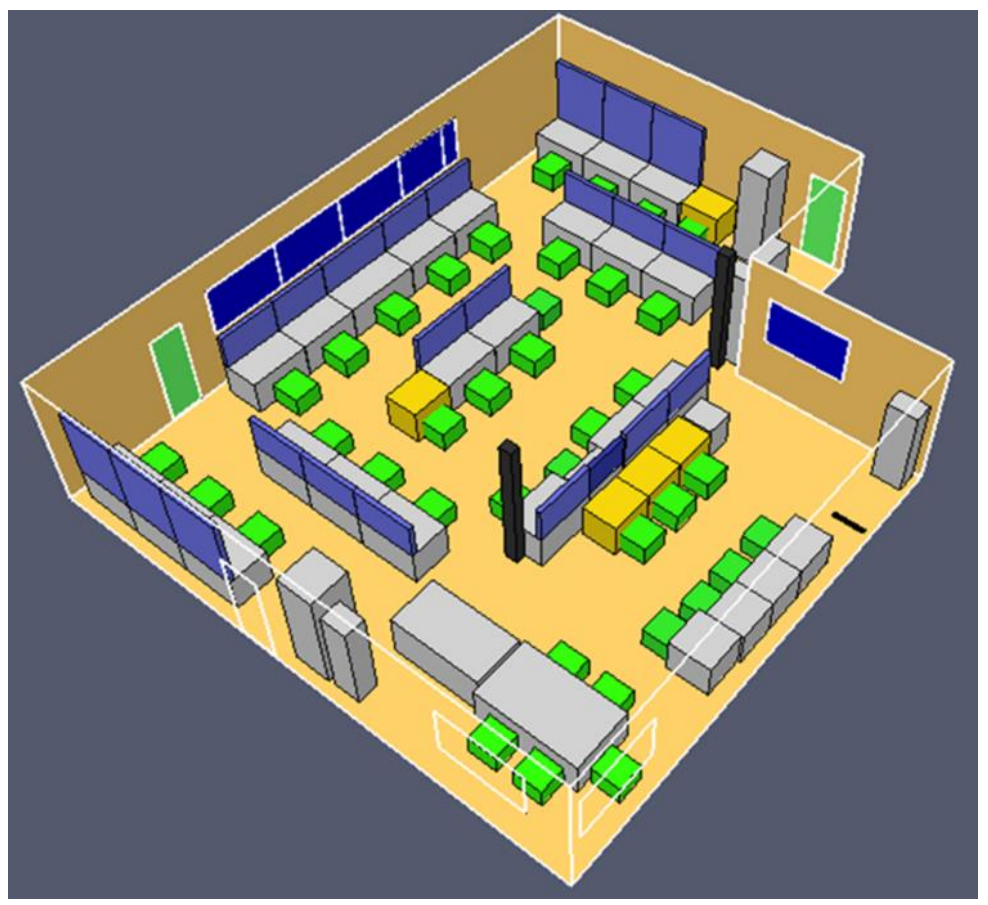

Figura en Apéndice A-6 CIC tipo LADO con número de pasillos igual a cero (Elaboración propia)

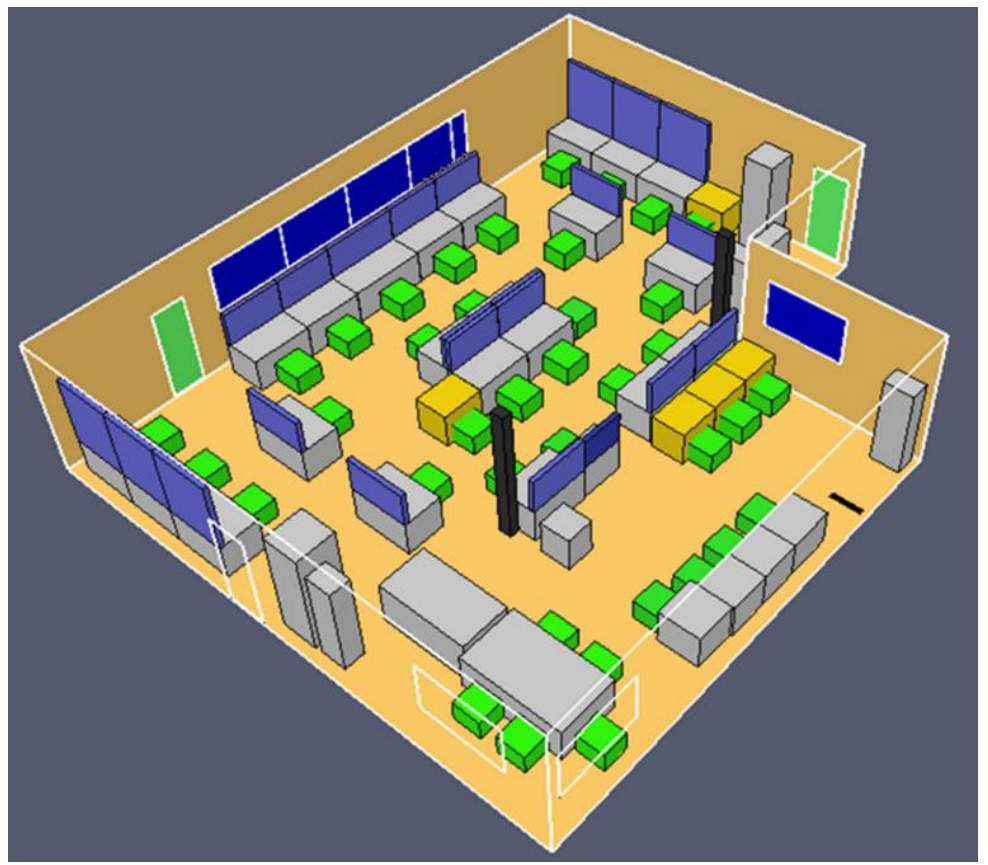

Figura en Apéndice A-7 CIC tipo LADO con número de pasillos igual a uno (Elaboración propia) 


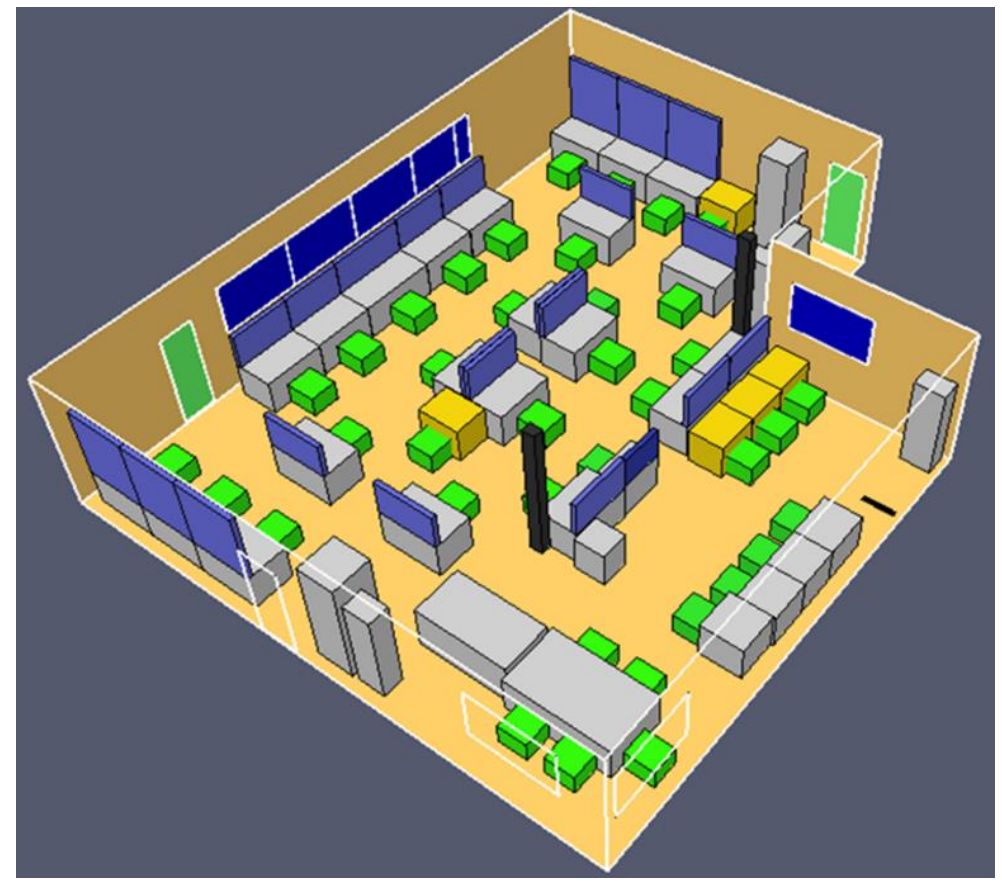

Figura en Apéndice A-8 CIC tipo LADO con número de pasillos igual a dos (Elaboración propia)

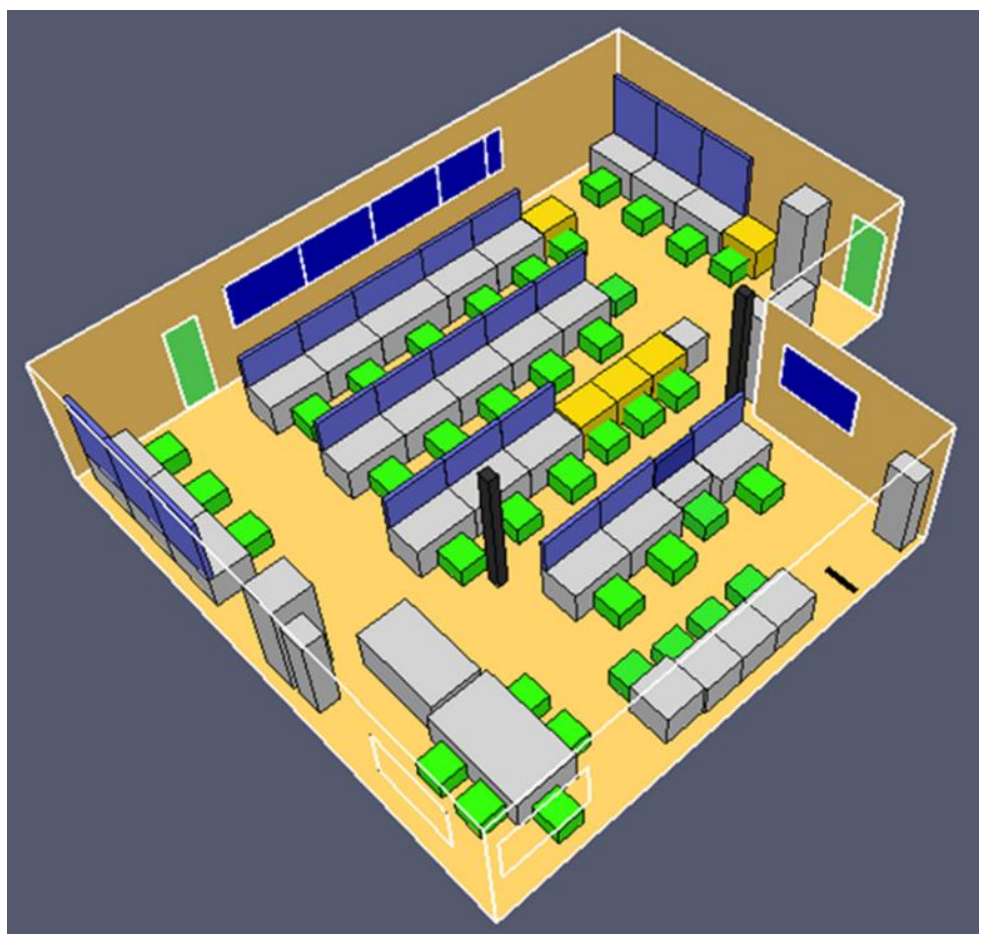

Figura en Apéndice A-9 CIC tipo NASA con número de pasillos igual a cero (Elaboración propia) 


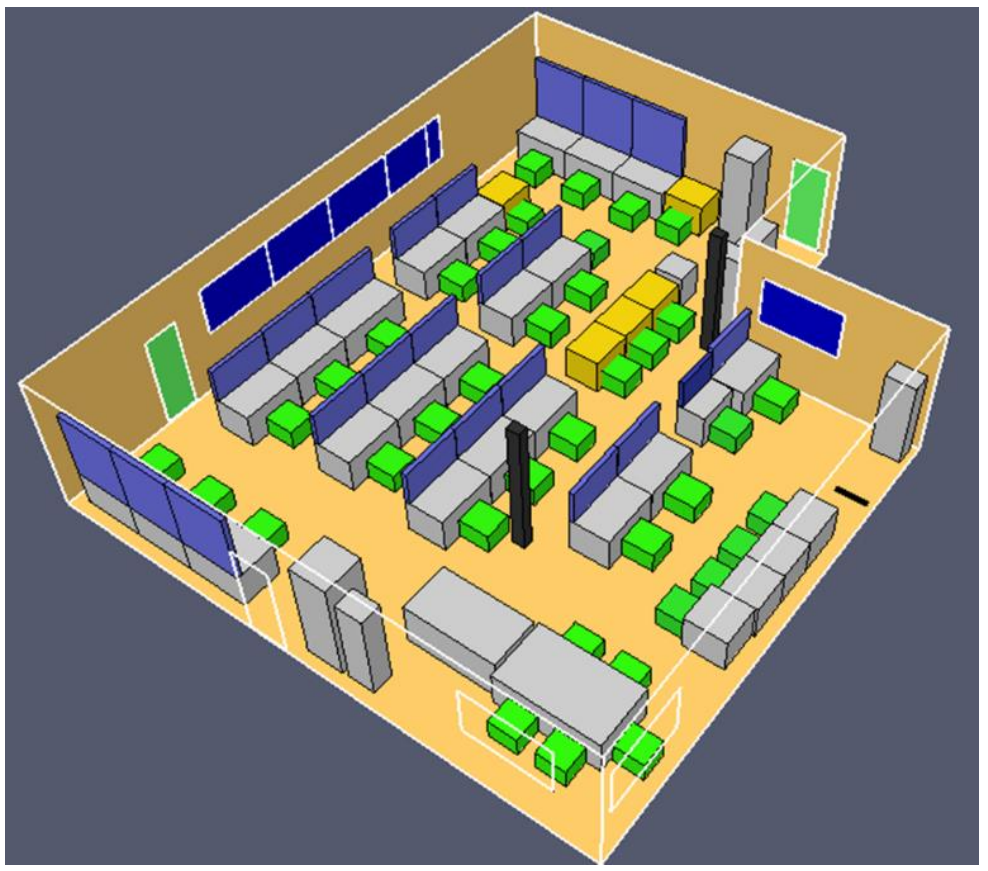

Figura en Apéndice A-10 CIC tipo NASA con número de pasillos igual a uno (Elaboración propia)

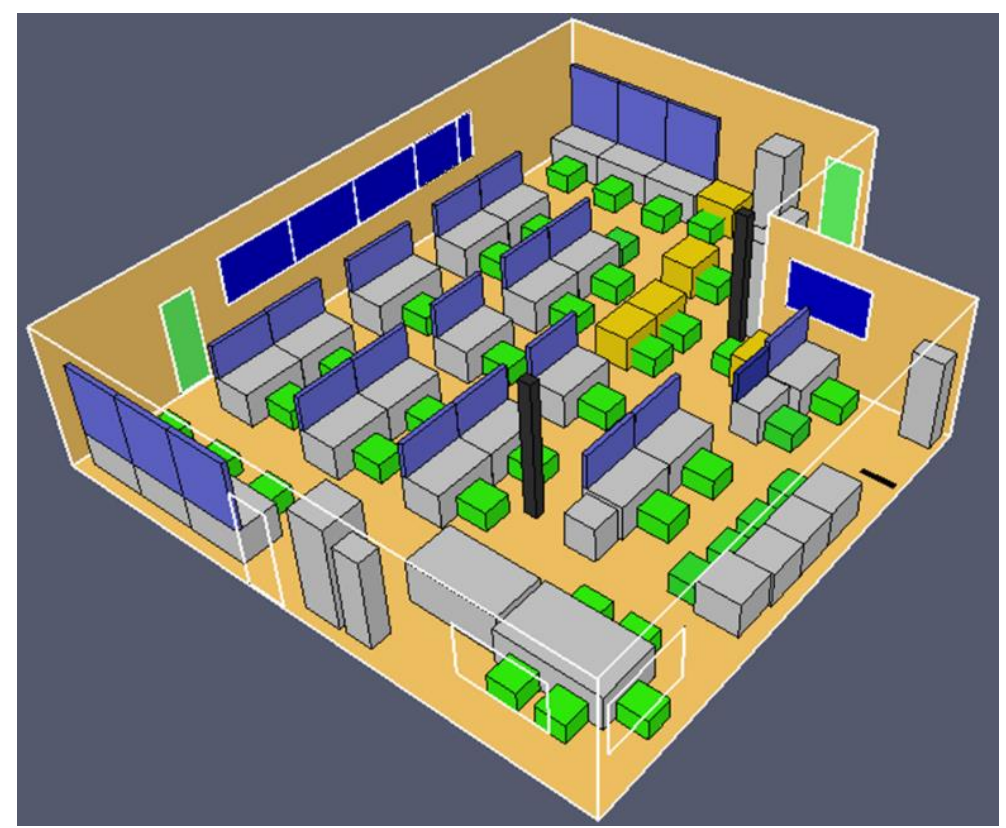

Figura en Apéndice A-11 CIC tipo NASA con número de pasillos igual a dos (Elaboración propia) 


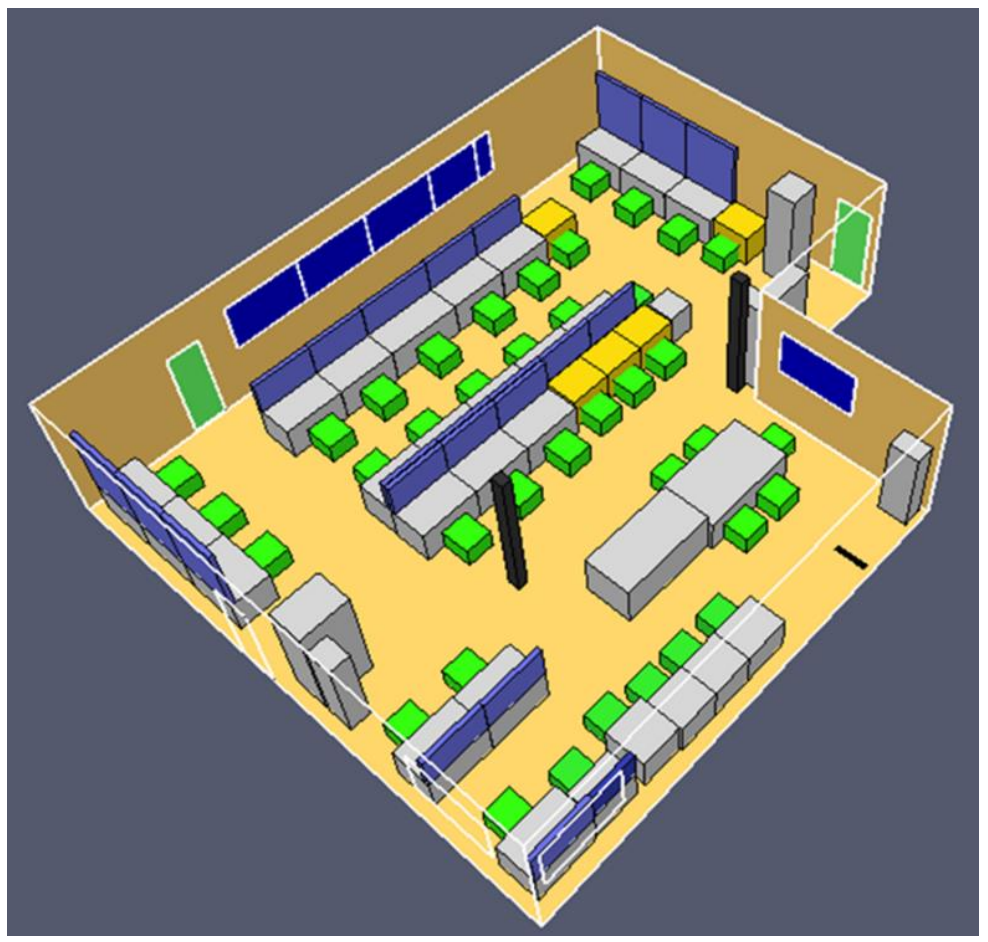

Figura en Apéndice A-12 CIC tipo CENTRO con número de pasillos igual a cero (Elaboración propia)

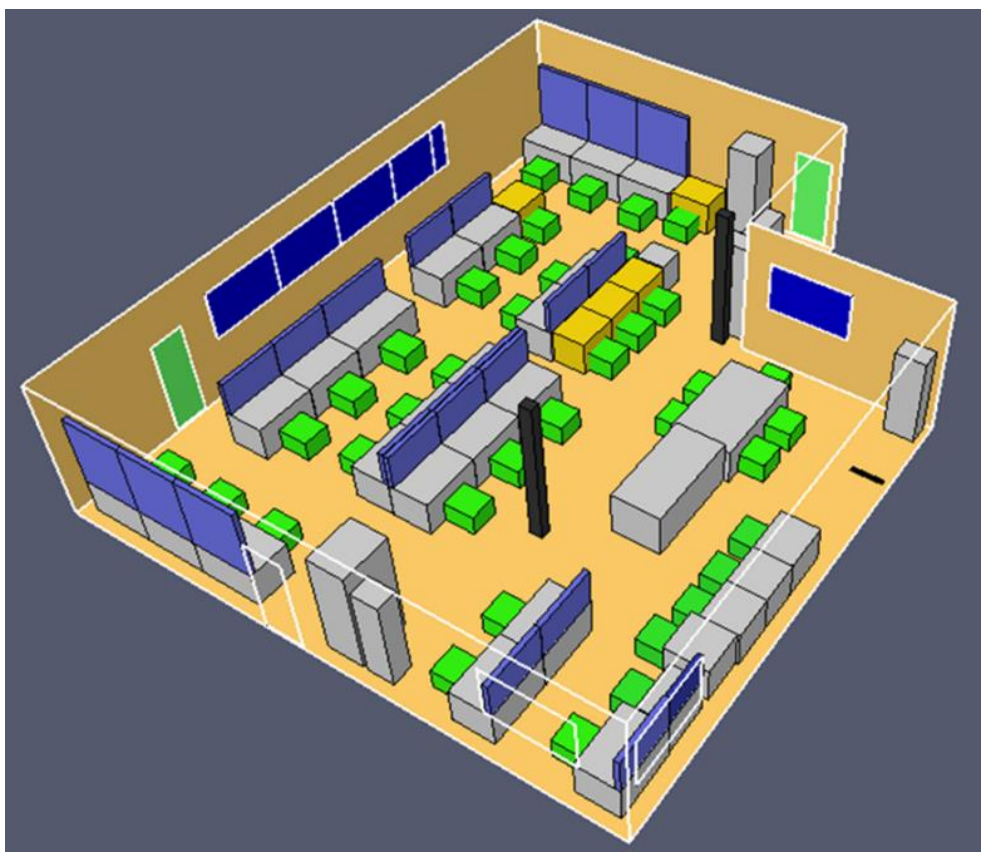

Figura en Apéndice A-13 CIC tipo CENTRO con número de pasillos igual a uno (Elaboración propia) 
Apéndice A. Estudio del $\mathrm{ClC}$

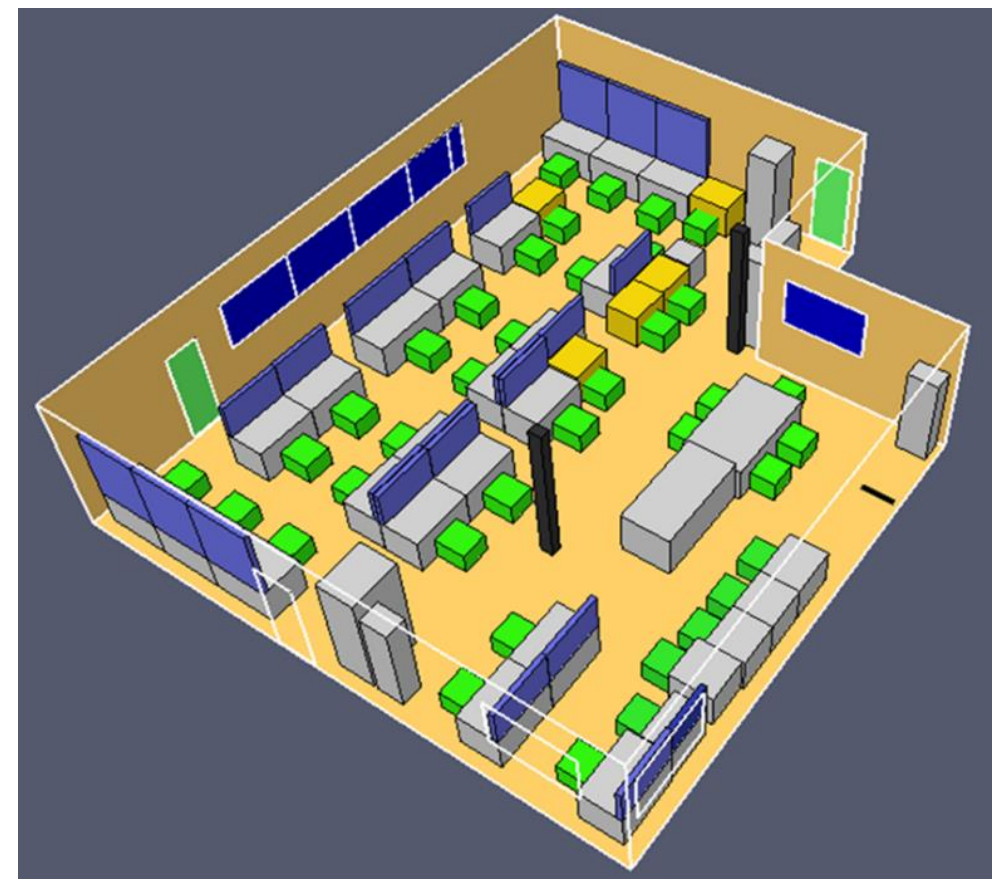

Figura en Apéndice A-14 CIC tipo CENTRO con número de pasillos igual a dos (Elaboración propia) 



\section{A.4. Modelo Social de Fuerzas}

Extraído de [148], en este modelo se asume que cada individuo $i$ se intenta mover en una determinada dirección a una determinada velocidad y adapta su velocidad actual a la que desea llevar en un cierto lapso:

$$
v_{i}=v_{i}^{0} e_{i}^{0}
$$

La parte sistemática de la aceleración que sufre el agente tiene la siguiente forma:

$$
f_{i j}^{S O C}(t)=A_{i} e^{\frac{r_{i j}-d_{i j}}{B_{i}}} n_{i j}\left(\lambda_{i}+\left(1-\lambda_{i}\right) \frac{1+\cos \varphi_{i j}}{2}\right)
$$

donde $A_{i}$ representa la fuerza de la interacción y $B_{i}$ el rango durante el que actúan las fuerzas repulsivas, las cuales son dependientes de las características culturales de los individuos, $d_{i j}=\left\|x_{i}-x_{j}\right\|$ es la distancia entre los centros de masa de los individuos $i$ y $j, r_{i j}=r_{i}+r_{j}$ es la suma de sus radios y

$$
n_{i j}(t)=\left(n_{i j}^{1}(t), n_{i j}^{2}(t)\right)=\frac{x_{i}(t)-x_{j}(t)}{d_{i j}}
$$

es el vector normalizado que apunta del individuo $j$ al $i$. Finalmente, el parámetro $\lambda_{i}$ representa la anisotropía de las interacciones entre los individuos, de tal forma, con este parámetro se puede representar que las cosas que ocurren enfrente del agente tienen mayor efecto en él que las que ocurren detrás. El ángulo $\varphi_{i j}$ representa el ángulo entre la dirección $e_{i}(t)=v_{i}(t) /\left\|v_{i}(t)\right\|$ del movimiento y la del vector $-n_{i j}$ del objeto que ejerce la fuerza repulsiva.

Este modelo no tiene en cuenta la dependencia que existe entre las velocidades y las fuerzas, así como tampoco tiene en cuenta la forma no circular de los cuerpos. No obstante, este modelo sí tiene en cuenta las fuerzas de atracción debidas a la existencia de ventanas, señalizaciones o relaciones entre individuos. Estas fuerzas de atracción entre individuos tienen esta forma $f_{i j}^{a t t}=-C_{i j} n_{i j}$.

En resumen, la fuerza total que actúa sobre un individuo toma la siguiente forma siempre y cuando la evacuación transcurra de un modo normal: 


$$
f_{i}(t)=\frac{v_{i}^{0}(t) e_{i}^{0}(t)-v_{i}(t)}{t_{i}}+\sum_{j(\neq i)}\left[f_{i j}^{s o c}(t)+f_{i j}^{a t t}(t)\right]+\sum_{b} f_{i b}(t)+\sum_{k} f_{i j}^{a t t}(t)
$$

Cuando la proximidad entre individuos es tal que existe contacto entre ellos entra en juego una fuerza debida al "pánico" y que tiene la siguiente forma:

$$
f_{i j}^{p h}(t)=k \theta\left(r_{i j}-d_{i j}\right) n_{i j}+K \theta\left(r_{i j}-d_{i j}\right) \Delta v_{j i}^{t} t_{i j}
$$

Donde $\theta(z)$ es igual a su argumento $z$ si $z \geq 0$ y en cualquier otro caso es igual a cero; $t_{i j}=\left(-n_{i j}^{2}, n_{i j}^{1}\right)$ representa la dirección tangencial, $\Delta v_{j i}^{t}=\left(v_{j}-v_{i}\right) \cdot t_{i j}$ es la diferencia entre las velocidades de los agentes y $k$ y $K$ son constantes.

Las interacciones con las paredes y otros obstáculos se tratan de forma análoga a como se tratan las fuerzas que actúan entre individuos:

$$
f_{i b}(t)=A_{i} e^{\frac{r_{i j}-d_{i j}}{B_{i}}}+k \theta\left(r_{i}-d_{i b}\right) n_{i b}+K \theta\left(r_{i}-d_{i b}\right)\left(v_{i} t_{i b}\right) t_{i b}
$$

El pánico puede ser desencadenado por pequeñas cantidades de individuos que pueden causar el retraso de toda la multitud que pretende abandonar el lugar. Consecuentemente, los individuos detenidos al fondo, los cuales no comprenden la razón por la que se detuvo la multitud, se vuelven impacientes y comienzan a empujar. De acuerdo con las observaciones, esto se puede representar mediante un incremento de la velocidad deseada de acuerdo con la siguiente fórmula

$$
v_{i}^{0}(t)=\left[1-n_{i}(t)\right] v_{i}^{0}(0)+n_{i}(t) v_{i}^{\max }
$$

donde $v_{i}^{\text {max }}$ es la máxima velocidad deseada y $v_{i}^{0}(0)$ es la inicial, correspondiente con la velocidad esperada de evacuación. El parámetro dependiente del tiempo, $n_{i}=1-$ $\frac{v_{i}(t)}{v_{i}^{0}(0)}$ refleja el nerviosismo y $v_{i}(t)$ denota la velocidad media en la dirección deseada de movimiento. 


\section{A.5. ANOVA Experimento LADO}

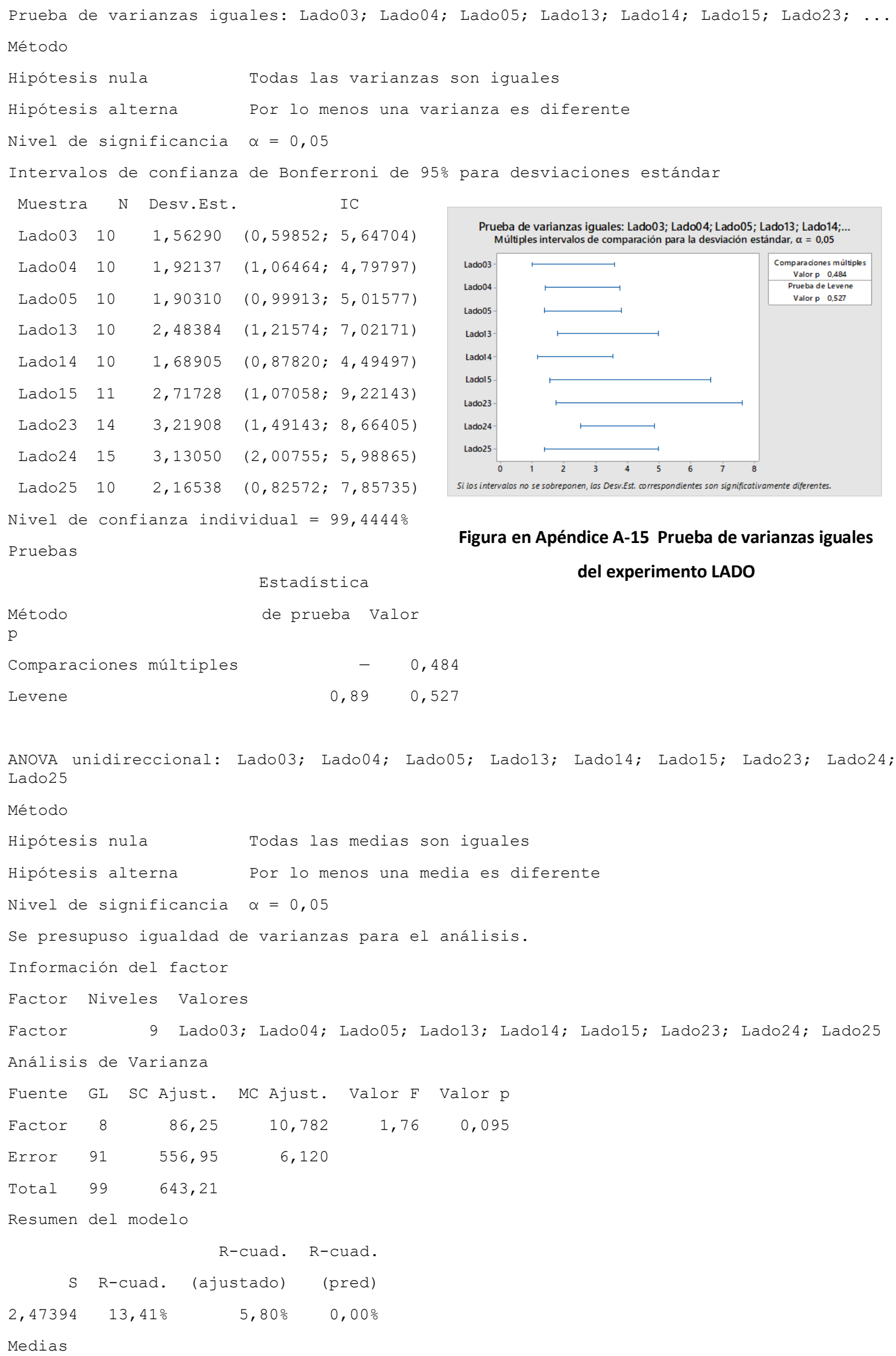

Figura en Apéndice A-15 Prueba de varianzas iguales del experimento LADO

Método de prueba Valor

$\mathrm{p}$

Comparaciones múltiples

$-\quad 0,484$

Levene

$0,89 \quad 0,527$

ANOVA unidireccional: Lado03; Lado04; Lado05; Lado13; Lado14; Lado15; Lado23; Lado24; Lado25

Método

Hipótesis nula Todas las medias son iguales

Hipótesis alterna Por lo menos una media es diferente

Nivel de significancia $\alpha=0,05$

Se presupuso igualdad de varianzas para el análisis.

Información del factor

Factor Niveles Valores

Factor 9 Lado03; Lado04; Lado05; Lado13; Lado14; Lado15; Lado23; Lado24; Lado25

Análisis de Varianza

Fuente GL SC Ajust. MC Ajust. Valor $\mathrm{F}$ Valor $\mathrm{p}$

$\begin{array}{lllll}\text { Factor } 8 & 86,25 & 10,782 & 1,76 & 0,095\end{array}$

Error $91 \quad 556,95 \quad 6,120$

Total $99 \quad 643,21$

Resumen del modelo

$$
\text { R-cuad. R-cuad. }
$$

$S$ R-cuad. (ajustado) (pred)

$2,47394 \quad 13,41 \% 5,80 \% \quad 0,00 \%$

Medias 
Apéndice A. Estudio del CIC

$\begin{array}{lrrrr}\text { Factor } & \text { N } & \text { Media } & \text { Desv.Est. } & \text { IC de 95\% } \\ \text { Lado03 } & 10 & 38,360 & 1,563 & (36,806 ; 39,914) \\ \text { Lado04 } & 10 & 36,050 & 1,921 & (34,496 ; 37,604) \\ \text { Lado05 } & 10 & 35,880 & 1,903 & (34,326 ; 37,434) \\ \text { Lado13 } & 10 & 37,850 & 2,484 & (36,296 ; 39,404) \\ \text { Lado14 } & 10 & 37,080 & 1,689 & (35,526 ; 38,634) \\ \text { Lado15 } & 11 & 35,982 & 2,717 & (34,500 ; 37,463) \\ \text { Lado23 } & 14 & 38,164 & 3,219 & (36,851 ; 39,478) \\ \text { Lado24 } & 15 & 37,400 & 3,130 & (36,131 ; 38,669) \\ \text { Lado25 } & 10 & 36,200 & 2,165 & (34,646 ; 37,754)\end{array}$

Desv.Est. agrupada $=2,47394$

Comparaciones en parejas de Tukey

Agrupar información utilizando el método de Tukey y una confianza de 95\%

$\begin{array}{lrrl}\text { Factor } & \text { N } & \text { Media } & \text { Agrupación } \\ \text { Lado03 } & 10 & 38,360 & \text { A } \\ \text { Lado23 } & 14 & 38,164 & \text { A } \\ \text { Lado13 } & 10 & 37,850 & \text { A } \\ \text { Lado24 } & 15 & 37,400 & \text { A } \\ \text { Lado14 } & 10 & 37,080 & \text { A } \\ \text { Lado25 } & 10 & 36,200 & \text { A } \\ \text { Lado04 } & 10 & 36,050 & \text { A } \\ \text { Lado15 } & 11 & 35,982 & \text { A } \\ \text { Lado05 } & 10 & 35,880 & \text { A }\end{array}$

Las medias que no comparten una letra son significativamente diferentes

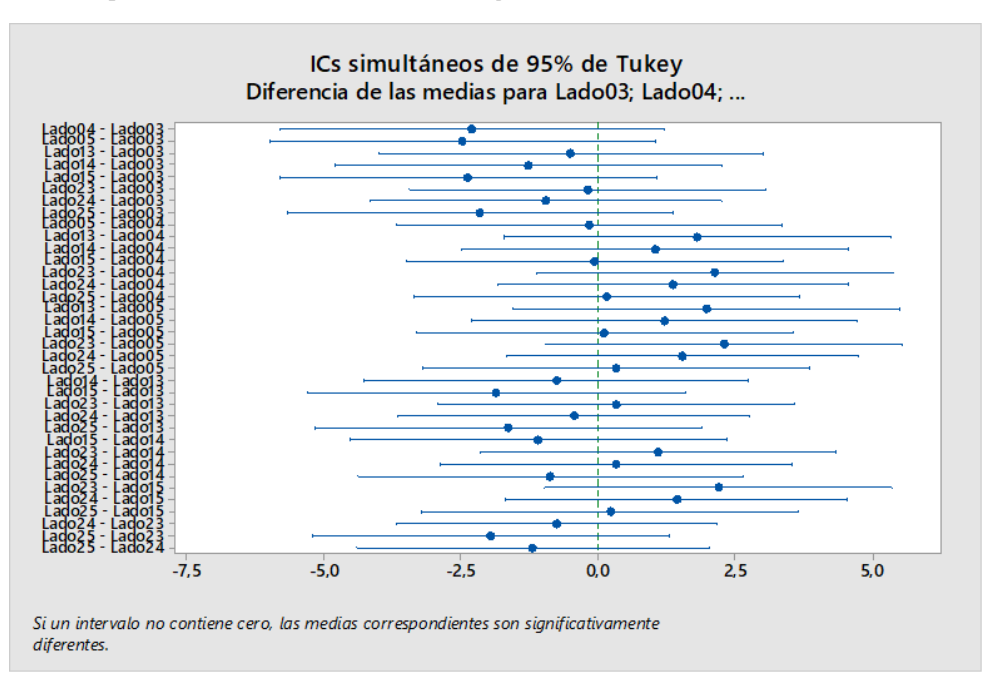

Figura en Apéndice A-16 ANOVA del experimento CIC tipo LADO 


\section{A.6. ANOVA Experimento CENTRO}

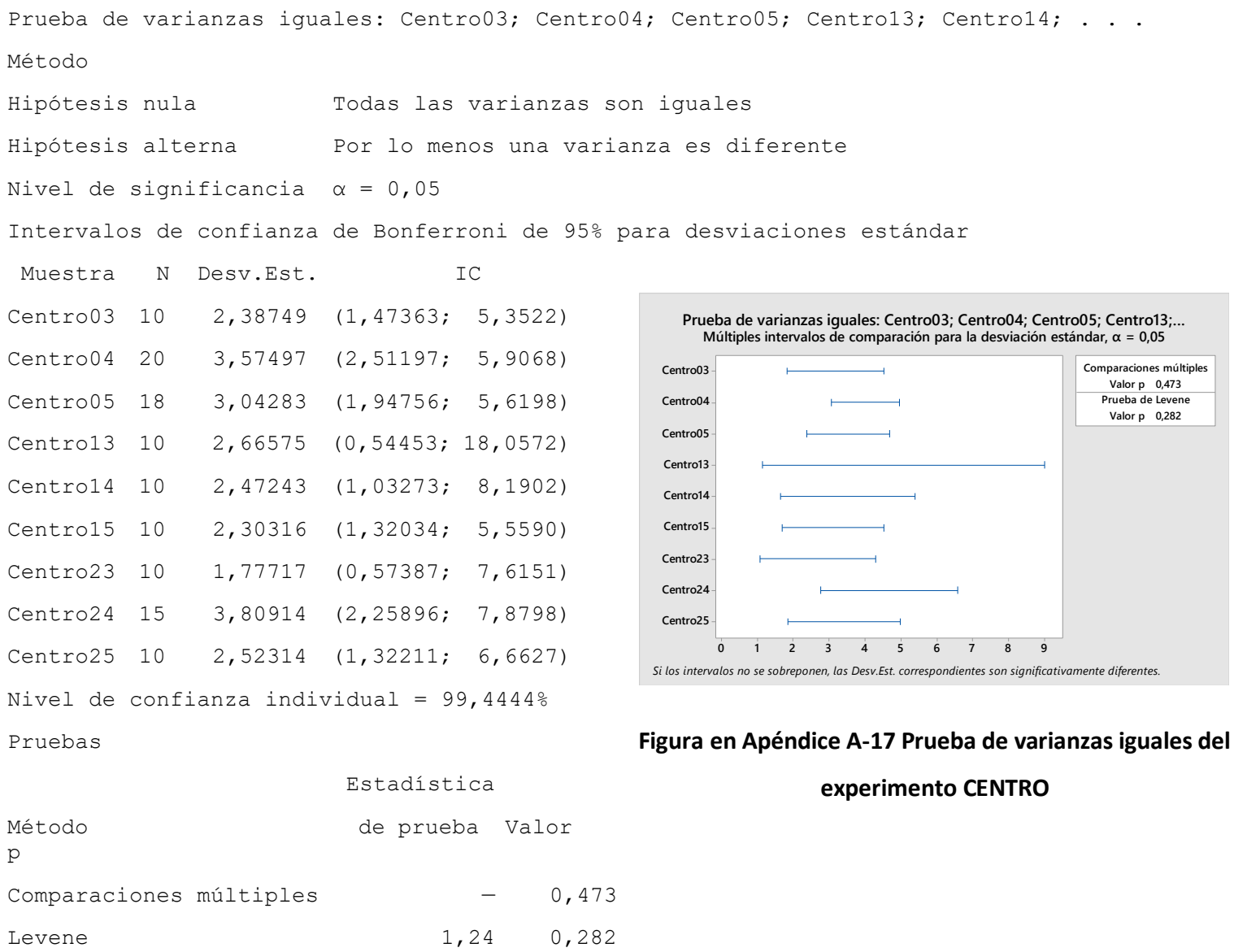

Figura en Apéndice A-17 Prueba de varianzas iguales del experimento CENTRO

ANOVA unidireccional: Centro03; Centro04; Centro05; Centro13; Centro14; Centro15; ... Método

Hipótesis nula Todas las medias son iguales

Hipótesis alterna Por lo menos una media es diferente

Nivel de significancia $\alpha=0,05$

Se presupuso igualdad de varianzas para el análisis.

Información del factor

Factor Niveles Valores

Factor 9 Centro03; Centro04; Centro05; Centro13; Centro14; Centro15; Centro23; Centro24; Centro25

Análisis de Varianza

Fuente GL SC Ajust. MC Ajust. Valor $\mathrm{F}$ Valor $\mathrm{p}$

Factor $8 \quad 116,1 \quad 14,513 \quad 1,66 \quad 0,116$

Error $104 \quad 907,1 \quad 8,722$

Total $112 \quad 1023,2$

Resumen del modelo

$$
\text { R-cuad. R-cuad. }
$$$$
S \text { R-cuad. (ajustado) (pred) }
$$

$2,95332 \quad 11,35 \% \quad 4,53 \% \quad 0,00 \%$

Medias 
Apéndice A. Estudio del CIC

$\begin{array}{lrrrr}\text { Factor } & \text { N } & \text { Media } & \text { Desv.Est. } & \text { IC de 95\% } \\ \text { Centro03 } & 10 & 38,830 & 2,387 & (36,978 ; 40,682) \\ \text { Centro04 } & 20 & 37,840 & 3,575 & (36,530 ; 39,150) \\ \text { Centro05 } & 18 & 36,667 & 3,043 & (35,286 ; 38,047) \\ \text { Centro13 } & 10 & 37,780 & 2,666 & (35,928 ; 39,632) \\ \text { Centro14 } & 10 & 36,180 & 2,472 & (34,328 ; 38,032) \\ \text { Centro15 } & 10 & 38,430 & 2,303 & (36,578 ; 40,282) \\ \text { Centro23 } & 10 & 38,550 & 1,777 & (36,698 ; 40,402) \\ \text { Centro24 } & 15 & 39,133 & 3,809 & (37,621 ; 40,645) \\ \text { Centro25 } & 10 & 36,380 & 2,523 & (34,528 ; 38,232)\end{array}$

Desv.Est. agrupada $=2,95332$

Comparaciones en parejas de Tukey

Agrupar información utilizando el método de Tukey y una confianza de 95\%

Factor N Media Agrupación

Centro24 $15 \quad 39,133 \quad$ A

Centro03 $10 \quad 38,830 \quad \mathrm{~A}$

Centro23 $10 \quad 38,550 \quad$ A

Centro15 $10 \quad 38,430 \quad \mathrm{~A}$

Centro04 $20 \quad 37,840 \quad$ A

Centro13 $10 \quad 37,780 \quad$ A

Centro05 $18 \quad 36,667 \quad$ A

Centro25 $10 \quad 36,380 \quad$ A

Centro14 $10 \quad 36,180 \quad$ A

Las medias que no comparten una letra son significativamente diferentes

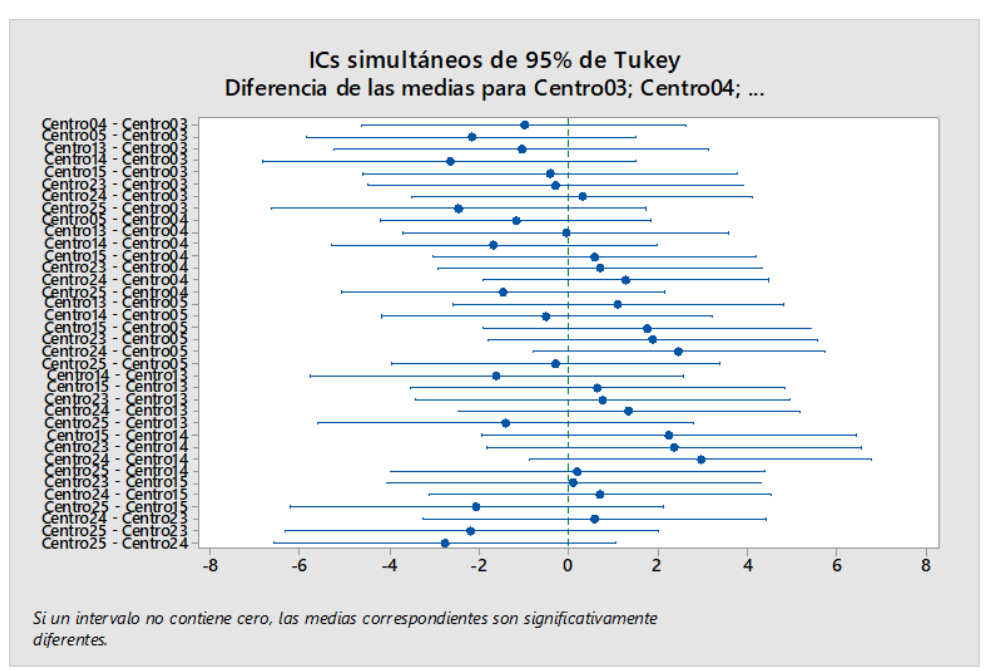

Figura en Apéndice A-18 ANOVA del experimento CIC tipo CENTRO 


\section{A.7. ANOVA Experimento CIC NASA}

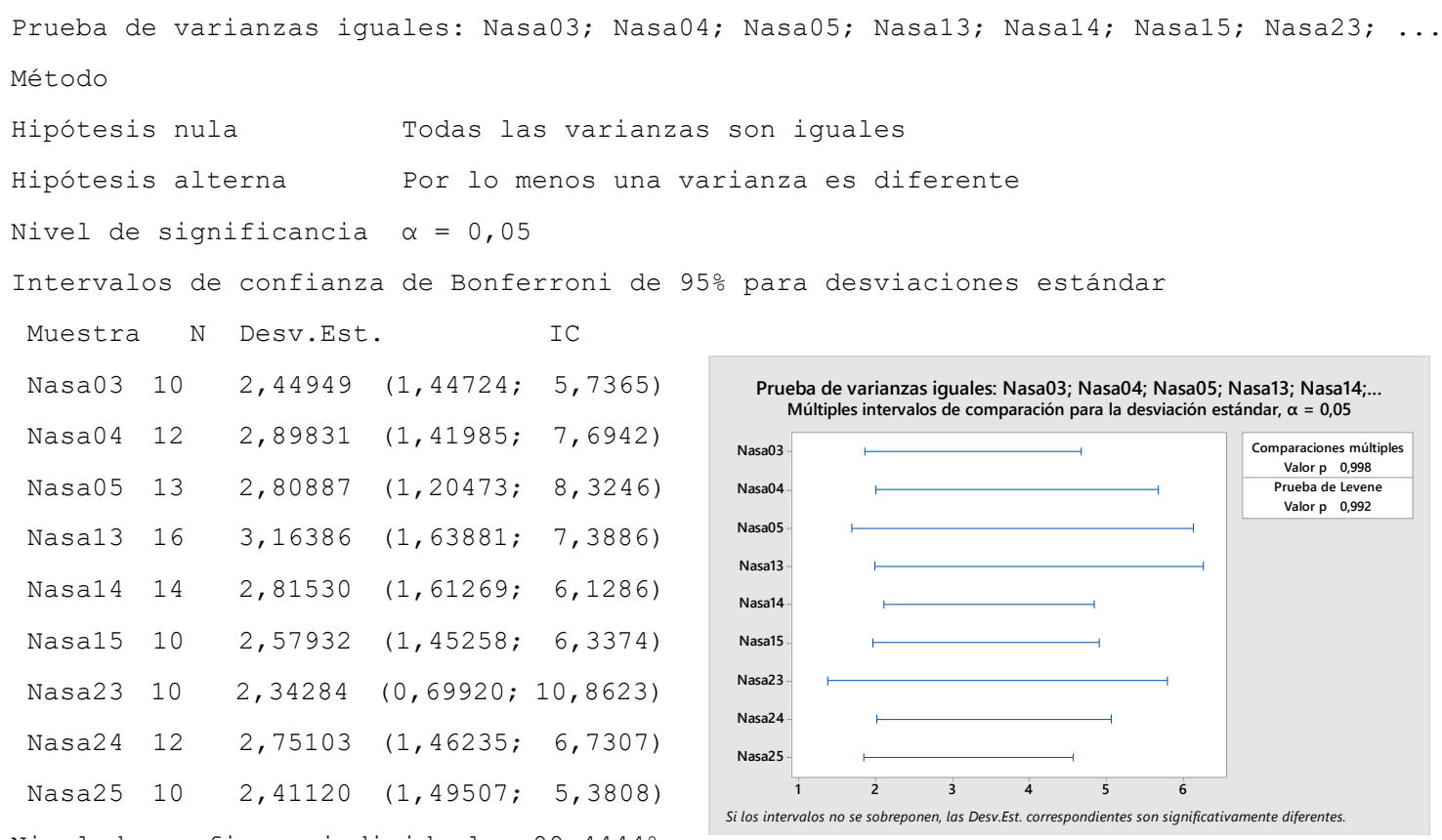

Nivel de confianza individual $=99,4444 \%$

Pruebas

Figura en Apéndice A-19 Prueba de varianzas iguales del Estadística

\section{experimento NASA}

$\begin{array}{lcc}\text { Método } & \text { de prueba } \\ \text { Valor p } & - & 0,998 \\ \text { Comparaciones múltiples } & 0,19 & 0,992 \\ \text { Levene } & \end{array}$

ANOVA unidireccional: Nasa03; Nasa04; Nasa05; Nasa13; Nasa14; Nasa15; Nasa23; Nasa24; Nasa 25

Método

Hipótesis nula Todas las medias son iguales

Hipótesis alterna Por lo menos una media es diferente

Nivel de significancia $\alpha=0,05$

Se presupuso igualdad de varianzas para el análisis.

Información del factor

Factor Niveles Valores

Factor 9 Nasa03; Nasa04; Nasa05; Nasa13; Nasa14; Nasa15; Nasa23; Nasa24; Nasa25

Análisis de Varianza

Fuente GL SC Ajust. MC Ajust. Valor $\mathrm{F}$ Valor $\mathrm{p}$

Factor $8 \quad 112,3 \quad 14,036 \quad 1,86 \quad 0,075$

Error $\quad 98 \quad 739,1 \quad 7,542$

Total $106 \quad 851,4$

Resumen del modelo

$$
\text { R-cuad. R-cuad. }
$$

S R-cuad. (ajustado) (pred)

$2,74627 \quad 13,19 \% \quad 6,10 \% \quad 0,00 \%$

Medias 
Apéndice A. Estudio del CIC

$\begin{array}{lrrrr}\text { Factor } & \text { N } & \text { Media } & \text { Desv.Est. } & \text { IC de 95\% } \\ \text { Nasa03 } & 10 & 38,400 & 2,449 & (36,677 ; 40,123) \\ \text { Nasa04 } & 12 & 37,075 & 2,898 & (35,502 ; 38,648) \\ \text { Nasa05 } & 13 & 37,915 & 2,809 & (36,404 ; 39,427) \\ \text { Nasa13 } & 16 & 39,625 & 3,164 & (38,263 ; 40,987) \\ \text { Nasa14 } & 14 & 37,886 & 2,815 & (36,429 ; 39,342) \\ \text { Nasa15 } & 10 & 38,220 & 2,579 & (36,497 ; 39,943) \\ \text { Nasa23 } & 10 & 36,200 & 2,343 & (34,477 ; 37,923) \\ \text { Nasa24 } & 12 & 38,050 & 2,751 & (36,477 ; 39,623) \\ \text { Nasa25 } & 10 & 36,350 & 2,411 & (34,627 ; 38,073)\end{array}$

Desv.Est. agrupada $=2,74627$

Comparaciones en parejas de Tukey

Agrupar información utilizando el método de Tukey y una confianza de 95\%

$\begin{array}{lrrl}\text { Factor } & \text { N } & \text { Media } & \text { Agrupación } \\ \text { Nasa13 } & 16 & 39,625 & \text { A } \\ \text { Nasa03 } & 10 & 38,400 & \text { A } \\ \text { Nasa15 } & 10 & 38,220 & \text { A } \\ \text { Nasa24 } & 12 & 38,050 & \text { A } \\ \text { Nasa05 } & 13 & 37,915 & \text { A } \\ \text { Nasa14 } & 14 & 37,886 & \text { A } \\ \text { Nasa04 } & 12 & 37,075 & \text { A } \\ \text { Nasa25 } & 10 & 36,350 & \text { A } \\ \text { Nasa23 } & 10 & 36,200 & \text { A }\end{array}$

Las medias que no comparten una letra son significativamente diferentes

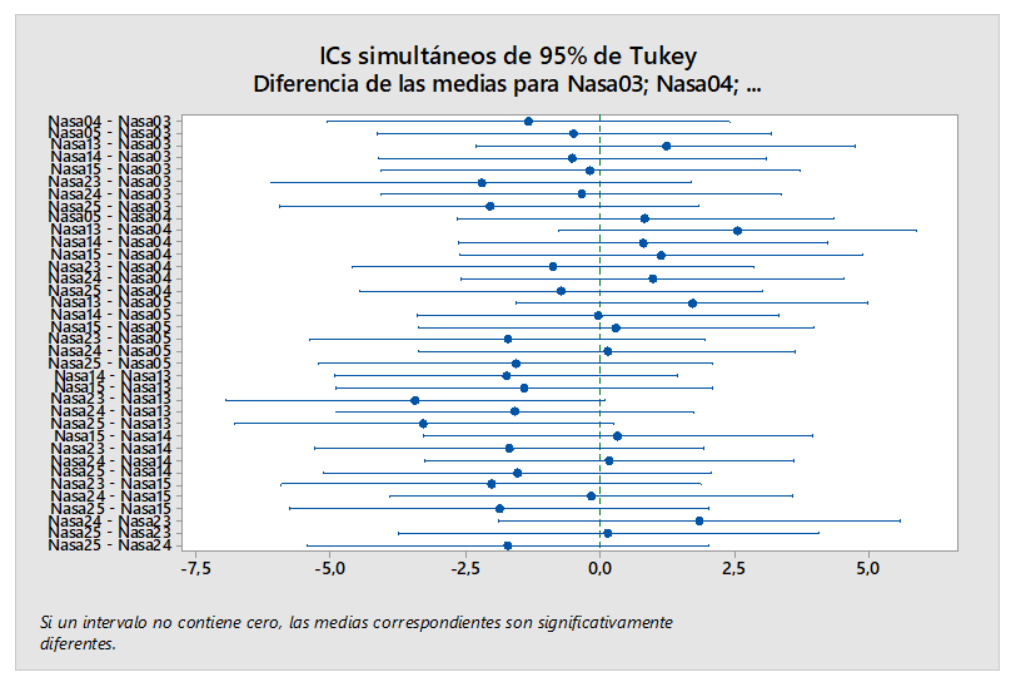

Figura en Apéndice A-20 ANOVA del experimento CIC tipo NASA 


\section{A.8. ANOVA entre Experimentos CIC: LADO; NASA; CENTRO}

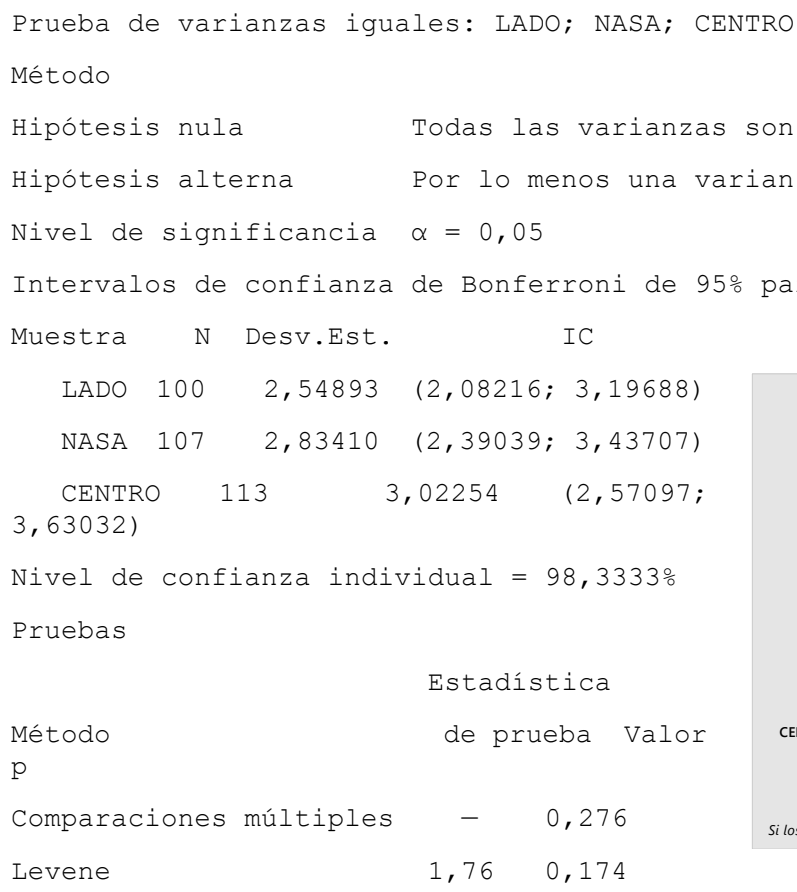

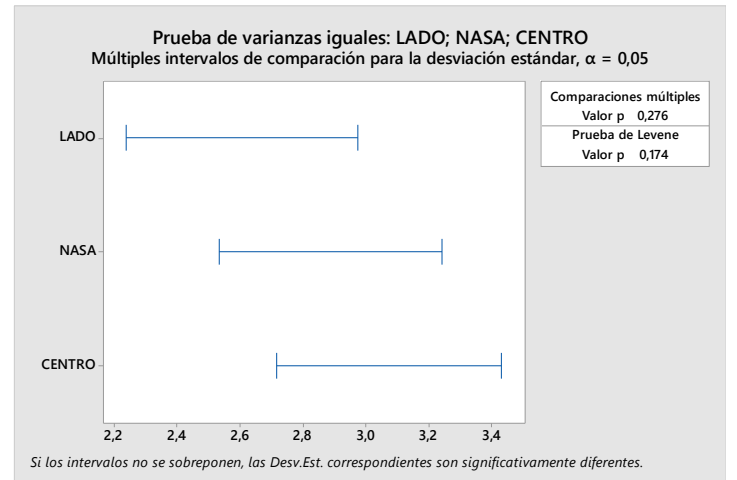

Figura en Apéndice A-21 Prueba de varianzas iguales entre experimentos $\mathrm{CIC}$

ANOVA unidireccional: LADO; NASA; CENTRO

Método

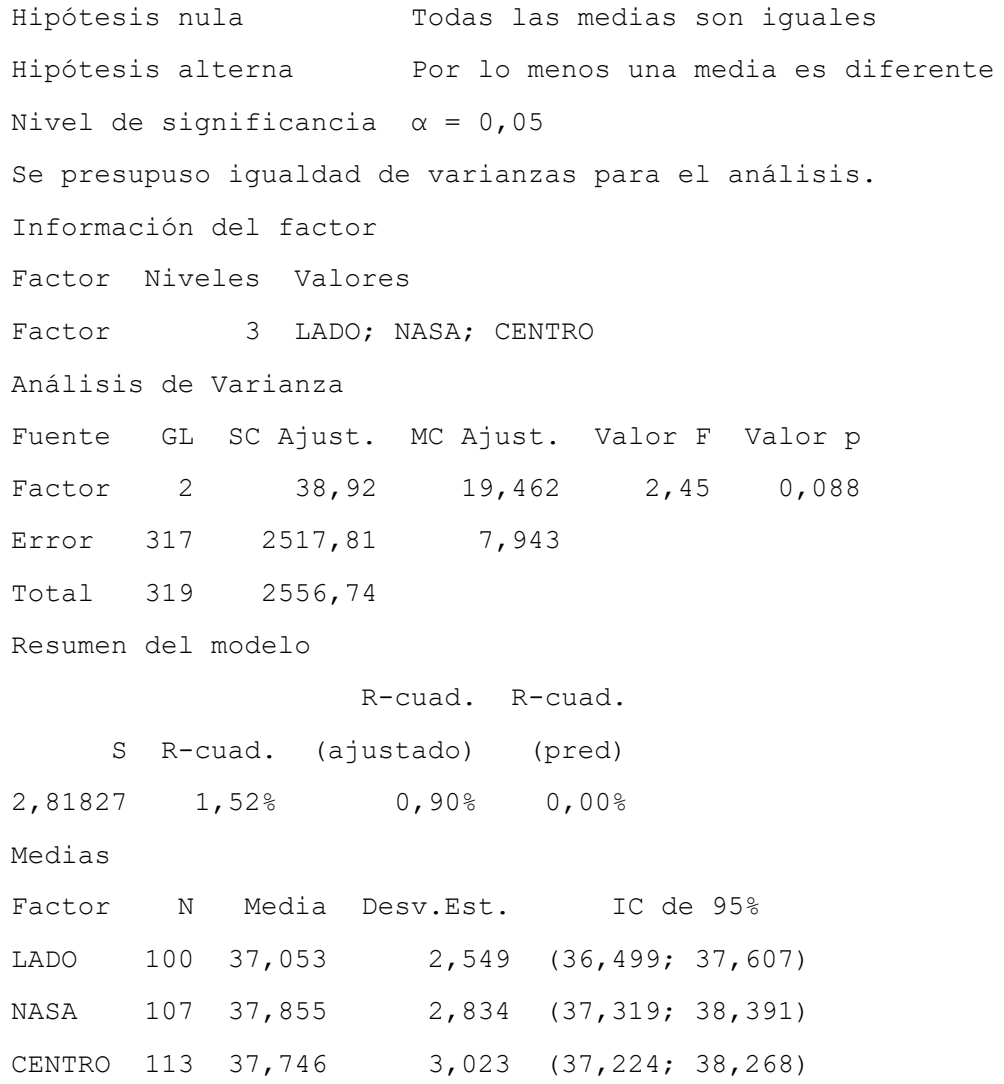


Apéndice A. Estudio del CIC

Comparaciones en parejas de Fisher

Agrupar información utilizando el método LSD de Fisher y una confianza de 95\%

Factor N Media Agrupación

NASA $\quad 107 \quad 37,855 \quad$ A

CENTRO $113 \quad 37,746$ A B

LADO $\quad 100 \quad 37,053 \quad$ B

Las medias que no comparten una letra son significativamente diferentes

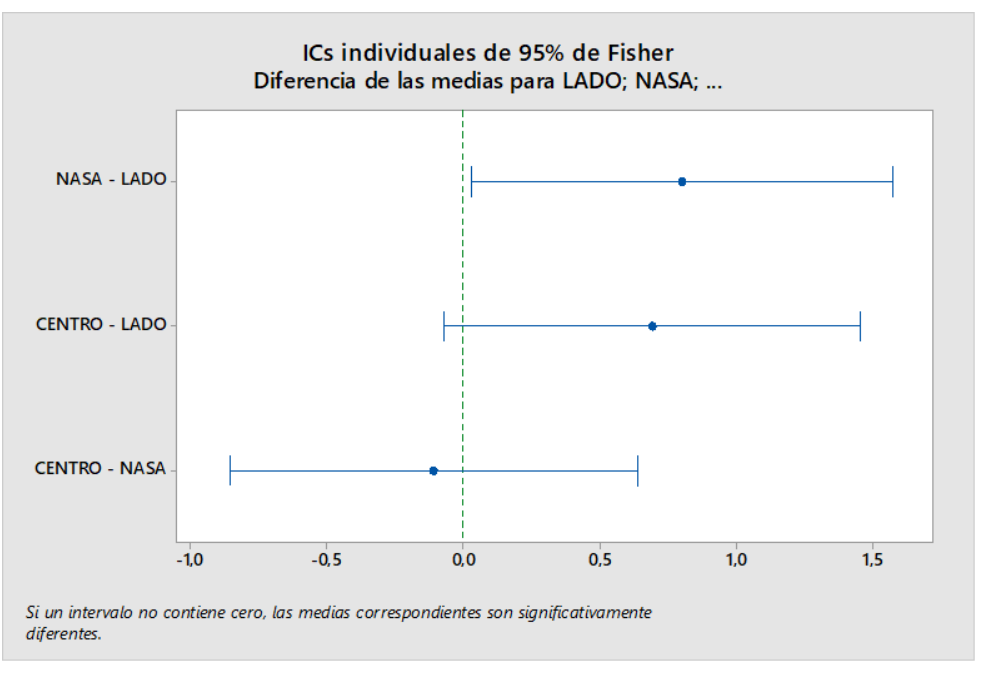

Figura en Apéndice A-22 ANOVA entre experimentos CIC 


\section{A.9. Análisis de Imágenes de Cuello de Botella y Gráficas de Evacuación}

del CIC

En este apéndice de muestran algunos ejemplos de gráficas e imágenes de las simulaciones de evacuación del CIC.

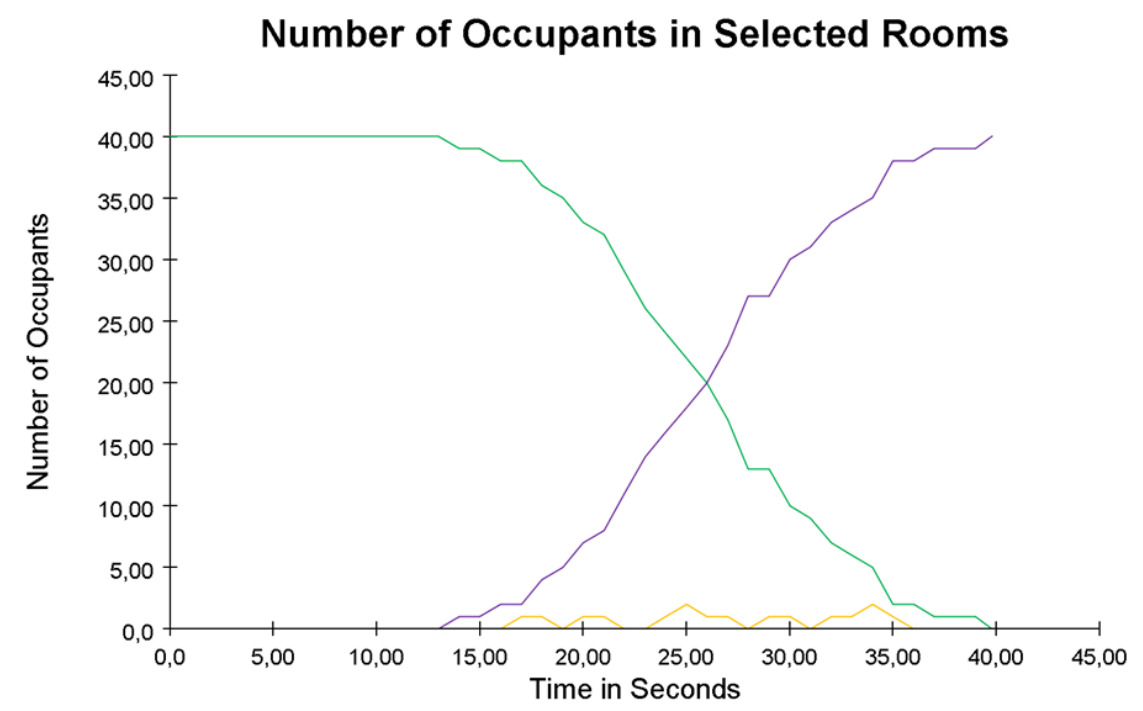

Figura en Apéndice A-23 Gráfica de evacuación/tiempo en una réplica de un experimento NASA 03
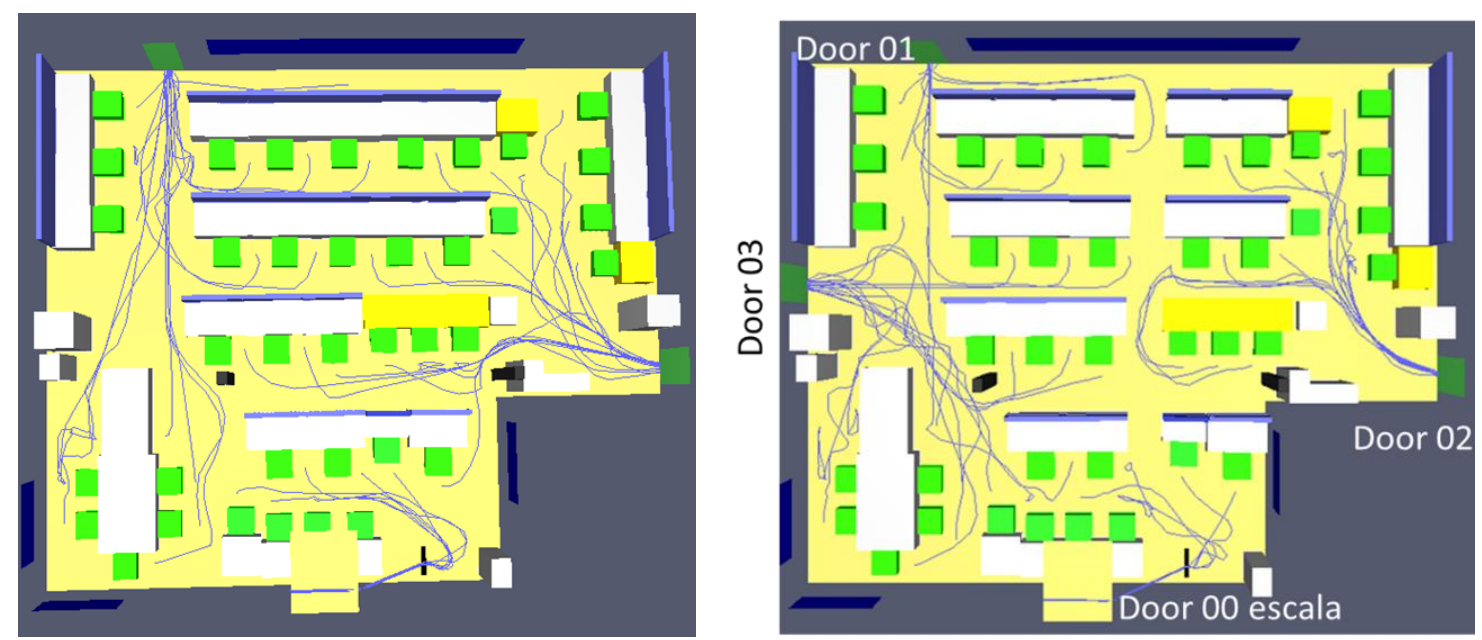

Figura en Apéndice A-24 Rutas seguidas por los individuos en dos réplicas 


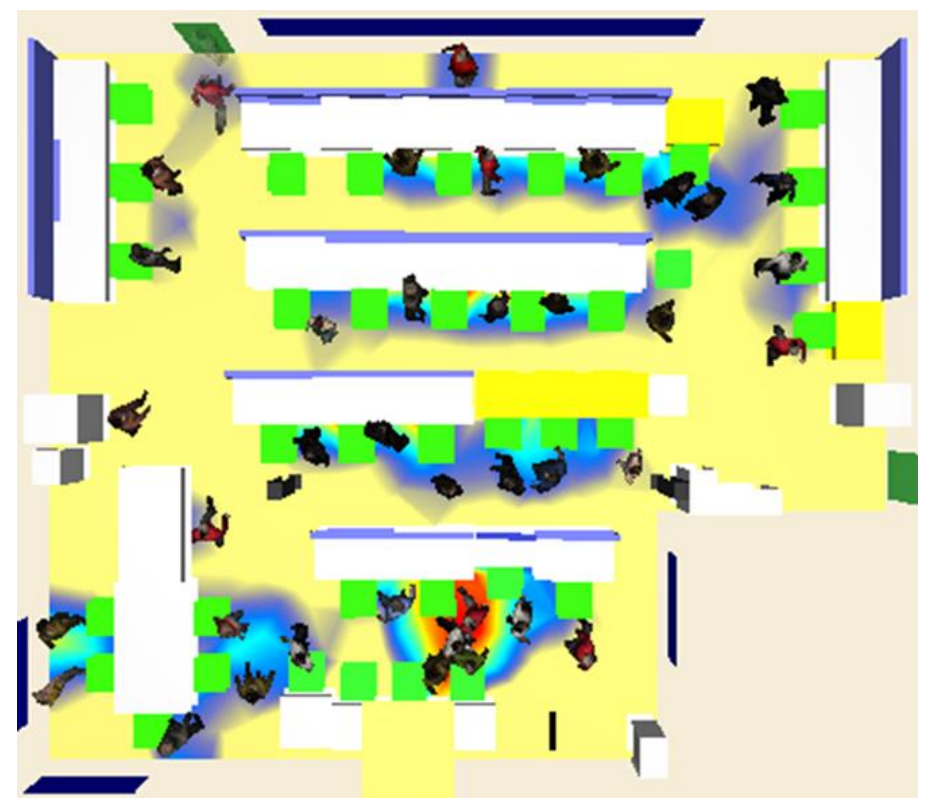

Figura en Apéndice A-25 Vista cenital de una réplica de un experimento NASA 03 en la que se aprecia un cuello de botella en rojo, cuya duración es inferior al $10 \%$ del tiempo total de evacuación

Flow Rates for Selected Doors

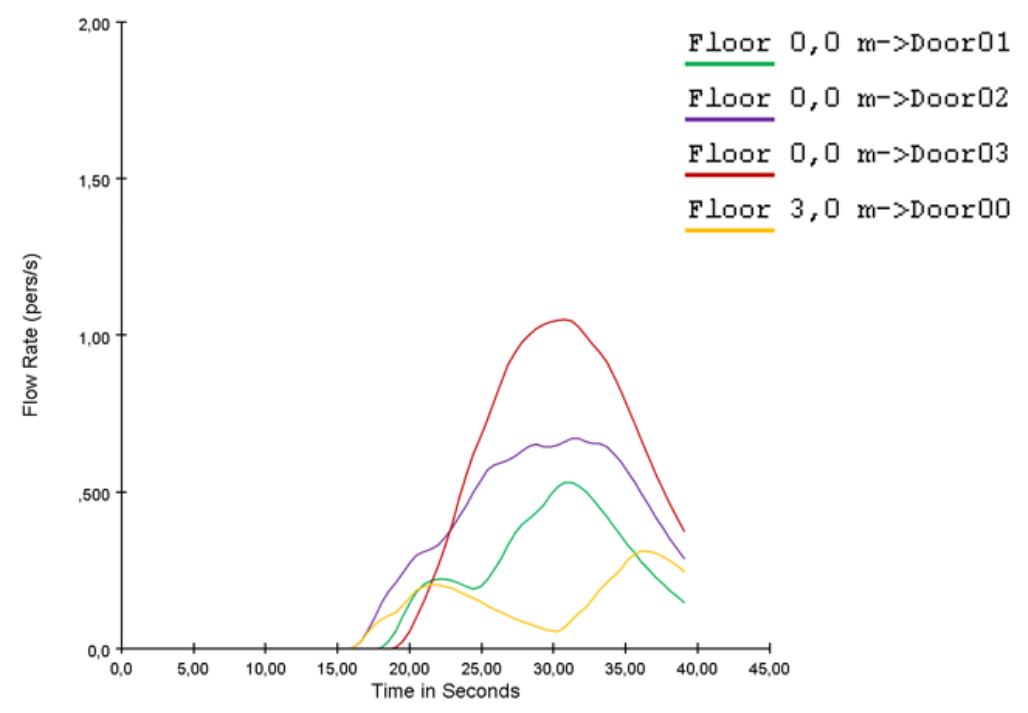

Figura en Apéndice A-26 Gráfica del flujo de personas por las distintas puertas (pers/seg) durante una réplica de un experimento NASA14 


\section{A.10. Instrucción de Organización del Experimento Evacuación en el}

Patio de Aulas

\section{Objetivo de las pruebas}

Ejecución de experimentos de evacuación del CIC simulado de la F-110 y medición de tiempos, para comprobación de validez del software Pathfinder.

Fecha: 03 junio 2016; Horario: 12:45 a 14:20; Ubicación: Patio de aulas ENM

Participantes: 40 alumnos ENM

Directores de la Prueba: CF G. González-Cela, D. Javier Martínez y D. Rafael Carreño Medios necesarios para la realización de las pruebas:

- 12 vallas de atletismo (coordinado con destino Educación Física)

- 10 conos de marcar (coordinado con destino Educación Física)

- Cinta para vallado (coordinado con destino Educación Física)

- Cronómetro (coordinado con destino Educación Física)

- Pupitres y sillas aula 9 (coordinado con Jefatura de Estudios)

\section{Ejecución de las pruebas}

A las 12:45 horas estarán formados en el patio de aulas los 40 alumnos designados para la prueba.

Se designarán 6 alumnos que acompañarán al CB1으 del destino de Educación Física, para la recogida de las vallas de atletismo y conos de marcar en el pañol del edificio Príncipe de Asturias. Los 34 alumnos restantes se dirigirán, coordinados por el CF. González-Cela, al aula №9 donde se recogerán los pupitres y sillas necesarias para la realización de las pruebas.

Sobre el suelo del patio de aulas estarán marcados con tiza una serie de puntos de referencia que permitirán adoptar rápidamente la disposición del CIC que se quiere representar. Una vez colocadas las vallas en las esquinas, con la cinta de vallado se marcará el perímetro del CIC y con los conos se simularán las puertas de escape. Inicialmente se adoptará la disposición de CIC denominada "Centro04" (ver Figura en Apéndice A-29). 
Los alumnos, aleatoriamente, se sentarán en una silla y se efectuarán varias réplicas de evacuación que serán cronometradas. En cada réplica se le notificará a cada alumno individualmente el valor de número aleatorio [distribución Normal $N(20 ; 6)$; mínimo 10, máximo 60], que representa el tiempo de destrucción de

equipos $y$, por tanto, supone el tiempo que cada alumno debe permanecer en su posición (sentado o de pie) antes de comenzar a dirigirse a una puerta para abandonar el compartimento.

Si la disponibilidad de tiempo lo permite, se tratará de adoptar la disposición de CIC denominada "Nasa04" (Figura en Apéndice A-32) y se repetirá el experimento.

Durante la realización de las pruebas se tomarán fotografías y se grabará un vídeo.

\section{$\underline{\text { Recogida }}$}

A la finalización de las pruebas se devolverán los pupitres y sillas al aula №9 quedando en su posición original. Las vallas serán depositadas en su pañol de origen.

\section{Precauciones de seguridad}

Antes del comienzo de los trabajos se advertirá a todo el personal de las normas de seguridad, con el objetivo de evitar accidentes durante el traslado de mobiliario. 


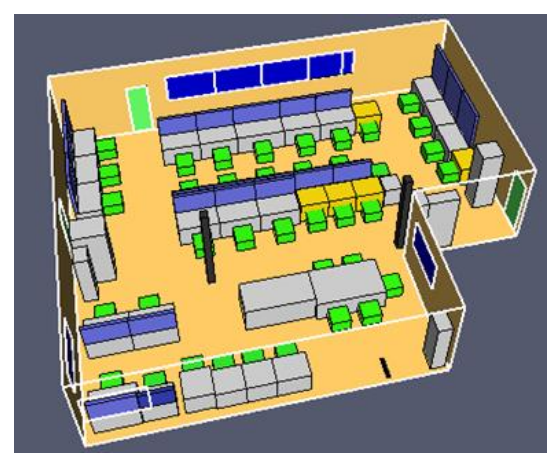

Figura en Apéndice A-27 CIC tipo Centro04

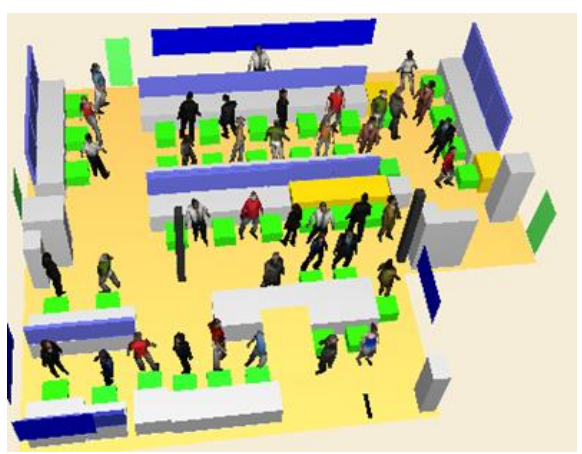

Figura en Apéndice A-28 CIC tipo Centro04 con personal en Zafarrancho de Combate

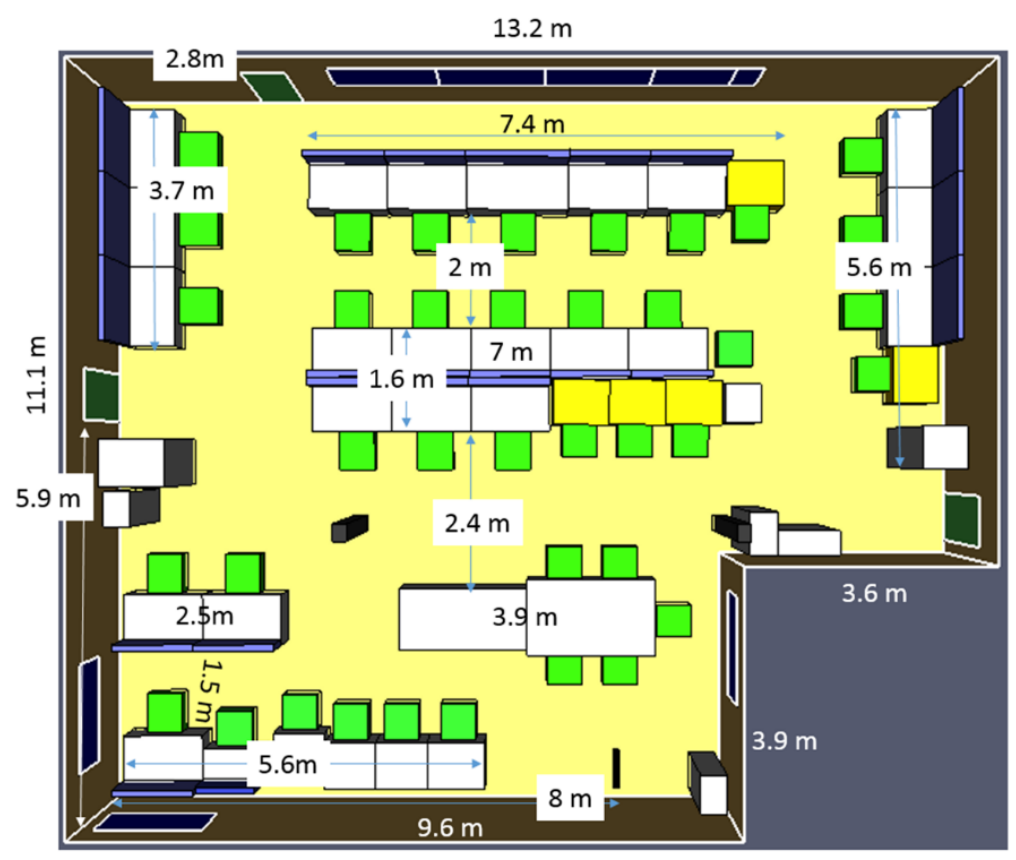

Figura en Apéndice A-29 Dimensiones reales de un CIC tipo Centro04 


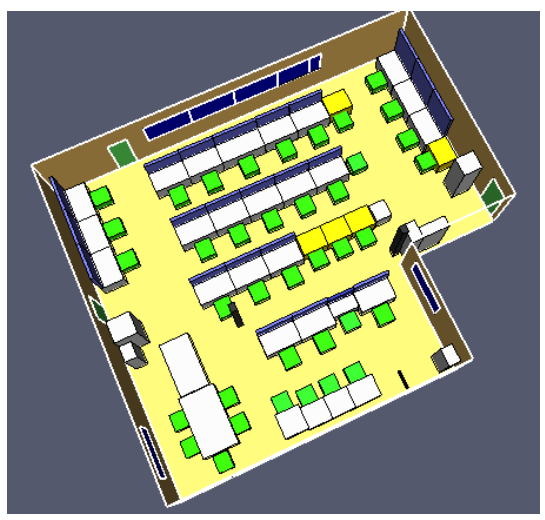

Figura en Apéndice A-30 CIC tipo Nasa04

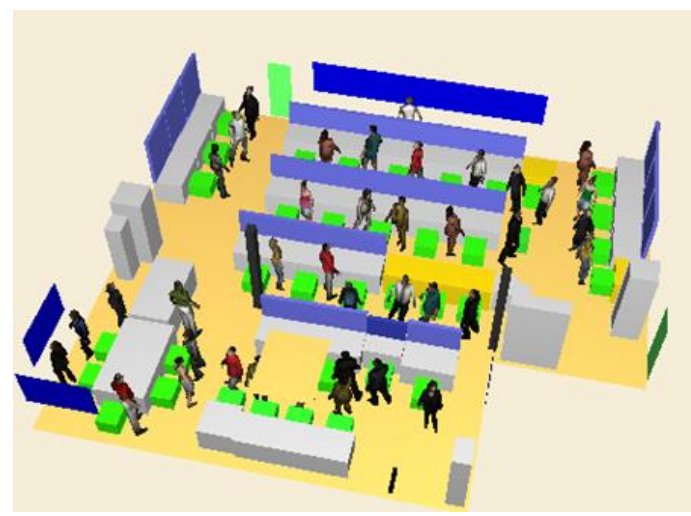

Figura en Apéndice A-31 CIC tipo Nasa04 con el personal en Zafarrancho de Combate

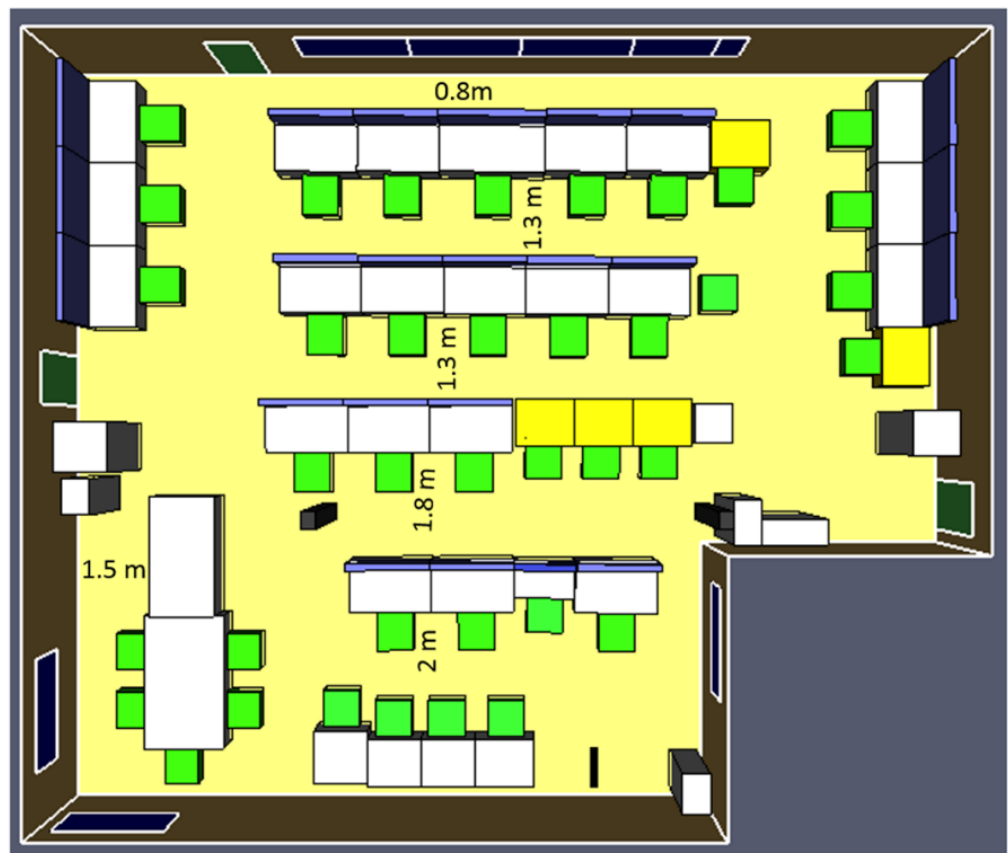

Figura en Apéndice A-32 Dimensiones reales de un CIC tipo Nasa04 


\section{A.11. Tabla de Tiempos Delay Time del Experimento Real de Evacuación}

CIC

\begin{tabular}{|c|c|c|c|c|c|c|c|c|c|c|c|c|c|c|c|c|c|c|c|c|c|}
\hline & \multicolumn{10}{|c|}{ Centro 04} & \multirow[b]{2}{*}{1} & \multicolumn{8}{|c|}{ Nasa 04} & \multirow[b]{2}{*}{19} & \multirow[b]{2}{*}{25} \\
\hline 1 & 31 & 24 & 11 & 28 & 19 & 28 & 23 & 23 & 22 & 26 & & 25 & 16 & 24 & 19 & 11 & 23 & 14 & 24 & & \\
\hline 2 & 19 & 21 & 11 & 19 & 29 & 14 & 28 & 29 & 15 & 21 & 2 & 15 & 26 & 12 & 21 & 29 & 10 & 10 & 19 & 13 & 21 \\
\hline 3 & 13 & 22 & 17 & 19 & 20 & 11 & 10 & 22 & 18 & 21 & 3 & 22 & 21 & 17 & 26 & 16 & 17 & 28 & 21 & 18 & 16 \\
\hline 4 & 31 & 19 & 20 & 26 & 19 & 29 & 19 & 23 & 28 & 19 & 4 & 221 & 21 & 21 & 20 & 15 & 25 & 16 & 25 & 10 & 27 \\
\hline 5 & 20 & 24 & 14 & 14 & 25 & 23 & 22 & 20 & 19 & 26 & 5 & 22 & 24 & 21 & 18 & 21 & 13 & 25 & 22 & 23 & 29 \\
\hline 6 & 12 & 27 & 23 & 32 & 24 & 36 & 15 & 26 & 14 & 24 & 6 & 16 & 13 & 10 & 10 & 16 & 13 & 14 & 16 & 24 & 25 \\
\hline 7 & 25 & 23 & 32 & 29 & 25 & 10 & 21 & 19 & 15 & 32 & 7 & 16 & 17 & 22 & 10 & 20 & 15 & 25 & 10 & 26 & 16 \\
\hline 8 & 19 & 12 & 22 & 17 & 21 & 10 & 29 & 22 & 31 & 12 & 8 & 19 & 16 & 27 & 22 & 20 & 32 & 21 & 14 & 27 & 10 \\
\hline 9 & 16 & 10 & 21 & 19 & 17 & 23 & 24 & 27 & 20 & 15 & 9 & 13 & 31 & 11 & 19 & 23 & 29 & 23 & 18 & 30 & 17 \\
\hline 10 & 10 & 30 & 11 & 23 & 20 & 30 & 26 & 22 & 16 & 20 & 10 & 30 & 18 & 15 & 26 & 10 & 29 & 23 & 10 & 20 & 28 \\
\hline 11 & 18 & 11 & 22 & 24 & 14 & 23 & 18 & 26 & 29 & 21 & 11 & 10 & 10 & 12 & 13 & 22 & 31 & 24 & 21 & 15 & 26 \\
\hline 12 & 14 & 21 & 16 & 26 & 15 & 19 & 33 & 26 & 24 & 17 & 12 & 10 & 18 & 30 & 28 & 22 & 23 & 33 & 23 & 21 & 19 \\
\hline 13 & 28 & 10 & 20 & 20 & 12 & 22 & 29 & 17 & 18 & 16 & 13 & 22 & 11 & 28 & 12 & 16 & 25 & 18 & 22 & 27 & 26 \\
\hline 14 & 26 & 15 & 24 & 21 & 17 & 26 & 24 & 21 & 12 & 25 & 14 & 20 & 14 & 18 & 30 & 23 & 23 & 10 & 17 & 18 & 15 \\
\hline 15 & 11 & 25 & 18 & 23 & 18 & 10 & 21 & 15 & 18 & 18 & 15 & 27 & 25 & 16 & 14 & 20 & 10 & 22 & 14 & 15 & 21 \\
\hline 16 & 13 & 21 & 13 & 27 & 12 & 20 & 21 & 25 & 24 & 30 & 16 & 15 & 25 & 25 & 23 & 13 & 29 & 33 & 19 & 21 & 23 \\
\hline 17 & 22 & 24 & 22 & 23 & 26 & 11 & 19 & 29 & 22 & 15 & 17 & 27 & 23 & 10 & 23 & 10 & 13 & 21 & 16 & 15 & 15 \\
\hline 18 & 16 & 22 & 15 & 14 & 23 & 27 & 17 & 22 & 34 & 19 & 18 & 22 & 19 & 19 & 13 & 19 & 12 & 17 & 15 & 29 & 15 \\
\hline 19 & 15 & 10 & 23 & 13 & 27 & 16 & 16 & 10 & 22 & 18 & 19 & 23 & 16 & 27 & 21 & 18 & 21 & 19 & 27 & 13 & 20 \\
\hline 20 & 18 & 14 & 18 & 14 & 11 & 17 & 26 & 14 & 22 & 17 & 20 & 14 & 22 & 12 & 30 & 13 & 16 & 23 & 20 & 21 & 12 \\
\hline 21 & 24 & 30 & 11 & 20 & 22 & 10 & 23 & 21 & 21 & 16 & 21 & 23 & 29 & 38 & 24 & 23 & 12 & 18 & 14 & 28 & 10 \\
\hline 22 & 24 & 21 & 21 & 30 & 18 & 15 & 18 & 12 & 24 & 26 & 22 & 22 & 21 & 27 & 20 & 24 & 15 & 26 & 24 & 29 & 23 \\
\hline 23 & 20 & 19 & 17 & 18 & 13 & 12 & 10 & 29 & 27 & 27 & 23 & 14 & 14 & 17 & 21 & 13 & 19 & 32 & 17 & 10 & 12 \\
\hline 24 & 25 & 13 & 32 & 21 & 16 & 19 & 33 & 28 & 11 & 20 & 24 & 18 & 24 & 28 & 26 & 23 & 15 & 13 & 20 & 23 & 21 \\
\hline 25 & 19 & 21 & 10 & 27 & 22 & 16 & 25 & 25 & 17 & 27 & 25 & 21 & 16 & 26 & 21 & 20 & 15 & 23 & 19 & 17 & 23 \\
\hline 26 & 22 & 25 & 20 & 17 & 17 & 21 & 27 & 33 & 24 & 15 & 26 & 12 & 19 & 29 & 30 & 19 & 14 & 13 & 23 & 18 & 31 \\
\hline 27 & 24 & 19 & 17 & 25 & 18 & 18 & 24 & 18 & 18 & 16 & 27 & 23 & 14 & 24 & 22 & 22 & 14 & 29 & 22 & 10 & 19 \\
\hline 28 & 25 & 23 & 23 & 18 & 19 & 24 & 15 & 24 & 19 & 11 & 28 & 19 & 17 & 34 & 29 & 17 & 24 & 23 & 12 & 28 & 14 \\
\hline 29 & 24 & 19 & 23 & 18 & 21 & 22 & 17 & 37 & 19 & 18 & 29 & 24 & 24 & 27 & 25 & 35 & 28 & 10 & 20 & 31 & 24 \\
\hline 30 & 26 & 17 & 16 & 21 & 24 & 10 & 19 & 10 & 20 & 25 & 30 & 16 & 22 & 24 & 23 & 14 & 19 & 21 & 25 & 12 & 33 \\
\hline 31 & 21 & 11 & 25 & 27 & 21 & 20 & 26 & 21 & 19 & 13 & 31 & 19 & 10 & 23 & 28 & 24 & 10 & 23 & 26 & 30 & 30 \\
\hline 32 & 21 & 17 & 19 & 15 & 21 & 25 & 32 & 25 & 20 & 37 & 32 & 13 & 15 & 16 & 29 & 11 & 26 & 23 & 25 & 18 & 12 \\
\hline 33 & 17 & 24 & 25 & 10 & 25 & 27 & 27 & 24 & 22 & 25 & 33 & 21 & 14 & 38 & 30 & 25 & 23 & 19 & 10 & 18 & 21 \\
\hline 34 & 16 & 28 & 26 & 15 & 24 & 18 & 17 & 19 & 34 & 14 & 34 & 23 & 16 & 16 & 28 & 31 & 24 & 26 & 28 & 22 & 20 \\
\hline 35 & 20 & 10 & 17 & 12 & 15 & 21 & 27 & 19 & 32 & 22 & 35 & 10 & 14 & 13 & 12 & 31 & 27 & 16 & 18 & 22 & 16 \\
\hline 36 & 11 & 22 & 11 & 22 & 10 & 20 & 27 & 22 & 16 & 16 & 36 & 17 & 26 & 16 & 15 & 27 & 25 & 22 & 24 & 12 & 15 \\
\hline 37 & 26 & 10 & 26 & 23 & 25 & 16 & 24 & 29 & 21 & 16 & 37 & 16 & 28 & 24 & 15 & 21 & 14 & 21 & 23 & 18 & 24 \\
\hline 38 & 27 & 16 & 25 & 20 & 20 & 18 & 18 & 24 & 24 & 10 & 38 & 17 & 14 & 21 & 16 & 19 & 10 & 23 & 16 & 11 & 24 \\
\hline 39 & 15 & 30 & 15 & 16 & 21 & 24 & 24 & 23 & 18 & 20 & 39 & 27 & 28 & 22 & 15 & 24 & 19 & 26 & 10 & 21 & 14 \\
\hline 40 & 24 & 18 & 13 & 20 & 23 & 21 & 23 & 10 & 19 & 34 & 40 & 16 & 20 & 28 & 22 & 15 & 12 & 20 & 10 & 14 & 28 \\
\hline
\end{tabular}

Tabla en Apéndice A-2 Tabla de tiempos generada para los experimentos 



\section{A.12. Prueba T para CIC Centro: Tiempo Real; Tiempo-Pathfinder}

Prueba T e IC de dos muestras: Real CENTRO04; Pathfinder

$\mathrm{T}$ de dos muestras para Real CENTRO04 vs. Pathfinder
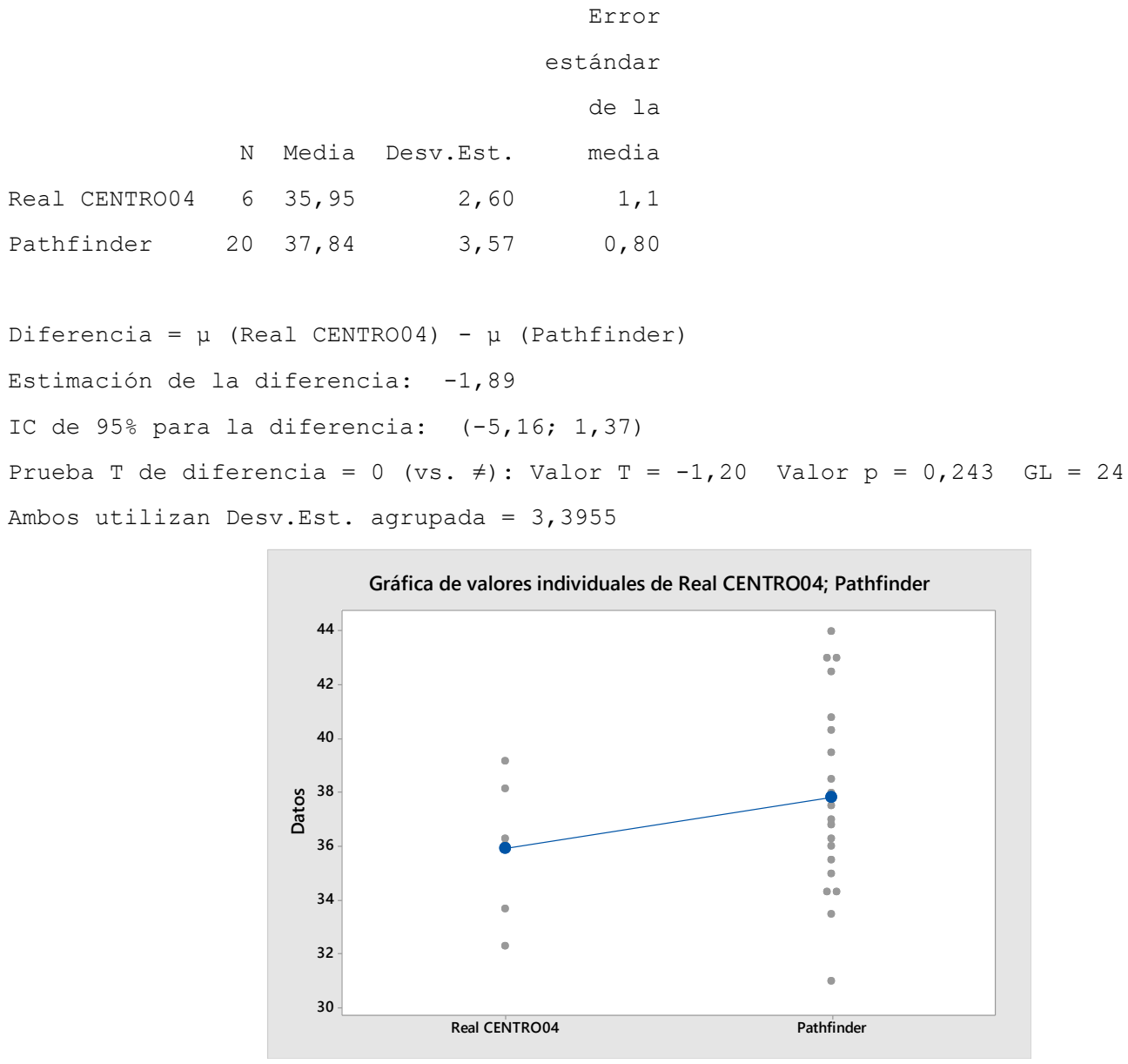

Figura en Apéndice A-33 Gráfica de valores individuales de Real_Centro04 - Pathfinder 




\section{A.14. ANOVA entre Experimentos Comedor: Alt40pt; Alt5; Alt6}
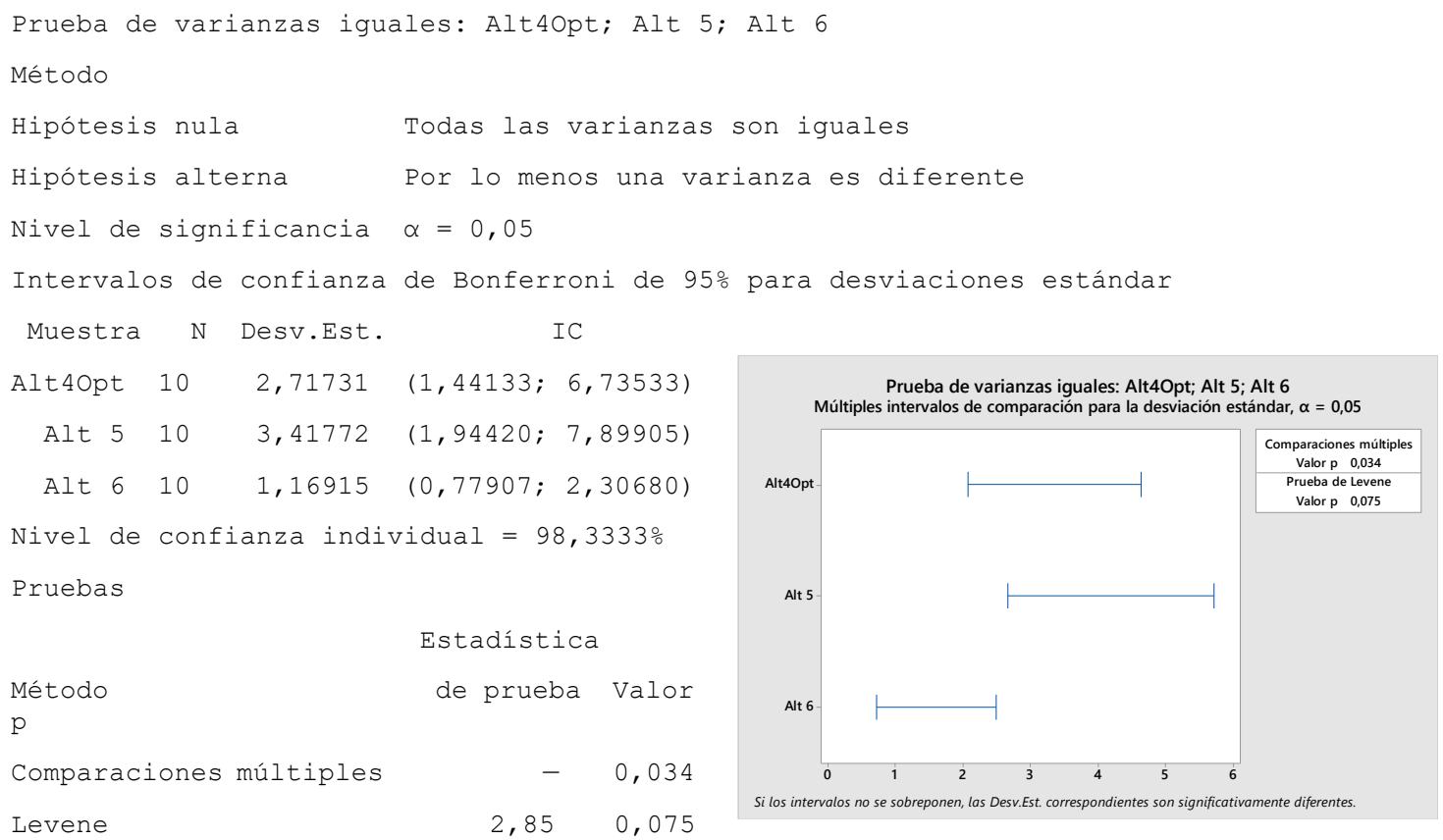

Figura en Apéndice A-35 Prueba de varianzas iguales entre experimentos Comedor

ANOVA unidireccional: Alt4opt; Alt 5;Alt 6

Método

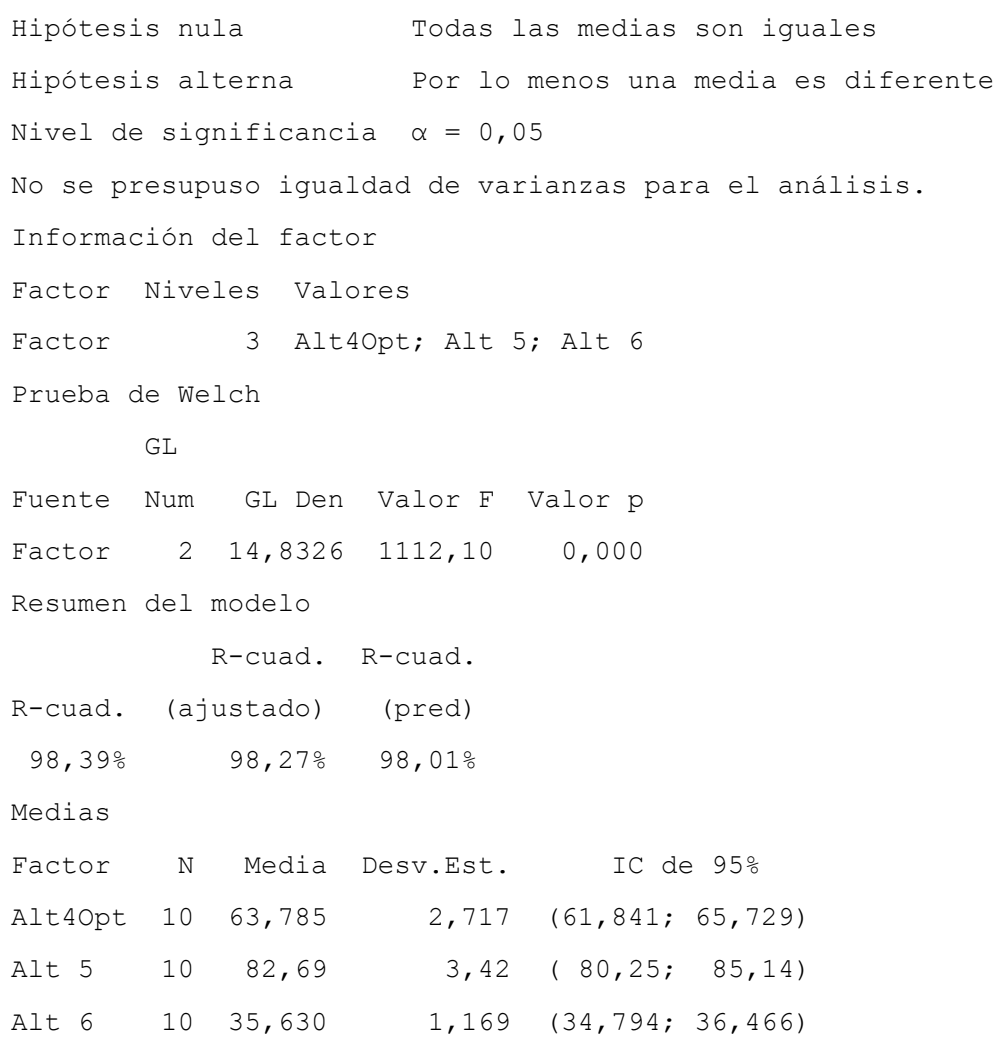

Comparaciones en parejas de Games-Howell

Agrupar información utilizando el método de Games-Howell y una confianza de 95\%

Factor N Media Agrupación 
Apéndice A. Estudio del CIC

$\begin{array}{llrlr}\text { Alt 5 } & 10 & 82,69 & \text { A } & \\ \text { Alt40pt } & 10 & 63,785 & & \text { B } \\ \text { Alt 6 } & 10 & 35,630 & & \text { C }\end{array}$

Las medias que no comparten una letra son significativamente diferentes

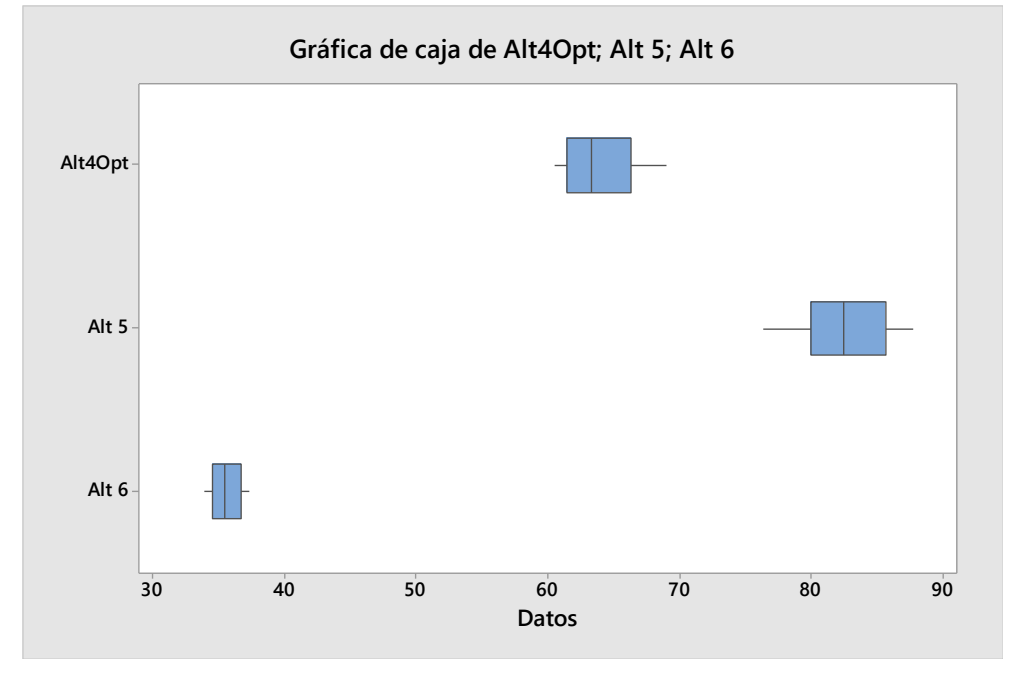

Figura en Apéndice A-36 ANOVA entre experimentos Comedor 


\title{
Apéndice B. Estudio del Comedor
}

\author{
B.1. Extracto de Datos Recopilados en los Buques
}

\section{N. DE PERSONAS QUE LLEGAN AL COMEDOR EN TRAMOS DE 5 MINUTOS}

N.@ DE PERSONAS QUE LLEGAN EN LOS PRIMEROS 5 MINUTOS (0-5min). NUMERO DE PERSONAS QUE LLEGAN ENTRE EL MINUTO 5 Y EL MINUTO $10(5 \mathrm{~min}-10 \mathrm{~min})$. NUMERO DE PERSONAS QUE LLEGAN ENTRE EL MINUTO $10 \mathrm{Y}$ EL MINUTO 15 (10min-15min). NUMERO DE PERSONAS QUE LLEGAN DESPUES DEL MINUTO 15 (más de 15min) finalizado el almuerzo.

\begin{tabular}{|c|c|c|c|c|c|c|c|c|c|}
\hline & \multicolumn{3}{|c|}{ DIA 1} & \multicolumn{3}{|c|}{ DIA 2} & \multicolumn{3}{|c|}{ DIA 3} \\
\hline & desayuno & Comida & cena & desayuno & comida & cena & desayuno & comida & cena \\
\hline $0-5 \mathrm{~min}$ & 4 & 7 & 11 & 5 & 6 & 18 & 3 & 19 & 11 \\
\hline $5 \mathrm{~min}-10 \mathrm{~min}$ & 4 & 8 & 3 & 0 & 3 & 2 & 4 & 11 & 11 \\
\hline $10 \mathrm{~min}-15 \mathrm{~min}$ & 3 & 10 & 6 & 4 & 2 & 7 & 2 & 0 & 8 \\
\hline más de $15 \mathrm{~min}$ & 19 & 5 & 10 & 21 & 19 & 3 & 21 & 0 & 0 \\
\hline
\end{tabular}

\section{TIEMPOS QUE TARDAN EN DESAYUNAR/COMER/CENAR}

Tiempo en minutos y segundos desde que el individuo se sienta para almorzar hasta que se levanta una vez finalizado el almuerzo.

TIEMPO EN
MINUTOS

\section{TIEMPOS EN SER SERVIDOS EN LA LINEA}

Tiempo en minutos y segundos desde que un individuo empieza a ser servido (el cocinero le empieza a servir la primera porción de comida) hasta que sale de la mesa caliente (línea) una vez servido.

\begin{tabular}{|c|c|c|c|c|c|c|c|c|c|}
\hline & \multicolumn{9}{|c|}{$\begin{array}{l}\text { TIEMPO EN } \\
\text { MINUTOS }\end{array}$} \\
\hline & \multicolumn{3}{|c|}{ DIA 1} & \multicolumn{3}{|c|}{ DIA 2} & \multicolumn{3}{|c|}{ DIA 3} \\
\hline & desayuno & comida & cena & desayuno & comida & cena & desayuno & comida & cena \\
\hline $\begin{array}{c}\mathrm{n} 0 \\
\text { Individuo }\end{array}$ & $\begin{array}{l}\text { Tiempo } \\
\text { en ser } \\
\text { servido }\end{array}$ & $\begin{array}{l}\text { Tiempo } \\
\text { en ser } \\
\text { servido }\end{array}$ & $\begin{array}{l}\text { Tiempo } \\
\text { en ser } \\
\text { servido }\end{array}$ & $\begin{array}{l}\text { Tiempo } \\
\text { en ser } \\
\text { servido }\end{array}$ & $\begin{array}{l}\text { Tiempo } \\
\text { en ser } \\
\text { servido }\end{array}$ & $\begin{array}{l}\text { Tiempo } \\
\text { en ser } \\
\text { servido }\end{array}$ & $\begin{array}{l}\text { Tiempo } \\
\text { en ser } \\
\text { servido }\end{array}$ & $\begin{array}{l}\text { Tiempo } \\
\text { en ser } \\
\text { servido }\end{array}$ & $\begin{array}{l}\text { Tiempo } \\
\text { en ser } \\
\text { servido }\end{array}$ \\
\hline 1 & 2,33 & 0,38 & 0,55 & 0,92 & 0,68 & 0,40 & 0,82 & 0,92 & 0,92 \\
\hline 2 & 1,38 & 0,58 & 0,53 & 3,10 & 0,42 & 0,60 & 0,63 & 0,82 & 0,57 \\
\hline$\ldots$ & 2,13 & 0,55 & 0,48 & 9,43 & 0,55 & 0,57 & 7,70 & 1,03 & 0,73 \\
\hline 30 & 0,78 & 0,92 & 0,55 & 5,20 & 0,68 & 0,68 & 2,75 & 0,97 & 0,68 \\
\hline
\end{tabular}




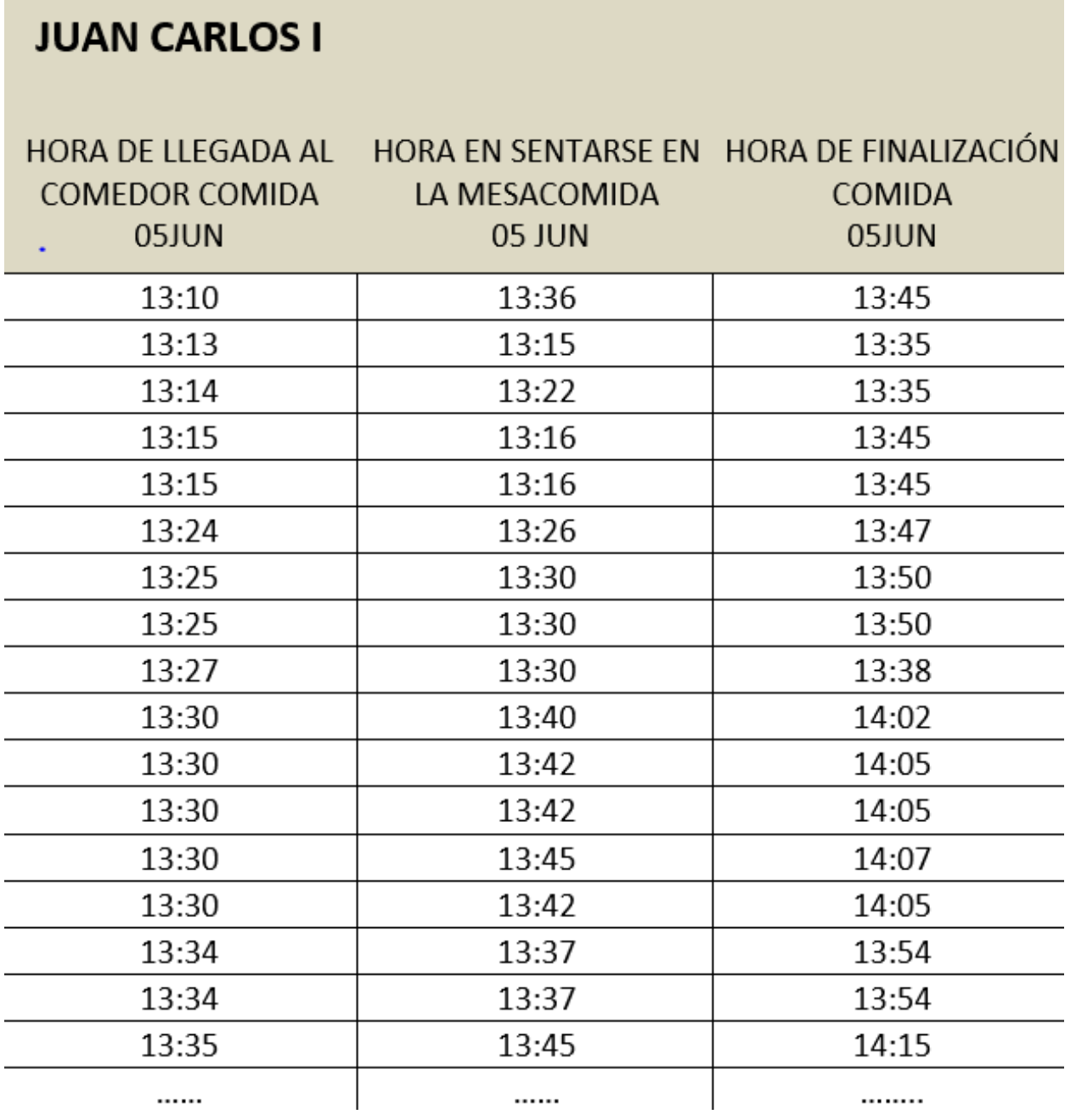




\section{B.2. Gráficas de Probabilidad para Tiempo Línea Desayuno F-103}

Gráficas de probabilidad de bondad de ajuste de los tiempos en línea para el desayuno en la F-103. De la muestra se han eliminado los datos atípicos (dos).
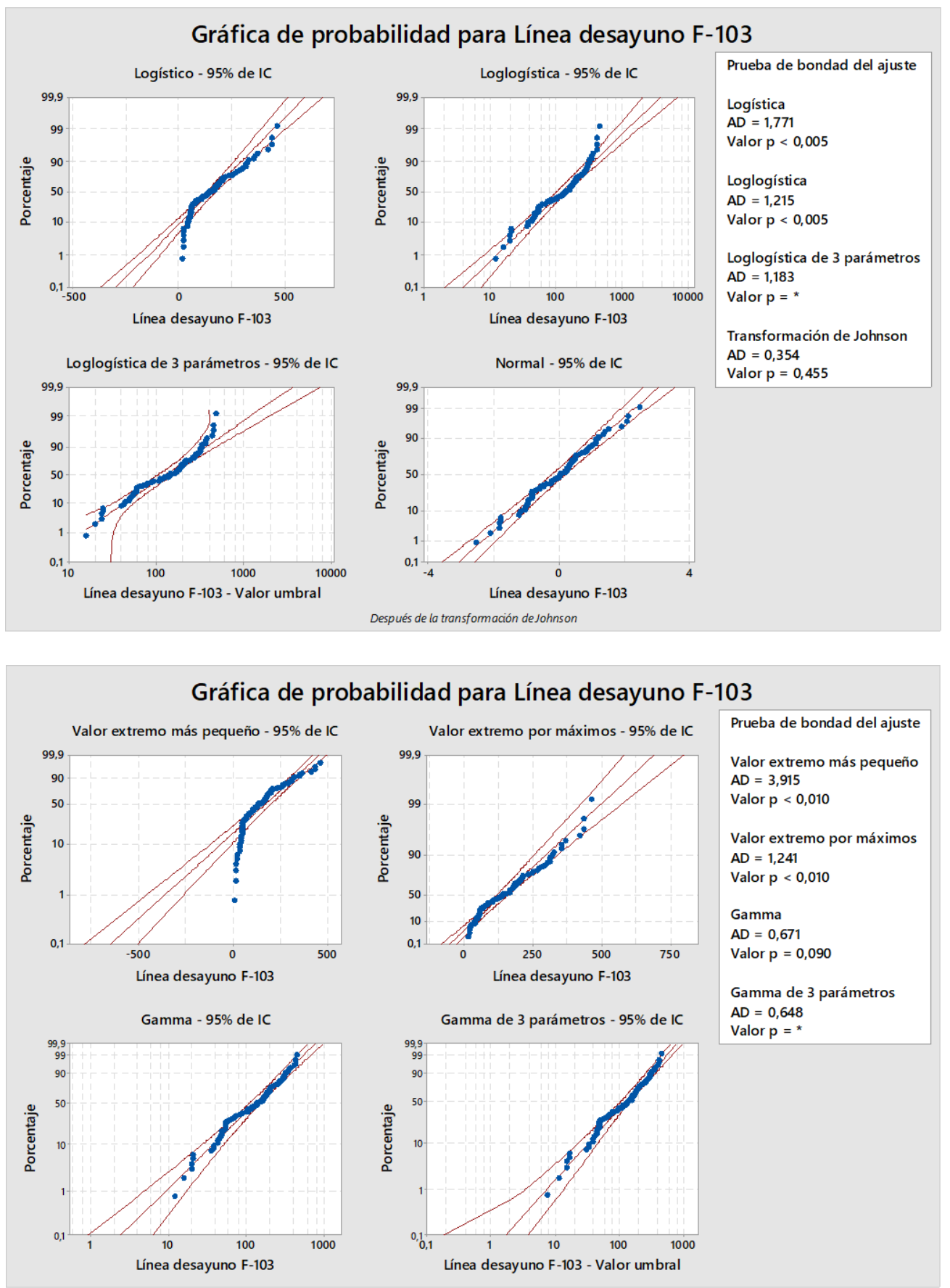

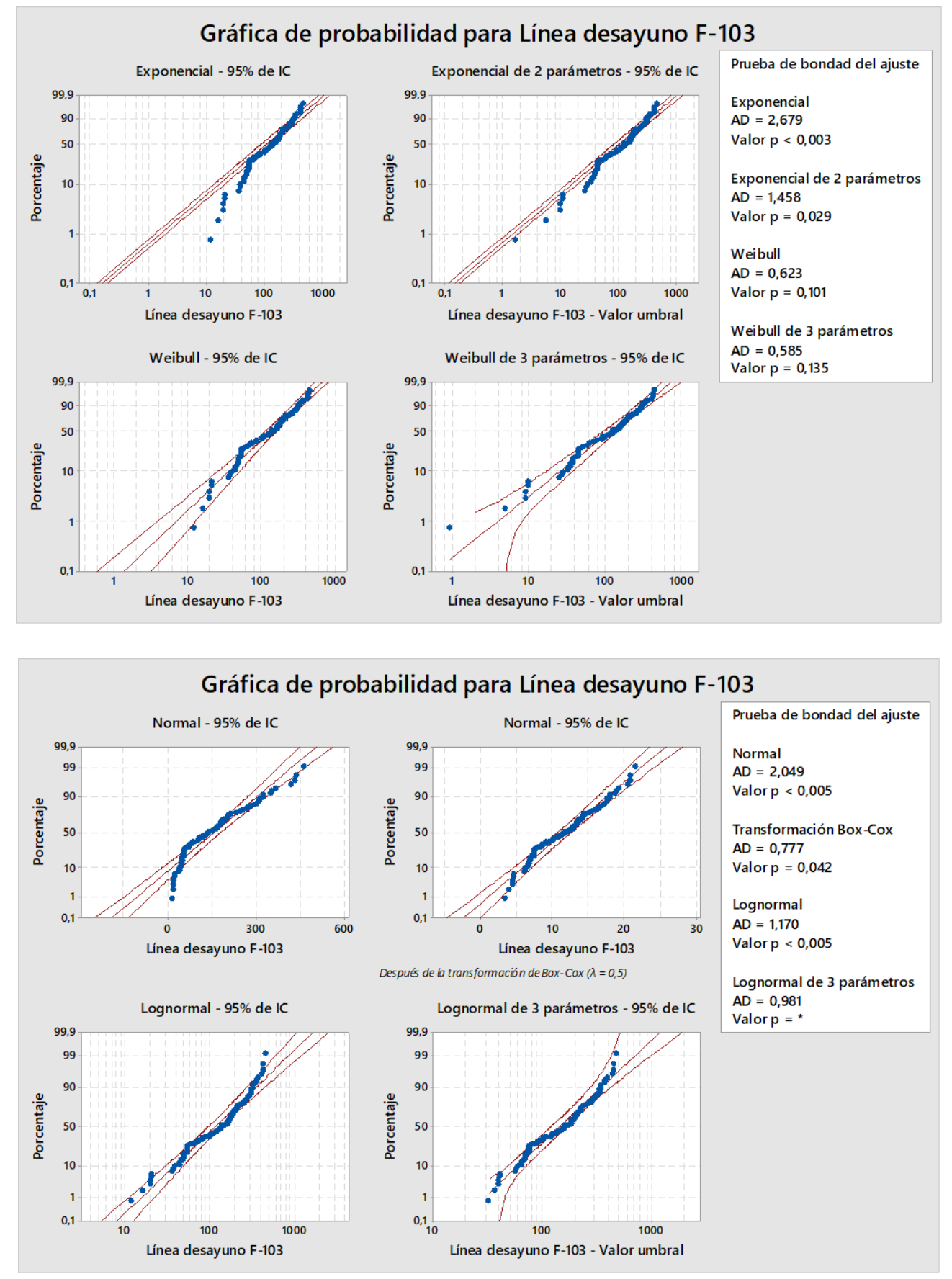


\section{B.3. Gráficas de Probabilidad para Tiempo Línea Desayuno F-105}

Gráficas de probabilidad de bondad de ajuste de los tiempos en línea para el desayuno en la F-105.
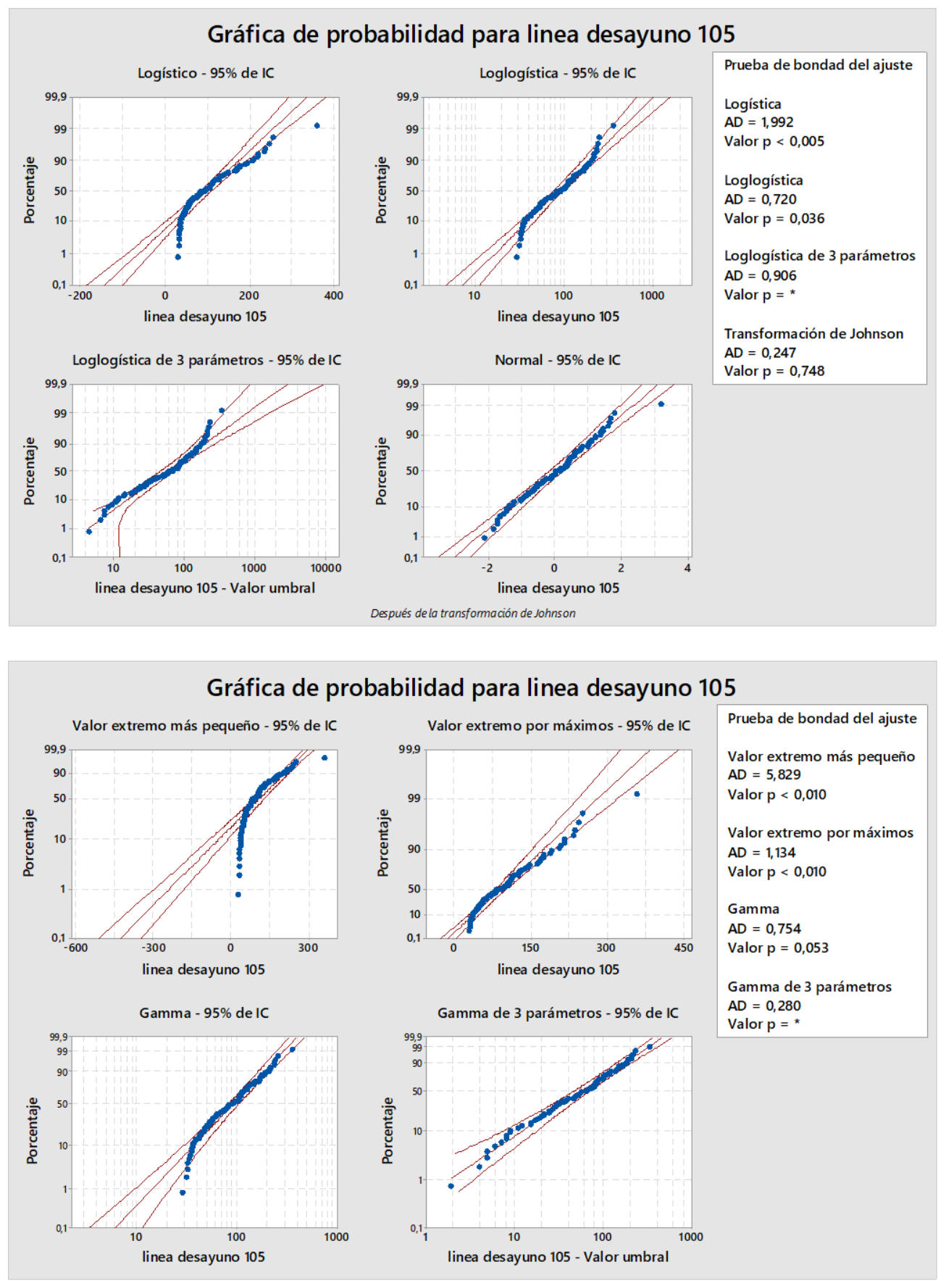

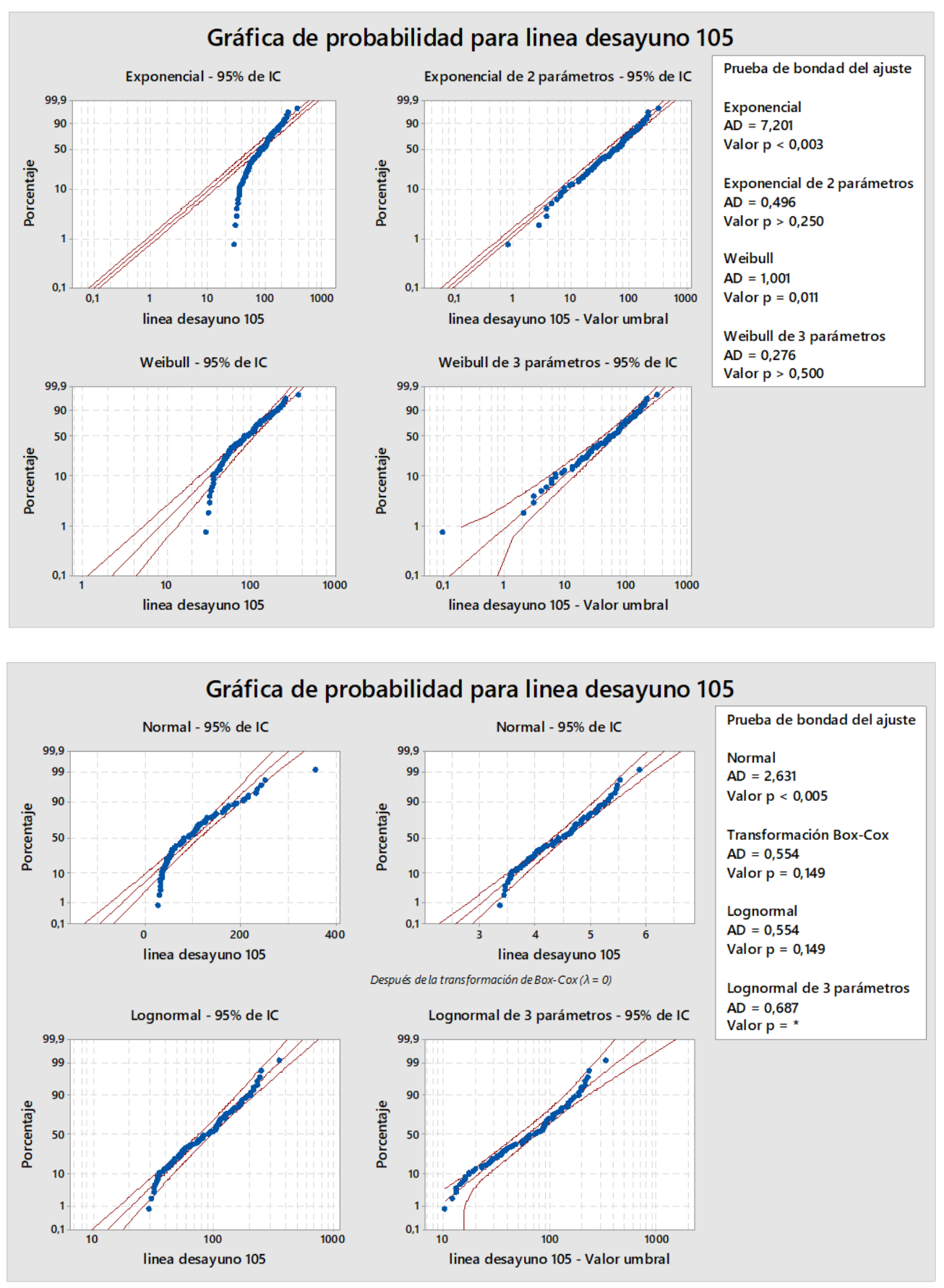


\section{B.4. Pruebas de hipótesis para los Tiempos en la Línea}

Prueba de Mann-Whitney e IC: T. línea desayuno F-103; T. línea desayuno F-105

\section{N Mediana}

T. línea desayuno F-103 90 140,50

T. línea desayuno F-105 $90 \quad 87,50$

La estimación del punto para $\eta 1$ - $\eta 2$ es 41,00

95,0 El porcentaje IC para $\eta 1$ - $\eta 2$ es $(14,00 ; 74,00)$

$W=9283,5$

Prueba de $\eta 1=\eta 2$ vs. $\eta 1 \neq \eta 2$ es significativa en 0,0011

La prueba es significativa en 0,0011 (ajustado por empates)

Prueba T e IC de dos muestras: T. línea comida F-103; T. línea comida F-105

$\mathrm{T}$ de dos muestras para T. línea comida F-103 vs. T. línea comida F-105

Error

estándar

de la

N Media Desv.Est. media

T. línea comida F-103 90 36,5 13,1 1,4

T. línea comida F-105 $90 \quad 57,8 \quad 18,9 \quad 2,0$

Diferencia $=\mu(T$. línea comida F-103) - $\mu$ (T. Iínea comida F-105)

Estimación de la diferencia: $-21,31$

IC de 95\% para la diferencia: $(-26,09 ;-16,53)$

Prueba $\mathrm{T}$ de diferencia $=0$ (vs. $\neq$ ): Valor $\mathrm{T}=-8,80$ Valor $\mathrm{p}=0,000$ GL $=158$

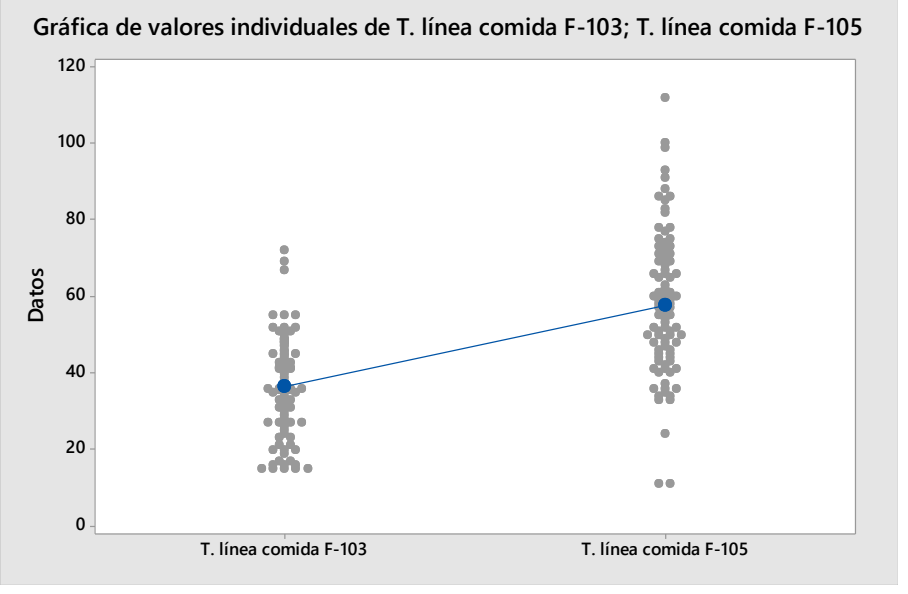

Prueba T e IC de dos muestras: T. línea cena F-103; T. línea cena F-105

T de dos muestras para T. línea cena F-103 vs. T. línea cena F-105 
Apéndice B. Estudio del Comedor
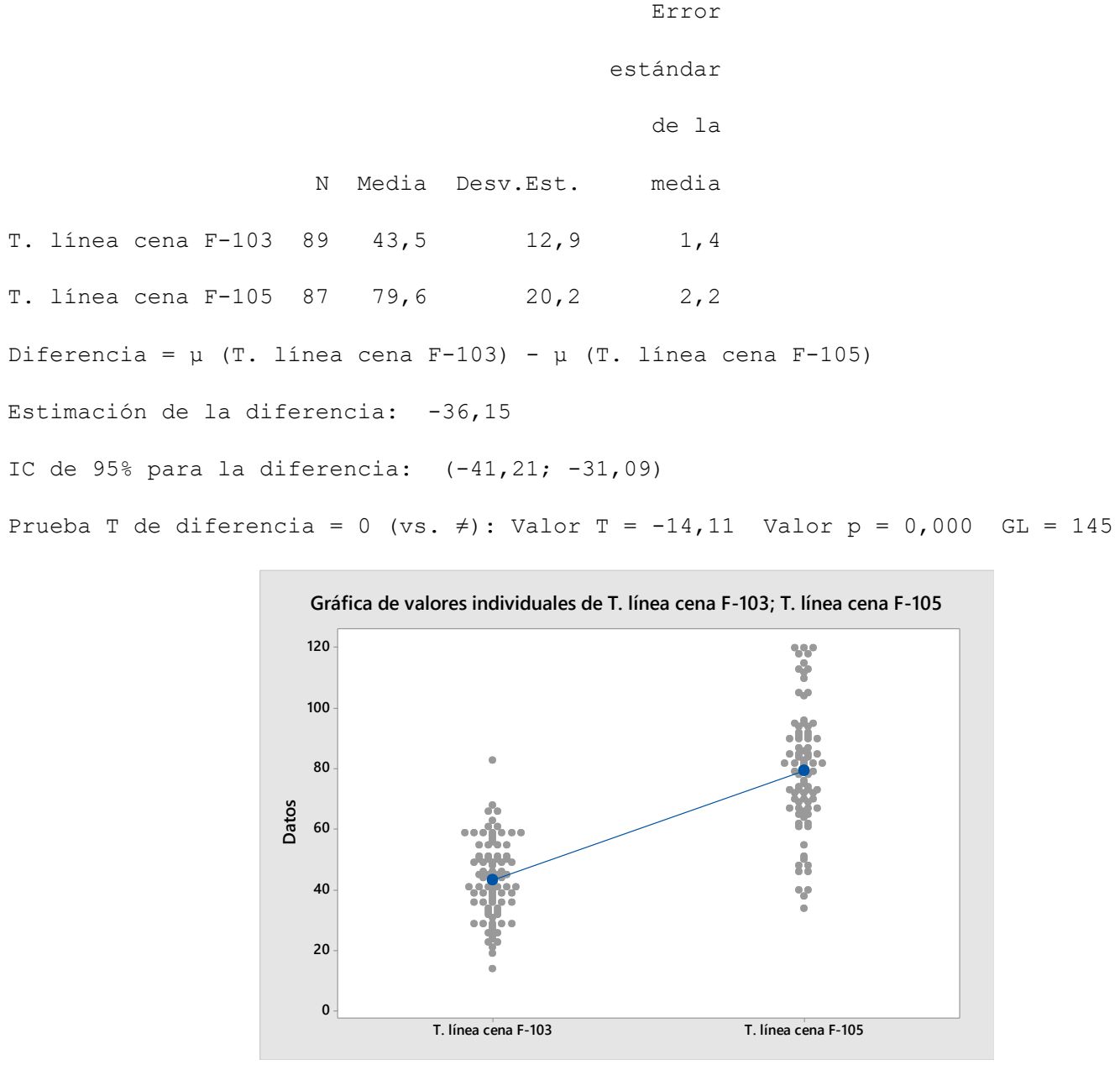

Prueba T e IC de dos muestras: T. línea comida F-103; T. línea cena F-103

$T$ de dos muestras para T. línea comida F-103 vs. T. línea cena F-103

Error

estándar

de la

N Media Desv.Est. media

T. línea comida F-103 $90 \quad 36,5 \quad 13,1 \quad 1,4$

T. línea cena F-103 $89 \quad 43,5 \quad 12,9 \quad 1,4$

Diferencia $=\mu(\mathrm{T}$. línea comida F-103) - $\mu$ (T. línea cena F-103)

Estimación de la diferencia: $-7,02$

IC de 95\% para la diferencia: $(-10,85 ;-3,18)$

Prueba $\mathrm{T}$ de diferencia $=0$ (vs. $\neq$ ) : Valor $\mathrm{T}=-3,61$ Valor $\mathrm{p}=0,000 \mathrm{GL}=176$ 
Apéndice B. Estudio del Comedor

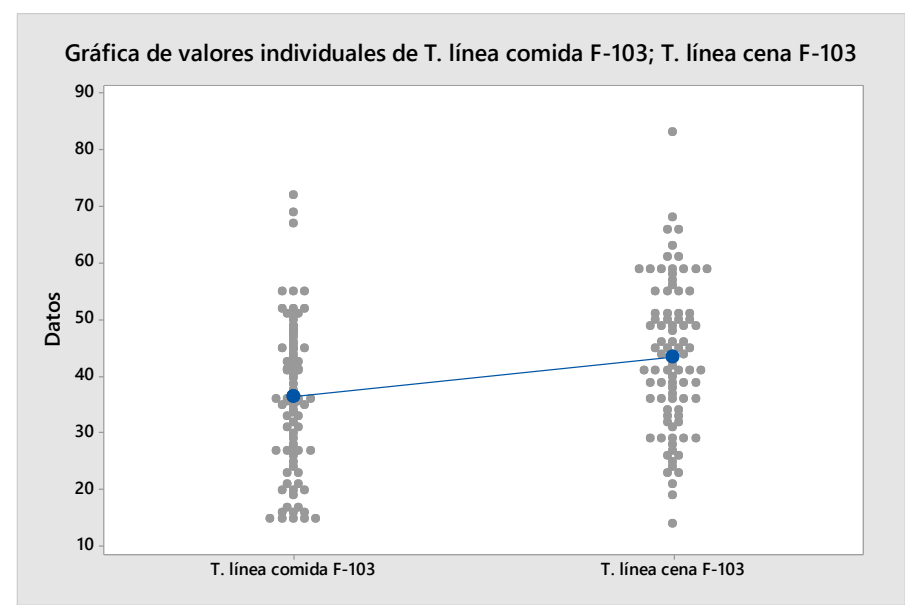

Prueba T e IC de dos muestras: T. línea comida F-105; T. línea cena F-105

T de dos muestras para T. línea comida F-105 vs. T. línea cena F-105

$$
\text { Error }
$$

estándar

de la

N Media Desv.Est. media

T. línea comida F-105 $90 \quad 57,8 \quad 18,9 \quad 2,0$

T. línea cena F-105 $87 \quad 79,6 \quad 20,2 \quad 2,2$

Diferencia $=\mu(\mathrm{T}$. línea comida F-105) - $\mu$ (T. línea cena F-105)

Estimación de la diferencia: $-21,85$

IC de 95\% para la diferencia: $(-27,66 ;-16,05)$

Prueba $\mathrm{T}$ de diferencia $=0$ (vs. $\neq$ ): Valor $\mathrm{T}=-7,43$ Valor $\mathrm{p}=0,000$ GL $=173$

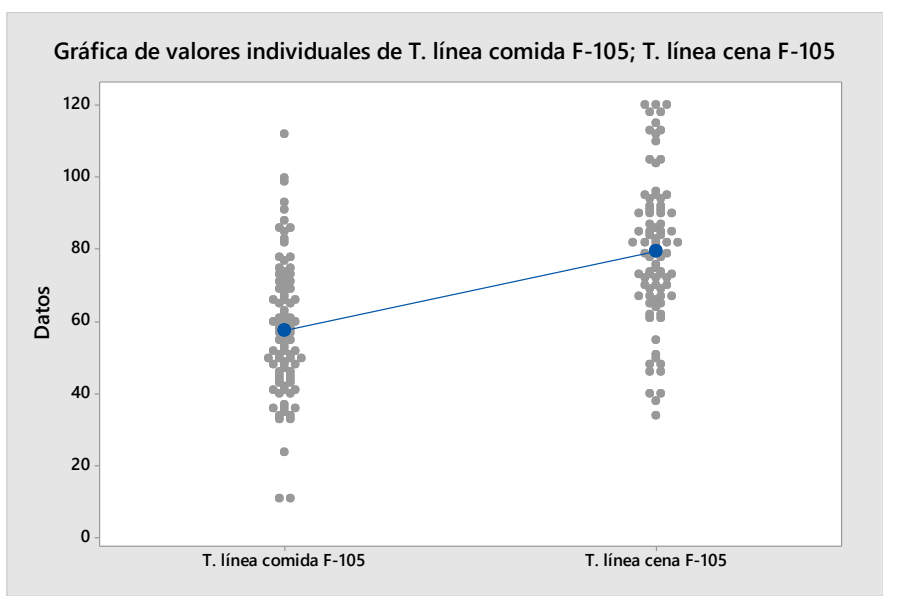





\section{B.5. Instrucción de Funcionamiento del Comedor de Marinería}

EJEMPLO DE INSTRUCCIÓN DE REPARTO DE COMIDAS EN EL COMEDOR DE MARINERÍA.

1) TEXTO:

Todas las comidas del personal embarcado se efectuarán en las áreas y compartimentos que rodean a la cocina: Comedor de Oficiales y Suboficiales, a popa; Comedor de Marinería, a babor; y Comedor de la Fuerza de Desembarco, a proa.

Existe prohibición expresa de utilizar a tal efecto los camarotes, camaretas, alojamientos, salas de estar, salas de lectura, bibliotecas, locutorio multimedia y otros compartimentos del buque, salvo que exista una autorización expresa del Segundo Comandante para casos y circunstancias puntuales.

2) Durante las comidas en el Comedor de Marinería queda prohibido todo tipo de racionamiento que sea ajeno al proporcionado por la cocina del buque, excepto las dietas especiales, prescritas por la Jefatura de Sanidad, que se harán aquí o en el hospital para el personal que se encuentre ingresado.

3) NORMAS:

a) El Grupo de Habitabilidad, dirigido por el Suboficial de Habitabilidad y/o el personal de la Guardia Interior, dirigido por el Suboficial de la Guardia Interior, alistará el Comedor de Marinería, la Mesa Caliente y el Lavaplatos, con antelación suficiente al inicio del reparto:

i) Mesas y sillones limpios.

ii) Jarras de agua, convoys y servilleteros llenos y repartidos por las mesas.

iii) Televisores apagados, música con el volumen bajo, y ventilación en marcha.

iv) Comedor desalojado.

v) Enseres del rancho limpios, secos y dispuestos para su utilización.

b) El Suboficial de Habitabilidad y/o Suboficial de Guardia Interior pasará revista al personal encargado de realizar el reparto de la comida. La uniformidad de este personal será:

i) Pantalón de faena azul.

ii) Chaqueta de repostero blanca.

iii) Gorro de cocinero transpirable (blanco). 
c) El personal implicado en el reparto de las comidas realizará éstas antes que el resto de la dotación según el horario establecido.

d) El Oficial de guardia, Suboficial de Habitabilidad y/o Suboficial de Guardia Interior estarán presentes en el reparto, coordinando con la Cocina las necesidades para el reparto de la comida y con el personal del Lavaplatos la reposición de los enseres del rancho, para que no se produzcan retenciones en la Línea. Además, velarán por el cumplimiento del horario establecido durante todo el reparto de la comida.

e) El reparto en la Línea comenzará por el personal de guardia/guardia entrante, y a continuación el resto por antigüedad.

f) Dado el elevado número de Marinería a bordo y que la capacidad del Comedor no es suficiente para que toda la dotación coma en un sólo turno, todo el personal evitará, al finalizar la comida, extenderse en la sobremesa, a fin de permitir que coma el mayor número de personal de marinería y tropa en el menor tiempo posible y evitar que se dilate mucho el reparto de la misma.

g) Durante los repartos se formará una cola de personal para pasar por la Línea y recoger los cubiertos, bandeja, vaso, etc. y proseguir hacia la Mesa Caliente para que les sea servida la comida.

h) En la citada cola, los Cabos Mayores y Cabos Primeros tienen preferencia sobre los demás y, a su vez, los Cabos tienen preferencia de paso sobre los Marineros y Soldados.

i) El personal de Marinería deberá comportarse de manera correcta, siguiendo las instrucciones del personal encargado del reparto, a fin de facilitar su labor.

j) Se prohíbe comer vestido con mono de trabajo, traje de frío, ropa de paisano, chaquetón de mar, mal aseado o incorrectamente uniformado.

k) Cada comensal, una vez que haya terminado, será responsable de:

i) Dejar recogida la plaza del Comedor que ha ocupado (no dejar residuos).

ii) Realizar la correcta separación de los residuos inorgánicos en los contenedores dispuestos en el Comedor.

iii) Trasladar la bandeja y enseres con los restos orgánicos hasta el Lavaplatos para su entrega.

I) El personal del Lavaplatos será responsable de: 
i) Recoger la bandeja de los comensales no admitiendo aquellas que contengan residuos inorgánicos.

ii) Separar los cubiertos y vaso/bol para su limpieza.

iii) Arrojar al triturador los residuos orgánicos, cumpliendo sus normas de utilización.

iv) Manejo correcto de la máquina lavaplatos, cumpliendo sus normas de utilización.

v) Reponer los enseres limpios en la Línea.

m) Una vez que haya finalizado el reparto de la comida, se arranchará el Comedor de Marinería, Mesa Caliente y Lavaplatos, se recontarán los enseres y el Suboficial de Habitabilidad y/o Suboficial de Guardia Interior dará la novedad al Oficial de Guardia.

4) TURNOS.

En la mar, normalmente habrá dos turnos de comida y de cena. DOS TURNOS:

El personal entrante de guardia o servicio tendrá prioridad en ambos turnos de comidas.

El personal comenzará y terminará las respectivas comidas dentro de los turnos indicados, desalojando las mesas para que se puedan preparar para el próximo turno.

\section{TURNO CORRIDO:}

El personal entrante de guardia o servicio y las dotaciones de vuelo en alerta o que vayan a estarlo inmediatamente tendrá prioridad en el reparto de las comidas, dado el gran número de personal embarcado.

En puerto, siempre que sea posible, se utilizará el sistema de los dos turnos, tanto en la Base como fuera de ella. 



\section{B.6. Informe Resumen de la Duración de las Ingestas}
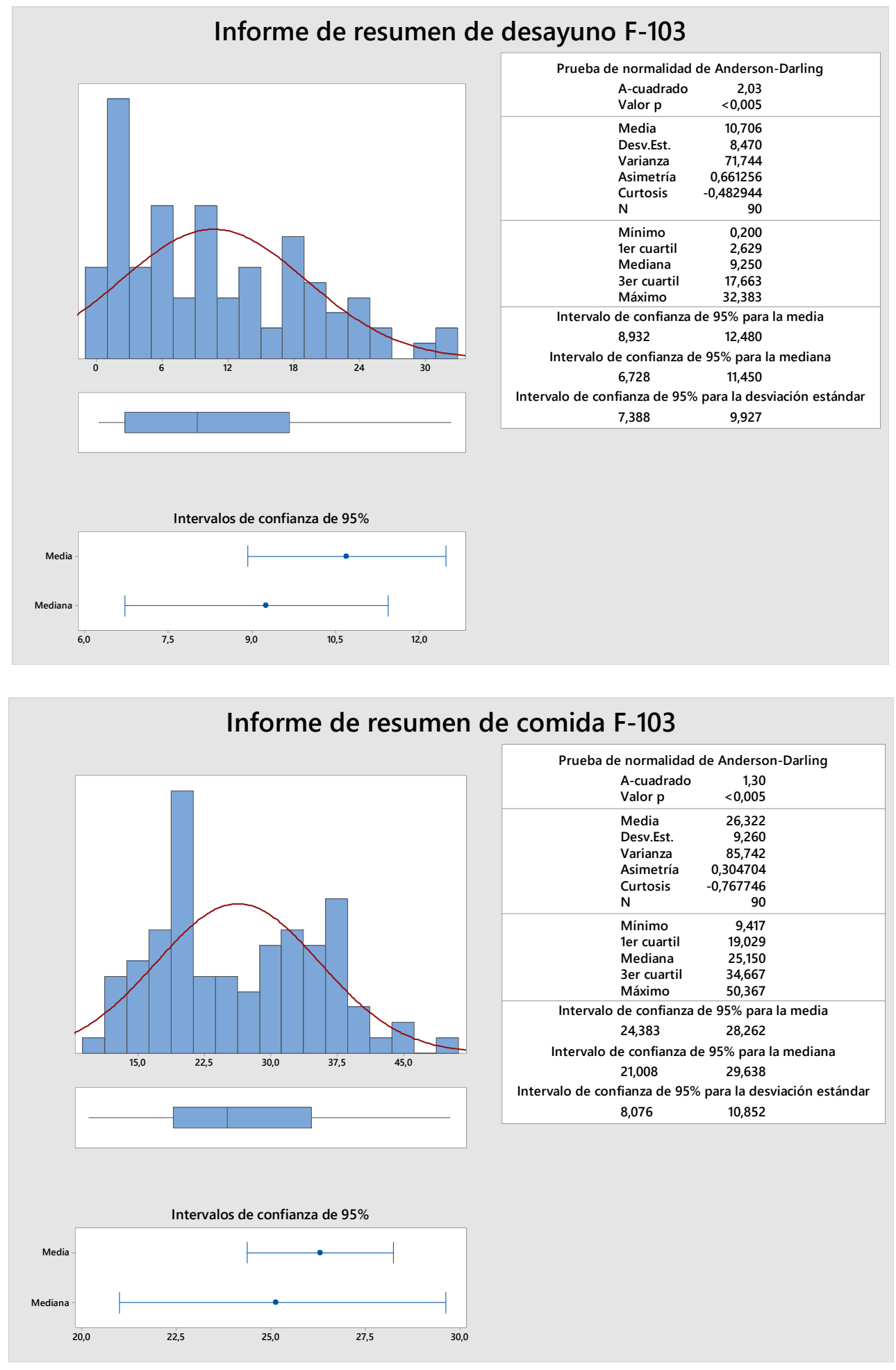

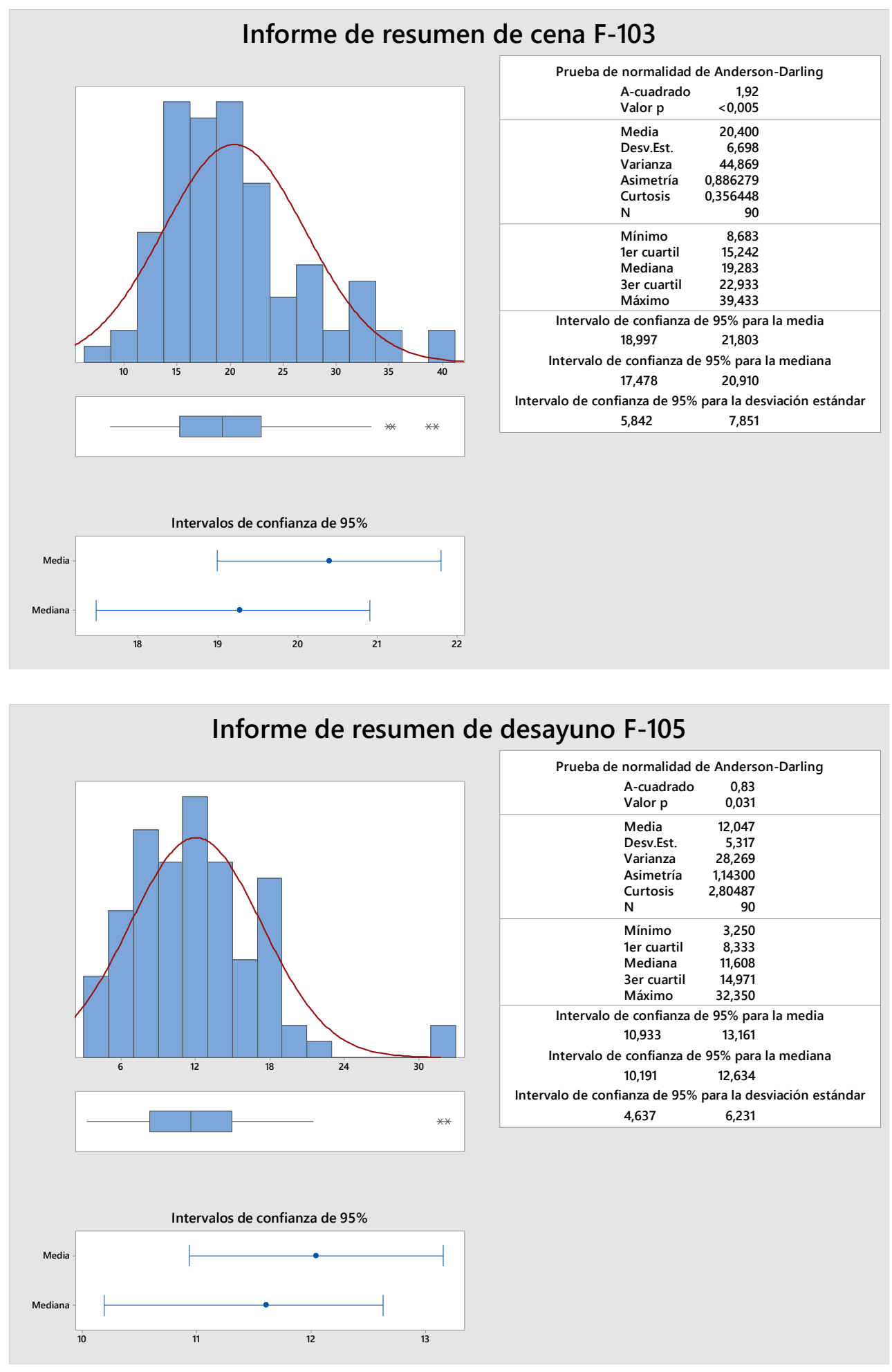

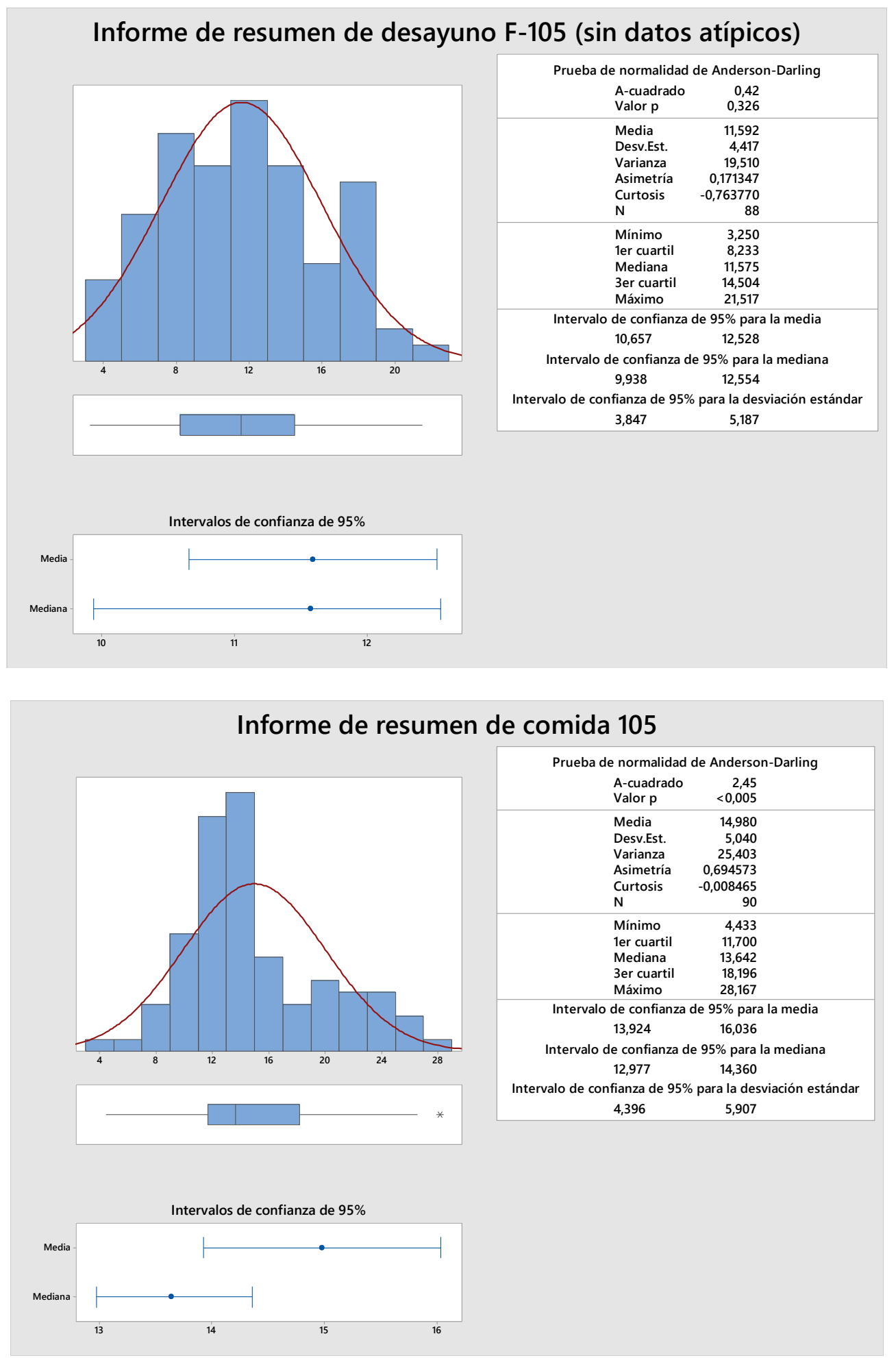

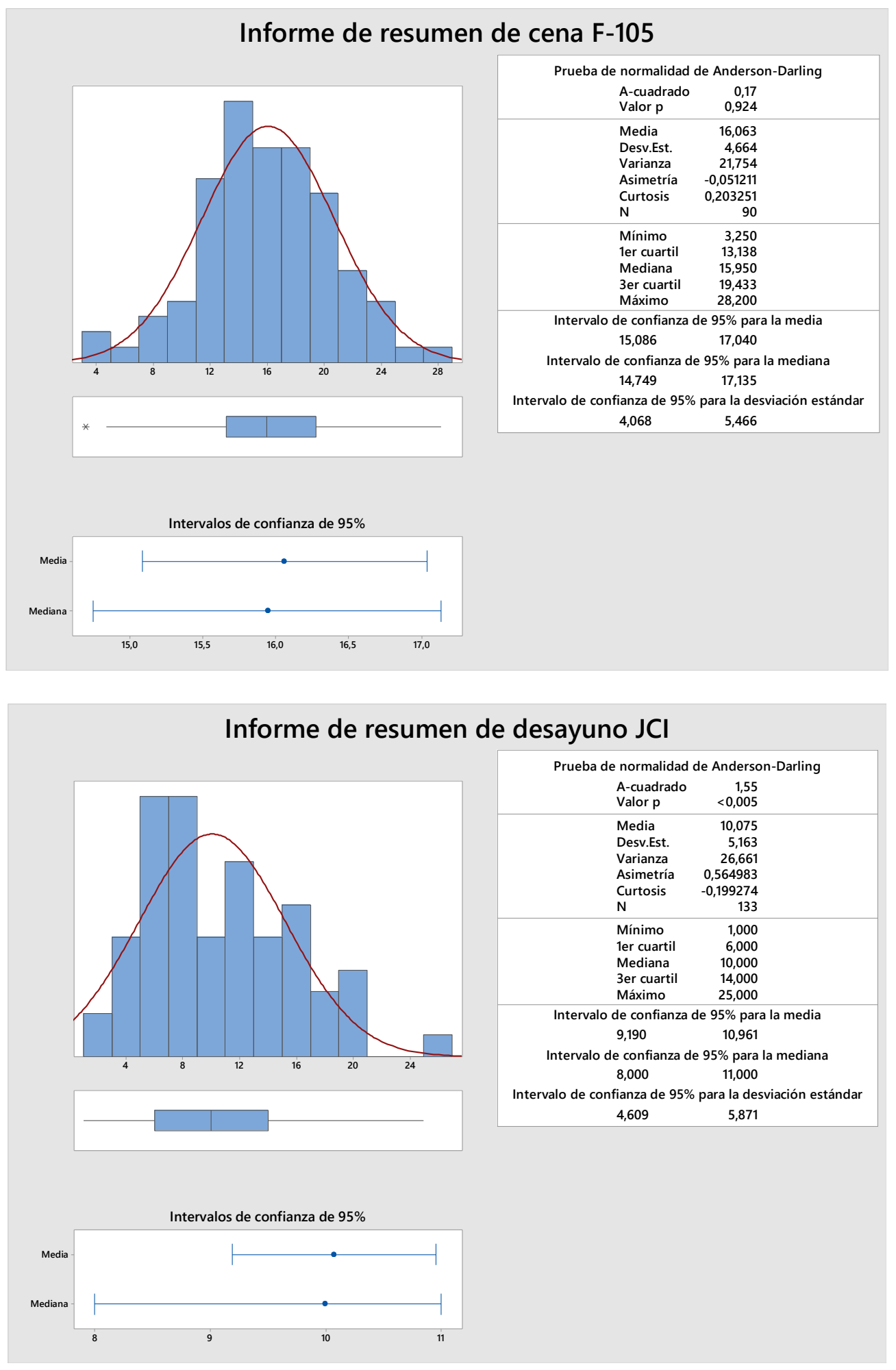

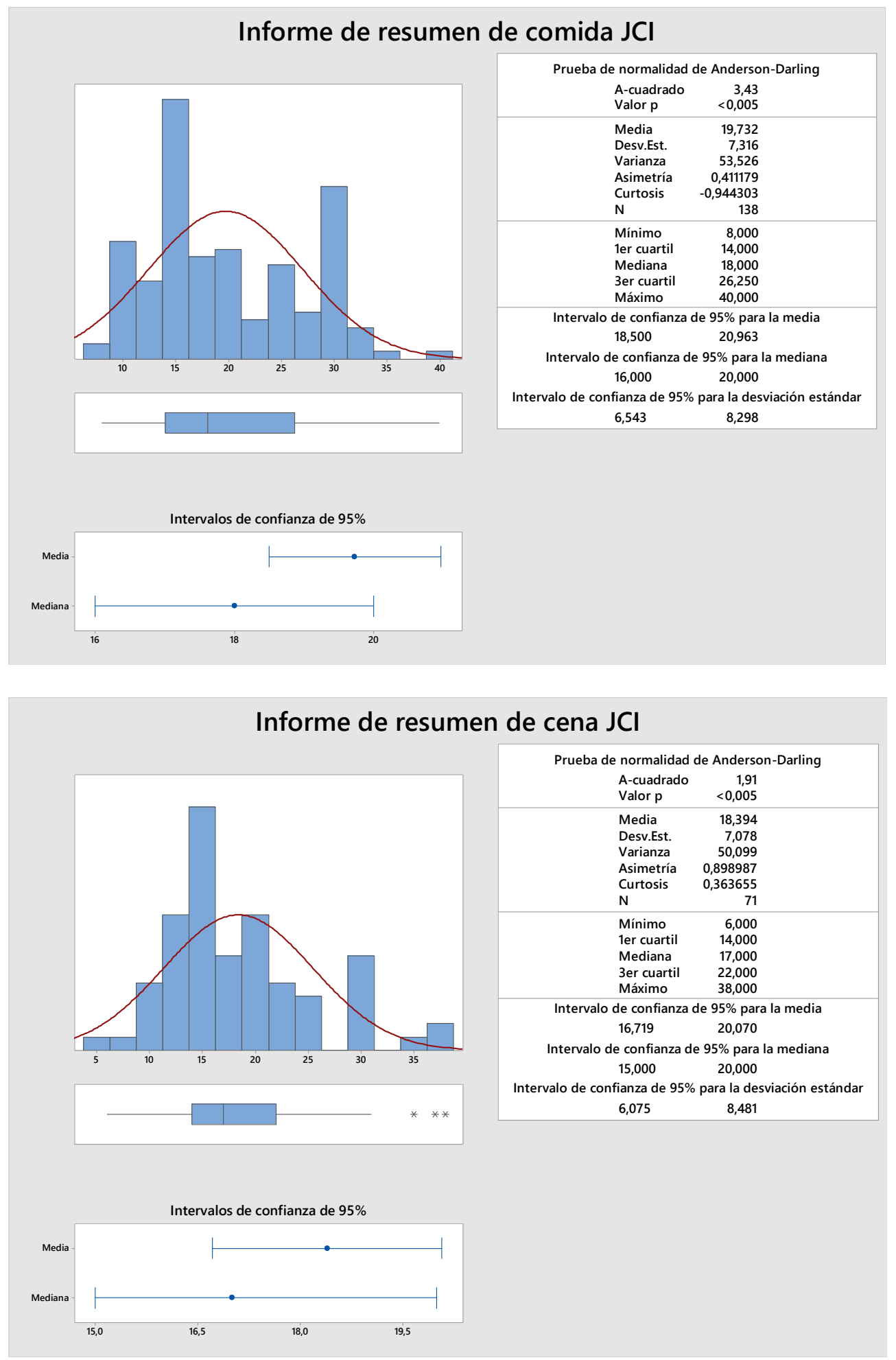



\section{B.7. Pruebas de Hipótesis de los Tiempos de Ingesta}

$\underline{\text { Prueba de Kruskal-Wallis: desayuno vs. Barco }}$

Prueba de Kruskal-Wallis en desayuno

Clasificación

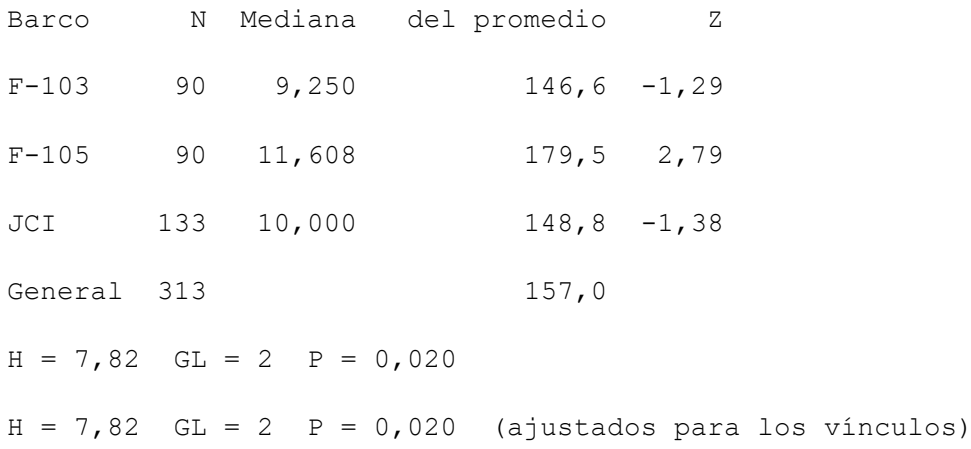

Prueba de Kruskal-Wallis: comida vs. Barco

Prueba de Kruskal-Wallis en comida

Clasificación

Barco_1 N Mediana del promedio Z

$\begin{array}{lllll}F-103 & 90 & 25,15 & 221,0 & 7,50\end{array}$

$\begin{array}{lllll}\mathrm{F}-105 & 90 & 13,64 & 99,7 & -7,29\end{array}$

JCI $138 \quad 18,00 \quad 158,4-0,19$

General $318 \quad 159,5$

$\mathrm{H}=78,40 \mathrm{GL}=2 \quad \mathrm{P}=0,000$

$\mathrm{H}=78,43 \mathrm{GL}=2 \mathrm{P}=0,000$ (ajustados para los vínculos)

Prueba de Kruskal-Wallis: cena vs. Barco

Prueba de Kruskal-Wallis en cena

Clasificación

Barco_2 N Mediana del promedio Z

$\begin{array}{lllll}\mathrm{F}-103 & 90 & 19,28 & 150,1 & 3,92\end{array}$

$\begin{array}{llll}\text { F-105 } 90 & 15,95 & 104,3-3,54\end{array}$

JCI $71 \quad 17,00 \quad 123,0 \quad-0,41$

$\begin{array}{lll}\text { General } 251 & 126,0\end{array}$

$\mathrm{H}=18,04 \quad \mathrm{GL}=2 \quad \mathrm{P}=0,000$
$\mathrm{H}=18,05 \quad \mathrm{GL}=2 \quad \mathrm{P}=0,000 \quad$ (ajustados para los vínculos) 
Apéndice B. Estudio del Comedor

ANOVA unidireccional: desayuno F-103; desayuno F-105; desayuno JCI

Método

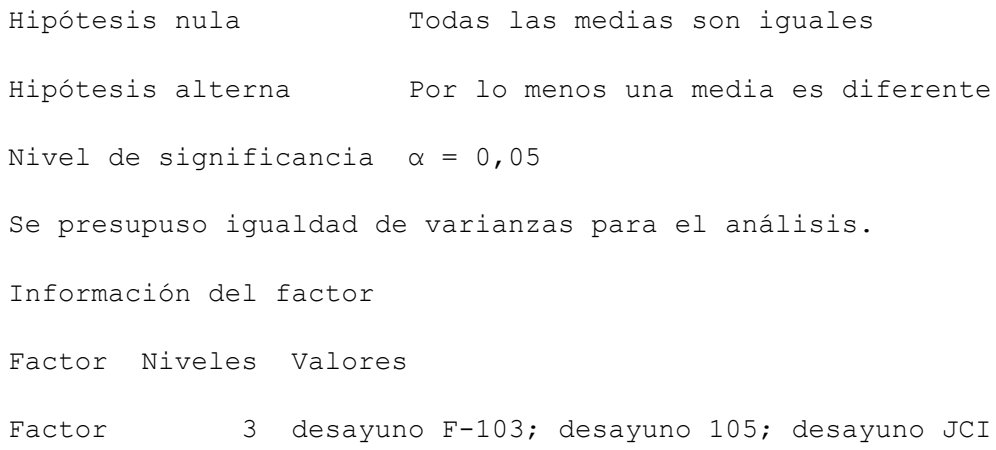

Resumen del modelo

R-cuad. R-cuad.

S R-cuad. (ajustado) (pred)

$6,13745 \quad 1,04 \% \quad 0,40 \% \quad 0,00 \%$

Medias

Factor N Media Desv.Est.

IC de $95 \%$

desayuno F-103 $90 \quad 10,706 \quad 8,470 \quad(9,433 ; 11,979)$

desayuno F-105 $88 \quad 11,592 \quad 4,417 \quad(10,305 ; 12,880)$

desayuno JCI $13310,075 \quad 5,163(9,028 ; 11,122)$

Desv.Est. agrupada $=6,13745$

Comparaciones en parejas de Fisher

Agrupar información utilizando el método LSD de Fisher y una confianza de 95\%

Factor N Media Agrupación

desayuno F-105 $88 \quad 11,592 \quad$ A

desayuno F-103 $90 \quad 10,706$ A

desayuno JCI 13310,075 A

Las medias que no comparten una letra son significativamente diferentes

ANOVA unidireccional: comida F-103; comida F-105; comida JCI

Método

Hipótesis nula

Todas las medias son iguales 
Apéndice B. Estudio del Comedor

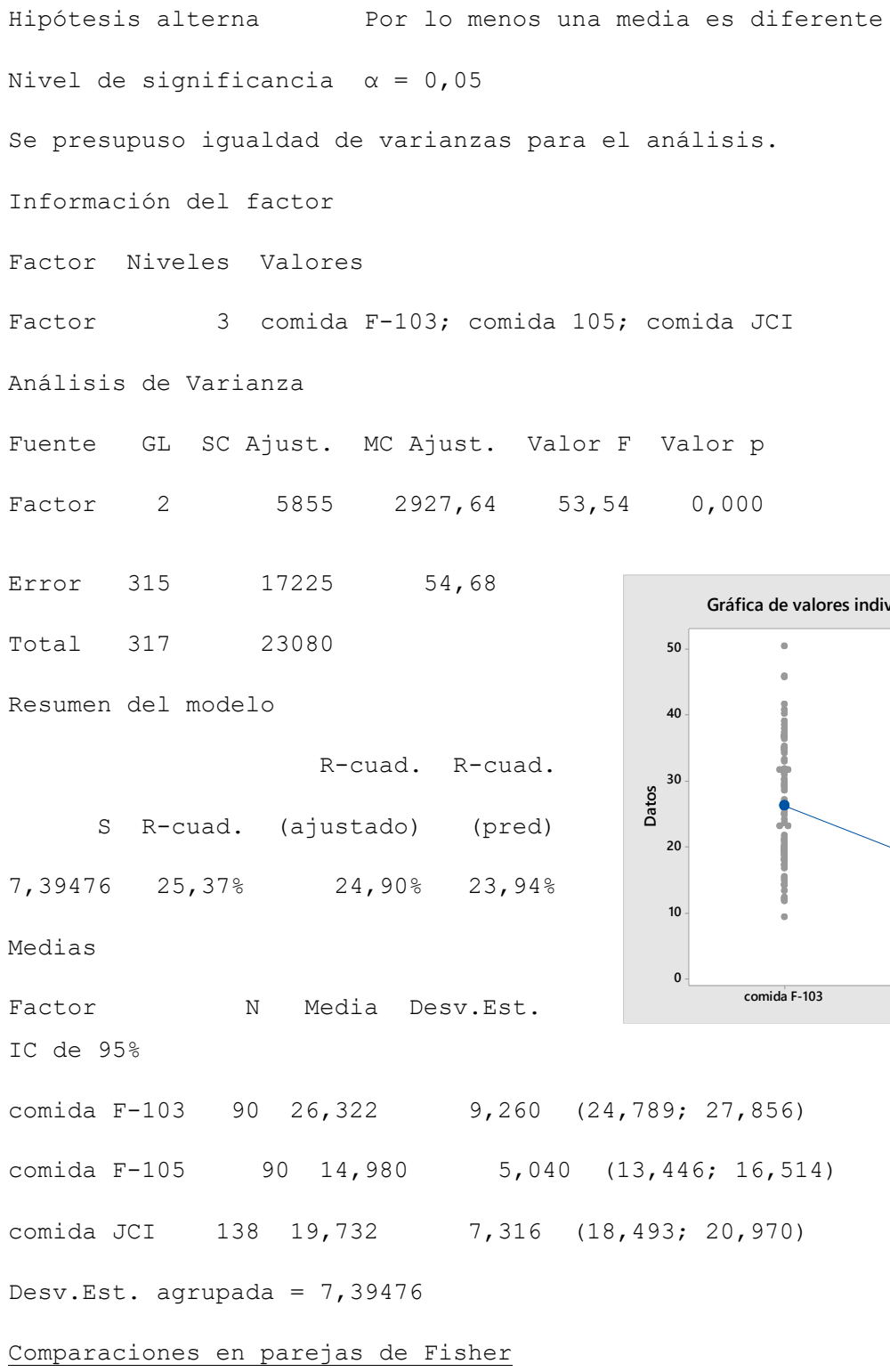


Apéndice B. Estudio del Comedor

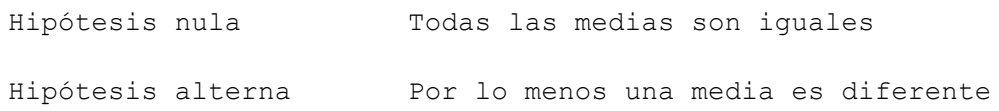




\section{B.8. Informe de Resumen de la Ingesta de la Comida en la F-103}
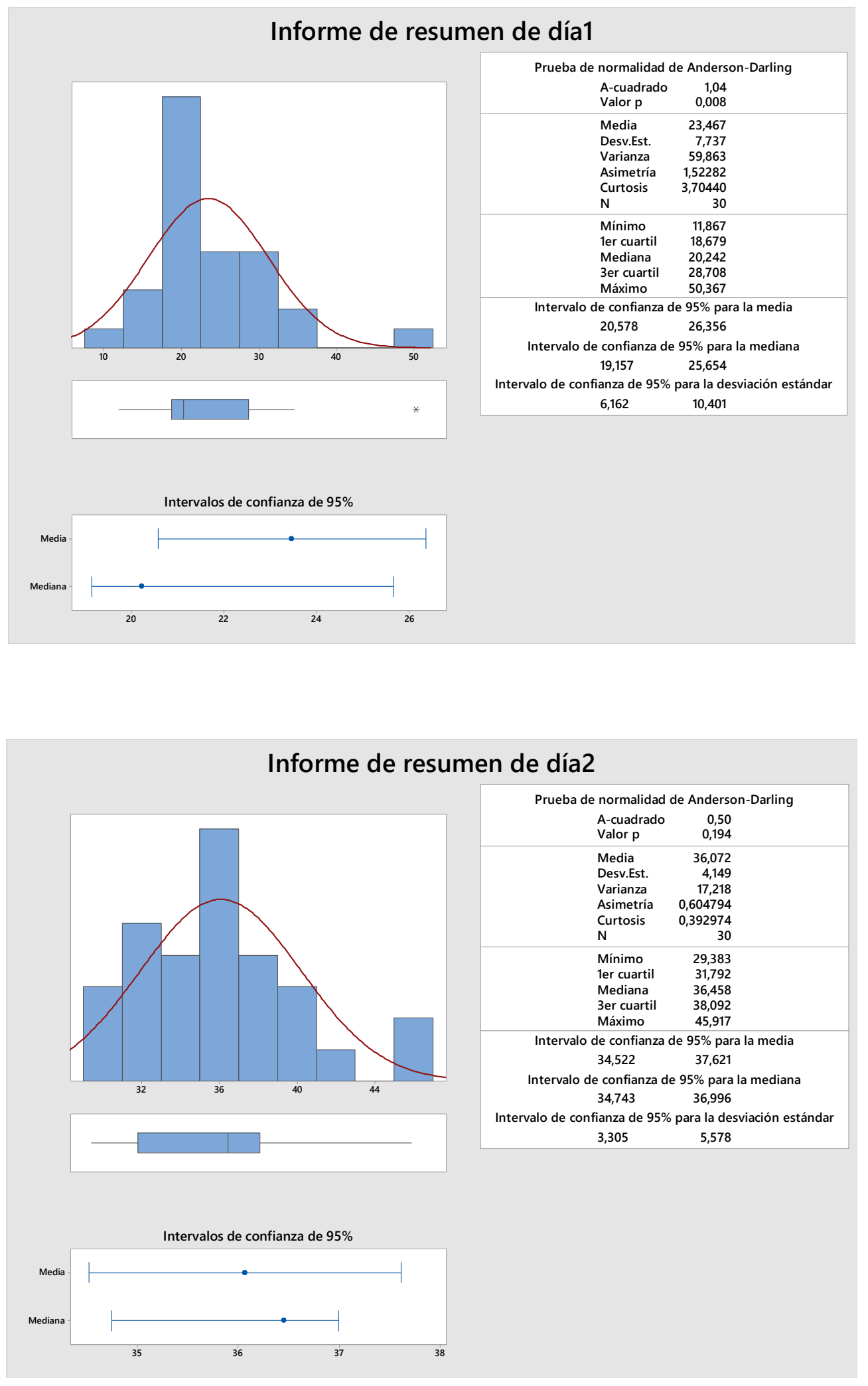


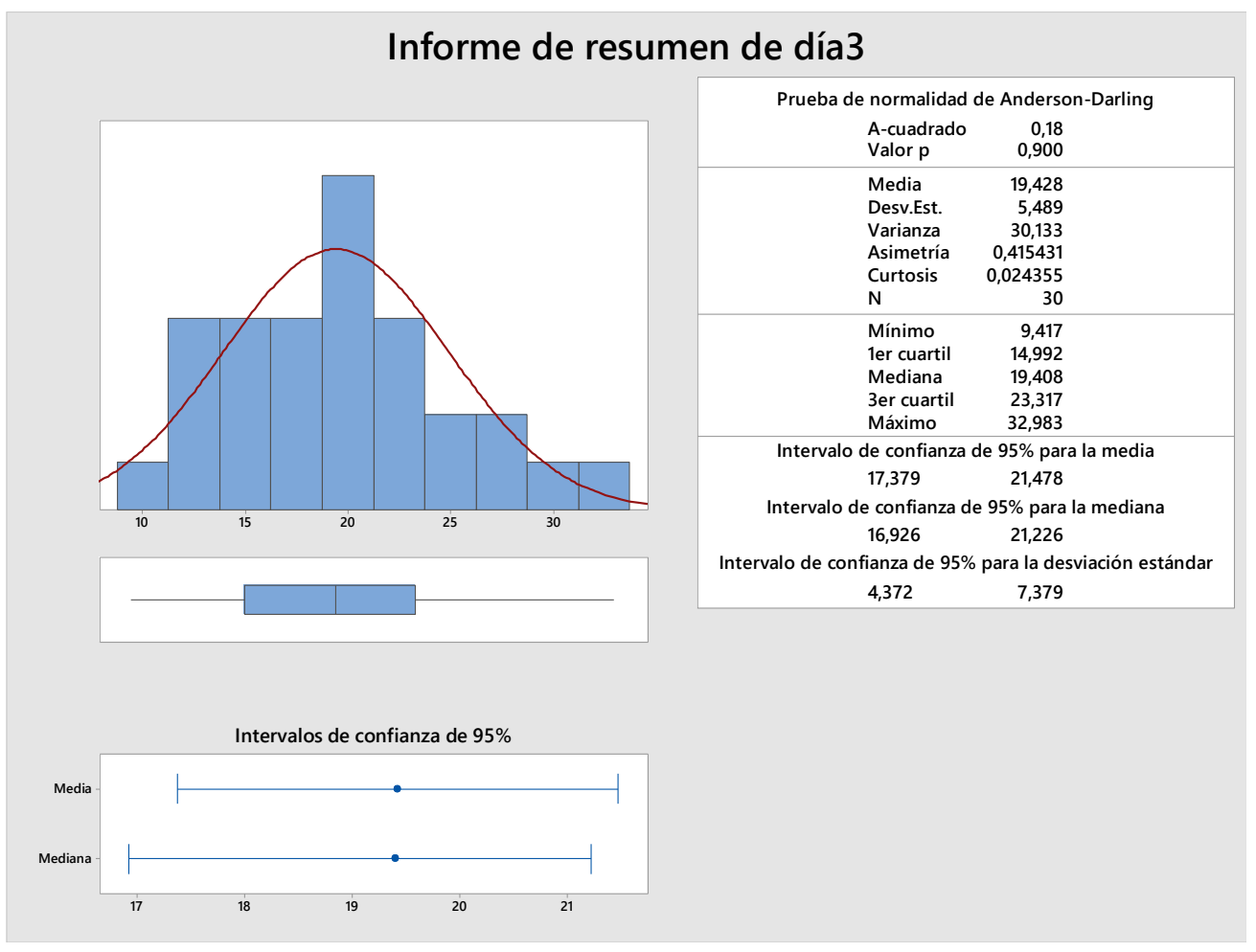




\section{B.9. Contrastes de Hipótesis Comida F-103}

Prueba de Kruskal-Wallis: T. comida F-103 vs. día

Prueba de Kruskal-Wallis en T. comida F-103

Clasificación

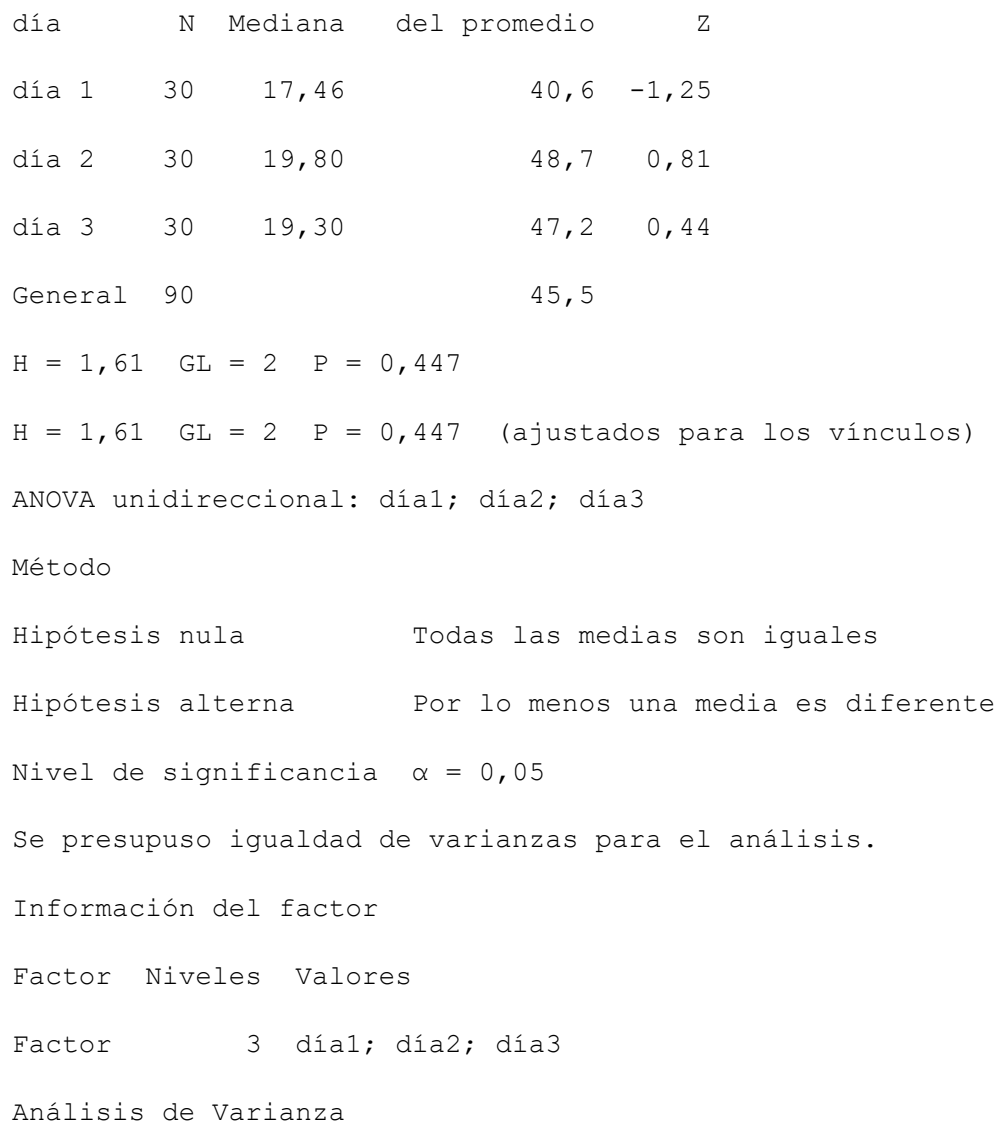


Apéndice B. Estudio del Comedor

Desv.Est. agrupada $=5,97812$

Comparaciones en parejas de Fisher

Agrupar información utilizando el método LSD de Fisher y una confianza de 95\%

Factor N Media Agrupación

día2 $30 \quad 36,072$ A

día1 $30 \quad 23,47 \quad B$

día3 $30 \quad 19,43 \quad$ C

Las medias que no comparten una letra son significativamente diferentes 


\section{B.10. ANOVA Tasa de Llegada Exp.80}

Análisis de varianza de un factor

Promedio de tiempo de ocupación del comedor

\begin{tabular}{ccccc} 
RESUMEN & \multicolumn{3}{c}{} \\
\hline Grupos & Cuenta & Suma & Promedio & Varianza \\
\hline Alt40pt & 10 & 1249 & 124,9 & 22,322 \\
Alt5 & 10 & 1253 & 125,3 & 18,011 \\
Alt6 & 10 & 1257 & 125,7 & 16,678 \\
\hline
\end{tabular}

\section{ANÁLISIS DE VARIANZA}

\begin{tabular}{|c|c|c|c|c|c|c|}
\hline Origen de las variaciones & Suma de cuadrados & Grados de libertad & Promedio de los cuadrados & $F$ & Probabilidad & Valor crítico para $F$ \\
\hline Entre grupos & 3,2 & 2 & 1,6 & 0,084 & 0,919 & 3,354 \\
\hline Dentro de los grupos & 513,1 & 27 & 19,004 & & & \\
\hline Total & 516,3 & 29 & & & & \\
\hline
\end{tabular}

Análisis de varianza de un factor

Promedio de tiempo empleado en comer

\begin{tabular}{ccccc} 
RESUMEN & Suenta & Suma & Promedio & Varianza \\
\hline Grupos & 10 & 489,415 & 48,9415 & 14,1147 \\
Alt4Opt & 10 & 506,846 & 50,6846 & 10,5330 \\
Alt5 & 10 & 490,657 & 49,0657 & 20,9008 \\
\hline
\end{tabular}


ANÁLISIS DE VARIANZA

\begin{tabular}{cccccc}
\hline Origen de las variaciones & Suma de cuadrados & Grados de libertad & Promedio de los cuadrados & $F$ & Probabilidad \\
\hline Entre grupos & 18,9155 & 2 & 9,458 & 0,623 & 0,544 \\
Dentro de los grupos & 409,9363 & 27 & 15,183 & & \\
Total & 428,8519 & 29 & & & \\
\hline
\end{tabular}

Análisis de varianza de un factor

Promedio tiempo en cola

\begin{tabular}{ccccc} 
RESUMEN & \multicolumn{3}{c}{} \\
\hline Grupos & Cuenta & Suma & Promedio & Varianza \\
\hline Alt4Opt & 10 & 65,201 & 6,520 & 10,813 \\
Alt5 & 10 & 86,529 & 8,653 & 10,313 \\
Alt6 & 10 & 66,302 & 6,630 & 17,592 \\
\hline
\end{tabular}

\section{ANÁLISIS DE VARIANZA}

Origen de las variaciones Suma de cuadrados Grados de libertad Promedio de los cuadrados

Entre grupos

Dentro de los grupos

Total
28,841

348,460

377,301
14,420

12,906

Probabilidad Valor crítico para $F$

$1,117 \quad 0,342$

3,354

27

29 


\begin{tabular}{ccccc} 
RESUMEN & \multicolumn{3}{c}{} \\
\hline Grupos & Cuenta & Suma & Promedio & Varianza \\
\hline Alt40pt & 80 & 43,057 & 0,538 & 0,011 \\
Alt5 & 80 & 43,676 & 0,546 & 0,011 \\
Alt6 & 80 & 45,023 & 0,563 & 0,009 \\
\hline
\end{tabular}

ANÁLISIS DE VARIANZA

\begin{tabular}{ccccccc}
\hline Origen de las variaciones & Suma de cuadrados & Grados de libertad & Promedio de los cuadrados & $F$ & Probabilidad & Valor crítico para F \\
\hline Entre grupos & 0,025 & 2 & 0,013 & 1,243 & 0,290 & 3,034 \\
Dentro de los grupos & 2,408 & 237 & 0,010 & & \\
Total & 2,433 & 239 & & & \\
\hline
\end{tabular}




\section{B.11. ANOVA Tasa de Llegada Exp.160}

Análisis de varianza de un factor

Promedio de tiempo de ocupación del comedor

\begin{tabular}{ccccc} 
RESUMEN & Cuenta & Suma & Promedio & Varianza \\
\hline Grupos & 10 & 1247 & 124,7 & 13,344 \\
Alt4Opt & 10 & 1248 & 124,8 & 23,067 \\
Alt5 & 10 & 1240 & 124 & 23,333 \\
Alt6 & &
\end{tabular}

\section{ANÁLISIS DE VARIANZA}

\begin{tabular}{|c|c|c|c|c|c|c|}
\hline Origen de las variaciones & Suma de cuadrados & Grados de libertad & Promedio de los cuadrados & $F$ & Probabilidad & Valor crítico para $F$ \\
\hline Entre grupos & 3,8 & 2 & 1,9 & 0,095 & 0,909 & 3,354 \\
\hline Dentro de los grupos & 537,7 & 27 & 19,915 & & & \\
\hline Total & 541,5 & 29 & & & & \\
\hline
\end{tabular}

Análisis de varianza de un factor

Promedio de tiempo empleado en comer

\begin{tabular}{ccccc} 
RESUMEN & Cuenta & Suma & Promedio & Varianza \\
\hline Grupos & 10 & 647,343 & 64,734 & 7,078 \\
Alt40pt & 10 & 648,926 & 64,893 & 1,848 \\
Alt5 & 10 & 648,228 & 64,823 & 2,751 \\
Alt6 &
\end{tabular}


ANÁLISIS DE VARIANZA

\begin{tabular}{|c|c|c|c|c|c|c|}
\hline Origen de las variaciones & Suma de cuadrados & Grados de libertad & Promedio de los cuadrados & $F$ & Probabilidad & Valor crítico para $F$ \\
\hline Entre grupos & 0,126 & 2 & 0,063 & 0,016 & 0,984 & 3,354 \\
\hline
\end{tabular}

Análisis de varianza de un factor

Promedio tiempo en cola

\begin{tabular}{ccccc} 
RESUMEN & Cuenta & Suma & Promedio & Varianza \\
\hline Grupos & 10 & 219,221 & 21,922 & 7,718 \\
Alt4Opt & 10 & 219,530 & 21,953 & 2,065 \\
Alt5 & 10 & 218,398 & 21,840 & 2,095 \\
Alt6 &
\end{tabular}

ANÁLISIS DE VARIANZA

\begin{tabular}{|c|c|c|c|c|c|c|}
\hline Origen de las variaciones & Suma de cuadrados & Grados de libertad & Promedio de los cuadrados & $F$ & Probabilidad & Valor crítico para $F$ \\
\hline Entre grupos & 0,068 & 2 & 0,034 & 0,009 & 0,991 & 3,354 \\
\hline Dentro de los grupos & 106,905 & 27 & 3,959 & & & \\
\hline Total & 106,974 & 29 & & & & \\
\hline
\end{tabular}




\begin{tabular}{ccccc} 
RESUMEN & Cuenta & Suma & Promedio & Varianza \\
\hline Grupos & 80 & 42,237 & 0,528 & 0,013 \\
Alt4Opt & 80 & 44,338 & 0,554 & 0,015 \\
Alt5 & 80 & 39,488 & 0,494 & 0,023 \\
Alt6 &
\end{tabular}

ANÁLISIS DE VARIANZA

\begin{tabular}{|c|c|c|c|c|c|c|}
\hline Origen de las variaciones & Suma de cuadrados & Grados de libertad & Promedio de los cuadrados & $F$ & Probabilidad & Valor crítico para $F$ \\
\hline Entre grupos & 0,148 & 2 & 0,074 & 4,353 & 0,014 & 3,034 \\
\hline Dentro de los grupos & 4,027 & 237 & 0,017 & & & \\
\hline Total & 4,175 & 239 & & & & \\
\hline
\end{tabular}




\section{B.12. ANOVA Tasa de Llegada Exp.320}

Análisis de varianza de un factor

Promedio de tiempo de ocupación del comedor

\begin{tabular}{ccccc} 
RESUMEN & Cuenta & Suma & Promedio & Varianza \\
\hline Grupos & 10 & 1203 & 120,3 & 26,9 \\
Alt4Opt & 10 & 1236 & 123,6 & 7,822 \\
Alt5 & 10 & 1222 & 122,2 & 19,956 \\
Alt6 & &
\end{tabular}

\section{ANÁLISIS DE VARIANZA}

\begin{tabular}{|c|c|c|c|c|c|c|}
\hline Origen de las variaciones & Suma de cuadrados & Grados de libertad & Promedio de los cuadrados & $F$ & Probabilidad & Valor crítico para $F$ \\
\hline Entre grupos & 54,867 & 2 & 27,433 & 1,505 & 0,240 & 3,354 \\
\hline Dentro de los grupos & 492,1 & 27 & 18,226 & & & \\
\hline Total & 546,967 & 29 & & & & \\
\hline
\end{tabular}

Análisis de varianza de un factor

Promedio de tiempo empleado en comer

\begin{tabular}{ccccc} 
RESUMEN & Cuenta & Suma & Promedio & Varianza \\
\hline Grupos & 10 & 709,854 & 70,985 & 2,932 \\
Alt40pt & 10 & 704,336 & 70,434 & 2,190 \\
Alt5 & 10 & 706,366 & 70,637 & 4,491 \\
Alt6 & &
\end{tabular}


ANÁLISIS DE VARIANZA

\begin{tabular}{|c|c|c|c|c|c|c|}
\hline Origen de las variaciones & Suma de cuadrados & Grados de libertad & Promedio de los cuadrados & $F$ & Probabilidad & Valor crítico para $F$ \\
\hline Entre grupos & 1,558 & 2 & 0,779 & 0,243 & 0,786 & 3,354 \\
\hline Dentro de los grupos & 86,520 & 27 & 3,204 & & & \\
\hline Total & 88,078 & 29 & & & & \\
\hline
\end{tabular}

Análisis de varianza de un factor

Promedio tiempo en cola

\begin{tabular}{ccccc} 
RESUMEN & Cuenta & Suma & Promedio & Varianza \\
\hline Grupos & 10 & 282,792 & 28,279 & 2,372 \\
Alt4Opt & 10 & 281,883 & 28,188 & 1,357 \\
Alt5 & 10 & 280,994 & 28,099 & 4,425 \\
Alt6 & &
\end{tabular}

ANÁLISIS DE VARIANZA

\begin{tabular}{|c|c|c|c|c|c|c|}
\hline Origen de las variaciones & Suma de cuadrados & Grados de libertad & Promedio de los cuadrados & $F$ & Probabilidad & Valor crítico para $F$ \\
\hline Entre grupos & 0,162 & 2 & 0,081 & 0,030 & 0,971 & 3,354 \\
\hline Dentro de los grupos & 73,389 & 27 & 2,718 & & & \\
\hline Total & 73,551 & 29 & & & & \\
\hline
\end{tabular}

Análisis de varianza de un factor 


\begin{tabular}{ccccc} 
RESUMEN & Cuenta & Suma & Promedio & Varianza \\
\hline Grupos & 80 & 42,099 & 0,526 & 0,017 \\
Alt4Opt & 80 & 41,000 & 0,513 & 0,014 \\
Alt5 & 80 & 37,088 & 0,464 & 0,033 \\
Alt6 &
\end{tabular}

ANÁLISIS DE VARIANZA

\begin{tabular}{|c|c|c|c|c|c|c|}
\hline Origen de las variaciones & Suma de cuadrados & Grados de libertad & Promedio de los cuadrados & $F$ & Probabilidad & Valor crítico para $F$ \\
\hline Entre grupos & 0,173 & 2 & 0,087 & 4,025 & 0,019 & 3,034 \\
\hline Dentro de los grupos & 5,107 & 237 & 0,022 & & & \\
\hline Total & 5,280 & 239 & & & & \\
\hline
\end{tabular}





\section{Apéndice C. Estudio de las Ametralladoras}

\section{C.1. Pruebas ANOVA de Promedios de Disparos por Ametralladora}

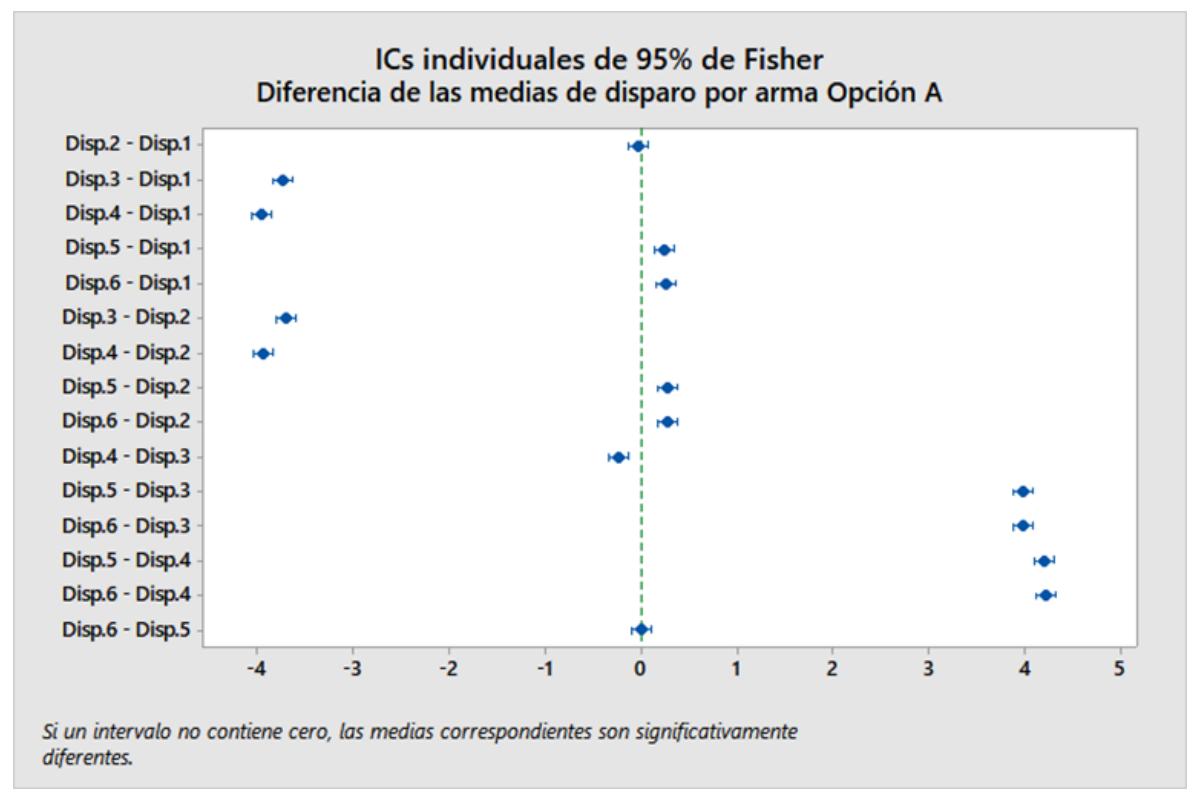

Figura en Apéndice C-1 ANOVA diferencia de las medias de disparo por arma. Opción A

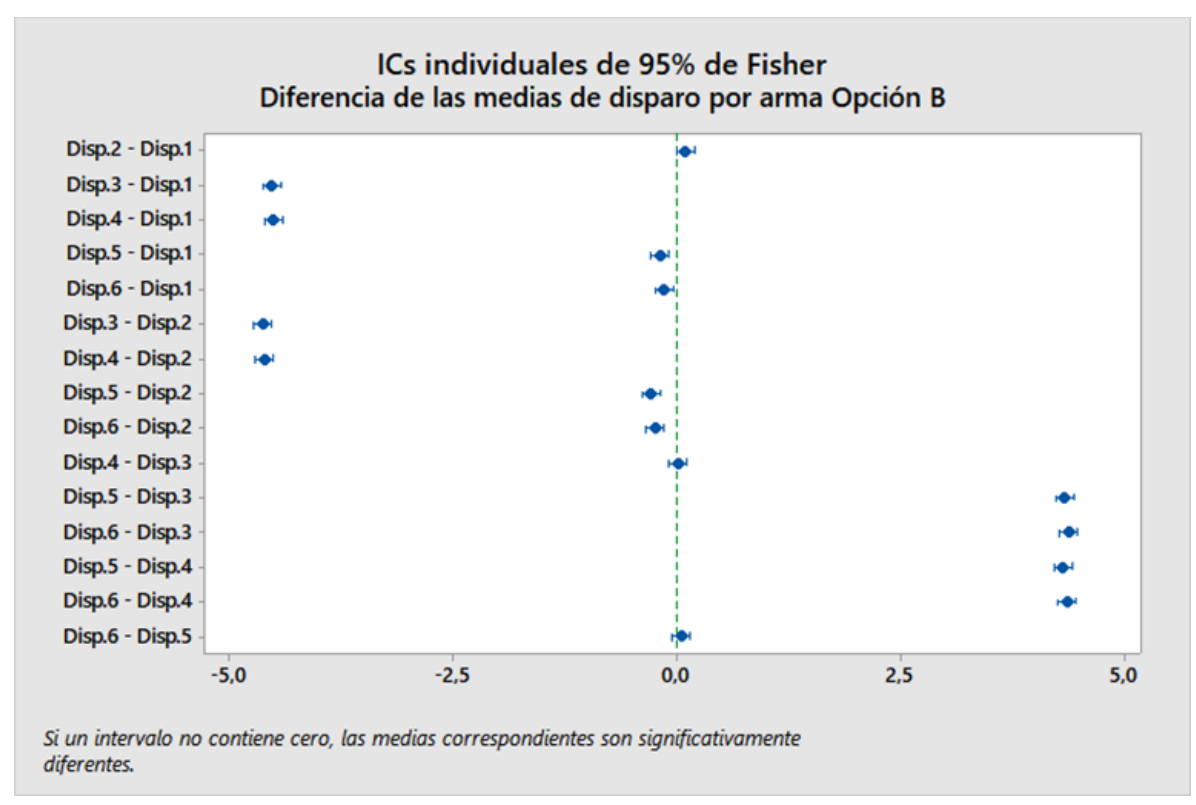

Figura en Apéndice C-2 ANOVA diferencia de las medias de disparo por arma. Opción B 


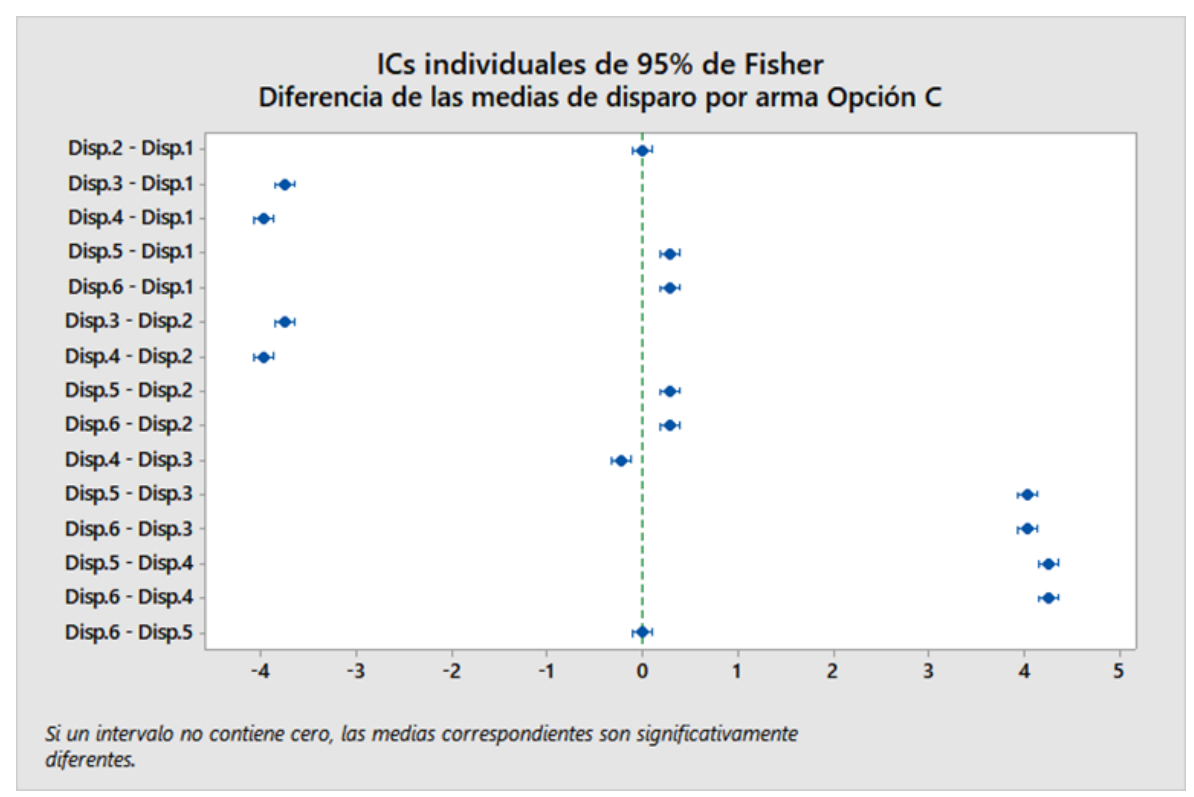

Figura en Apéndice C-3 ANOVA diferencia de las medias de disparo por arma. Opción C

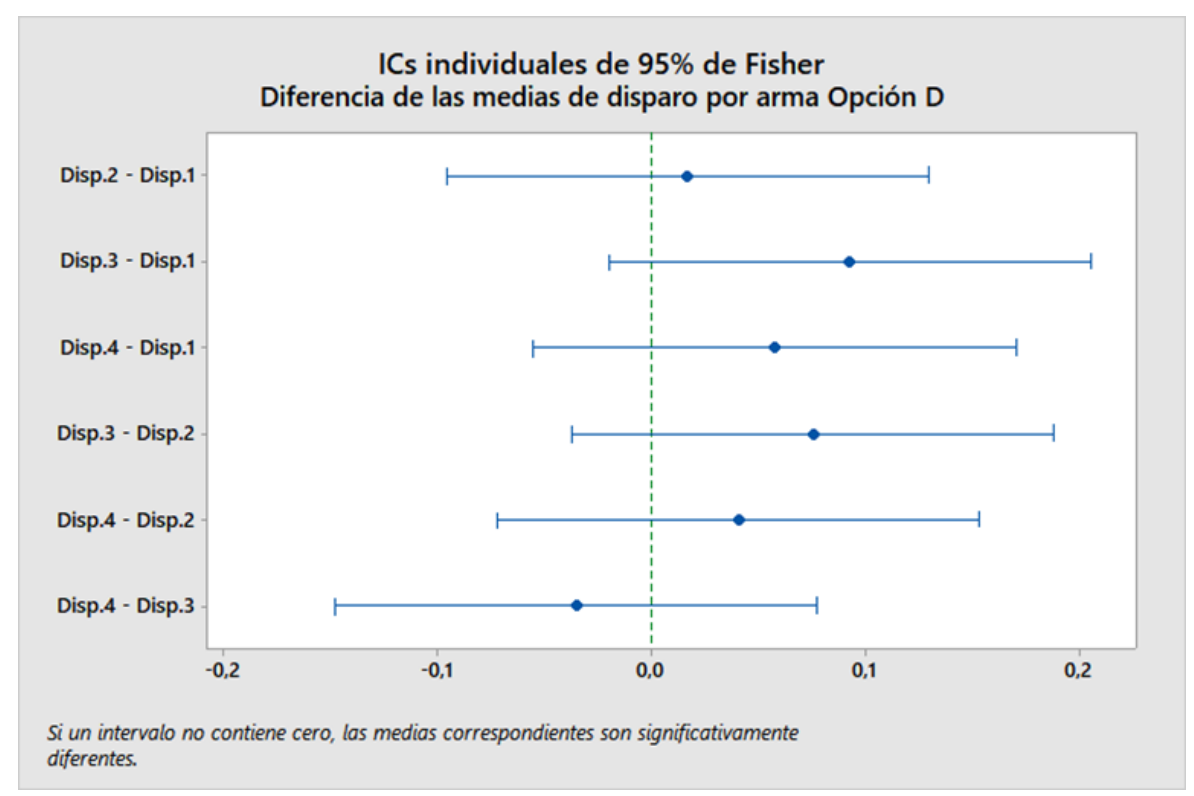

Figura en Apéndice C-4 ANOVA diferencia de las medias de disparo por arma. Opción D 


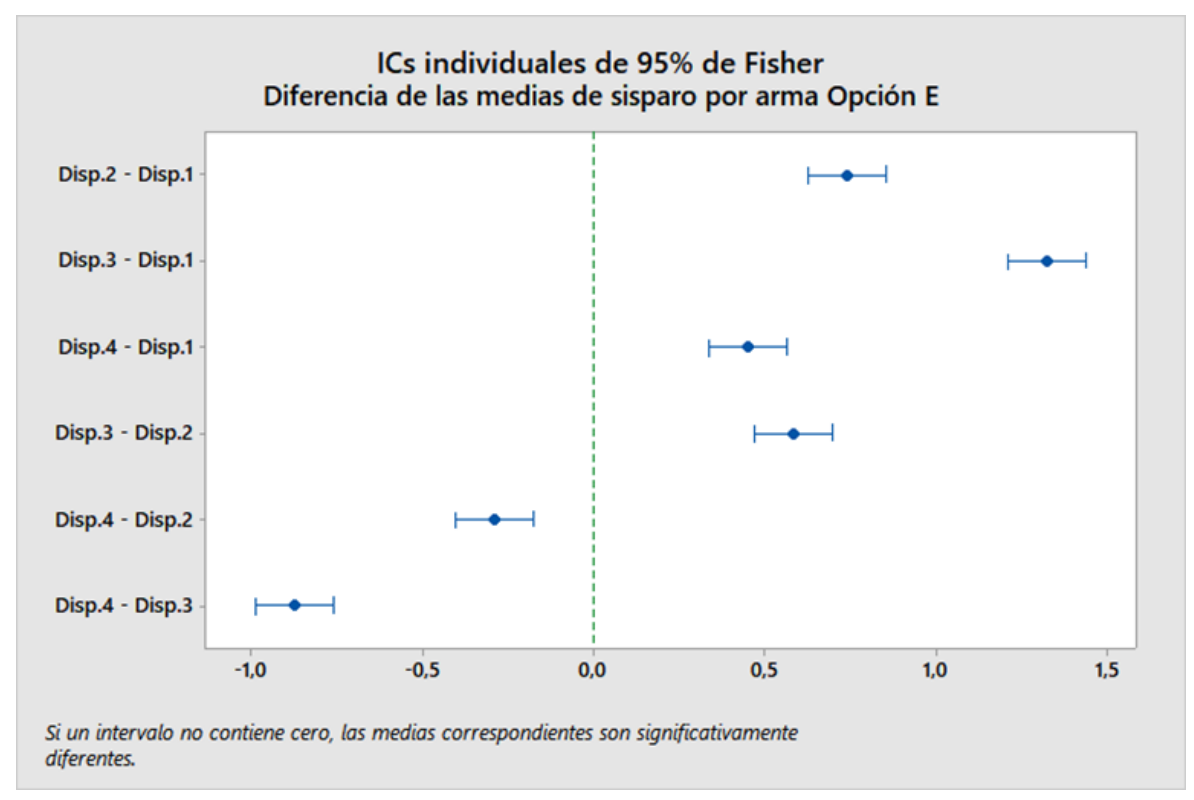

Figura en Apéndice C-5 ANOVA diferencia de las medias de disparo por arma. Opción E

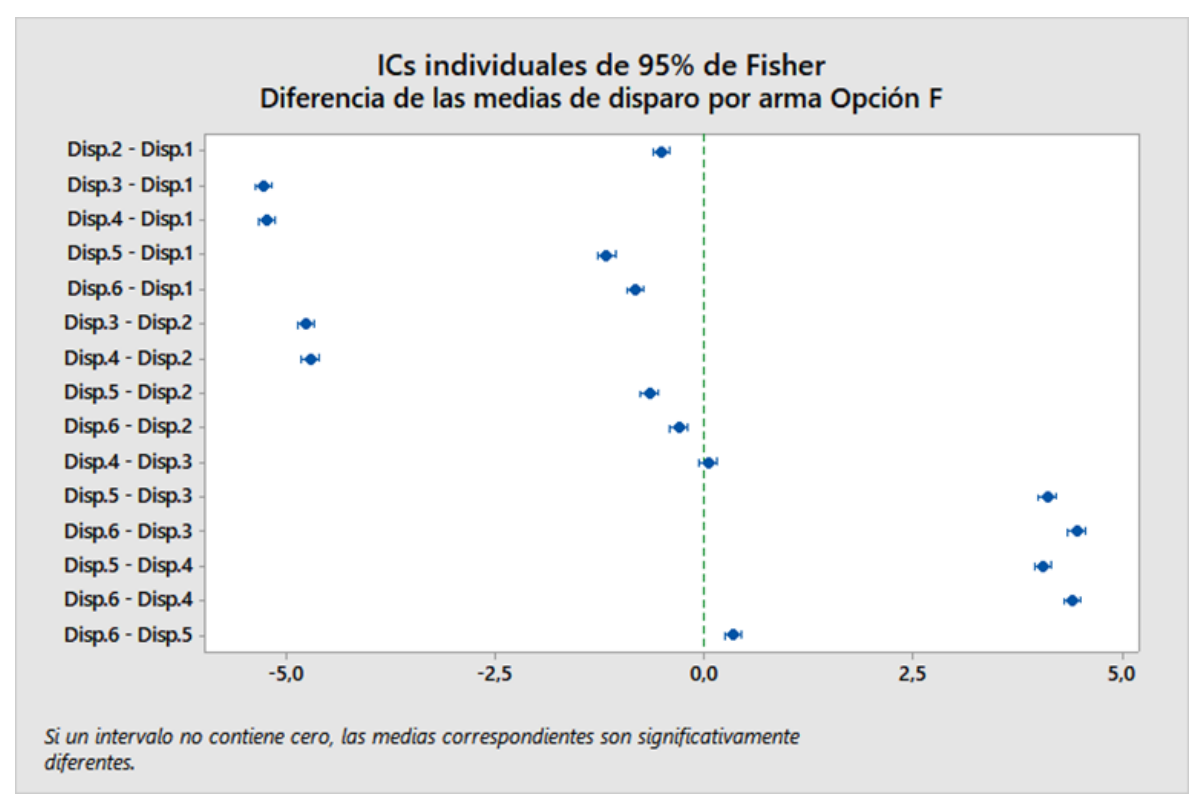

Figura en Apéndice C-6 ANOVA diferencia de las medias de disparo por arma. Opción F 



\section{Apéndice C. Estudio de las Ametralladoras}

$\begin{array}{llll}1 & 280 & 324 & 0,864198 \\ 2 & 294 & 334 & 0,880240\end{array}$

Diferencia $=p(1)-p(2)$

Estimación de la diferencia: $\quad-0,0160420$

IC de 95\% para la diferencia: $(-0,0670706 ; 0,0349866)$

Prueba para la diferencia $=0$ vs. $\neq 0: \quad \mathrm{Z}=-0,62$ Valor $\mathrm{p}=0,538$

Prueba exacta de Fisher: Valor $\mathrm{p}=0,561$

$\underline{\text { Prueba e IC para dos proporciones Sector Banda Br }}$

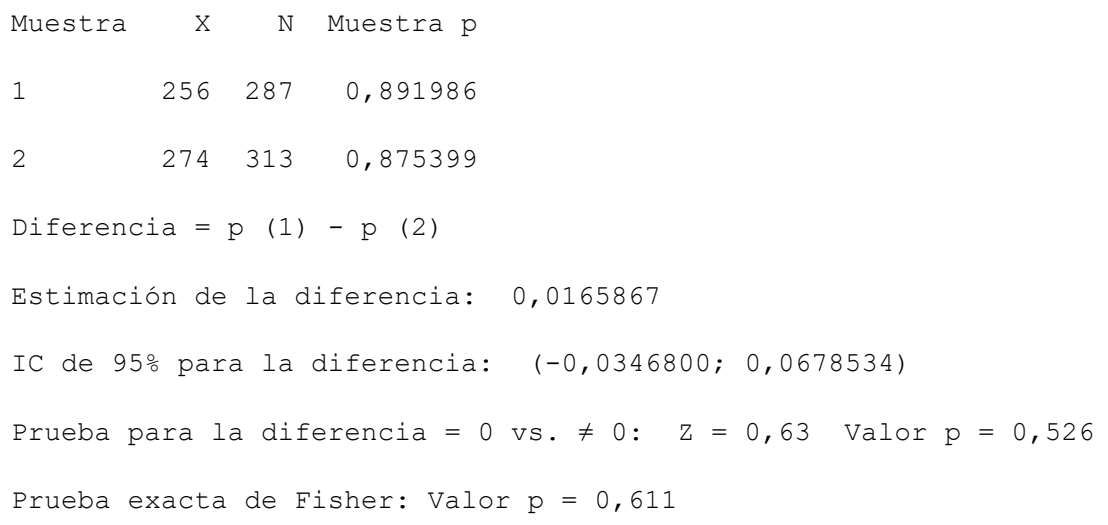




\section{C.3. Distribuciones y Estadísticas del Consumo de Munición de las Opciones B y F}
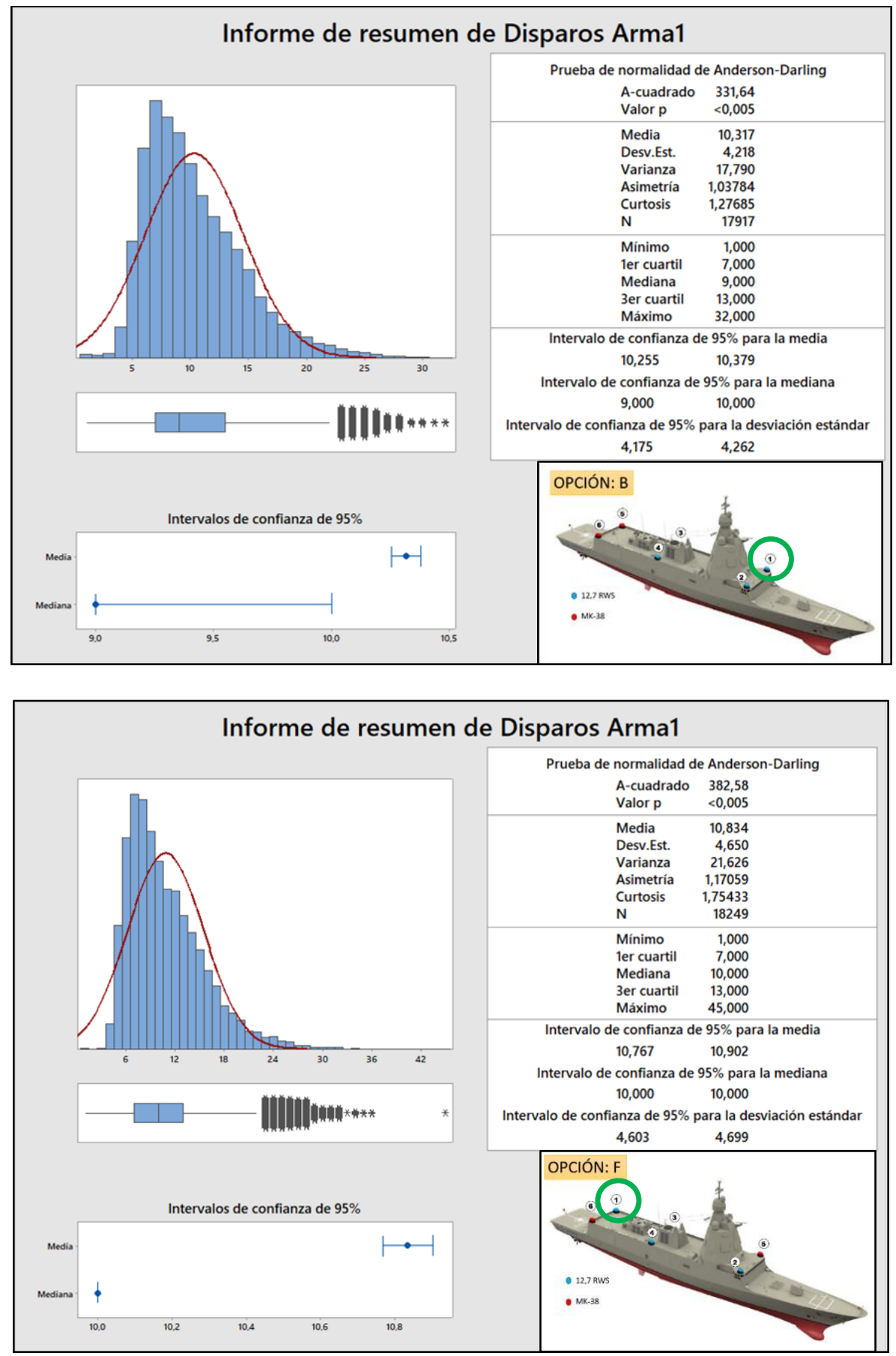

Figura en Apéndice C-7 Distribuciones y estadísticos descriptivos de la ametralladora de $12,7 \mathrm{~mm}$ de $\mathrm{Br}$ que se intercambia de posición. Arriba en la opción B está a proa y abajo en la opción F está a popa 

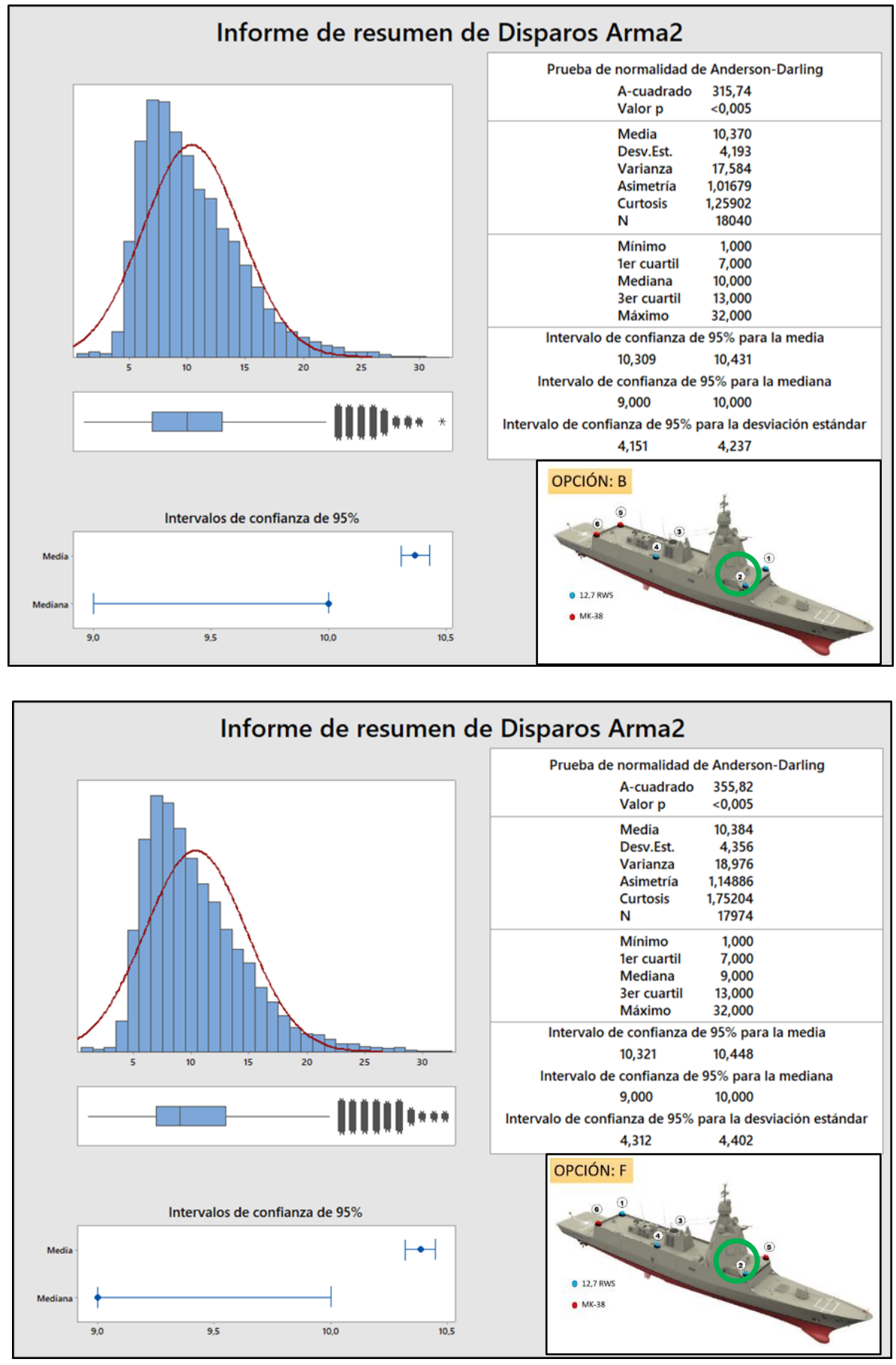

Figura en Apéndice C-8. Distribuciones y estadísticos descriptivos de la ametralladora №2. Arriba la opción B, abajo la opción $\mathbf{F}$ 

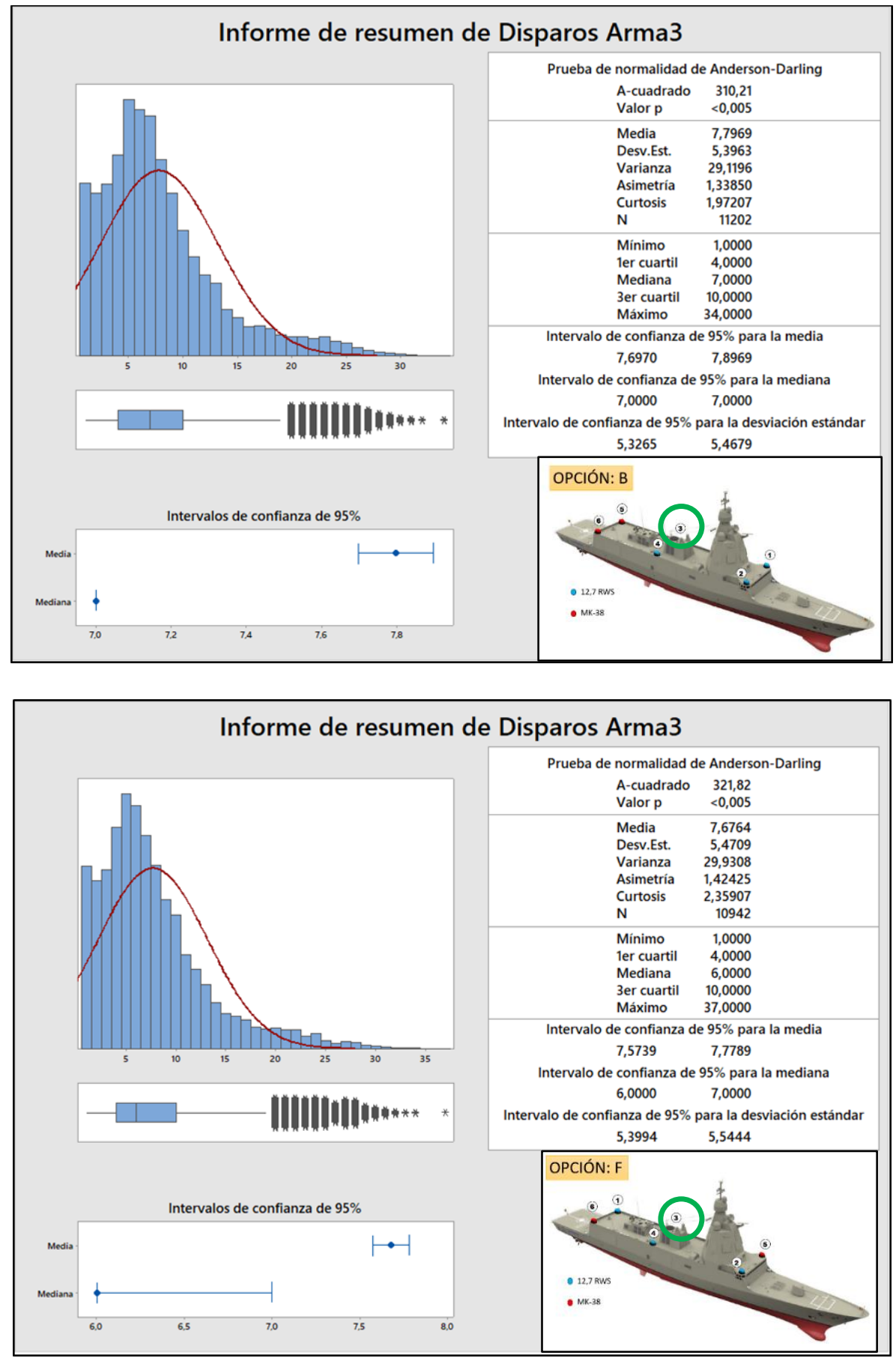

Figura en Apéndice C-9 Distribuciones y estadísticos descriptivos de la ametralladora №3. Arriba la opción B, abajo la opción $\mathrm{F}$ 

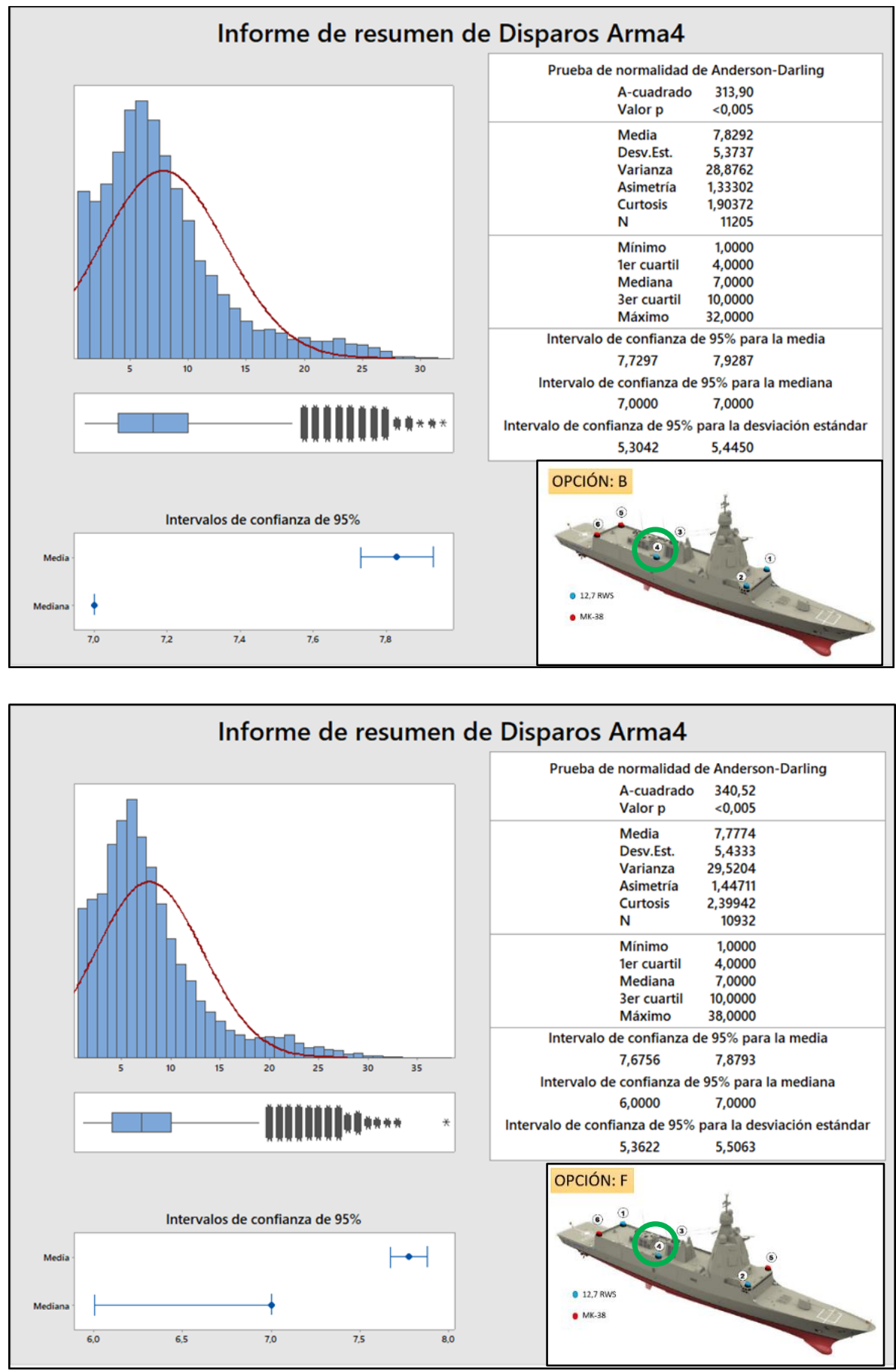

Figura en Apéndice C-10 Distribuciones y estadísticos descriptivos de la ametralladora №4. Arriba la opción B, abajo la opción $F$ 

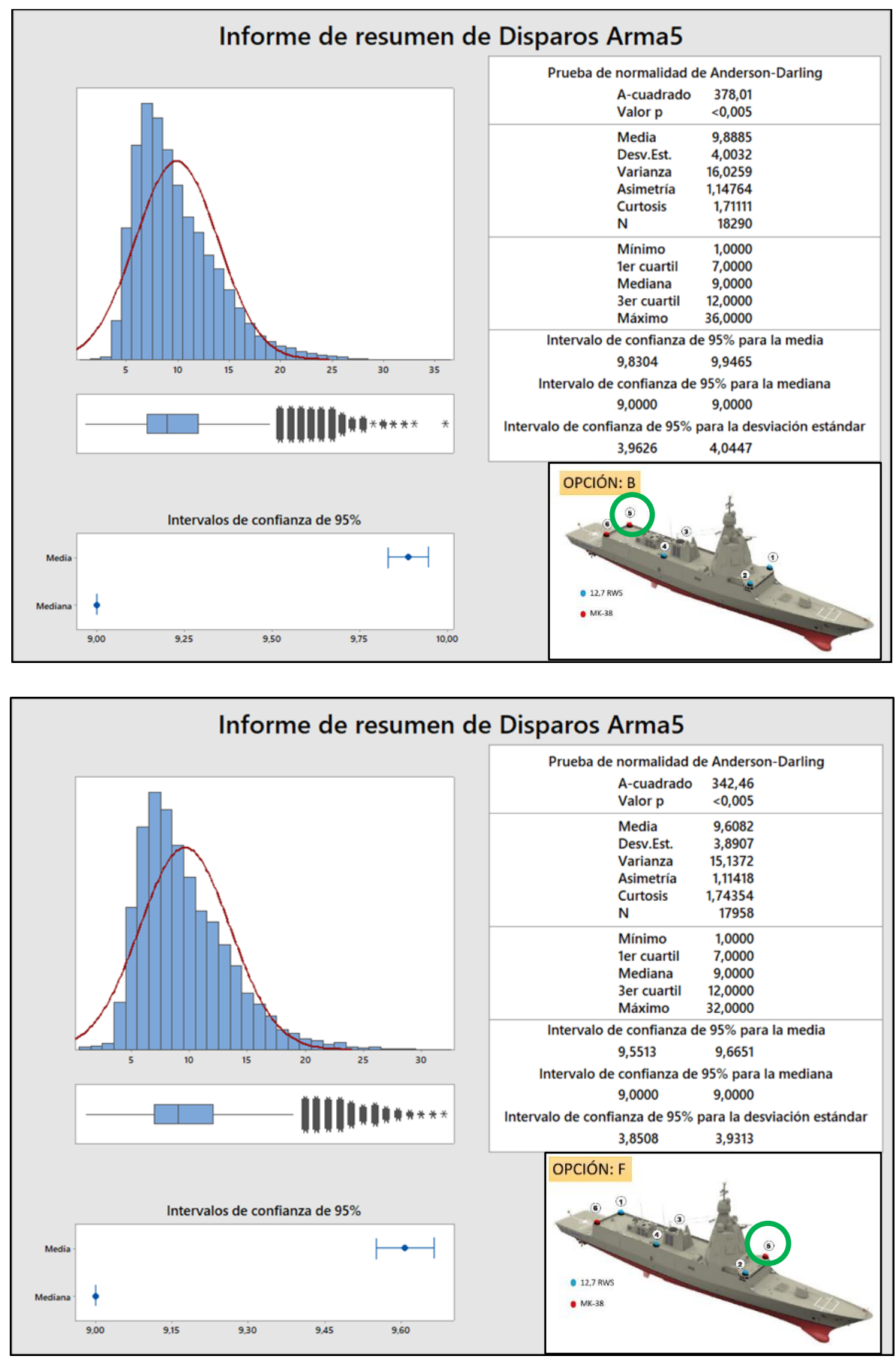

Figura en Apéndice C-11 Distribuciones y estadísticos descriptivos de la ametralladora Mk38 de $\mathrm{Br}$ que se intercambia de posición. Arriba en la opción B está a popa y abajo en la opción F está en proa 

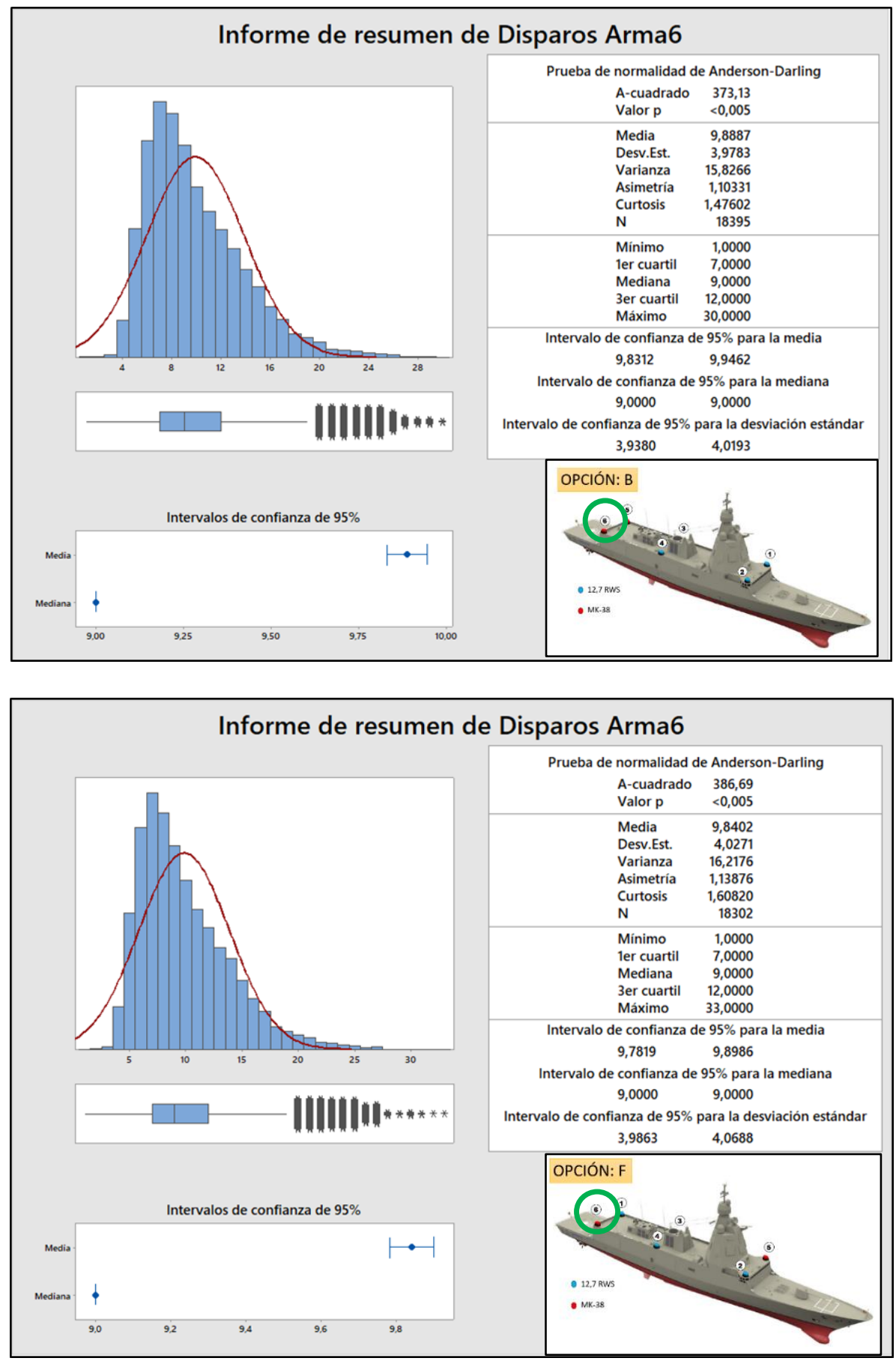

Figura en Apéndice C-12 Distribuciones y estadísticos descriptivos de la ametralladora №6. Arriba la opción B, abajo la opción $\mathrm{F}$ 